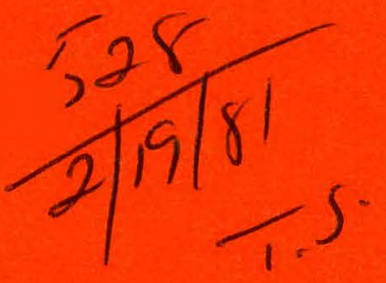

\title{
Active Solar Heating and Cooling Information User Study
}

W. W. Belew

B. L. Wood

T. L. Marle

C. L. Reinhardt

\section{MHSTER}
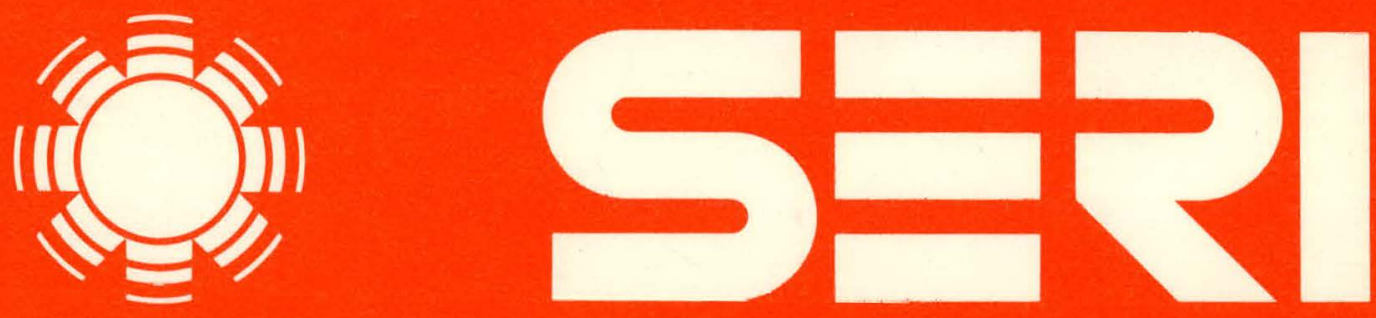

Solar Energy Research Institute

A Division of Midwest Research Institute

1617 Cole Boulevard

Golden, Colorado 80401

Operated for the

U.S. Department of Energy

under Contract No. EG-77-C-01-4042 


\section{DISCLAIMER}

This report was prepared as an account of work sponsored by an agency of the United States Government. Neither the United States Government nor any agency Thereof, nor any of their employees, makes any warranty, express or implied, or assumes any legal liability or responsibility for the accuracy, completeness, or usefulness of any information, apparatus, product, or process disclosed, or represents that its use would not infringe privately owned rights. Reference herein to any specific commercial product, process, or service by trade name, trademark, manufacturer, or otherwise does not necessarily constitute or imply its endorsement, recommendation, or favoring by the United States Government or any agency thereof. The views and opinions of authors expressed herein do not necessarily state or reflect those of the United States Government or any agency thereof. 


\section{DISCLAIMER}

Portions of this document may be illegible in electronic image products. Images are produced from the best available original document. 
Printed in the United States of America Available from:

National Technical Information Service

U.S. Department of Commerce

5285 Port Royal Road

Springfield, VA 22161

Price:

Microfiche $\$ 3.00$

Printed Copy $\$ 13.00$

\begin{abstract}
NOTICE
This report was prepared as an account of work sponsored by the United States Government. Neither the United States nor the United States Department of Energy, nor any of their employees, nor any of their contractors, subcontractors, or their employees, makes any warranty, express or implied, or assumes any legal liability or responsibility for the accuracy, completeness or usefulness of any information, apparatus, product or process disclosed, or represents that its use would not infringe privately owned rights.
\end{abstract}


W. W. BELEW

B. L. WOOD

T. L. MARLE

C. L. REINHARDT

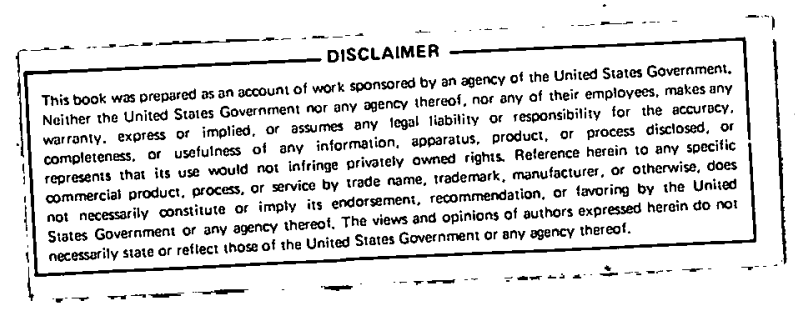

PREPARED UNDER TASK NO. 8420.11

\section{Solar Energy Research Institute}

A Division of Midwest Research Institute

1617 Cole Boulevard

Golden, Colorado 80401

Prepared for the

U.S. Department of Energy

Contract No. EG-77-C-01-4042 
THIS PAGE

WAS INTENTIONALLY

LEFT BLANK : 


\section{FOREWORD}

This document reports the results of a series of studies of users of active solar heating and cooling (SHAC) information.' It identifies specific SHAC information user group needs, the priority of those needs, and methods of disseminating information to each group. This is one of a series of ten reports covering many different solar technologies. These results will play an integral part in the planning of new information products and data bases for the Solar Energy Information Data Bank (SEIDB).

This study was performed under Contract No. EG-77C-01-4042, FY 1980 Task Number 8420.11.

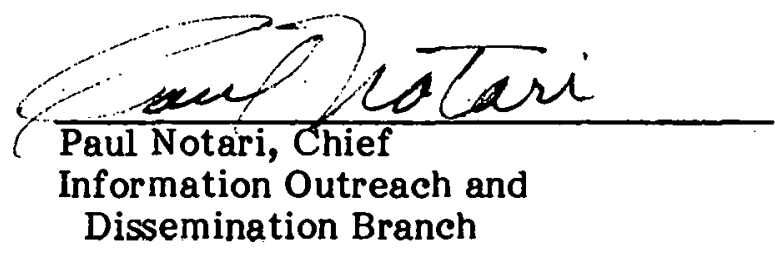

Approved for

SOLAR ENERGY RESEARCH INSTITUTE

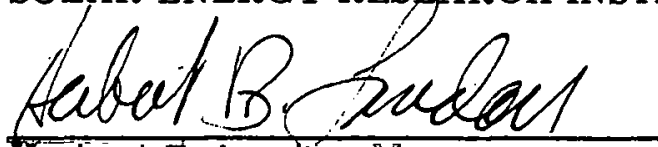

Herbert B. Landáu, Manager

Information Systems Division 
THIS PAGE

WAS INTENTIIONALLY

LEFT BLANK 


\section{ACKNOWLEDGMENTS}

The authors would like to thank the following for their valuable technical advice and review.

M. Ballen

National Solar Heating and Cooling Information Center

E. Barvir

Vitro Laboratories

J. O. Borden

Southern Solar Energy Center

D. S. Bremer

AIA Research Corporation

D. Chan

Northeast Solar Energy Center

S. Chen

Northeast Solar Energy Center

R. Farrington

Systems Development Branch

SERI

L. Morrison

Building Systems Dévelopment Branch SERI
P. A. Perucci

Meridian Corporation

P. Pollock

Community and Consumer Branch SERI

D. M. Roha

Vitro Laboratories

J. C. Sesso

National Center for Appropriate

Technology

R. Vories

Community and Consumer Branch

SERI

F. C. Weinstein

Franklin Research Center 


\section{THIS PAGE \\ WAS INTENTIONALLY \\ LEFT BLANK}




\section{ACTIVE SOLAR HEATING AND COOLING INPORMATION USER STUDY MANAGEMENT SUMMARY}

This report describes the results of a series of telephone studies of potential users of information on active solar heating and cooling (SHAC). These studies, part of a larger study covering many different solar technologies, identified:

- the types of information each group of information users needed, and

- the ways to get information to that group.

This SHAC report is one of ten discussing the results of these studies.

\section{BACKGROUND}

The purpose of the overall study was to obtain baseline data about the information needs of the solar community. Very little previous work has been done in this area; the studies that have been done were generally restricted to solar heating and cooling of buildings. The present study is the only known to investigate all of the following technological areas:

- Photovoltaics

- Passive Solar Heating and Cooling

- Active Solar Heating and Cooling

- Biomass Energy

- Solar Thermal Electric Power

- Industrial and Agricultural Process Heat

- Wind Ėnergy

- Ocean Energy

- Solar Energy Storage.

There have been a few previous studies which asked homeowners what solar information they needed, but this is the only known study to provide data on the solar information that such groups as researchers, manufacturers, architects, engineers, installers, lawyers, bankers, insurers, public interest groups, state energy offices, and agricultural extension agents themselves say they want.

The data from this study will be used along with other data to determine what new information products and services the Solar Energy Research Institute (SERI), the Solar Energy Information Data Bank (SEIDB) Network, and the entire solar information outreach community should be preparing for and disseminating to the solar community. 


\section{STUDY CHARACTERISTICS}

Between 3 September 1979 and 13 October 1979 Market Opinion Research, Inc. of Detroit, Michigan-under subcontract to SERI-conducted telephone interviews with 86 distinct groups of solar information users taken from across the nine different technological areas. Approximately nine respondents were interviewed from each group. Interviews were based upon professionally reviewed and tested questionnaires that utilized a mixture of open- and closed-ended questions. The interviews took an average of 18 minutes to complete.

The respondents proved to be very cooperative. Considering the length and nature of the telephone interviews, it was surprising that only about $3 \%$ of the respondents terminated an interview or refused to be interviewed. This finding supported the interviewers' statements that the respondents were very interested in telling what they were doing in solar energy, in obtaining solar information, and in specifying what solar information would prove tlie niost valuáble.

\section{SAMPLE SIZE}

Studies of 86 groups, each interested either in one of nine specific solar technologies or in solar energy in general, provided an extremely broad view of the information needs of the solar community. Although the sample size of only nine respondents per group was small, the data still proved to be adequate for planning purposes. It was possible to determine the information most important to the respondents and the best channel for dissemination. A variety of valid statistical tests were performed, both to compare the priorities a group gave to different information items and to compare the priorities different groups gave to the same item (See Section 2.3 and Appendix E).

\section{ACTIVE SOLAR HEATING AND COOLING GROUPS STUDIED}

The results of an earlier study identified the groups of information users constituting the SHAC community (see Solar Information User Priority Study [1]) and determined the priority (to accelerate commercialization of solar energy) of getting information to each user group. In the current study only high-priority groups were included. Considerable effort (e.g.; library searches, phone calls, subcontractors) went into obtaining the names of people professionally involved in SHAC. When the phone interviews were cunducled, an elaborate screening process was used to guarantee that the potential respondent was truly involved in SHAC. Respondents in the following 19 groups were queried about their need for information on active solar heating and cooling technologies:

- DOE-Funded SHAC Researchers,

- Non-DOE-Funded SHAC Researchers,

- Representatives of SHAC System Manufacturers,

- Representatives of Solar Hot Water System Manufacturers,

- Representatives of Nonconcentrating Collector Manufacturers,

- Representatives of Other SHAC Component Manufacturers,

- Distributors of SHAC systems and components, 
- Installers of SHAC systems,

- Architects who had been involved in SHAC projects,

- Builders who had been involved in SHAC projects,

- Planners who were interested in SHAC,

- Heating, Ventilating, and Air Conditioning (HVAC) Engineers who had been involved in SHAC projects,

- Industrial Engineers who were interested in SHAC,

- Representatives of Utilities conducting SHAC experiments or demonstrations,

- Educators teaching college-level courses in SHAC,

- Cooperative Extension Service (CES) County Agents who will be needing information on SHAC,

- Owners/managers of buildings with operating SHAC systems,

- Homeowners with active solar space heating and cooling systems, and

- Homeowners with active solar hot water systems.

Several of the groups discussed in another report from this study [2] also indicated an interest in information on SHAC (see Section 2.2.4).

\section{RESULTS}

In most cases the results from both groups of researchers were similar. Thus, in the following tables the data for SHAC Researchers have all been combined. Similarly, results for the four groups of SHAC Manufacturers have been combined, as have those for the two groups of SHAC Engineers and those for the three groups of SHAC Owners.

\section{Usefulness of General Types of Information}

The most important result obtained from this study was the identification of the SHAC information categories ranked the most useful by each group of respondents (see Table S-1). SHAC respondents in almost every group gave high ratings to information on:

- Cost/performance;

- Installation/operation costs;"

- Local building codes, regulations;

- 'Iax credits, grants, incentives; and

- Standards, specifications, or certification programs.

Most notable, however, was the wide range of rankings the groups gave to the information items. For example, even for these generally high-ranked items, there were several groups who ranked the item 10 th or worse. Similarly for the generally low-ranked items, there were of ten several groups ranking the item 5 th or better. This underlines the need to design most information products on a group by group basis. 
Table S-1. COMPARATIVE USEFULNESS OF GENERAL TYPES OF INFORMATION ON ACTIVE SOLAR HEATING AND́ COOLNG (SHAC)

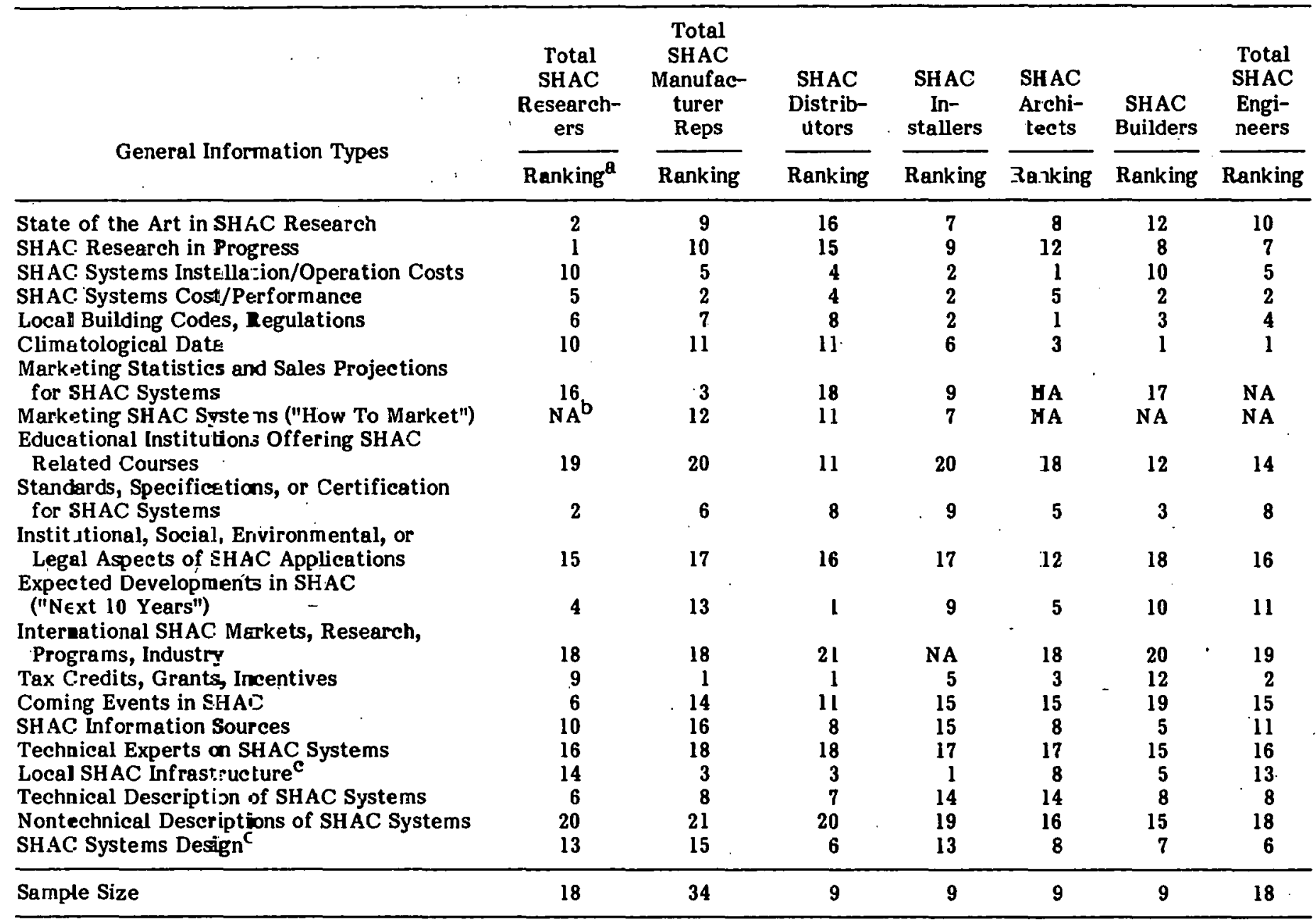

a The Ranking was based upon asking respondents how useful each item would be to them (see tex. of main report). If items were tied, they were all given the highest possible rank.

b"NA" means the question was not asked of this particular set of respondents.

cLocal lenders, insurers, builders, engineers, installers, distributors, or manufacturers of SHAC şstems.

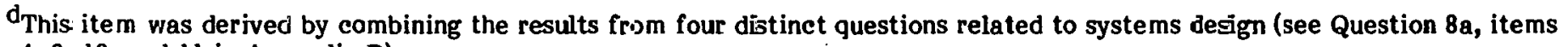
4, 8, 10, and 11 in Appendix D). 
Table S-1. COMPARATIVE USEFULNESS OF GENERAL TYPES OF INFORMATION ON ACTIVE SOLAR HEATING AND COOLING (SHAC) (Concluded)

\begin{tabular}{|c|c|c|c|c|c|}
\hline \multirow{2}{*}{ General Information Types } & $\begin{array}{c}\text { SHAC } \\
\text { Utility } \\
\text { Reps }\end{array}$ & $\begin{array}{c}\text { SHAC } \\
\text { Planners }\end{array}$ & $\begin{array}{c}\text { SHAC } \\
\text { Educa- } \\
\text { tors }\end{array}$ & $\begin{array}{l}\text { SHAC } \\
\text { County } \\
\text { Agents }\end{array}$ & $\begin{array}{c}\text { Total } \\
\text { SHAC } \\
\text { Owners/ } \\
\text { Managers }\end{array}$ \\
\hline & Ranking $^{\mathrm{a}}$ & Ranking & Ranking & Ranking & Ranking \\
\hline State of the Art in SHAC Research & 9 & 5 & 2 & 10 & 14 \\
\hline SHAC Research in Progress & 9 & 5 & 7 & 10 & 15 \\
\hline SHAC Systems Installation/Operation .Costs & 2 & 1 & 2 & 1 & 2 \\
\hline SHAC Systems Cost/Performance & 1 & 2 & $\overline{7}$ & 2 & 6 \\
\hline Local Building Codes, Regulations & 7 & 3 & 13 & 14 & 1 \\
\hline Climatological Data & 13 & 11 & 4 & 3 & 2 \\
\hline \multicolumn{6}{|l|}{ Marketing Statistics anc Sales Projections } \\
\hline for SHAC Systems & 17 & NA & 17 & NA & 19 \\
\hline Marketing SHAC Systerns ("How To Market") & 20 & NA & 17 & NA & NA \\
\hline \multicolumn{6}{|l|}{ Educational Institutions Offering SHAC } \\
\hline Related Courses & 18 & 17 & 13 & 9 & 17 \\
\hline Standards, Specifications, or Certification & & & & & \\
\hline for SHAC Systems & 3 & 15 & 12 & 10 & 8 \\
\hline \multicolumn{6}{|l|}{ Institutional, Social, Environmental, or } \\
\hline Legal Aspects of SHAC Applications & 15 & 5 & 16 & 15 & 18 \\
\hline Expected Developments in SHAC & & & & & \\
\hline ("Next 10 Years") & 13 & 8. & 1 & 10 & 11 \\
\hline \multicolumn{6}{|l|}{ International SHAC Markets, Research, } \\
\hline Programs, Industry & $\mathbf{N A}^{\mathrm{b}}$ & 19 & 17 & NA & NA \\
\hline Tax Credits, Grants, Incentives & 7 & 3 & 7 & 8 & 5 \\
\hline Coming Events in SHAC & 18 & 16 & 7 & 18 & 16 \\
\hline SHAC Information Sources & 3 & 9 & 4 & 6 & 7 \\
\hline Technical Experts on SHAC Systems & 15 & 14 & 17 & 15 & 12 \\
\hline Local SHAC Infrastructure $\mathrm{c}$ & 6 & 10 & 13 & 3 & 4 \\
\hline Technical Description oí SHAC Systems & 9 & 11 & 4 & 17 & 10 \\
\hline Nontechnical Descriptions of SHAC Systems & 5 & 17 & 21 & 3 & 9 \\
\hline SHAC Systems Design & 9 & 13 & 11 & 7 & 13 \\
\hline Sample Size & 9 & 9 & 9 & 9 & 27 \\
\hline
\end{tabular}

a The Ranking was based upon asking respondents how useful each item would be to them (see text of main report). If items were tied, they were all given the highest possible rank.

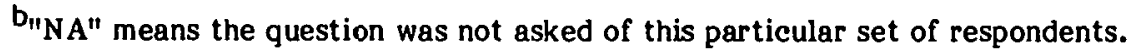

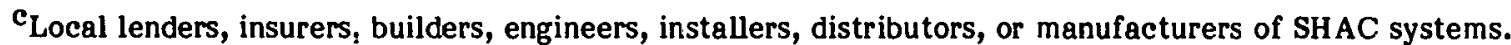

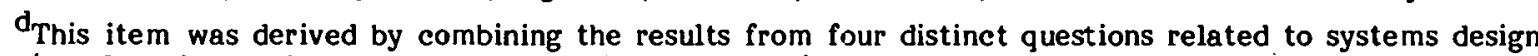
(see Question 8a, items 4, 8, 10, and 11 in Appendix D). 


\section{Usefulness of Specific Information Products}

The same questions also provided information on how valuable a set of specifically proposed information products would be to the respondents (see Table S-2). The first seven of these products could be targeted for large segments of the SHAC community rather than for specific groups. Probably the most interesting results were:

- The high level of interest in lists of the local infrastructure and in systems design information;

- The greater usefulness of manual analytical tools than of computer models for SHAC system design; and

- The relative lack of interest in bibliographies, conference calendars, lists of technical experts, and nontechnical descriptions.

\section{Sources Used to Obtain Information}

Table S-3 lists the proportion of each group that had used different sources to obtain any type of solar information in the past few years. It will be noted that a column is given for all SHAC respondents; these summary figures are indicators (not estimates) of the familiarity of the entire SHAC community with these information sources. In planning how specific information is to be transmitted, however, it will be essential to fully specify both the information products or services and the groups to be reached before making the decision of which information channels are to be used. One cannot assume, for example, that the two or three top-rated sources should be used for all-or even most-of the information transmission to the SHAC community.

The information sources most familiar to the SHAC groups surveyed were:

- Periodicals, newspapers, or magazines;

- A solar installer, builder, designer, or manufacturer;

o Workshops, conferences, or training sessions; and

- The Government Printing Office (GPO).

\section{Technical Areas of Interest}

Table S-4 lists the proportion of each group interested in information on different types of SHAC applications. The major results were:

- Fairly high levels of interest in all applications except "swimming pool heating";

- Surprisingly high interest in "space cooling"; and

- Somewhat higher interest by Installers, Architects, and Planners in "space cooling" than in "space heating." 
Table S-2. VALUE ASSESSMENT OF SPECIFIC ACTIVE SOLAR HEATING \& COOLING (SHAC) INFORMATION PRODUCTS

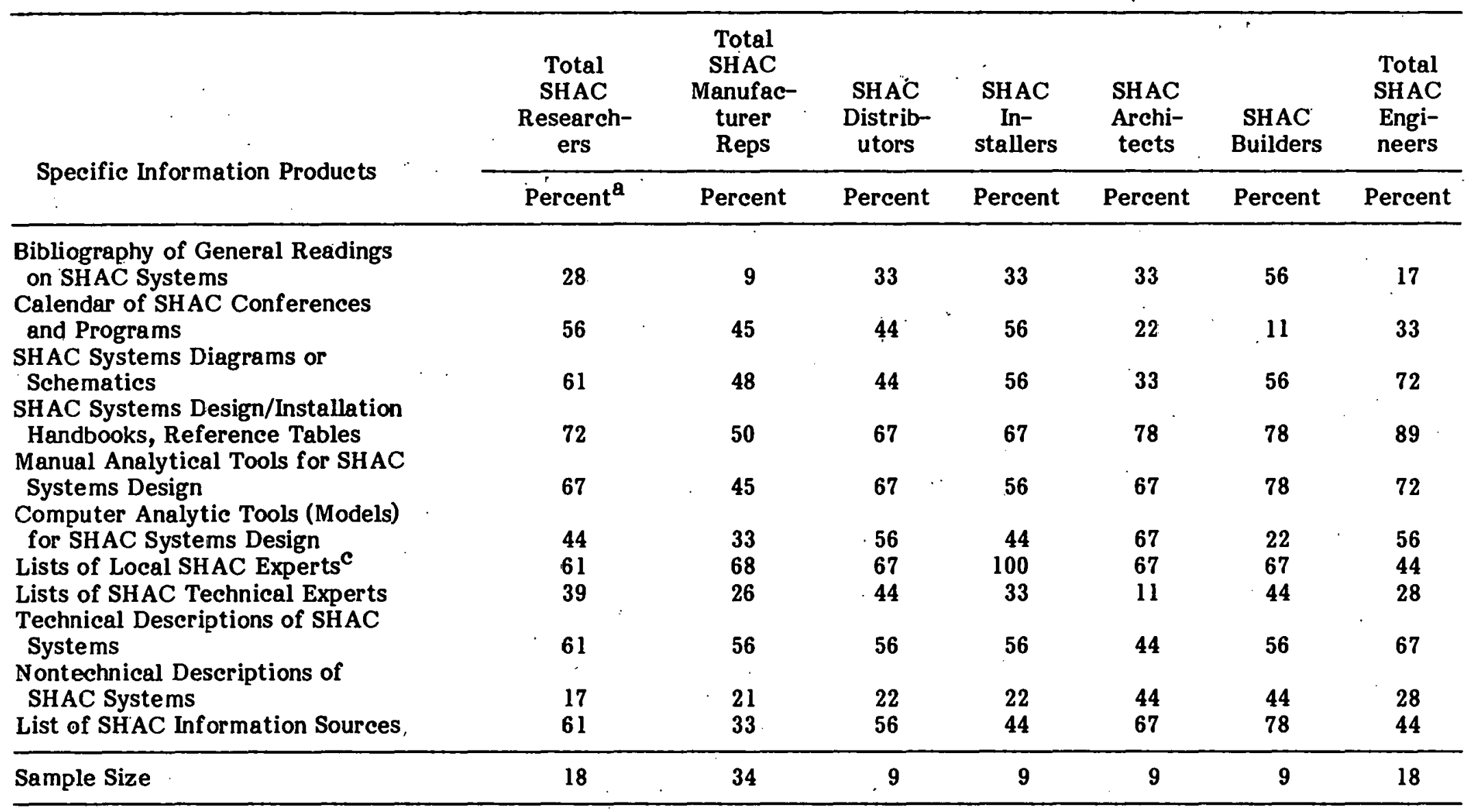

apercent is the percentage of respondents rating the item as "essential" or "very useful" (as opposed to "somewhat useful" or "not at all useful").

${ }^{b}$ Although a percentage is given for All SHAC Respondents, it may not be indicative of the percentage of the whole SHAC community interested in that item (since the proportion of each type of respondent in this study may not correspond to the proportion that group constitutes of the entire population).

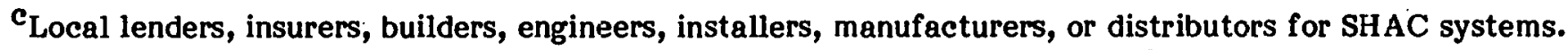

d"X" indicates no overall percentage was calculated. For these items it may be necessary to develop different products/services for each group if their information needs are to be fully met. 
Table 5-2. VALUE ASSESSMENT OF SPECIFIC ACTIVE SOLAR HEATING \& COOLNG (SHAC) INFORMATION PRODUCTS (Concluded)

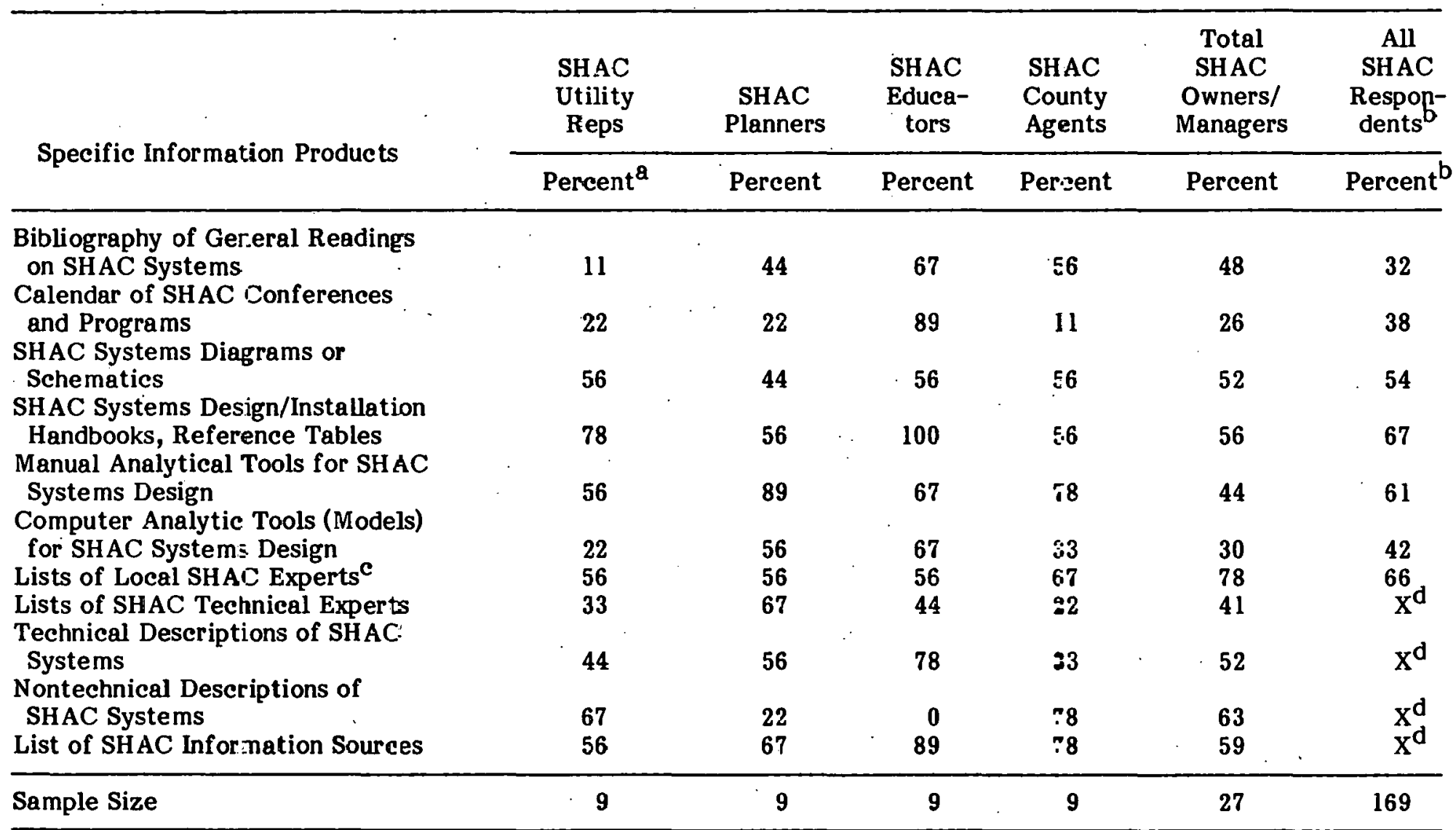

${ }^{a}$ Percent is the percentage of respondents rating the item as "essential" or "very useful" (as opposed to "somewhat. useful" or "not at all useful").

${ }^{b}$ Although a percentage is given for All SHAC Respondents, it may not be indicative of the percentage of the whole SHAC community interested in that item (since the proportion of each type of respondent in this study may not correspond to the proportion that group constitutes of the entire population).

${ }^{c_{L o c a l}}$ lenders, insurers, builders, engineers, irstallers, manufacturers, or distributors for SHAC systems.

$d_{1} X "$ indicates no overall percentage was calculated: For these items it will be necessary to develop different products/services for each group if their information needs are to be fully met. 
Table S-3. SOURCES USED TO OBTAIN SOLAR INPORMATION

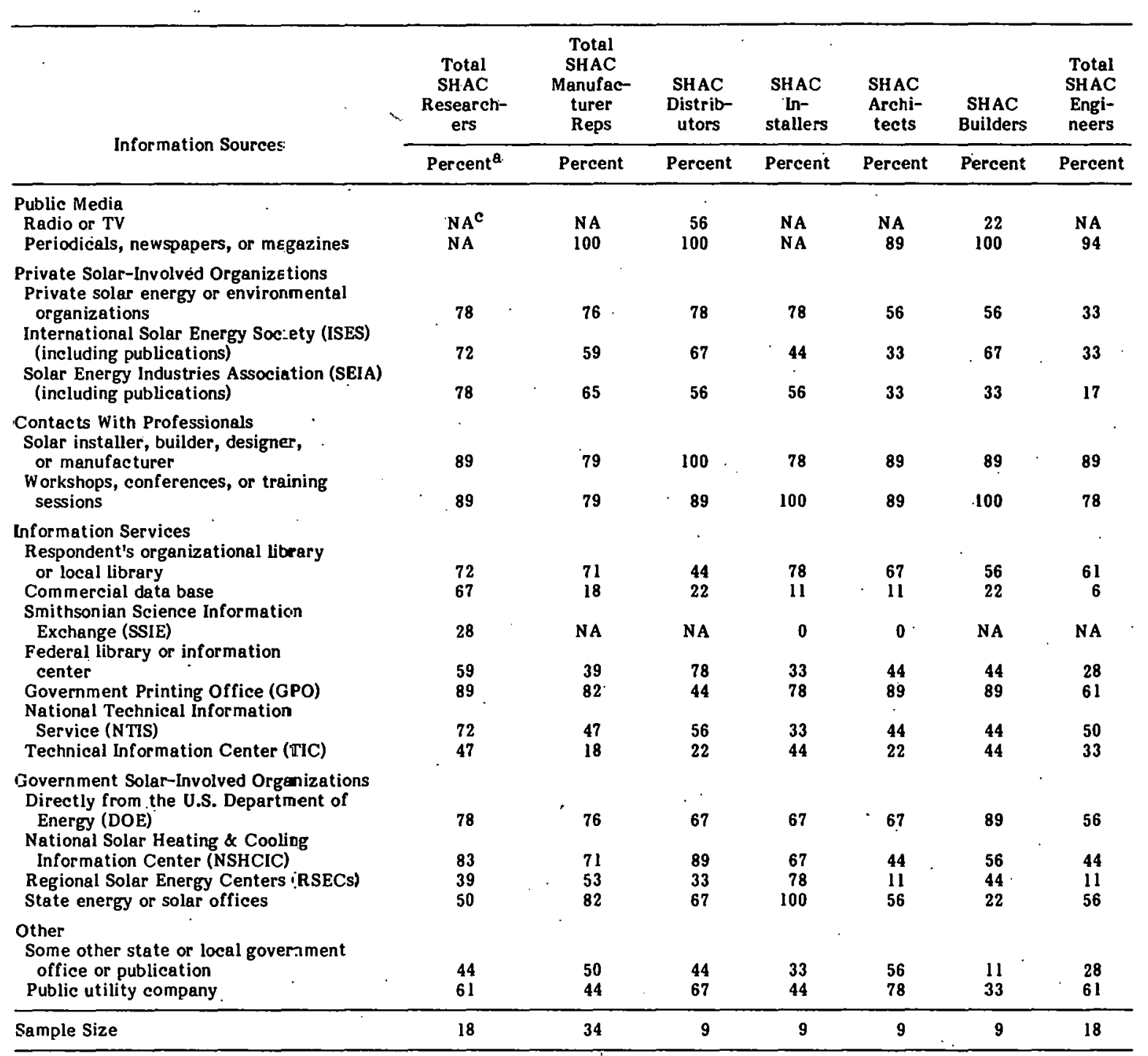

$\varepsilon_{\text {Percent }}$ is the percentage of respondents who used the source to obtain any solar information in the past few years.

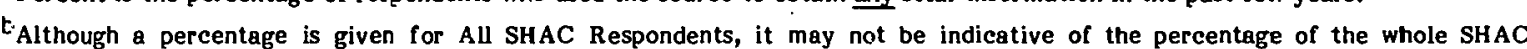
community interested in that item (since the proportion of each type of respondent in this study may not correspond to the proportion that group constitutes of the entire population).

C"NA" means the question was nct asked of this particular set of respondents. 
Table S-3. SOURCES USED TO OBTAIN SOLAR INFORMATION (Concluded)

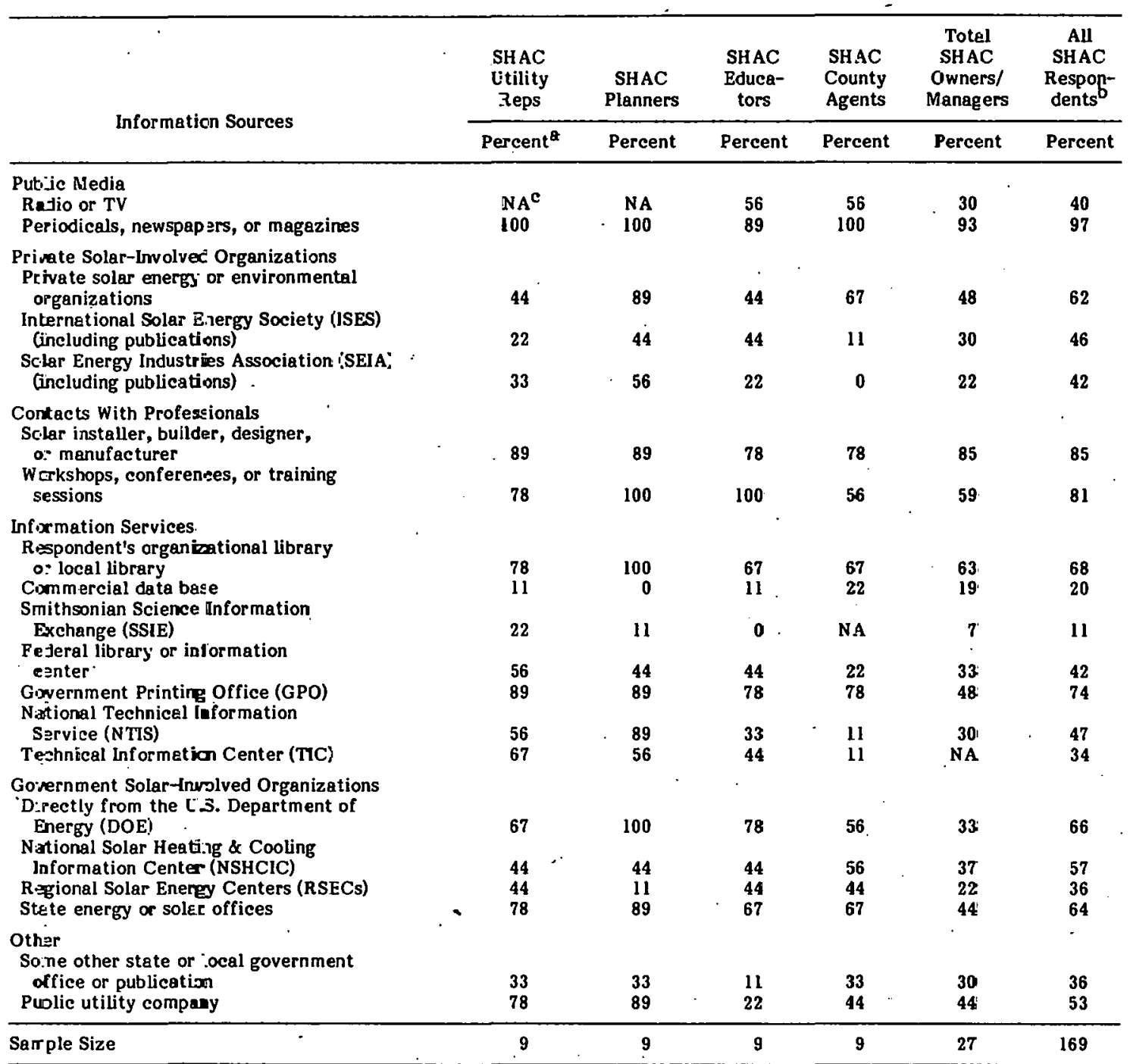

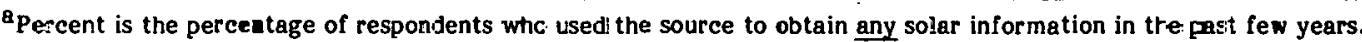

${ }^{b}$ Al:hough a percentage is given for All SHAC Reפordents, it may not be indicative of the percentege of the whole SHAC conmunity interested in that item isince the proport:on of each type of respondent in this study nay not correspond to the proportion that group constitutes of the entire popsla:ion.

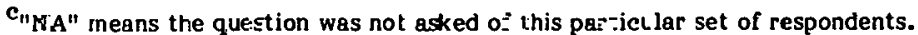


Table S-4. INTEREST IN INFORMATION ON ACTIVE SOLAR HEATING AND COOLING (SHAC) TOPICS ${ }^{a}$

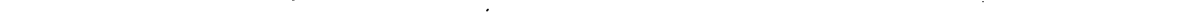

\begin{tabular}{|c|c|c|c|c|c|c|c|}
\hline Topic & $\begin{array}{c}\text { Total } \\
\text { SHAC } \\
\text { Research- } \\
\text { ers }\end{array}$ & $\begin{array}{c}\text { Total } \\
\text { SHAC } \\
\text { Manufac- } \\
\text { turer } \\
\text { Reps }\end{array}$ & $\begin{array}{c}\text { SHAC } \\
\text { Distrib- } \\
\text { utors }\end{array}$ & $\begin{array}{c}\text { SHAC } \\
\text { In- } \\
\text { stallers }\end{array}$ & $\begin{array}{l}\text { SHAC } \\
\text { Archi- } \\
\text { tects }\end{array}$ & $\begin{array}{l}\text { SHAC } \\
\text { Builders }\end{array}$ & $\begin{array}{c}\text { Total } \\
\text { SHAC } \\
\text { Engi- } \\
\text { neers }\end{array}$ \\
\hline . & Percent $^{b}$ & Percent & Percent & Percent & Percent & Percent & Percent \\
\hline Water Heating & 67 & 89 & 89 & 100 & 89 & 89 & 100 \\
\hline Swimming Pool Heating & 44 & 56 & 78 & 67 & 56 & 33 & 44 \\
\hline Space Heating & 78 & 89 & 100 & 78 & 78 & 100 & 89 \\
\hline Space Cooling & 67 & 44 & 67 & 89 & 100 & 78 & 89 \\
\hline Hybrid Systems & 72 & 56 & 89 & 78 & 100 & 89 & 89 \\
\hline Sample Size & 18 & 18 & 9 & 9 & 9 & 9 & 18 \\
\hline
\end{tabular}

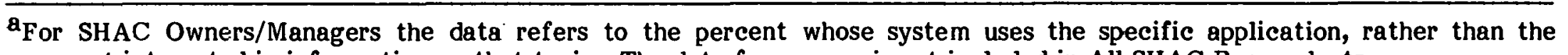
percent interested in information on that topic. The data for owners is not included in All SHAC Respondents.

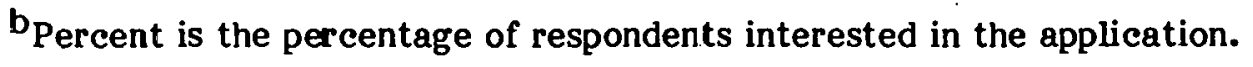

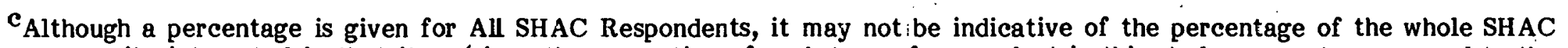
community interested in that item (since the proportion of each type of respondent in this study may not correspond to the proportion that group constitutes of the entire population). 
Table s-4. . INTEREST IN INPORMATION ON ACTIVE SOLAR HEATING AND COOLING (SHAC) TOPICS $^{Q}$ (Concluded)

\begin{tabular}{|c|c|c|c|c|c|c|c|}
\hline Topic & $\because$ & $\begin{array}{l}\text { SHAC } \\
\text { Utility } \\
\text { Rees }\end{array}$ & $\begin{array}{c}\text { SHAC } \\
\text { Planners }\end{array}$ & $\begin{array}{l}\text { SHAC } \\
\text { Educa- } \\
\text { tors }\end{array}$ & $\begin{array}{l}\text { SHe.C } \\
\text { County } \\
\text { Agents }\end{array}$ & $\begin{array}{c}\text { Total } \\
\text { SHAC } \\
\text { Owners/ } \\
\text { Managers }^{\mathrm{a}}\end{array}$ & $\begin{array}{c}\text { All } \\
\text { SHAC } \\
\text { Respon- } \\
\text { dents }^{\mathrm{a}, \mathrm{c}}\end{array}$ \\
\hline & & Persent $^{b}$ & Percent & Percent & Percent & Percent ${ }^{\mathbf{a}}$ & Percent $^{a, c}$ \\
\hline Water Heating & & 78 & 100 & 89 & 100 & 67 & 89 \\
\hline Swimming Pool Heating & & 33 & 56 & 44 & 0 & 22 & 47 \\
\hline Space Heating & & 130 & 67 & 100 & 100 & 74 & 88 \\
\hline Space Cooling & & 67 & 89 & 78 & 78 & 26 & 75 \\
\hline Hybrid Systems & & 67 & 89 & 100 & 89 & 26 & 81 \\
\hline Sample Size & & $\mathbf{g}$ & 9 & 9 & 9 & 27 & 126 \\
\hline
\end{tabular}

${ }^{a}$ For SHAC Owners/Managers the data refers to the percent whose system uses the specific application, rather than the percent interested in information on that topic. The data for owners is not included in All SHAC Respondents.

$\mathrm{b}_{\text {Percent }}$ is the percentage of res:ondents interes:ed in the application.

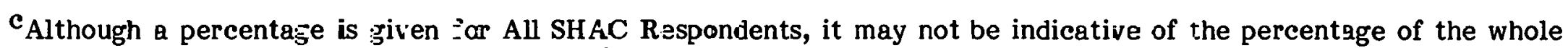
SHAC community interested in that item (since the proportion of each type of respondent in th:s study may not correspond to the propo:tion that group constituies of the entire population). 


\section{Advanced Information Acquisition Methods Used}

Table S-5 lists the proportion of each group that had used selected advanced acquisition methods to obtain inf ormation in the past year. The following results were observed:

- SHAC respondents, in general, were not very accustomed to using these techniques;

- Computer terminals were used more widely than microforms; and

- SHAC Educators and SHAC Distributors were the least likely of SHAC respondents to use these methods (the non-use was unique among Educators interviewed in this study).

\section{Additional Findings}

- Non-DOE-Funded SHAC Researchers seemed especially concerned about their ability to obtain information. DOE-Funded-SHAC Researchers were not nearly as interested in "lists of SHAC information sources" or in "calendars of SHAC conference and programs."

- Representatives of SHAC Manufacturers were much more interested in marketing information and identifying the local infrastructure than were the representatives of other solar manufacturers studied but were less interested in research results.

- A significantly higher proportion of SHAC Manufacturer Representatives than of Passive Manufacturer Representatives had obtained information from the Regional Solar Energy Centers (RSECs).

- SHAC Distributors did not attach much utility to information on how to market and sell systems or on marketing statistics and sales projections.

- SHAC Installers had a surprisingly high level of technical education (8 were college graduates, 5 in engineering) and had been in their current profession for a long time ( 5 for over 10 years). Most seemed to be working for engineering firms. Either the typical SHAC Installer was not as blue-collar as had previously been believed, or the engineering firms were virtually the only businesses successful in getting listed in the local state's directory of solar professionals (from which the sample was drawn).

- A significantly lower proportion of SHAC Architects than of Passive Architects had obtained information from the RSECs.

- SHAC Builders rated "manual methods for sizing and predicting the engineering performance or life cycle costs" as their second most useful information product, but rated "computer models for sizing and predicting" as 20 th. They were significantly less interested in information on tax credits, grants, and incentives than were the Passive Builders, but appeared more interested in systems designrelated information. It appears that SHAC Builders used fewer information sources than Passive Builders. SHAC Builders were significantly less likely than SHAC Architects to belong to an organization with an interest in solar energy.

- Planners were far above average in their familiarity with the information sources listed and gave the highest ratings (of any of the 86 groups in the study) ton the utility of the potential information categories and products. 
Table S-5. ADVANCED INFORMATION ACQUISTTION METHODS USED

\begin{tabular}{|c|c|c|c|c|c|c|c|}
\hline Acquisition Methods & $\begin{array}{c}\text { Total } \\
\text { SHAC } \\
\text { Research- } \\
\text { ers }\end{array}$ & $\begin{array}{c}\text { Total } \\
\text { SHAC } \\
\text { Manufac- } \\
\text { turer } \\
\text { Reps }\end{array}$ & $\begin{array}{c}\text { SHAC } \\
\text { Distrib- } \\
\text { utors }\end{array}$ & $\begin{array}{l}\text { SHAC } \\
\text { ln- } \\
\text { stallers }\end{array}$ & $\begin{array}{l}\text { SHAC } \\
\text { Arehi- } \\
\text { tects }\end{array}$ & $\begin{array}{l}\text { SHAC } \\
\text { Bu:Iders }\end{array}$ & $\begin{array}{c}\text { Total } \\
\text { SHAC } \\
\text { Engi- } \\
\text { neers }\end{array}$ \\
\hline & Percent $^{Q}$ & Percent & Percent & Percent & Percent & Percent & Percent \\
\hline $\begin{array}{l}\text { Computer Terminal Access to } \\
\text { Data Banks }\end{array}$ & 56 & 24 & 11 & 33 & 56 & 33 & 33 \\
\hline $\begin{array}{l}\text { Microf orm (microfiche, microfilm } \\
\text { sheets or rolls, COM, etc.) }\end{array}$ & 39 & 12 & 0 & 22 & 33 & 33 & 11 \\
\hline Sample Size & 18 & 34 & 9 & 9 & 9 & 9 & 18 \\
\hline
\end{tabular}

a Percent is the percentage of respondents who usec the method in the past year.

${ }^{b}$ Although a percentage is given for All SHAC Respondents, it may not be indicative of the percentage oi the whole SHAC community interested in that item (since the proportion of each type of respondent in this study may not correspond to the proportion that group constitutes of the entire population). 
Table S-5. ADVANCED INFORMATION ACQUISITION METHODS USED (Concluded)

\begin{tabular}{|c|c|c|c|c|c|c|}
\hline Acquisition Methods & $\begin{array}{c}\text { SHAC } \\
\text { Utility } \\
\text { Reps }\end{array}$ & $\begin{array}{l}\text { SHAC } \\
\text { Planners }\end{array}$ & $\begin{array}{c}\text { SHAC } \\
\text { Educa- } \\
\text { tors }\end{array}$ & $\begin{array}{l}\text { SHAC } \\
\text { County } \\
\text { Agents }\end{array}$ & $\begin{array}{c}\text { Total } \\
\text { SHAC } \\
\text { Owners/ } \\
\text { Managers }\end{array}$ & $\begin{array}{c}\text { All } \\
\text { SHAC } \\
\text { Respon- } \\
\text { dents }^{b}\end{array}$ \\
\hline & Percent $^{Q}$ & Percent & Percent & Percent & Percent & Percent ${ }^{b}$ \\
\hline $\begin{array}{l}\text { Computer Terminal Access to } \\
\text { Data Banks }\end{array}$ & 44 & 44 & 0 & 33 & $\mathrm{NA}^{\mathrm{C}}$ & 33 \\
\hline $\begin{array}{l}\text { Microf orm (microfiche, microfilm } \\
\text { sheets or rolls, COM, etc.) }\end{array}$ & 33 & 67 & 0 & 11 & NA & 22 \\
\hline Sample Size & 9 & 9 & 9 & 9 & . & 142 \\
\hline
\end{tabular}

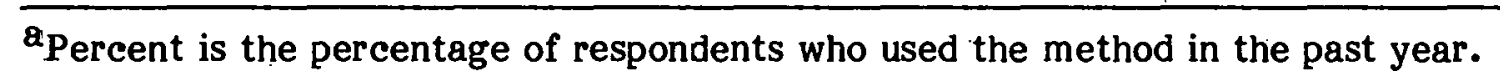

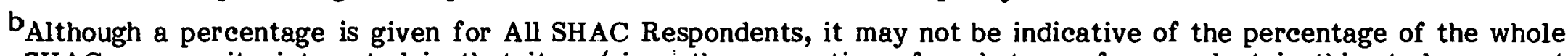
SHAC community interested in thet item (since the proportion of each type of respondent in this study may not correspond to the proportion that group constitutes of the entire population). 
- Compared to All Engineers surveyed in this study, a significantly lower proportion of SHAC HVAC Engineers had obtained information from GPO, RSECs, and the state solar/energy offices.

- Compared to many of the educators studied, the SHAC Educators were much more involved in applications (6 of the 9) than in research (3 of the 9).

- CES County Agents were involved in collecting and disseminating SHAC information. Their use of information sources, however, seemed very much restricted to U.S. Department of Agriculture (USDA) origins. The most efflelent way to get additional solar information to them would probably be through cooperative agreements between USDA and DOE or by getting information directly to the state-level CES specialists who would, in turn, channel it to the county-level agents.

- Homeowners with solar heating and cooling systems, homeowners with solar hot water systems, and owners/managers of buildings with BIIAC syetoms were surveyed. In all three groups many of the respondents cuuld be classificd as "early innovators" [3]. As such, care must be taken in extrapolating the results to all potential purchasers of SHAC systems.

- Solar Space Heating Homeowners, much like Passive Homeowners, were interested in very in-depth types of information (e.g., they rated "state of the art" and "technical descriptions of systems" very high, but "nontechnical descriptions" very low). They were very much aware of the many potential sources of information and made use of them.

- In contrast, Solar Water Heating Homeowners did not need highly technical information and appeared to rely heavily on the local installers for information. They seemed to be virtually unaware of many of the potential sources of information.

- Owners/managers of buildings with SHAC systems lay between solar Space Heating Homeowners and Solar Water Heating Homeowners in familiarity with information sources. They were much more interested in obtaining information verbally than from books. 
TABLE OF CONTENTS

$\underline{\text { Page }}$

Management Summary $\ldots \ldots \ldots \ldots \ldots \ldots \ldots \ldots \ldots \ldots \ldots \ldots \ldots \ldots \ldots \ldots \ldots \ldots \ldots$

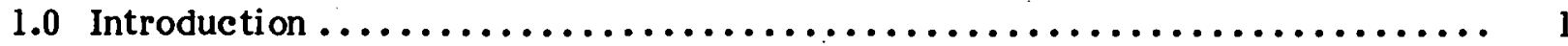

1:1 Background.................................... 1

1.2 Solar Energy Information Data Bank (SEIDB) Program Planning . . . . . . . 2

1.3 Report Contents .................................. 2

2.0 Study Description $\ldots \ldots \ldots \ldots \ldots \ldots \ldots \ldots \ldots \ldots \ldots \ldots \ldots \ldots \ldots \ldots \ldots \ldots \ldots \ldots \ldots$

2.1 Study Characteristics $\ldots \ldots \ldots \ldots \ldots \ldots \ldots \ldots \ldots \ldots \ldots \ldots \ldots \ldots \ldots \ldots \ldots$

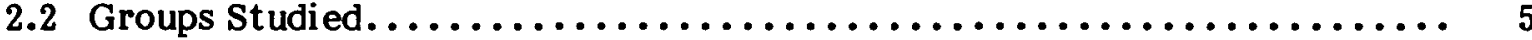

2.2.1 Target Audiences, Classes, and Groups ................. 6

2.2.2 Criteria for Selection of Groups to Study ............... 7

2.2.3 Groups Included in Active Solar Heating and

2.2.4 Solar Heating and Cooling-Concerned Groups Included in General Solar Study $\ldots \ldots \ldots \ldots \ldots \ldots \ldots \ldots \ldots \ldots \ldots \ldots \ldots \ldots$

2.3 Data Interpretation. ................................. 14

2.3.1 Impact of the Sample Frames: Who was Sampled? ........... 14

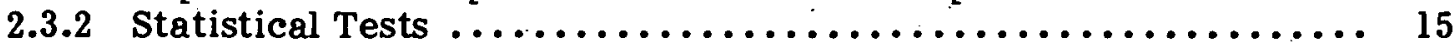

2.3.3 Hypotheses Versus Conclusions ...................... 15

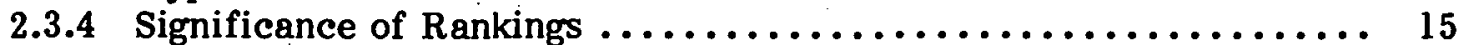

2.3.5 Alternative Measures of Usefulness ................... 15

2.3.6 Combining Results from Different Groups ................ 16

2.3.7 Specific Information Products...................... 16

2.3 .8 Information Sources $\ldots \ldots \ldots \ldots \ldots \ldots \ldots \ldots \ldots \ldots \ldots \ldots \ldots \ldots \ldots \ldots$

3.0 Active Solar Heating and Cooling Researchers .................. 19

3.1 Description of Respondents $\ldots \ldots \ldots \ldots \ldots \ldots \ldots \ldots \ldots \ldots \ldots \ldots \ldots \ldots \ldots \ldots, 19$

3.1.1 Desitiplion of Sample $\ldots \ldots \ldots \ldots \ldots \ldots \ldots \ldots \ldots \ldots \ldots \ldots \ldots \ldots \ldots$

3.1.2 Current Status of Respondents ...................... 20

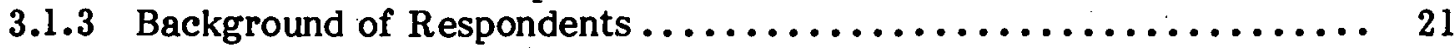

3.2 Information Needs of Respondents ...................... 22

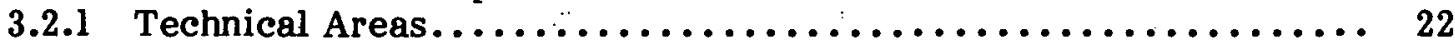

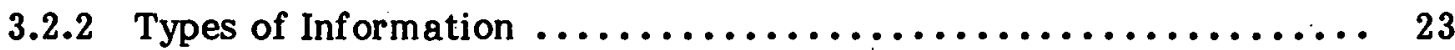

3.3 Acquisition of Information by Respondents . . . . . . . . . . . . . . . 29

3.3.1 Use of Selected Information Sources ................... 29

3.3.2 Membership in Solar-Interested Organizations .............. 35

3.3.3 Exposure to Publications on Solar Energy ................. 35

3.3.4 Use of Special Acquisition Methods .................... 36

3.4 Summary and Comments $\ldots \ldots \ldots \ldots \ldots \ldots \ldots \ldots \ldots \ldots \ldots \ldots \ldots \ldots \ldots$ 
TABLE OF CONTENTS (Continued)

Page

4.0 Active Solar Heating and Cooling Manufacturer

Representatives

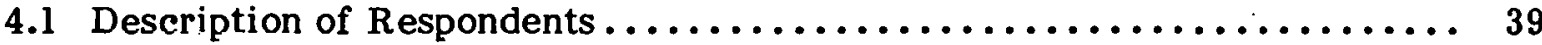

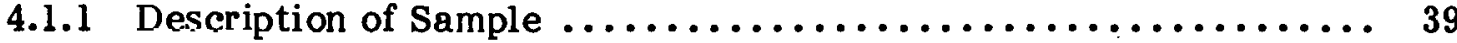

4.1.2 Current Status of Respondents ...................... 41

4.1.3 Background of Respondents ....................... 43

4.2 Information Needs of Respondents $\ldots \ldots \ldots \ldots \ldots \ldots \ldots \ldots \ldots \ldots \ldots \ldots, \ldots$

4.2 .1 Technical Areas............................... 44

4.2 .2 Types of Information $\ldots \ldots \ldots \ldots \ldots \ldots \ldots \ldots \ldots \ldots \ldots \ldots \ldots \ldots \ldots$

4.3 Acquisition of Information by Respondents ................ 50

4.3.1 Use of Belected Information Souroes . . . . . . . . . . . . . . . 50

4.3.2 Membership in Solar-Interested Organizations ............. 56

4.3.3 Exposure to Publications on Solar Energy ................. 56

4.3.4 Use of Special Acquisition Methods ................... 56

4.4 Summary and Comments ........................... 56

5.0 Active Solar Heating and Cooling Distributors.................. 61

5.1 Description of Respondents ......................... 61

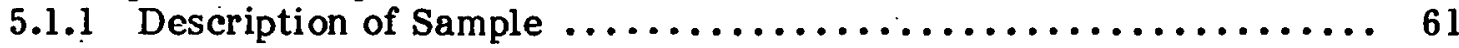

5.1.2 Current Status of Respondents ..................... 61

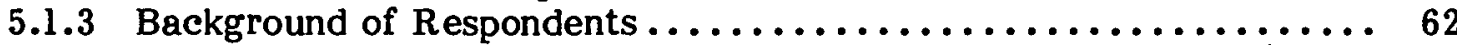

5.2 Information Needs of Respondents ....................... 63

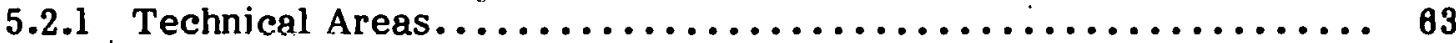

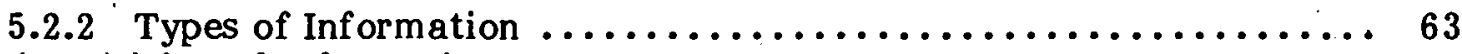

5.3 Acquisition of Information by Respondents................. 66

5.3 .1 Use of Selecled Inf ormation Sourccs .................. 66

5.3.2 Membership in Solar-Interested Organizations .............. 69

5.3.3 Exposure to Publications on Solur Energy ............... 70

5.3.4 Use of Special Acquisition Methods .................. 70

5.4 Summary and Comments $\ldots \ldots \ldots \ldots \ldots \ldots \ldots \ldots \ldots \ldots \ldots \ldots \ldots \ldots \ldots$

6.0 Active Solar Heating and Cooling Installers $\ldots \ldots \ldots \ldots \ldots \ldots \ldots \ldots \ldots \ldots \ldots$

6.1 Description of Respondents .......................... 73

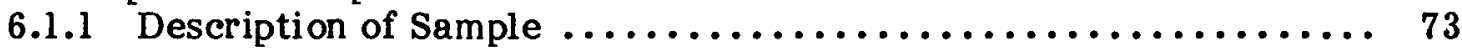

6.1 .2 Current Status of Kespondents ..................... 73

6.1 .3 Background of Respondents ........................ 74

6.2 Information Needs of Respondents $\ldots \ldots \ldots \ldots \ldots \ldots \ldots \ldots \ldots \ldots \ldots \ldots \ldots$

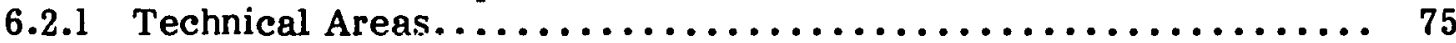

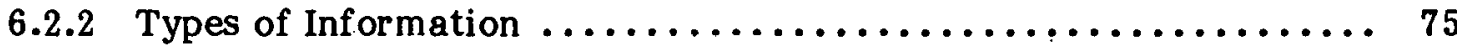

6.3 Acquisition of Information by Respondents................. 77

6.3 .1 Use of Selected Information Sulces .................. 77

6.3.2 Membership in Solar-Interested Organizations .............. 79

6.3.3 Exposure to Publications on Solar Energy ................ 79

6.3.4 Use of Special Acquisition Methods ................... 80

6.4 Summary and Comments $\ldots \ldots \ldots \ldots \ldots \ldots \ldots \ldots \ldots \ldots \ldots \ldots \ldots \ldots \ldots \ldots \ldots$ 
TABLE OF CONTENTS (Continued)

7.0 Active Solar Heating and Cooling Architects $\ldots \ldots \ldots \ldots \ldots \ldots \ldots \ldots \ldots \ldots$

7.1 Description of Respondents $\ldots \ldots \ldots \ldots \ldots \ldots \ldots \ldots \ldots \ldots \ldots \ldots \ldots \ldots$

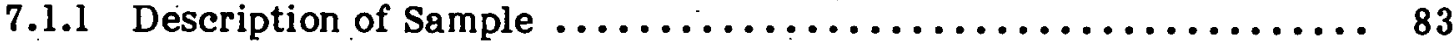

7.1 .2 Current Status of Respondents ................... 83

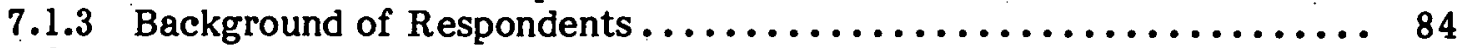

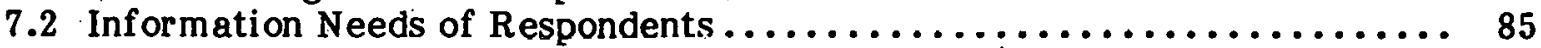

7.2 .1 Technical Areas............................ 85

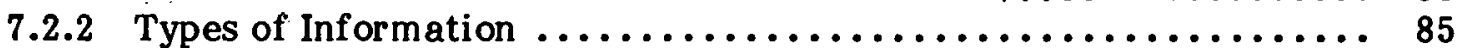

7.3 Acquisition of Information by Respondents ................ 89

7.3.1 Use of Selected Information Sources ................... 89

7.3.2 Membership in Solar-Interested Organizations . . . . . . . . . . . . . 92

7.3.3 Exposure to Publications on Solar Energy ................... 92

7.3.4 Use of Special Acquisition Methods .................... 92

7.4 Summary and Comments $\ldots \ldots \ldots \ldots \ldots \ldots \ldots \ldots \ldots \ldots \ldots \ldots \ldots \ldots \ldots$

8.0 Active Solar Heating and Cooling Builders $\ldots \ldots \ldots \ldots \ldots \ldots \ldots \ldots \ldots \ldots \ldots \ldots$

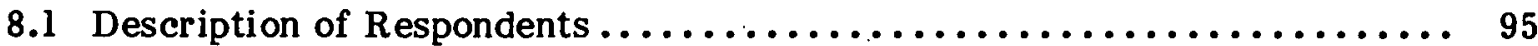

8.1.1 Description of Sample ......................... 95

8.1 .2 Current Status of Respondents .................... 95

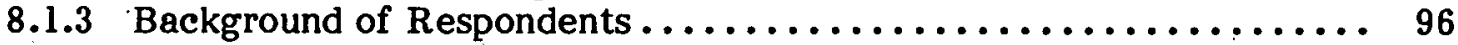

8.2 Information Needs of Respondents $\ldots \ldots \ldots \ldots \ldots \ldots \ldots \ldots \ldots \ldots \ldots \ldots . \ldots 7$

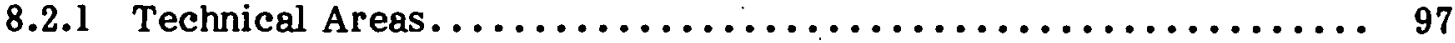

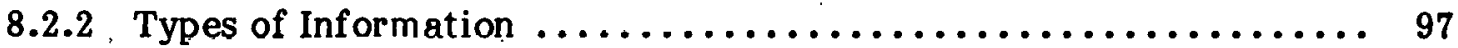

8.3 Acquisition of Information by Respondents.................. 101

8.3.1 Use of Selected Information Sources .................. 101

8.3.2 Membership in Solar-Interested Organizations .............. 104

8.3.3 Exposure to Publications on Solar Energy ................. 104

8.3.4 Use of Special Acquisition Methods . ................... 104

8.4 Summary and Comments ........................... 105

9.n Antive Solar Heating and Cooling Planners................... 107

9.1 Description of Respondents ......................... 107

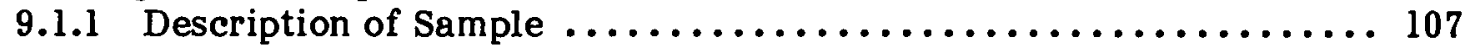

9.1.2 Current Status of Respondents ...................... 107

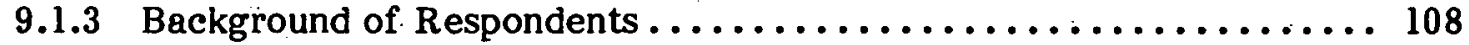

9.2 Information Needs of Respondents $\ldots \ldots \ldots \ldots \ldots \ldots \ldots \ldots \ldots \ldots \ldots \ldots$

9.2.1 Technical Areas................................. 109

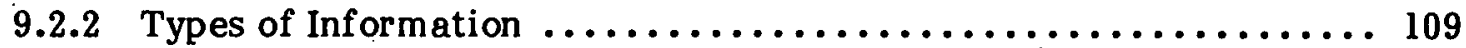

9.3 Acquisition of Information by Respondents.................. 111

9.3.1 Use of Selected Information Sources ................... 111

9.3.2 Membership in Solar-Interested Organizations .............. 113

9.3.3 Exposure to Publications on Solar Energy ................ 113

9.3.4 Use of Special Acquisition Methods .................... 114

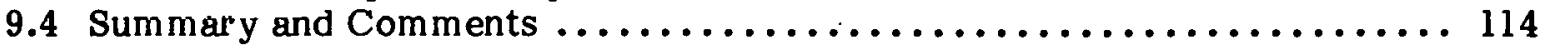


TABLE OF CONTENTS (Continued)

Page

10.0 Active Solar Heating and Cooling Heating, Ventilating, and

Air Conditioning Engineers .......................... 117

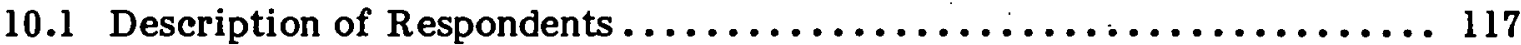

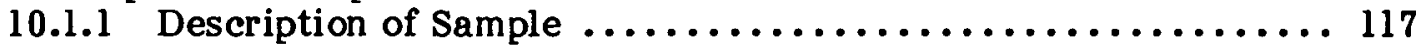

10.1.2 Current Status of Respondents .................... 117

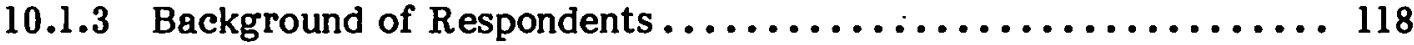

10.2 Information Needs of Respondents $\ldots \ldots \ldots \ldots \ldots \ldots \ldots \ldots \ldots \ldots \ldots \ldots \ldots$

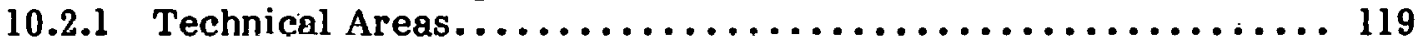

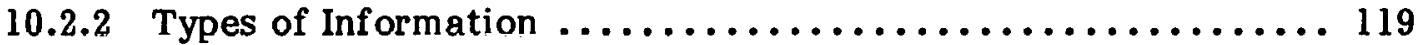

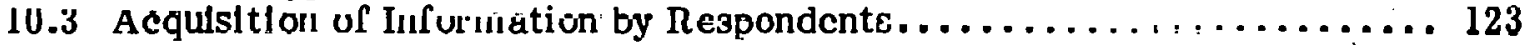

10.3.1 Usè of Selec led Infurnution Jources . . . . . . . . . . . . . . . 12.3

10.3.2 Membership in Solar-Interested Organizations ........... 126

10.3.3 Exposure to Publications on Solar Energy .............. 126

10.3.4 Use of Special Acquisition Methods ................ 127

10.4 Summ ary and Comments .......................... 127

11.0 Active Solar Heating and Cooling Industrial Engineers . . . . . . . . . . . 129

11.1 Description of Respondents ......................... 129

11.1 .1 Description of Sample ........................ 129

11.1.2 Current Status of Respondents .................... 129

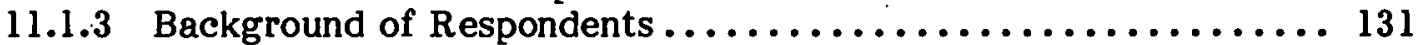

11.2 Information Needs of Respondents ...................... 131

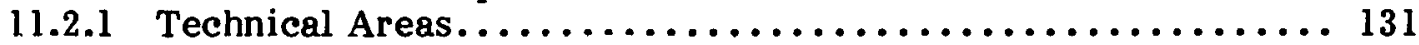

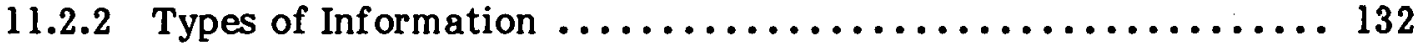

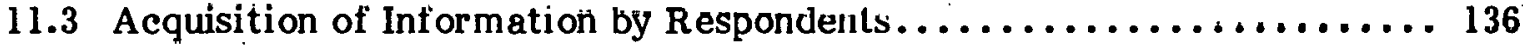

11.3.1 Use of Selected Information Sources ................. 136

11.3.2 Membership in Solar-Interested Organizations ............ 140

11.3.3 Exposure to Publications on Solar Energy ............... 141

11.3 .4 Use of Special Acquisition Methods .................. 141

11.4 Summary and Comments $\ldots \ldots \ldots \ldots \ldots \ldots \ldots \ldots \ldots \ldots \ldots \ldots \ldots \ldots \ldots$

12.0 Active Solar Heating and Cooling Utility Representatives............ 143

12.1 Description of Respondents $\ldots \ldots \ldots \ldots \ldots \ldots \ldots \ldots \ldots \ldots \ldots \ldots \ldots \ldots \ldots$

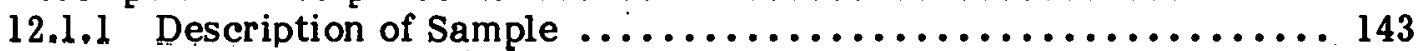

12.1.2 Current Status of Respondents ................... 144

12.1.3. Background of Respondents .................... 145

12.2 Information Needs of Respondents $\ldots \ldots \ldots \ldots \ldots \ldots \ldots \ldots \ldots \ldots \ldots \ldots \ldots 145$

12.2.1 Technical Areas............................. 145

12.2 .2 Types of Inf ormation $\ldots \ldots \ldots \ldots \ldots \ldots \ldots \ldots \ldots \ldots \ldots \ldots \ldots \ldots \ldots \ldots$

12.3 Acquisition of Information by Respondents................. 150

12.3.1 Use of Selected Information Sources ................ 150

12.3.2 Membership in Solar-Interested Organizations ............ 154

12.3.3 Exposure to Publications on Solar Energy ............... 154

12.3.4 Use of Special Acquisition Methods ................. 155

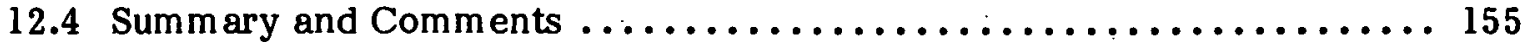


TABLE OF CONTENTS (Continued)

Page

13.0 Active Solar Heating and Cooling Educators $\ldots \ldots \ldots \ldots \ldots \ldots \ldots \ldots \ldots \ldots$

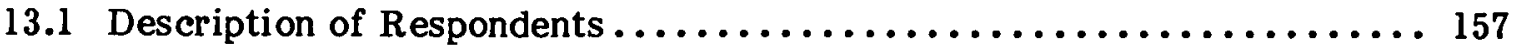

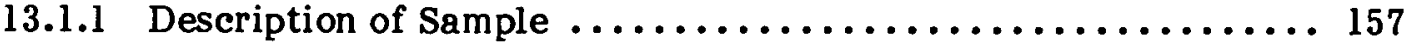

13.1.2 Current Status of Respondents .................... 158

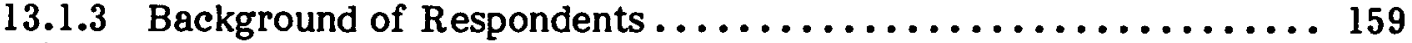

13.2 Information Needs of Respondents $\ldots \ldots \ldots \ldots \ldots \ldots \ldots \ldots \ldots \ldots \ldots \ldots$

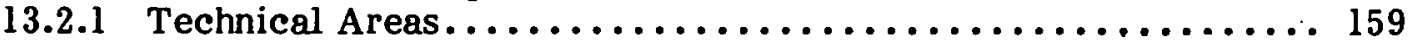

13.2.2 Types of Information ........................... 159

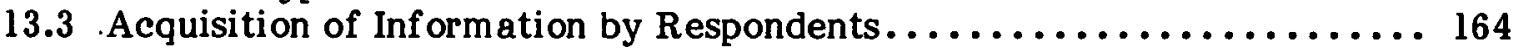

13.3.1 Use of Selected Information Sources ................... 164

13.3.2 Membership in Solar-Interested Organizations ............ 168

13.3.3 Exposure to Publications on Solar Energy ................ 169

13.3.4 Use of Special Acquisition Methods ................... 170

13.4 Summary and Comments $\ldots \ldots \ldots \ldots \ldots \ldots \ldots \ldots \ldots \ldots \ldots \ldots \ldots \ldots \ldots$

14.0 County Agents, Cooperative Extension Service $\ldots \ldots \ldots \ldots \ldots \ldots \ldots \ldots \ldots$

14.1 Description of Respondents ........................... 171

14.1.1 Description of Sample ............................. 171

14.1.2 Current Status of Respondents .................... 172

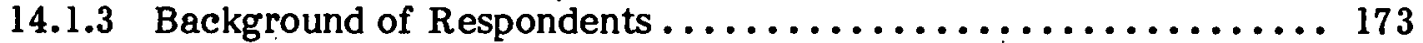

14.2 Information Needs of Respondents $\ldots \ldots \ldots \ldots \ldots \ldots \ldots \ldots \ldots \ldots \ldots \ldots \ldots$

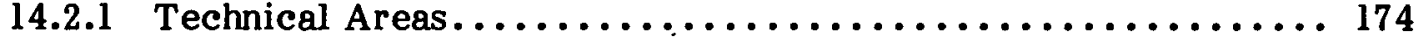

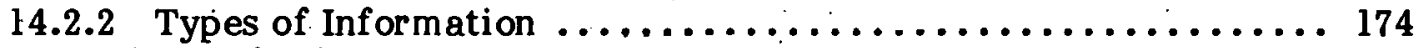

14.3 Acquisition of Information by Respondents................ 180

14.3.1 Use of Selected Information Sources ................. 180

14.3.2 Membership in Solar-Interested Organizations ............ 180

14.3.3 Exposure to Publications on Solar Energy ................. 185

14.3.4 Use of Special Acquisition Methods .................. 185

14.4 Summary and Comments .......................... 185

15.0 Active Solar Heating and Coniling Owners/Managers............... 187

15.1 Description of Respondents ......................... 187

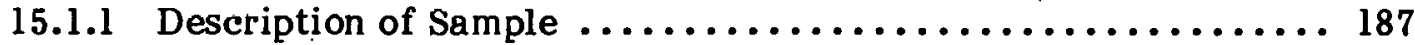

15.1.2 Current Status of Respondents .................... 189

15.1.3 Background of Respondents ...................... 189

15.2 Information Needs of Respondents $\ldots \ldots \ldots \ldots \ldots \ldots \ldots \ldots \ldots \ldots \ldots \ldots$

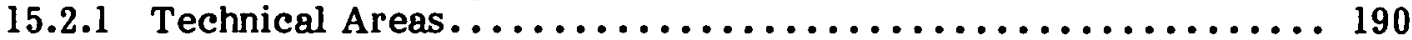

15.2.2 Types of Information $\ldots \ldots \ldots \ldots \ldots \ldots \ldots \ldots \ldots \ldots \ldots \ldots \ldots \ldots$

15.3. Acquisition of Information by Respondents ................. 198

15.3.1. Initial Information Sources $\ldots \ldots \ldots \ldots \ldots \ldots \ldots \ldots \ldots \ldots \ldots \ldots$

15.3.2 Use of Selected Inf ormation Sources ................. 198

15.3.3 Membership in Solar-Interested Organizations ............ 206

15.3.4 Exposure to Publications on Solar Energy ............... 207

15.4 Summary and Comments ........................... 209 
TABLE OF CONTENTS (Concluded)

Page

16.0 References............................................

Appendix A: Groups Included in Study .......................... 215

Appendix B: Study Development and Procedure $\ldots \ldots \ldots \ldots \ldots \ldots \ldots \ldots \ldots \ldots \ldots . . \ldots 33$

Appendix C: Letter of Introduction $\ldots \ldots \ldots \ldots \ldots \ldots \ldots \ldots \ldots \ldots \ldots \ldots \ldots \ldots$

Appendix D: Study Questionnaire $\ldots \ldots \ldots \ldots \ldots \ldots \ldots \ldots \ldots \ldots \ldots \ldots \ldots \ldots \ldots . \ldots \ldots$

Appendix E: $\quad$ Statistical Testing........................... 267

Appendix F: Active Solar Heating and Cooling Data Tables............. 2T1 


\section{LIST OP FIGURES}

$\underline{\text { Page }}$

3-1 Usefulness of Selected Information Items: DOE-Funded Active

Solar Heating and Cooling Researchers........................ 24

3-2 Usefulness of Selected Information Items: Non-DOE-Funded Active Solar Heating and Cooling Researchers ................... 25

3-3 Usefulness of Selected Information Items: Passive Researchers ........ 26

3-4 Usefulness of Selected Information Items: All Researchers $\ldots \ldots \ldots \ldots \ldots 27$

3-5 Use of Selected Information Sources: DOE-Funded Active Solar Heating and Cooling Researchers....................... 30

3-6 Use of Selected Information Sources: Non-DOE-Funded Active Solar Heating and Cóoling Researchers....................... 31

3-7 Use of Selected Inf ormation Sources: Passive Researchers........... 32

3-8 Use of Selected Information Sources: All Researchers $\ldots \ldots \ldots \ldots \ldots \ldots . . \ldots 33$

4-1 Usefulness of Selected Information Items: Total Active Solar Heating and Cooling Manufacturer Representatives........... 46

4-2 Usefulness of Selected Information Items: All Manufacturer

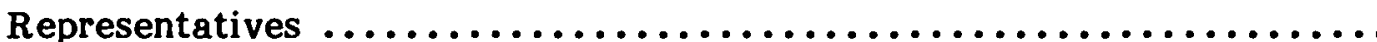

4-3 Usefulness of Selected Inf ormation Items: Passive Manuf acturer

Representatives $. \ldots \ldots \ldots \ldots \ldots \ldots \ldots \ldots \ldots \ldots \ldots \ldots \ldots \ldots \ldots, 48$

4-4 Usefulness of Selected Information Items: Total Active Solar

Heating and Cooling Collector Manufacturer Representatives .......... 51

4-5 Usefulness of Selected Information Items: Concentrating Collector

Manufacturer Representatives ...............................

4-6 Use of Selected Inf ormation Sources: Total Active Solar Heating and Cooling Manuf acturer Representatives .................... 53

4-7 Use of Selected Information Sources: All Manuf acturer

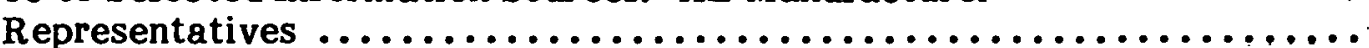

4-8 Use of Selected Information Sources: Passive Manufacturer Representatives

5-1 Usefulness of Selected Inf ormation Items: Active Solar Heating

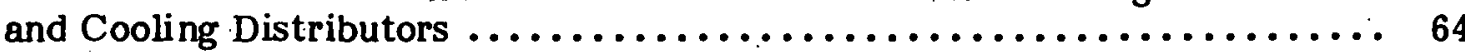

5-2 Usefulness of Selected Information Items: Wind Distributors $\ldots \ldots \ldots \ldots \ldots 65$ 
LIST OF FIGURES (Continued)

Page

5-3 Use of Selected Inf ormation Sources: Active Solar Heating and

Cooling Distributors ................................ 67

5-4 Use of Selected Inf ormation Sources: Wind Distributors $\ldots \ldots \ldots \ldots \ldots \ldots, 68$

6-1 Usefulness of Selected Information Items: Active Solar Heating and Cooling Installers $\ldots \ldots \ldots \ldots \ldots \ldots \ldots \ldots \ldots \ldots \ldots \ldots \ldots, 76$

6-2 Use of Selected Information Sources: Active Solur Heating

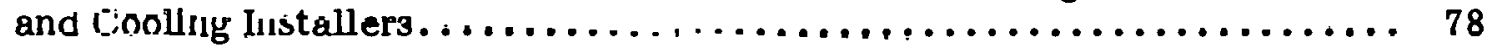

7-1 Usefulness of Selected Information Items: Active Solar Heating

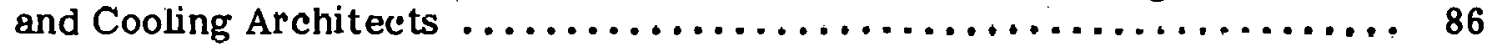

7-2 Usefulness of Selected Information Items: Passive Architects ......... 87

7-3 Use of Selected Inf ormation Sources: Active Solar Heating and

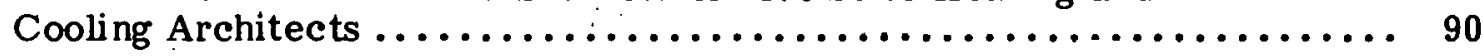

7-4 Use of Selected Information Sources: Passive Architects ............ 91

8-1 Usefulness of Selected Information Items: Active Solar Heating and Cooling Builders................................. 99

8-2 Usefulness of Selected Information Items: Passive Builders $\ldots \ldots \ldots \ldots \ldots \ldots 100$

8-3 Use of Selected Informution Sources: Motive Solar Heating and Cooling Builders................................... 102

8-4 Use of Selected Information Sources: Passive Builders $\ldots \ldots \ldots \ldots \ldots \ldots \ldots 103$

9-1 Usefulness of Selected Information Items: Active Solar Heating and Cooling Planners $\ldots \ldots \ldots \ldots \ldots \ldots \ldots \ldots \ldots \ldots \ldots \ldots \ldots \ldots, 110$

9-2 Use of Selected Inf ormation Sources: Active Solar Heating and

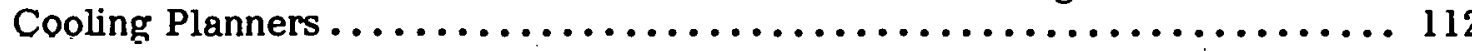

10-1 Usefulness of Selected Informution Items: Active Solar Heating and Cooling Heating, Ventilating, and Air Conditioning Engineers $\ldots \ldots \ldots \ldots 121$

10-2 Usefulness of Selected Information Items: All Engineers $\ldots \ldots \ldots \ldots \ldots \ldots 122$

10-3 Use of Selected Inf ormation Sources: Active Solar Heating and Cooling Heating, Ventilating, and Air Conditioning Engineers ......... 124

10-4 Use of Selected Information Sources: All Engineers............... 125

11-1 Usefulness of Selected Information Items: Active Solar Heating and Cooling Industrial Engineers $\ldots \ldots \ldots \ldots \ldots \ldots \ldots \ldots \ldots \ldots \ldots \ldots \ldots \ldots$ 


\section{LIST OF PIGURES (Continued)}

11-2 Usefulness of Selected Information Items: Industrial Process Heat

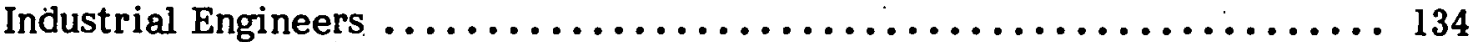

11-3 Usefulness of Selected Information Items: Industrial Process Heat Plant Engineers .................................... 135

11-4 Use of Selected Inf ormation Sources: Active Solar Heating and Cooling Industrial Engineers ........................... 137

11-5 Use of Selected Information Sources: Industrial Process Heat Industrial Engineers . . . . . . . . . . . . . . . . . . . . . . . . 138

11-6 Use of Selected Inf ormation Sources: Industrial Process Heat Plant Engineers .................................... 139

12-1 - Usefulness of Selected Information Items: Active Solar Heating and Cooling Utility Representatives

12-2 Usefulness of Selected Information Items: All Solar Utility

Representatives

12-3 Usefulness of Selected Information Items: Nonsolar Utility Representatives ................................... 148

12-4 Use of Selected Inf ormation Sources: Active Solar Heating and Cooling Utility Representatives ......................... 151

12-5 Use of Selected Information Sources: All Solar Utility Representatives

12-6 Use of Selected Information Sourccs: Nonsolai Utility Representatives

13-1 Usefulness of Selected Information Items: Active Solar Heating and Cooling Educators

13-2 Usefulness of Selected Information Items: Passive Educators $\ldots \ldots \ldots \ldots \ldots$

13-3 Usefulness of Selected Information Items: All Educators $\ldots \ldots \ldots \ldots \ldots \ldots$

13-4 Use of Selected Inf ormation Sources: Active Solar Heating and Cooling Educators................................ 165

13-5 Use of Selected Information Sources: Passive Educators . . . . . . . . . . . 166

13-6 Use of Selected Information Sources: All Educators $\ldots \ldots \ldots \ldots \ldots \ldots \ldots$ 


\section{IST OF FIGURES (Continued)}

Page

14-1 Usefulness of Selected Information Items: Active Solar Heating and Cooling Cooperative Extension Service County Agents............ 175

14-2 Usefulness of Selected Information Items: Passive Cooperative Extension Service County Agents........................ 176

14-3 Usefulness of Selected Information Items: All Cooperative Extension Service County Agents.............................. 177

14-1 Usefulness of Selected Information Items: All Couper'utive Lxtcnolon Service State Specialists ............................ 178

14-5 Use of Selected Information Sources: Active Solar Heating and Cooling Cooperative Extension Service County Agents

14-6 Use of Selected Information Sources: Passive Cooperative Extension Service County Agents............................... 182

14-7 Use of Selected Information Sources: All Cooperative Extension Service County Agents............................... 183

14-8 Use of Selected Information Sources: All Cooperative Extension Service State Specialists

15-1 Usefulness of Selected Information Items: Active Space Healing Homeowners

15-2 Usefulness of Selected Information Items: Active Water Heating Homeowners

15-3 Usefulness of Selected Information Items: Active Solar Heating and Cooling Building Owners/Managers ....................... 195

15-4 Usefulness of Selected Information Items: Total Active Solar Heating and Cooling Homeowners ......................... 199

15-5 Usefulness of Selected Information Items: Passive Hom eowners ........ 200

15-6 Use of Selected Information Sources Active Space Heating Homeowners

15-7 Use of Selected Information Sources: Active Water Heating Hom eowners

15-8 Use of Selected Information Sources: Active Solar Heating and

Cooling Building Owners/Managers 


\section{LIST OF FIGURES (Concluded)}

C-1 Letter of Introduction $\ldots \ldots \ldots \ldots \ldots \ldots \ldots \ldots \ldots \ldots \ldots \ldots \ldots \ldots \ldots \ldots \ldots$

D-1 Questionnaire.................................... 242

D-2 Questionnaire.................................... 252

F-1 Active Solar Heating and Cooling Data Tables.................. 279 


\section{THIS PAGE}

\section{WAS INTENTIONALLY \\ LEFT BLANK}




\section{LST OF TABLES}

Page

S-1 Comparative Usefulness of General Types of Information on Active

Solar Heating and Cooling (SHAC) $\ldots \ldots \ldots \ldots \ldots \ldots \ldots \ldots \ldots \ldots \ldots \ldots \ldots$

S-2 Value Assessment of Specific Active Solar Heating and Cooling (SH AC)

Information Products ................................... xiii

S-3 Sources Used to Obtain Solar Information.................... xv

S-4 Interest in Information on Active Solar Heating and Cooling (SHAC)

Topies .............................................

S-5 Advanced Information Acquisition Methods Used $\ldots \ldots \ldots \ldots \ldots \ldots \ldots \ldots$

2-1 Active Solar Heating and Cooling (SHAC) Information Users $\ldots \ldots \ldots \ldots \ldots$

3-1 Completion of Interviews: Active Solar Heating and Cooling

Researchers ...................................... 20

3-2 Areas of Interest: Active Solar Heating and Cooling Researchers ........ 22

4-1 Completion of Interviews: Total Active Solar Heating and Cooling

Manuf acturer Representatives ......................... 4

4-2 Levels of Involvement: Active Solar Heating and Cooling

Manuf acturer Representatives ............................ 42

4-3 Levels of Informedness: Active Solar Heating and Cooling

Manufacturer Representatives ........................... 43

4-4 Areas of Interest: Active Solar Heating and Cooling System

Manuf acturer Representatives and Active Solar Water

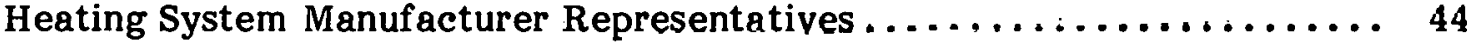

4-5 Membership in Solar-Interested Organizations: Active Solar Heating and Cooling Manufacturer Representatives .................. 57

4-6 Publications Read Which Included Information on Solar Energy:

Active Solar Heating and Cooling Manufacturer Representatives ........ 58

5-1 Completion of Interviews: Active Solar Heating and Cooling

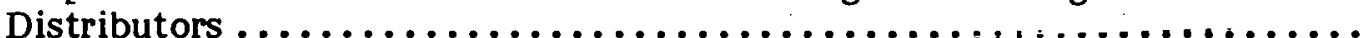

6-1 Completion of Interviews: Active Solar Heating and Cooling

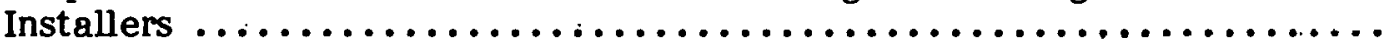

7-1 Completion of Interviews: Active Solar Heating and Cooling

Architects 
LST OF TABLES (Continued)

Page

7-2 Areas of Interest: Active Solar Heating and Cooling Architects

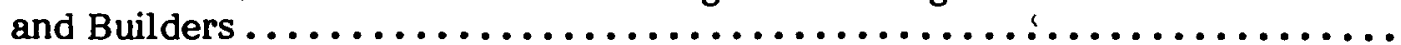

8-1 Completion of Interviews: Active Solar Heating and Cooling Builders

8-2 Areas of Interest: Active Solar Heating and Cooling

Builders and Architects ...................................

9-1 Completion of Interviews: Active Solar Hcating and Conling

Planner's

10-1 Completion of Interviews: Active Solar Heuting und Cooling Heating;

Ventilating, and Air Conditioning Engineers.................... 118

10-2 Areas of Interest: Active Solar Heating and Cooling Heating,

Ventilating, and Air Conditioning (HVAC) Engineers and

Active Solar Heating and Cooling Industrial Engineers.

11-1 Completion of Intervews: Active Solar Heating and Cooling

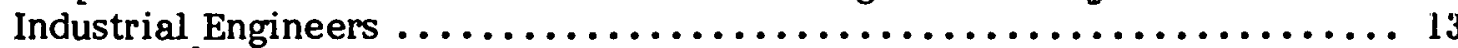

11-2 Areas of Interest: Active Solar Heating and Cooling Industrial

Engineers and Heating, Ventilating, and Air Conditioning (HVAC)

Ëngineers

12-1 Completion of Int erviews: Active Solar Heating and Cooling Utility

Representatives

13-1 Completion of Interviews: Active Solär Heuting and Cooling

Educators ........................................... 158

14-1 Completion of Interviews: Active Solar Heating and Cooling

Conperative Extension Service County Agents $\ldots \ldots \ldots \ldots \ldots \ldots \ldots \ldots \ldots . \ldots \ldots$

15-1 Completion of Inter views: Active Solar Space Heating Hom eowners, Active Solar Water Heating Homeowners, and Active Solar Heating and Couling Building Owners/Managers.

15-2 Current Need for Active Solar Heating and Cooling Informution by Active Solar Space Heating Hom eowners, Active Solar Water Heating Homeowners, Active Solar Heating and Cooling Building Owners/Managers, and Passive Homeowners

15-3 Types of Systems Used by Active Solar Space Heating Homeowners, Active Solar Water Heating Homeowners, and Active Solar Heating and Cooling Building Owners/Managers

15-4 Membership in Solar-Interested Organizations: Active Solar Space Heating Homeowners, Active Solar Water Heating Homeowners, and Active Solar Heating and Cooling Owners/Managers 
LIST OF TABLES (Concluded)

15-5 Publications Read Which Included Information on Solar Energy: Active Solar Space Heating Homeowners, Active Solar Water Heating Homeowners and Active Solar Heating and Cooling Owners/Managers

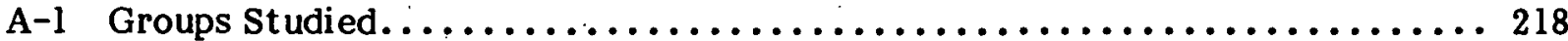

B-1 Cooperative Extension Service (CES): States Represented in Samples ...................................... 231

D-1 Selected Organizations About Which Active Solar Heating and

Cooling (SHAC) Respondents were Asked .................... 266

F-1 Groups and Combination Groups with Data Included in Appendix F ....... 274

F-2 Combination Groups $\ldots \ldots \ldots \ldots \ldots \ldots \ldots \ldots \ldots \ldots \ldots \ldots \ldots \ldots \ldots \ldots$

F-3 List of Active Solar Heating and Cooling Data Tables $\ldots \ldots \ldots \ldots \ldots$ 


\section{THIS PAGE \\ WAS INTENTIONALLY \\ LEFT BLANK}




\section{SECTION 1.0}

\section{NTRODUCTION}

This report describes the results of a series of interviews with potential users of information on active solar heating and cooling (SHAC). These interviews, part of a larger study covering nine different solar technologies, attempted to identify:

- the type of information each distinctive group of information users needed, and

- the best way of getting information to that group.

This section explains the background of the study, places this report in the context of the overall program, and describes the structure of this report.

\subsection{BACKGROUND}

The rapid, widespread commercialization of solar energy will be necessary if the United States is to meet the energy crises of the next 50 years, but the use of solar energy will never reach meaningful levels without both the recognition that information transfer is essential to commercialization and the deliberate development of systems for the transfer of information. For example, scientists need the latest solar research results to enhance their own efforts; engineers and installers need performance data to design solar systems; public interest groups need environmental impact data to support solar technologies against conventional energy alternatives; potential owners of solar energy systems need cost information to make purchase decisions; and the general public needs basic information to weigh which public policies to support.

In 1974 the Congress, noting the importance of information transfer and recognizing the value to the solar community of an integrated, comprehensive data collection and information dissemination system, called for the implementation of a Solar Energy Information Data Bank (SEIDB). In The Solar Energy Research and Development Act (P.L. 93473) Congress stated that the SEIDB should be established "for the purpose of collecting, reviewing, processing, and disseminating information and data ... in all of the solar energy technologies."

The U.S. Department of Energy (DOE) has assigned the Solar Energy Research Institute (SERI) the task of serving as the lead center to fulfill this Congressional mandate to collect all types of solar-related information, to convert it into a user-oriented format, and to disseminate this information to the widest possible range of persons and groups with an interest in solar energy. These groups range from decision makers at all levels of government to manufacturers of solar products; from solar architects, installers, and service persons to home or farm owners; and from banks and financial institutions to scientists and researchers. In accord, SERI's Information Systems Division (ISD) is now in the process of collecting solar information, building data bases, and preparing and disseminating information through a variety of products and services.

The long-range objective of the SEIDB is a centrally coordinated network to ensure that all individuals concerned with solar energy have prompt and efficient access to whatever information is necessary to support sound decisions. Ultimately, this information will be accessible through a variety of means (publications, computer data systems, audiovisual products, the Solar Energy Information Center (SEIC), inquiry and referral services, etc.) to serve the diverse requirements of the solar community. 


\subsection{SOLAR ENERGY INFORMATION DATA BANK (SEIDB) PROGRAM PLANNING}

In the past decade, information scientists have studied many organizations responsible for data collection and information product development. A consistent finding of this research is that a key to the successful, efficient operation of such an organization is to design the entire system with the potential information user in mind. It is essential that development of information products and data bases be targeted for specific users rather than merely developed spontaneously. The information users, their information needs, and the priority of those needs must all be identified before effective information products and services can be developed efficiently. To ensure that the SEIDB is responsive to the high-priority information needs of the solar community, the Information Market Research Section of ISD is performing the following tasks:

1. Defining the community of solar information users;

2. Setting priorities as to which groups of liformation users have the most important near-term information needs;

3. Determining the near-term information needs of the high-priority users;

4. Determining the information channels that can be effectively used to reach the high-priority users;

5. Determining what high-priority information needs are being met fully by existing products and services; and

6. Recommending additional, targeted, cost-effective information products and services to meet high-priority needs.

The results of the first two tasks are described in a previous document, the Solar Information User Priority Study [1]. First, for each solar technology, those members or potential members of the solar community who will need solar information were identified; and second, the relative importance of meeting the near-term information needs of each group of information users was described. This document provides guidelines to SFIDB planners as to who might be using the SEIDB and whose near-ler'll lieeds are thc most important.

The results of the third and fourth tasks are described in the current set of ten reports (see Section 1.3). These reports document the high-priority information needs and the most familiar information channels for each of 86 groups which were interviewed by telephone.

There have been a few previous studies that asked homeowners what solar information they needed, but this is the only known study to provide data on the solar information that such groups as researchers, manufacturers, architects, engineers, installers, lawyers, bankers, insurers, public interest groups, state energy offices, and agricultural exteinsion agents themselves say they want.

The data from this study will be used along with other data to determine what new information products and services SERI, the SEIDB Network, and the entire solar information outreach community should be preparing for and disseminating to the solar community. These data will include (but not be limited to): contacts with SERI specialists; review of the Annual Operating Plans, Institutional Plans, and Program Plans of DOE and SERI; reviews of other solar literature; development of an "information user profile" data base from mailing list response cards; information user panels; direct contacts with 
members of the solar community at conferences, training sessions, etc.; visits to headquarters of national associations of users; and feedback provided by users of existing information products. Since information needs and priorities will continuously change, these tasks will necessarily be ongoing.

\subsection{REPORT CONTENTS}

This SHAC report is one of ten issued on the results of these studies of solar energy information users. The full set of reports covers:

- Photovoltaics

- Passive Solar Heating and Cooling

- Active Solar Heating and Cooling

- Biomass Energy

- Solar Thermal Electric Power

- Industrial and Agricultural Process Heat

- Wind Energy

- Ocean Energy

- Solar Energy Storage

- General Solar Energy

Section 2.0 of this report describes the type of study conducted and the resulting constraints. The method used to select these groups is also described in Section 2.0. Several groups discussed in other reports from this study also indicated an interest in information on SHAC. These groups are listed in Section 2.2.4. Sections 3.0 through 15.0 describe the results of studies of:

- DOE-Funded SHAC Rescarchers and Non-DOE-Funded SHAC Resarchers;

- Representatives of Solar Heating and Cooling System Manufacturers, Solar Hot Water System Manufacturers, Nonconcentrating Collector Manufacturers; and nther SHAC Component Manufacturers;

- Distributors of SHAC systems and components;

- Installers of SHAC systems;

- Architects who had been involved in SHAC projects;

- Builders who had been involved in SHAC technologies;

- Planners who were interested in SHAC;

- Heating, Ventilating, and Air Conditioning (HVAC) Engineers who had been involved in SHAC;

- Industrial Engineers who were interested in SHAC;

- Representatives of Utilities conducting SHAC experiments or demonstrations;

- Educators teaching college level courses in SHAC; 
- Cooperative Extension Service (CES) County Agents who will be needing information on SHAC;

- Owners/managers of buildings with SHAC systems, Homeowners with space heating and cooling systems, and Homeowners with hot water systems.

These respondents were asked specifically about their needs for information on SHAC. In each of these sections describing study results, a standard presentation format has been used.

The appendices contain a list of all 86 groups interviewed (including the technologies other than SHAC). They also contain a description of how the study was developed, a copy of the letter of introduction, a sample questionnaire, a description of the statistical tests used, and the data from the studies of the SHAC groups. 
SECTION 2.0

\section{STUDY DESCRIPTION}

This section gives a brief description of the study. Appendix B gives additional information on how the study was designed and conducted. This section also explains how groups from the active solar heating and cooling (SHAC) community were selected as those to be sampled and gives a few comments on interpretation of study results. The study findings are reported in Sections 3.0 through 15.0.

\subsection{STUDY CHARACTERISTICS}

Between 3 September 1979 and 13 October 1979 Market Opinion Research, Inc. (MOR) of Detroit, Michigan-under subcontract to SERI-conducted telephone interviews with 86 distinet groups of solar information users. Approximately nine respondents were interviewed from each group. Interviews were based upon professionally reviewed and tested questionnaires (see Appendix D) and took an average of 18 minutes to complete. The 86 groups, selected to cover 9 solar technologies/applications, are listed in Appendix A. The results discussed in this report are from the 19 of those 86 studies which dealt specifically with SHAC.

Studies of 86 groups, each interested either in one of nine different solar technologies or in solar technologies in general, provided an extremely broad view of the information needs of the solar community. Although the sample size of nine respondents per group was small, the data still proved to be quite adequate for planning purposes. It was possible to determine which information was the most important to the respondents and what was the best channel for disseminating that information. A variety of valid statistical tests were performed, both to compare the priorities a group gave to different information items and to compare the priorities different groups gave to the same item.

The respondents proved to be very cooperative. Considering the length and nature of the telephone interviews, it was surprising that only about $3 \%$ of the respondents terminated an interview or refused to be interviewed. This finding supported the interviewers' statements that the respondents were very interested in telling what they were doing in solar energy, in obtaining solar information, aild in specifying what solar information would prove the most valuable. It was also observed that the number of respondents answering "don't know" or not answering a question was quite low. Including those cases where the potential respondent could not be reached within three attempts (or before the required number of interviews was completed), where the respondent ref used to be interviewed, where the respondent terminated the interview prematurely, etc., the completion rate for the entire study was about $75 \%$. The completion rate for each individual group is given in the section in which that group is discussed.

\subsection{GROUPS STUDIED}

One of the most important tasks was the selection of the groups of potential users of solar information to be studied. Before this could be done, however, it was necessary to list the important groups constituting the SHAC community and to develop a conceptual framework within which selections could he made. 


\subsubsection{Target Audiences, Classes, and Groups}

An important information science concept in developing information products and services is that of the "target audience" or "target group." These are generally defined as a collection of individuals or organizations who have similar information needs and information-acquiring habits. People in the same group tend to need information on the same subjects, at a similar technical level, and within a similar timeframe. In developing an information product program, it is important to begin with a typology that assigns information users who have similar needs to common groupings. This allows development of efficient, targeted information products to meet identified needs of specific users without inundating other members of the solar community with unneeded information.

In Solar Information User Priority Study [1] such a typology was developed. Under this system members of the solar community were placed in distinet "user groups." A set of user groups formed a "user class" and a collection of user classes form ed a "target audience." For more precise definitions:

- A User Group is the most basic category of information users who can be combined together under a single definitive title (e.g., Civil Engineers). A single information user group should be addressable by many specific information products. The purpose of defining distinct information User Groups is to identify a single set of users who can be served by the same information product (e.g., a civil engineers' handbook).

- A User Class is a set of information user groups that exhibit many common distinguishing characteristics (e.g., Facility or System Designers). A single information user class should be addressable by many general information products. The purpose of defining separate information User Classes is to identify sets of two or more groups of users who asn be served by similiar information products (e.g., solar heating and cooling system design models).

- A Target Audience is a set of information user classes that exhibit some common distinguishing characteristics (e.g., Researchers). A single target audience should be addressable by one or more distinct types of information products. The purpose of defining separate information-user Target Audiences is to identify broad sets of users who can be served by the same generic types of information products (e.g., research-in-progress newsletters).

Following this system, all solar information users fall within one or more of five Target Audiences. These Target Audiences are:

Researchers - those who are actively involved in researching, developing, and testing of new state-of-the-art technical developments in solar energy.

Applications Technologists - those involved in translating rescarch results into marketable equipment and services. This classification includes manufacture, distribution, sales, design, installation, and maintenance of solar systems or components.

Facilitators - those whose decisions or actions directly aid (in either a positive or negative manner) the commercialization of solar energy. Thus, Congressmen would be Facilitators in that they have the ability to pass legislation giving incentives; lobbyists in that they can affect legislation; state energy offices in that they can initiate demonstration projects; and the Environmental Protection Agency (EPA) in that it can forbid construction of a manufacturing plant at a specific site. 
Users or Prospective Users - those individuals or organizations who have already applied this type of solar energy technology in their operations, or have a reasonable chance of doing so in the near future.

General Public - Individuals who are not likely to utilize solar technology in the near future. An important aspect of this audience is its ability to influence the course of solar technologies through political influence, pro or con.

Based upon this scheme, the SHAC information user community has been defined. Table 2-1 enumerates the user groups comprising the SHAC information community and shows into which target audience each falls [1].

\subsubsection{Criteria for Selection of Groups to Study}

From Table 2-1, it is rapidly evident that there are many user groups who will event ually be needing information on SHAC. The problem was, thus, to select those groups to be included as a part of this study. To determine which groups would be studied, each group was evaluated with respect to the following selection criteria:

- appropriateness of using a structured telephone interview to collect information from the group on information needs and habits,

- relative priority of the group's short- or medium-range information needs, and

- availability of a sample frame for the group.

First, for many groups a sturctured telephone interview was not an appropriate method for defining information needs. It was not practical to interview DOE or an organization like the Electric Power Research Institute, or to interview a group like Congressional committee staff which would be too busy to respond. Rather than defining the information needs of these groups by telephone interviews, they will be contacted directly in FY 1981.

Second, only those groups with a high immediate or potential need for SHAC information were selected. Further, since fulfilling short-range information needs is critical, it was decided that in most cases those people who were already involved with SHAC would be sampled. It was felt that these were the people who would be primary users of the SEIDB over the next few years. These gioups had been identified earlier in the Solar Information User Priority Study [1].

Finally, for many of the groups, lists of persons to be interviewed could not be developed or acquired. In the absence of sample frames, studies of such groups were not possible. (For more detail on sample frame development, see Appendix B.)

\subsubsection{Groups Included in Active Solar Heating and Cooling Study}

After all decision criteria and constraints had been applied, it was determined that studies of the following 19 groups would be conducted to ask respondents about their need for information on SHAC:

- DOE-Funded SHAC Researchers;

- Non-DOE-Fundèd SHAC Researchers; 
Table 2-1. ACTIVE SOLAR HEATING AND COOLING (SHAC) INFORMATION USERS

Target Audiences

User Classes

User Groups

1.0 Researchers

1.1 DOE-Funded Researchers or Developers

Contractors

National Laboratories

1.2 Non-DOE, Federally Funded Researchers ur Developers

Department of Housing and Urban Development (HUD)

1.3 Nonfederally Funded Researchers or Developers

Universities

Solar Manufacturers

Trade Research Associations

Electric Power Research Institute (EPRI)

Gas Research Institute

Independent Research Organizations

Utilities

2.0 Applications Technologists

2.1 Active SHAC or SHAC-Related Manufacturers

Hot Water Systems Manufacturers

Collector Manufacturers

Component Manufacturèrs

2.2 Active SHAC Facility or System Designers

Architects

System Designers/Engineers

Architectural/Engineering Design Firms

Mechanicul Engineers

Heating, Ventilating, and Air Conditioning

(HVAC) Engineers

2.3 Builders, Developers or Contractors

Homebuilders, Developers

General Contractors

Architectural/Engineering Construction Firms

Mechanical Engineering Contractors

HVAC Contractors

Plumbing Contractors

Construction Engineers 
Table 2-1. ACTIVE SOLAR HEATING AND COOLING (SHAC) INPORMATION USERS (Continued)

2.4 Active SHAC Installers or Maintainers

Installers

Carpenters

Plumbers

Electricians

HVAC Installers

Sheet Metal Workers

Solar Maintenance Workers

Construction Workers

Roofing Contractors

2.5 Active SHAC Equipment Distributors

2.6 Technical Specialists for Utility, Government, Commercial, or Industrial Organization Using an Active SHAC System

Operations Managers

Planners

\subsection{Facilitators}

3.1 Legislators or Staff

Congressmen

Congressional Committee Staff

State Legislators

National Conference of State Legislatures

3.2 Local Government Organizations

County Government Officials

Local Government Officials

Municipal Planners

Tax Assessors and Officials

3.3 Government Solar-Active Organizalions

DOE-Conservation and Solar Energy (C\&SE)

DOE-Energy Information Administration (EIA)

DOE-Regional Solar Energy Centers (RSECs)

DOE/HUD-National Solar Heating and Cooling Information Center (NSHCIC)

DOE-Regional Energy Offices

DOE-Energy Fxtension Service

United Stated Department of Agriculture (USDA)-Cooperative Extension Service (CES)

USDA-Other

HUD

Department of Labor (DOL)-Comprehensive Employment and Training Act (CETA)

Tennessee Valley Authority (TVA)

National Center for Appropriate Technology (NCAT) 
Table 2-1. ACTIVE SOLAR HEATING AND COOLING (SHAC) INFORMATION USERS (Continued)

3.3 Cont'd.

State Governors' Offices

State Energy Offices

State Solar Energy Offices

State Agricultural Offices

Municipal Energy Offices

3.4 Government Solar-Concerned Organizations

General Services Administration (GSA)

Department of Defensc (DOD)

Small Business Administration (SBA)

Internal Revenue Service (IRS)

Council on Environmentul Quality (CEQ)

Department of Commerce (DOC)

3.5 Nongovernment Solar-Active Organizations

Solar Trade Associations

Solar Professional Societies

Solar Public Interest Groups

Solar Lobbyists

3.6 Nongovernment Solar-Concerned Organizations

Community/Home Improvement Associations

Public Interest Organizations

Enviromil ental Organizations

Chambers of Commeroe

Non-Solar Professional Societies

Non-Solar Trade Associations

Farm er Co-ops

Farmer's Education and Cooperative Union of America

3.7 Regulatory, Codes, or Standards Community

Environmental Protection Agency (EPA)

Occupational Safety and Health Administration (OSHA) .

American Society of Heating, Refrigerating, and

Air Conditioning Engineers (ASHRAE)

American National Standards Institute (ANSI)

Building nfficials and Code Administrators (BOCA), Council of American Building Officials (CABU), Interrational Conference of Building Officials (ICBO), Suuthern Builuing Code Congress (SBCC)

American Society of Mechanical Engineers (ASME)

Better Business Bureaus

Building Inspectors

3.8 Utility Community

Electric Power Companies

Gas Utilities

National Association of Regulatory Utility Commissioners

State Utility Commissions 
Table 2-1. ACTIVE SOLAR HEATING AND COOLING (SHAC) INFORMATION USERS (Continued)

3.8 Cont'd.

Utility Trade Associations

Federal Power Marketing Agencies

DOE-Bonneville Power Administration

Tennessee Valley Authority (TVA)

3.9 Financial Community

Bankers

Venture Capital Brokers

Government Loan Agencies

Stockbrokers

3.10 Legal Community

3.11 Real Estate Community

Agencies

Salesmen

Appraisers

3.12 Insurance Community

Management

Agents

Actuaries

3.13 Educational Community

High School Science Teachers

University Faculty

Vocational Instructors

Career Counselors

Seminar Organizers and Instructors

3.14 Information Intermediaries

Federal Technical Libraries

Industrial Techniçal I.ihraries

Academic or Non-profit Technical Libraries

Public Libraries

Federal Information Centers

On-Line Information Services

Bookstores

Film Distributors

3.15 Media

Newspapers or Magazines

Technical and Trade Journals

Television

Radio

Book Publishers

Newspaper Farm Editors of America 
Table 2-1. ACTIVE SOLAR HEATING AND COOLING (SHAC) INPORMATION USERS (Concluded)

3.16 Labor Organizations

Carpentry Unions

Construction Unions

Sheet Metal Workers' International Association (SM WIA)

Plumbing Unions

Electrical Unions

4.0 Users or Prospective Users

4.1 Government, Commercial, or Industrial SHAC Users

Department of Defense (DOD)

GSA-Public Bullding Berviec

U.S. Department of Agriculture (USDA)

Other Federal/State/Local Agencies Owning or Holding Titles to Buildings

Owners of Large Buildings

New

Retrofits

Owners of Small Buildings

New

Retrofits

4.2 Residential or Farming Users

IIom cowners

Custom Homes

Speculative Houses

Retrofits

Farmers, Ranchers

Pool Owners

Mobile Home Owners

\subsection{General Public}

Secondary Schiool studenls

College Students

Adults 
- Representatives of SHAC System Manufacturers;

- Representatives of Solar Hot Water System Manufacturers;

- Representatives of Nonconcentrating Collector Manufacturers;

- Representatives of Other SHAC Component Manufacturers;

- Distributors of SHAC systems and components;

- Installers of SHAC systems;

- Architects who had been involved in SHAC projects;

- Builders who had been involved in SHAC technologies;

- Planners who were interested in SHAC;

- Heating, Ventilating, and Air Conditioning (HVAC) Engineers who had been involved in SHAC;

- Industrial Engineers who were interested in SHAC;

- Representatives of Utilities conducting SHAC experiments or demonstrations;

- Educators teaching college level courses in SHAC;

- Cooperative Extension Service (CES) County Agents who will be needing information on SHAC;

- Building owners/managers with SHAC systems;

- Hom eowners with space heating and cooling systems; and

- Homeowners with hot water systems.

The results from these studied are reported in Sections 3.0 through 15.0.

\subsubsection{Solar Heating and Cooling-Concerned Groups. Included in General Solar Study}

Additionally, as a part of the overall study a number of groups were queried about their need for information on solar energy in general, rather than on a specific technology like SHAC. While it was determined that all respondents in these groups had some involvement with solar energy, for many of them it was likely that this involvement was not, nor would it become, a primary factor in their professional work. Rather, for most-if not all - of them, solar energy was a new but minor issue which they were beginning to address within the scope of their existing jobs. Because each of these groups had peripheral interests in more than one solar technology, but had not yet become fully involved with any, they were asked for general solar information needs rather than technology-specific solar information needs.

The results of the General Solar Study are reported in another document [2]. For SHAC, the following nine groups were especially relevant because for each group at least seven of the nine respondents indicated SHAC was one of the areas in which they were "particularly interested in obtaining information":

- Loan Officers,

- Tax Assessors,

- Insurers, 
- Information specialists at State CES Offices,

- Real Estate Appraisers,

- Lawyers,

- Public Interest Groups,

- Utilities not known to have conducted solar experiments or demonstrations, and

- Agricultural engineering specialists at State CES Offices.

The General Solar Information User Study [2] also discusses the results of studies in which state solar/energy office representatives were asked about their general, rather than technology-specific, solar information needs. Ninety-four percent of these representatives were interested in SHAC information.

\subsection{DATA INTERPRELATION}

This subsection describes several points the reader should keep in mind in interpreting the data and results presented in the following sections.

\subsubsection{Impact of the Sample Frames: Who was Sampled?}

There were several ways in which the method of constructing the sample frames impacted the data. First, in some of the sample frames one geographic region was relatively over-represented, while another was relatively under-represented. For a study of sample size nine, however, such biases were generally not bothersome since the results were principally qualitative rather than quantitative.

Second, the sample frames were only as good as the sources. For example, the Smithsonian Science Information Exchange (SSIE) data base and DOE's Research in Progress (RIP) data base were principal sources in developing lists of researchers. The SSIE was not always current, of ten did not include the name of the correct principal investigutor, and did not contain much of the nonfederally funded research. RIP had similar problems, varying greatly in quality according to which technology was involved. Each of these problems could cause biases as to which researchers were included and which were excluded from the samples.

- Third, many arbitrary decisions were necessary in developing the sample frames. For example, it was important not to interview a respondent more than once, even if he or she wao working in more than one technical area. Thus, if Researcher $X$ at Company $Y$ was listed as principal investigator both for vite jroject in active SHAC and for another in passive, then $X$ was arbitralily assigned to ons of the two technologies, usually to the one with the smaller set of names.

The most important advice for the reader is to study carefully the description of how the sample frame was developed for each individual group. Often a generic title was assigned to a group; the reader must review sample frame development carefully to understand just who was being surveyed. 


\subsubsection{Statistical Tests}

The statistical tests used are described in Appendix E. In the following sections test results are reported only if the statistical tests were significant at the $P \quad 0.05$ level. Thus, if a test result indicated that a difference between two means was statistically significant ( $P$ 0.05), it meant that there was a maximum of a $1-i n-20$ chance that the two means were not different.

\subsubsection{Hypotheses Versus Conclusions}

Because of the limitations of sample size, it was not always possible to draw definitive conclusions. In certain cases, when definitive conclusions could not be drawn, the authors have instead formed hypotheses based upon the results.

\subsubsection{Significance of Rankings}

One of the most valuable results of this study was the development of a ranked list of information topics or products that would be useful to the members of each group (for example, see Fig. 3-1). Typically, statistical significance tests (see Appendix E) indicated that the four-to-six top-ranked items were rated significantly higher than the bottom four-to-six items. Thus, typically there was no statistically significant difference between the top-rated item and the second-rated item-or even between the toprated and the fourteenth-rated item. If the sample size had been greater, the number of combinations in which one item was rated significantly higher than the other would also have been greater. Even if every sample size had been raised by a factor of 10, however, it is highly unlikely that all pairs of items would have had significantly different ratings.

How, then, should the reader treat two items which were not significantly different in rating? Was there any meaning to the ranking system?

Yes, the fact that there were statistically significant differences between the top-rated and the bottom-rated items established the validity of the ranking scale as a whole. Despite the fact that two ratings are not significantly different, they still have the statistical property of being the Best Linear Unbiased Estimators. For example, even if Item 1 (with a rating of 3.4 ) was not significantly greater than Item 2 (with a rating of 3.1), Item.1 should still be considered the more important need unless there is additional, outside information to the contrary. (In determining which information products to develop, of course, one must also consider additional factors such as the cost of the product, the proportion of the group which will be reached, and the degree to which the information need will be met.)

\subsubsection{Alternative Measures of Usefulness}

The ranking of selected information items (in usefulness to the respondent) was based upon the rating developed by assigning a "4" for each response of "essential," a " 3 " for "very useful," a "2" for. "somewhat useful," and a "l" for "not at all useful;" summing the responses for the entire group; then dividing by the number of responses in the group. Using the rating was the preferable way to establish rankings within a group because it fully used the information on the differences between "essential" and "very useful," between "som ewhat useful" and "not at all useful." 
There were several alternative ways of comparing the usefulness of items, one of which was to calculate the percentage of respondents who classified the item as either "essential" or "very useful." Using this percentage was quite handy in considering how useful a product designed for more than one group would be. For example, both "a calendar (of solar events)" and "lists of local lenders (etc.)" were examples of information products that would be designed for many groups to use. In comparing the two potential products as to usefulness, the method (calculating for each item the percentage of the respondents who considered the item either "essential" or "very useful") provided a much more meaningful comparison than, for example, summing the ranks for all groups.

\subsubsection{Combining Results From Different Groups}

It should be pointed out that combining results from all SHAC groups interviewed will not provide unisiased estimates of the total SHAC community. First, the proportions of respondents from vile group interviewed in this study may not correspond to the proportion of such persons in the entire community. Second, the peculiarities of eaph individual sample frame were responsible for varying degrees of bias for each group. Third, some of the important groups in the SHAC community were not surveyed (see Section 2.2).

Great care should be exercised in interpreting results from a combination of groups. It is too easy to get the impression that one product can fully meet the needs of all groups when, in fact, it may only partially meet the information needs of some of the groups involved.

\subsubsection{Specific Information Products}

Several specific information products were included among the items for which usefulness was assessed. It is important that responses to these items not be interpreted as totally generic responses. People who gave "a bibli ography of general readings on SHAC" a low rating may have done so either hecause of the level and content of the subject matter (i.e., general readings on SHAC) or because of the format (i.e., bibliography). These people may or may not want bibliographies on other topics.

\subsubsection{Information Sources}

Another important question investigated how many respondents hud used spcoific information sources. In using these results to plan how sperific information is to be transmitted, it will be essential to specify fully both the information products or services and the groups to be reached before making the final decision of which information channels are to be used. Une caniot assume, for example, that the two or three top-rated sources should be used for all, or even most, of the information trunsmissions to the group.

There were two other issues related to this question. The first was the decision not to ask respondents whether they had used SERI as an information source. The reasons are discussed in Appendix D.

The second issue concerned possible bias in responses to the question "have you obtained any solar information directly from the U.S. Department of Energy?" The intent of the question was to find out if respondents had contacted DOE directly for information, rather than if they had obtained DOE-produced information from other sources (such as 
SERI, National Technical Information Service (NTIS), Government Printing Office (GPO), National Solar Heating and Cooling Information Center (NSHCIC), Regional Solar Energy Centers (RSECs), libraries, etc.). There was, however, no assurance that respondents interpreted the question in this light. In cases where the response "directly from DOE" was high, there was the possibility that respondents were referring to information authored or funded by DOE but obtained from other sources. 


\section{,}

SEPI 
SECTION 3.0

\section{ACTIVE SOLAR HEATING AND COOLING RESEARCHERS}

\subsection{DESCRIPTION OF RESPONDENTS}

\subsubsection{Description of Sample}

This section describes the results of two telephone studies to determine the needs of researchers for information on active solar heating and cooling (SHAC). In one study 9 DOE-Funded SHAC Researchers were interviewed, in the other 9 Non-DOE-Funded SHAC Researchers were interviewed.

The sample frame for DOE-Funded SHAC Researchers was constructed from the May 1978 U.S. Department of Energy (DOE) Solar Heating and Cooling Research and Development Project Summaries [4], and the Research in Progress (RIP) [5] and the Smithsonian Science Information Exchange (SSIE) [6] data bases. Only those projects in progress during some part of Fiscal Year 1978 (FY 1978) or FY 1979 were included. From the data-base searches, only those projects receiving at least some funding from DOE and involving SHAC but not passive solar heating and cooling were selected. Entries without contact names (i.e., principal investigator) were eliminated. Duplicates between this list and any other lists of active solar heating and cooling contacts were eliminated on all other lists. In addition, this sample frame was compared to other Researcher sample frames (for passive solar heating and cooling, photovoltaics, wind, solar thermal, ocean systems, solar industrial process heat, solar agricultural process heat, and energy storage) and duplicate principal investigator names were deleted. No organization was sampled more than once within the two SHAC Researcher sample frames, nor was any organization sampled for SHAC Researchers also included in another SHAC sample frame. After all adjustments were made, the 9 interview candidates were randomly selected from a sample frame of 170 names.

The sample frame for Non-DOE-Funded SHAC Researchers was constructed from the SSIE and RIP files, selecting those projects and principal investigators who had not received any funding from DOE. Only those projects in progress during some part of FY 1978 or FY 1979 were included. Duplicates were handled the same as for the DOEFunded SH $\Lambda \mathrm{C}$ Resieurchers. After all adjustments were made, the 9 interview candidates were randomly selected from a sample frame of 100 names.

Respondents. In making the telephone calls to contact the randomly selected interview candidates, it sometimes occurred that the person could not be reached. In this event another randomly selected name was substituted for the original name. When individuals were contacted, it was verified that they had been involved in SHAC research (and had or had not received funding from DOE, as appropriate for the specific group), and that they would be needing information on SHAC within the ncxt year. If they were not both involved and needing information, they were asked if they could refer the interviewer to someone else in their organization who would be an appropriate respondent. If such a referral was made, a call was then made to this new candidate; if no intraorganizational referral was made, a new candidate was randomly selected from the sample frame. The results of this process may be seen in Table 3-1. 


\section{Table 3-1. COMPLETION OF INTERVIEWS: ACTIVE SOLAR HEATING AND COOING RESEARCHERS}

Event

Number of Candidates

\begin{tabular}{|c|c|c|}
\hline \multirow{2}{*}{ Event } & \multirow[b]{2}{*}{ DOE-Funded } & \multirow[b]{2}{*}{ Non-DOE-Funded } \\
\hline & & \\
\hline Interview completed with samplo frame candidate & 6 & 7 \\
\hline Interview completed with referral candidate & 3 & 2 \\
\hline Refusal or candidate termination & 1 & 1 \\
\hline \multirow{2}{*}{\multicolumn{3}{|c|}{$\begin{array}{l}\text { Contact attempted: could not reach candidate } \\
\text { within three attempts or before interviews } \\
\text { were completed }\end{array}$}} \\
\hline & & 9 \\
\hline Subtotal & 11 & 19 \\
\hline \multirow{2}{*}{\multicolumn{3}{|c|}{$\begin{array}{l}\text { Contact attempted: invalid candldate } \\
\text { (e.g., inappropriate field of interest, no } \\
\text { telephone) }\end{array}$}} \\
\hline & & 11 \\
\hline TOTAL & 21 & 30 \\
\hline $\begin{array}{l}\text { Sample frame error rate }{ }^{a} \text { (Percent) } \\
\text { Completion rate }^{b} \text { (Percent) }\end{array}$ & $\begin{array}{l}48 \\
82\end{array}$ & $\begin{array}{l}37 \\
47\end{array}$ \\
\hline
\end{tabular}

Invalid candidates divided by TOTAL

${ }^{\mathrm{b}}$ Completed interviews divided by Subtotal

Comparisons. For additional insight into the information needs and the information habits of these two groups of SHAC Researchers, results from these groups are cumpared to the results both from all of the researchers interviewed in this study (All Researchers) and from Passive Researchors. The list of all the groups contained in All Researchers can be found in Table F-2 of Appendix F. In performing any statistical comparisons the totals for SHAC Researchers (one or both groups as apprujriate) have been subtracted from the totals for All Researchers. The data for DOE-Funded SHAC Researchers, NonDOE-Funded SHAC Researchers, Passive Researchers, and All Researchers can be found in Appendix F.

\subsubsection{Current Status of Respondents}

Role. Four of the DUE-Funded MIIAC Researchers were employed by manufacturers, 3 were working lor unlversities, 1 for a research institute, and 1 for a nitunicipal puhlis. works department. Five of the Non-DOE-Funded SHAC Késeuruliers wcre employed by universities, 1 by the research center of a large manufacturer, 1 by a utility company, and 1 was self-employed (for 1 , place of employment was not ascertained). Only 1 of the Non-DOE-Funded SHAC Researchers mentioned receiving federal funding (not from DOE).

Current activities of the DOE-Funded respondents included: teaching, consulting, writing a solar manual for DOE, operation of solar projects, proposal preparation, product development, and manufacturing and marketing. Specific topics in which they were involved covered: economical components for SHAC systems, "solar thermal," 
collectors, "photoelectrics," utility involvement in SHAC, silicone heat transfer fluids, self-pumping of circulants from collectors to thermo-energy storage, solar panels, solar storage units, and municipal building applications.

Current activities of the Non-DOE-Funded respondents included: heating and cooling research, proposal evaluation for funding state building programs, monitoring hot water usage at state hospitals, research (monitoring and analysis) on residential solar heating and cooling, construction of an experimental solar house, and solar retrofitting. a house.

Involvement. Seven of the 9 (78\%) DOE-Funded SHAC Researchers and 6 of the 9 (67\%) Non-DOE-Funded SHAC Researchers said that they were "very involved" with active solar heating and cooling. This compares to 6 of the $9(67 \%)$ Passive Researchers who were "very involved" with passive, and 107 of the 181 (59\%) All Researchers who said they were very involved with their respective solar technologies.

Informedness. Eight of the 9 (89\%) DOE-Funded SHAC Researchers and the same number of Passive Researchers considered themselves "very informed," compared to 7 of the 9 (78\%) Non-DOE-Funded SHAC Researchers and 117 of the 181 (65\%) All Researchers. Only two of the other 18 groups of researchers interviewed in this study gave themselves as high marks for informedness as did the DOE-Funded SHAC Researchers and Passive Researchers.

Need for Information. All respondents indicated they would need information on SHAC either on the job and/or outside the job during the next year. All of the Non-DOEFunded group and 8 of the DOE-Funded group needed this information on the job. Only 3 of the 9 (33\%) DOE-Funded SHAC Researchers needed information outside the job (2 needed it both on and off the job). This was somewhat lower than the results for NonDOE-Funded SHAC Researchers, where 6 (67\%) indicated they would need information on active SHAC outside the job. The result for All Researchers who were asked this question was 48 of the 117 (41\%) expecting to need information on their specific technology outside the job. Results for Passive Researchers were similar to those of DOE-Funded Active SHAC Researchers.

\subsubsection{Background of Respondents}

Four of the 9 (44\%) DOE-Funded SHAC Researchers and 3 of the 9 (33\%) Non-DOEFunded SIIAC Researchers held a PhD. More of the Passive Researchers (56\%) held PhD degrees, as did 51\% (93 of the 181) of All Researchers. The remainder of the DOEFunded SHAC Researchers held bachelor's or master's degrees, as did all but 1 of the Non-DOE-Funded SHAC Researchers.

Two of the DOE-Funded SHAC Researchers had received their most recent degree within the last 10 years, 3 from 10-20 years ago, and 4 over 20 years ago. Similarly, 2 of the Non-DOE-Funded SHAC Researchers had degrees granted within the past 10 years, 4 from 10-20 years ago, and 2 over 20 years ago. This was fairly typical for Researchers, as 122 of the 181 (67\%) of All Researchers had received degrees within the past 20 years.

Five of the DOE-Funded group had their most recent degrees in engineering (ceramics, mechanical, or electrical). Two held physics degrees, 1 had a degree in industrial management, and 1 a degree in marketing. Two respondents in this group appeared to have changed professions since receiving their degrees: their statements about current profession related specifically to solar energy or other forms of energy and their length 
of time in that profession was more brief than was the period of time since receipt of degree. One of the recent degree recipients also mentioned solar expertise and had been in the same profession since receipt of degree. Two respondents were teaching as well as doing research. Other professions mentioned included president of a solar company, technical director, engineer, and salesman.

Six of the Non-DOE-Funded SHAC Researchers also held advanced degrees in engineering (mechanicul, civil, electrical, engineering science). The remainder (2) held degrees in meteorology and physics. Two specifically mentloned solar cnergy as an aspect of their current profession. Three respondents were currently teaching, and 4 specifically mentioned researcher as their present profession. All but 1 had been in their present profession for over 10 years.

\subsection{INPORMATION NEEDS OF RPSPONDENTS}

\subsubsection{Technical Areas}

SHAC Researchers were asked to choose those areas in which they were "particularly interested in obtaining information" from a list of selected technical areas in SHAC. Both groups seemed somewhat more interested in "space heating" (7 of the 9 DOEFunded SHAC Researchers and 7 of the 9 Non-DOE-Funded SHAC Researchers) than they were in the other areas. More than half of the respondents in each group were interested in four of the five areas. In each group fewer respondents (4) were interested in "swimming pool heating" than in any of the other areas (see Table 3-2).

Table 3-2. $\quad$ AREAS UF INTEREST: $\Lambda$ CTIVE SOLAR HEA'IING AND COOLING RESEARCHFRS

\begin{tabular}{|c|c|c|c|c|}
\hline \multirow{2}{*}{$\begin{array}{c}\text { Technical } \\
\text { Area of Interest }\end{array}$} & \multicolumn{2}{|c|}{$\begin{array}{l}\text { DOE } \\
\text { Funded }\end{array}$} & \multicolumn{2}{|c|}{$\begin{array}{c}\text { Non- } \\
\text { DOE } \\
\text { Funded }\end{array}$} \\
\hline & No. & Percent & No. & Percent \\
\hline Space Healing & 7 & 78 & 7 & 78 \\
\hline Hybrid Systems & 3 & 56 & 8 & 89 \\
\hline Watcr Heating & 5 & 56 & 7 & 78 \\
\hline Space Cooling & 5 & 56 & 7 & 78 \\
\hline $\begin{array}{l}\text { Swimming Pool } \\
\text { Heating }\end{array}$ & 4 & 44 & 4 & 44 \\
\hline
\end{tabular}

At least 1 respondent in each group volunteered an interest in industrial applications. Another area of interest volunteered by the Non-DOE-Funded group was agricultural use of active solar systems. 


\subsubsection{Types of Information}

SHAC Researchers were asked to name the information about SHAC that was important for them to obtain. In the DOE-Funded group 7 of the 9 respondents volunteered one or more items of information which they considered important. One mentioned the need for a "professionally-run center for dependable information." Topics that were volunteered by respondents included: market conditions, standards; economics, new work being done, cooling systems, heat pumps, "process units," collectors (updated information), heat transfer media, DOE-sponsored solar update seminars, and government goals, direction, and support.

All 9 in the Non-DOE-Funded group responded to the question regarding important information. Two respondents requested cost information and 2 performance data. Information of primary concern to this group also included government activities, contracts, descriptions of work, contractors, and future plants. In addition, the following topies were named: heating and cooling basics, commercial availability of new products, ways to use solar energy, residential energy needs, air and water flow data, hot air systems, fans for active systems, wind power for heating and cooling, Rankine engine "absorption" systems, Sterling engine "absorption" systems, and heat storage (pressure over different volumes of rock).

Information that the DOE-Funded SHAC Researchers volunteered that they needed but were not able to get included: current market figures, potential markets (five-year forecast), variations in weather conditions for specific sites, control strategies for heat pumps, and cooling equipment. One respondent again stated the need for a central information center with a "large amount of information."

Two Non-DOE-Funded SHAC Researchers needed but were not able to get cost and performance data, wind system design data, methods for averaging insolation data, and data on the effect of fog blankets on insolation.

Choice Between Specific Needs. A list of 11 types of SHAC information products and 13 types of SHAC information categories was read to each respondent. Each rcspondent described the usefulness of each particular item by assigning it a value of "essential," "very useful," "somewhat useful," or "not at all useful." The results are given in Fig. 3-1 (DOE-Funded SHAC Researchers) and 3-2 (Non-DOE-Funded SHAC Researchers). For the purpose of comparison, Fig. 3-3 shows the results for Passive Researchers and Fig. 3-4 the results for All Researchers.

DOE-Funded SHAC Researchers gave both items in the research category high ratings. Their five top-rated information categories/products were:

- Standards, specifications, or certification programs;

- Design handhooks, installation handbooks, or reference tables;

- The state of the art;

- Research in progress; and

- Manual methods for sizing and predicting performance or costs.

Non-DOE-Funded SHAC Researchers also gave high ratings to the two items in the research information category. In addition, their five top-rated information category/ products included: 
Question \#8. I will read a list of potential information or information products on solar systems. For each, please tell me how useful that information would be to you. Would the following be: èssential, very useful, somewhat useful, or not at all useful?

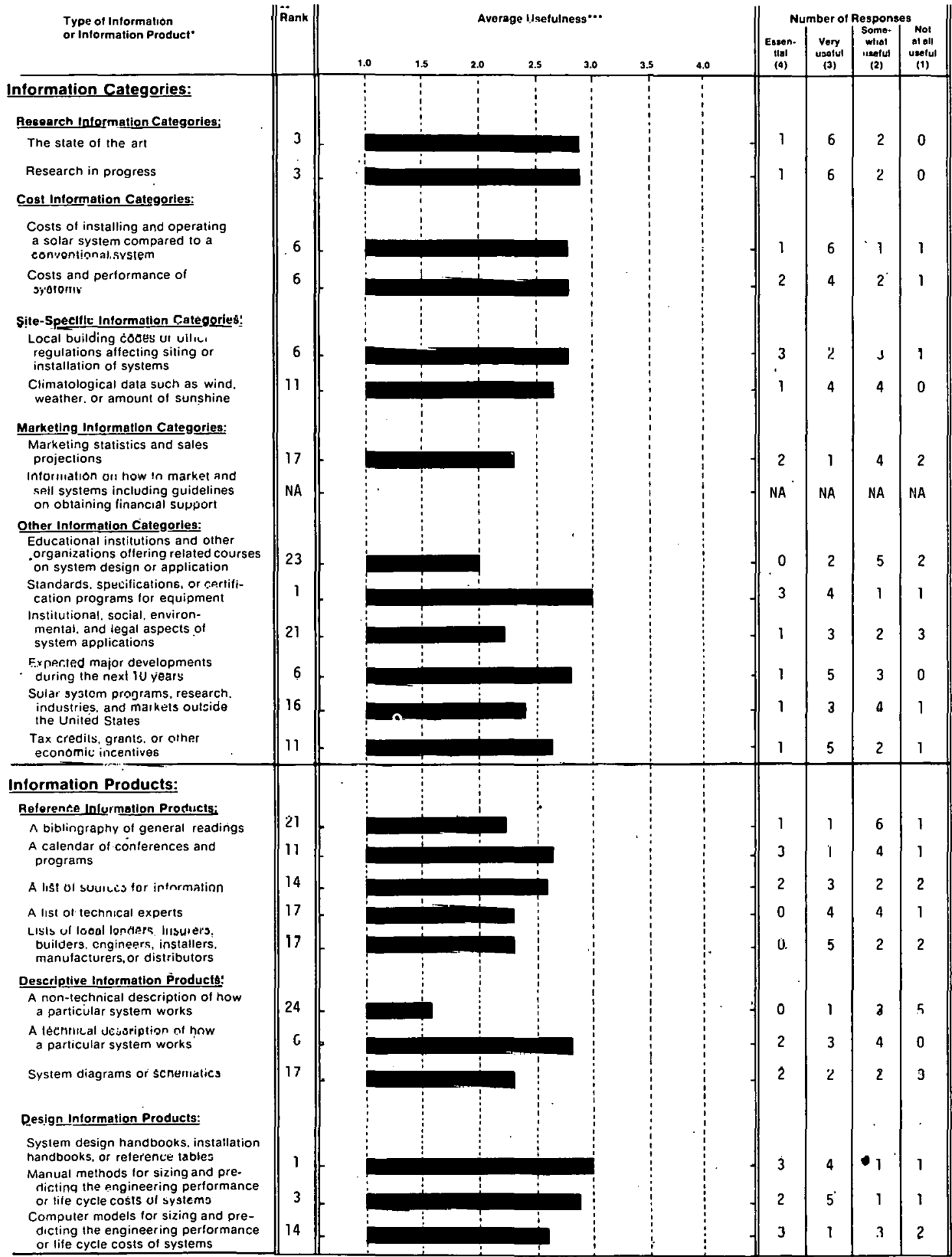

Each sample trame of users was questioned on information and information products in the context of their specific technology. For example. biomass ssmpta trames were

Rank-Each intormation product was assigned a rank based on average usefulness. Thus, the product with the highest sverage usefulness was assigned ine rank of " $1 "$ : Ihe product with the lowest average useluiness would oe,

.. Average usefulness was calculated by assigning the responses on a $1-4$ scale trom a "a" lor "essential" to a "1" for "not very uselul".

Figure 3-1. Usefuiness of Selected Information Items: DOE-Funded Active Solar Heating and Cooling Researchers 
Question \#8. I will read a list of potential information or information products on solar systems. For each, please tell me how useful that information would be to you. Would the following be: essential, very useful, somewhat useful, or not at all useful?

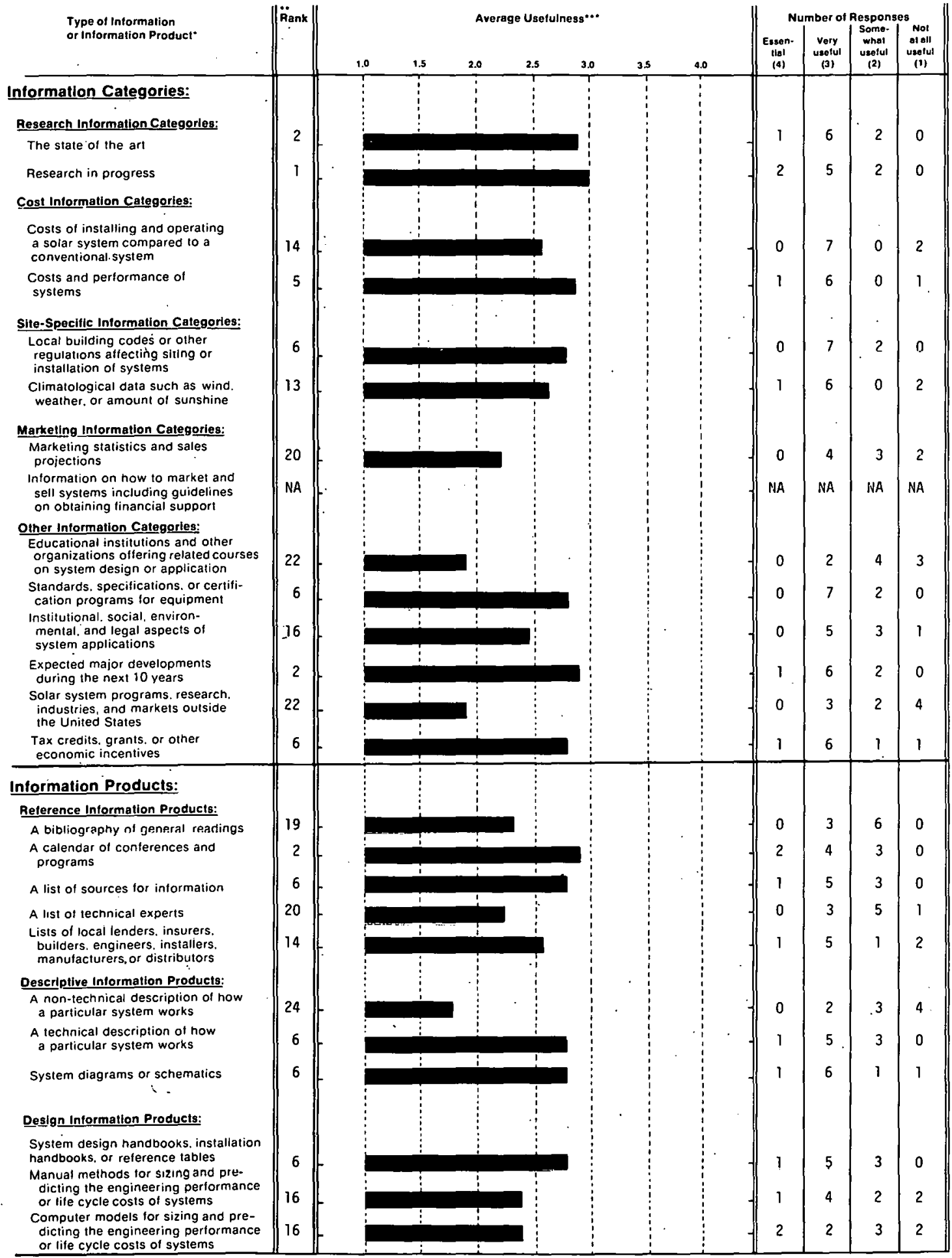

- Each sample trame of users wás questioned on intormation and intormation products in the context of their specilic technology. For example, bromass sample frames were

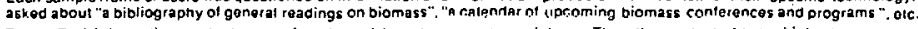

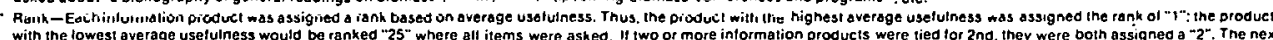
nith the lowest average userulness would

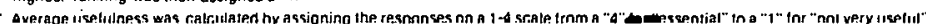

Figure 3-2. Usefulness of Selected Information Items: Non-DOE-Funded Active Solar Heating and Cooling Researchers 
Question \#8. I will read a list of potential information or information products on solar systems. For each, please tell me how useful that information would be to you. Would the following be: essential, very useful, somewhat useful, or not at all useful?

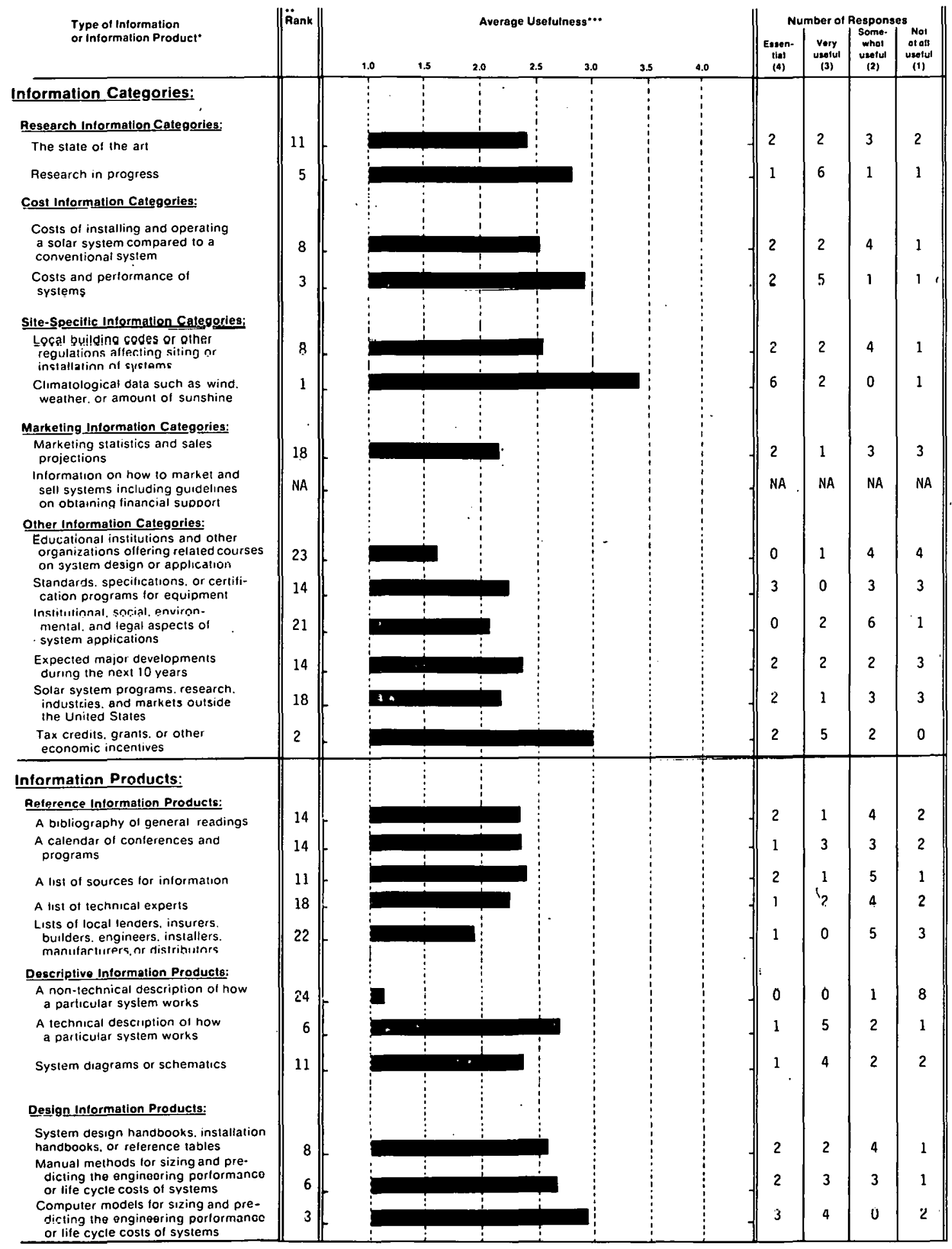

Each sample trame of users was questioned on int ormation and information products in the context of their specific lechnology. For example, biomass sample trames were asked aboul "a bibliography of general readings on bioma s3". "a calendar of upcoming biomass conferences and programs ". etc.

Rank-Each intormation product was assigned a tank based on average useluiness. Thus, the product with the highest average usel ulness was assigned ine rank ol "1"; the product with the lowest average usetuliness would
nignest ranking was then assigneo a -4 :"

... Average usefulness was calculated by assigning the responses on a 1.4 scale trom a "4" tor "essential" to a "1" tor "not very usetul".

Figure 3-3. Usefulness of Selected Information Items: Passive Researchers 
Question \$8. I will read a list of potential information or information products on solar systems. For each, please tell me how useful that information would be to you. Would the Iollowing be: essential, very useful, somewhat useful, or not at all useful?

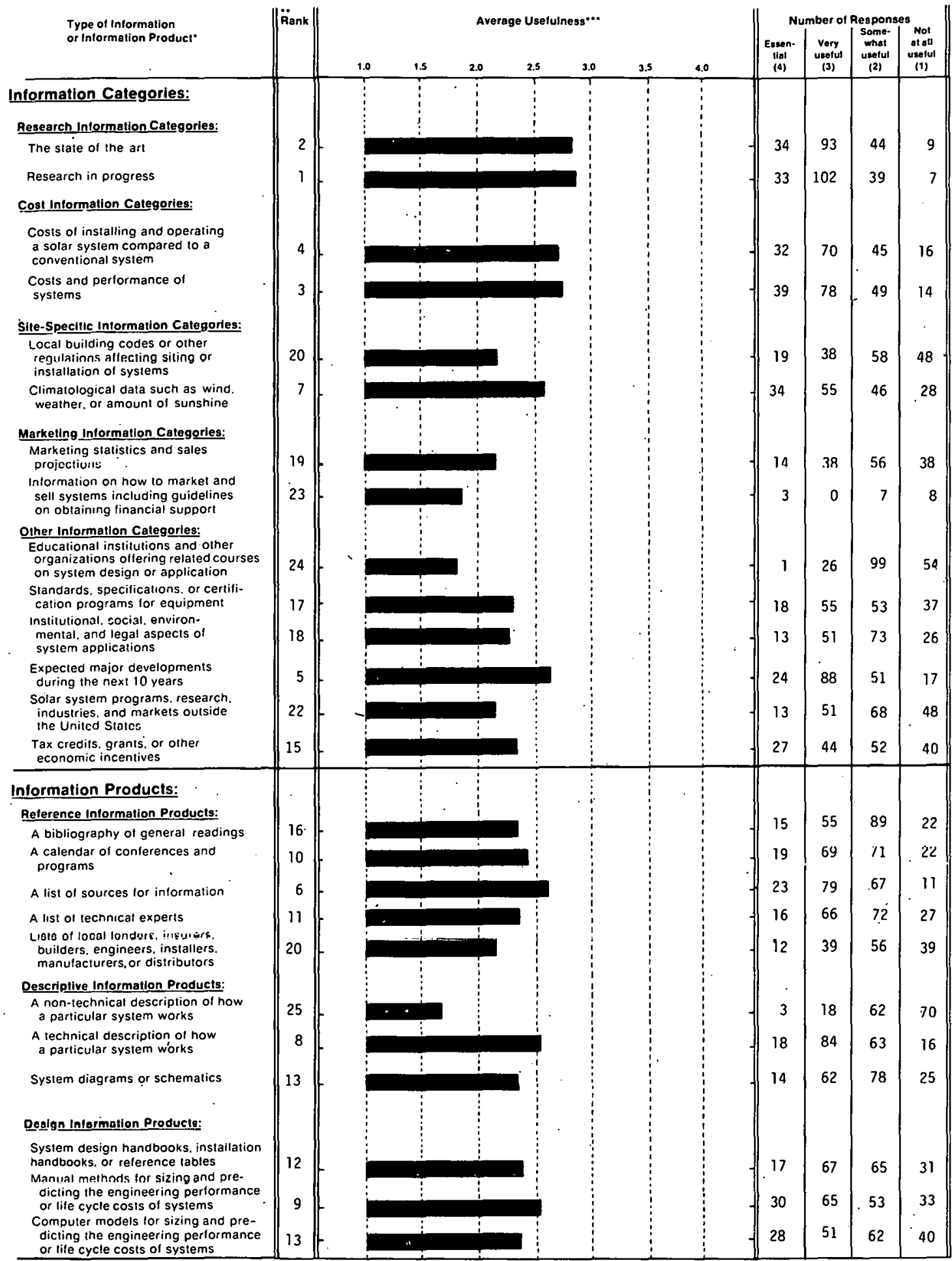

- Each sample trame ol users was questioned on intormation and information products in the context of their specitic tecnnology. For example. biomass sample trames were - asked aboul a biblogrephy ol general readings on biomass. a calendar of upcoming biomass conterences ond programs ${ }^{-}$. eic.

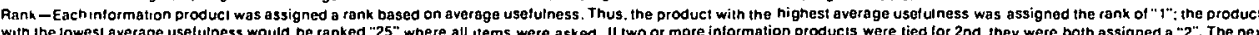
"A "Al" "

Figure 3-4. Usefulness of Selected Information Items: All Researchers 
- Expected major developments during the next 10 years,

- Calendars of conferences and programs, and

- Costs and performance of systems.

DOE-Funded SHAC Researchers assigned the lowest relative ratings to:

- A nontechnical description of how a particular system works;

- Educational institutions and other organizúliuns uffering courses;

- Institutional, social, environmental, and legal aspects; and

- A bibliography of general readings.

Non-DOE-Funded SHAC Researchers assigned their lowest relative ratings to:

- A nontechnical description of how a particular system works;

- Educational institutions and other organizations of ering courses;

- Solar energy programs, research, industries, and markets outside the United States;

- Marketing statistics and sales projections; and

- Lists of technical experts.

Statistical tests indicated that for DOE-Funded SHAC Researchers differences between the five highest-rated and four lowest-rated items were significant $\left(\begin{array}{ll}0.05\end{array}\right)$. Similarly, differences between the five highest-rated and five lowest-rated items for Non-DOEFunded SHAC Researchers were statistically significant ( $P$ 0.05) except for the comparison between "marketing statistics" versus "the state of the art" and "expected major developments."

The low ratings for "educational institutions" and "a nontechnical description," which were found for both groups of SHAC Researchers were typical of All Researchers. This probably reflects relatively high educational levels of Researchers as well as high levels of technical involvement.

It should be noted that these lower-rated items were not necessarily of no worth to the SHAC Researchers. For example, 2 of the 9 (22\%) DOE-Funded SHAC Resarchers and 2 of the 9 (22\%) Non-DOE-Funded SHAC Researchers thought "educational institutions ... offering courses" was "very useful." Thus, these information categories/products could be useful to some SHAC Researchers but were of a lower relative priority to the entire group.

Statistical tests were also used to determine whether the DOE-Funded SHAC Researchers rated any of these information items significantly higher (or lower) than they were rated by the Non-DOE-Funded SHAC Researchers, or whether either of these groups differed significantly from Passive Researchers or All Researchers. Some groups, however, tended to give higher scores in general than did other groups. To compensate for this effect, these statistical tests compared the "relative rating" given by one group to the "relative rating" given by the other groups. The procedure for calculating the relative rating is described in Appendix $\mathrm{E}$. The average overall rating both SHAC. Researchers gave to all items was 2.56; for Passive Researchers it was 2.42; for All Researchers, 2.41. 
No statistically significant differences were found in comparing the results for DOEFunded SHAC Researchers to those for Non-DOE-Funded SHAC Researchers, nor in comparing the results of each group of SHAC Researchers to those for Passive Researchers. Although the results were not statistically significant, Non-DOE-Funded SHAC Researchers were relatively more interested in "calendars,". "lists of "sources for information," and "system diagrams or schematics." iThe first two seemed to support a finding observed in other technologies that Non-DOE-Funded Researchers seem ed. to feel less secure than DOE-Funded Researchers that they were obtaining all of the information that was available [7]. The DOE-Funded Researchers seemed to be relatively more interested in "costs of installing" and in "manual methods."

In comparing the results for the two groups of SHAC Researchers (Total SHAC Researchers) to those for Passive Researchers, statistical tests indicated that Total SHAC Researchers rated "climatological data" significantly lower $(P<0.05)$ than did Passive Researchers. Although results were not significant, Passive Researchers seemed less interested in "state of the art," "standards, (etc.)," and "expected developm ents," but more interested in "tax credits, (etc.)" and "computer models."

In comparing the results of each of these two groups of SHAC Researchers to All Researchers, DOE-Funded SHAC Researchers were found to rate "standards, (etc.)" significantly $(\mathrm{P}<0.05)$ higher than did All Researchers. Total SHAC Researchers rated "local building codes" and "design handbooks" significantly higher $(P<0.05)$ than did All Researchers. These results may reflect SHAC's status as one of the few solar technologies that is already in the commercialization stage.

\subsection{ACQUISITION OF INFORMATION BY RESPONDENTS}

\subsubsection{Use of Selected Information Sources}

SHAC Researchers were asked which of 18 different potential sources of solar information had they used in the past few years. For this question the respondents were not asked if they had obtained information on SHAC, but instead were asked if they had obtained any solar information from each specific source. Thus, the question sought to determine which information sources were the most familiar to respondents. The results for the DOE-Funded and Non-DOE-Funded groups are shown in Figs. 3-5 and 3-6. For comparison, Figs. 3-7 and 3-8 show the results for Passive Researchers and All Researchers.

The information sources mentioned most of ten by DOE-Funded SHAC Researchers were:

- The Government Printing Office (GPO);

- An installer, builder, designer, or manufacturer;

- Workshops, conferences, or training sessions;

- Directly from the U.S. Department of Energy (DOE);

- Private solar energy or environmental organizations; and

- The Solar Energy Industries Assocation (SEIA). 
Question \#11. In the past few years, have you obtained any type of solar information from any of the following sources?

Information Sources
Percentage Responding Yes"

Public Media:

Radio or TV

Periodicals, newspapers or magazines

Private Solar-Involved Organizations:

Private solar energy or environmental organizations

The local chapter or national headquarters of International Solar Energy Society (ISES), including their publications

The local chapter or national headquarters of Solar Energy

Industries Association (SEFA), including their publications

Contàcis with Protessionals:

An installer, builder, designer or manufacturer of solar systems

Workshops, conferences or training sessions

Information Services*:

Your organizational library or a local library

A commercial data base; for example. Lockheed, SDC, BRS

Smithsonian Science Information Exchange (SSIE)

A Federal library or information center; for example, the Nationa Agricultural Library or the Environmental Data System

The Government Printing Office (GPO)

National Technical Information Service (NTIS)

Technical Information Center at Oak Ridge (TIC)

Government Solar-Involved Organizalions

Directly from the U.S. Department of Energy

National Solar Heating \& Cooling Information Centel

Regional Solar Energy Centers

State Energy or Solar Offices

Other:

Some other state or local government office or publication

A oublic utility company

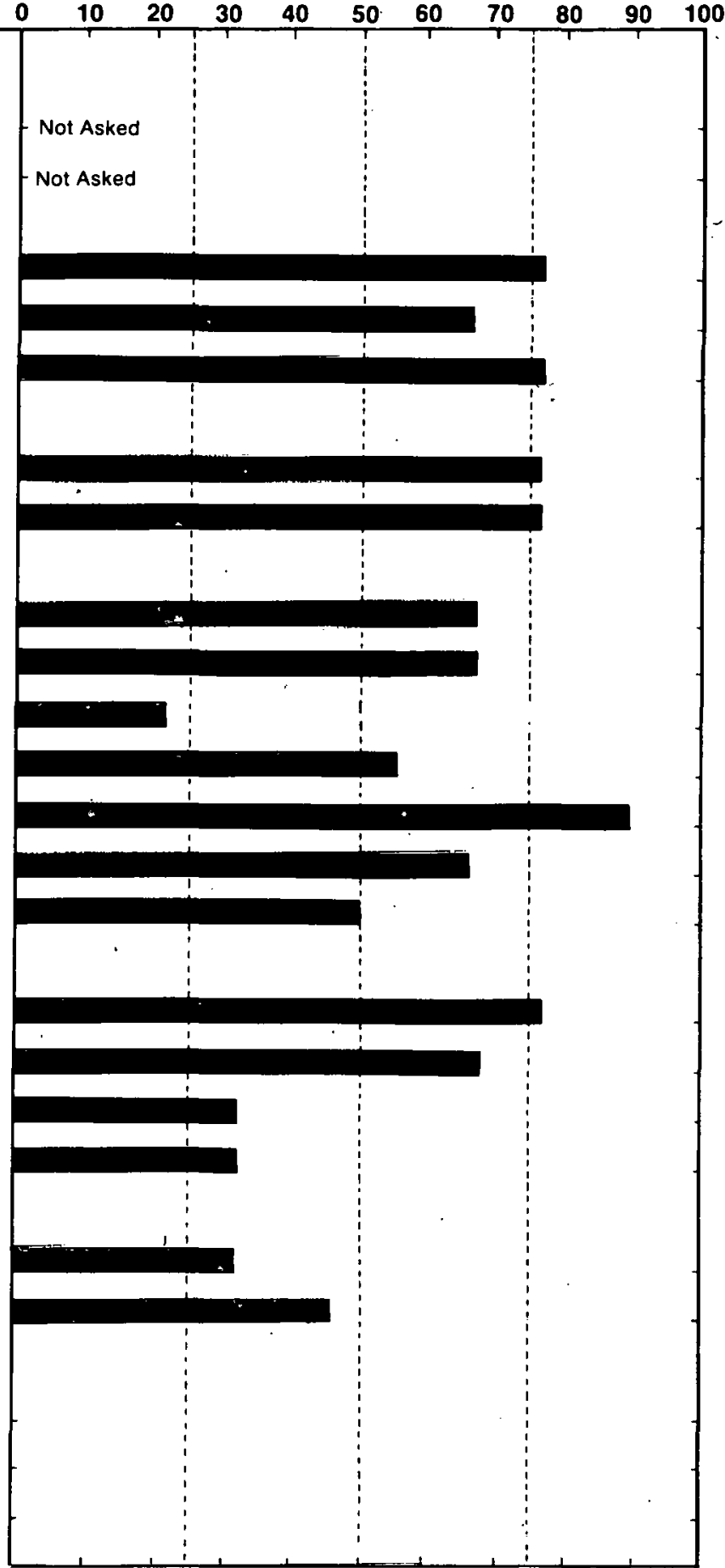

- Services and centers whose primary purpose is to disseminate information.

These data are based upon a total of 9 respondents.

Figure 3-5. Use of Selected Information Sources: DOE-Funded Active Solar Heating and Cooling Researchers 
Question \#11. In the past few years, have you obtained any type of solar information from any of the following sources?

\section{Information Sources}

Percentage Responding Yes *

Public Media:

Radio or TV

Periodicals. newspapers or magazines

Private Solar-Involved Organizations:

Private solar energy or environmental organizatıons

The local chapter or national headquarters of Internationa

Solar Energy Society (ISES), including their publications

The local chapter or national headquarters of Solar Energy

Industries Association (SEIA), including their publicalions

Contacts with Professionals:

An installer, builder, designer or manufacturer of solar systems

Workshops, conferences or training sessions

\section{Information Services*:}

Your organizational library or a local library

A commercial data base; for example. Lockheed. SDC, BRS

Smithsonian Science Information Exchange (SSIE)

A Federal library or information center: for example, the National Agricultural Library or the Environmental Data System

The Government Printing Office (GPO)

National Technical Information Service (NTIS)

Technical Information Center at Oak Ridge (TIC)

Government Solar-Involved Organizations

Directly from the U.S. Department of Energy

National Solar Heating \& Cooling Information Center

Regional Solar Energy Centers

State Energy or Solar Offices

Other:

Some other state or local government office or publication

A public utility company

Not Asked
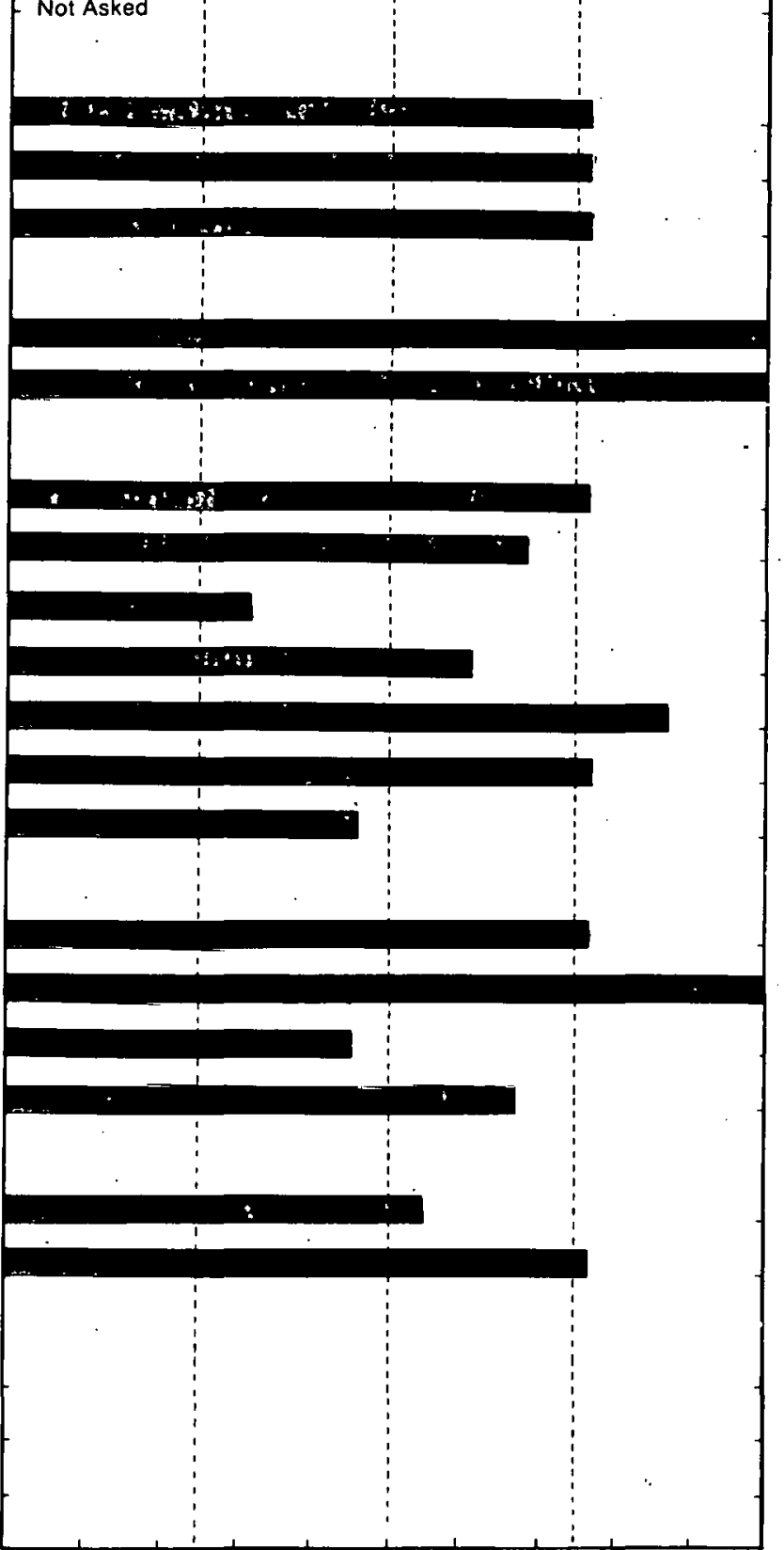

- Services and centers whose primary purpuse is to disseminatc information.

- These data are based upon a total of 9 respondents.

Figure 3-6. Use of Selected Information Sources: Non-DOE-Funded Active Solar Heating and Cooling Researchers 
Question \#11. In the past few years, have you obtained any type of solar information from any of the following sources?

Information Sources
Percentage Responding Yes *

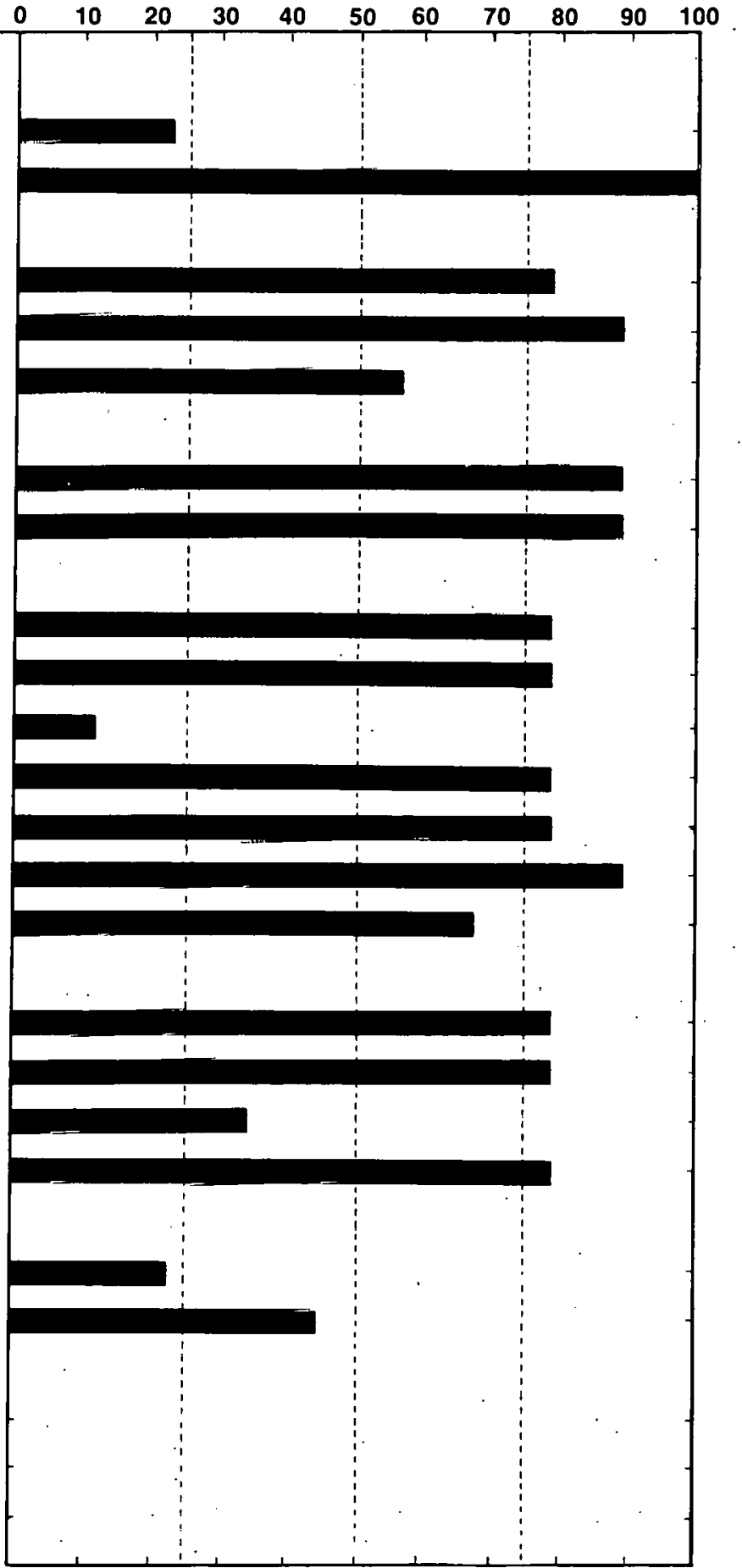

Private solar energy or environmental organizations

The local chapter or national headquarters of International 3uldr Energy Society (ISES), including their publications

The local chapter or national headquarters of Solar Energy Industrics Association (SEIA), including their publications

rontaoto with Profossivirals.

An installer, builder, designer or manufacturer of solar systems

Workshops, conferences or training sessions

Information Services":

Your organizational library or a local library

A commercial data base: for example, Lockheed. SDC. BRS

Smithsonian Science Information Exchange (SSIE)

A Federal library or information center; for example. the Nationa Agricultural Library or the Environmental Data System

The Government Printing Office (GPO)

Natiónal Technical Information Service (NTIS)

Technical Information Center at Oak Ridge (TIC)

Government Solar-Involved Organizations

Directly from the U.S. Department of Energy

National Solar Heating \& Cooling Information Centeı

Regional Solar Energy Centers

State Energy or Solar Offices

Other:

Some other state or local government office or publication

A public utility company

These data are based upon a total of 9 respondents.

Figure 3-7. Use of Selected Information Sources: Passive Researchers 
Question \#11. In the past few years, have you obtained any type of solar information from any of the following sources?

Information Sources

Public Media:

Radio or TV

Periodicals, newspapers or magazines

Private Solar-Involved Organizations:

Private solar energy or environmental organizations

The local chapter or national headquarters of International

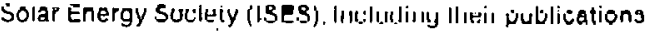

The local chapter or national headquarters of Solar Energy Industries Association (SE|A), including their publications

\section{Contacts with Professionals:}

An installer, builder, designer or manufacturer of solar systems

Workshops, conferences or training sessions

Information Services*:

Your organizational library or a Jocal library

A commercial data base: for example. Lockheed. SDC. BRS

Smithsonian Scienr.e Information Exchange (SSIE)

A Federal library or information center; for example, the National

Agricultural Library or the Environmental Data System

The Government Printing Otfice (GPO)

National Technical Information Service (NTIS)

Technical Information Center at Oak Ridge (TIC)

Government Solar-Involved Organizations

Directly from the U.S. Department of Energy

National Solar Heating \& Cooling Information Center

Regional Solar Energy Centers

State Energy or Solar Offices

Other:

Some other state or local government office or publication

A public utility company
Percentage Responding Yes

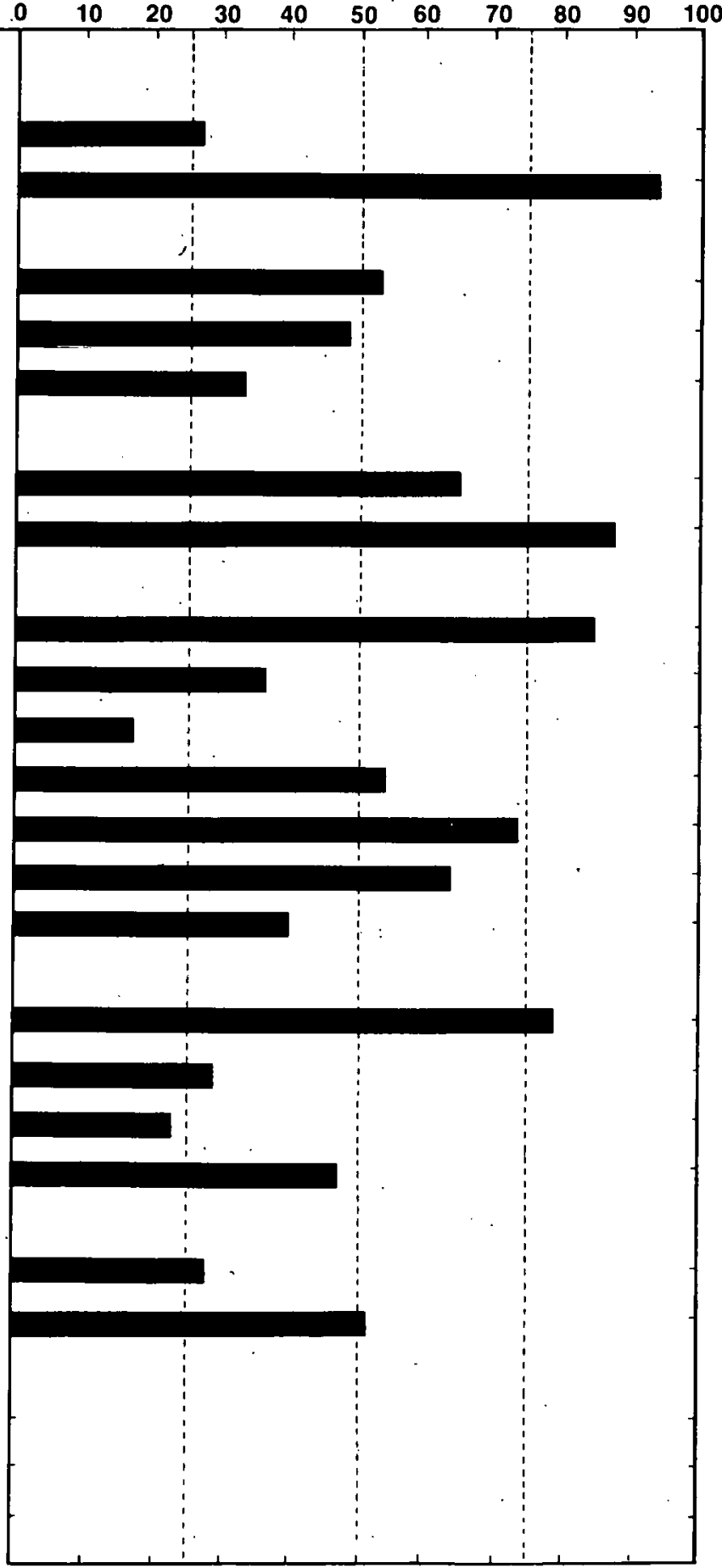

- Services and centers whose primary purpose is to disseminate information

- These data are based upon a total of 181 respondents.

Figure 3-8. Use of Selected Information Sources: All Researchers 
Those mentioned most of ten by Non-DOE-Funded SHAC Researchers were:

- An installer, builder, designer, or manufacturer;

- Workshops, conferences, or training sessions;

- The National Solar Heating and Cooling Information Center (NSHCIC); and

- GPO.

Most of these sources had also been used by at least half of All Researchers. The high level of familiarity with SEIA by DOE-Funded Researchers and with NSHCIC by NonDOE-Funded SHAC Researchers was not typical of All Researchers, however. This level of familiarity was shared only by Passive Researchers. The result might be expected as both active and passive heating and cooling are the purview of NSHCIC.

The information sources used least of ten by DOE-Funded SH AC. Researchers were:

- Smithsonian Science Information Exchange (SSIE),

- Regional Solar Energy Centers (RSECs),

- State energy or solar offices, and

- Some other state or local government of fice or publication.

The information sources mentioned least often by Non-DOE-Funded SHAC Researchers were:

- SSIE,

- Technical Information Center (TIC), and

- RSECs.

The low level of use of SSIE by both groups might be a bit surprising considering that one of the categories of information of most use to these groups was "research in progrccos" It appears that both groups, but especially the Non-DOE-Funded SHAC Researchers (with low ratings for TIC), may have inadequate access to sources for research in progress information. No one volunteered (see Section 3.2.2) research in progress information, however, as information they were unable to get. The low familiarity with the RSECs was typical of Researchers generally and reflected the orientation of the RSECs toward comm ercialization.

No significant differences were found between SHAC and Passive Researchers in the information sources they had used. There were some significant $(P<0.05)$ differences, however, between SHAC Researchers and All Researchers: both DOE-Funded and NonDOE-Funded SHAC Researchers were more likely than were All Researchers to have used NSHCIC and SEIA. The Non-DOE-Funded group was also more likely than were All Researchers to be familiar with "an installer, (etc.)" and the RSECs as sources of information. Total SHAC Researchers (the two groups combined) were significantly $(\mathrm{P}<0.05)$ more likely than were All Researchers to have used "a commercial data base" and DOE. 


\subsubsection{Membership in Solar-Interested Organizations}

Seven of the 9 DOE-Funded SHAC Researchers interviewed were members of a professional, technical, or other organization with an interest in solar energy. These organizations (and the number of times mentioned) included:

- American Ceramic Society;

- American Optical Association;

- American Physical Sóciety;

- American Society of Heating, Refrigerating and Air Conditioning Engineers (ASHRAE);

- American Society of Mechanical Engineers (ASME) (2);

- American Society for Testing and Materials;

- Georgia Solar Energy Assocation;

- International Solar Energy Society (ISES) (3);

- Michigan SEIA;

- SEIA; and

- Southern California Solar Energy Association.

Also mentioned were some organizations which the authors could not verify. These included "ASC" and "MASEC."

Six of the 9 Non-DOE-Funded SHAC Researchers mentioned belonging to:

- Alternate Energy Resources Organization,

- ASHRAE,

- ISES,

- Institute of Electrical and Electronics Engineers (2),

- New Mexico Solar Energy. Association,

- Solär Engineering Society, and/or

- SEIA.

Also mentioned were some organizations which the authors could not verify. These included "ASEE" (either the Am erican Society. for Engineering, Education or for Environmental Education?) and "AMME." The only organizations mentioned by more than 2 respondents (both groups combined) were ISES and SEIA, although 3 mentioned local solar energy assocations.

\subsubsection{Exposure to Publications on Solar Energy}

During the past 6 months, all 9 DOE-Funded Researchers and all 9 Non-DOE-Funded Researchers had read publications that included information on SHAC. These publications (and the number mentioning each) included for DOE-Funded SHAC Researchers: 
- ASHRAE Journal;

- American Society of Safety Engineers Journal;

- DOE publications;

- Energy Insider;

- Heating, Piping and Air Conditioning;

- ISES publications;

- Mayor's Energy Office publications (Los Angeles, California);

- Popular Science;

- Scientific American;

- Snlar Age (4);

- Solar Energy;

- Solar Engineering (2);

- Solar Heating and Cooling; and

- Southern California Solar Energy Assocation publications.

Also mentioned was "Solar," a publication that could not be verified by the authors.

The Non-DOE-Funded SHAC Researchers had read:

- DOE publications (3),

- Electric Power Research Institute Journal,

- Northeast Solar Energy Center publications,

- Solar $\Lambda \mathrm{g} c$

- Solar Engineering (2),

- Solar Heating and Cooling,

- Sun-Times (AERO), and

- Sunworld.

Also mentioned was "Solar" and "NSERI," publications that could not be verified by the authors.

\subsubsection{Use of Special Acquisition Methods}

The respondents were asked whether they had obtained any information (not just SHAC or solar energy) in the past year by computer terminal, by Computer Output Microform (COM), or by other microform (e.g., microfiche, microfilm sheets or rolls). . NonDOE-Funded SHAC Researchers were more accustomed to using these special acquisition methods than were the DOE-Funded group, and than were All Researchers. Six of the 9 Non-DOE-Funded SHAC Researchers had used computer terminals within the past year, compared to 4 of the 9 DOE-Funded SHAC Researchers. While none of the DOE-Funded group had used COM, 2 of the Non-DOE-Funded group had done so. In addition, more (4) of the Non-DOE-Funded Researchers than DOE-Funded Researchers (2) had used other 
microforms. All Researchers made less use of computer terminals than did either group of SHAC Researchers-34\% (62 of the 181) of All Researchers. Nine percent (16 of the 181) of All Researchers had used COM and 72 of the 181 (40\%) had used other microf orms.

\subsection{SUMMARY AND COMMENTS}

Eighteen active solar heating and cooling researchers were interviewed. Nine of them had received DOE research funding, and nine had not. These researchers were employed by manufacturers, universities, research institutes, utility companies, and municipalities. They considered themselves very involved with and very informed about SHAC.

SHAC Researchers attributed the most importance to information about:

- SHAC research in progress;

- The state of the art in SHAC;

- Standards, specifications, or certification programs for SHAC systems;

- SHAC system design handbooks, installation handbooks, or reference tables;

- Expected major developments in SHAC during the next 10 years;

- Costs and performance of SHAC systems; and

- Local building codes or regulations for SHAC systems.

DOE-Funded SHAC Researchers also gave high ratings to:

- Manual methods for sizing and predicting performance or costs of SHAC systems. Non-DOE-Funded SHAC Researchers also gave high ratings to:

- Calendars of SHAC conferences and programs;

- Lists of sources for information on SHAC; and

- Tax credits, grants, or other economic incentives for SHAC systems.

They gave low ratings to information on "a nontechnical description," "educational institutions," "institutional, social ... aspects," "a bibliography of general readings," "solar energy programs, research ... outside the United States," "marketing statistics," and "lists of technical experts."

SHAC Researchers (either DOE-Funded or Non-DOE-Funded) displayed marked similarities in their information needs and information habits. There seemed to be some evidence of one important difference: that, as in other technologies studied, the NonDOE-Funded Researchers seemed to feel less secure that they were obtaining all of the information available [7]. They differed from All Researchers in ways that are assumed to relate to the readiness for commercialization of these technologies as compared to other solar technologies.

Both groups of SHAC Researchers (but especially the Non-DOE-Funded group) were familiar with a wide range of solar information sources but also expressed a need for more information sources and more information than they were currently getting. Climatological, cost, and performance data all presented unm et information needs. 
SHAC Researchers most of ten received information through "an installer, builder, designer, or manufacturer," GPO, and "workshops, conferences or training sessions." The DOE-Funded group also relied on DOE and private solar organizations. Most respondents belonged to a number of organizations, professional and solar-specific, from which they obtained solar inf ormation. 


\section{SECTION 4.0}

\section{ACTIVE SOLAR HEATING AND COOLING MANUFACTURER REPRESENTATIVES}

\subsection{DESCRIPTION OF RESPONDENTS}

\subsubsection{Description of Sample}

This section describes the combined results of four telephone studies to determine the needs of representatives of manufacturers of active solar heating and cooling (SHAC) components and systems for information on SHAC. A total of 34 representatives of SHAC Manufacturers were interviewed. Data from Total SHAC Manufacturer Representatives were originally collected in the following groups:

1. Representatives of SHAC Heating/Cooling System Manufacturers,

2. Representatives of SHAC Water Heating System Manufacturers,

3. Representatives of SHAC Nonconcentrating Collector Manufacturers (who did not produce systems), and

4. Representatives of SHAC Other Component Manufacturers (who did not produce systems or collectors).

The exact definitions of these four groups are given below. Occassionally the text will refer to a subset of the total, Total SHAC Collector Manufacturer Representatives, which consists of the first three of the four groups: representatives of manufacturers of SHAC Heating/Cooling Systems, SHAC Water Heating Systems, and SHAC Nonconcentrating Collectors.

SHAC Heating/Cooling System Manufacturer Representatives produced active solar heating and cooling systems. They may not all have necessarily produced collectors but, instead, may have had them produced by a subcontractor. The sample frame for SHAC Heating/Cooling System Manufacturer Representatives was constructed from the Solar Energy Information Data Base (SEIDB) Manufacturers Data Base [8]. Manufacturers with products specified as space heating systems or climate control systems were included, but some of these manufacturers produced hot water systems as well. Duplicates with all other Manufacturers sample frames were eliminated. Entries with no contact name were removed. After all adjustments were made, 9 interview candidates were randomly selected from a sample frame of 55 names.

SHAC Water Heating System Manufacturer Representatives produced active solar hot water systems. They may not all have necessarily produced collectors but, instead, may have had them produced by a subcontractor. The sample frame was also constructed from the SEIDB Manufacturers Data Base. Manufacturers were selected who produced domestic hot water systems but not space heating systems or climate control systems. Duplicates with all other manufacturers' sample frames were eliminated. Entries with no contact name were removed. After all adjustments were made, 9 interview candidates were randomly selected from a sample frame of 72 names.

SHAC Nonconcentrating Collector Manufacturer Representatives produced active solar nonconcentrating collectors, but not complete systems (with the exception of swimming 
pool heating systems). The sample frame was constructed from the SEIDB Manufacturers Data Base. Manufacturers who produced one or more of the following were chosen: flatplate collectors (liquid or air), liquid type collectors, freon charged collectors, or special liquid collectors. Manufacturers of concentrating collectors, space heating systems, hot water systems, or climate control systems were eliminated. Manufacturers without a contact name were eliminated. After all adjustments were made, 11 interview candidates were randomly selected from a sample frame of $\mathbf{5 0}$ manufacturers.

The SHAC Other Component Manufacturer Representatives group consisted of manufacturers of components (other than solar collectors, reflectors, and refractors) but not complete systems. The sample frame was also constructed from the SEIDB Manufacturers Data Base. Manufacturers of hot water systems, climate control systems, space heating systems, nonconcentrating collectors, concentrating collectors, and reflectors and refractors were eliminated. Entries were eliminated if no contact name was listed or if the only products listed were one of the following: AC-DC inverters, comnuter programs, educational packages, valves, or meters. Manufacturers who produced one or more of the following were used: heat exchangers, heat recovery systems, radiant panels, sunlight sensors, solar sensors, power conversion equipment, thermochemical storage systems, water chillers, air handling equipment, liquid handling equipment, heat transfer fluids, tank insulation, heat pumps, solar controllers, heat storage units, heat storage unit insulation, phase change storage modules, heat flow sensors, sun tracking devises, electrical storage systems, liquid storage tanks, or collector insulation support systems. After all adjustments were made, 5 interview candidates were randomly selected from a sample frame of 90 manufacturer representatives.

Respondents. In making the telephone calls to contact the randomly selected interview candidates, it sometimes occurred that the person could not be reached. In this event another randomly selected name was substituted for the original name. When individuals were contacted, it was verified that the company they worked for was really a SHAC Manufacturer and that they would be needing information on SHAC within the next year. If they were not both involved and needing information, they were asked if they could refer the interviewer to someone else in their organization who would be an appropriate respondent. If such a referral was made, a call was then made to this new candidate; if no intraorganizational referral was made, a new candidate was randomly selected from the sample frame. The results of this process may be seen in Table 4-1.

Comparisons. For additional insight into the information needs and the information habits of these representatives of Total SHAC Manufacturers, the results are compared to those of representatives of Passive Manufacturers and of All Manufacturers. Total SHAC Collector Manufacturer Representatives are also compared to Concentrating Collector Manufacturer Representatives. The Concentrating Collector Manufacturer Representatives consisted of representatives of manufacturers of concentrating collectors, reflectors, and refractors; technologies more commonly used with solar thermal electric and industrial process heat systems. In performing any statistical comparisons, the totals for Total SHAC Manufacturer Representatives have been subtracted from the totals for All Manufacturer Representatives. The list of groups contained in All Manufacturer Representatives can be found in Fig. F-2 of Appendix F. The data for these groups and combinations can be found in Appendix F. 
Table 4-1. COMPLETION OF INTERVIEWS: TOTAL ACTIVE SOLAR HEATING AND COOLING MANUFACTURER REPRESENTATIVES

Interview completed with sample frame candidate

Interview completed with referral candidate

Refusal or candidate termination

Contact attempted: could not reach candidate within three

attempts or before interviews were completed

Subtotal

Contact attempted: invalid candidate (e.g., not a SHAC manufacturer, no telephone)

TOTAL

Sample frame error rate ${ }^{a}$ (Percent)

Completion rate ${ }^{b}$ (Percent)

$a_{\text {Invalid candidates divided by TOTAL }}$

$\mathrm{b}_{\text {Completed interviews divided by Subtotal }}$

\subsubsection{Current Status of Respondents}

Role. All 9 of the SHAC Heating/Cooling System Manufacturer Representatives manufactured space heating systems, and 4 of the 9 manufactured space cooling systems. Eight of the 9 SHAC Heating/Cooling Systems Manufacturer Representatives also manufactured domestic hot water systems, and 6 manufactured other components.

All 9 of the SHAC Water Heating System Manufacturer Representatives interviewed manufactured liquid collector, domestic hot water systems. Six of the 9 manufactured liquid flat plate collectors, three also manufactured swimming pool heating systems, and 4 also manufactured other components.

Nine of the 11 SHAC Nonconcentrating Collector Manufacturer Representatives manufactured collectors for liguid systems and 2 of the 11 manufactured collectors for air systems. None manufactured heating/cooling systems or domestic hot water systems. Five of the 9 also manufactured swimming pool heating systems and 4 of the 9 manufactured other components.

Types of components manufactured by Other Component Manufacturer Representatives included: instrumentation and measurement equipment (3), valves (2), pyranometers (2), piping, fiberglass glazing, fittings, joints, insulation, storage tanks, control units, prefabricated ducting, actuators, thermometers, back-up heaters, net radiometers, pyrheliometers, and thermal sensors.

Involvement. Of the Total SHAC Manufacturers, 26 of the 34 (76\%) representatives felt that they were "very involved" in SHAC, and 4 of the 34 (12\%) felt they were "moderately involved." The level of involvement by Total SHAC Manufacturer Representatives 
did not significantly differ from that of Concentrating Collector Manufacturer Representatives, of Passive Manufacturer Representatives, or of All Manufacturer Representatives. Table 4-2 compares the levels of informedness of the various groups of manufacturers.

Table 4-2. LEVELS OF INVOLVEMENT: ACTIVE SOLAR HEATING AND COOLING MANUPACTURER REPRESENTATIVES

\begin{tabular}{|c|c|c|c|c|c|c|c|c|}
\hline \multirow{2}{*}{ Manufacturer Group } & \multicolumn{2}{|c|}{$\begin{array}{c}\text { Very } \\
\text { Involved }\end{array}$} & \multicolumn{2}{|c|}{$\begin{array}{l}\text { Moderately } \\
\text { Involved }\end{array}$} & \multicolumn{2}{|c|}{$\begin{array}{l}\text { Slightly } \\
\text { Involved }\end{array}$} & \multicolumn{2}{|c|}{$\begin{array}{l}\text { Not at All } \\
\text { Involved }\end{array}$} \\
\hline & No. & $\begin{array}{l}\text { Per- } \\
\text { cent }\end{array}$ & No. & $\begin{array}{l}\text { Per- } \\
\text { cent }\end{array}$ & No. & $\begin{array}{l}\text { Per- } \\
\text { cent }\end{array}$ & No. & $\begin{array}{l}\text { Per- } \\
\text { cent }\end{array}$ \\
\hline $\begin{array}{l}\text { Total SHAC Collectors } \\
\text { SHAC Heating/Cooling }\end{array}$ & 23 & 79 & 3 & 10 & 2 & 7 & $\mathbf{0}$ & 0 \\
\hline $\begin{array}{l}\text { Systems } \\
\text { SHAC Water Heating }\end{array}$ & 7 & 78 & 1 & 11 & 1 & 11 & .0 & 0 \\
\hline $\begin{array}{l}\text { Systems } \\
\text { SHAC Nonconcentrating }\end{array}$ & 5 & 56 & 2 & 22 & 1 & 11 & 0 & 0 \\
\hline Collectors & 11 & 100 & $\mathbf{0}$ & 0 & 0 & 0 & 0 & 0 \\
\hline SHAC Other Components & 3 & 60 & 1 & 20 & 1 & 20 & 0 & 0 \\
\hline Total SHAC Manufacturers & 26 & 76 & 4 & 12 & 3 & 9 & 0 & 0 \\
\hline $\begin{array}{l}\text { Concentrating Collector } \\
\text { Manufacturers }\end{array}$ & 7 & 00 & 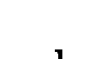 & 19 & 0 & 0 & 0 & 0 \\
\hline Passive Manufacturers & 7 & 78 & 1 & 11 & 1 & 11 & 0 & 0 \\
\hline All Manufacturers & 77 & 80 & 10 & 10 & 7 & 7 & 1 & 1 \\
\hline
\end{tabular}

Informedness. Of the Total SHAC Manufacturers, 28 of the 34 (82\%) representatives felt they were "very informed," and 5 of the 34 (15\%) were "moderately informed." The level of informedness of Total SHAC Manufacturer Representatives did not differ significantly from that of Concentrating Collector Manufacturer Representatives, of Passive Manufacturer Representatives, or of All Manufacturer Representatives. Table 4-3 compares the levels of informedness of the six manufacturer groups.

Need for Information. All respondents indicated they would need information on active solar heating and cooling either on the job and/or outside the job. On the job, 33 of the 34 (97\%) of Total SHAC Manufacturer Representatives expected to need information. Eighteen of the 34 (53\%) Total SHAC Manufacturer Representatives also expected to need information on SHAC outside the job. 
Table 4-3. LEVELS OF INFORMEDNESS: ACTIVE SOLAR HEATING AND COOLNG MANUFACTURER REPRESENTATIVES

\begin{tabular}{|c|c|c|c|c|c|c|c|c|}
\hline \multirow{2}{*}{ Manufacturer Group } & \multicolumn{2}{|c|}{$\begin{array}{c}\text { Very } \\
\text { Informed }\end{array}$} & \multicolumn{2}{|c|}{$\begin{array}{l}\text { Moderately } \\
\text { Inform ed }\end{array}$} & \multicolumn{2}{|c|}{$\begin{array}{l}\text { Slightly } \\
\text { Inf orm ed }\end{array}$} & \multicolumn{2}{|c|}{$\begin{array}{l}\text { Not at All } \\
\text { Informed }\end{array}$} \\
\hline & No. & $\begin{array}{l}\text { Per- } \\
\text { cent }\end{array}$ & No. & $\begin{array}{l}\text { Per- } \\
\text { cent }\end{array}$ & No. & $\begin{array}{l}\text { Per- } \\
\text { cent }\end{array}$ & No. & $\begin{array}{l}\text { Per- } \\
\text { cent }\end{array}$ \\
\hline $\begin{array}{l}\text { Total SHAC Collectors } \\
\text { SHAC Heating/Cooling }\end{array}$ & 26 & 90 & 2 & 7 & 1 & 3 & 0 & 0 \\
\hline $\begin{array}{l}\text { Systems } \\
\text { SHAC Water Heating }\end{array}$ & 8 & 89 & 0 & 0 & 1 & 11 & 0 & 0 \\
\hline $\begin{array}{l}\text { Systems } \\
\text { SHAC Nonconcentrating }\end{array}$ & 7 & 78 & 2 & 22 & 0 & 0 & 0 & 0 \\
\hline Collectors & 11 & 100 & 0 & 0 & 0 & 0 & 0 & 0 \\
\hline SHAC Other Components & 2 & 40 & 3 & 60 & 0 & 0 & 0 & 0 \\
\hline Total SHAC Manufacturers & 28 & 82 & 5 & 15 & 1 & 3 & 0 & 0 \\
\hline $\begin{array}{l}\text { Concentrating Collector } \\
\text { Manufacturers }\end{array}$ & 7 & 88 & 1 & 13 & 0 & 0 & n & 0. \\
\hline Passive Manufacturers & 5 & 56 & 4 & 44 & $\mathbf{0}$ & 0 & 0 & 0 \\
\hline All Manufacturers & 72 & 75 & 21 & 22 & 3 & 3 & 0 & 0 \\
\hline
\end{tabular}

\subsubsection{Background of Respondents}

Nineteen (56\%) of the representatives of Total SHAC Manufacturers held bachelor's degrees, 6 (18\%) held masters degrees, and 1 held a doctoral degree. The educational level of Total SHAC Manufacturer Representatives did not differ from that of Concentrating Collector Manufacturer Representatives or of Passive Manufacturer Representatives. The degree field most common to the SHAC Manufacturer Representatives was engineering, received by 7 of the 26 (27\%) respondents with degrees. Another 4 manufacturer representatives received degrees in business. The remaining 15 respondents had received degrees in various fields including: architecture (2), chemistry (2), management, banking, law, education, marine transportation, marine science, aeronautics, geology, history, and physics. One received his most recent degree over 30 years ago, 10 from 20-30 years ago, 6 from 10-20 years ago, and 10 within the past 10 years. The educational level and the year of most recent degree for Total SHAC Manufacturer Representatives did not differ significantly from those of Concentrating Collector Manufacturer Representatives nor those of Passive Manufacturer Representatives. The degree field for Concentrating Collector Manufacturer Representatives was also predominantly engineering. For Passive Manufacturer Representatives, however, only 1 of the 9 had an engineering degree, with 4 of the 9 having degrees in chemistry.

Professional experience was dispersed among the group, with 1 in his/her current profession for 2 or fewer years, 12 for 3-5 years, 10 for 6-10 years, and 11 for over 10 years. Similarly, the professional experience of Concentrating Collector Manufacturer Representatives and Passive Manufacturer Representatives also varied widely. As their current profession, 12 of the 34 representatives of Total SHAC Manufacturers mentioned 
they were in management, 12 were engineers, and the other 10 mentioned manufacturer (4), solar energy specialist (2), marketing (2), architect (1), and salesman (1).

\subsection{INPORMATION NEEDS OF RESPONDENTS}

\subsubsection{Technicel Areas}

Representatives of SHAC Heating/Cooling System Manufacturers and SHAC Water Heating System Manufacturers were asked to choose those areas in which they were "particularly interested in obtaining information" from a list of five selected technical areas of SHAC. As would be expected, interest was dominant in "water heating" and "space heating," the two product areas their companies are currently actively manufacturing. Conversely, the least interest was for "space cooling" systems (see Table 4-4).

Table 4-4. AREAS OF INTEREST: ACTIVE SOLAR HEATING AND COOUNG SYSTEM MANUFACTURER REPRESENTATIVES AND ACTIVE SOLAR WATER HEATING SYSTEM MANUFACTURER REPRESENTATIVES

\begin{tabular}{lccccc}
\hline \multirow{2}{*}{ Technical Area of Interest } & \multicolumn{2}{c}{ Heating/Cooling Systems } & & \multicolumn{2}{c}{ Water Heating Systems } \\
\cline { 2 - 3 } \cline { 5 - 6 } & No. & Percent & & No. & Percent \\
\hline Total Respondents & 9 & 100 & 9 & 100 \\
\hline Water Heating & 7 & 78 & 9 & 100 \\
Space Heating & 9 & 100 & 7 & 78 \\
Swimming Pool Heating & 5 & 56 & 5 & 56 \\
Ilybrid Systems & 4 & 44 & 6 & 67 \\
Spuce Couling & 6 & 61 & 2 & 22 \\
\hline
\end{tabular}

Two representatives of SHAC Heating/Cooling System Manufacturers volunteered that they were also interested in information on process heating and on hybrid systems combining photovoltaics and space heating. SHAC Water Heating System Manufacturer Representatives did not mention any other areas of interest.

\subsubsection{Types of Information}

Representatives of SHAC Manufacturers were asked to name the information about SHAC that was important for them to obtain. Of Total SHAC Manufacturer Representatives, 31 of the $34(91 \%)$ volunteered one or more items of information they considered important. Seven felt marketing information was important (including sales trends, market analysis, pricing, and how to sell). This seemed to be a typical response for manufacturer representatives; for example, Passive Manufacturer Representatives also mentioned marketing information as a high priority need. Other topics cited as important by Total SHAC Manufacturer Representatives included: new products/new development and design breakthroughs (4), government and financial incentives (3), nontechnical descriptions (3), standards (2), cost information (cost versus efficiency of systems 
and comparative costs of collectors).(2), insolation data (2), and l mention each for: test results, research on cooling, product availability, "storage capacity of solar ovens," lowtemperature collectors, solar demonstration projects, industrial and commercial applications data, applications data from users of the manufacturer's products, information on hybrid systems of solar assisted heat pumps, conference papers from International Solar Energy Society (ISES), information on "how to get government out of the business," performance data on characteristies of residential solar heating systems, performance test data on the longevity of various solar systems on the market, and government projects/ activities.

Thirteen representatives of Total SHAC Manufacturers stated that there was information that they needed but were not able to get on SHAC. This included climatological data (3), performance/reliability information (including verification of heat pump loadings for homes) (2), marketing information (2), comparative cost data on solar versus conventional systems, applications data from users of their products, computer and manual methods for computation of passive applications, information on retrofits, transport components, piping, control equipment, government projects on solar, data on installations by geographical area, building codes, air collectors, and data on etched glass for reduction of reflection.

Choice Between Specific Needs. A list of 11 types of SHAC information products and 14 types of SHAC information categories was read to each respondent. Each respondent described the usefulness of each particular item by assigning it a value of "essential," "very useful," "somewhat useful," or "not at all useful." The results for Total SHAC Manufacturer Representatives are shown in Fig. 4-1. For the purpose of comparison, the results for All Manufacturer Representatives and Passive Manufacturer Representatives are shown in Figs. 4-2 and 4-3, respectively. (See Appendix F for the results on SHAC Other Component Manufacturer Representatives.)

Not surprisingly, the type of information on which Total SHAC Manufacturer Representatives placed the highest priority was "tax credits, grants, or other economic incentives," an area which could affect production costs and/or market demand. This information category was also rated number one by All Manufacturer Representatives. The six information categories/products rated highest by Total SHAC Manufacturer Representatives were:

- Tax credits, grants, or other economic incentives;

- Costs and performance of systems;

- Marketing statistics and sales projections;

- Lists of local lenders, insurers, builders, engineers, installers, manufacturers, or distributors;

- Costs of installing and operating a SHAC system compared to a conventional system; and

- Slandards, specifications, or certification programs.

Total SHAC Manufacturer Representatives assigned the lowest ratings to:

- A bibliography of general readings;

- A nontechnical description of how a particular system works;

- Educational institutions and other organizations off ering courses; 
Question \#8. I will read a list of potential information or information products on solar systems. For each, please tell me how useful that information would be to you. Would the following be: essential, very useful, somewhat useful, or not at all useful?

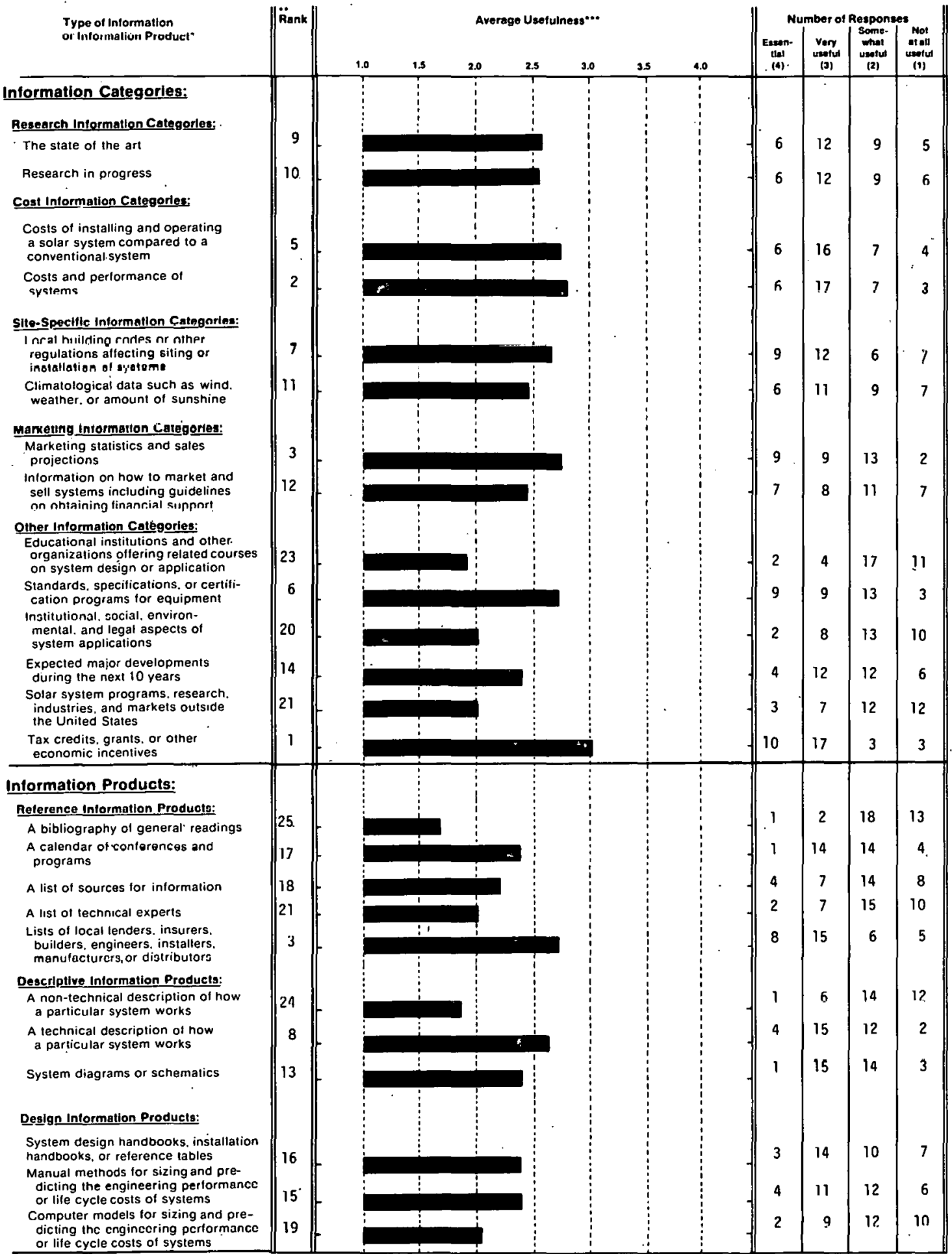

Each sample trame of users was questioned on intormation and intormation products in the context of their specific technology. For example. biomass sample trames wero

- Rank - Eachintormation producl was assigned a rank based on average usefulness. Thus. the procuct with the highest average usetulness was assigned the rank of "I": the product wish the lowest average usetulness would be ranked "25" where all items were asked, It two or mofe information products were tied lor 2 nd, they were both assigned a -2 -. The next highest ranking was men assignso

-.. Average usefulness was calculated by assigning the responses on a 1-4 scale trom a -4 " lor "essential "lo a "1" lor "not very usetu".

Figure 4-1. Usefulness of Selected.Information Items: Total Active Solar Heating and Cooling Manufacturer Representatives 
Question \#8. I will read a list of potential information or information products on solar systems. For each, please tell me how useful that information would be to you. Would the following be: essential, very usefut, somewhat useful, or not at all useful?

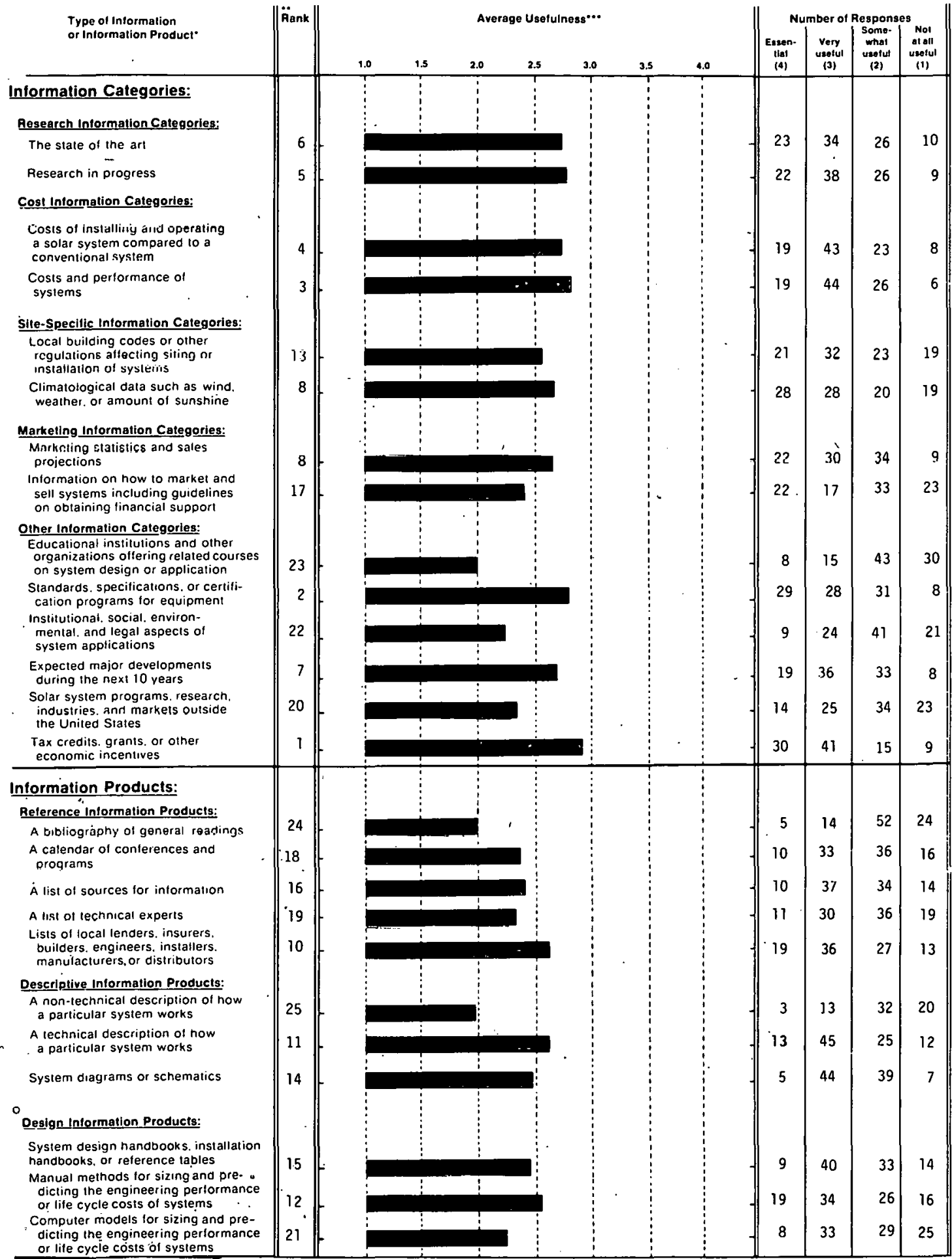

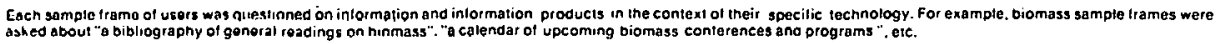

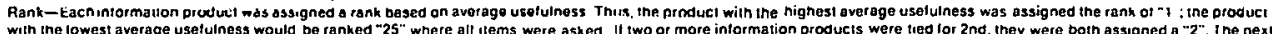
mith ine lowest average usetulness would

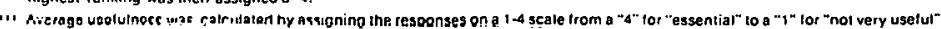

Figure 4-2. Usefulness of.Selected Information Items: All Manufacturer Representatives 
Question \#8. I will read a list of potential information or information products on solar systems. For each, please tell me how useful that information would be to you. Would the following be: essential, very useful, somewhat useful, or not at all useful?

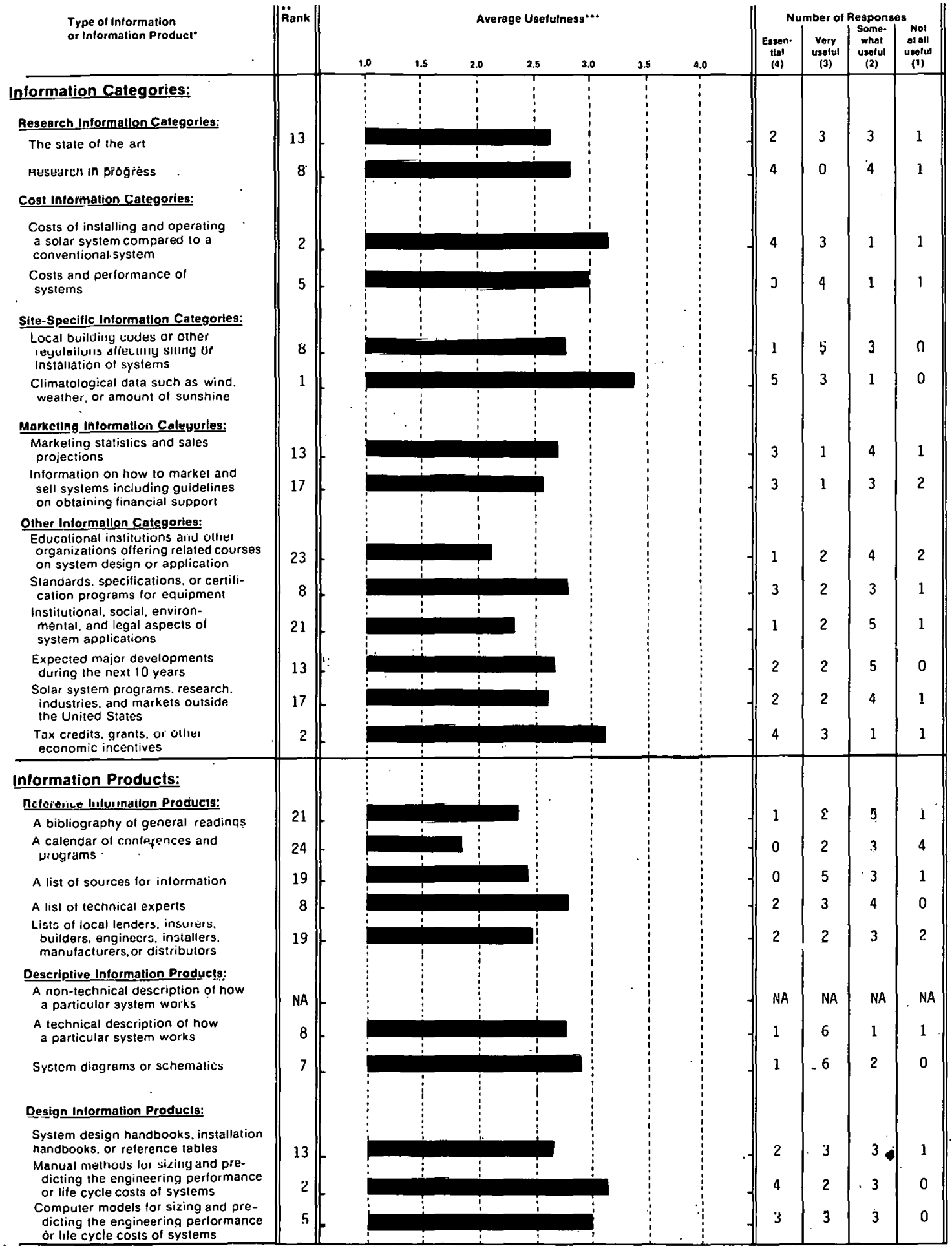

Each sample frame of users was questioned on intormation and information products in the contẹxil ol theit specific lechnology. For example. biomass sample trames were asked about "a bibliography of general readings on biomass"," a calendar of upcoming biomass conferences and programs ". eic. Pank-Eacn intormation product was assigned a rank based on average usefulness. Thus. the producl with the highest average uset uness was assigned ine rank of "1"; the product with the lowest average usefulness wauld be ranked "25" where alt ilems were asked. II two or more inlormation products were tied lor 2 nd, they were both assigned a " 2 ". The next

.. Average usetulness was carculared by assigning ine responses on a $1-4$ scale trom a "4" tor "essential" 10 a "1" tor "not very usetul".

Figure 4-3. Usefulness of Selected Information Items: Passive Manufacturer Representatives 
- Solar energy programs, research, industries, and markets outside the United States; and

- Lists of technical experts.

Statistical tests indicated all six of the top categories/products were rated significantly $(P<0.05)$ higher than were the five lowest-rated items.

It should be noted that these lower-rated items were not necessarily of no worth to Total SHAC Manufacturer Representatives. For example, 9 of the 34 (27\%) representatives of Total SHAC Manufacturers thought "lists of technical experts" were either "essential" or "very useful." Thus, these information categories/products could be useful to some SHAC Manufacturer Representatives but were of a lower relative priority to the entire group.

Comparisons. Statistical tests were used to determine whether the representatives of Total SHAC Manufacturers rated any of these information items significantly higher (or lower) than they were rated by the representatives of Concentrating Collector Manufacturers and Passive Manufacturers. Some groups, however, tended to give higher scores in general than did other groups. To compensate for this effect, these statistical tests compared the "relative rating". given by one group to the "relative rating" given by the other groups. The procedure for calculating the relative rating is described in Appendix E. The overall average rating was 2.40 for Total SHAC Manufacturer Representatives, 2.57 for Concentrating Collector Manufacturer Representatives, 2.70 for Passive Manufacturer Representatives, and 2.51 for All Manufacturer Representatives.

Total SHAC Manufacturer Representatives Compared to All Manufacturer Representatives. Besides "tax credits, (etc.)" mentioned above, other similarities between Total

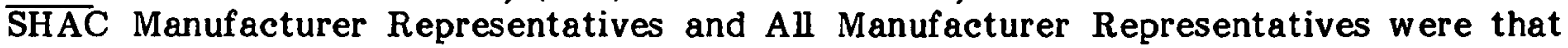
both groups wanted cost-related information but were in little need of either design or reference information products (with the exception of "lists of local lenders"). Other comparisons, however, noted some differences between manufacturers of SHAC products versus manufacturers of other solar products. Total SHAC Manufacturer Representatives were significantly $(\mathrm{P}<0.05)$ more interested in "lists of local lenders" and somewhat more interested in marketing information and "local building codes." In contrast, All Manufacturer Representatives appeared to be oriented more towards monitoring research and technological progress ("expected major developments") of their respective solar technologies. One explanation for these variations may be the differences in levels of commercial readiness of the products manufactured. With the exception of Passive Manufacturer Representatives, the majority of products produced by the other solar manufacturers have not progressed to the same commercial level as SHAC products.

Total SHAC Manufacturer Representatives Compared to Passive Manufacturer Representatives. Of all Manufacturer groups studied, Total SHAC Manufacturer Representatives and Passive Manufacturer Representatives were most similar overall. Some differences noted, however, showed Total SHAC Manufacturer Representatives giving significantly $(\mathrm{P}<0.05)$ higher ratings to "calendars of conferences". and significantly low er ratings to "a nontechnical description," "computer models," and "climatological data." Total SHAC Manufacturer Representatives appeared slightly more marketing oriented and in need of information on "lists of local lenders, (etc.)," but less interested than Passive Manufacturer Representatives in methods to calculate engineering performance or life cycle costs (both manually and by computer). 
Total SHAC Collector Manufacturer Representatives Compared to Representatives of Manufacturers of Concentrating Collectors. Figures 4-4 and 4-5 present the results for Total SHAC Collector Manufacturer Representatives (nonconcentrating collectors only) and Concentrating Collector Manufacturer Representatives, respectively. Total SHAC Collector Manufacturer Representatives were found to rate the importance of "lists of technical experts" significantly $(\mathrm{P}<0.05)$ lower than did the Concentrating Collector Manufacturer Representatives. The Total SHAC Collector Manufacturer Representatives also appeared slightly less interested in information on "research in progress," "climatological data," and "solar energy programs, research . . . outside the United States."

\subsection{ACQUISITION OF INFORMATION BY RESPONDENTS}

\subsubsection{Use of Selected Information Sources}

Reprèsentatives of Total SHAC Manufacturers were asked which of 18 different potential sources of solar information they had used in the past few years. For this question the respondents were not asked if they had obtained information on SHAC, but instead were asked if they had obtained any solar information from each specific source. Thus, the question sought to determine which information sources were the most familiar to the respondents. The results are shown in Fig. 4-6. For the purpose of comparison, those for All Manufacturer Representatives and Passive Manufacturer Representatives are shown in Figs. 4-7 and 4-8, respectively.

The information sources mentioned most of ten by representatives of Total SHAC Manufacturers were:

- Periodicals, newspapers, or magazines;

- The Government Printing Office (GPO);

- State energy or solar offices;

- An installer, builder, designer, or manufacturer (outside your own organization);

- Workshops, conferences, or training sessions;

- Directly from the U.S. Department of Energy (DOF);

- Private solar energy or environmental organizations;

- The National Solar Heating and Cooling Information Center (NSHCIC);

- An organizational library or a local library; and

- The Sular Energy Industries Association (SEIA).

Each of these sources were mentioned by at least $60 \%$ of all respondents.

The information sources mentioned least of ten by Total SHAC Manufacturer Representatives were:

- Smithsonian Science Information Exchange (SSIE),*

- Technical Information Center (TIC),

*SSIE was asked only of Nonconcentrating Collector Manufacturer Representatives and Other Component Manufacturer Representatives. 
Question \#8. I will read a list of polential information or information products on solar systems. For each, please tell me how useful that information would be to you. Would the following be: essential, very useful, somewhat useful, or not at all useful?

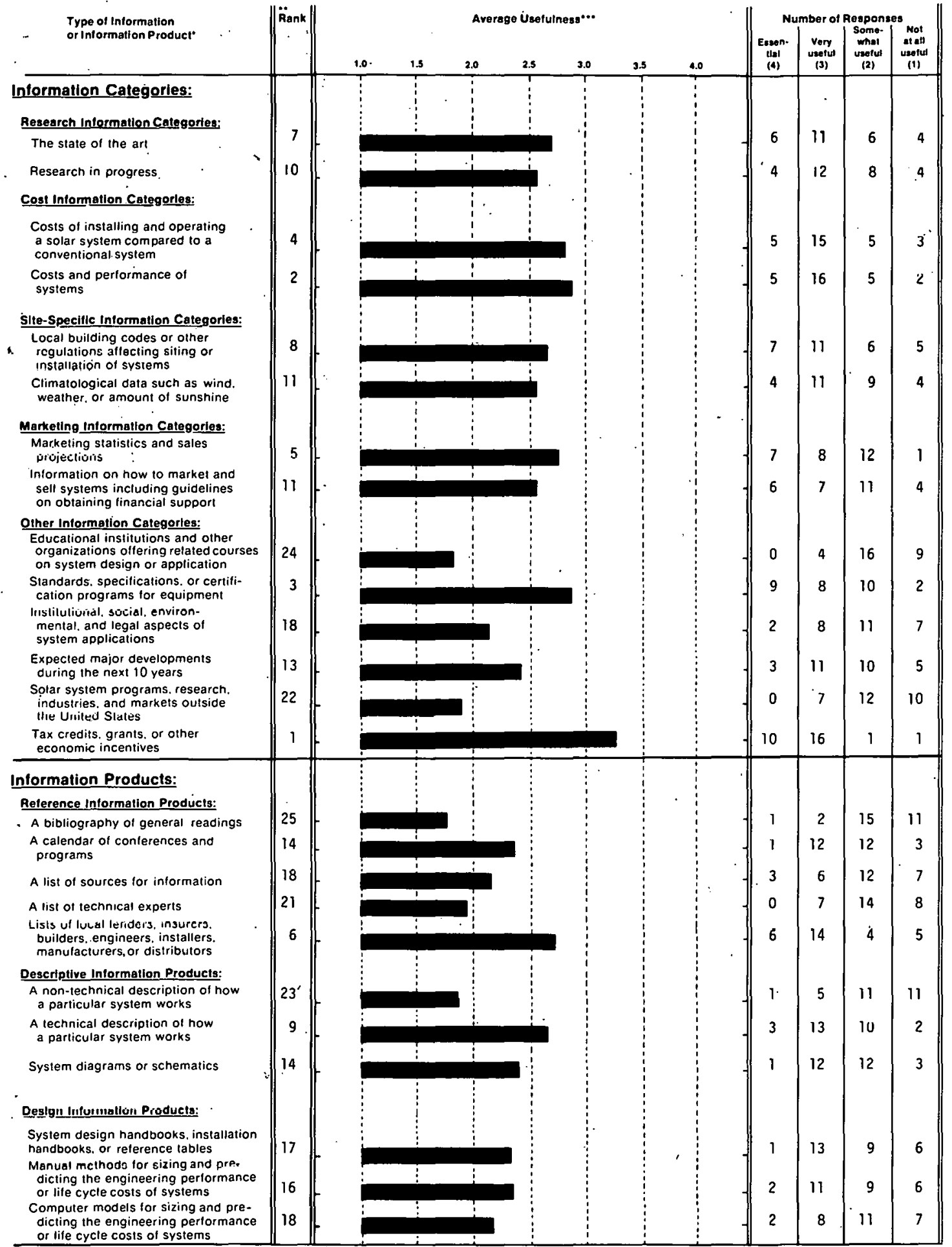

Each sample frame of users was questioned on intormation ind information products in the conlext of theit specific lechnology: For example. biomass semple frames were

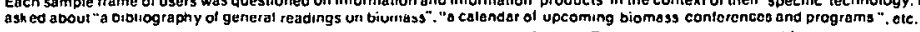
Rank-Eachintormation producl was assigned a rank based on average usefulness: Thus. the product with the hignest average usefuiness was assigned the rank of ":": the producl with the lowest average uselutness would be ranked "25" where all llems were askeo. If iwo or more intormation products were tied tor 2 nde, they were both assigned a " 2 ". The next

... Average useturness was calculated by assigning the responses on a 1.4 gcele trom a "4" tor "essenlial" 10 a "1" tor "not very usefur".

Figure 4-4. Usefulness of Selected Information Items: Total Active Solar Heating and Cooling Collectors Manufacturer Representatives 
Question \#8. I will read a list of potential information or information products on solar systems. For each, please tell me how useful that information would be to you. Would the following be: essential, very useful, somewhat useful, or not at all useful?

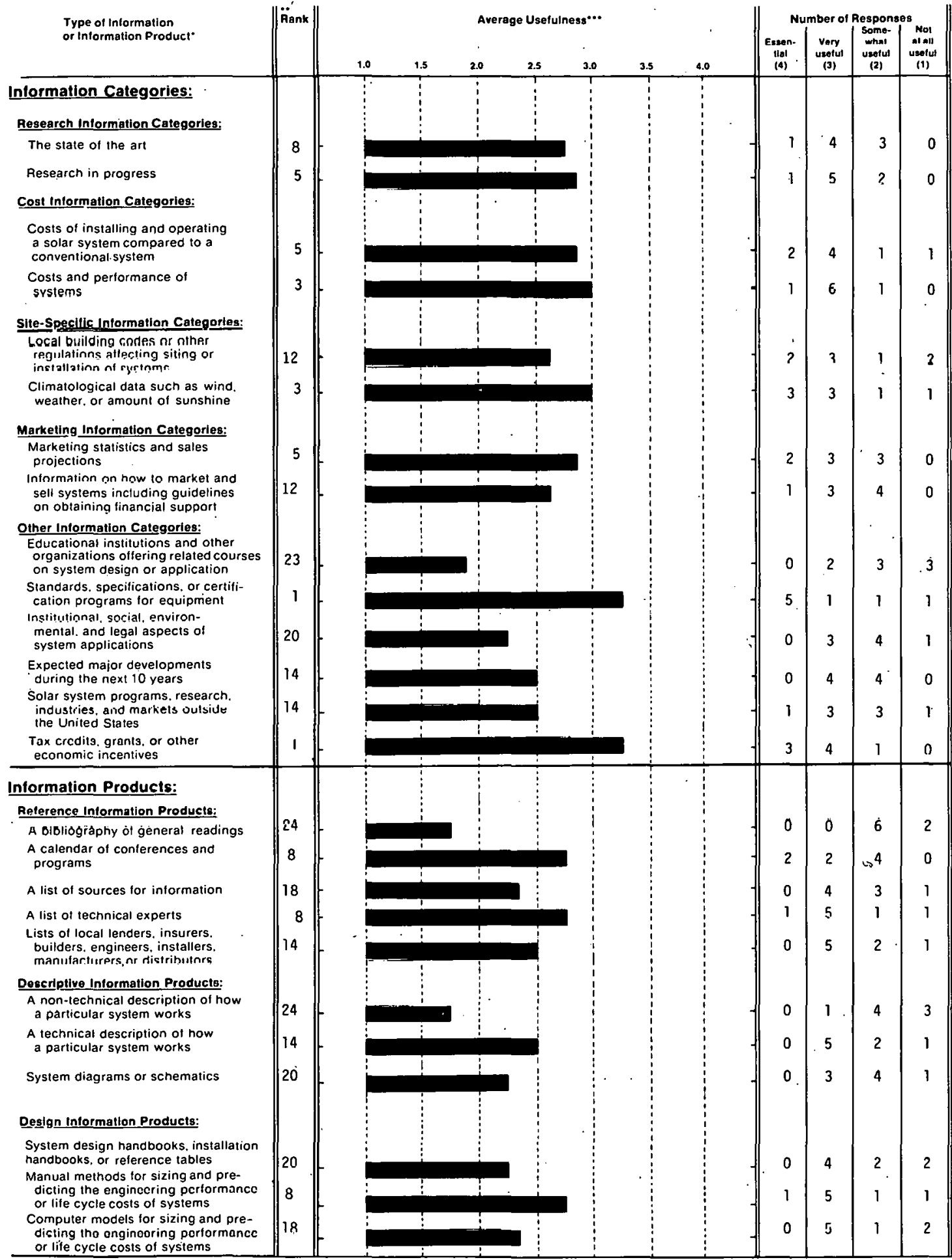

- Each sample trame of users was questioned on information and intormation products in the context ol their specitic technology. For example. biomass sample frames were asked about "a bibliography of general readings on biomass"." "a calendar of upcoming biomass conterences and programs ". etc.

Rank-Each intormation product was assigned a rank based on average usefulness. Thus. the product with the highest average usetulness was assigned the rank of " 1 ": the product with the lowest overage usefulness would
nignest tanking was inen assigned a " 4 "

Average usefulness was calculated by assigning the responses on a i-4 scale trom a "4" for "essential" 10 a " " " for "not very useful-

Figure 4-5. Usefulness of Selected Information Items: Concentrating Collectors Manufacturer Representatives 
Question \#11. In the past few years, have you obtained any type of solar information from any of the following sources?

Information Sources

Percentage Responding Yes"*

\section{Public Media:}

Radio or TV

Periodicals, newspapers or magazines

Private Solar-Involved Organizations:

Private solar energy or environmental organizations

The local chapter or national headquarters of International Solar Energy Society (ISES), including their publications

The local chapter or national headquarters of Solar Energy Industries Association (SEIA), including their publications

\section{Contacts with Professionals:}

An installer, builder, designer or manufacturer of solar systems

Workshops, conferences or training sessions

Information Services*:

Your organizational library or a local library

A commercial data base: for example. Lockheed, SDC, BRS

Smithsonian Science Information Exchange (SSIE)

A Federal library or information center; for example, the National Agricultural Library or the Environmental Data System

The Government Printing Office (GPO)

National Technicàl Information Service (NTIS)

Technical Information Center at Oak Ridge (TIC)

Government Solar-Involved Organizations

Directly from the U.S. Department of Energy

National Solar Heating \& Cooling Information Center

Regional Solar Energy Centers

State Energy or Solar Offices

\section{Other:}

Some other state or local government office or publication

A public utility company

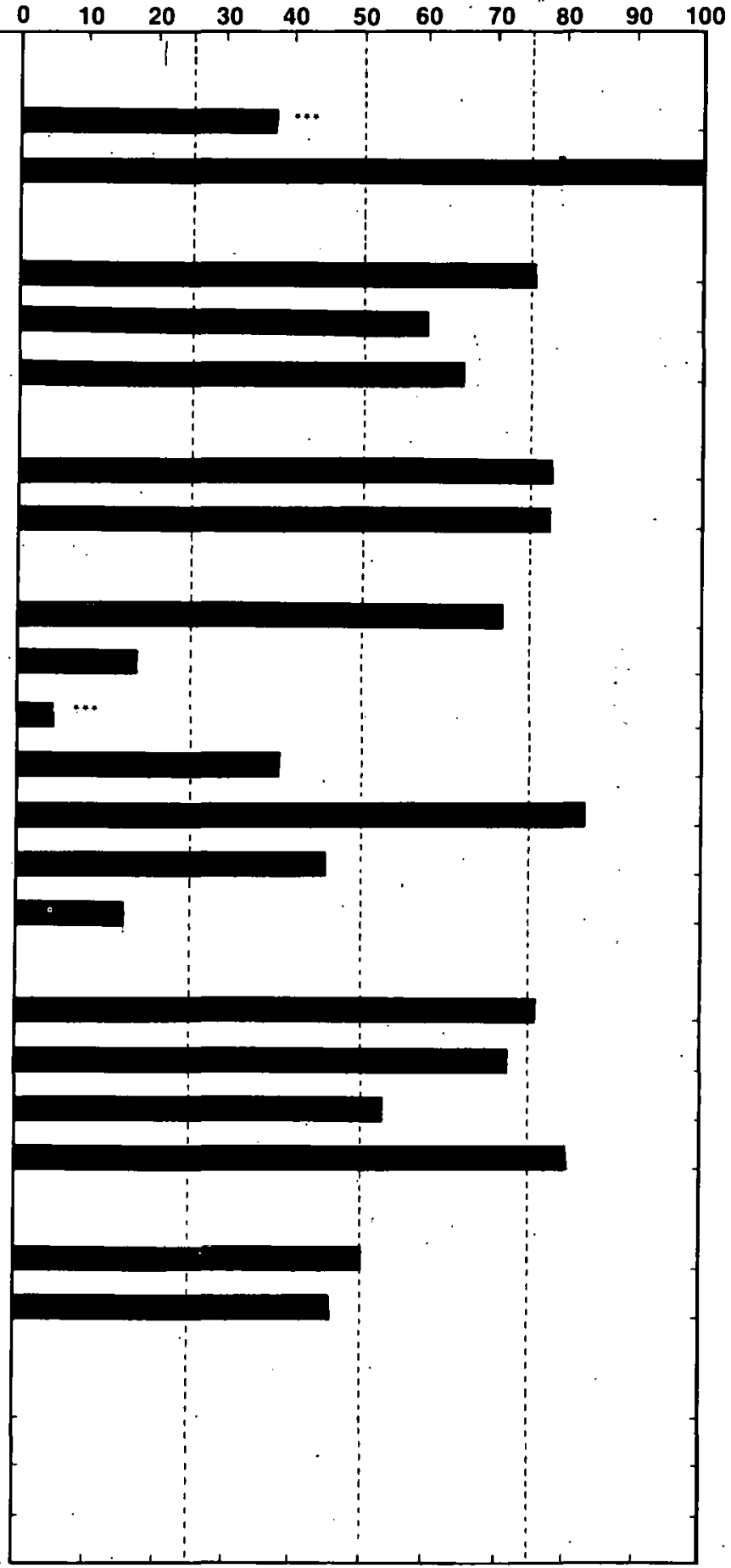

- Services and centers whosc primary purpose is to disseminate information.

- These data are based upon a total ol 34 iespuondents.

**Only asked of Non-concentrating Collectors Manufacturers and Other Components Manufacturers.

Figure 4-6. Use of Selected Information Sources: Total Active Solar Heating and Cooling Manufacturer Representatives 
Question \#11. In the past tew years, have you obtained any type of solar information from any of the following sources?

Information Sources

Percentage Responding Yes".

Public Media:

Radio or TV

Periodicals, newspapers or magazines

Private Solar-Involved Organizations:

Private solar energy or environmental organizations

The local chapter or national headquarters of International Solar Energy Society (ISES), including their publications

The local chapter or national headquarters of Solar Energy Industries Association (SEIA), including their publications

\section{Oontocts with riofebsiuinals:}

An installer, builder, designer or manufacturer of solar systems

Workshops, conferences or training sessions

Information Services*:

Your organizational library or a local library

A commercial data base; for example, Lockheed. SDC. BRS

Smithsonian Science Information Exchange (SSIE)

A Federal library or information center; for example, the National Agricultural Library or the Environmental Data System

The Government Printing Office (GPO)

National Technical information Service (NTIS)

Technical Information Center at Oak Ridge (TIC)

Government Solar-Involved Organizations

Directly from the US.S. Department of Energy

National Solar Heating \& Cooling Information Center

Regional-Solar Energy Centers

State Energy or Solar Offices

Other:

Some other state or local government office or publication

A public utility company

Services and centers whose primary purpose is to disseminate information.

- These data are based upon a total of 96 respondents.

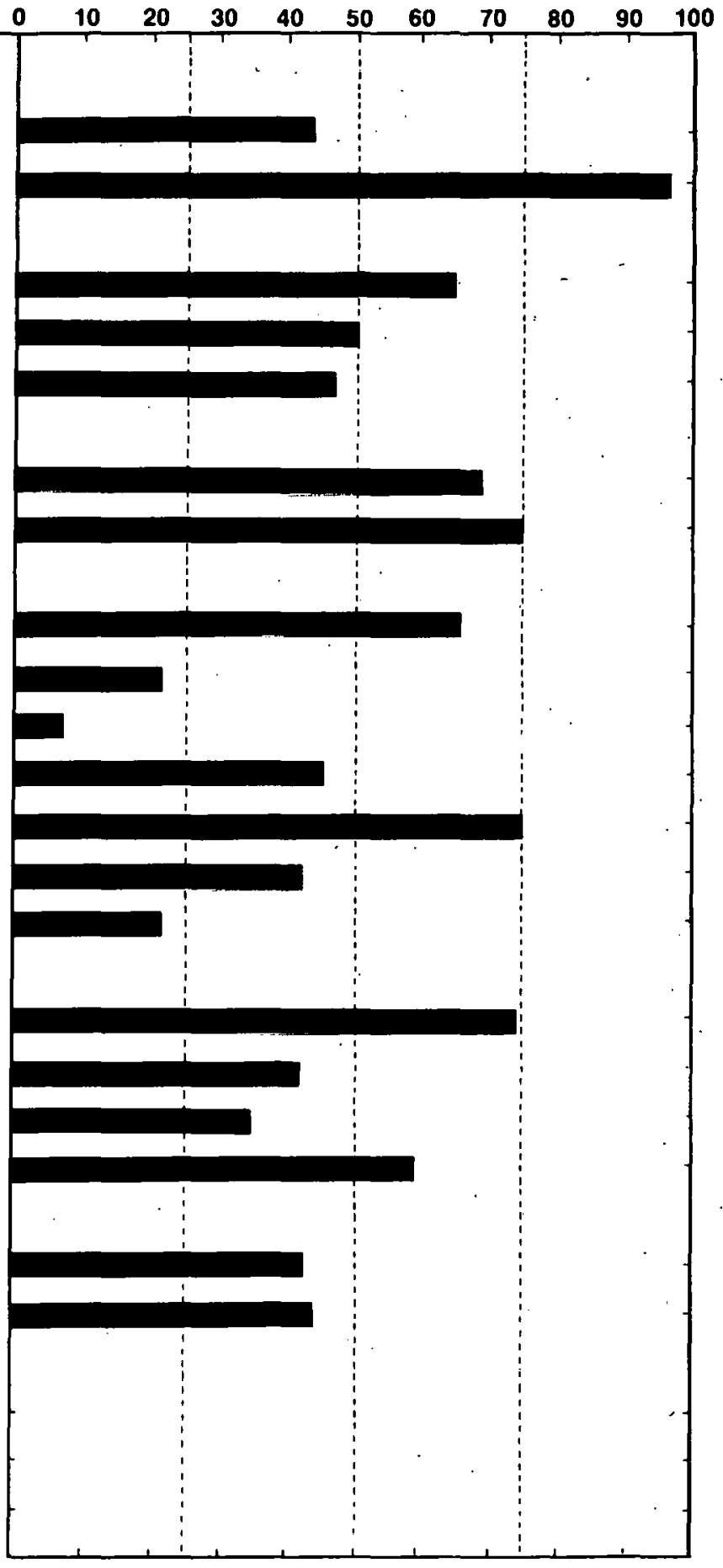


Question \#11. In the past few years, have you obtained any type of solar information from any of the following sources?

Information Sources

Percentage Responding Yes $\cdots$

Public Media:
Radio or TV
Periodicals. newspapers or magazines
Private Solar-Involved Organizations:
Private solar energy or environmental organizations
The local chapter or national headquarters of International
Solar Energy Socicty (ISES). Including thair pubiicationis
The local chapter or national headquarters of Solar Energy
lidustiies Association (SEIA). including their publications
Contacts with Prolessionals:

An installer, builder, designer or manufacturer of solar systems

Workshnps conferences or training sessions

Intormation Services::

Your organizational library or a local library

A commercial data base: for example, Lockheed, SDC. BRS

Smithsonian Science Information Exchange (SSIE)

A Federal library or information center; for example, the National Agricultural Library or the Environmental Data System

The Government Printing Office (GPO)

National Technical Information Service (NTIS)

Technical Information Center at Oak Ridge (TIC)

Government "Solar-Involved Organizations

Directly from the U.S. Department of Energy

National Solạ Heating \& Cooling Information Center

Regional Solar Energy Centers

State Energy or Solar Offices

Other:

Some other state or local government office or publication

A public utility company

Sources for this specific sample frame**:

American Institute of Architects

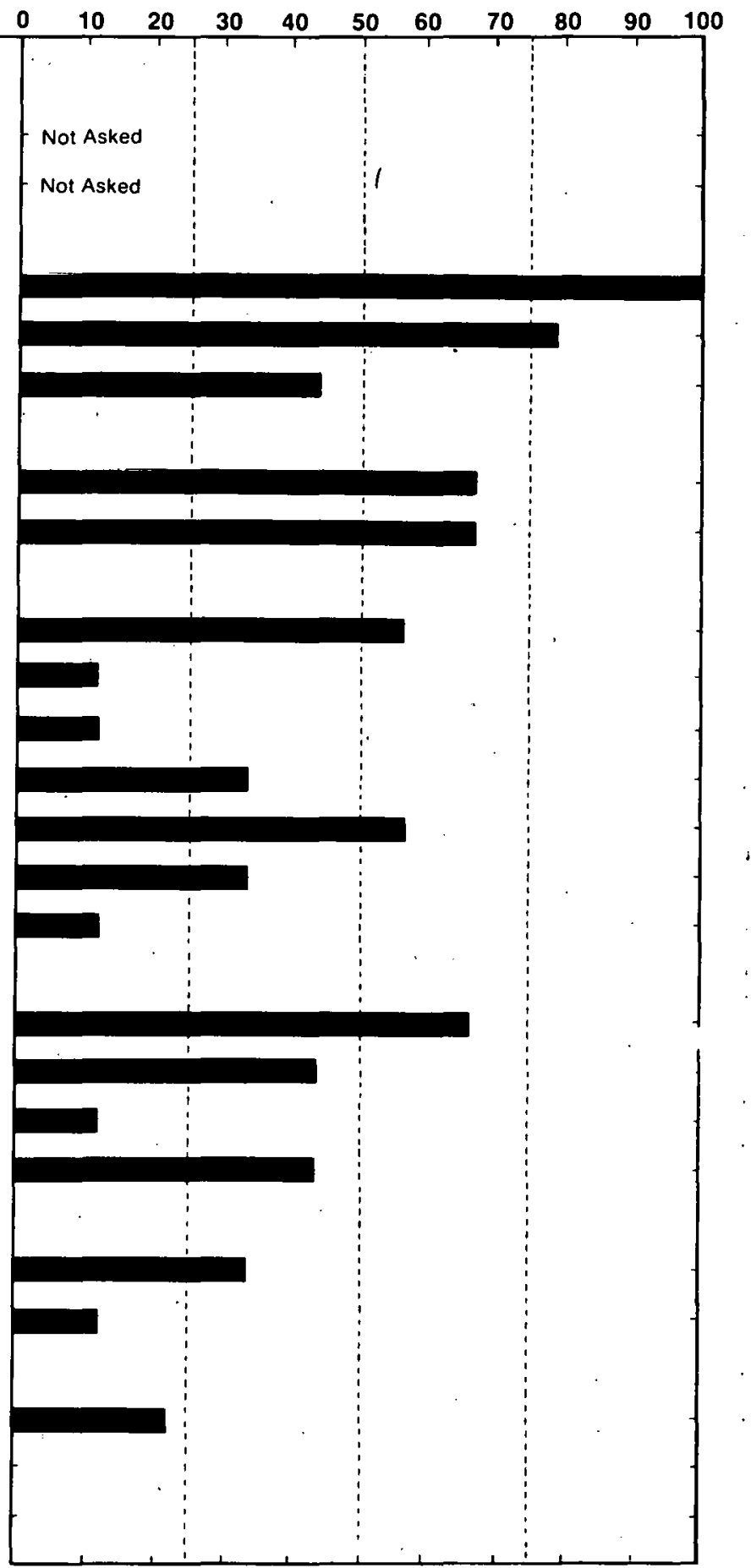

- Services and conters whose primary purpose is to disseminate information.

- Some sample frames were questioned about additional information sources which are applicable to their technology. For example. the manufacturers of biomass conversion equipment were also asked it they have obtained any type of solar information from: "the local or national office of the U.S. Lepartment of Agriculiure. includiry Exlenisivin and rorestry:"

*.. These data are based upon a total of 9 respondents.

Figure 4-8. Use of Selected Information Sources: Passive Manufacturer Representatives 
- A commercial data base, and

- Some other state or local government office or publications.

In comparison to other manufacturer representatives, Total SHAC Manufacturer Representatives mentioned Regional Solar Energy Centers (RSECs) and state energy or solar offices significantly $(\mathrm{P}<0.05)$ more of ten than did Passive Manufacturer Representatives.

\subsubsection{Membership in Solar-Interested Organizations}

Twenty-four of the 34 representatives of Total SHAC Manufacturers interviewed were members of a professional, technical, or other organization with an interest in solar energy. These organizations (and the number of times mentioned) are displaycd in Table 4-5.

Also mentioned were several organizations the authors could not verify. These included "American Electrical Society," "International Solar Institute," "Mineral Insulation Manufacturers Association," and "Oceanographic Institute."

\subsubsection{Exposure to Publications on Solar Energy}

During the past 6 months, 33 of the 34 representatives of Total SHAC Manufacturers had read publications that included information on SHAC. The publications they could specify (and the number of times mentioned) are displayed in Table 4-6.

Also mentioned were several publications the authors could not verify. These included "Leonard Eiserer publication (Silver Springs, Florida)," "Eric Farber's publication," "Heating and Cooling," "International Solar Engineer," "Passive Systems by Bruce Anderson," "Pool and Spa News," "Solar Energy Newsletter," "Solar Engineering and Cooling," "Solar Primer by David Wright," "Sun -Digest," "Solar Electric," "newspapers," "swimming pool trade journals," "technical journals," and "trade magazines."

\subsubsection{Use of Special Acquisition Methods}

The respondents were asked whether they had obtained any information (not just SHAC or other solar energy) in the past year by computer terminal, by Computer Output Microform (COM), or by other microform (e.g., microfiche, microfilm sheets or rolls). Few SHAC Manufacturer Representatives appeared accustomed to using these sperial acquisition methods, a trait common to Manufacturer. Representatives in all technologies studied. In the past year, only 8 of the 34 (24\%) Total SHAC Manufacturer Representatives had used a computer terminal, 2 of the 34 (6\%) had used COM, and only 4 of the 34 (12\%) had used other microform.

\subsection{SUMMARY AND COMMENTS}

Total SHAC Manufacturer Representatives included four groups and contained representatives from 34 manufacturers of SHAC systems and components. The four groups included: 9 SHAC Heating/Cooling System Manufacturer Representatives, 9 SHAC Water Heating System Manufacturer Representatives, 11 SHAC Nonconcentrating 
Table 4-5. MBMBERSHIP IN SOLAR-INTERESTED ORGANIZATIONS: ACTIVE SOLAR HEATING AND COOLNG MANUFACTURER REPRESENTATIVES

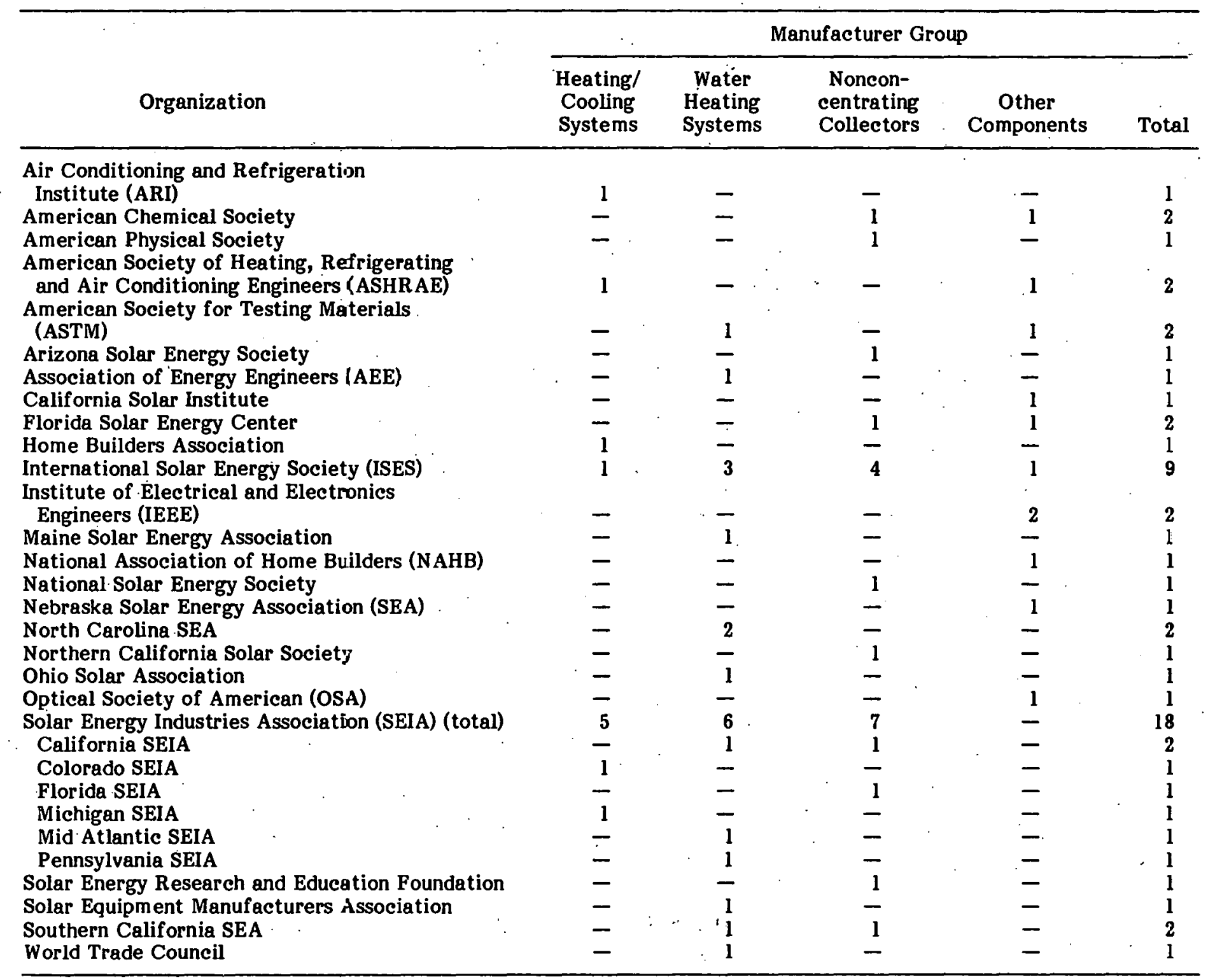


Table 4-6. PUBLICATIONS READ WHICH INCLUDED INFORMATION ON SOLAR ENERGY: ACTIVE SOLAR HEATING AND COOLING MANUPACTURER REPRESENTATTYES

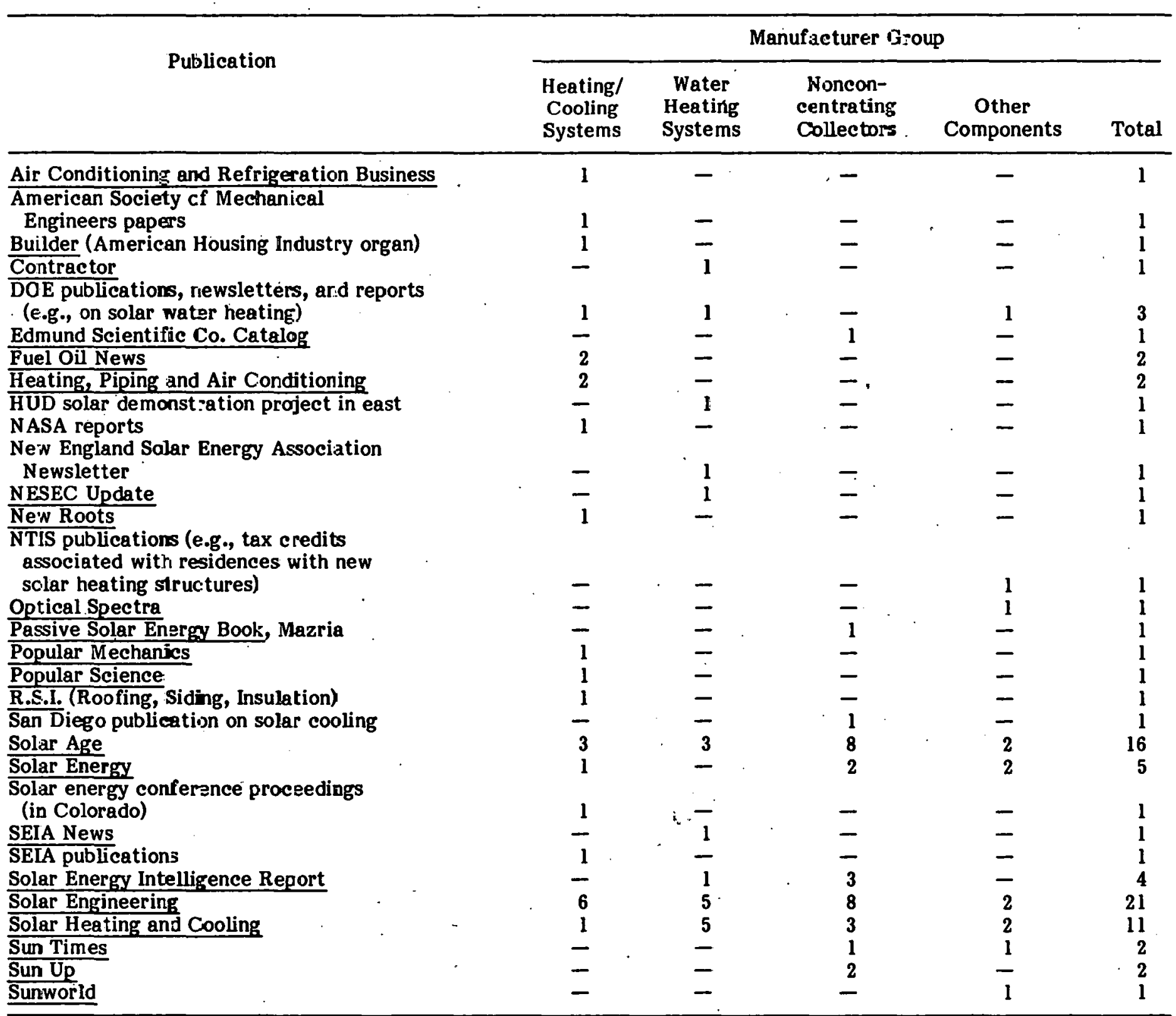


Collector Manufacturer Representatives, and 5 SHAC Other Component Manufacturer Representatives. The level of informedness, the degree of involvement, and the educational level of representatives of Total SHAC Manufacturers were similar to those of Passive Manufacturer Representatives and of All Manufacturer Representatives.

Representatives of Total SHAC Manufacturers gave the highest priority to receiving information on:

- Tax credits, grants, or other economic incentives for SHAC systems;

- Costs and performance of SHAC systems;

- Marketing statistics and sales projections for SHAC equipment;

- Lists of local lenders, insurers, builders, engineers, installers, manufacturers, or distributors for SHAC systems;

- Costs of installing and operating a SHAC system compared to a conventional system; and

- Standards, specifications, or certification programs for SHAC systems.

Total SHAC Manufacturer Representatives gave low ratings to "a bibliography," "educational institutions,". "a nontechnical description," "solar energy programs, research ... outside the United States," and "lists of technical experts."

The resulting picture of the SHAC Manufacturer Representatives was similar to that of All Manufacturer Representatives in that both were in need of information on costs and economic incentives. Beyond this point, however, SHAC Manufacturer Representatives differed in that they were more marketing oriented, whereas manufacturers of other technologies were more oriented towards monitoring research and technological progress. This was most likely a result of the more advanced stage of commercialization of SHAC compared to the other solar technologies. Overall, the information needs of SHAC Manufacturer Representatives appeared more similar to those of Passive Manufacturer Representatives than to those of All Manufacturer Representatives.

Representatives of Total SHAC Manufacturers most of ten received solar information through "periodicals," GPO, contacts with professionals including "an installer, (etc.)," "workshops, (etc.)," "state energy or solar offices," DOE, and "private solar energy or environmental organizations." Compared to Passive Manufacturer Representatives, Total SHAC Manufacturer Representatives were more frequent users of the "RSECs" and "state energy or solar offices." At least 21 of the $34(62 \%)$ of the representatives of SHAC Manufacturers were members of a local or national solar energy association. Solar Age, Solar Engineering, and Solar Heating and Cooling served as important information disseminators. 


\section{SEPI鹌}


SECTION 5.0

\section{ACTIVE SOLAR HEATING AND COOLING DISTRIBUTORS}

\subsection{DESCRIPTION OF RESPONDENTS}

\subsubsection{Description of Sample}

This section describes the results of a telephone study to determine the needs of distributors of active solar heating and cooling systems and components for information on SHAC. A total of 9 SHAC Distributors were interviewed.

The sample frame for SHAC Distributors was constructed from various state and regional directories including: the MASEC Solar Yellow Pages [9]; the Northeast Yellow Pages of Solar Energy Resources [10]; the "Preliminary List of Solar Equipment Manufacturers, Dealers/Distributors, Contractors/Installers, and Consultants in New Jersey" [11]; the Summaries of the Responses of the Participating Jurisdictions to the Southern Solar Energy Center Planning Project Information Request [12] (Section 11, Industry Identification); the Nevada Solar Energy Handbook [13] (section on Solar Manufacturers, Suppliers and Dealers); the Washington State Solar Networking Project [14] (section on Solar Businesses and Professionals by County); the Solar Energy Directory for Utah [15]; the Arizona Solar Industries Guide [16]; the Oregon Solar Energy Directory [17]; the New Mexico Solar Business Directory [18]; and the Western Regional Solar Energy Directory (California Edition) [19]. In states where high numbers of distributing companies were listed, only a subset of these names were used. Companies that listed no contact name were also eliminated. For all states, some of the businesses listed as solar distributors might also have been involved in another facet of solar energy; therefore, the contact person listed might have been an sngineer, architect, builder, installer, manufacturer, researcher, and/or distributor. After all adjustments were made, the 9 interview candidates were randomly selected from a sample frame of 383 names.

Respondents. In making the telephone calls to contact the randomly selected interview candidates, it sometimes occurred that the person could not be reached. In this event another randomly selected name was substituted for the original name. When individuals were contacted, it was verified that they really were distributors of SHAC systems and/or components and that they would be needing information on SHAC within the next year. If they were not both involved and needing information, they were asked if they could refer the interviewer to someone else in their organization who would be an appropriate respondent. If such a referral was made, a call was then made to this new candidate; if no intraorganizational referral was made, a new candidate was randomly selected from the sample frame. The results of this process may be seen in Table 5-1.

Comparisons. For additional insight into the information needs and the information habits of these SHAC Distributors, results from this group are compared to the results from Wind Distributors. The data for SHAC Distributors and for Wind Distributors can be found in Appendix F.

\subsubsection{Current Status of Respondents}

Role. Five of the 9 SHAC Distributors specifically mentioned that they were distrib-

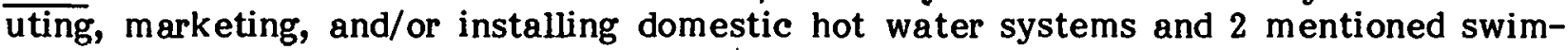
ming pool heating systems. Other types of SHAC systems that received single mentions included solar heating and solar air conditioning. One respondent "installed solar townhouses," and 1 supplied companies with electronic solar controls. 
Table 5-1. COMPLETON OP INTERVIEWS: ACTIVE SOLAR HEATING AND COOLNG DISTRIBUTORS

Event

Number of

Candidates

Interview completed with sample frame candidate

Interview completed with referral candidate

Refusal or candidate termination

Contact attempted: could not reach candidate within three

attempts or before interviews were completed

Subtotal

Contact attempted: invalid candidate (e.g., inappropriate field of inter'est, nu Leleplịune)

TOTAL .

Sample frame error rate ${ }^{a}$ (Percent)

Completion rate (Percent) $^{\mathrm{b}}$

$a_{\text {Invalid candidates divided by TOTAL }}$

${ }^{\mathrm{b}}$ Completed interviews divided by Subtotal

Involvement. Slightly fewer of the SHAC Distributors (4 of the 9 or 44\%) said that they were "very involved" in SHAC compared to 7 of the 9 (78\%) Wind Distributors who were "very involved" with wind energy:

Informedness. Seven of the 9 (78\%) SHAC Distributors considered themselves "very informed," compared to 5 of the 9 (56\%) Wind Distributors.

Need for Information. All respondents indicated they would need information on SHAC on the job. Only 3 of the 9 (33\%) SHAC Distributors, however, indicated they would need information on SHAC outside the job during the next year. This was similar to the results for Wind Distributors, where all 9 indicated they would need information on their own technology on the job and 2 of the 9 (22\%) outside the job.

\subsubsection{Background of Respondents}

Five of the 9 SHAC Distributors held a bachelor's degree, and the remaining 4 had received no college degree. Two had received degrees in cngineering, and the other 3 in business, economics, and finance. Wind Distributors also had a mix of business and engineering degrees; however, some had received advanced degrees (3 of the 9 or 33\%) compared to none of the SHAC Distributors. One SHAC Distributor received his/her most recent degree 35 years ago, one 16 years ago, and 3 from 5-10 years ago.

Only 1 SHAC Distributor had been in the current profession for 2 or fewer years, 4 for 3-5 years, 2 for 6-10 years, and 2 for over 10 years; levels of experience were similar for Wind Distributors. Two of the SHAC Distributors were managers, 2 were engineers, 1 . was a consultant, 1 was an "entrepreneur of renewable energy," and 3 were in a skilled trade (a contractor, a technician, and a plumber). 


\subsection{INPORMATION NEEDS OF RESPONDENTS}

\subsubsection{Technical Areas}

SHAC Distributors were asked to choose those areas in which they were "particularly interested in obtaining information" from a list of selected technical areas of SHAC. All 9 were interested in "space heating," 8 of the 9 (89\%) were interested in "water heating" and in "hybrid systems," 7 of the 9 (78\%) in "swimming pool heating," and 6 of the 9 (67\%) in "space cooling."

Two SHAC Distributors volunteered that they were also interested in information on photovoltaics.

\subsubsection{Types of Information}

SHAC Distributors were asked to name the information about SHAC that was important for them to obtain. Seven of the 9 SHAC Distributors volunteered one or more items of information that they considered important. Four felt updates on advances in SHAC technology were important, including: updates on experiments, new technologies, and "anything new." Another 2 mentioned information on what systems are available on the market. Other topics included: new information on electronics, information on marketing domestic hot water systems, specifications and applications information, and residential and commercial usage of SHAC systems.

Two SHAC Distributors volunteered that they needed but were not able to get marketing information (including trends) on SHAC systems.

Choice Between Specific Needs. A list of 11 types of SHAC information products and 14 types of SHAC information categories was read to each respondent. Each respondent described the usefulness of each particular item by assigning it a value of "essential," "very useful," "somewhat useful," or "not at all useful." The results are given in Fig. 5-1. For the purpose of comparison, the results for Wind Distributors are shown in Fig. 5-2.

SHAC Distributors selected information on "expected major developments" and the economics of SHAC systems as the most important. The six top-rated information categories/products were:

- Expected major developments during the next 10 years;

- Tax credits, grants, or other economic incentives;

- Lists of local lenders, insurers, builders, engineers, installers, manufacturers, or distributors;

- Manual methods for sizing and predicting performance or costs;

- Costs of installing and operating a SHAC system compared to a conventional system; and

- Costs and performance of systems. 
Question \#8. I will read a list of potential information or information products on solar systems. For each, please tell me how useful that information would be to you. Would the following be: essential, very useful, somewhat useful, or not at all useful?

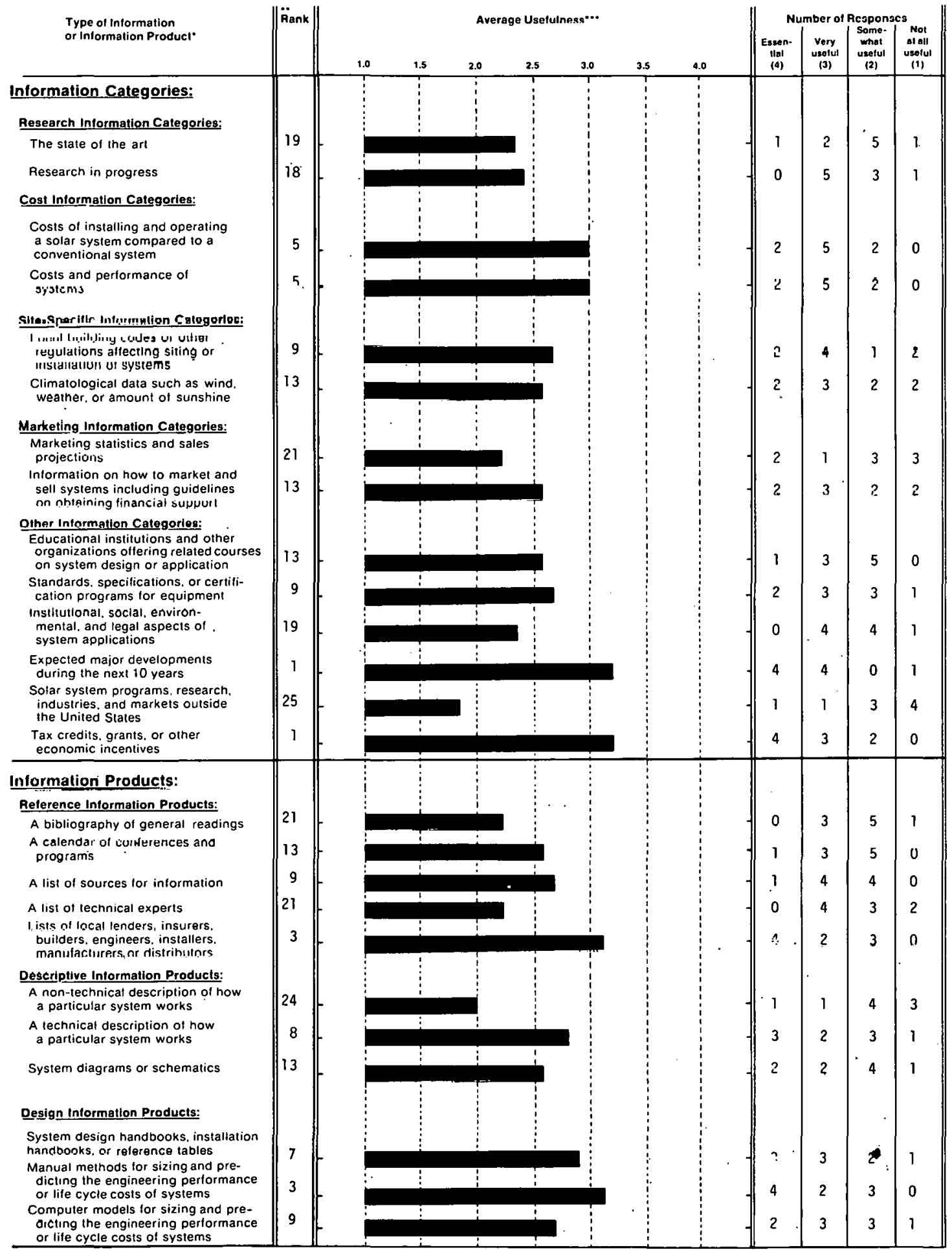
- Each sample frame of users was questioned on inlormation and intormation producis in the context of their specitic technology. For example. biomass sample trames were
asked about "a bibliography ol general readings on biomass". "a calendar of upcoming biomass conterences and programs ". etc.

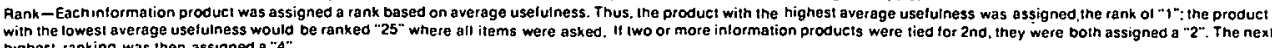

.... Avest ans was was colculated by assigning the responses on a 1.4 scate trom a "A"

Figure 5-1. Usefulness of Selected Information Items: Active Solar Heating and Cooling Distributors 
Question \#8. I will read a list of potential information or information products on solar systems. For each, please tell me how useful that information would be to you. Would the following be: essential, very uselul, somewhat useful, or not at all useful?

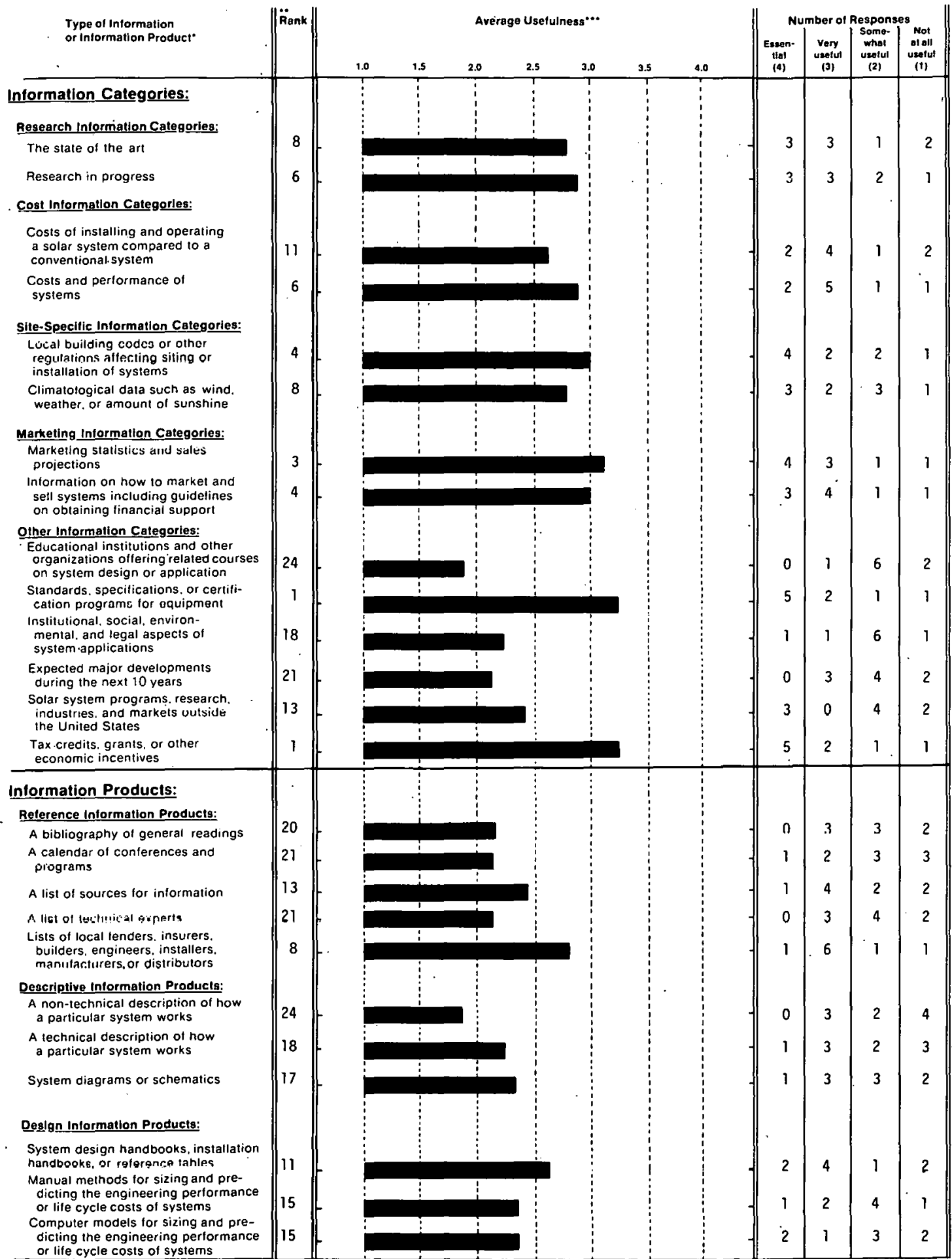
- Far.h sample lrame of users was questioned on intormation and intormation products in the context of their specific technology. For example. biomass sample trames were
Asked about "a bibliography of general readings on biomass". "a calendar ol upcoming biomass conferences and programs ". elc. Aank-Each information product was assigned a rank based on average usefulness. Thus, the product with the highest averege usefulness was assigned the rank of " 1 "; the product with the lowest average usefulness would be ranxed "25" where all ilems were asked. It two or more intormation procucts were tied for 2nd. they were boin assigned a "2". The next

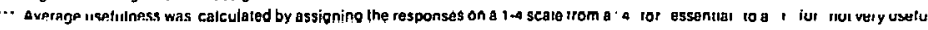

Figure 5-2. Usefulness of Selected Information Items: Wind Distributors 
SHAC Distributors assigned the lowest relative ratings to:

- Solar energy programs, research, industries, and markets outside the United States;

- A nontechnical description of how a particular system works;

- Marketing statistics and sales projections;

- A bibliography of general readings;

- Lists of technical experts;

- The state of the art; and

- Institutional, social, environmental, and legal aspects.

The low rating assigned to marketing statistics and sales projections was surprising.

Statistical tests indicated all six of the top categories/products were rated significantly $(P<0.05)$ higher than were the seven lowest-rated items.

It should be noted that these lower-rated items were not necessarily of no worth to the SHAC Distributors. For example, 4 of the 9 (44\%) thought "institutional, social ... aspects" was "very useful." Thus, these information categories/products could be useful to some SHAC Distributors but were of a lower relative priority to the entire group.

Statistical tests were also used to determine whether the SHAC Distributors rated any of these information items significantly higher (or lower) than they were rated by the Wind Distributors. Some groups, however, tended to give higher scores in general than did other groups. To compensate for this effect, these statistical tests compared the "relative rating" given by one group to the "relative rating" given by the other groups. The procedure for calculating the relative rating is described in Appendix $E$. The average overall rating was slightly higher for SHAC Distributors (2.62) than it was for Wind Distributors (2.55).

Compared to Wind Distributors, SHAC Distributors rated the need for information on "educational institutions" and "expected major developments" as significantly $(P<0.05)$ higher and "marketing statisties and sales. projections" as significantly $(\mathrm{P}<0.05)$ lower. There also seemed to be indications that SHAC Distributors were less interested in research information, international programs, and "standards, etc.)" but more interested in systems design information.

\subsection{ACQUISTION OF INFORMATION BY RESPONDENTS}

\subsubsection{Use of Selected Information Sources}

SHAC Distributors were asked which of 19 different potential sources of solar information they had used in the past few years. For this question the respondents were not asked if they had obtained information on SHAC, but instead were asked if they had obtained any solar information from each specific source. Thus, the question sought to determine which information sources were the most familiar to the respondents. The results are shown in Fig. 5-3. For the purpose of comparison, those for Wind Distributors are provided in Fig. 5-4. 
Question \#11. In the past few years, have you obtained any type of solar information from any of the following sources?

Information Sources

Percentage Responding Yes*

Public Media:

Radio or TV

Periodicals, newspapers or magazines

Private Solar-Involved Organizations:

Private solar energy or environmental organizations

The local chapter or national headquarters of International Solar Energy Society (ISES), including their publications

The local chapter or national headquarters of Solar Energy Industries Association (SE|A), including thelr publicatiorls

\section{Contacts with Professionals:}

An instalter, builder, designer or manufacturer of solar systems

Workshops. conferences or training sessions

Information Services*:

Your organizational library or a local library

A commercial data base: for example. Lockheed. SDC. BRS

Smithsonian Science Information Exchange (SSIE)

A Federal library or information center; for example. the National

Agricultural Library or the Environmental Data System

The Government Printing Office (GPO)

National Technical Information Service (NTIS)

Technical Information Center at Oak Ridge (TIC)

Government Solar-Involved Organizations

Directly from the U.S. Department of Energy

National Solar Heating $\&$ Cooling Information Centel

Regiona! Solar Energy Centers

State Energy.or Solar Offices

Other:

Some other state or local government office or publication

A public utility company

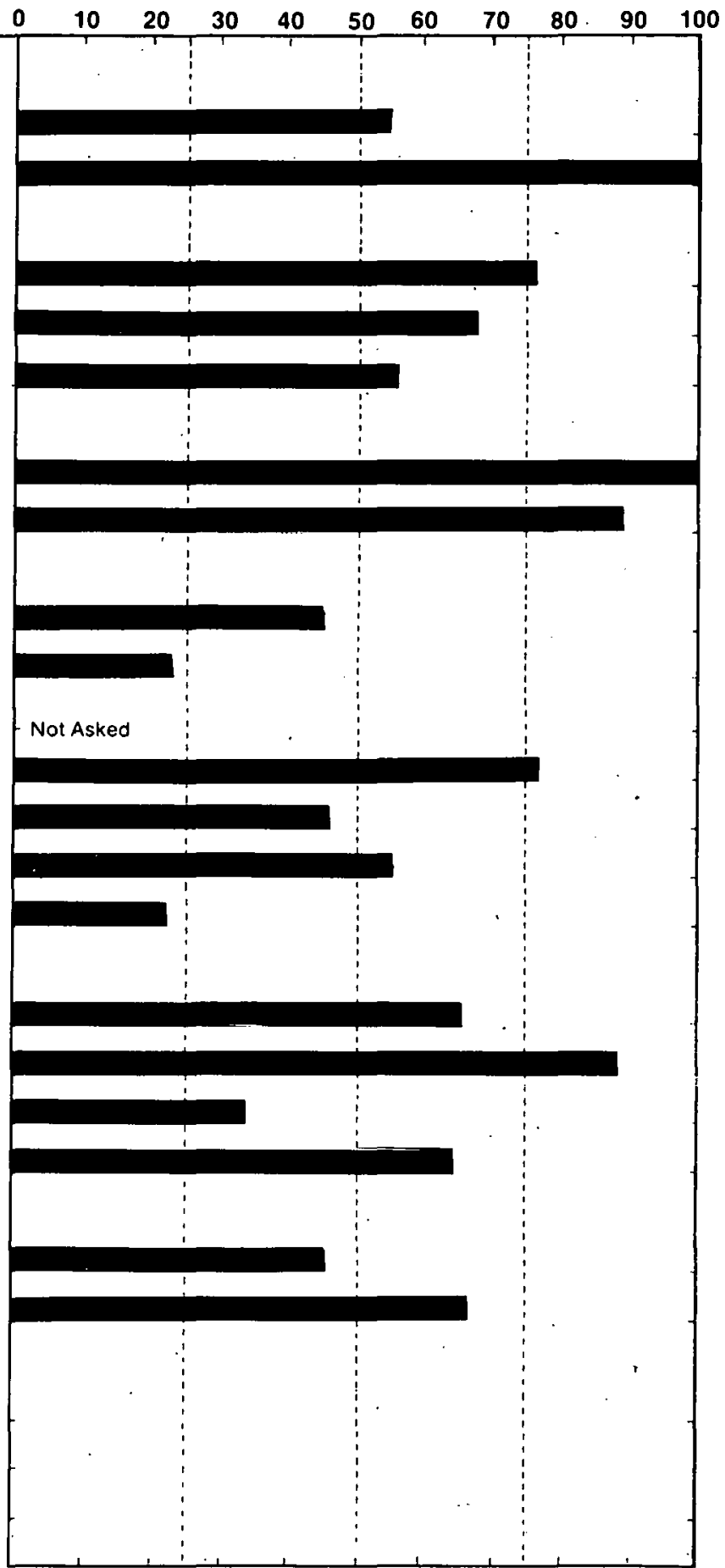

- Services and centers whuse primary purpose is to disscminatc information.

These data are based upon a total of 9 respondents.

Figure 5-3. Use of Selected Information Sources: Active Solar Heating and Coollng Distributurs 
Question \#11. In the past few years, have you obtained any type of solar information from any of the following sources?

\section{Information Sources}

Public Media:
Radin nr TV
Periodicals, newspapers or magazines

Private Solar-Involved Organizations:

Private solar energy or environmental organizations

Thie lucal chapter or national neadquarters of International Solar Energy Society (ISES), including their publications

The local chapter or national headquarters of Solar Energy

Industries Association (SEIA), including their publicationş

Contacts with Professionals:

An installer, builder, designer or manufacturer of solar systems

Workshops. conferences or training sessions

\section{Information Services*:}

Your organizational library or à lucal library

A commercial data base: for example. Lockheed, SDC, BRS

Smithsonian Science Information Exchange (SSIE)

A Federal library or information center; for example, the National Agricultural Library or the Environmental Data System

The Government Printing Office (GPO)

National Technical Information Service (NTIS)

Technical Information Center at Oak Ridge (TIC)

Government Solar-Involved Organizations

Directly from the U.S. Department of Energy

National Solar Heating \& Cooling Information Centel

Regional Solar Energy Centers

State Energy or Solar Otfices

Other:

Some other state or local government office or publication

A public villity cumpariy

Sourcecs for this specitic sample frame ${ }^{+t}$ :

American Wind Energy Association
Percentage Responding Yes

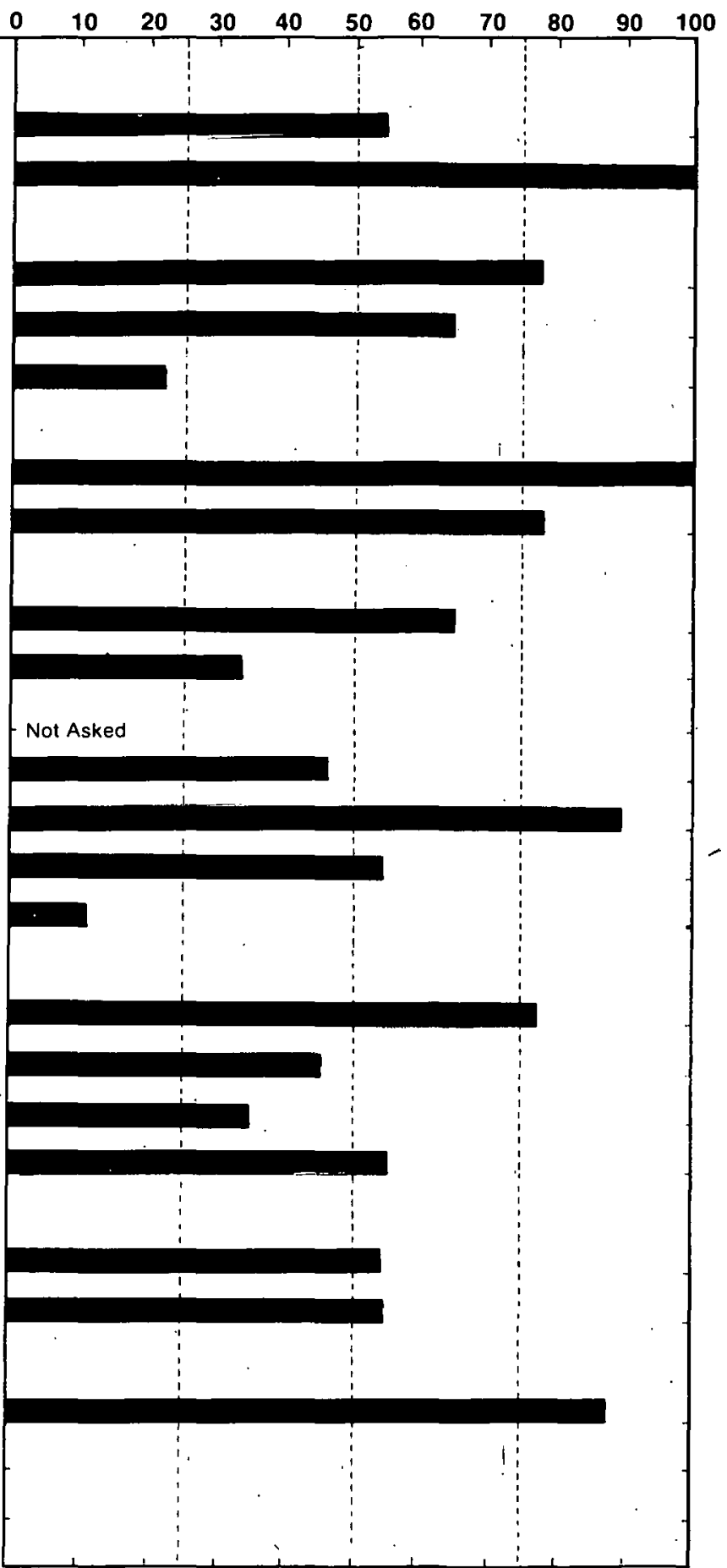

- Services and centers whose primary purpose is to disseminate information.

- Some sample frames were questioned about additional information sources which are applicable to their technology. For example. the manufacturefs of biomass conversion equipment were also asked it they have obtained any type of solar information from: "the local or national office of the U.S. Department of Agriculture, including Extension and Forestry."

.... These data are based upon a total of 9 respondents.

Figure 5-4. Use of Selected Information Sources: Wind Distributors 
The information sources mentioned most of ten by SHAC Distributors were:

- Periodicals, newspapers, or magazines;

- An installer, builder, designer, or manufacturer;

- Workshops, conferences, or training sessions;

- National Solar Heating and Cooling Information Center (NSHCIC);

- Private solar energy or environmental organizations; and

- A federal library or information center.

The information sources mentioned least of ten by SHAC Distributors were:

- A commercial data base,

- Technical Information Center (TIC), and

- Regional Solar Energy Centers (RSECs).

In comparing the information sources used by SHAC Distributors to those used by Wind Distributors, no statistically significant differences were found.

\subsubsection{Membership in Solar-Interested Organizations}

Six of the 9 SHAC Distributors interviewed were members of a professional, technical, or other organization with an interest in solar energy. These organizations (and the number of times mentioned),included:

- Air Conditioning Contractors of America;

- American Society of Heating, Refrigerating, and Air Conditioning Engineers (ASHRAE);

- Eastern New York State Solar Energy Society;

- Empire State Solar Association;

- International Solar Energy Society (ISES) (2);

- Master Electricians Guild;

- New England Solar Association;

- New England Solar Energy Society;

- San Diego Contractors Association;

- Solar Energy Engineers; and

- Solar Energy Industries Association.

Also mentioned was one organization which the authors could not verify; i.e., a "local solar association" (San Diego, California). 


\subsubsection{Exposure to Publications on Solar Energy}

During the past 6 months, all 9 SHAC Distributors had read publications that included information on SHAC. The publications. they could specify (and the number of times mentioned) included:

- ASHRAE Journal,

- ISES publications,

- Mechanix Illustrated,

- Solar Age (4),

- Solar Engineering (3), and

- Solar Heating and Cooling (3).

Also mentioned were several publications the authors could not verify. These included "Heating and Cooling Digest" and "Plumbing Journal."

\subsubsection{Use of Special Acquisition Methods}

The respondents were asked whether they had obtained any information (not just SHAC or solar energy) in the past year by computer terminal, by Computer Output Microform (COM), or by other microform (e.g., microfiche, microfilm sheets or rolls). Few SHAC Distributors appeared accustomed to using these special acquisition methods, a trait also common to Wind Distributors. In the past year, only 1 of the 9 had used a computer terminal and no one had used either COM or other microform. A comparison of SHAC Distributors with Wind Distributors showed no statistically significant differences in the proportion using computer terminals, COM, or other microf orms.

\subsection{SUMMARY AND COMMENTS}

Nine distributors involved in SHAC were interviewed. These respondents specifically mentioned distributing SHAC systems including: domestic hot water systems (5), swimming pool heating (2), solar heating, and air conditioning. One respondent "installed solar townhouses" and one supplied companies with electronic controls. Seven of the nine considered themselves "very informed" about SHAC.

SHAC Distributors expressed a high level of interest for all five technical areas of SHAC about which they were asked. Areas receiving the most interest included "space heating," "water heating," and "hybrid systems." Only slightly fewer in this group were interested in "swimming pool systems" and "space cooling."

SHAC Distributors gave the highest priority to receiving information on:

- Expected major developments in SHAC technology during the next 10 years;

- Tax credits, grants, or other economic incentives for SHAC systems;

- Lists of local lenders, insurers, builders, engineers, installers, manufacturers, or distributors for SHAC systems;

- Manual methods for sizing and predicting performance or costs for SHAC systems; 
- Costs of installing and operating a SHAC system compared to a conventional system; and

- Costs and performance of SHAC systems.

They gave low ratings to "solar energy programs, research . . . outside the United States," "a nontechnical description," "marketing statistics," "a bibliography," "lists of technical experts," "the state of the art," and "institutional, social . . a aspects."

The resulting picture of the SHAC Distributor is one who needs four types of information: first, expected major developments; second, information on cost, performance, tax credits, etc.; third, systems design; and fourth, the local solar infrastructure. Surprisingly, the SHAC Distributors did not attach much utility to marketing information.

SHAC Distributors most often received solar information through "periodicals," professional contacts including "an installer, (etc.)," "workshops and conferences," NSHCIC, "private solar energy ... organizations," and "a federal library." Solar Age also served as an important information source. 


\section{SEPI}




\section{SECTION 6.0}

\section{ACTIVE SOLAR HEATING AND COOLING INSTALLERS}

\subsection{DESCRIPTION OF RESPONDENTS}

\subsubsection{Description of Sample}

This section describes the results of a telephone study to determine the needs of installers for information on active solar heating and cooling (SHAC). Nine SHAC Installers were interviewed.

The sample frame for SHAC Installers was constructed from various state and regional directories including: MASEC Solar Yellow Pages [9]; Northeast Yellow Pages of Solar Energy Resources [10]; Summaries of the Responses of the Participating Jurisdictions to the Southern Solar Energy Center Planning Project Information Request [12], (Section II, Industry Identification, and Section 13, Local Specialists); Solar Energy Directory for Utah [15]; Arizona Solar Industries Guide [16], (people listed under the category of Contractor/Installer in the Collectors Components and/or Systems Design Section, the Space Heating Systems Section, the Swimming Pool Heating Systems Section, or the Water Heating Systems Section); Washington State Solar Networking Project [14], (in the section titled Solar Businesses and Professionals by County); New Mexico Solar Business Directory [18], (under the sections Residential Heating/Cooling and Commercial Heating] Cooling and Residential Hot Water); and Western Regional Solar Energy Directory, California Edition [19]. For all states, some of the businesses listed as installation companies could also have been involved in another facet of solar energy; therefore, the contact person listed might have been an engineer, architect, builder, distributor, manufacturer, researcher, and/or installer. After all adjustments were made, the 9 interview candidates were randomly selected from a sample frame of 312 names.

Respondents. In making the telephone calls to contact the randomly selected interview candidates, it sometimes occurred that the person could not be reached. In this event another randomly selected name was substituted for the original name. When individuals were contacted, it was verified that they really were SHAC Installers and that they would be needing information on SHAC within the next year. If they were not both involved and needing information, they were asked if they could refer the interviewer to someone else in their organization who would be an appropriate respondent. If such a referral was made, a call was then made to this new candidate; if no intraorganizational referral was made, a new candidate was randomly selected from the sample frame. The results of this process may be seen in Table 6-1.

The data for SHAC Irstuller's can be found in Appendix F.

\subsubsection{Current Status of Respondents}

Role. Three of the 9 (33\%) SHAC Installers specifically mentioned that they installed hot water systems; two installed space heating systems; and 1 each mentioned installing swimming pool heating systems, space cooling systems, and collection pumps for heating and cooling. Two also mentioned that they designed systems. 


\section{Table 6-1. COMPLETION OF INTERVIEWS: ACTIVE SOLAR HEATING AND} COOLNG INSTALLERS

Interview completed with sample frame candidate

Refusal or candidate termination

Contact attempted: could not reach candidate within three

attempts or before interviews were completed

Subtotal

Contact attempted: invalid candidate (e.g., inappropriate field of interest, no telephone)

TOTAL

Sample frame error rate ${ }^{a}$ (Percent)

Completion rate ${ }^{\mathrm{b}}$ (Percent)

anvalid candidates divided by TOTAL

${ }^{\mathrm{b}}$ Completed interviews divided by Subtotal

Involvement. Three of the 9 (33\%) SHAC Installers said that they were "very involved" in SHAC, 2 were "moderately involved," and 4 were "slightly involved."

Informedness. Six of the 9 (67\%) SHAC Installers considered themselves "very informed," and. 3 were "moderately inform ed" about active solar heating and cooling.

Need for Information. All respondents indicated they would need information on SHAC on the job during the next year. - Five of the $9(56 \%)$ SHAC Installers also expected to need information on SHAC outside the job.

\subsubsection{Background of Respondents}

Six of the 9 SHAC Installers held bachelor's degrees, and the remaining 3 respondents held an associate, a master's, and a doctoral degree. The degree field most common to the group was in engineering ( 5 respondents) with the other 3 degrees in economics, business, and political science (respondents with associate degrees were not asked about degree field). One received the most recent degree over 20 years agn, 4 were 10-20 years ago, 2 were 5-10 years ago, and 1 within the past 5 years.

Three had been in their current profession for 3-5 years, 1 for 6-10 years, and 5 for over 10 years. Four were engineers, 2 were in management positions, and 1 each was a technician, an electrical contractor, and a president of an engineering corporation.

Considering the image of the SHAC Installer as a blue-collar worker, both the level and type of education and the amount of time in the current profession were surprising. 


\subsection{NPORMATION NEEDS OF RESPONDENTS}

\subsubsection{Technical Areas}

SHAC Installers were asked to choose those areas in which they were "particularly interested in obtaining information" from a list of selected technical areas of SHAC. All 9 respondents were interested in "water heating," 8 of the 9 in "space cooling," 7 of the 9 in "space heating" and "hybrid systems," and 6 of the 9 in "swimming pool systems."

Four SHAC Installers volunteered that they were also interested in information on agricultural applications (2), photovoltaics, or heat pumps.

\subsubsection{Types of Information}

SHAC Installers were asked to name the information about SHAC that was important for them to obtain. Eight of 9 SHAC Installers volunteered one or more items of information they considered important. Four felt systems/equipment performance information was important; two mentioned availability of components/equipment and 2 mentioned lists of suppliers/developers/manufacturers. . Other topics included the economics of different systems, marketing data (e.g., prospecting for new business), information on matching equipment to the appropriate application (including size of components), and information on hardware problems.

Four of the 9 SHAC Installers stated that there was information they needed but were not able to get on SHAC. This included "technology transfer" information, lists of new companies and new solar products available, government grant data, product availability (including benefits to the customer), performance data, and unusual applications information.

Choice Between Specific Needs. A list of 11 types of SHAC information products and 13 types of SHAC information categories was read to each respondent. Each respondent described the usefulness of each particular item by assigning it a value of "essential," "very useful,". "som ewhat useful," or "not at all useful." The results are given in Fig. 6-1.

SHAC Installers selected lists of members of the local infrastructure as the most important information item. Both cost and site-specific information categories also tended to receive high ratings as classes. The six top-rated information categories/products were:

- Lists of local lenders, insurers, builders, engineers, installers, manufacturers, or distributors;

- Costs of installing and operating a SHAC system compared to a conventional system;

- Custs and performance of systems;

- Local building codes or other regulations;

- Tax credits, grants, or other economic incentives; and

- Climatological data. 
Question.\#8. I will read a lisl of potential information or information products on solar systems. For each, please tell me how useful that information would be to you. Would the following be: essential, very useful, somewhat useful, or not at all useful?

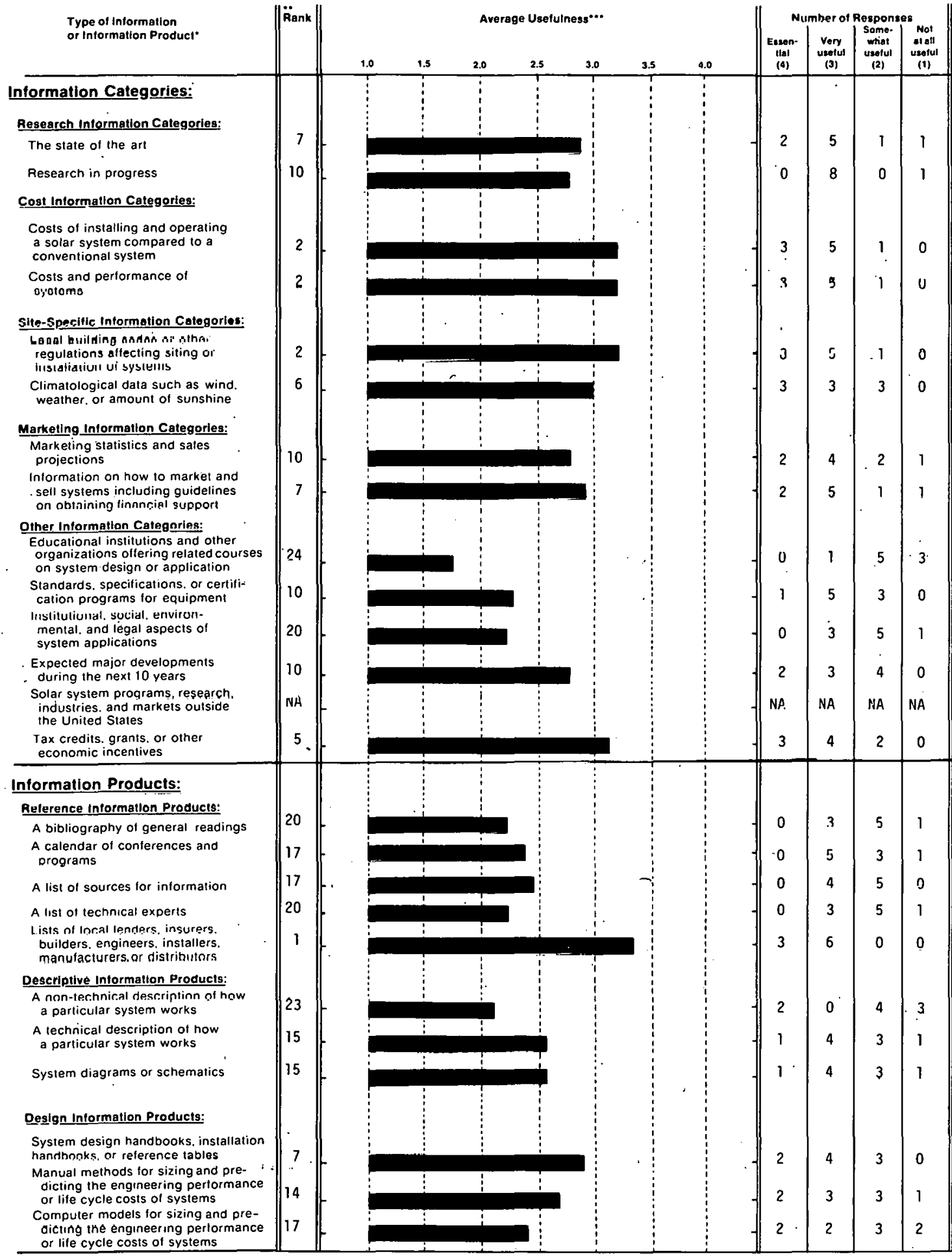

Each sample frame of users was questioned on information and information products in the contexi of their specitic technology. For example. biomass sample frames were (

Pank - Each intormation product was assigned a rank based on average usefulness. Thus, the product wilt the highest average usefulness was assigned the rank of "1": Ihe product highest ranking was then assigned a "4.

Figure 6-1. Usefulness of Selected Information Items: Active Solar Heating and Cooling Installers 
SHAC Installers assigned the lowest relative ratings to:

- Educational institutions and other organizations off ering courses;

- A nontechnical description of how a particular system works;

- Institutional, social, environmental, and legal aspects;

- A bibliography of general readings; and

- Lists of technical experts.

Statistical tests indicated that all six of the top categories/products were rated significantly $(P<0.05)$ higher than were the five lowest-rated items.

It should be noted that these lower-rated items were not necessarily of no worth to the SHAC Installers. For example, 3 of the 9 (33\%) thought "lists of technical experts" was "very useful." Thus, these information categories/products could be useful to some SHAC Installers but were of a lower relative priority to the entire group.

\subsection{ACQUISITION OF INFORMATION BY RESPONDENTS}

\subsubsection{Use of Selected Information Sources}

SHAC Installers were asked which of 19 different potential sources of solar information they had used in the past few years. For this question the respondents were not asked if they had obtained information on SHAC, but instead were asked if they had obtained any solar information from each specific source. Thus, the question sought to determine which information sources were the most familiar to the respondents. The results are shown in Fig. 6-2.

The information sources mentioned most of ten by SHAC Installers were:

- Workshops, conferences, or training sessions;

- State energy or solar offices;

- Private sular energy or environmental organizations;

- An installer, builder, designer, or manufacturer;

- An organizational library or a local library;

- The Government Printing Office (GPO); and

- The Regional Solar Energy Centers (RSECs).

The information sources mentioned least of ten by SHAC Installers were:

- Smithsonian Science Information Exchange (SSIE),

- A commercial data base,

- Sheet Metal and Air Conditioning Contractors National Association,

- A federal library or information center,

- National Technical Information Service (NTIS), and

- Some other state or local government office or publications. 
Question \#11. In the past few years, have you obtained any type of solar information from any of the following sources?

Information Sources

Percentage Responding Yes **

Public Media:

Radio or TV

Periodicals، newspapers or magazines

Private Solar-Involved Organizations:

Private solar energy or environmental organizations

The local chapter or national headquarters of International

Solar Energy Society (ISES), including their publications

The local chapter or national headquarters of Solar Energy

Industries Association (SEIA), including their publications

\section{Contacts with Professionals:}

An installer, builder, designer or manufacturer of solar systems

Workshops, conferences or training sessions

intormation Services*:

Your organizational library or a local library

A commercial data base: for example, Lockheed, SDC, BRS

Smithsonian Science Information Exchange (SSIE)

A Federal library or information center; for example, the National Agricultural Library or the Environmental Data System

The Government Printing Office (GPO)

National Technical Information Service (NTIS)

Technical Information Center at Oak Ridge (TIC)

Government Solar-Involved Organizations

Directly from the U.S. Department of Energy

National Solar. Heating \& Cooling Information Center

Regional Solar Energy Centers

State Energy or Solar Offices

Other:

Some other state or local government office or publication

A public utility company,

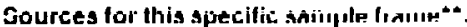

Sheet Metal and Air Conditioning Contractors' National Association

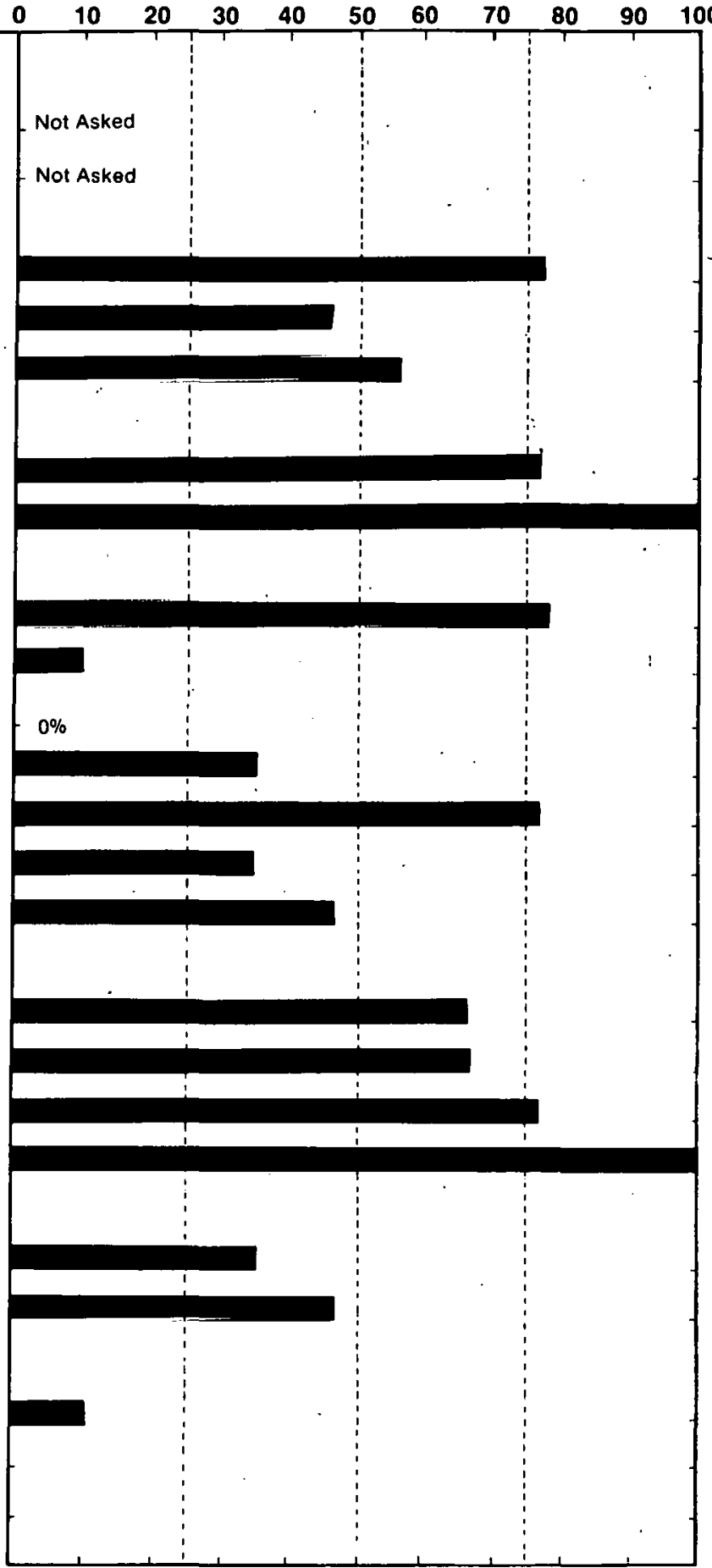

Services and centers whose primary purpose is to disseminate information

- Some sample frames were questioned about additional information sources which are applicable to their technology. For example. the manufacturers of biomass conversion equipment were also asked if they have obtained any type of solar information from: "the local or national office of the U.S. Department of Agriculture, including Extension and Forestry."

... These data are based upon a total of 9 respnndents. 


\subsubsection{Membership in Solar-Interested Organizations}

Seven of the 9 SHAC Installers interviewed were members of a professional, technical, or other organization with an interest in solar energy. These organizations (and the number of times mentioned) included:

- American Society of Heating, Refrigerating and Air Conditioning Engineers (ASHRAE) (2);

- American Society of Mechanical Engineers (ASME);

- International Solar Energy Society (ISES);

- National Association of Solar Contractors;

- National Society of Professional Engineers;

- New England Fuel Institute;

- New England Solar Energy Association (2);

- New Hampshire Solar Energy Association;

- Northern Illinois Solar Energy Association;

- Solar Energy Industries Association (SEIA); and

- Vermont Oil and Heat, Inc.

One also mentioned a solar organization in New Jersey the authors could not further define.

\subsubsection{Exposure to Publications on Solar Energy}

During the past 6 months, all 9 SHAC Installers had read publications that included information on SHAC. The publications they could specify (and the number of times mentioned) included:

- Day Star literature,

- Fuel Oil News,

- Fueloil and Oil Heat and Solar Systems,

- New Roots,

- Popular Science (2),

- Solar Age (3),

- Solar Energy,

- Solar Engineering (4),

- Solar Heating and Cooling (2), and

- Sun Times.

Other publications were mentioned that the authors could not verify. These included "Solar," "textbooks," and "trade journals." 


\subsubsection{Use of Special Acquisition Methods}

The respondents were asked whether they had obtained any information (not just SHAC or solar energy) in the past year by computer terminal, by Computer Output Microform (COM), or by other microform (e.g., microfiche, microfilm sheets or rolls). Few SHAC Installers appeared accustomed to using these special acquisition methods. In the past year, 3 of the 9 (33\%) had used a computer terminal, no one had used COM, and only 2 of the 9 (22\%) had used other microforms.

\subsection{SUMMARY AND COMMENTS}

Nine installers involved in SHAC were interviewed. Types of systems installed included: hot water, space heating, swimming pool heating, space cooling, and collection pumps for heating and cooling. Two also mentioned that they were invnlver in designing SHAC systems. Six of the nine considered themselves "very informed" about SHAG, but only three considered themselves "very involved."

The educational level of the SHAC Installers was surprisingly high: 6 held bachelor's degrees and 2 held advanced degrees. Six had been in their current profession over 5 years, 3 for 3-5 years. Four were engineers, 2 were in management positions, and one each was a technician, an electrical contractor, and a president of an engineering corporation.

Both the profusion of engineers and the amount of time in the current profession were very surprising considering the image of the solar installer as an ex-plumber who only recently got into solar energy. Based upon these results one must wonder whether the image is wrong or whether the installers with the initiative and know-how to get listed in the state and regional directories (see Section 6.1.1) were members of the long-standing engineering firms for whom installing solar energy systems was only a new sideline. The authors are inclined towards the latter explanation.

SHAC Installers gave the highest priority to receiving information on:

- Lists of local lenders, insurers, builders, engineers, installers, manufacturers, or distributors for SHAC systems;

- Costs of installing and operating a SHAC system compared to a conventional syslem

- Costs and performance of SHAC systems;

- Local building codes or other regulations affecting SHAC systems;

- Tax credits, grant.s, or other economio inoentives for SHAC aystems; and

- Climatological data.

They gave low ratings to "educational institutions," "a nontechnical descriṕtion," "institutional, social ... aspects," "a bibliography," and "lists of technical experts."

SHAC Installers appeared to need three types of information: first, they needed a list of members of the local solar infrastructure, especially distributors and manufacturers. Second, they needed information on the costs, the performance, and economic incentives (e.g., tax credits) of SHAC systems. Third, they needed site-specific types of data (local building codes and climatological data). 
SHAC Installers most of ten received solar information through contacts with professionals ("workshops" and "an installer, builder"), from "an organizational ... library," GPO, solar-involved organizations, and solar-related sources. At least four were members of a local or national solar energy association. 
SER*ㅜ 


\section{SECTION 7.0}

\section{ACTIVE SOLAR HEATING AND COOUNG ARCHITECTS}

\subsection{DESCRIPTION OF RESPONDENTS}

\subsubsection{Description of Sample}

This section describes the results of a telephone study to determine the needs of architects/designers for information on active solar heating and cooling (SHAC). Nine SHAC Architects were interviewed.

The sample frame for SHAC Architects was constructed from the National Solar Heating and Cooling Commercial Demonstration Program - Key Personnel Directory (KPD) [20], which lists personnel associated with the SHAC Demonstration Projects (DOE-CS). The demonstrations were on commercial, federal, and nonfederal buildings and residential federal buildings. Architects working on SHAC demonstrations were separated from those working on passive demonstrations by use of the KPD in conjunction with Solar Heating and Cooling Demonstration Project Summaries [21]. Contact names listing a federal agency association and duplications with mechanical engineers and active builders selected for other sample frames were eliminated. After all adjustments were made, the 9 interview candidates were randomly selected from a sample frame of 180 names.

Respondents. In making the telephone calls to contact the randomly selected interview candidates, it sometimes occurred that the person could not be reached. In this event another randomly selected name was substituted for the original name. When individuals were contacted, it was verified that they really were SHAC Architects, and that they would be needing information on SHAC within the next year. If they were not both involved and needing information, they were asked if they could refer the interviewer to someone else in their organization who would be an appropriate respondent. If such a referral was made, a call was then made to this new candidate; if no intraorganizational referral was made, a new candidate was randomly selected from the sample frame. The results of this process may be seen in Table 7-1.

Comparisons. For additional insight into the information needs and the information habits of these SHAC Architects, results from this group are compared to the results from SHAC Builders (Section 8.0) and Passive Architects interviewed in this study. The data for SHAC Architects, SHAC Builders, and Passive Architects can be found in Appendix F.

\section{7:1.2 Current Status of Respondents}

Role. Six of the 9 SHAC Architects specifically mentioned that they were working on active solar heating applications, 5 on hot water applications, 2 on space cooling, 1 with applications to swimming pools, and 1 on hydronic air to air systems. Three of the respondents also mentioned that they design systems: one, SHAC system with concentrating collectors; one, water-heating system for building use; and one, collectors for hot water and heating. 


\section{Table 7-1. COMPLETION OF INTERVIEWS: ACTIVE SOLAR HEATING AND COOLING ARCHTECTS}

Event

Number of

Candidates

Interview completed with sample frame candidate

Interview completed with referral candidate

4

Refusal or candidate termination

Contact attempted: could not reach candidate within three

attempts or before interviews were completed

0

Subtotal

Contact attempted: invalid candidate (e.g., inappropriate field

of interest, no telephone)

TOTAL

Sample frame error ràte ${ }^{\mathbf{u}}$ (Percent)

Completion rate ${ }^{\mathrm{b}}$ (Percent)

Invalid candidates divided by TOTAL

bompleted interviews divided by Subtotal

Involvement. All 9 SHAC Architects said that they were either "very involved" or "moderately involved" in SHAC compared to 5 of the $9(56 \%)$ of the SHAC Builders and 7 of the 9 (78\%) of the Passive Architects.

Informedness. Eight of the 9 (89\%) SHAC Architects considered themselves either "very informed" or "moderately informed" compared to all 9 for both SHAC Builders and Passive Architects.

Need for Information. All respondents indicated they would need information on SHAC on the job during the next year. Only 3 of the 9 (33\%) SHAC Architects, however, expected to need information outside the job. This was similar to the results for SHAC Builders and for Passive Architects.

\subsubsection{Background of Respondents}

One of the 9 SHAC Architects held a master's degree, 7 held bachelor's degrees, and 1 held an associate degree. Six had received degrees in architecture and 3 in engineering. One received his most recent degree over 40 years ago, 2 from 25-30 years ago, 3 from 10-15 years ago, and 3 within the past 10 years. A comparison of SHAC Architects with Passive Architects and SHAC Builders showed no significant difference in educational level or year of most recent degree. Also similar were the types of degrees earned; engineering and architectural degrees were predominant for all three groups.

Only 1 had been in the current profession for 2 or fewer years, 1 for 3-5 years, 2 for 6-10 years, and 5 for over 10 years. Five were architects and 4 were engineers. These two professions were also stated most of ten by both SHAC Builders and Passive Architects. The length of professional experience for SHAC Architects appeared to be similar to that of Passive Architects, but slightly less than that of the SHAC Builders. 


\subsection{INFORMATION NEEDS OF RESPONDENTS}

\subsubsection{Technical Areas}

SHAC Architects were asked to choose those areas' in which they were "particularly interested in obtaining information" from a list of selected technical areas of SHAC (see Table 7-2). They seemed to be somewhat more interested in "space cooling" (9 of the 9), "hybrid systems" (9 of the 9), and "water heating" (8 of the 9) than in "swimming pool heating" ( 5 of the 9). Areas of information interest selected by SHAC Builders did not differ significantly.

Table 7-2. AREAS OF INTEREST: ACTIVE SOLAR HEATING AND COOLING ARCHITECTS AND BUILDERS

\begin{tabular}{lccccc}
\hline & \multicolumn{2}{c}{ Architects } & & \multicolumn{2}{c}{ Builders } \\
\cline { 2 - 3 } \cline { 5 - 6 } Technical Area of Interest & No. & Percent & & No. & Percent \\
\hline Space Cooling & 9 & 100 & 7 & 78 \\
Hybrid Systems (Combining Active & & & & \\
$\quad$ and Passive) & 9 & 100 & 8 & 89 \\
Water Heating & 8 & 78 & 8 & 89 \\
Space Heating & 7 & 56 & 9 & 33 \\
Swimming Pool Heating & 5 & & 3 & 100 \\
\hline
\end{tabular}

One SHAC Architect volunteered that he was also interested in passive systems and greenhouses.

\subsubsection{Types of Information}

SHAC Architects were asked to name information about SHAC that was important for them to obtain. Eight of the 9 SHAC Architects volunteered one or more items of information they considered important. Three felt cost (e.g., installation cost (1) and financial analysis of payback (1)) data on SHAC systems was important; two mentioned new information on improved collectors; and two mentioned information on available equipment (e.g., cooling equipment). Other topics receiving single mentions included information on: lists of manufacturers, new cooling equipment, general information on SHAC, improved means of heat storage, availability of hardware, data on the efficiency of collectors, and data on the "new package by DOW Chemical Company used in heat storage and cooling systems."

Choice Between Specific Needs. A list of 11 types of SHAC information products and 12 types of SHAC information categories was read to each respondent. Each respondent described the usefulness of each particular item by assigning it a:value of "essential," "very useful," "somewhat useful," or "not at all useful." The results are given in Fig. 7-1. For the purpose of comparison, the results for SHAC Builders are shown in Section 8.2.2 and the results for Passive Architects are shown in Fig. 7-2. 
Question \#8. I will, read a list of potential information or information products on solar systems. For each, please lell me how useful that information would be to you. Would the following be: essential, very useful, somewhat useful, or not at all useful?

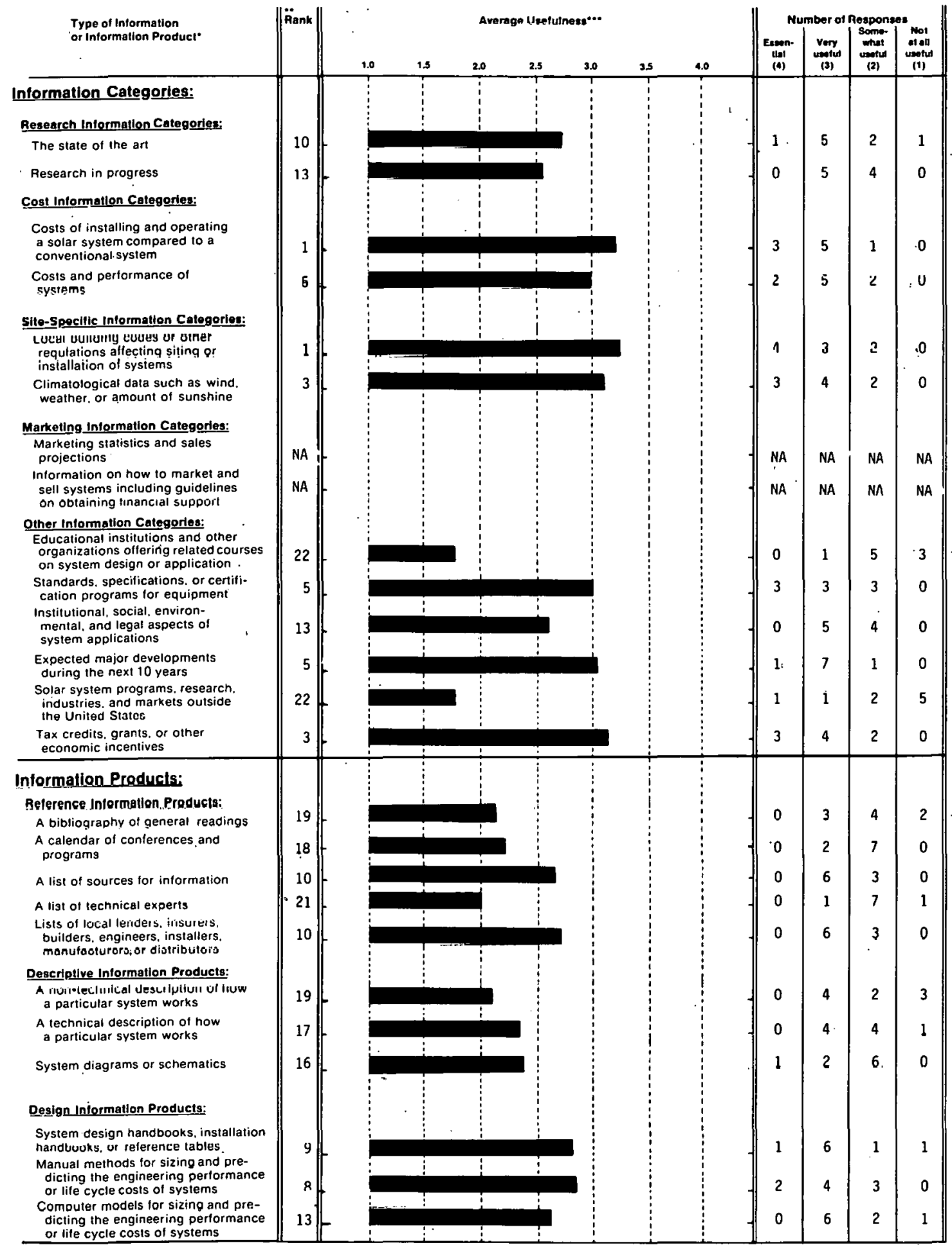

Each sample frame of users was questioned on intormation and information products in the context of theit specific lechnology. For example. biomass sample trames were

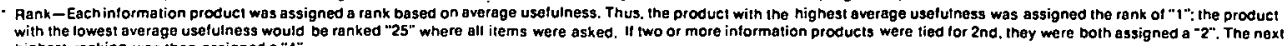
nighesi ranking was whe assignoda"di:

‥ Average usetulness was calcufated by assigning the responses on a $1-4$ scale trom a "4" tor "essential" to a "i " for "nnt very useful.

Figure 7-1. Usefulness of Selected Information Items: Active Solar Heating and Cooling Architects 
Question \#8. I will read a list of potential information or information products on solar syslems. For each, please tell me how useful that information would be to you. Would the following be: essential, very useful, somewhat useful, or not at all useful?

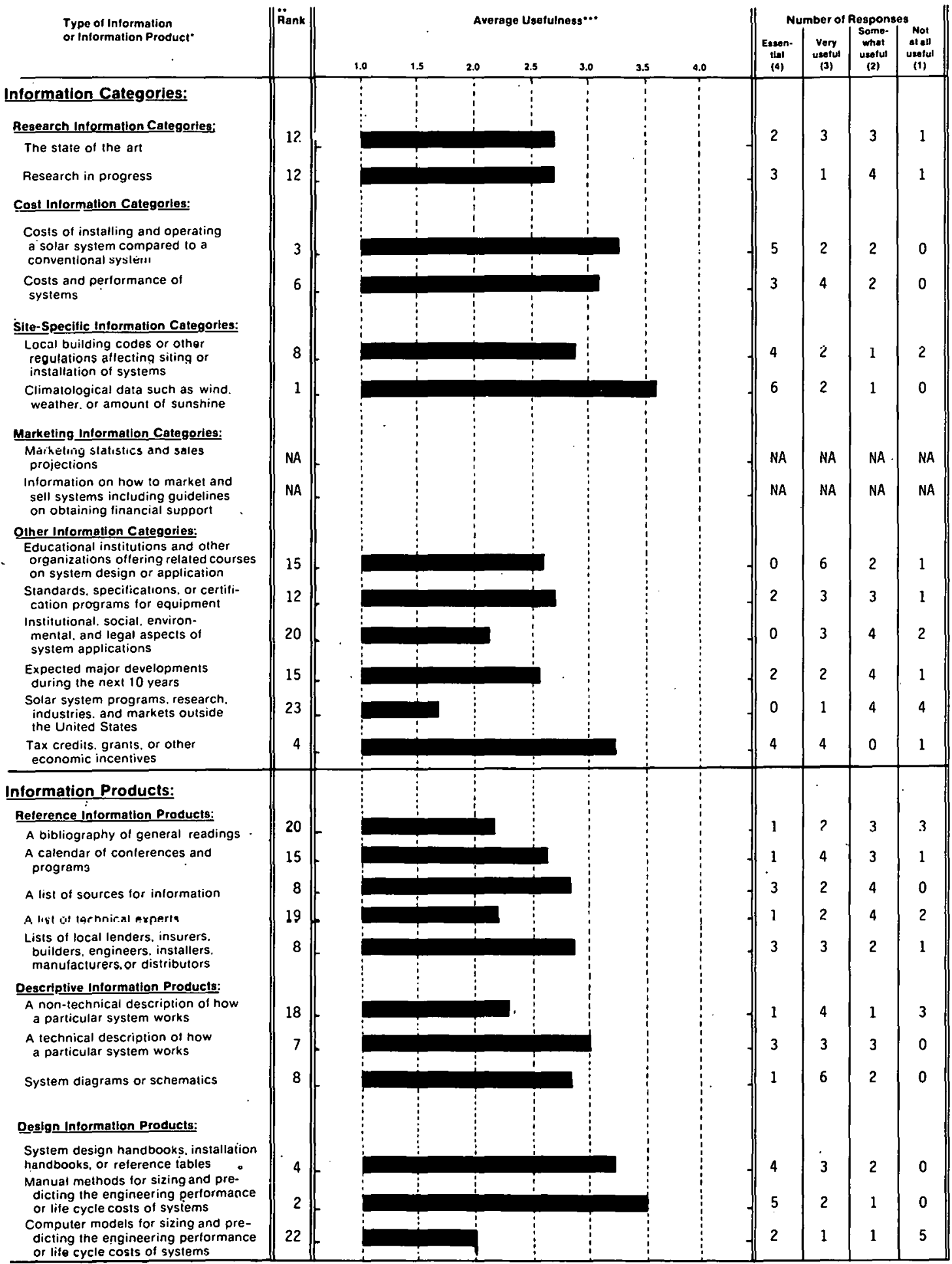

- Each samale trame of users was questioned on intormation end intormation producls in the context of their specilic technology. For example. biomass sample trames were asked about "a biblicoraphy ol cer

Renk-Eachintormation product was assigned a rank based on average usefulness. Thus. The produel with the hignest bvera ge usefulness was assigned the rank of " 1 : the producl with the lowest average usefulness would
highest ranking was then assigned a 4 :

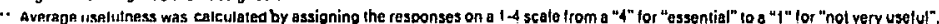

Figure 7-2. Usefulness of Selected Information Items: Passive Architects 
SHAC Architects selected cost and site-specific information categories as most important. The seven top-rated information categories/products were:

- Costs of installing and operating a SHAC system compared to a conventional system;

- Local building codes or other regulations;

- Climatological data;

- Tax credits, grants, or other economic incentives;

- Costs and perform ance of systems;

- Standards, specifications, or certification programs; and

- Expected major developments during the next 10 years.

SHAC Architects assigned the lowest relative ratings to:

- Educational institutions and other organizations off ering courses;

- Solar energy programs, research, industries, and markets outside the United States;

- Lists of technical experts;

- A bibliography of general readings;

- A nontechnical description of how a particular system works;

- Calendars of conferences and programs; and

- A technical description of how a particular system works.

Statistical tests indicated that differences between the ratings for these seven highestand the seven lowest-rated information items were significant $(P<0.05)$ for SHAC Architects.

It should be noted that these lower-rated items were not necessarily of no worth to the SHAC Architects. For example, 4 of the 9 (44\%) thought "a technical description" was "very useful." Thus, these information categories/products could be useful to some SHAC Architects but were of a lower relative priority to the entire group.

Statistical tests were also used to determine whether the SHAC Architects rated any of these information items significantly higher (or lower) than they were rated by the SHAC Builders or the Passive Architects. Some groups, however, tended to give higher scores In general than did other groups. 'l'o compensate for this effect, these statistical tests compared the "relative rating" given by onc group to the "relative rating" given by the other groups. The procedure for calculating the relative rating is described in Appendix E. The average overall rating for SHAC Architects (2.60) was similar to that of SHAC Builders (2.54), but slightly lower than that for Passive Architects (2.72).

Statistical tests indicated that, compared to SHAC Builders, SHAC Architects rated the need for information on "costs of installing and operating" significantly $(P<0.05)$ higher and "educational institutions" significantly $(\mathrm{P}<0.05)$ lower. There also seemed to be evidence that SHAC Architects were more interested in "tax credits, (etc.)" and "expected major developments," but less interested in information on systems design. 
Looking at Passive Architects for another comparison, SHAC Architects rated the need for information on "institutional, social, environmental, and legal aspects" significantly ( $P$ 0.05) higher and "educational institutions" significantly $(P<0.05)$ lower. There also seemed to be evidence that SHAC Architects were more interested in "local building

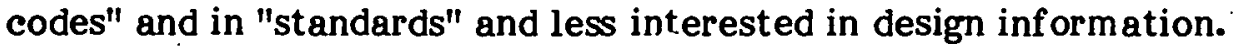

\subsection{ACQUISITION OF INFORMATION BY RESPONDENTS}

\subsubsection{Use of Selected Information Sources}

SHAC Architects were asked which of 20 different potential sources of solar information they had used in the past few years. For this question the respondents were not asked if they had obtained information on SHAC, but instead were asked if they had obtained any solar information from each specific source. Thus, the question sought to determine which information sources were the most familiar to the respondents. The results are shown in Fig. 7-3. For the purpose of comparison, the results for SHAC Builders are shown in Section 8.0, and the results for Passive Architects are shown in Fig. 7-4.

The information sources mentioned most of ten by SHAC Architects were:

- Periodicals, newspapers, or magazines;

- An installer, builder, or manufacturer;

- Workshops, conferences, or training sessions;

- The Government Printing Office (GPO); and

- A public utility company.

The top three sources listed above were also the most frequently mentioned sources for both SHAC Builders and Passive Architects.

The information sources mentioned least often by SHAC Architects were:

- Smithsonian Science Information Exchange (SSIE),

- A commercial data base,

- Regional Solar Energy Centers (RȘEĆs),

- Technical Information Center (TIC),

- International Solar Energy Society (ISES), and

- Solar Energy Industries Association (SEIA).

In romparing the information sources used by SHAC Architects to those used by SHAC Builders, no statistically significant differences were found. Compared to Passive Architects, however, significantly $(P<0.05)$ fewer SHAC Architects mentioned using the services of RSECs. 
Question \#11. In the past few years, have you obtained any type of solar information from any of the following sources?

Information Sources

Percentage Responding Yes $\cdots$

Public Media:

Radio or TV

Periondicals, newspapers or magazines

Private Solar-Involved Organizations:

Private solar energy or environmental organizations

The local chapter or national headquarters of International Solar Energy Society (ISES). including their publications

The local chapter or national headquarters of Solar Energy Industries Association (SEIA), including their publications

\section{Contacls with Prolessionais}

An Installer, bullder. designer or manutacturer of solar systems

Workshops, conferences or training sessions

Information Services":

Your organizational library or a local library

A commercial data base; for example. Lockheed. SDC. BRS

Smithsonian Science Information Exchange (SSIE)

A Federal library or information center: for example. the National Agricultural Library or the Environmental Data System

The Government Printing Office (GPO)

- National Technical Information Service (NTIS)

Technical Information Center at Oak Ridge (TIC)

Government Solar-Involved Organizations

Directly from the U.S. Department of Energy

National Solar Heating \& Cooling Information Centel

Regional Solar Energy Centers

State Energy or Solar Offices

Other:

Some other state or local government office or publication

A publir: utility rommany

Souroes for this opeoifie sample frame**:

American Institute of Architects (A|A) or A|A Research Corporation

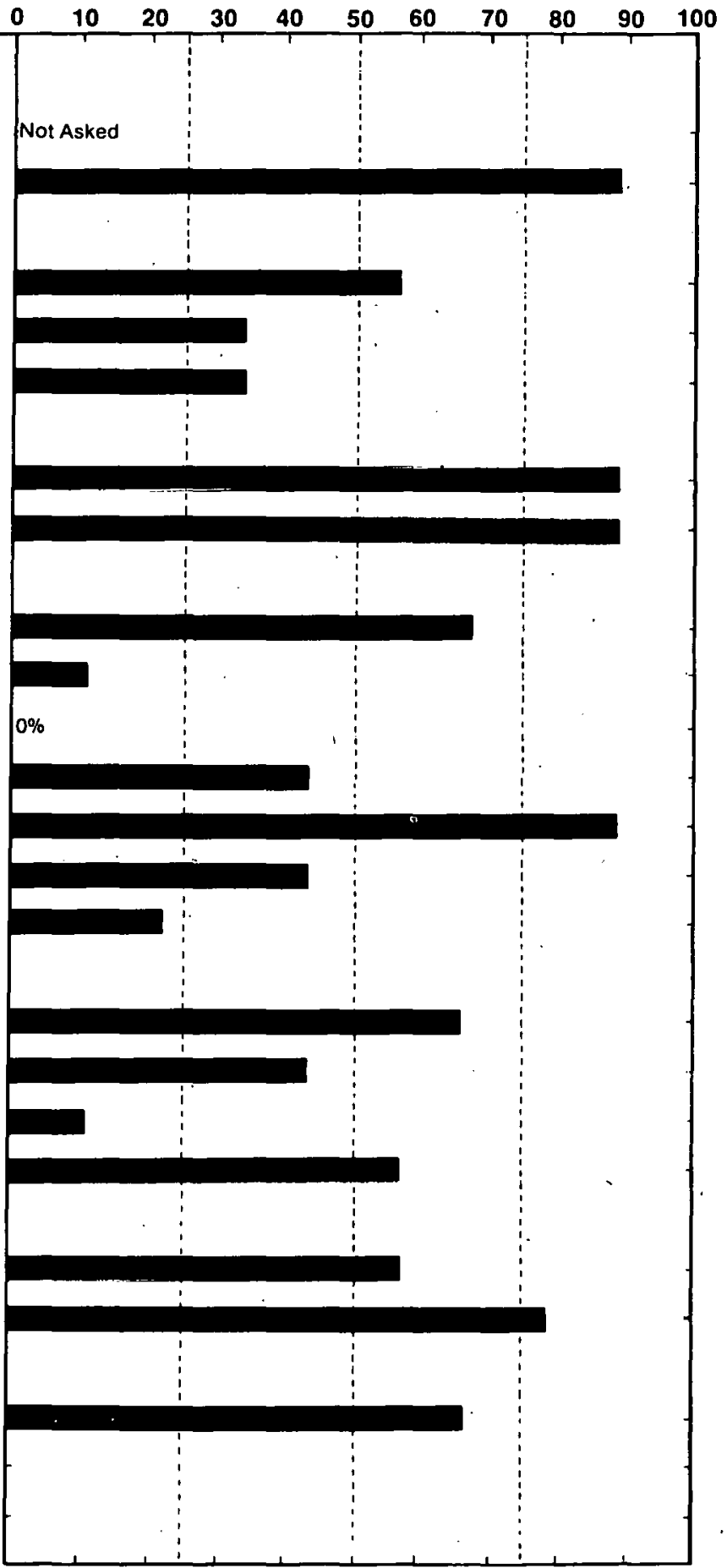

- Services and centers whose primary purpose is to disseminate information.

Some sample frames were questioned about additional information sources which are applicable to their technology. For example, the manufacturers of biomass conversion equipment were also asked if they have obtained any type of solar information from: "the local or national office of the U.S. Department of Agriculture, including Extension and Forestry."

$\because$ These data are based upon a total of 9 respondents.

Figure 7-3. Use of Selected Information Sources: Active Solar Heating and Cooling Architects 
Question \#11. In the past few years, have you obtained any type of solar information from any of the following sources?

information Sources

Public Media:
Radio or TV
Periodicals. newspapers or magazines
Privale Solar-Involved Organizations:
Private solar energy or environmental organizations
Thre lucal chapter or national hcadquärtorc of International
Solar Energy Society (ISES). including their publications
The local chapter or national hearniuarters of Solar Energy
Industries Association (SEIA), including their publications
Contacts with Professionals:

An installer, builder, designer or manufacturer of solar systems

Workshops, conferences or training sessions

\section{Information Services*:}

Your organizational library or a local library

A commercial data base; for example, Lockheed' SDC, BRS

Smithsonian Science Information Exchange (SSIE)

A Federal library or information center: for example, the National

Agricultural Library or the Environmental Data System

The Government Printing Office (GPO)

National Technical linformation Service (NTIS)

Technical Information Center at Oak Ridge (TIC)

Government Solar-Involved Organizations

Directly from the U.S. Department of Energy

National Solar Heating \& Cooling Information Centel

Regional Solar Energy Centers

State Energy or Solar Óffices

Other:

Some other-state or local government office or publication

A public utility company

Sources for this specific sample frame"*:

American Institute of Architects (AIA) or AIA Research Corporation
Percentage Responding Yes *.*

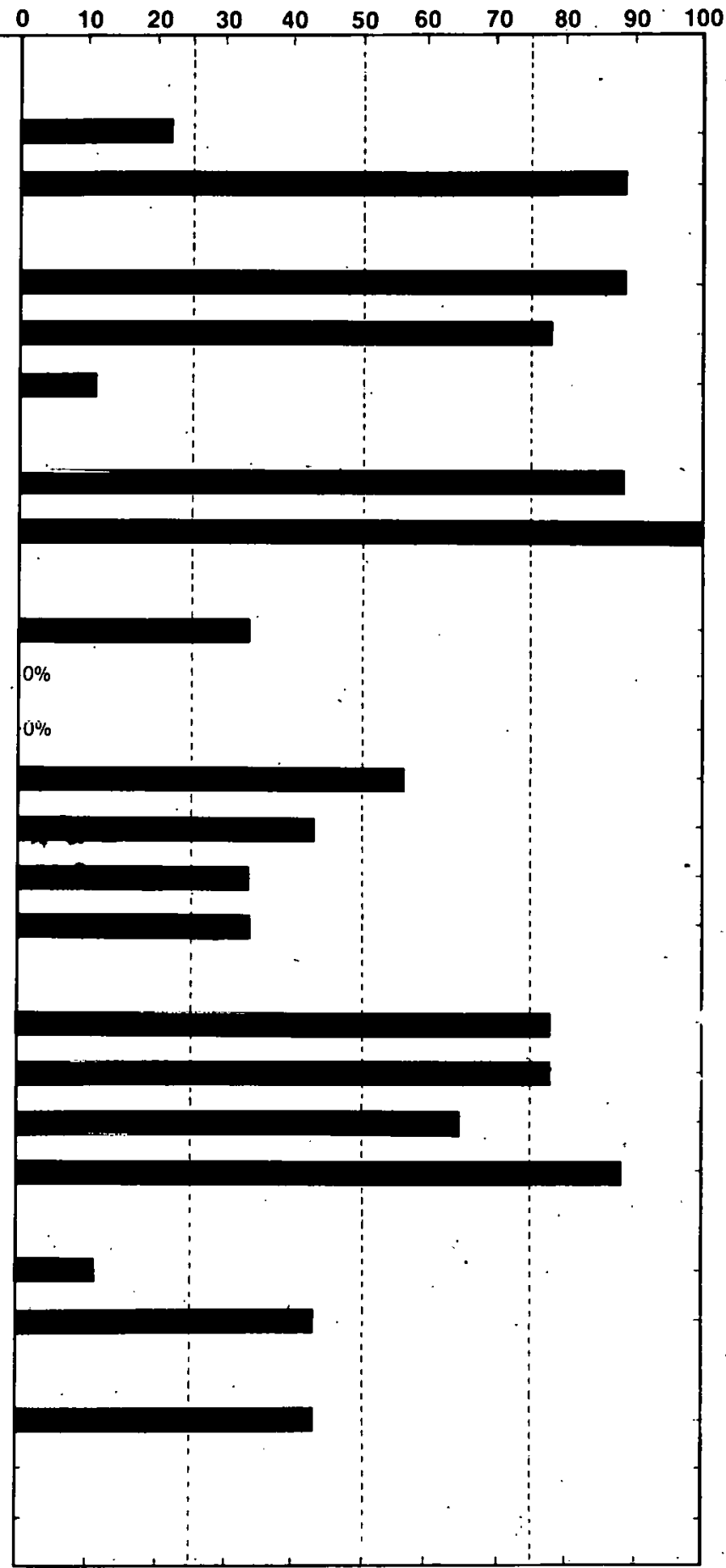

- Services and centers whose primary purpose is to disseminate information.

- Some sample frames were questioned about additional information sources which are applicable to their technology. For example. the

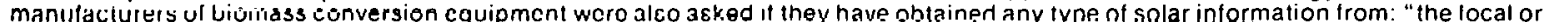
national office of the U.S. Department of Agriculture, including Extension and Forestry"

... These data are based upur à lutal ol 9 réspondents.

Figure 7-4. Use of Selected Information Sources: Passive Architects 


\subsubsection{Membership in Solar-Interested Organizations}

Eight of the 9 SHAC Architects interviewed were members of a professional, technical, or other organization with an interest in solar energy. These organizations (and the number of times mentioned) included:

- American Institute of Architects (AIA) (including committees and local chapters, e.g., Energy Task Force, Boston Society) (4);

- American Society of Heating, Refrigerating and Air Conditioning Engineers (ASHRAE) (2);

- Connecticut Engineers in Private Practice (CEIPP);

- Dallas-Ft. Worth Solar Energy Association;

- ISFS;

- Northern California Solar Energy Association; and

- Texas Solar Energy Society.

Also mentioned were several organizations that the authors could not verify. These included "American Solar Energy" and "Building Trades Organization."

\subsubsection{Exposure to Publications on Solar Energy}

During the past 6 months, all 9 SHAC Architects had read publications which included information on SHAC. The publications they could specify (and the number of times mentioned) included:

- AIA Journal,

- ASHRAE publications (2),

- Architectural Record,

- Consulting Engineer,

- Progressive Architecture (3),

- Solar Age,

- Solar Energy Digest,

- Solar. Energy Intelligence Report, and

- Sular Engineering (2).

Also mentioned were several publications that the authors could not verify: These included "Building and Design Construction" and "Solar Heating."

\subsubsection{Use of Special Acquisition Methods}

The respondents were asked whether they had obtained any information (not just SHAC or solar energy) in the past year by computer terminal, by Computer Output Microform (COM), or by other microform (e.g., microfiche, microfilm sheets or rolls). Few SHAC Architects appeared accustomed to using these special acquisition methods, a trait 
common to architects and builders interviewed in both passive technologies and SHAC. In the past year, 5 of the $9(56 \%)$ had used a computer terminal and only 2 of the 9 (22\%) had used either COM or other microform.

\subsection{SUMMARY AND COMMENTS}

Nine architects involved in SHAC were interviewed. Specific types of SHAC applications included: heating, hot water, space cooling, swimming pool heating, and hydronic air to air systems. Three also designed systems and 1 designed collectors. SHAC Architects were slightly more involved than either SHAC Builders or Passive Architects; all three groups, however, felt they were highly informed. The educational level and types of degrees earned (predominantly in engineering and architecture) were also similar for all three groups. Professionally, SHAC Architects as well as Passive Architects had slightly fewer years of experience than did the SHAC Builders.

SHAC Architects gave the highest priority to receiving information on:

- Costs of installing and operating a SHAC system compared to a conventional system;

- Local building codes or other regulations affecting SHAC systems;

- Climatological data;

- Tax credits, grants, or other economic incentives for SHAC systems;

- Cósts and performance of SHAC systems;

- Standards, specifications, or certification programs for SHAC systems; and

- Expected major developments in SHAC technology during the next 10 years.

They gave low ratings to "educational institutions," "SHAC programs, research ... outside the United States," "lists of technical experts," "a bibliography of general readings," "a nontechnical description," "calendars," and "a technical description.".

Overall, SHAC Architects needed two principal types of information: first, they needed site-specific data including "climatological data" and "local building codes." Second, they needed cost information (installation/operating costs, system cost and performance, and "tax credits"). Additionally, they needed information on "standards" and on "expected major developments."

SHAC Architects, as well as SHAC Builders and Passive Architects, most of ten received solar information through "periodicals" and professional contacts ("workshops, (etc.)" and "an installer, builder, (etc.)"). Other sources frequented included GPO and a public utility company. At.least four were members of a local or national solar energy association, with the AIA also serving as an important information disseminator. 


\section{SEPI}




\section{SECTION 8.0}

\section{ACTIVE SOLAR HEATING AND COOLING BUILDERS}

\subsection{DESCRIPTION OF RESPONDENTS}

\subsubsection{Description of Sample}

This section describes the results of a telephone study to determine the needs of builders for information on active solar heating and cooling (SHAC). Nine SHAC Builders were interviewed.

The sample frame for SHAC Builders was constructed from the National Solar Heating and Cooling Commercial Demonstration Program - Key Personnel Directory (KPD) [20], which included a listing of builders involved in the SHAC Demonstration Projects (DOE-CS). These demonstrations were on commercial, federal, and nonfederal buildings and residential federal buildings. Builders working on SHAC demonstrations were separated from those working on passive demonstrations by use of the KPD in conjunction with Solar Heating and Cooling Demonstration Project Summaries [21]. Builders employed by a federal, state, or local office and duplicates with builder and architect sample frames for other technologies were eliminated. After all adjustments were made, the 9 interview candidates were randomly selected from a sample frame of 78 names.

Respondents. In making the telephone calls to contact the randomly selected interview candidates, it sometimes occurred that the person could not be reached. In this event another randomly selected name was substituted for the original name. When individuals were contacted it was verified that they really were SHAC Builders, and that they would be needing information on SHAC within the next year. If they were not both involved and needing information, they were asked if they could refer the interviewer to someone else in their organization who would be an appropriate respondent. If such a referral was made, a call was then made to this new candidate; if no intraorganizational referral was made, a new candidate was randomly selected from the sample frame. The results of this process may be seen in Table 8-1.

Comparisons. For additional insight into the information needs and the information habits of these SHAC Builders, results from this group are compared to the results from SHAC Architects (Section 7.0) and from Passive Builders interviewed in this study. The data for SHAC Builders, for SHAC Architects, and for Passive Builders can be found in Appendix F.

\subsubsection{Current Status of Respondents}

Role. SHAC-related activities in which the SHAC Builders were involved included solar hot water systems (2) (1 specifically mentioned domestic applications and 1 mentioned both residential and commercial applications); building a house (with plans for building two more with SHAC systems); working on a building with an active air heating system with rock storage; installing a SHAC system in a building; developing and applying solar concentrating collectors; installing large arrays $(10,000 \mathrm{ft})$ of collectors; and monitoring completed projects with SH $\Lambda$ C systems. 
Table 8-1. COMPLETION OF INTERVIEWS: AC'TIVE SOLAR HEATING AND COOLING BUILDERS

Event

Number of

Candidates

Interview completed with sample frame candidate

Interview completed with referral candidate

Refusal or candidate termination

Contact attempted: could not reach candidate within three

attempts or before interviews were completed

Subtotal

Contact attempted: invalid candidate (e.g., inappropriate field of interest, no telephone)

TOTAL

Sample frame error rate ${ }^{a}$ (Percent)

Completion rate ${ }^{b}$ (Percent)

${ }^{\text {a Invalid candidates divided by TOTAL }}$

${ }^{\mathrm{b}}$ Completed interviews divided by Subtotal

Involvement. Five of the $9(56 \%)$ SHAC Builders said that they were "very involved" or "moderately involved" in SHAC, compared to all 9 of the SHAC Architects and 6 of the 9 (67\%) Passive Builders.

Informedness. All 9 of the SHAC Builders considered themselves "very informed". or "moderately informed" compared to 8 of the 9 (89\%) SHAC Architects and all 9 Passive Builders.

Need For Information. All respondents indicated they would need information on SHAC on the job during the next year. Four of the 9 SHAC Builders also expected to need information outside the job. This was similar to the results for SHAC Architects and Passive Builders where all respondents needed information on their own technology on the job; 3 of the 9 (33\%) SHAC Architects and 6 of the 9 (67\%) Passive Builders needed information outside the job.

\subsubsection{Background of Respondents}

Six of the 9 SHAC Builders held bachelor's degrees and 3 held master's degrees. Three had received degrees in architecture, 3 in engineering, and 1 each in busjness management, history, and education. Two received their most recent degree over 25 years ago, 2 degrees were received 10-15 years ago, 3 received 5-10 years ago, and 2 within the past 5 years. A comparison of SHAC Builders with Passive Builders and SHAC Architects showed no significant difference in educational level or year of most recent degree. The type of degree earned, however, showed more concentration of engineering and architectural degrees in the SHAC Builder group (6 of the 9) and SHAC Architect group (9 of the 9) and more variety of degrees within the Passive Builder group. 
Six SHAC Builders had been in their current profession for 6-10 years, three for over 10 years. This length of current professional experience was slightly longer than that of SHAC Architects and that of Passive Builders. In their current profession, 4 SHAC Builders mentioned that they were engineers, 3 were architects, 1 a builder, and 1 a manager. Similarly, SHAC Architects also mentioned the professions of engineer and architect most often, but Passive Builders cited professions related to eight different fields.

\subsection{INFORMATION NEEDS OF RESPONDENTS}

\subsubsection{Technical Areas}

SHAC Builders were asked to choose those areas in which they were "particularly interested in obtaining information" from a list of selected technical areas of solar heating and cooling. Significantly $(P<0.05)$ more of the respondents were interested in "space heating" (9 of the 9), "water heating" ( 8 of the 9), and "hybrid systems" ( 8 of the 9) than in "swimming pool heating" (3 of the 9). The level of interest expressed by SHAC Builders did not differ significantly from that of SHAC Architects in any technical area (see Table 8-2).

Table 8-2. AREAS OF INTEREST: ACTIVE SOLAR HEATING AND COOLING BUILDERS AND ARCHITECTS

\begin{tabular}{lcccccr}
\hline & \multicolumn{2}{c}{ Builders } & & \multicolumn{2}{c}{ Architects } \\
\cline { 2 - 3 } \cline { 6 - 7 } Technical Area of Interest & No. & Percent & & No. & Percent \\
\hline Space Heating & 9 & 100 & & 7 & 78 \\
Water Heating & 8 & 89 & & 8 & 89 \\
Hybrid Systems (combining & & & & & 100 \\
Active and Passive) & 8 & 89 & & 9 & 100 \\
Space Cooling & 7 & 78 & & 9 & 56 \\
Swimming Pool Heating & 3 & 33 & & 5 & \\
\hline
\end{tabular}

One SHAC Builder also volunteered an interest in information on industrial applications.

\subsubsection{Types of Information}

SHAC Builders were asked to name information about SHAC that was important for them to obtain. All 9 of the SHAC Builders volunteered one or more items of information which they considered important. Two felt information on new products, cost of systems, and performance data on existing products and systems were important. Other topies receiving single mentions included: availability of component parts from manufacturers, calculation methods for designing systems, technical information, marketing information, system design handbooks (e:g., details as to what materials to use), air systems, data on the most efficient collector on the market, and data on the technical equipment involved for joining collectors together. 
Information that the SHAC Builders volunteered they needed but were unable to get included data on heat transfer, air flow in rock beds, simple methods for monitoring systems, and hard data on costs and real life cycles of systems. It is interesting to note that only 2 of the 9 SHAC Builders mentioned that they were unable to get information they needed compared to 6 of the 9 Passive Builders.

Choice Between Specific Needs. A list of 11 types of SHAC information products and 13 types of SHAC information categories was read to each respondent. Each respondent described the usefulness of each particular item by assigning it a value of "essential," "very useful," "somewhat useful," or "not at all useful." The results are given in Fig. 8-1. For the purpose of comparison, the results for SHAC Architects are shown in Section 7.0 and those for Passive Builders are shown in Fig. 8-2.

SHAC Builders selected information directed toward application as the most important information. The six top-rated information categories/products were:

- Climatological data;

- Cost and performance of systems;

- Design handbooks, installation handbooks, or reference tables;

- Manual methods for sizing and predicting performance or costs;

- Local building codes or other regulations; and

- Standards, specifications, or certification programs.

SHAC Builders assigned the lowest relative ratings to:

- Solar energy programs, research, industries, and markets outside the United States;

- Calendars of conferences and programs;

- Institutional, social, environm ental, and legal aspects;

- Marketing statistics and sales projections; and

- Computer models for sizing and predicting performance or costs.

It was particularly interesting to note the difference between the ratings they assigned to "manual methods" and to "computer models."

Statistical tests indicated that differences between the ratings for these six highest and the five lowest-rated information items were significant $(P<0.05)$ for SHAC Builders.

It should be noted that these lower-rated items were not necessarily of no worth to the SHAC Builders. For example, 2 of the 9 (22\%) thought "computer models" were "very useful." Thus, these information categories/products could be useful to some SHAC Builders but were of a lower relative priority to the entire group.

Statistical tests were also used to determine whether the SHAC Builders rated any of these information items significantly higher (or lower) than they were rated by SHAC Architects and by the Passive Builders. Some groups, however, tended to give higher scores in general than did other groups. To compensate for this effect, these statistical tests compared the "relative rating" given. by one group to the "relative rating" given by 
Question \#8. I will read a list of potential information or information products on solar systems. For each, please tell me how useful that information would be to you. Would the following be: essential, very useful, somewhat useful, or not at all useful?

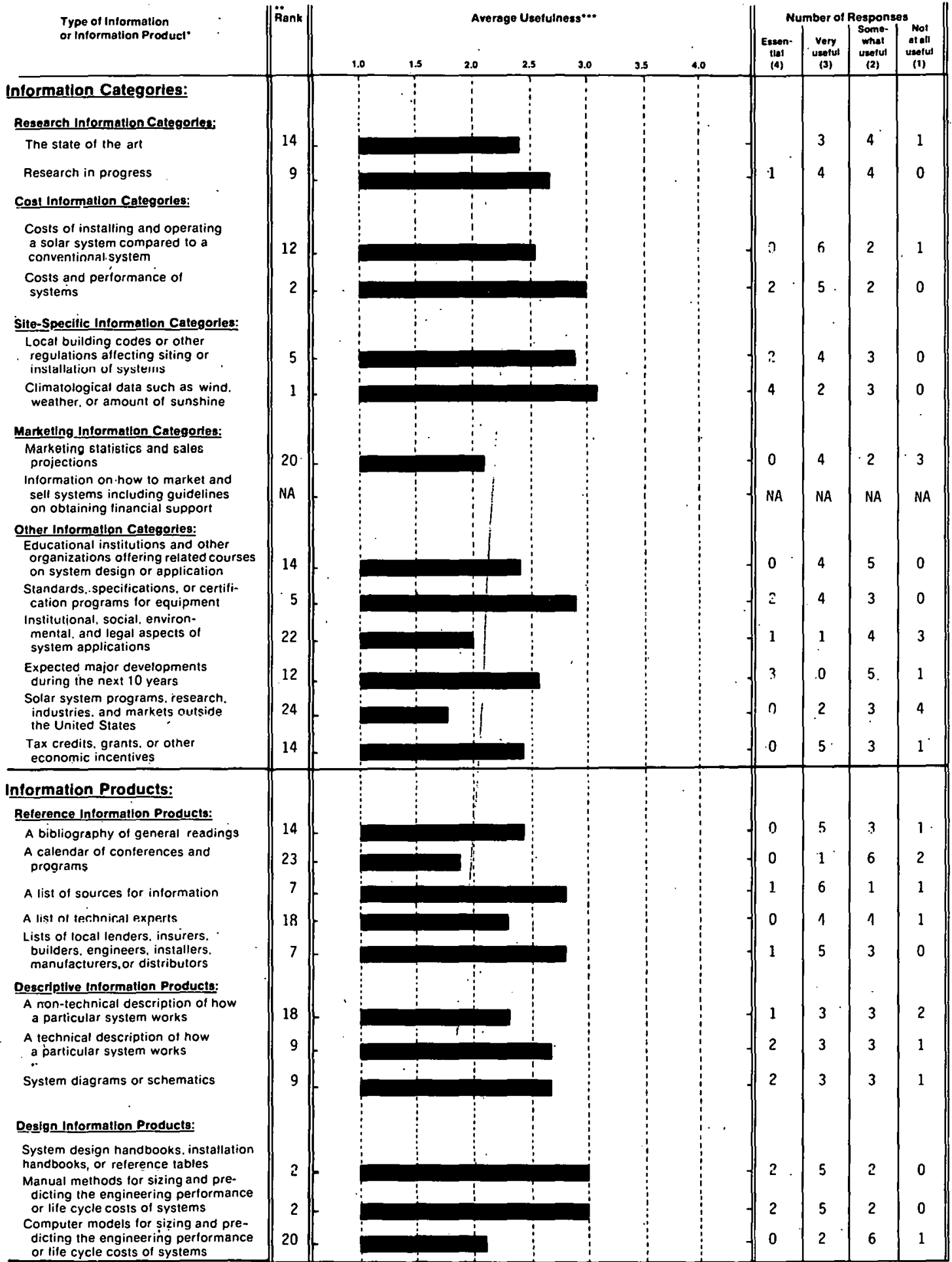

Each sample frame of users was questioned on intormation ano intormation products in ine context of ineir specific technology. For exampte. bromass sample trames were

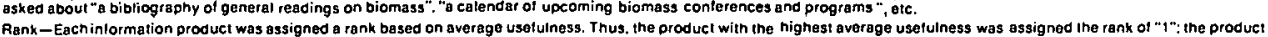
with the lowest average usefulness would be ranked "25" where all items were asked. II two or more intormation products were tied for 2 nd. they were both assigned a " $2 "$. The next highest ranking was

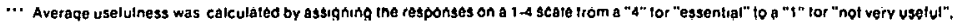

Figure 8-1. Usefulness of Selected Information Items: Active Solar Heating and Cooling Duilders 
Question \#8. I will read a list of potential information or information products on solar systems. For each, please tell me how useful that information would be to you. Would the following be: essential, very useful, somewhat useful, or not at all useful?

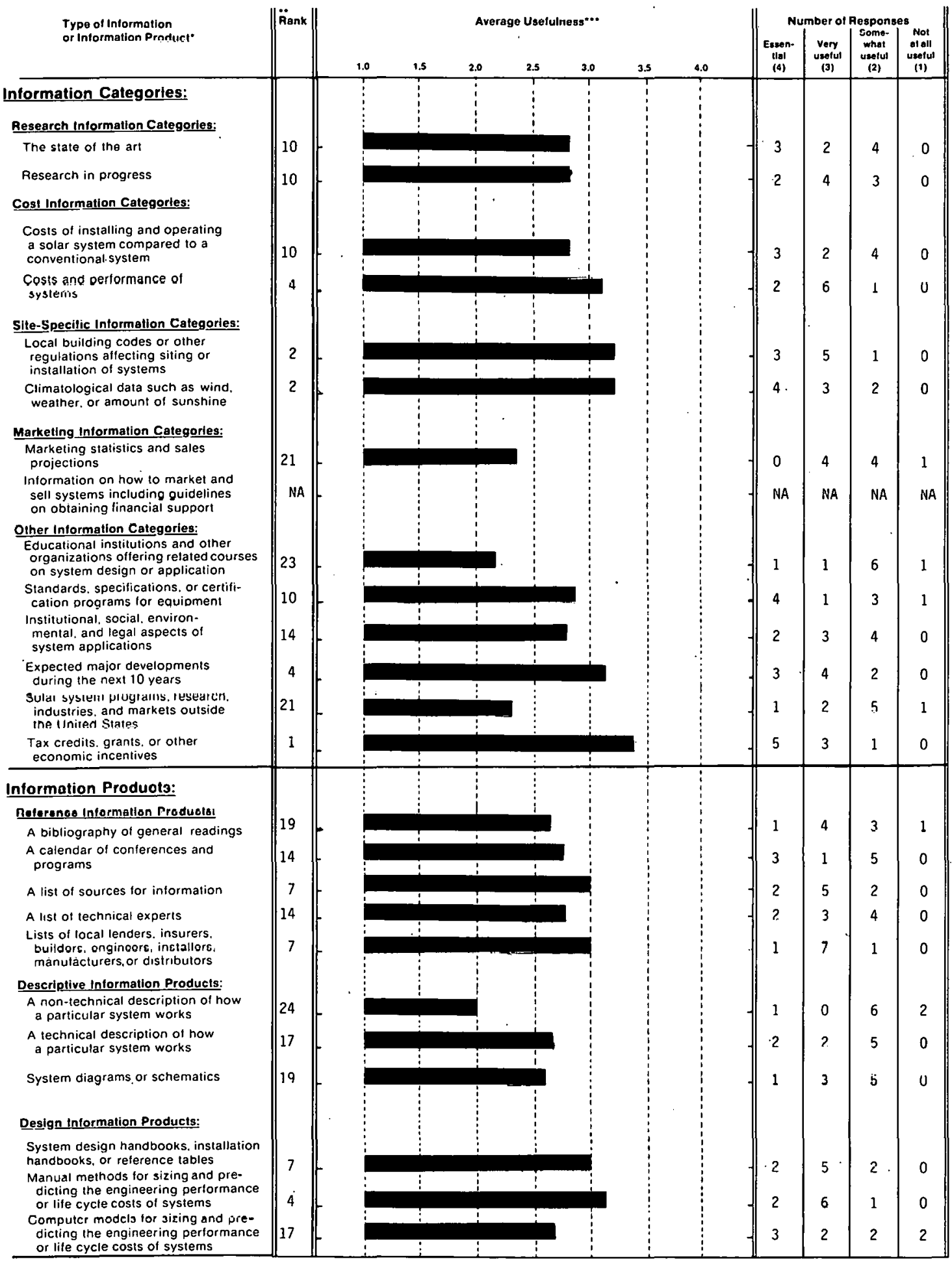

Each sample frame of users was questioned on intormation and intormation producls in ine context of their specific technology. For example. biomass sample irames were "askes aboul t bloilography ol general readings on biomass". "a cilendar ol upcoming biomass conterences and programs ". etc. " were thed tor 2nd, they were both assigned a " 2 ". The next Average usefulness was catculated by assigning the responses on a 1.4 gcale from a " " $"$ " lor "essential" to a " " tor "not very useful".

Figure 8-2. Usefulness of Selected Information Items: Passive Builders 
the other groups. The procedure for calculating the relative rating is described in Appendix E. The average overall rating SHAC Builders gave to all items was 2.54; for SHAC Architects it was 2.60; and for Passive Builders 2.81.

Statistical tests indicated that, compared to SHAC Architects, SHAC Builders rated the need for information on "educational institutions" significantly $(P<0.05)$ higher and "costs of installing and operating" significantly $(\mathrm{P}<0.05)$ lower. There also seemed to be some evidence that SHAC Builders were more interested in systems design and less interested in "tax credits, (etc.)" and "expected major developm ents."

Compared to Passive Builders, SHAC Builders rated the need for information on "tax credits, grants" significantly $(\mathrm{P}<0.05)$ lower. There also seemed to be evidence that the SHAC Builders were more interested in information on systems design, but less interested in "expected major developments" and "institutional, social, environmental, and legal aspects."

\subsection{ACQUISITION OF INFORMATION BY RESPONDENTS}

\subsubsection{Use of Selected Information Sources}

SHAC Builders were asked which of 20 different potential sources of solar information they had used in the past few years. For this question, the respondents were not asked if they had obtained information on SHAC, but instead were asked if they had obtained any solar information from each specific source. Thus, the question sought to determine which information sources were the most familiar to the respondents. The results are shown in Fig. 8-3. For the purpose of comparison, the results for Passive Builders (Fig. 8-4) are also included and those for SHAC Architects appear in Section 7.3.1.

The information sources mentioned most of ten by SHAC Builders were:

- Periodicals, newspapers, or magazines;

- Workshops, conferences, or training sessions;

- An installer, designer, or manufacturer;

- The Government Printing Office (GPO); and

- Directly from the U.S. Department of Energy (DOE).

The first three sources listed above were also the three most mentioned sources for both SHAC Architects and Passive Builders.

The Information suurees mentioned least of ten by SH $\Lambda \mathrm{C}$ Builders were:

- Sume other state or local government office or publications,

- Radio or TV,

- A commercial data base, and

- State energy or solar offices. 
Question \#11. In the past few years, have you obtained any type of solar information from any of the following sources?

Information Sources

Percentage Responding Yes ${ }^{* * *}$

Public Media:
Radio or TV
Periodicals. newspapers or magazines

Private Solar-Involved Organizations:

Private solar energy or environmental organizations

The local chapter or national headquarters of International Solar Energy Society (ISES), including their publications

The local chapter or national headquarters of Solar Energy Industries Association (SEIA), including their publications

\section{Euntacis witn proressionals:}

An installer, builder, designer or manufacturer of solar systems

Workshops, conferences or training sessions

Information Services":

Your organizational library or a local library

A commercial data base: for example. Lockheed. SDC. BRS

Smithsonian Science Information Exchange (SSIE)

A Federal library or information center: for example, the National Agricultural Library or the Environmental Data System

The Government Printing Office (GPO)

National Technical Information Service (NTIS)

Technical Information Center at Oak Ridge (TIC)

\section{Government Solar-Involved Organizations}

Uirectly fróm the U.S. Department of Energy

National Solar Heating \& Cooling Information Center

Regional Solar Energy Centers

State Energy or Solar Offices

\section{Other:}

Some other state or local government office or publication

A public utility company

Snurces for this epecific sample frame*t

National Association of Home Builders

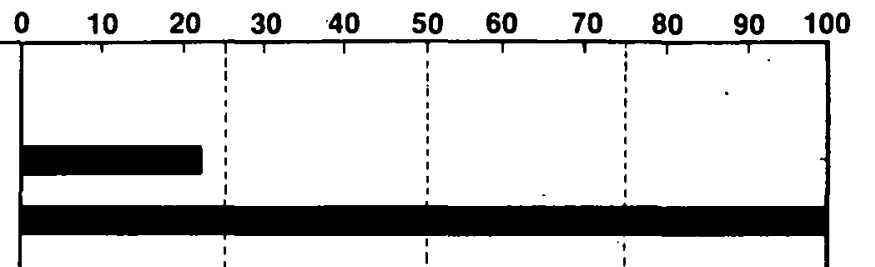


Question \#11. In the past few years, have you obtained any type of solar information from any of the following sources?

\section{Information Sources}

Public Media:
Radio or TV
Periodicals. newspapers or magazines

Private Solar-Involved Organizations:

Private solar energy or environmental organizations

The local chapter or national headquarters of International Solar Energy Society (ISES), including their publications

The local chapter or national headquarters of Solar Energy Industries Association (SE|A), including their publications

\section{Contacts with Professionals:}

An installer, builder. designer or manufacturer of solar systems

Workshops, conferences or training sessions

\section{Information Services*:}

Your organizational library or a local library

A commercial data base; for example, Lockheed. SDC. BRS

Smithsonian Science Information Exchange (SSIE)

A Federal library or information center; for example. the National Agricultural Library or the Environmental Data System

The Government Printing Office (GPO)

National Technical Information Service (NTIS)

Technical Information Center at Oak Ridge (TIC)

Government Solar-Involved Organizations

Directly from the U.S. Department of Energy

National Solar Heating \& Cooling Information Cente

Regional Solar Energy Centers

State Energy or Solar Offices

Other:

Some other state or local government office or publication

A public utility company

Sources for this specilic sample frame":

National Association of Home Builders
Percentage Responding Yes $\cdots$

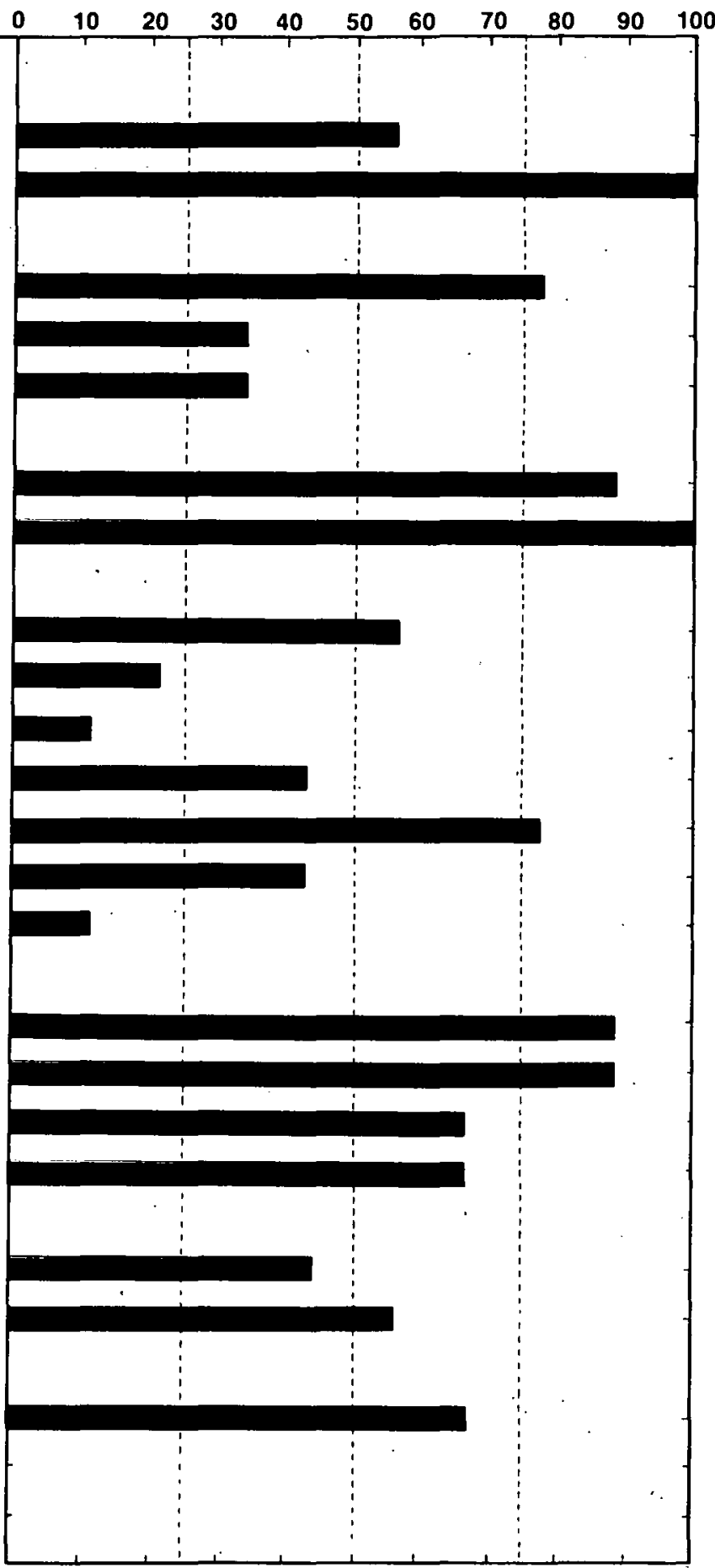

Services and centers whose primary purpose is lo disseminate information.

- Some sample frames were questioned about additional information sources which are applicable to their technology. For example. the manufacturers of biomass conversion equipment were also asked it they have obtained any type of solar information trom: "the local or national office of the U.S. Department of Agriculture including Extension and Forestry:"

"* These data arc based upon a total of $y$ responoents.

Figure 8-4. Use of Selected Information Sources: Passive Builders 
In comparing the information sources used by SHAC Builders to those used by SHAC Architects and by Passive Builders, no statistically significant differences were found. There seemed to be evidence, however, that SHAC Builders had not used as many information sources as had Passive Builders.

\subsubsection{Membership in Solar-Interested Organizations}

Significantly fewer SHAC Builders than SHAC Acrhitects were members of a professional, technical, or other organization with an interest in solar energy. Only 3 of the 9 (33\%) SHAC Builders interviewed were members of such organizations compared to 8 of the 9 (89\%) SHAC Architects and 5 of the 9 (56\%) Passive Builders. These organizations (each receiving a single mention) included:

- American Institute of Architects (AIA),

- American Society of Heating, Refrigerating and Air Conditioning Engineers (ASHRAE),

- American Society of Mechanical Engineers (ASIME), and

- International Solar Energy Society (ISES).

\subsubsection{Exposure to Publications on Solar Energy}

During the past 6 months, all 9 SHAC Builders had read publications that included information on SHAC. The publications they could specify (and the number of times mentioned) included:

- Argonne National Lab publications,

- ASHRAE publications,

- ASME journals,

- NUE information,

- Government publications (periodicals, mailing lists) (2),

- National Engineer,

- Progressive Architecture,

- Solar Age (2),

- Solar Energy Information Data Bank (SEIDB) publications, and

- Solar Engineering (2).

Also mentioned were some publications that the authors could not verify. These included "Engineering Record," "HS," "Solar Heating and Cooling by Kapner," "trade magazines," "reference manuals," "literature on seminars," and "technical data plans and specifications."

\subsubsection{Use of Special Acquisition Methods}

The respondents were asked whether they had obtained any information (not just SHAC or solar energy) in the past year by computer terminal, by Computer Output Microform 
(COM), or by other microform (e.g., microfiche, microfilm sheets or rolls). Few SHAC Builders appeared accustomed to using these special acquisition methods, a trait common to builders and architects interviewed in both passive technology and SHAC. In the past year, only 3 of the 9 (33\%) had used a computer terminal, no one COM, and 3 of the 9 (33\%) had used other microforms.

\subsection{SUMMARY AND COMMENTS *}

Nine builders involved in SHAC were interviewed. Specific types of SHAC-related activities mentioned included: hot water systems, air heating system with rock storage, solar concentrating collectors, and large arrays of collectors. Both SHAC Builders and Passive Builders were slightly less involved than were SHAC Architects; all three groups, however, were similarly well-informed and had comparable levels of education. The degrees earned by the SHAC group (both Builders and Architects) were predominantly in engineering and architecture, whereas Passive Builders had a wide range of educational backgrounds. Professionally, SHAC Builders appeared to have slightly more years of experience in their current profession than did either SHAC Architects or Passive Builders; all nine SHAC Builders had been in their current profession at least 5 years.

SHAC Builders gave the highest priority to receiving information on:

- Climatological data;

- Cost and performance of SHAC systems;

- SHAC system design handbooks, installation handbooks, or reference tables;

- Manual methods for sizing and predicting performance or costs of SHAC systems;

- Local building codes or other regulations affecting SHAC systems; and

- Standards, specifications, or certification programs for SHAC systems.

The gave low ratings to "SHAC programs, research ... outside the United States," "calendars," "institutional, social . . aspects," "marketing statistics," and "computer models."

The resulting picture of the SHAC Builder was of one who needed information in three major areas. First, site-specific data including "climatological data" and "local building codes" was needed. Second, information on system cost and performance was needed. Third, systems design information was needed, including information on "standards."

SHAC Builders, as well as SHAC Architects and Passive Builders, most of ten received solar information through "periodicals," prof essional contacts ("workshops, (etc.)" and "an installer, builder, designer, (etc.)"), GPO, and DOE. Only 1 of the 9 SHAC Builders, however, was known to be a member of a solar energy association. There seemed to be evidence that SHAC Builders used fewer information sources than did Passive Builders. 
SEPI 
SBCTION 9.0

ACTIVE SOLAR HEATING AND COOLNG PLANNERS

\subsection{DESCRIPTION OF RESPONDENTS}

\subsubsection{Description of Sample}

This section describes the results of a telephone study to determine the needs of planners for information on active solar heating and cooling (SHAC). Nine SHAC Planners were interviewed.

The sample frame for SHAC Planners was constructed from three sources. First, the Chairman of the Energy Planners Network of the American Planning Association identified 54 planners from the "Master List of the Energy Planners Network" [22] who were known to him to be involved in solar energy. An additional 26 planners were identifed by Solar Energy Research Institute (SERI) staff members. The third source was the National Solar Heating and Cooling Information Center's (NSHCIC) professional (architectural planners) data bank [23]. This source yielded 13 names of individuals whose titles specified planner. Duplicate names from the three sources were eliminated, as well as duplicates between this sample frame and that for SHAC Architects. After all adjustments were made, the 9 interview candidates were randomly selected from a sample frame of 91 names. By chance, the respondents for all 9 completed interviews were members of the Energy Planners Network.

Respondents. In making the telephone calls to contact the randomly selected interview candidates, it sometimes occurred that the person could not be reached. In this event another randomly selected name was substituted for the original name. When individuals were contacted it was verified that they really were planners with some experience with solar systems, and that they would be needing information on SHAC within the next year. If they were not both involved and needing information, they were asked if they could refer the interviewer to someone else in their organization who would be an appropriate respondent. If such a referral was made, a call was then made to this new candidate; if no intraorganizational referral was made, a new candidate was randomly selected from the sample frame. The results of this process may be seen in Table 9-1.

The data for SHAC Planners can be found in Appendix F.

\subsubsection{Current Status of Respondents}

Role. Two SHAC Planners were affiliated with large consulting firms and two worked at universities. The other 5 worked for: a state solar energy center, a utility company, a community planning periodical, a city planning office, and a large manufacturer. They thus appeared to represent a broad range of interests. Activities concerning SHAC in which these Planners are presently engaged included: consulting (for both public and private clients), planning, research, education, examining public policy issues, reviewing ordinance proposals relating to solar energy, reviewing solar legislation, monitoring SHAC technologies and installed domestic systems, developing better systems, providing advice on technical monitoring, and watching new developments. 
Table 9-1. COMPLETION OF INTERVIEWS: ACTIVE SOLAR HEATING AND COOLNG PLANNERS

Event

Number of

Candidates

Interview completed with sample frame candidate

Interview completed with referral candidate

Refusal or candidate termination

Contact attempted: could not reach candidate within three

attempts or before interviews were completed

Subtotal

Contact attempted: invalid candidate (e.g., inappropriate field of interest, no telephone)

'I'U'I'AL

Sample frame error rate (Percent) $^{\mathbf{a}}$

Completion rate ${ }^{\mathrm{b}}$ (Percent)

${ }_{\text {Invalid candidates divided by TOTAL }}$

$\mathrm{b}_{\text {Completed interviews divided by Subtotal }}$

Involvement. Four of the 9 (44\%) SHAC Planners said that they were "very involved" in SHAC. Seven of the 9 (78\%) were at least "moderately involved."

Informedness. Three of the 9 (33\%) SHAC Planners considered themselves "very informed." All 9 considered themselves at least "moderately inform ed."

Need for Information. All respondents indicated they would need information on the jnh during the next year. Three of the 9 (33\%) also expected to need information on SHAC. outside the job.

\subsubsection{Background of Respondents}

Two of the 9 SHAC Planners held a PhD. Five held a master's degree, and 2 had bachelor's degrees. Degree fields covered a broad range: chemistry (2), public administration, city and regional planning, American history, management, business, physics, and journalism. Five had received their most recent degree over 10 years ago, and 4 from 5-10 years ago.

Four of the SHAC Planners had been in their current profession for 5 or fewer years, 3 for 5-10 years, and 2 for over 10 years. Their present professions included: consultant (2), administrator (2:1 public, 1 research), city planner, director of a nonprofit organization, program manager, scientist, and journalist. 


\subsection{INFORMATION NEEDS OF RESPONDENTS}

\subsubsection{Technical Areas}

SHAC Planners were asked to choose those areas in which they were "particularly interested in obtaining information" from a list of selected technical areas of SHAC. They seemed to be somewhat more interested in water heating (9), hybrid systems (8), and space cooling (8) than in swimming pool heating (5) or in space heating (6).

Some SHAC Planners volunteered that they were also interested in industrial process heat (2), energy storage, and "any applications."

\subsubsection{Types of Information}

SHAC Planners were asked to name the information about SHAC that was important for them to obtain. All 9 Planners volunteered one or more items of information which they considered important. Six of the 9 felt economics and cost information were important. One of these specified life-cycle costing, while another wanted "accurate" economics based on "real system performance in the field." Other topics included: heat loss data on solar storage tanks; thermodynamies of roof ponds in warm and humid climates; optical properties of glazings; systems performance; work experience of physical systems; comparative testing; impact of solar energy on present regulations; net energy analysis; technical break throughs; and the number, type; and location of present solar installations.

Information that the SHAC Planners volunteered they needed but were unable to get included: good performance data, economics, testing, actual cost of installed projects, manual cost calculation methods, installation and manufacturing costs for different types of equipment, a homeowners' guide for purchasing solar systems, and a homeowners' guide for diagnosis of solar system problems.

Choice Between Specific Needs. A list of 11 types of SHAC information products and 12 types of SHAC information categories was read to each respondent. Each respondent described the usefulness of each particular item by assigning it a value of "essential," "very useful," "somewhat useful," or "not at all useful:" The results are given in Fig. 9-1.

SHAC Planners selected both items in the cost category as most important, and both items in the research category as almost as important. The seven top-rated information categories/products were:

- Costs of installing and operating a SHAC system compared to a conventional system;

- Costs and performance of systems;

- Local building codes or other regulations;

- Tax credits, grants, or other economic incentives;

- The state of the'art;

- Research in progress; and

- Institutional, social, environmental, and legal aspects. 
Question \#8. I will read a list of potential information or information products on solar syslems. For each, please tell me how useful that information would be to you. Would the following be: essential, very useful, somewhat useful, or not at all useful?

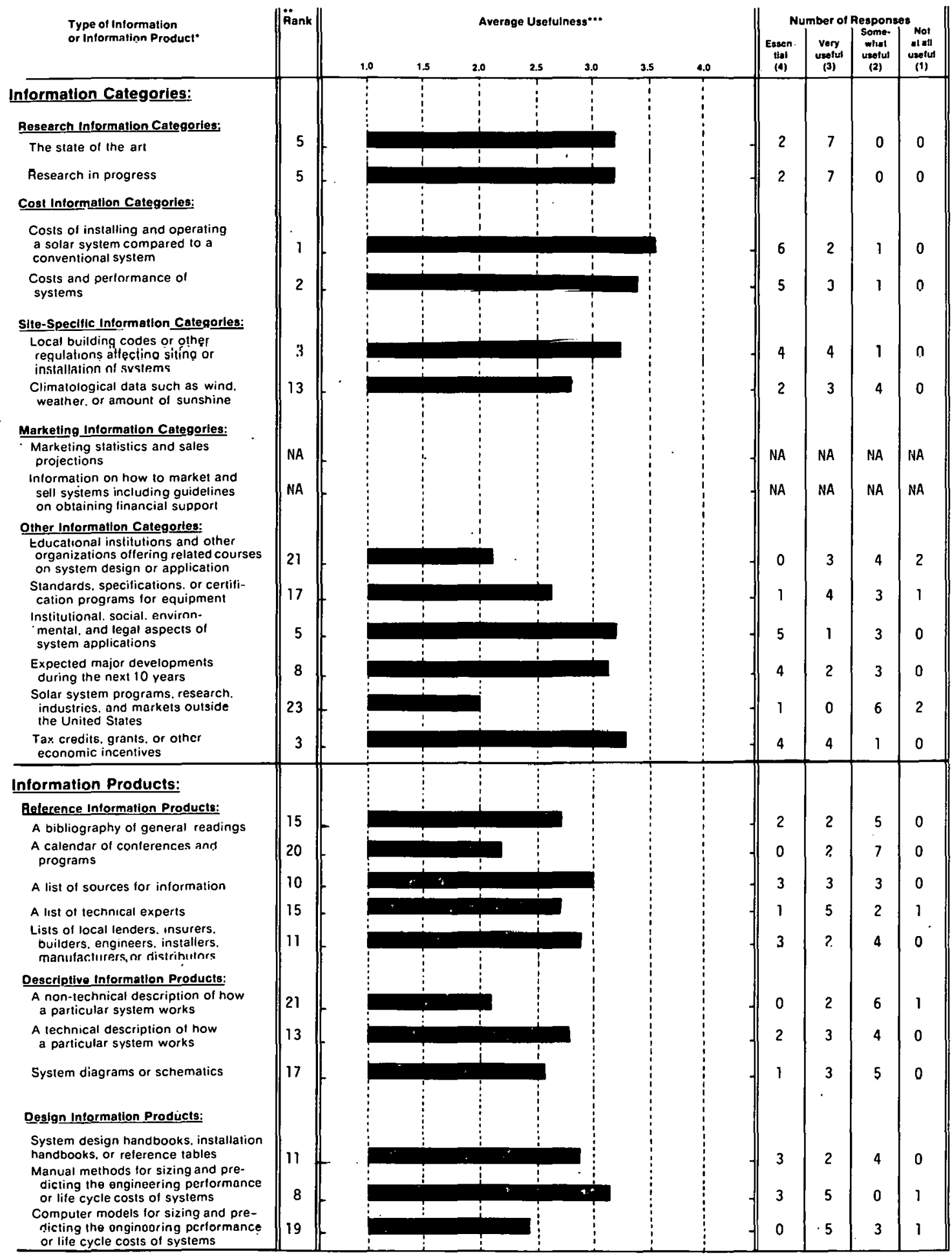

Each sample trame of users was questioned on intormation and intormation products in the context of their specitic technology. For example. biomass sample trames were

- Rank - Each inlormation product was assigned a rank based on average usetulness. Thus, the product with the highest average usefulness was assigned the rank of "1"; the product with ine lowest average useturness would
highesi ranking was then assigned a "4?

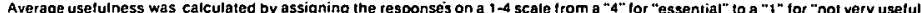

Figure 9-1. Usefulness of Selected Information Items: Active Solar Heating and Cooling Planners 
SHAC Planners tended to give high ratings to a substantial number of information items. The average rating across all of the information categories and products was tied (at 2.84) with that for Tax Appraisers, and was among the highest average ratings given by any of the 86 groups in this study.

SHAC Planners assigned the lowest relative ratings to:

- Solar energy programs, research, industries, and markets outside the United States;

- Educational institutions and other organizations offering courses;

- A nontechnical description of how a particular systems works; and

- Calendars of conferences and programs.

Statistical tests indicated that differences between the ratings for the seven highestrated information items and the four lowest-rated ones were significant $(P<0.05)$.

These results pictured the SHAC Planner as wanting information on the current and changing status of SHAC (costs, local regulations, tax credits, environmental and institur. tional aspects, state of the art) and on research. They also indicated that SHAC Planners were not particularly interested in learning programs (courses, conferences, descriptions), or non-U.S. solar activities.

It should be noted that these lower-rated items were not necessarily of no worth to the SHAC Planners. For example, 3 of the $9(33 \%)$ thought "educational institutions" was "very useful." Thus, these information categories/products could be useful to some SHAC Planners but were of a lower relative priority to the entire group.

\subsection{ACQUISITION OF INFORMATION BY RESPONDENTS}

\subsubsection{Use of Selected Information Sources}

SHAC Planners were asked which of 20 different potential sources of solar information they had used in the past few years. For this question the respondents were not asked if they had obtained information on SHAC, but instead were asked if they had obtained any solar information from each specific source. Thus, the question sought to determine which information sources were the most familiar to the respondents. The results are shown in Fig. 9-2.

The information sources mentioned most often by SHAC Planners (all 9 respondents had used them) were:

- Periodicals, newspapers, or magazines;

- Workshops, conferences, or training sessions;*

- Directly from the U.S. Department of Energy (DOE); and

- An organizational library or a local library.

*Note that calendars of these events were considered to be of relatively little utility to this group. 
Question \#11. In the past few years, have you obtained any type of, solar information from any of the following sources?

\section{Information Sources}

Public Medra:

Radio or TV

Periodicals. newspapers or magazines

Private Solar-Involved Organizations:

Private solar energy or environmental organizations

The local chapter or national headquarters of International

Solar Energy Society (ISES), including their publications

The local chapter or national headquarters of Solar Energy

Industries Association (SEIA), including their publications

Cuilacits will, Fiulesslunals

An instalter, builder, designer or manufacturer of solar systems

Workshops, conferences or training sessions

\section{Information Services*:}

Your organizational library or a local library

A commercial data base; for example, Lockheed, SDC, BRS

Smithsonian Science Information Exchange (SSIE)

A Federal library or information center; for example, the National Agricultural Library or the Environmental Data System

The Government Printing Office (GPO)

National Technical Information Service (NTIS)

Technical Information Center at Oak Ridge (TIC)

Government Solar-Involved Organizations

Directly from the U.S. Department of Energy

National Solar Heating \& Cooling Information Center

Regional Solar Energy Centers

State Energy or Solar Offices

Other:

Some uiner state or local government office or publication

A public utility company

Sources for this specific sample frame**:

American Planning Association
Percentage Responding Yes

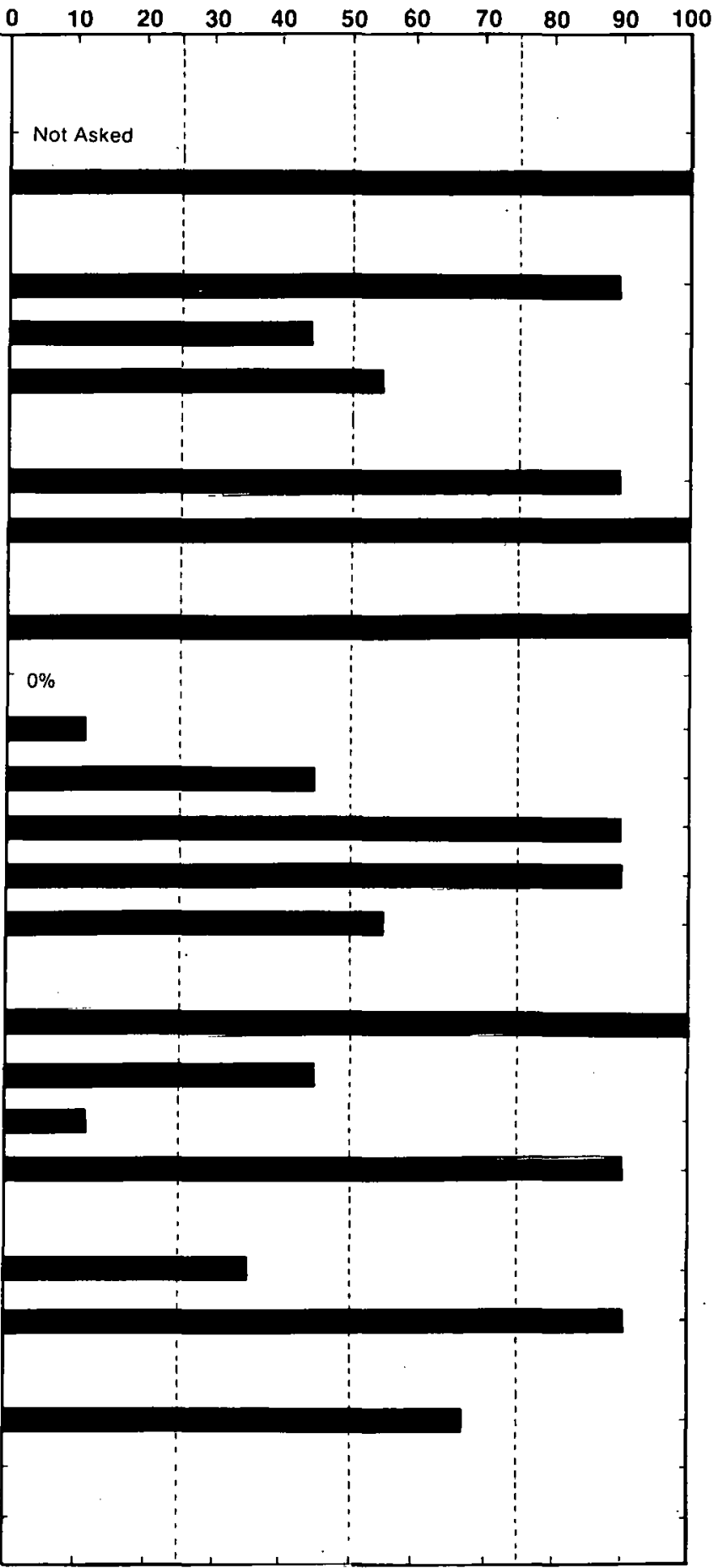

- Services and centers whose primary purpose is to disseminate information.

- Some sample frames were questioned about additional information sources which are applicable to their technology. For example, the manufacturers of biomass conversion equipment were also asked it they have obtained any type of solar intormation trom: "the local or national office of the U.S. Department of Agriculture, including Extension and Forestry."

** These data are based upon a total of 9 respondents.

Figure 9-2. Use of Selected Information Sources: Active Solar Heating and Cooling Planners 
In addition, 8 of the 9 SHAC Planners had used:

- Private solar energy or environmental organizations;

- An installer, builder, designer, or manufacturer;

- The Government Printing Office (GPO);

- National Technical Information Service (NTIS);

- State energy or solar offices; and

- A public utility company.

The information sources mentioned least of ten by SHAC Planners were:

- A comm ercial data base;

- Smithsonian Science Information Exchange (SSIE);

- Regional Solar Energy Centers (RSECs); and

- Some other state or local government office or publications.

\subsubsection{Membership in Solar-Interested Organizations}

Six of the 9 SHAC Planners interviewed were members of a professional, technical, or other organization with an interest in solar energy. These organizations (and the number of times mentioned) included:

- American Association for the Advancement of Science;

- American Planning Association, Energy Task Force (3);

- Institute of Electrical and Electronics Engineers;

- Intermarket Association of Advertising Agencies;

- International Solar Energy Society (ISES) (3);

- Optical Society of America; and

- Urban and Regional Information Systems Association.

Also mentioned by 1 respondent was an organization that the authors could not verify. This was the "MEC" (either the Massachusetts Energy Council or Manufacturing Engineering Council?). The American Planning Association and ISES were clearly the most popular.

\subsubsection{Exposure to Publications on Solar Energy}

During the past 6 months, all 9 SHAC Planners had read publications that included information on SHAC. The publications they could specify (and the number of times mentioned) included:

- American Society of Planning Officials publications,

- CERIE (journal, California),

- Electric Power Research Institute publications, 
- Government publications,

- New Roots,

- Science,

- Solar Age (4),

- Solar Energy (3),

- Solar Energy Intelligence Report,

- Solar Engineering (2),

- Solar Heating and Cooling (DOE),

- Sunworld, and

- Urban Land.

Alśo mentıoned was "proprietary information," information that the authors could not further define.

\subsubsection{Use of Special Acquisition Methods}

The respondents were asked whether they had obtained any information (not just SHAC or solar energy) in the past year by-computer terminal, by Computer Output Microform (COM), or by other microform (e.g., microfiche, microfilm sheets or rolls). SHAC Planners appeared more accustomed to using some of these special acquisition methods than did most of the other groups studied. In the past year, 4 of the 9 had used a computer terminal, none had used COM, but 6 of the 9 SHAC Planners had used other microforms.

\subsection{SUMMARY AND COMMENTS}

Nine members of the Energy Planners Network of the American Planning Association were interviewed. They represented a variety of affiliations: a state solar energy center, a university, a utility company, an appropriate technology network, a community planning periodical, a city planning office, a manufacturer, and two consulting firms. Their activities relating to.SHAC covered technology review and awareness, research, consulting, education, legislative review, and monitoring installations.

Although all nine respondents considered themselves well informed, SHAC Planners were far above average in their interest in obtaining additional information. They attached the greatest utility to SHAC information on:

- The state of the art in SHAC technology;

- SHAC research in progress;

- Costs of installing and operating a SHAC system compared to a conventional system;

- Costs and performance of SHAC systems;

- Local building codes or other regulations affecting siting or installation of SHAC systems; 
- Institutional, social, environmental, or legal aspects affecting SHAC installations; and

- Tax credits, grants, or other economic incentives for SHAC systems.

Their lowest ratings went to "SHAC system programs, research . . . outside the United States," "educational institutions," "a nontechnical description," and "calendars."

SHAC Planners appeared to be interested in three primary areas: research information, cost information (including financial.incentives), and the area of institutional and legal aspects including local ordinances.

At least eight of the nine SHAC Planners had received solar information from: "periodicals, (etc.)," "workshops, conferences," "an organizational library or a local library," federally funded sources, " environmental organizations," "an installer, builder, designer, or manufacturer," state energy or solar offices, and "a public utility company." Both the American Planning Association and ISES also served as information disseminators. 


\section{S=Plष्:}


SECTION 10.0

\author{
ACTIVE SOLAR HEATING AND COOLNG \\ HEATING, VENTHLATING, AND AIR CONDITONING ENGINEERS
}

\title{
10.1 DESCRIPTION OF RESPONDENTS
}

\subsubsection{Description of Sample}

This section describes the results of a telephone study to determine the needs of Heating, Ventilating, and Air Conditioning (HVAC) engineers for information on active solar heating and cooling (SHAC). Nine SHAC HVAC Engineers were interviewed.

The sample frame for SHAC HVAC Engineers was constructed from the National Solar Heating and Cooling Commercial Demonstration Program-Key Personnel Directory (KPD) [20], and The AEE Directory of Energy Professionals (Association of Energy Engineers) [24]. Names selected from the AEE Directory were those who specified solar and HVAC specialties. The KPD Directory listed personnel associated with DOE-CS SHAC Demonstration projects. Names and addresses of mechanical/HVAC engineers were selected. Duplicates with researchers, engineers in other technologies, and architects and builders in all technologies were eliminated. After all adjustments were made, the 9 interview candidates were randomly selected from a sample frame of about 200 names.

Respondents. In making the telephone calls to contact the randomly selected interview candidates, it sometimes occurred that the person could not be reached. In this event another randomly selected name was substituted for the original name. When individuals were contacted it was verified that they really were HVAC Engineers and that they would be needing information on SHAC within the next year. If they were not both involved and needing information, they were asked if they could refer the interviewer to someone else in their organization who would be an appropriate respondent. If such a referral was made, a call was then made to this new candidate; if no intraorganizational referral was made, a new candidate was randomly selected from the sample frame. The results of this process may be seen in Table 10-1.

Comparisons. For additional insight into the information needs and the information habits of these SHAC HVAC Engineers, results from this group are compared to the results from SHAC Industrial Engineers (see Section 11.0), and All Engineers interviewed in this study. The list of all the groups contained in All Engineers can be found in Fig. F-2 of Appendix F. In performing any comparisons, the totals for SHAC HVAC Engineers have been subtracted from the total for All Engineers. The data for SHAC HVAC Engineers, SHAC Industrial Engineers, and All Engineers can be found in Appendix F.

\subsubsection{Current Status of Respondents}

Role. Eight of the 9 SHAC HVAC Engineers were working for enginering firms and 1 for the state government. None had described their current activities in similar terms. Solar activities in which they were engaged included: teaching, system design, planning applications, system inslallution, system monitoring, system debugging, feasibility studies, collector design, and domestic hot water system design. Space heating, flatplate, liquid, and air collectors were also mentioned-as were residential, commercial, and industrial buildinge. 
Table 10-1. COMPLETION OF INTERVIEWS: ACTIVE SOLAR HEATING AND COOLNG HEATING, VENTILATING, AND AIR CONDITIONING ENGIN EERS

Event Number of Candidates

Interview completed with sample frame candidate

Interview completed with referral candidate

8

1

Refusal or candidate termination

Contact attempted: could not reach candidate within three

attempts or before interviews were completed

Subtotal

12

Contact attempted: invalid candidate (e.g., inappropriate field

of interest, no telephone)

TOTAL

Sample frame error rate ${ }^{a}$ (Percent)

Completion rate ${ }^{b}$ (Percent)

Invalid candidates divided by TOTAL

${ }^{\mathrm{b}}$ Completed interviews divided by Subtotal

Involvement. Three of the 9 (33\%) SHAC HVAC Engineers said that they were "very involved," and another 3 were "moderately involved" in solar heating and cooling. The same numbers of SHAC Industrial Engineers reported these levels of involvement. For All Engineers, involvement levels were somewhat lower, with 46 of the 96 (48\%) at least "moderately involved" compared to 6 of the $9(67 \%)$ of HVAC Engineers.

Informedness. Five of the 9 (56\%) SHAC HVAC Engineers considered themselves "very informed," compared to the same number of SHAC Industrial Engineers; but only 35 of the $96(36 \%)$ of All Engineers. The remainder of the SHAC HVAC Engineers (and SHAC Industrial Engineers) considered themselves "moderately informed."

Need For Information. All respondents indicated they would need information on SHAC on the job during the next year. All 9 SHAC Industrial Fngineers also indicated a need for SHAC information on the job. Six of the 9 (67\%) SHAC HVAC Engineers also expected to need information on SHAC outside the job. This was somewhat higher than the results for SHAC Industrial Engineers, where 4 of the 9 (44\%) indicated they would need SHAC information outside the job. All Engineers had results similar to those for SHAC Industrial Engineers.

\subsubsection{Background of Respondents}

Three of the 9 SHAC HVAC Engineers held master's degrees, the remainder held bachelor's degrees. All had degrees in engineering, 8 of them in mechanical engineering. Two of the 9 received their most recent degree within the past 5 years, 3 from 10-20 years ago, and 4 over 30 years ago. Seven of the 9 had been in their current profession for more than 10 years, the other 2 for 3-5 years. All ref erred to their present profession as engineer (professional, consulting, or mechanical), and 2 specifically 
mentioned solar applications in their professional description. The educational level, field of degree (all engineering), year of most recent degree, and years of current prof essional experience of SHAC HVAC Engineers did not differ significantly from.those for SHAC Industrial Engineers or for All Engineers.

\subsection{INPORMATION NEEDS OF RESPONDENTS}

\subsubsection{Technical Areas}

SHAC HVAC Engineers were asked to choose those areas in which they were "particularly interested in obtaining information" from a list of selected technical areas of $\overline{\text { SHAC }}$. They seemed to be somewhat less interested in swimming pool heating than in the other areas listed (see Table 10-2).

Table 10-2. AREAS OF INTEREST: ACTVE SOLAR HEATING AND COOLING HRATING, VENTILATING, AND AIR CONDITIONING (HVAC) ENGINEBRS AND ACTIVE SOLAR HEATING AND COOLING INDUSTRIAL ENGINEERS

\begin{tabular}{|c|c|c|c|c|}
\hline \multirow{2}{*}{$\begin{array}{c}\text { Technical } \\
\text { Area of Interest }\end{array}$} & \multicolumn{2}{|c|}{ HVAC Engineers } & \multicolumn{2}{|c|}{ Industrial Engineers } \\
\hline & No. & Percent & No. & Percent \\
\hline Hybrid Systems & 9 & 100 & 7 & 78 \\
\hline Space Heating & 9 & 100 & 7 & 78 \\
\hline Water Heating & 9 & 100 & 9 & 100 \\
\hline Space Cooling & 8 & 89 & 8 & 89 \\
\hline Swimming Pool Heating & 5 & 56 & 3 & 33 \\
\hline
\end{tabular}

Four SHAC HVAC Engineers volunteered that they were also interested in solar distillation, electrical conversion, automotive air conditioning, or power generation.

\subsubsection{Types of Information}

SHAC HVAC Engineers were asked to name information about SHAC that was important for them to obtain. All 9 SHAC HVAC Engineers volunteered one or more items of information which they considered important. Three felt performance information was important. Other topics included: lists of manufacturers (2), simplified economic data and costs (2), state of the art (2), improvements in the economics of solar cooling, equipment dependability (expected life), types of collectors and systems, storage techniques, design parameters, test results for available equipment, and information on available analysis techniques (including a "good computer program").

Six of the 9 (67\%) SHAC HVAC Engineers stated that there was information they needed but were unable to get. Information items mentioned included: life cycle cost, computer models, accurate performance data, heat storage data, design data, insolation data, solar space heating to supplement solar pool heating, and where to get slides for presentation to lay audiences. Many of these items were the same ones mentioned as information that 
was important for them to obtain. Comparatively, only 1 of the 9 (11\%) SHAC Industrial Engineers stated that there was information he/she needed but was unable to get. One SHAC HVAC Engineer wanted information on passive roof shading design requirements.

Choice Between Specific Needs. A list of 11 types of SHAC information products and 12 types of SHAC information categories was read to each respondent. Each respondent described the usefulness of each particular item by assigning it a value of "essential," "very useful," "somewhat useful," or "not at all useful." The results for SHAC, HVAC. Engineers are given in Fig. 10-1. For the purpose of comparison, the results for SHAC Industrial Engineers are in Fig. 11-1 (Section 11.2.2), and those for All Engineers in Fig. 10-2.

SHAC HVAC Engineers selected both cost and site specific information as the most important information classes.

The seven top-rated information categories/products for HVAC Engineers were:

- Climatological data;

- Costs and performance of systems;

- Tax credits, grants, or other economic incentives;

- Local building codes or other regulations;

- Research in progress;

- Costs of installing and operating a SHAC system compared to a conventional system; and

- System design handbooks, installation handbooks, or reference tables.

SHAC HVAC Engineers assigned the lowest relative ratings to:

- A nontechnical description of how \& purticulur system works;

- Solar energy programs, research, industries, and markets outside the United States;

- A bibliography of general readings;

- Lists of technical experts; and

- Lists of local lenders, insurers, builders, engineers, installers, manufacturers, or distributor.

Statistical tests indicated all seven of the top categories/products were rated significantly $(P<0.05)$ higher than were the five lowest-rated items.

It should be noted that these lower-rated items were not necessarily of no worth to the SHAC HVAC Engineers. For example, 4 of the $9(44 \%)$ thought "solar system programs . . . outside the United States" was either "essential" or "very useful." Thus, these information categories/products could be useful to some SHAC HVAC Engineers but were of a lower relative priority to the entire group.

Statistical tests were also used to determine whether the SHAC HVAC Engineers rated any of these information items significantly higher (or lower) than they. were rated by the SHAC Industrial Engineers or All Engineers. Some groups, however, tended to give 
Question \#8. I will read a list of potential information or information products on solar systems. For each, please tell me how useful that information would be to you. Would the following be: essential, very useful, somewhat useful, or not at all useful?

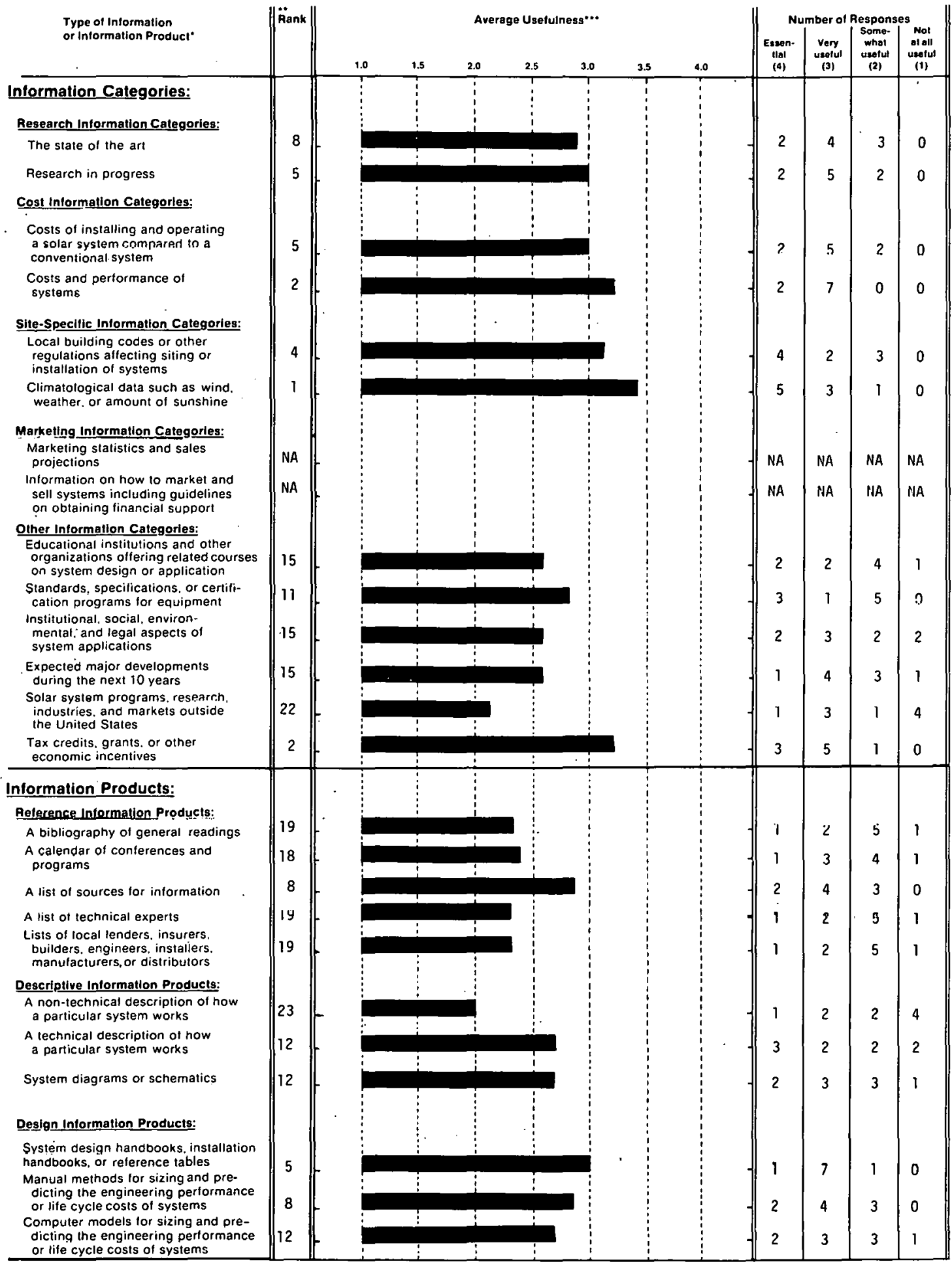

Each sample frame of users was questioned on intormation and intormation producls in the context of theit specilic tectrruluyy. For example, biomass samplc tramc3 werc asked aboul abibiogshy grograms ". eic. "

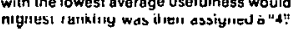

-.. Average usetulness was calculated by assigning the responses on a $1-4$ scale trom a " " " for "es sential" to a " " " tor "not very usetur. 
Question \#8. I will read a list of potential information or information products on solar systems. For each, please tell me how useful that information would be to you. Would the following be: essential, very useful, somewhat useful, or not at all useful?

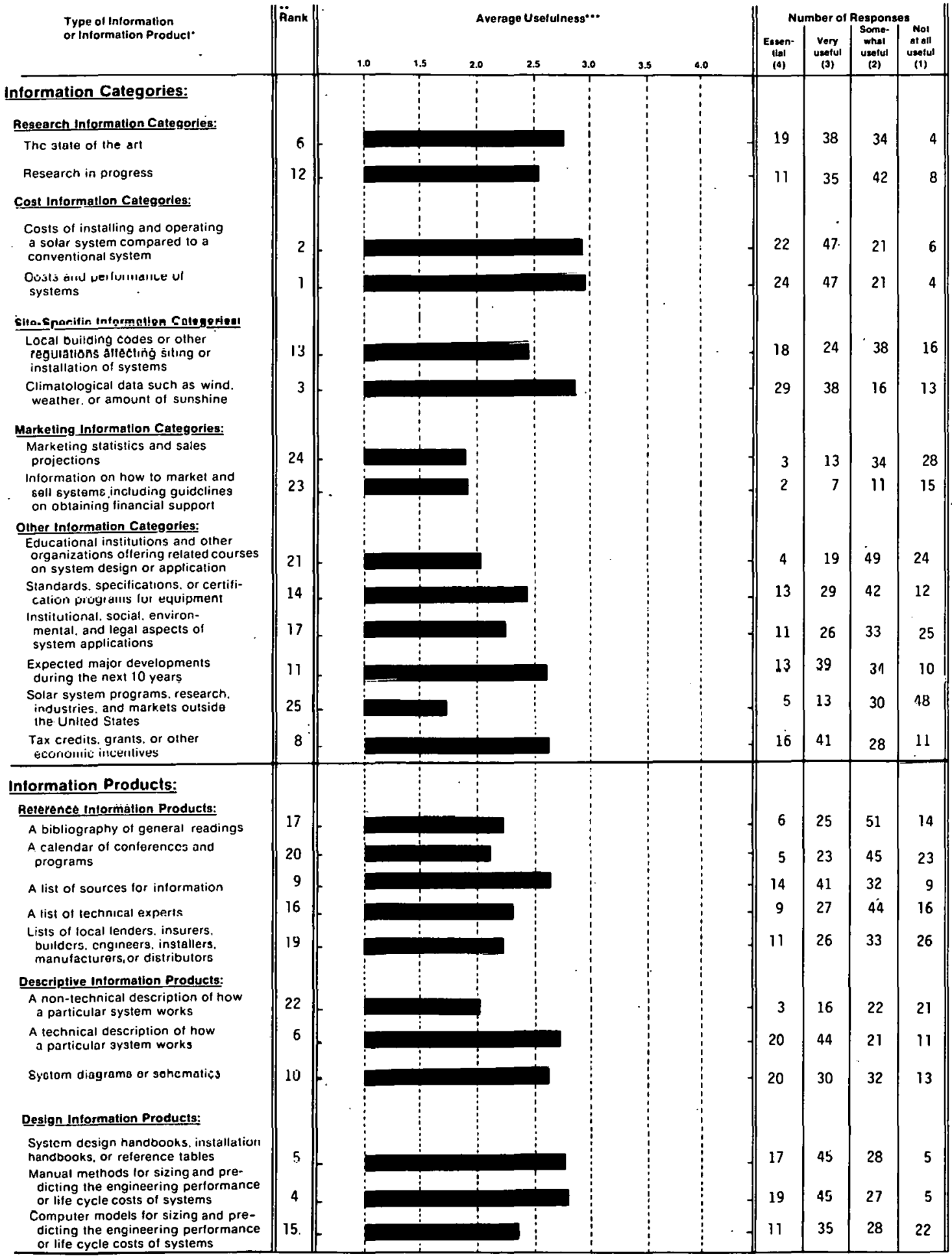

Each sample trame of users was questioned on intormation and intormation products in the context of their specitic tochnology. For example. biomass sample trames were.

asked aboul "a bibliography of general seadings on biomass". "a calendar of upcorning biomass conferences and programs ". elc.

Rank-Each intormation product was assigned a rank based on average uselulness. Thus. the product with the highest average usefulness was assigned the rank of ${ }^{-1}$; the product with ine lowest average usetulness woutd be ranked "25" where all items were asked. It two or more information products were tied lor 2nd. thay were both assigned a " 2 ". The nex

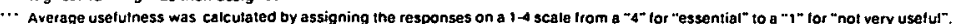

Figure 10-2. Usefulness of Selected Information Items: All Engineers 
higher scores in general than did other groups. To compensate for this effect, these statistical tests compared the "relative rating" given by one group to the "relative rating" given by the other groups. The procedure for calculating the relative rating is described in Appendix. E. The average overall rating was much higher for SHAC HVAC Engineers (2.72) than it was for SHAC Industrial Engineers (2.38) or for All Engineers (2.45). Among SHAC groups interviewed in this study, only SHAC Planners had a higher average.

In comparing the results for SHAC HVAC Engineers with the results for SHAC Industrial Engineers and for All Engineers, no significant differences were found. The data seemed to indicate, however, that SHAC HVAC Engineers were more interested in research information and in "lists of sources for information," but less interested in systems design/descriptive information than were SHAC Industrial Engineers.

\subsection{ACQUISITION OF INPORMATION BY RESPONDENTS}

\subsubsection{Use of Selected Information Sources}

SHAC HVAC. Engineers were asked which of 21 different potential sources of solar information they had used in the past few years. For this question the respondents were not asked if they had obtained information on SHAC, but instead were asked if they had obtained any solar information from each specific source. Thus, the question sought to determine which information sources were the most familiar to the respondents. The results are shown in Fig. 10-3. For the purpose of comparison, the results for SHAC Industrial Engineers are in Fig. 11-4 (Section 11.3.1), and those for All Engineers are in Fig. 10-4.

The information sources mentioned most often by SHAC HVAC Engineers were:

- An installer, builder, designer, or manufacturer;

- Periodicals, newspapers, or magazines;

- American Society of Heating, : Refrigerating and Air Conditioning Engineers (ASHRAE); and

- An organizational library or a locul library.

The information sources mentioned least of ten by SHAC HVAC Engineers were:

- A commercial data base,

- Solar Energy Industries Association (SEIA),

- A federal library or information center,

- State cnergy or solar of fices, and

- Some other state or local government office or publications.

In comparing SHAC HVAC Engineers to SHAC Industrial Engineers, both groups appeared to use the services of "periodicals, (etc.)" and "an installer, (etc.)" but made little use of SEIA and "a commercial data base." Differences between the two groups identified significantly $(P<0.05)$ fewel SHAC HVAC Engineers than SHAC Industrial Engineers using "state energy or solar offices." In comparing the information sources used by SHAC 
Question \#11. In the past few years, have you obtained any type of solar information from any of the following sources?

Information Sources

Public Media:
Radio or TV.
Periudiculs. newspapers or magazines
Private Solar-Involved Organizations:
Private solar energy or environmental organizations
The local elıduler ur natlonal neadquarters of International
Solar Energy Society (ISES), including their publications
The local chapter or national headquarters of Solar Energy
Industries Association (SEIA), Includinn their nuihlirations
Contacts with Professionals:

An installer, builder, designer or manufacturer of solar systems

Workshops, conferences or training sessions

\section{Information Services*:}

Your organizaliunal library or a local library

A commercial data base; for example, Lockheed, SDC. BRS

Smithsonian Science Information Exchange (SSIE)

A Federal library or information center; for example, the National Agricultural Library or the Environmental Data System

The. Government Printing Office (GPO)

National. Technical Information Service (NTIS)

Technical Information Center at Mak Ridge (TIC)

Government Solar-Involved Orgenizalluns

Directly from the U.S. Department of Energy

Natıonal Solar Heating \& Cooling Information Center

Regional Solar Energy Centers

State Energy or Solar Offices

Other:

Some other state or local government office or publication

A publlc utility company

Sources for this specifle sample frame*":

American Society of Heating, Refrigerating and Air Conditioning Engineers

Sheet Metal and Air Conditioning Contractors' National Association

American Eociety of Mechanical Engineers
Percentage Responding Yes ${ }^{\cdots}$

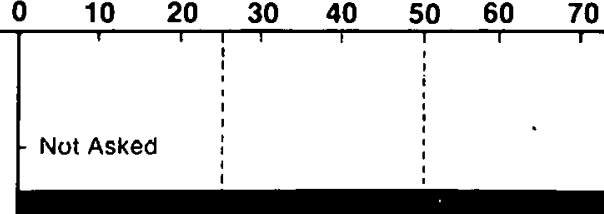
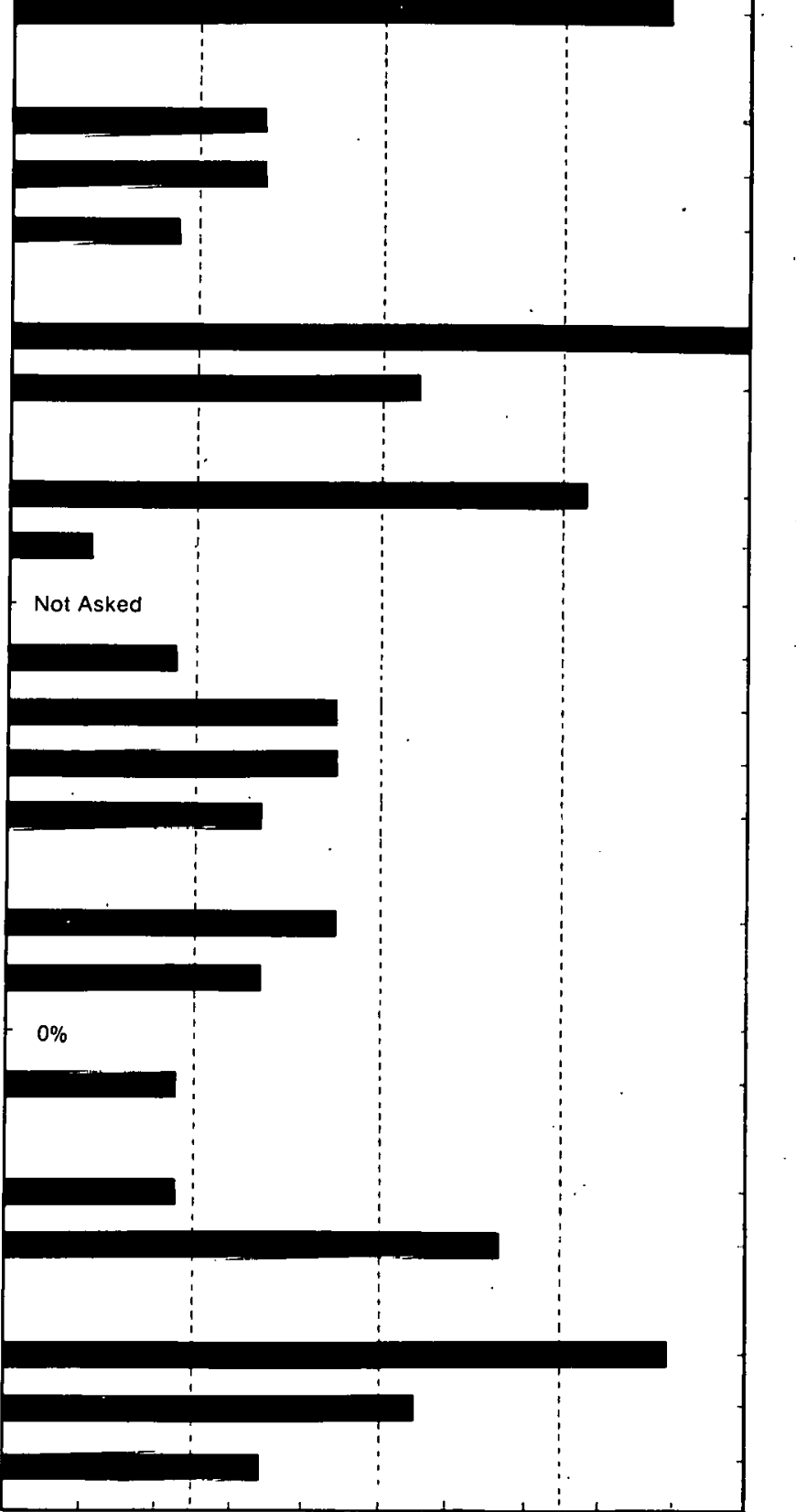

- Services and centers whose primary purpose is to disseminate information.

Some sample frames were questioned about additional information sources which are applicable to their technology. For example. the manufacturers of biomass conversion equipment were also asked it they have obtained any type of solar information from: "the local or national office of the U.S. Department of Agriculture, including Extension and Forestry."

... These data are based upon a total of 9 respondents.

Figure 10-3.Use of Selected Information Sources: Active Solar Heating and Cooling Heating, Ventilatíng, and Air Conditioning Engineers 
Question \#11. In the past few years, have you obtained any type of solar information from any of the following sources?

Information Sources

Public Media:
Radio or TV
Periodicals. newspapers or magazines
Private Solar-Involved Organizations:
Private solar energy or environmental organizations
Tho local chapter or national headquarters of International
Solar Energy Society (ISES). including their publications
The lucal chapter or national hcadquarters of Solar Energy
lindustries Association (SEI $\wedge$ ). including their publications
Contacts with Professionals:

An insialler, builder. designer or manufacturer of solar systems

Workshops. conferences or training sessions

Information Services*:

Your organizational library or a local library

A commercial data base: for example. Lockheed. SDC. BRS

Smithsonian Science Information Exchange (SSIE)

A Federal library or information center; for example. the National Agricultural Library or the Environmental.Data System

The Government Printing Office (GPO)

National Technical Intormation Service (NTIS)

Technical Information Center at Oak Ridge (TIC)

Government Solar-Involved Organizations

Directly from the U.S. Department of Energy,

National Solar Heating \& Cooling Information Center

Reyiurlal Jülar Energy Centero

State Energy or Solar Offices

\section{Other}

Sóme other state or local government office or publication

A public utility company
Percentage Responding Yes "

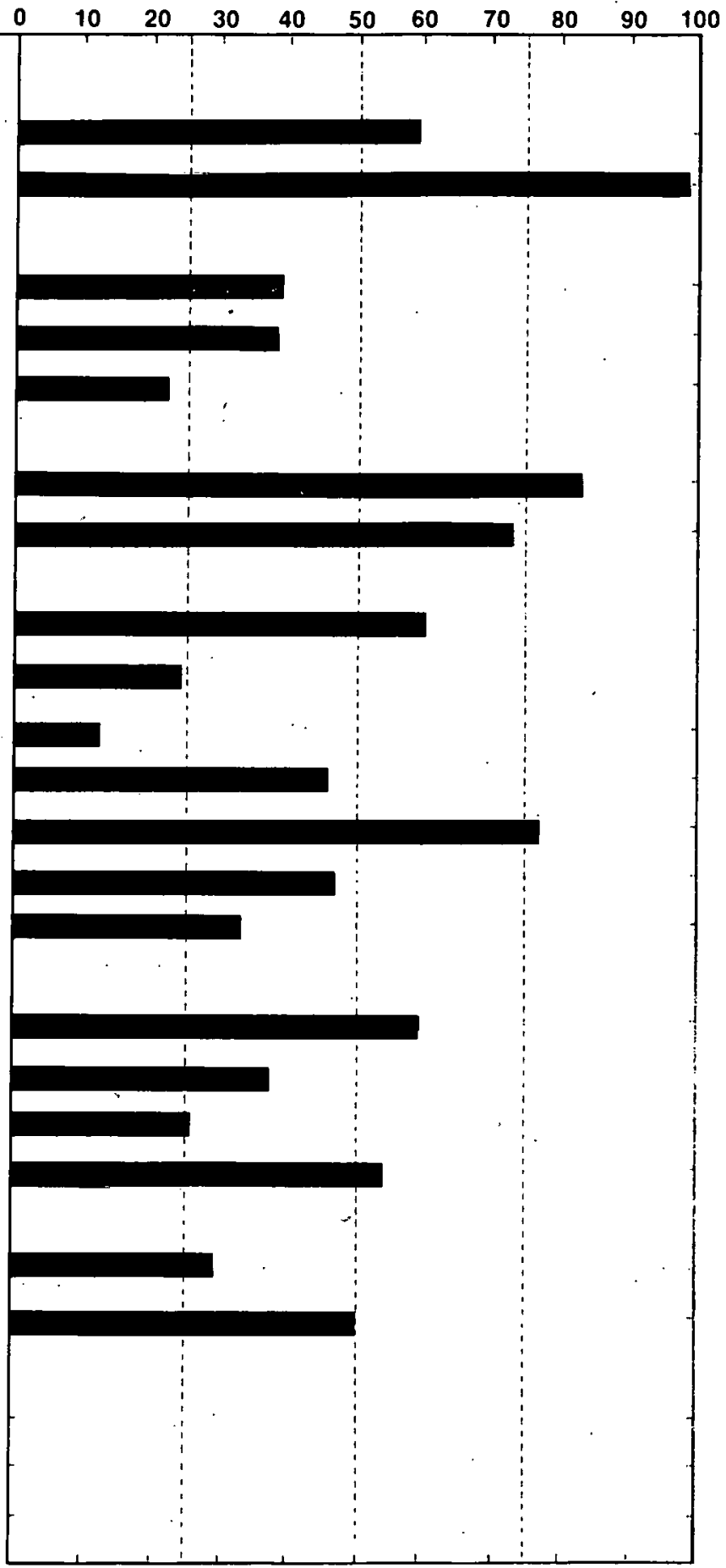

- Services and centers whose primary purpose is to disseminate information.

- These data are based upon a total of 96 respondents.

Fig!ıre 10-4. Use of Selected Information Sources: All Engineers 
HVAC Engineers to those used by All Engineers, SHAC HVAC Engineers made significantly $(P<0.05)$ less use of the Government Printing Office (GPO), the Regional Solar Energy Centers (RSECs), and the state energy or solar offices.

\subsubsection{Membership in Solar-Interested Organizations}

All of the 9 SHAC HVAC Engineers interviewed were members of a professional, technical, or other organization with an interest in solar energy. These organizations (and the number of times mentioned) included:

- American Society of Civil Engineers,

- ASHRAE (7),

- Association of Energy Engineers (2),

- International Solar Energy Society (4),

- Missouri Solar Energy Associates,

- National Association of Power Engineers,

- National Society of Prof essional Engineers (3), and

- Texas Solar Energy Society.

Also mentioned by I SHAC HVAC Engineer was the "Energy Engineers of America," an organization that could not be verified by the authors.

\subsubsection{Exposure to Publications on Solar Energy}

During the past 6 months, all 9 SHAC HVAC Engineers had read publications which included information on SHAC. The publications they could specify (and the number of times mentioned) included:

- ASHRAE Guide,

- ASHRAE Journal (3),

- U.S. Department of Energy (DOE) publications (2),

- Plant Engineering,

- Solar Age (2),

- Solar Energy (2),

- Solar Energy: Concepts and Economics (Colorado State University)

- Solar Engineering,

- Solar Heating and Cooling,

- Sunworld, and

- The Solar Survey (book by the National Center for Appropriate Technology)

Also mentioned by SHAC HVAC Engineers were "Energy Engineers of America literature," and "periodical solar journals"; titles which could not be verified or further specified by the authors. 


\subsubsection{Use of Special Acquisition Methods}

The respondents were asked whether they had obtained any information (not just SHAC or solar energy) in the past year by computer terminal, by Computer Output Microform (COM), or by other microform (e.g., microfiche, microfilm sheets or rolls). Computer terminals were not unfamiliar to most SHAC HVAC Engineers. Five of the 9 (56\%) had used them in the past year, compared to only 1 of the 9 SHAC Industrial Engineers. However, only 1 (11\%) SHAC HVAC Engineer recalled using COM, and 2 (22\%) had used other microform. None of the SHAC Industrial Engineers had used either of the special acquisition methods besides computer terminals.

\subsection{SUMMARY AND COMMENTS}

Nine active solar-involved HVAC Engineers were interviewed. These SHAC HVAC Engineers were involved in varied applications and functions of SHAC, with no two respondents describing their role in similar terms. Compared to All Engineers, SHAC HVAC Engineers had slightly higher levels of involvement and informedness. The educational level, type of degree earned, and years of current professional experience of SHAC HVAC Engineers were found to be typical of engineers interviewed in this study.

SHAC HVAC Engineers gave the highest priority to receiving information on:

- Climatological data;

- Costs and performance of SHAC systems;

- Tax credits, grants, or other economic incentives for SHAC systems;

- Local building codes or other regulations affecting SHAC systems;

- SHAC research in progress;

- Costs of installing and operating a SHAC system compared to a conventional system; and

- SHAC system design handbooks, installation handbooks, or reference tables.

They gave low ratings to "a nontechnical description," "solar energy programs, research. . . outside the United States," "a bibliography," "lists of technilcal experts," und "lists of local lenders, (etc.)."

These engineers needed three principal things. First, they needed site-specific data (climatological data and local building codes). Second, they needed to be kept aware of the costs, economic incentives (e.g., tax credits) available, and current research on SHAC systems. Third, they needed handbooks on system design.

SHAC HVAC Engineers most often received solar information through "an installer, builder, (etc.)," "periodicals," ASHRAE, and "an organizational . . . library." Seven of the nine were members of ASHRAE and at least five were members of a local or national solar energy association, with the Sheet Metal and Air Conditioning Contractor's National Association also serving as an important information disseminator. 
SERI: 
SECTION 11.0

\section{ACTIVE SOLAR HEATING AND COOLNG INDUSTRIAL ENGINEERS}

\subsection{DESCRIPTION OF RESPONDENTS}

\subsubsection{Description of Sample}

This section describes the results of a telephone study to determine the needs of industrial engineers for information on active solar heating and cooling (SHAC). Nine SHAC Industrial Engineers were interviewed.

The sample frame for SHAC Industrial Engineers was constructed by reviewing the entries in The AEE Directory of Energy Professionals (Association of Energy Engineers) [24] for industrial engineers. Those industrial engineers who specified Industrial Process Heat (IPH), or Heating, Ventilating, and Air Conditioning (HVAC), or electrical specialties were eliminated from this sample frame and incorporated into other engineering sample frames used in this study. Those names from the remaining industrial engineers for which "solar energy" or "energy audit" was specified were selected. These names were cross-checked against all other Engineer and Researcher sample frames in the study and duplicates eliminated. After all adjustments were made, the 9 interview candidates were randomly selected from a sample frame of 37 names.

Respondents. In making the telephone calls to contact the randomly selected interview candidates, it sometimes occurred that the person could not be reached. In this event another randomly selected name was substituted for the original name. When individuals were contacted, it was verified that they really were industrial engineers with SHAC experience and that they would be needing information on SHAC within the next year. If they were not both involved and needing information, they were asked if they could refer the interviewer to someone else in their organization who would be an appropriate respondent. If such a referral was made, a call was then made to this new candidate; if no intraorganizational referral was made, a new candidate was randomly selected from the sample frame. The results of this process may be seen in Table 11-1.

Comparisons. For additional insight into the information needs and the information habits of these SHAC Industrial Engineers, results from this group are compared to the results from IPH Industrial Engineers, IPH Plant Engineers, SHAC HVAC Engineers, and all of the engineers interviewed in this study (All Engineers). The list of all the groups contained in All Engineers can be found in Fig. F-2 of Appendix F. In performing any comparisons, the totals for SHAC Industrial Engineers have been subtracted from the totals for All Engineers. The data for SHAC Industrial Engineers, IPH Industrial Engineers, IPH Plant Engineers, SHAC HVAC Engineers, and All Engineers can be found in Appendix F.

\subsubsection{Current Status of Respondents}

Role. Seven of the 9 SHAC Industrial Engineers were employed by engineering firms, one was on a university faculty, and 1 was self-employed. Three respondents mentioned involvement with domestic applications of SHAC (hot water or space heating), so their involvement was not exclusively industrial. The activities specifically mentioned by the 
9 SHAC Industrial Engineers included 4 involved in design ( 3 in heating and 1 in development of moderate-temperature and nontracking concentrating collectors); 2 in consulting ( 1 was an energy consultant and 1 advised clients on energy conservation systems); and, of the remaining 3, 1 was installing collectors for solar hot water systems, l was evaluating experimental installations, and 1 was "waiting for the government to stop fooling around so we can use (active solar heating and cooling)."

Table 11-1. COMPLETION OF INTERVIEWS: ACTIVE SOLAR HEATING AND COOLNG INDUSTRIAL ENGINERRS

Interview completed with sample frame candidate

Interview completed with referral candidate

Refusal or candidatc tcrmination

Contact attempted: could not reach candidate within three

attempts or before interviews were completed

Subtotal

Contact attempted: invalid candidate (inappropriate field of interest, no telephone)

TOTAL

Sample frame error rate ${ }^{a}$ (Percent)

Completion rate ${ }^{b}$ (Percent)

anvalid candidates divided by TOTAL

${ }^{\mathrm{b}}$ Completed interviews divided by Subtotal

Involvement. Three of the 9 (33\%) SHAC Industrial Engineers said that they were "very involved" in SHAC, compared to 3 of the 9 (33\%) SHAC HVAC Engineers and 25 of the 96 (26\%) of All Engineers. None of the IPH Engineers (either group) considered themselves "very involved" with solar IPH.

Informedness. Five of the 9 (56\%) SHAC Industrial Engineers considered themselves "very informed" on SHAC, compared to 5 of the 9 (56\%) of SHAC HVAC Engineers and 35 of the $96(36 \%)$ of All Engineers. Fewer of the IPH Plant Fngineprs (2.\%) and IPH Industrial Engineers (1 1\%) were as involved in solar industrial applications.

Need for Information. All respondents indicated they would need information on SHAC on the job during the next year. Four of the 9 (44\%) SHAC Industrial Engineers also expected to need information on SHAC outside the job. This was somewhat lower than the results for SHAC HVAC Engineers, where 6 of the $9(67 \%)$ indicated they would nee. such information outside the job. It was higher than the results for All Engineers, where 29 of the 62 (47\%) of those who were asked the question indicated they would need solar information on their specific technologies outside of their job. (The IPH Engineers were not asked this question.) 


\subsubsection{Background of Respondents}

Two of the 9 SHAC Industrial Engineers held a PhD, 1 held a master's degree, and 5 held bachelor's degrees. Two had received their most recent degree over 30 years ago, 5 from 10-30 years ago, and 1 from 5-10 years ago. All 8 of the respondents with college degrees had received these degrees in engineering (mechanical, electrical, or architectural).

Only 1 had been in his current profession for 5 or fewer years; the other 8 for over 10 years. Seven of the 9 mentioned "engineering" in their definition of current profession; qualifying descriptions included: consulting (3), professor (2), control systems, and professional. Other professions included architect, energy consultant, and "leader in solar energy and energy conversion."

The educational level, field of degree (all engineering), year of most recent degree, and years of professional experience of SHAC Industrial Engineers did not differ significantly from those of SHAC HVAC Engineers.

\subsection{INFORMATION NEEDS OF RESPONDENTS}

\subsubsection{Technical Areas}

SHAC Industrial Engineers were asked to choose those areas in which they were "particularly interested in obtaining information". from a list of selected technical areas of $\overline{\mathrm{SHAC}}$. They were more interested in "water heating" (all 9) than in "swimming pool heating" ( 3 of the 9) (see Table 11-2).

Table 11-2. AREAS OF INTEREST: ACTIVE SOLAR HEATING AND COOLING INDUSTRIAL ENGINEERS AND HEATING, VENTLLATING, AND AIR CONDITIONING (HVAC) ENGINEERS

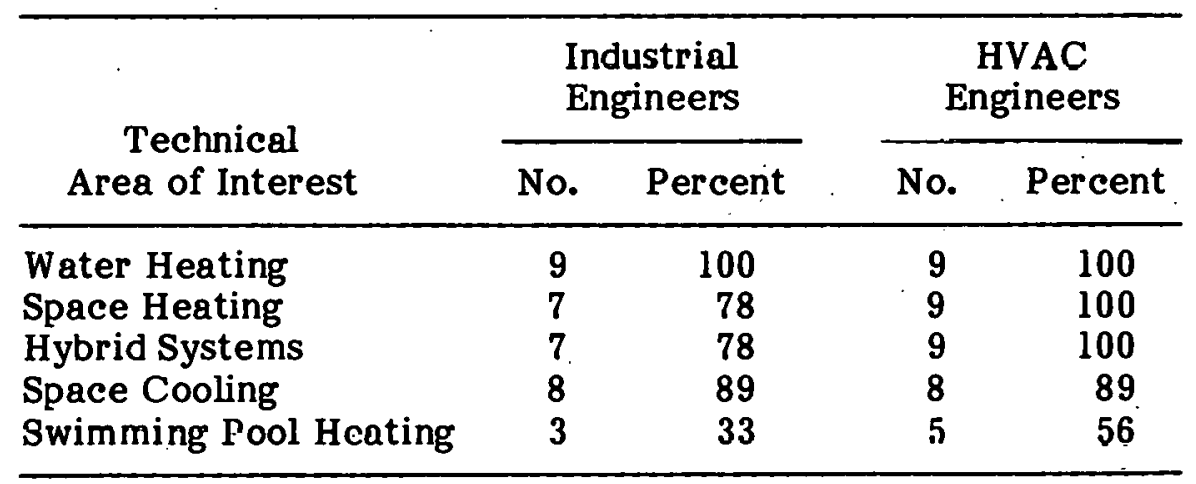

Two SHAC Industrial Engineers volunteered that they were also interested in hightemperature collectors and control systems (gathering and processing data). 


\subsubsection{Types of Information}

SHAC Industrial Engineers were asked to name the information about SHAC that was important for them to obtain. All of the 9 SHAC Industrial Engineers volunteered one or more items of information which they considered important. Two felt cost and new product information were important. Other topies included: weather data, sources of research funding, new methods, equipment performance and certification, simple and inexpensive techniques for testing collectors, heat products/systoms for speeific applications, collectors, cooling techniques, storage, $R \& D$ breakthroughs (state of the art), optics of nonimaging collectors, and filters for good versus bad information.

Choice Between Specific. Needs. A list of 11 types of SHAC information products and 13 types of SHAC information categories was read to each respondent. Each respondent described the usefulness of each particular item by assigning it a value of "essential," "very useful," "somewhat useful," or "not at all useful." The results are given in Fig. 11-1. For the purpose of comparison, the results for SHAC HVAC Engineers are shown in Fig. 10-1 (see Section 10.2.1), those for IPH Industrial Engineeers are in Fig. 11-2, IPH Plant Engineers in Fig. 11-3, and All Engineers in Fig. 10-2 (see Section 10.2.1).

For SHAC Industrial Engineers the nine top-rated information categories/products were:

- System diagrams or schematics;

- Manual methods for sizing and predicting performance or costs;

- Design handbooks, installation handbooks, or reference tables;

- Climatological data;

- Costs of installing and operating a SHAC system compared to a conventional system;

- Costs and performance of systems;

- Lucul bullding codés or other regulations;

- Tax credits, grants, or other economic incentives; and

- A technical description of how a particular system works.

SHAC Industrial Engineers assigned the lowest relative ratings to:

- Solar energy programs, research, industries, and markets outside the United States;

- Marketing statistics and sales projections;

- Institutional, social, environmental, and legal aspects;

- Educational institutions and other organizations off ering courses;

- A bibliography of general readings; and

- A nontechnical description of how a particular system works.

Statistical tests indicated all nine of the top categories/products were rated significantly $(P<0.05)$ higher than were the six lowest-rated items. 
Question \#8. I will read a list of potential information or information products on solar systems. For each, please tell me how useful that information would be to you. Would the following be: essential, very useful, somewhat useful, or not at all useful?

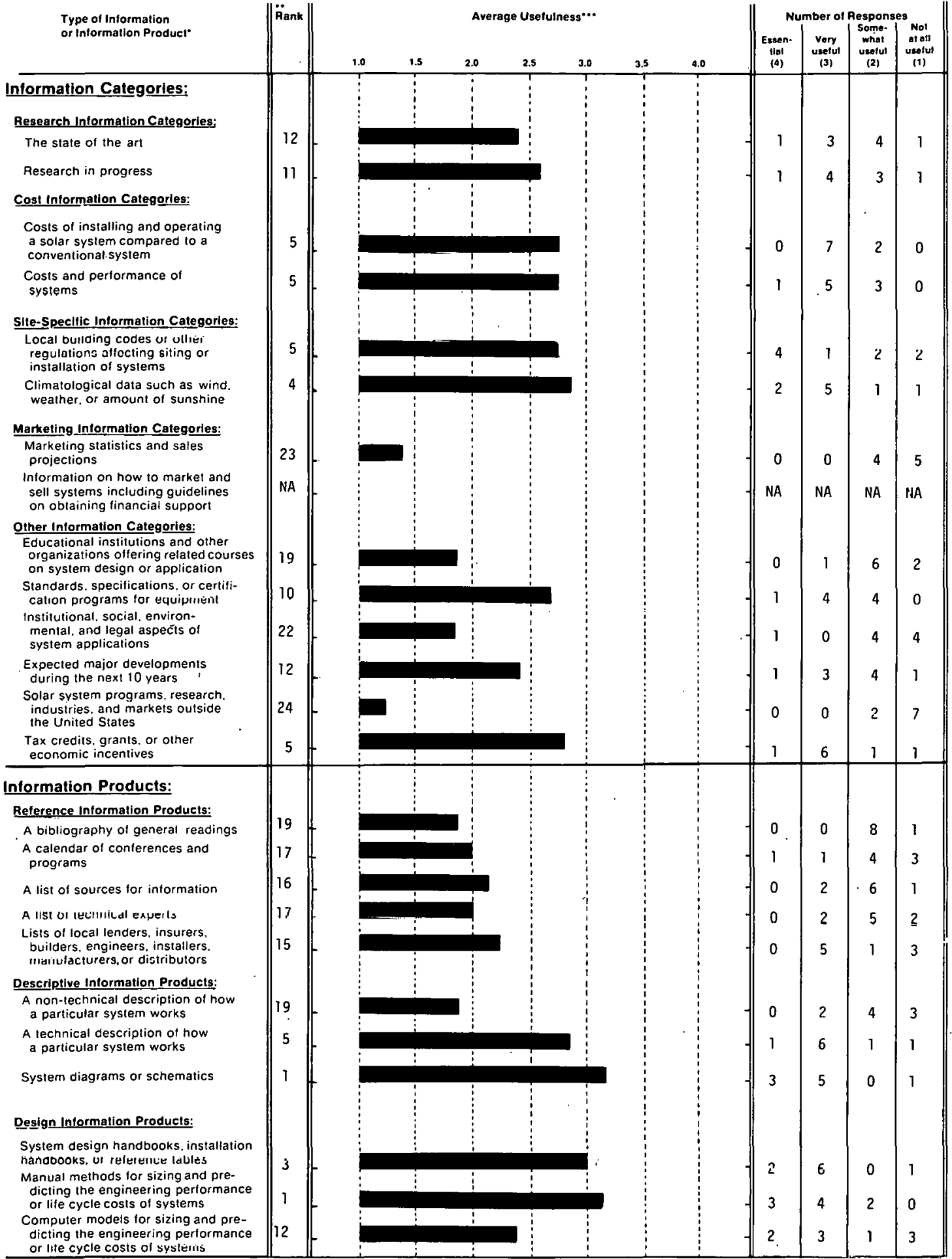

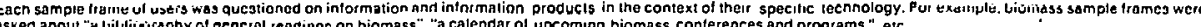
askeo aboul "a Liulicicy rsphy of gencral readingo on biemass". "a c,alendar ol udsom!ng biomass conterences and programs ". etc. Fank - Each intormation product was assigned a rank based on average usetulness. Thus. the producl with ine highest average uselulness was assigned the rank ot " $" 1$; the proouct

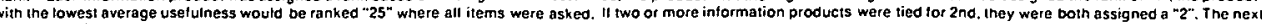

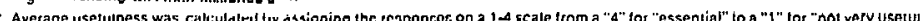

Figure 11-1. Useiulness of Selected Information Items: Active Solar Heating and Cooling Indusirlal Englneers 
Question \#8. I will read a list of potential information or information products on solar systems. For each, please tell me how useful that information would be to you. Would the following be: essential, very useful, somewhat useful, or not at all useful?

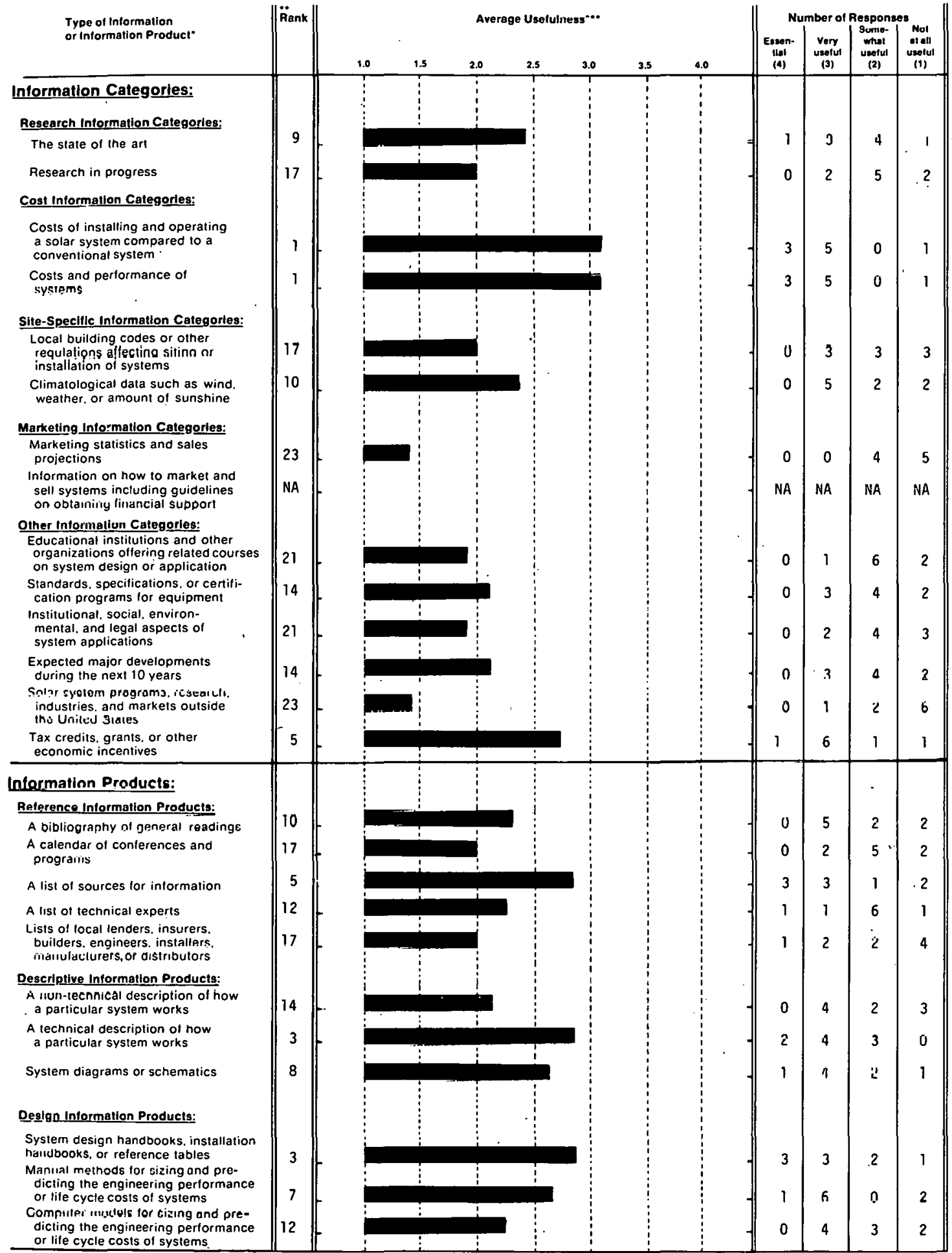

Each sample trame of users was questioned on intormation and intormation products in the contexl of their specitic technology. For example, biomass sample trames were

"Rank - Each intormation product was assigned a rank based on average usetulness. Thus. the product with the highest average usefutness was assigned the rank of "1": the product with the lowest average useturness would be ranked "25" where all items were asked. If iwo or more intormation producls were tied for 2 nd. they were both assigned a " 2 ". The next thighest ranking was then assigned a "4.

... Average usetulness was calculated by assigning the responses on a t-4 scale trom a " " " for "essential" to a "1" tor "not very uselul"

Figure 11-2. Usefulness of Selected Information Items: Industrial Process Heat Industrial Engineers 
Question \#8. I will read a list of polential information or information products on solar systems. For each, please tell me how useful that information would be to you. Would the following be: essential, very useful, somewhat useful, or not at all useful?

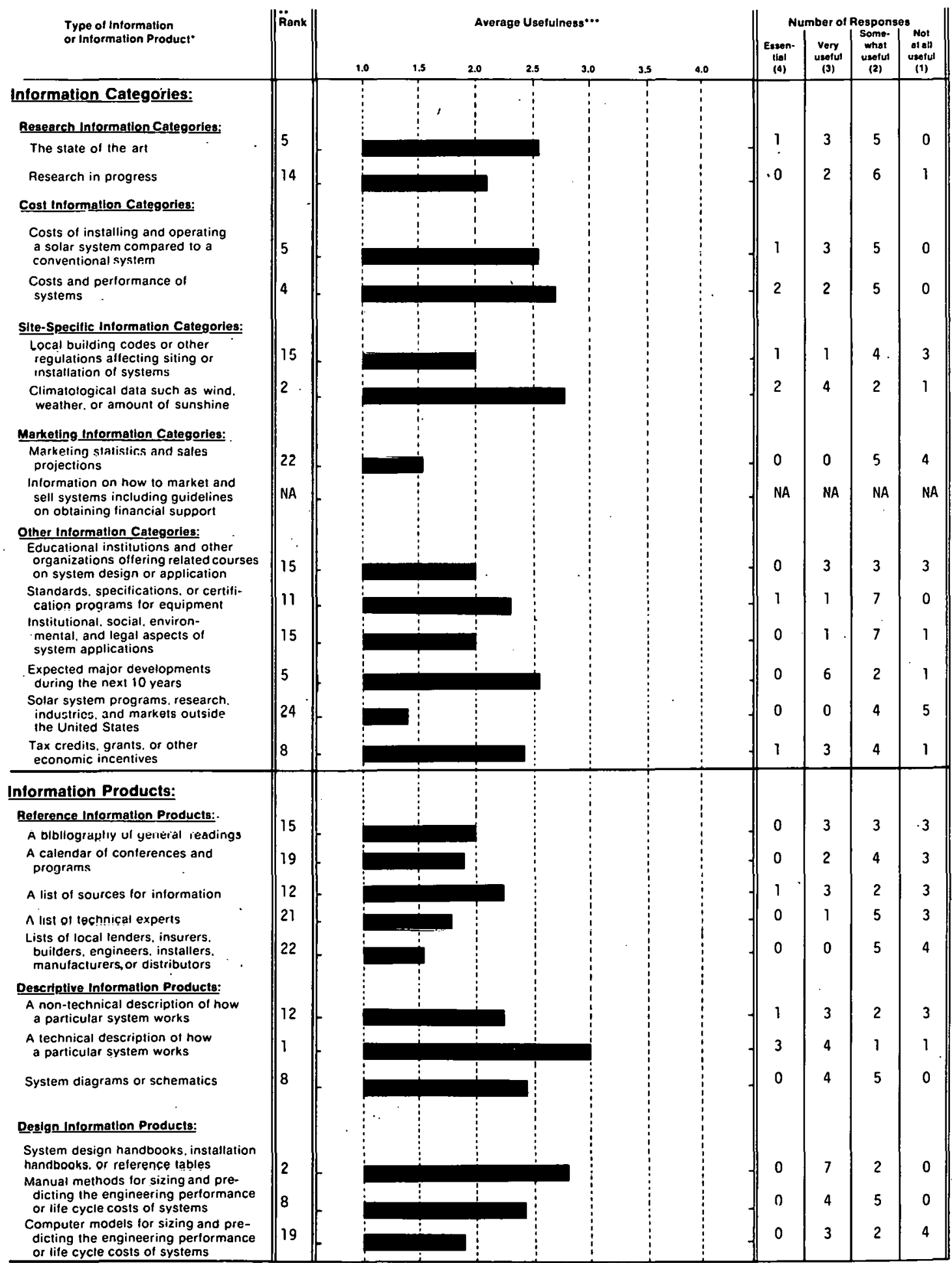

Each sample frame of users was questioned on information and intormation products in the context of their specific lechnology. For example. biomass sample lrames were

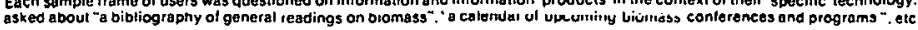
Rank-Each intormation product was assigned a rank Dased on average usefulness. Thus. the product with the highost avorage usefulness was essigned ine rank of ${ }^{-1}$ ": ine product with the lowest average uselulness would be ranked "25" where all iterms were asked. II two or more inlormation products were tied lor 2 nd, they were both assigned a " 2 ". The ne $x$

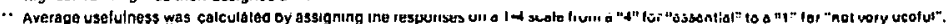


It should be noted that these lower-rated items were not necessarily of no worth to the SHAC Industrial Engineers. For example, 2 of the 9 (22\%) thought "a nontechnical description" was "very useful." Thus, these information categories/products could be useful to some SHAC Industrial Engineers but were of a lower relative priority to the entire group.

Statistical tests were also used to determine whether the SHAC Industrial Engineers rated any of these information items significantly higher (or lower) than they were rated by SHAC HVAC Engineers, IPH Industrial Engineers, IPH Plant Engineers, or All Engineers. Some groups, however, tended to give higher scores in general than did other groups. To compensate for this effect, these statistical tests compared the "relative rating" given by one group to the "relative rating" given by the other groups. The procedure for calculating the relative rating is described in Appendix E. The average overall rating was lower for SHAC Industrial Engineers (2.38) than it was for SHAC HVAC Engineers (2.72) or for All Engineers (2.45) but slightly higher than that of IPH Industrial Engineers (2.31) or IPH Plant Engineers (2.22).

In comparison to All Engineers, SHAC Industrial Engineers rated "system diagrams or schematics "significantly $(P<0.05)$ higher and "lists of sources" significantly $(P<0.05)$ lower.

No statistically significant differences were found between ratings by SHAC Industrial Engineers and by SHAC HVAC Engineers. There was some evidence, however, that SHAC Industrial Engineers were more interested in systems design/descriptive information and less interested in research information and in "lists of sources for information."

Although no comparisons were statistically significant, there was some evidence that SHAC Industrial Engineers were more interested in site-specific and systems design information than were either IPH Plant Engineers or IPH Industrial Engineers.

\subsection{ACQUISITION OF INPORMATION BY RESPONDENTS}

\subsubsection{Use of Selected Information Sources}

SHAC Industrial Engineers were asked which of 21 different potential sources of solar information they had used in the past few years. For this question the respondents were not asked if they had obtained information on SHAC, but instead were asked if they had obtained any solar information from each specific source. Thus, the question sought to determine which information sources were the most familiar to the respondents. The results are shown in Fig. 11-4. For the purpose of comparison, the results for IPH Industrial Engineers appear in Fig. 11-5, and IPH Plant Engineers in Fig. 11-6. Comparative results for SHAC HVAC Engineers and All Engineers are in Figs. 10-3 and 10-4 (Section 10.3.1).

The information sources mentioned most of ten by SHAC Industrial Engineers were:

- Periodicals, newspapers, or magazines;

- Workshops, conferences, or training sessions;

- State energy or solar offices; 
Question \#11. In the past few years, have you obtained any type of solar information from any of the following sources?

Information Sources

Percentage Responding Yes ${ }^{\cdots}$

Public Media:

Radio or TV

Periodicals. newspapers or magazines

Private Solar-Involved Organizations:

Private solar energy or environmental organizations

The local chapter or national headquarters of International Sular Eriergy Society (ISES). including their publications

The local chäpter or national headquarters of Solar Energy

Industries Association (SEIA). Including their jublications

Contacts with Professionals:

An insialler. builder. designer or manufacturer of solar systems

Workshops. conferences or training sessions"

Information Services*:

Your organizational library or a local library

A commercial data base: for example, Lockheed. SDC. BRS

Smithsonian Science Information Exchangc (SSIE)

A Federal library or information center; for example, the National Agriculfural Library or the Environmental Data System.

The Government Printing Office (GPO)

National Techinical Information Service (NTIS

Technical Information Center at Oak Ridge (TIC)

Government Solar-Involved Organizations

Direclly fiurn the U.S. Department of Energy

National Sular Healing \& Cooling Information Center

Regional Solar Energy Centers

State Energy or Solar Offices

Other

Some other state or local government office or publication

A public utility compairy

Sources for this specific sample trame**:

Association of Energy Engineers

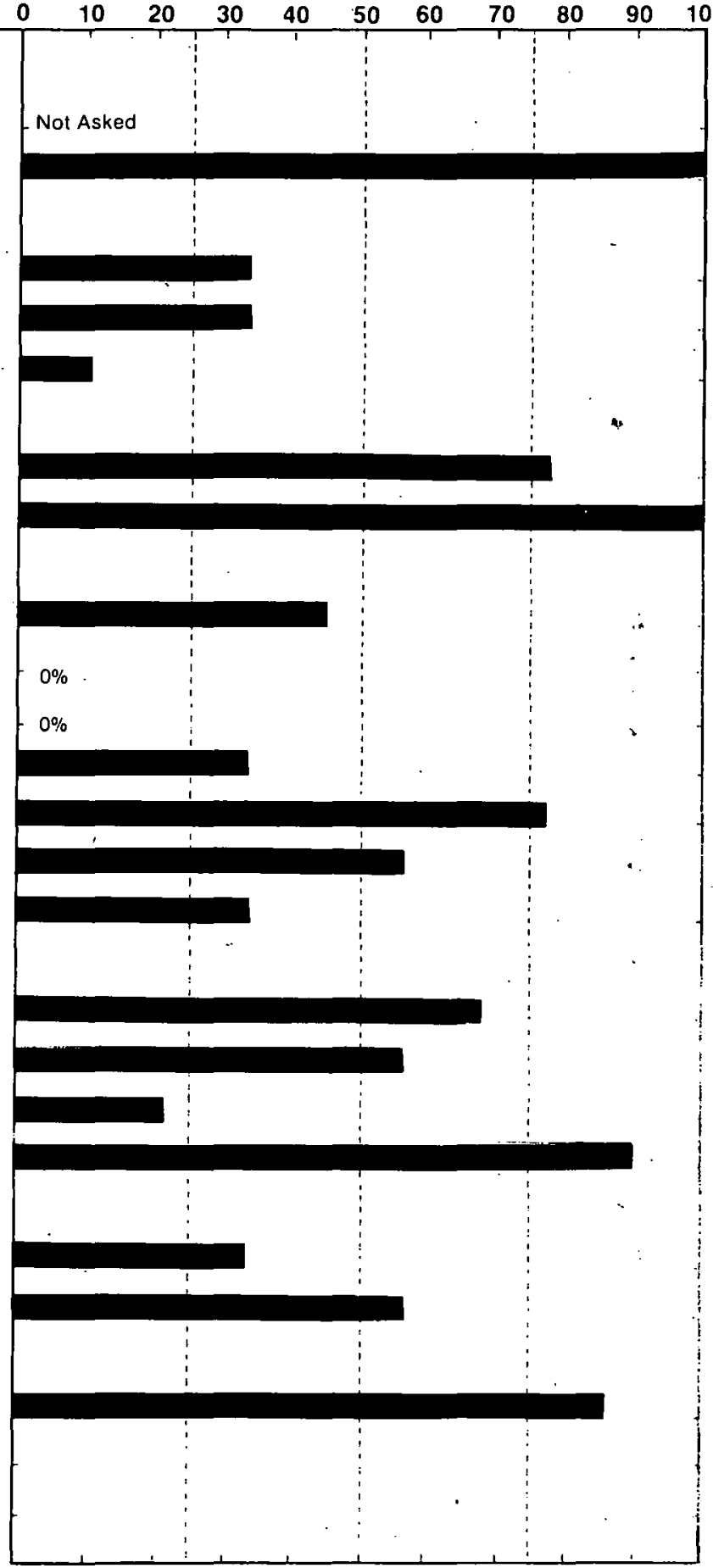

- Services and centers whuse pritrary purpose is to disseminate information

- Some sample frames were questioned about additional information sources which are applicable to their technology. For example the manufacturers of biomass conversion equipment were also asked if they have obtained any type of solar intornation ti om: "the local or rialioital office of the U.S. Department of Agriculturc. including Extension and rorestry."

... These data are based upon a total of 9 respondents.

Figure 11-4.Use of Selected Information Sources: Active Solar Heating and Cooling Industrial Englneers 
Question \#11. In the past few years, have you obtained any type of solar information from any of the following sources?

Information Sources
Percentage Rcsponding Yes “

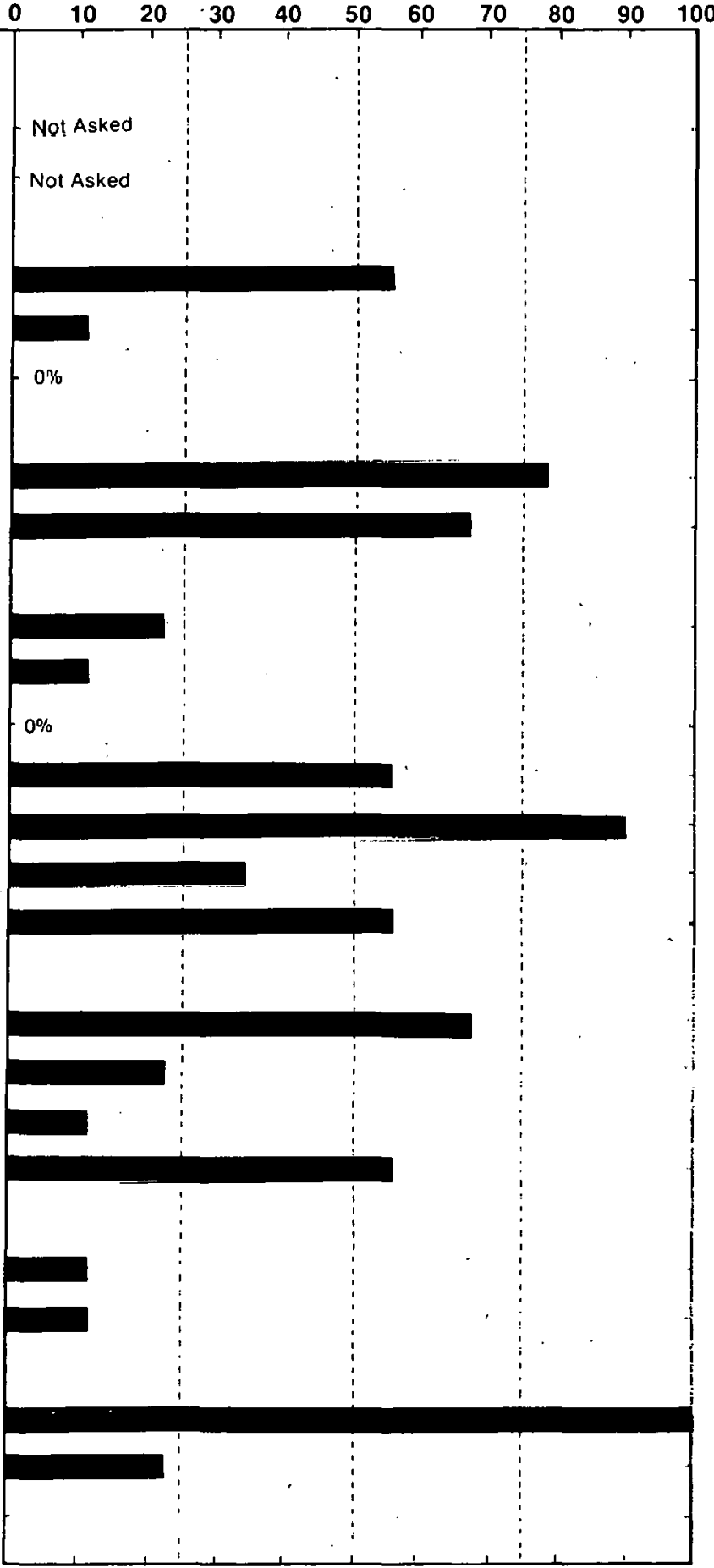

Private solar energy or environmental organizalıons

The local chapter or national headquarters of International Solar Energy Society (ISES). including their publications

The local chapter or national headquarters of Solar Energy industries Association (SE|A). including their publications

Contacts'with Protessionals:

An installer, builder, designer or manufacturer of.solar systems

Workshops. conferences or training sessions

Information Services*:

Your organizational library or a local library

A commercial data base: for example. Lockheed. SDC. BRS

Smithsonian Science Information Exchange (SSIE)

A Federal library or information center: for example the National Agricultural Library or the Environmental Data System

The Government Printing Office (GPO)

National Technical Information Service (NTIS)

Technical Information Center at Oak Ridge (TIC)

Government Solar-Involved Organizations

Directly from the U.S. Department of Energy

Nationat Solar Heating \& Cooling Information Cente

Regional Solar Energy Centers

State Energy or Solar Offices

Other:

Some other state or local government office or publication

A sublic ulility curnpany

Sources ior thie cpocitio jämple trame"":

Association of Energy Engineers

Institute of Electrical and Electronics Engineers

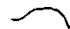

- Services and centers whose primary purpose is to disseminate information.

Some sample frames were questioned about additional information sources which are applicable to their technology. For example. the manufacturers of biomass conversion equipment were also asked it they have obtained any type of solar information from: "the local or national office of the U.S. Department of Agriculture. including Extension and Forestry."

$\because$ These data are based upon a total of 9 respondents.

Figure 11-5. Use of Selected Information Sources: Industrial Process Heat Industrial Engineers 
Question \#11. In the past few years, have you obtained any type of solar information from any of the following sources?

Information Sources

Percentage Responding Yes ${ }^{\cdots}$

Public Media:
Radio or TV
Periodicals. newspapers or magazines
Private Solar-Involved Organizations:
Private solar energy or environmental organizations
The local chapter or national headquarters of International
Solar Energy Society (ISES). including their publications
The local chapter or national headquarters of Solar Energy
Industries Association (SEIA). including their publlcatlons
Contacts with Prolessionals:

An installer, builder. designer or manutacturer of solar systems

Workshops. curferences or training sessions

Intormation Services*:

Your organizational lıbrary or a lócal library

A conımercial data base: for example. Lockheed.'SOC. BRS

Smithsonian Science Iniformaliơn Exchange (SSIE)

A Federal library or information center: for example. the National Agricultural Library or the Environmental Data System

The Government Printıng Office (GPO)

National Technical Information Service (NTIS)

Technical Information Center at Oak Ridge (TIC)

Government Solar-Involved Organizations

Directly from the U.S. Department of Energy

National Sciar Heating \& Cooling Information Center

Regional Solar Energy Centers

State Eneigy or Solar Offices

Other:

Some other state or local government office or publication

A public utility company

Sources for this specitic sample frame**:

Association of Energy Engineers

Institute of Electrical and Electronics Engineers

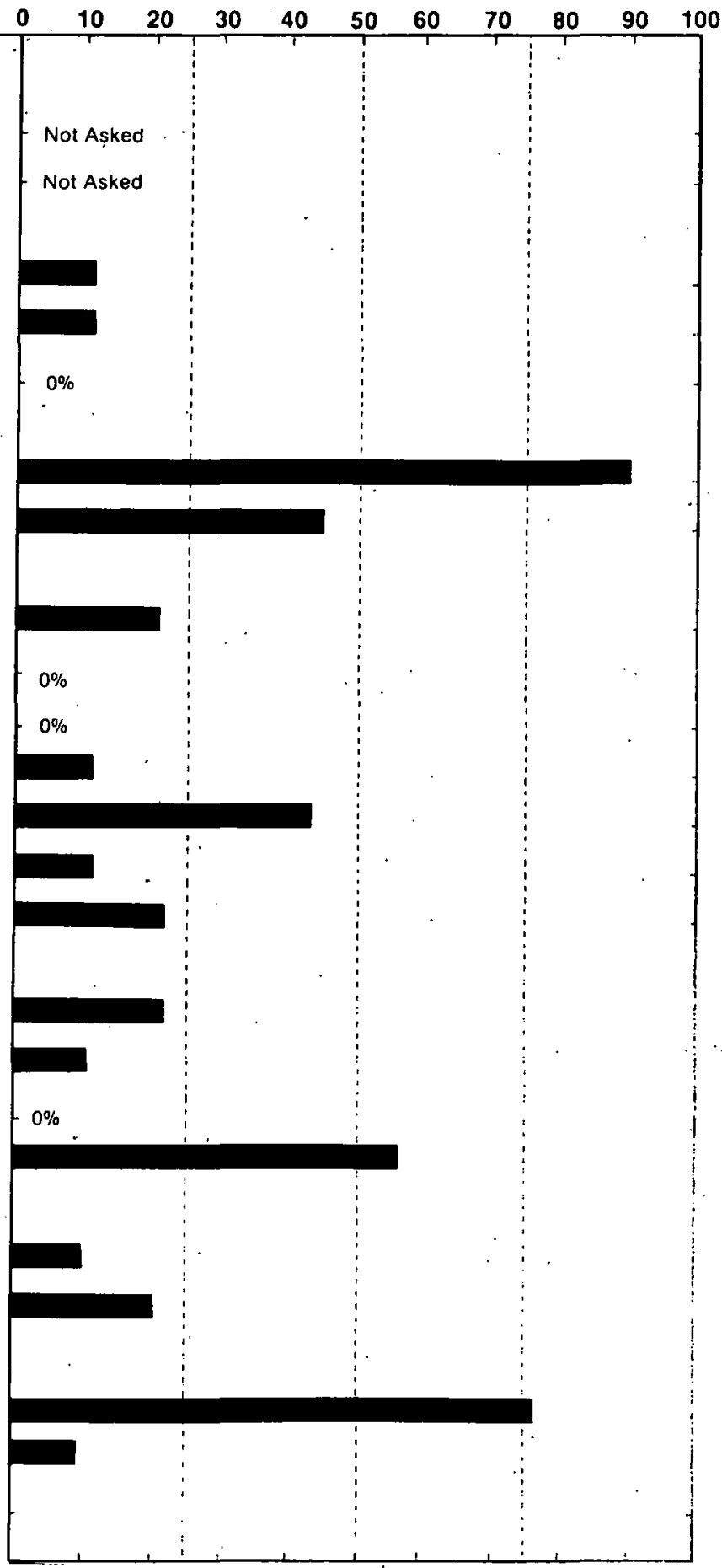

Services and centers whose primary purpose is to disseminale infurmation.

Some sample frames were questioned about additional information sources which are applicable to their technology. For example. the manufacturers of hinmass ronversinn equipment were also asked if they have obtained any type of solar intormatıon from: "Ihe local or nalional office of the U.S. Deparlmerit ol Agriculture. including Extension and Forestry."

... These data are hase. upon a total of 9 respondents.

Figure 11-6.Use of Selected Information Sources: Industrial Process Heat Plant Engineers 
- Association of Energy Engineers (AEE);

- An installer, builder, designer, or manufacturer; and

- The Government Printing Office (GPO).

The frequent mentioning of "periodicals, (etc.)," "workshops, (etc.)," "an installer, (etc.)," and GPO was consistent with the results for All Engineers. However, the SHAC HVAC Engineers made less use of "workshops" but mentioned "an organizational ... library" more of ten. Although AEE was mentioned frequently, it must be noted that the sampling procedure for this group consisted of reviewing entries from the AEE Directory, which may easily have biased the results.

The information sources mentioned least often by SHAC Industrial Engineers were:

- A commercial data base,

- 3mitlisuirizu Buience Information Exchänge (SSIE),

- Solar Encrgy Industries Association (SEIA), und

- Regional Solar Energy Centers (RSECs).

These low ratings, as with the high ratings, were quite similar to those of SHAC HVAC Engineers and All Engineers. In general, the two groups of IPH Engineers appeared to make more restricted use of the variety of information sources suggested to them than did the two SHAC Engineer groups.

\subsubsection{Membership in Solar-Interested Organizations}

All of the 9 SHAC Industrial Engineers interviewed were members of a professional, technical, or other organization with an interest in solar energy. These organizations (and the number of times mentioned) included:

- Am erican Insțitute of Industrial Engineers;

- American Institute of Plant Engineers;

- American Society of Heating, Refrigerating and Air Conditioning Engineers (ASHRAE) (2);

- American Society of Mechanical Engineers (ASME);

- AEE (6);

- Consulting Engincers Council;

- Institute of Electrical and Electronics Engineers;

- International Solar Energy Society (ISES), and

- National Society of Professional Engineers (2).

Also mentioned was "American Society of Heating, Ventilating, and Air Conditioning" an organization that could not be verified by the authors. 


\subsubsection{Exposure to Publications on Solar Energy}

During the past 6 months, all 9 of the SHAC Industrial Engineers had read publications which included information on SHAC. The publications they could specify (and the number of times mentioned) included:

- ASHRAE Journal,

- California Energy Resource Commission newsletter,

- Chemical Engineering,

- Consulting Engineer,

- Heating, Piping and Air Conditioning (3),

- ISES publications,

- Plant Engineering (3),

- Solar Age (3),

- Solar Energy (2),

- Solar Engineering (3), and

- Specifying Engineer (3).

Also mentioned by one SHAC Industrial Engineer was a publication on "Heating of Domestic Water;" a title that could not be verified by the authors.

\subsubsection{Use of Special Acquisition Methods}

The respondents were asked whether they had obtained any information (not just SHAC or solar energy) in the past year by computer terminal, by Computer Output Microform (COM), or by other microform (e.g., microfiche, microfilm sheets or rolls). Almost none of the SHAC Industrial Engineers appeared accustomed to using these special acquisition methods. In the past year, only 1 of the 9 (11\%) had used a computer terminal, and no one had used COM, or other microform. A comparison of SHAC Industrial Engineers with SHAC HVAC Engineers shows the latter group to have had more recent experience with all three types of acquisition methods. IPH Industrial and Plant Engineers also tended to be more familiar with using these methods than were the SHAC Industrial Engineers.

\subsection{SUMMARY AND COMMENTS}

Nine industrial engineers involved in SHAC systems were interviewed. Seven of the SHAC Industrial Engineers were employed by engineering firms, one by a university, and one was self employed. Involvement by this group was not exclusively in industrial applications, with three involved in residential domestic hot water or space heating. Of the nine SHAC Industrial Engineers, four were involved in design (three in heating systems and one in collectors), two in consulting activities, one in installation, one in evaluating experimental installations, and one was "waiting for the government to stop fooling around so we can use (active solar heating and cooling)."

The educational level, field of degree earned, year of most recent degree, and years of professional experience of SHAC Industrial Engineers were found to be typical of engineers interviewed in this study. 
SHAC Industrial Engineers gave the highest priority to receiving information on:

- SHAC system diagrams or schematies;

- Manual methods for sizing and predicting performance or costs of SHAC systems;

- SHAC system design handbooks, installation handbooks, or reference tables;

- A technical description of how a particular SHAC system works;

- Climatological data;

- Local building codes or other regulations aff ecting SHAC systems;

- Costs of installing and operating a SHAC system compared to a conventional system;

- Costs and performance of SHAC systems; and

- Tax credits, grants, or other economic incentives for SHAC systems.

They gave low ratings to "solar energy programs, research ... outside the United States," "marketing statistics," "institutional, social . . . aspects," "educational institutions," "a bibliography," and "a nontechnical description."

As such, SHAC Industrial Engineers were interested in three major areas: systems design information, performance and cost-related information (including "tax credits"), and sitespecific information ("climatological data" and "local building codes").

SHAC Industrial Engineers most often received solar information from "periodicals," professional contacts ("workshops, conferences, (etc.)" and "an installer, builder, (etc.)), and GPO, typical of All Engineers. "State energy or solar offices" and AEE were also mentioned quite of ten; however, the results for the latter may have been biased due to the sampling procedure. 


\section{SECTION 12.0}

\section{ACTIVE SOLAR HEATING AND COOLING UTLLTY REPRESENTATIVES}

\subsection{DESCRIPTION OF RESPONDENTS}

\subsubsection{Description of Sample}

This section describes the results of a telephone study to determine the needs of utility representatives involved in active solar heating and cooling (SHAC) for information on SHAC. Nine SHAC Utility Representatives were interviewed.

The sample frame for SHAC Utility Representatives was constructed from four sources. The Electric Utility Solar Energy Activities, 1978 Survey [25] listed contacts at Electric Pow er Research Institute (EPRI) utilities conducting $\mathrm{SH} A \mathrm{C}$ experiments or demonstrations. Solar Energy Utilization: Natural Resource Conservation by the Gas Utility Industry [26 , a booklet put out by the American Gas Association, listed contacts at gas companies involved with SHAC. These companies all had solar installations or demonstration projects, often with gas energy as the backup. The Summaries of the Responses of the Participating Jurisdictions to the Southern Solar Energy Center Planning Project Information Request [12] listed utilities by state. Duplicates with EPRI utilities or Gas Association utilities were eliminated. Utilities which were also involved with wind, solar thermal, or photovoltaics were eliminated. After all adjustments were made, the 9 interview candidates were randomly selected from a sample frame of 135 names.

Respondents. In making the telephone calls to contact the randomly selected interview candidates, it sometimes occurred that the person could not be reached. In this event another randomly selected name was substituted for the original name. When individuals were contacted it was verified that they really were affiliated with a utility which had experimented with SHAC and that they would be needing information on SHAC within the next year. If they were not both involved and needing information, they were asked if they could refer the interviewer to someone else in their organization who would be an appropriate respondent. If such a referral was made, a call was then made to this new candidate; if no intraorganizational referral was made, a new candidate was randomly selected from the sample frame. The results of this process may be seen in Table 12-1.

Comparisons. For additional insight into the information needs and the information habits of these SHAC Utility Representatives, results from this group are compared to the results from All Solar Utility Representatives (including photovoltaics, wind, solar thermal electric power, and solar heating and cooling) and from Nonsolar Utility Representatives. In performing any statistical comparisons; the totals for SHAC Utility Representatives have been subtracted from the totals for All Solar Utility Representatives. The data for SHAC Utility Representatives, All Solar Utility Representatives, and Nonsolar Utility Representatives can be found in Appendix F. 
Table 12-1. COMPLETION OF INTERVIEWS: ACTIVE SOLAR HEATING AND COOLNG UTHITY REPRESENTATTVES

Event

Number of

Candidates

Interview completed with initial candidate

5

Interview completed with referral candidate

4

Refusal or candidate termination

0

Contact attempted: could not reach candidate within three

attempts or before interviews were completed

Subtotal

Contact attempted: invalid candidate (e.g., inappropriate

field of interest, no telephone)

TOTAL

Sample frame error rate rercent) $^{\mathrm{a}}$ (Percion

Completion rate ${ }^{b}$ (Percent)

${ }_{\text {Invalid candidates divided by TOTAL }}$

${ }^{b}$ Completed interviews divided by Subtotal

\subsubsection{Current Status of Respondents}

Role. SHAC-related activities in which the SHAC. Ittility Representatives were involvcd inclüded: installing a unit in a vocational technical college for training purposes; operating an office building with $100 \%$ solar heat, $60 \%$ hot water, and solar air conditioning; monitoring a solar hot water heater in a residential home on an experimental basis; conducting research on the practical applications of solar space heating and solar hot water heating; electric meter reading on solar homes; "subm etering"; test metering in residential homes; calculating special rate structures for 12 solar heated homes; promoting SHAC; distributing technical information through various contact people; and offering $\$ 200$ subsidies to schools that set up and operate SHAC systems. One utility represcntative also mentioned being involved in the development of a solar preheater, including sponsoring the setup of solar preheaters in 16 homes for local demonstrations and involvement in designing passive solar mobile homes.

Involvement. Three of the 9 (33\%) SHAC Utility Representatives felt that they were "very involved" in SHAC, 3 were "moderately involved," and 3 "slightly involved." A statistical comparison with results from All Solar Utility Representatives and Nonsolar Utility Representatives showed no significant differences.

Informedness. In the SHAC Utility group, 3 of the 9 (33\%) respondents felt they were "very informed," and the remaining 6 were "moderately informed." . Compared to the results from other utilities surveyed, there were no significant differences.

Need for Information. All respondents indicated they would need information on SHAC on the job during the next year. Six of the $9(67 \%)$ SHAC Utility Representatives also needed information on SHAC outside the job. Comparatively, this off-the-job information need was slightly higher than for All Solar Utility Representatives (13 of the 27 or 48\%), but similar to that of Nonsolar Utility Representatives (5 of the 8 or $63 \%$ ). 


\subsubsection{Background of Respondents}

Seven of the 9 SHAC Utility Representatives held bachelor's degrees, and 2 held master's degrees. Five of the respondents received their most recent degree 20-30 years ago, 2 from 15-20 years ago, and 2 from 5-10 years ago. Three of the degrees were in engineering; the other 6 were in agriculture, geology, science, marketing, business, and journalism. In the other utility groups studied, engineering degrees were predominant with between $66 \%-89 \%$ earning such a degree.

In their current profession, 4 mentioned that they were in management. Other professions mentioned included: engineer, communicator, consultant, professor, and public relations. Six of the 9 had been in their current profession for over 10 years, 2 for 6-10 years, and 1 for 3-5 years. No significant differences were found in levels of current experience among representatives of SHAC utilities and the other utilities.

\subsection{INFORMATION NEEDS OF RESPONDENTS}

\subsubsection{Technical Areas}

SHAC Utility Representatives were asked to choose those areas in which they were "particularly interested in obtaining information" from a list of selected technical areas of SHAC. All 9 were interested in "space heating," 7 of 9 (78\%) in "water heating," and 6 of the $9(67 \%)$ in "space cooling" and "hybrid systems," while "swimming pool heating" had only 3 of the 9 (33\%) interested.

One SHAC Utility Representative volunteered that he was also interested in industrial process heat.

\subsubsection{Types of Information}

SHAC Utility Representatives were asked to name the information about SHAC that was important for them to obtain. All 9 volunteered one or more items of information which they considered important. Three felt cost information was important, including equipment cost, operation cost, and cost justification. Other topies included: where to get information, new developments, new products and ideas, methods to make systems the most cost-effective, applications information, tax incentives, promotional information, system design schemes, and information on the effectiveness of different technologies.

One SHAC Utility Representative volunteered that he needed but was unable to get information on the specifics of landmark installations (in their area).

Choice Between Specific Needs. A list of 11 types of SHAC information products and 13 types of SHAC information categories was read to each respondent. Each respondent described the usefulness of each particular item by assigning it a value of "essential," "very useful," somewhat useful," or "not at all useful." The results are given in Fig. 12-1. For the purpose of comparison, the results for All Solar Utility Representatives (Fig. 12-2) and Nonsolar. Utility Representatives (Fig. 12-3) are also included. 
Question \#8. I will read a list of potential information or information products on solar systems. For each, please lell me how useful that information would be to you. Would the following be: essential, very useful, - somewhat useful, or nol at all useful?

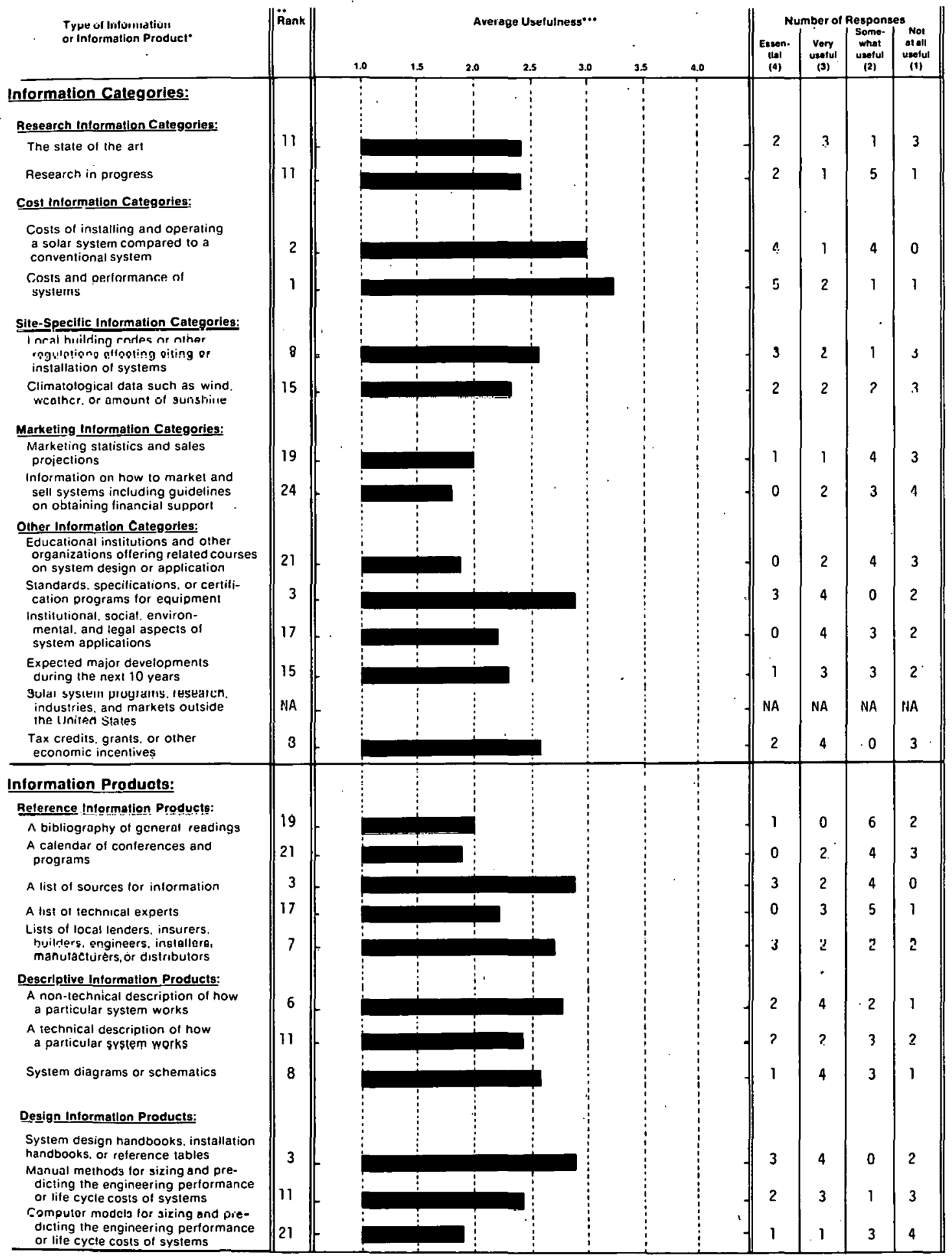

- Each sample frame of users was questioned on inlormation and information products in the context of their specific technology. For example. biomass sample trames were

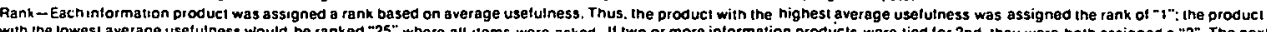
with ine lowesi average usetulness would
nignest renking was then assigned a $-4:$

Average usefulness was calculated by assigning the responses on a 1-4 scale trom a "4" for "essential" to a "1" for "not very usetul"

Figure 12-1. Usefulness of Selected Information Items: Active Solar Heating and Cooling Utility Representatives 
Question \#8. I will read a list of potential information or information products on solar systems. For each, please tell me how useful that information would be to you. Would the following be: essential, very useful, somewhat useful, or not at all useful?

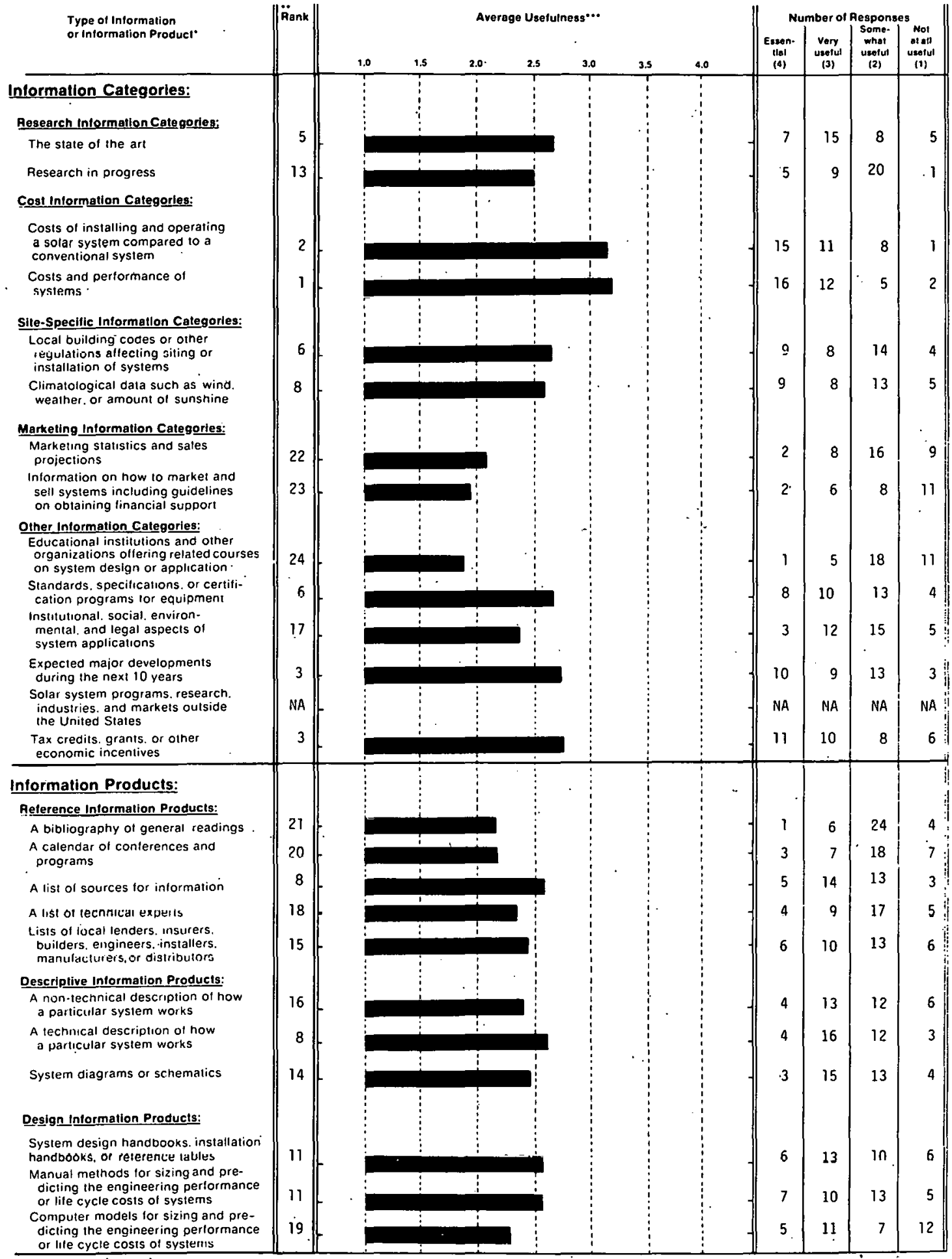

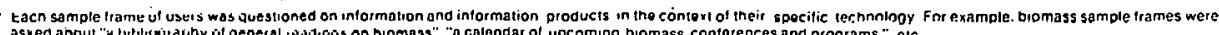

- Ranh - Each nntormalion product was assigned a rank based on average usetulness. Thus. The product with the highest average usefutness was assigned ithe rank o! " 1 ". the product with ine lowest average uselulness would
highur" ranh ing was then as sipners a "4"

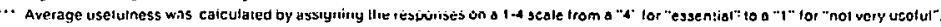

Figure 12-2. Usefulness of Selected Information Items: All Solar Utility Representatives 
Question \#8. I will read a list of potential information or information products on solar systems. For each, please tell me how useful that information would be to you. Would the following be: essential, very useful, somewhat useful, or not at all usseful?

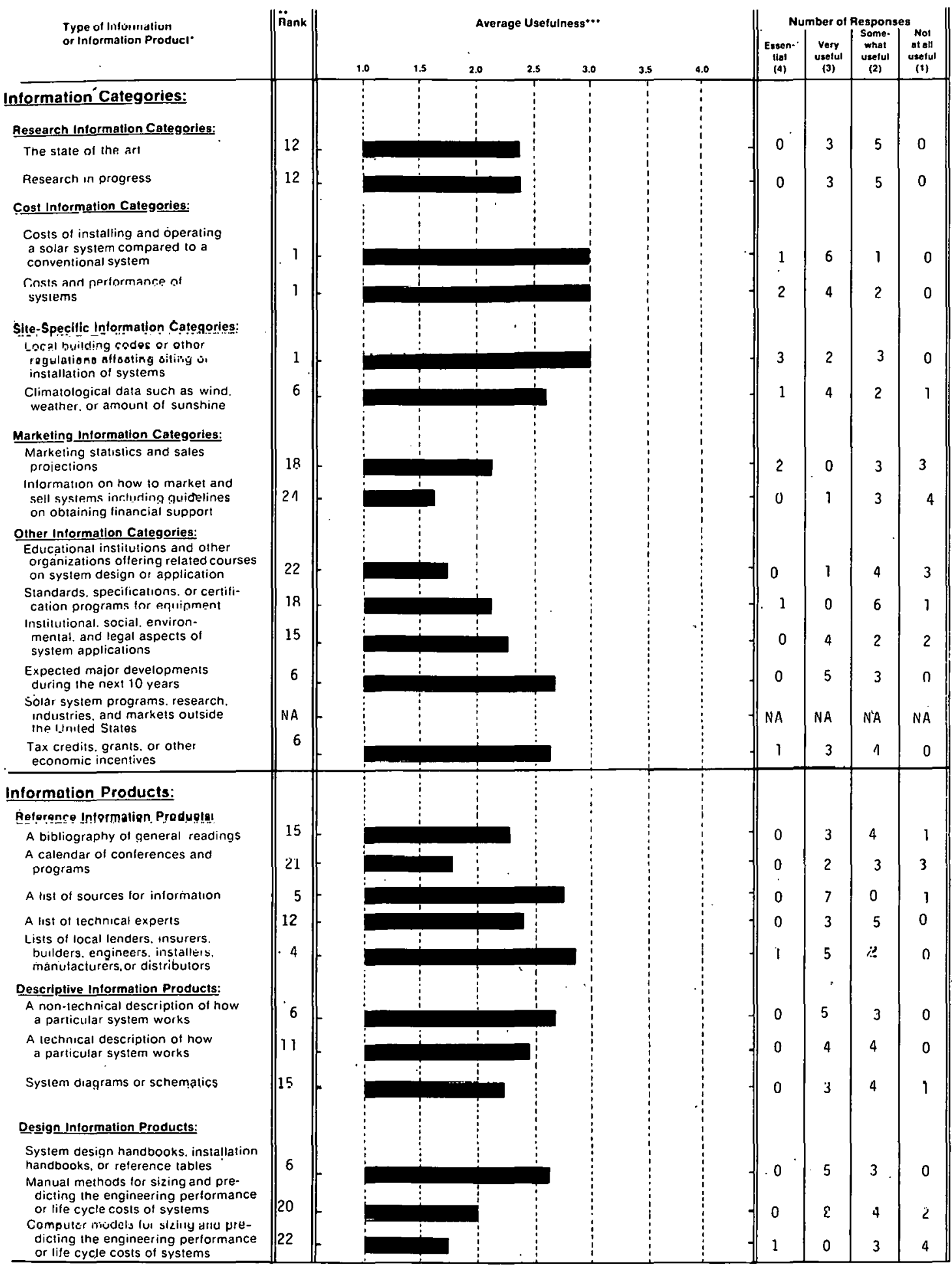

Each sample lrame ol users was questioned on intormation and inlormation products in the context of their specitic technology. For example. biomass sample lrames were asked abouls mibiography or ger with the rowest average usetutness wout be nighesi ranking was then assigned a "4:

Average usetulness was calculated by assigning ine responses on a 1-4 scale lrom a "4" lor "essential" to a " " " lor "not very useful"

Figure 12-3. Usefulness of Selected Information Items: Non-Solar Utility Representatives 
SHAC Utility Representatives selected the cost information category as most important. The seven top-rated information categories/products were:

- Costs and performance of systems;

- Costs of installing and operating a SHAC system compared to a conventional system;

- Standards, specifications, or certification programs;

- Lists of sources for information;

- Design handbooks, installation handbooks, or reference tables;

- A nontechnical description of how a particular system works; and

- Lists of local lenders, insurers, builders, engineers, installers, manuf acturers, or distributors.

SHAC Utility Representatives assigned the lowest relative ratings to:

- How to market and sell solar systems,

- Educational institutions and other organizations offering courses,

- Calendars of conferences and programs,

- Computer models for sizing and predicting performance or costs,

- Marketing statistics and sales projections, and

- A bibliography of general readings.

Statistical tests indicated all seven of the top categories/products were rated significantly $(P<0.05)$ higher than were the six lowest-rated items.

It should be noted that these lower-rated items are not necessarily of no worth to the SHAC Utility Representatives. For example, 2 of the 9 (22\%) thought "computer models" was either "essential" or "very useful." Thus, these information categories/products could be useful to some SHAC Utility Representatives but were of a lower relative priority to the entire group.

Statistical tests were also used to determine whether the SHAC Utility Representatives rated any of these information items significantly higher (or lower) than they were rated by the All Solar Utility Representatives or the Nonsolar Utility Representatives. Some groups, however, tended to give higher scores in general than did other groups. To compensate for this effect, these statistical tests compared the "relative rating" given by one group to the "relative rating" given by the other groups. The procedure for calculating the relative rating is described in Appendix E. The average overall rating SHAC Utility Representatives gave to all items was 2.43; for All Solar Utility Representatives it wus 2.49; and for Nonsolar Utility Rcprceentatives, 2.39.

A comparison of SHAC Utility Representatives to All Solar Utility Representatives and to Nonsolar Utility Representatives showed no significant differences in ratings of the information products and information categories. All three groups rated the cost information categories highest and the marketing information categories the lowest. There was evidence, however, that SHAC Utility Representatives rated "lists of sources for information," lists of members of the local infrastructure, and systems design informa- 
tion higher than did All Solar Utility Representatives, but "expected major developments" and "climatological data" much lower. Compared to Nonsolar Utility Representatives, SHAC Utility Representatives gave higher ratings to "standards" and lower ratings again to "expected major developments" and to "climatological data."

\subsection{ACQUISITION OF INFORMATION BY RESPONDENTS}

\subsubsection{Use of Selected Information Sources}

SHAC Utility Representatives were asked which of 20 different potential sources of solar information they had used in the past few years. For this question the respondents were not asked if they had obtained information on SHAC, but instead were asked if they had obtained any solar information from each specific source. Thus, the question sought to determine which information sources were the most familiar to the respondents. The results are shown in Fig. 12-4. For the purpose of comparison, the results for All Solar Utility Representatives and Nonsolar Utility Representatives are shown in Figs. 12-5 and $12-6$, respectively.

The information sources mentioned most of ten by SHAC Utility Representatives were:

- Periodicals, newspapers, or magazines;

- An installer, builder, designer, or manufacturer;

- The Government Printing Office (GPO);

- EPRI;

- Workshops, conferences, or training sessions;

- An organizational library or a local library;

- State energy or solar offices; and

- A public utility company (other than your employer).

In comparison, more than half of All Solar Utility Representatives also mentioned the above sources. Compared to the Nonsolar Utility group, how ever, significantly $(P<0.05)$ more SHAC Utility Representatives (5 or $56 \%$ ) used the services of "a federal library or information center" than did the Nonsolar Utility group (0\%). Not surprisingly, the use of government solar-involved organizations was also much higher for the SHAC Utility group than for the Nonsolar Utility group.

The information sources mentioned least of ten by SHAC Utility Representatives were:

- A commercial data base,

- International Solar Energy Society (ISES),

- Smithsonian Science Information Exchange (SSIE),

- Solar Energy Industries Association, and

- Some other state or local government office or publications. 
Question \#11. In the past few years, have you obtained any type of solar information from any of the following sources?

\section{Information Sources}

Public Media:
Radio or TV
Periodicals. newspapers or magazines
Private Solar-Involved Organizations:
Private solar energy or environmental organizations
The local chapter or national headquarters of International
Solar Energy Society (ISES). including their publications
i The Iocal chapter or national headquarters of Solar Energy
Industries Association (SEIA), including their publications
Contacts with Professionals:

An installer, builder. designer or manufacturer of solar systerns

Workshops. conferences or training sessions

Information Services:

Your organizational library or a local library

- A commercial data base: for example. Lockheed. SDC. BRS

Smithsonian Science Information Exchange (SSIE)

A Federal library or information center: for example. the National Agricultural Library or the Environmental Data System

The Government Printing Office (GPO)

National Technical Information Service (NTIS)

Technica! Information Center at Oak Ridge (TIC)

\section{Government Solar:Involved Organizations}

Directly iris the U.S. Department of Energy

National Solar Heating \& Cooling Informatıon Center

Regional Solar Energy Centers

State Energy or Solar Offices

Other:

Some other state or local government office or publication

A public utility company

Sources for this specific sample frame **:

Electric Power Research Institute
Percentage Responding Yes

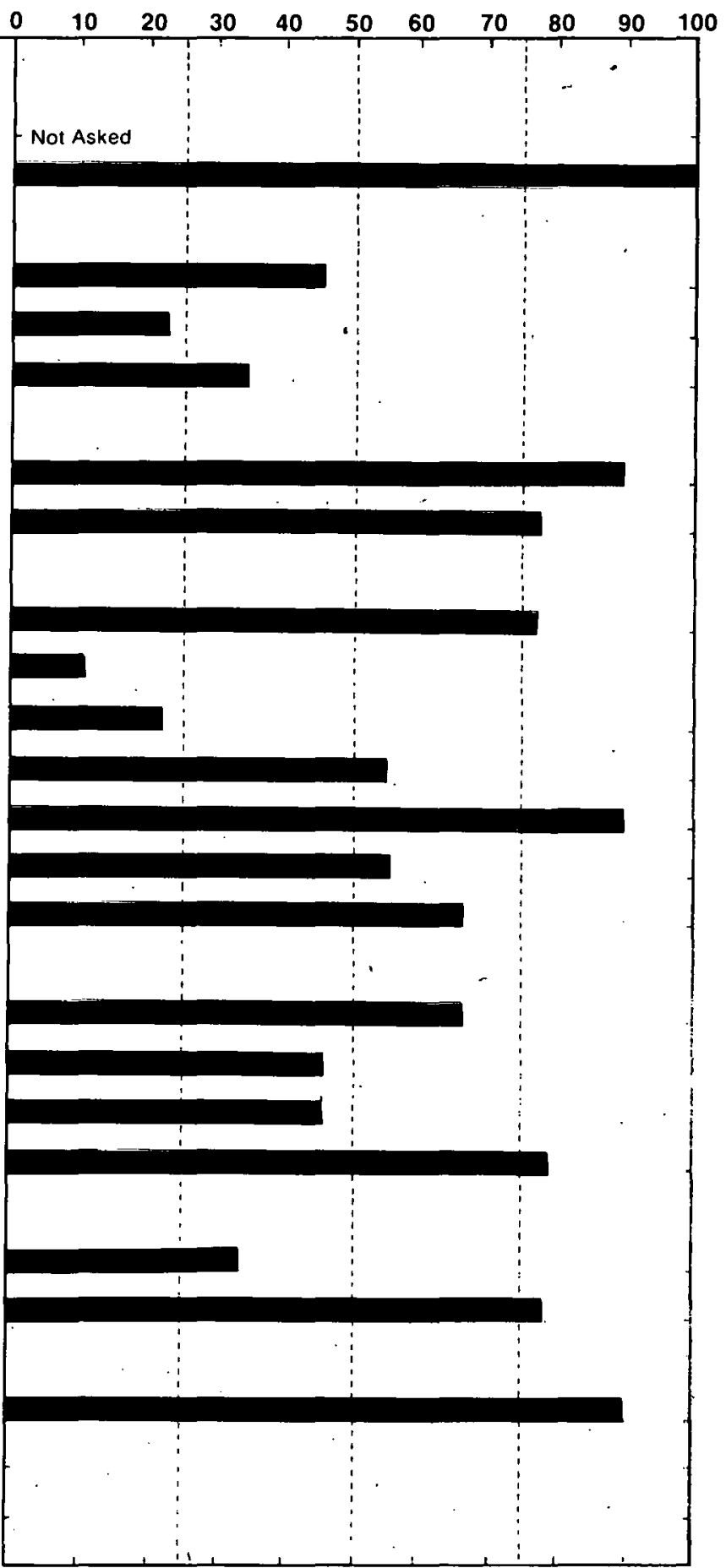

- Services and centers whose primary purpose is 10 disseminate information.

Some sample frames were questioned about additional information sources which are applicable to their technology. For example. the manufacturers of biomass conversion equipment were also asked if they have obtained any type of solar information from: "the local or national office of the U.S. Department of Agriculture. including Extension and Forestry:"

... These data are based upon a lotal ul 9 respun iderils.

Figure 12-4.Use of, Selected Information Sources: Active Solar Heating and Cooling Utility Representatives 
Question \#11. In the past few years, have you obtained any type of solar information from any of the following sources?

\section{Information Sources}

Percentage Responding Yes $\cdots$

\section{Public Media:}

Radio or Ty

Periodicals. newspapers or magazines

\section{Private Solar-involved Organizations:}

Private solar energy or environmental organizations

I he local chapter or national headquarters of Internationa Solar Energy Society (ISES). including their publications

The local chapter or national headquarters of Solar Enerqy Industries Association (SEIA), including their publications Contacts with Professionals:

An installer. builder. designer or manufacturer of solar systems

Workshops, conferences or training sessions

Information Services":

Your organizational library or a local library

A commercial data base: for example. Lockheed. SDC. BRS

Smithsonian Science Information Exchange (SSIE)

A Federal library or information center: for example. the National Agricultural Library or the Environmental Data System

The Government Printing Office (GPO)

National Technical Information Service (NTIS)

Technical Information Center at Oak Ridge (TIC)

\section{Government Solar-Involved Organizatlons}

Directly from the U.S. Department of Energy

National Solar Heating \& Cooling Information Center

Regional Solar Energy Centers

State Energy or Solar Offices

Other:

Some other state or local government office or publication

A pubilic utility company

Sources for this specitic sample frame**:

Electric Power Research Institute

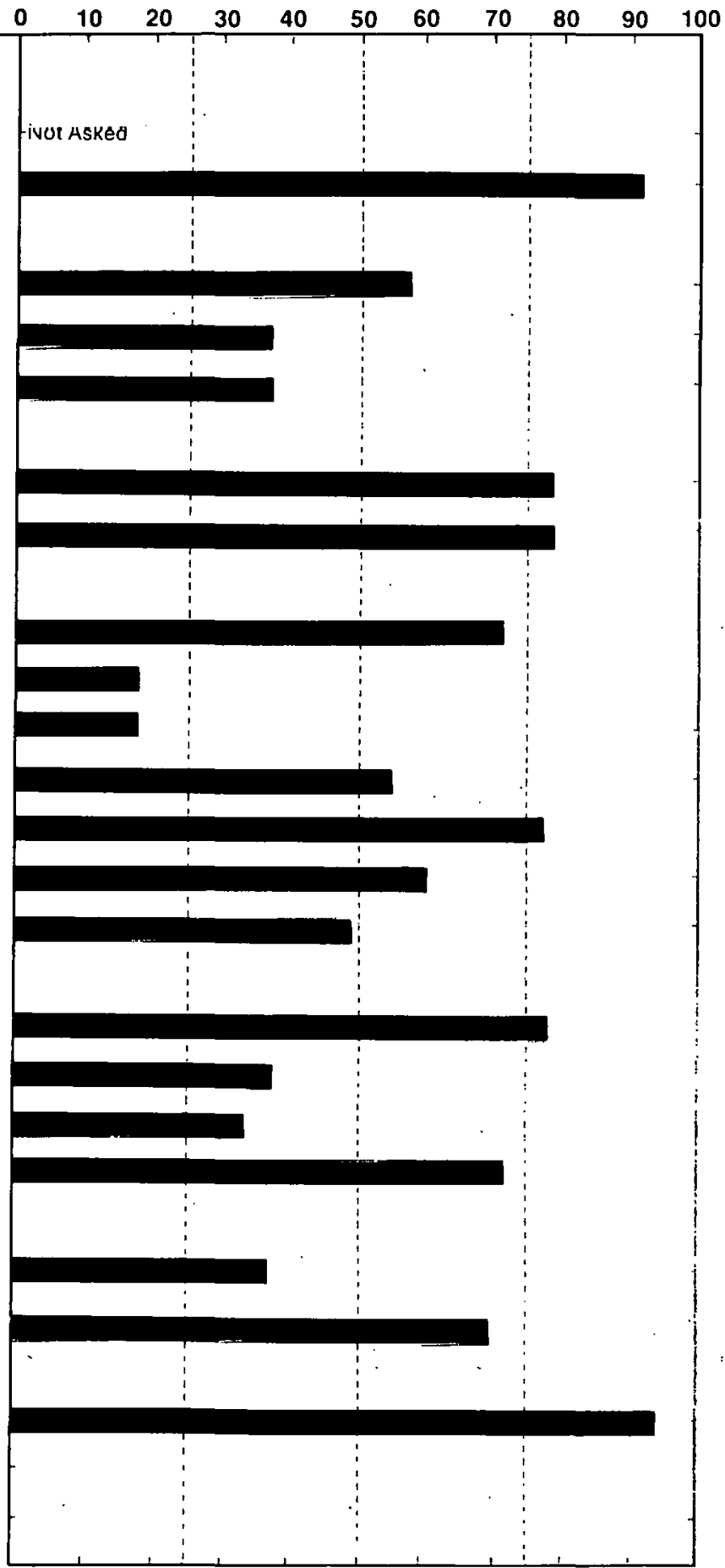

Services and centers whose primary purpose is to disseminate information.

- Some sample frames were questioned about additional information sources which are applicable to their technology. For example. the manufacturers of biomass conversion equipment were also asked If they have obtained any type of solar intormatıon trom: "the Iocal or national office of the U.S. Department of Agriculture including Extension and Forestry."

*.. These data are based upon a total of 35 respondents.

Figure 12-5. Use of Selected Information Sources: All Solar Utility Representatives 
Question \#11. In the past few years, have you obtained any type of solar information from any of the following sources?

Information Sources
Percentage Responding Yes $\cdots$

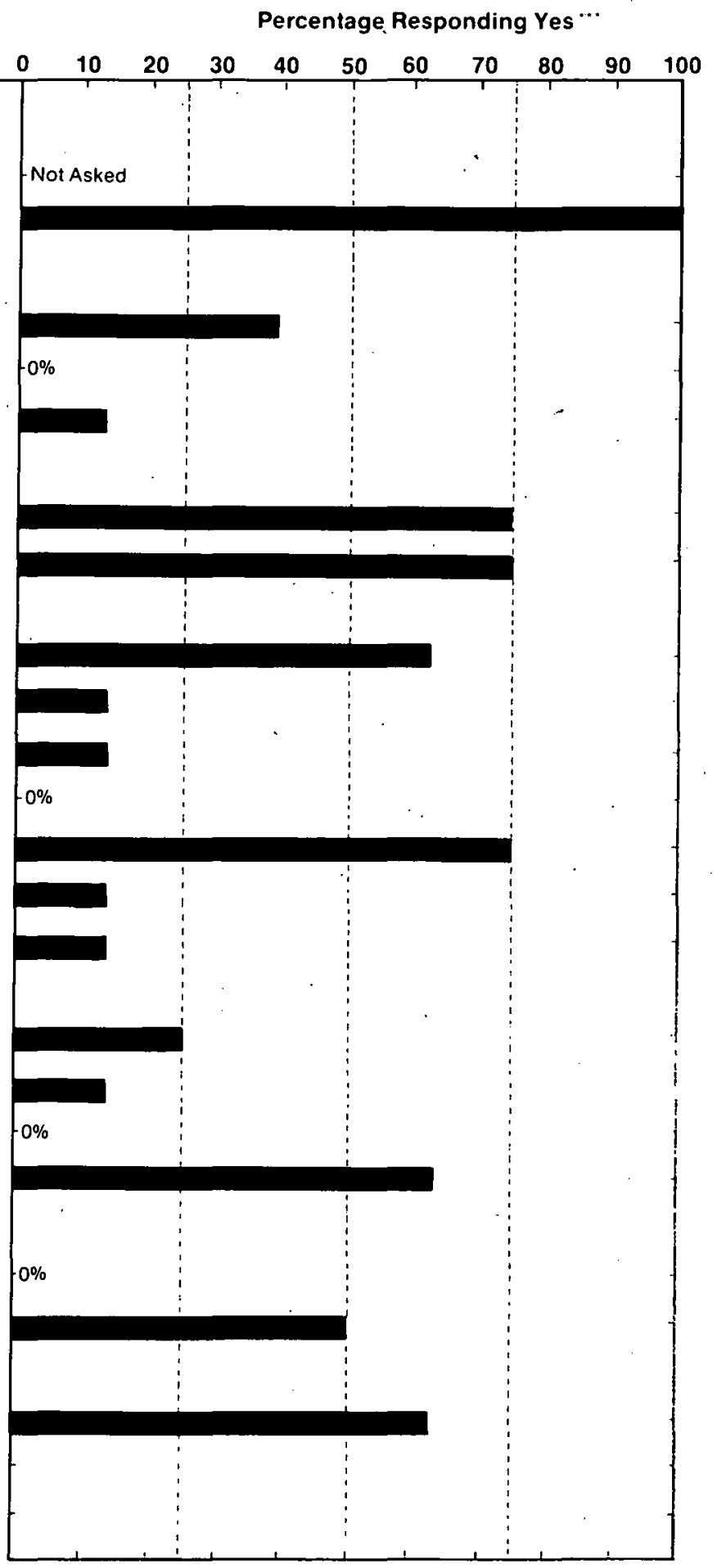

Private solar energy or environmental organizations

The local chapter or national headquarters of International Solar Energy Society (ISES), includirig their publications

The local chapter or national headquarters of Solar Energy Industries Association (SEIA), including theit publications

Contacts with Professionals:

An installer. builder. designer or manufacturer of solar systems

Workshiops. conferences or training sessions.

Information Services*:

Your organizational library or a local library

A commercial data base: for example. Lockheed. SDC. BRS

Smithsurlian Scierice Information Exchange (SSIE)

A Federal library or information center: for example. the National Agricultural Library or the Environmental Data System

The Government Printing Office (GPO)

Nationai Technicai Information Service (NTIS)

Technical Information Center at Oak Ridge (TIC)

Government Solar-Involved Organizations

Directly from the U.S. Department of Energy

National Solar Heating \& Cuoling lifformation Centel

Regional Solar Energy Centers

State [neigy or Solar Offices

Other

Some other state or local government office or publication

A public utitity company

Sources for this specific sample frame**:

Electric Power Research Institute (EPRI)

- Services and centers whuse primary juipose is to disseminate information.

- Some sample frames were questioned about additional information sources which are applicable to their technology. For example. the manifacturers of biomass conversion equipment were also asked it they have obtained any type of solar information from: "the local or national uflice of the U.G. Department of Agriculture. including Extension and Fnirestry"

*. These data are hased upon a total of 8 respondents

Figure 12-6. Use of Selected Information Sources: Non-Solar Utility Representatives 


\subsubsection{Membership in Solar-Interested Organizations}

Eight of the 9 SHAC Utility Representatives interviewed were members of a professional, technical, or other organization with an interest in solar energy. The organizations (and the number of times mentioned) included:

- American Society of Heating, Refrigerating and Air Conditioning Engineers (ASHRAE);

- American Wind Energy Association;

- Association of Energy Engineers;

- Chattanooga Engineer's Club;

- Electric League of Chattanooga;

- EF KI (z);

- Institute of Electrical and Electronics Engineers;

- ISES;

- Minnesota Society of Professional Engineers;

- Missouri Farm Electrification Council; and

- Missouri Valley Electric Association.

\subsubsection{Exposure to Publications on Solar Energy}

During the past 6 months, all 9 SHAC Utility Representatives had read publications which included information on SHAC. The publications they could specify (and the number of times mentioned) included:

- $\Lambda$ ir Conditioning, Ileating and Refrigeration News (2);

- American Wind Energy Association (AWEA) publications;

- U.S. Department of Energy (DOE) publications;

- Energy User News (2);

- Engineering News Record;

- Government publications (i.e., federal, brochures, periodicals) (3);

- Industry;

- ISES publications;

- Kentucky Energy Office publications;

- Rural Electrification Magazine;

- Solar Age;

- Solar Energy;

- Solar Energy Intelligence Report; and

- Wind Power Digest. 
One respondent also mentioned "utility brochures," a publication that could not be further specified by the authors.

\subsubsection{Use of Special Acquisition Methods}

The respondents were asked whether they had obtained any information (not just SHAC or solar energy) in the past year by computer terminal; by Computer Output Microform (COM), or by other microf orm (e.g., microfiche, microfilm sheets or rolls). Few of the SHAC Utility Representatives appeared accustomed to using these special acquisition methods. In the past year, 4 of the 9 (44\%) had used a computer terminal, 1 of the 9 (11\%) had used COM, and 3 of the 9 (33\%) had used other microform. Use of these methods was also minimal for all other Utility Representatives studied-Solar and Nonsolar.

\subsection{SUMMARY AND COMMENTS}

Nine representatives of utilities involved in SHAC were interviewed. Four of the nine respondents were active in SHAC technology through system design, development, and/or installation. One utility had installed a SHAC system(s) for training purposes, one for experimentation, one for local demonstrations, and one was operating an office building with $100 \%$ solar heat and $60 \%$ solar hot water/solar air conditioning. Two were involved in monitoring meters, and one was involved in establishing a special rate structure for solar heated homes. Of the remaining two respondents, one was promoting SHAC as an alternative to save energy, and one was researching the practical applications of solar space heating and solar water heating. The level of involvement, degree of informedness, and educational level were typical of Utility Representatives interviewed in this study. The fields of degrees earned; however, showed the other Solar and Nonsolar Utility groups to have slightly more degrees in engineering than did the SHAC Utility group.

SHAC Utility Representatives gave the highest priority to receiving information on:

- Costs and performance of SHAC systems;

- Costs of installing and operating a SHAC system compared to a conventional system;

- Standards, specifications, or certification programs for SHAC systems;

- Lists of sources for information on SHAC;

- SHAC systems design handbooks, installation handbooks, or reference tables;

- A nontechnical description of how a particular SHAC system works; and

- Lists of Ineal lenders, insurers, builders, engineers, installers, manufacturers, or distributors for SHAC systems.

They gave low ratings to "how to market," "educational institutions," "calendars of conferences," "computer models," "marketing statistics," and "a bibliography."

The resulting picture of the SHAC Utility Representative was similar to that of representatives of All Utilities-Solar and Nonsolar. They were most interested in cost information and "standards, specifications," and least interested in marketing information, 
"educational institutions," "calendars of conferences," "computer models," and "a bibliography." An area in which SHAC Utility Representatives appeared to be more interested than All Solar Utility Representives was design information, with less interest in information on the progress of SHAC.

SHAC Utility Representatives most often received information from "periodicals," "an installer, builder, (etc.)," GPO, EPRI, "workshops, conferences," "an organizational ... library," state energy or solar offices, and "a public utility company (other than your employer)." They also received solar information through membership in engineering organizations. The high ratings given to both EPRI and "a public utility" suggests that a significant degree of their information transfer is intra-industry. 
SECTION 13.0

\section{ACTIVE SOLAR HEATING AND COOLING EDUCATORS}

\subsection{DESCRIPTION OF RESPONDENTS}

\subsubsection{Description of Sample}

This section describes the results of a telephone study to determine the needs of educators for information on active solar heating and cooling (SHAC). Nine SHAC Educators were interviewed.

The sample frame for SHAC Educators was constructed by searching the Solar Energy Information Data Base (SEIDB) Education Data Base [27]. Over 375 schools listed courses that included SHAC information. Instructors were identified for each course. Only instructors of supposedly advanced-level courses were used. Instructors who also appeared in education sample frames for other technologies were eliminated. In many cases course descriptions nam ed several technologies, and it was necessary to make some arbitrary decisions about in which sample frame to place the course instructor. After all adjustments were made, the 9 interview candidates were randomly selected from a sample frame of 150 names.

Respondents. In making the telephone calls to contact the randomly selected interview candidates, it sometimes occurred that the person could not be reached. In this event another randomly selected name was substituted for the original name. When individuals were contacted it was verified that they really had been teaching SHAC and that they would be needing information on SHAC within the next year. (No attempt was made to determine if the respondent was currently teaching a course on SHAC.) If they were not both involved and needing information, they were asked if they could refer the interviewer to someone else in their organization who would be an appropriate respondent. If such a referral was made, a call was then made to this new candidate; if no intraorganizational referral was made, a new candidate was randomly selected from the sample frame. The results of this process may be seen in Table 13-1.

Comparisons. For additional insight into the information needs and the information habits of these SHAC Educators, results from this group are compared to the results from all of the educators interviewed in this study (All Educators). In addition to SHAC, the technologies included in All Educators were solar thermal electric power, passive solar heating and cooling, photovoltaics, biomass, wind, and industrial process heat. In performing any statistical comparisons, the totals for SHAC Educators have been subtracted from the totals for All Educators. Comparisons are also made with Passive Educators. The data for SHAC Educators, Passive Educators, and All Educators can be found in Appendix F. 
Table 13-1. COMPLETION OF INTERVIEWS: ACTIVE SOLAR HEATING AND COOLING EDUCATORS

Event
Number of

Candidates

Interview completed with sample frame candidate Interview completed with referral candidate Refusal or candidate termination

Contact attempted: could not reach candidate within three

attempts or before interviews were completed

Subtotal

Contact attempted: invalid candidate (e.g., inappropriate field of interest, ho telelphone)

TOTAL

Sample frame error rate (Percent) $^{a}$

Completion rate ${ }^{b}$ (Percent)

Invalid candidates divided by TOTAL

${ }^{\mathrm{b}}$ Completed interviews divided by Subtotal

\subsubsection{Current Status of Respondents}

Role. Six of the 9 SHAC Educators were on the faculties of four-year colleges or universities. Two were at two-year colleges, and 1 at a technical institute. The courses that these instructors had taught were mostly in mechanical engineering or mechanical technology departments (6). Other departmental titles included: air conditioning/refrigeration, earth sciences and geography, materials sciences, and urban and environmental studies. Seven or more of these instructors covered the following topics in their courses: solar collector evaluation and design (9), introduction to solar energy (8), heat and energy transfer (8), solar system design (8), solar space heating (8), domestic hot water (8), and solar system components (7). Topics covered somewhat less frequently were: energy storage (5), solar economics (5), passive solar technology (4), swimming pool heating (3), solar system testing and evaluation (3), and solar system installation (3). Only 1 or 2 Educators mentioned that their courses covered: solar home construction (2), solar space cooling (2), energy conservation (2), energy conversion (2), appropriate technology, solar system maintenance, plumbing techniques, and small-scale electricity generation. Three of the respondents taught two courses, the remainder (6) taught one course. In describing what they presently were doing in the area of SHAC, only 4 specifically mentioned teaching. Other mentions included: consulting (3), research (3), and testing, design, and/or construction (3).

Involvement. Five of the 9 (56\%) SHAC Educators said that they were "very involved" in SHAC technologies, compared to 2 of the 9 (22\%) Passive Educators and 27 of the 63 (43\%) All Educators who said they were "very involved" in their respective solar technologies.

Informedness. Six of the $9(67 \%)$ SHAC Educators considered themselves "very informed," compared to 2 of the 9 (22\%) Passive Educators and 31 of the 63 (49\%) All 
Educators. Of the Educators, only the Solar Thermal Educators gave themselves higher marks for informedness than did the SHAC Educators.

Need for Information. All respondents indicated they would need information on SHAC on the job during the next year. Six of the 9 (67\%) SHAC Educators also needed information on SHAC technologies outside the job. While the reason for this relatively high level of need for off-the-job information may have been a general interest in current awareness (educators and researchers are known for doing a fairly large amount of professional reading and writing outside of office hours), their involvement with solar energy may also have resulted in their becoming potential users of solar heating and cooling for their own residences. There are of course, alternative explanations for this avocational interest (organizational memberships, community involvement, etc.).

\subsubsection{Background of Respondents}

Three of the 9 SHAC Educators held a $\mathrm{PhD}$, and five held master's degrees. The percentage holding advanced degrees (beyond bachelor's) was the same for All Educators (89\%) as for SHAC Educators. Five SHAC Educators had received their most recent degree in engineering. Other degree fields were: occupational education, chemistry, and geography. Two of the SHAC Educators had received their most recent degree within the past 10 years, 5 from 10-20 years ago, and 1 over 30 years ago. One respondent did not hold a college degree.

Five of the 9 SHAC Educators had been in their present profession (not necessarily teaching) for over 10 years, 3 for at least 5 years, and 1 for 3-5 years. Eight of the 9 described their present profession as educator, teacher, or professor. Instructional specialties included: mechanical engineering, solar engineering, air conditioning, solar heating, energy conservation, environmental studies, climate control, and geography. One respondent considered himself a research engineer in testing, analysis, and computer work (teaching was not including in his description).

\subsection{INFORMATION NEEDS OF RESPONDENTS}

\subsubsection{Technical Areas}

SHAC Educators were asked to choose those areas in which they were "particularly interested in obtaining information" from a list of selected technical areas of SHAC. They seemed to be somewhat more interested in "space heating" (9 of the 9 ) and in "hybrid systems" (9 of the 9) than in "swimming pool heating" (4 of the 9). Seven of the 9 were interested in "space cooling" and 8 of the 9 in "water heating."

Some SHAC Educators volunteered that they were also interested in: solar refrigeration, industrial applications, agricultural process heat applications, and research and development in storage systems.

\subsubsection{Types of Information}

SHAC Educators were asked to name the information about SHAC that was important for them to obtain. All of the 9 volunteered one or more items of information which they 
considered important. Two respondents felt that state-of-the-art information (on integrated systems control, heat pump design, and absorption chillers) was important. Other topics included: cost analyses (2); government funding of research (2); performance of collectors in actual solar installations (2); durability (2); storage (2); research results (on $\mathrm{PV}$ as well as SHAC); economics (PV as well as SHAC); solar collectors for grain drying; and current information on government policy, programs, and subsidies for $R \& D$ and installation. One was interested in employers' requirements for trained employees: "What are the requirements for solar technician versus solar mechanic?"

Four of the 9 SHAC Educators stated that there was information that they needed but were unable to get. This information included: solar engineering, relative material properties, integrated systems control research results (from National Aeronautics and Space Administration (NASA) and other investigators), list of manufacturers of heat pumps, heat pump state of the art, and results of research on absorption chillers operating at $80^{\circ}-190^{\circ} \mathrm{F}$ (at the University of Indiana).

Choice Between Specific Needs. A list of 11 types of SHAC, information products and 14 types of SHAC information categories was read to each respondent. Each respondent described the usefulness of each particular item by assigning it a value of "essential," "very useful," "somewhat useful," or "not at all useful." The results are given in Fig. 13-1. For the purpose of comparison, those for Passive Educators are in Fig. 13-2 and those for All Educators are in Fig. 13-3.

For SHAC Educators the four top-rated information categories/products were:

- Expected major developments during the next 10 years;

- The state of the art;

- Costs of installing and operating a SHAC system compared to a conventional system; and

- Design handbooks, installation handbooks, or reference tables.

They also gave high ratings to "climatological data," "lists of sources for information," "a technical description of how a particular system works," and "manual methods for sizing and predicting performance or costs" (all tied for fifth place).

SHAC Educators assigned the lowest relative ratings to five items including both items in the marketing category:

- A nontechnical description of how a particular system works;

- Marketing statistics and sales projections;

- How to market and sell solar systems;

- Solar energy programs, research, industries, and markets outside the United States; and

- Lists of technical experts.

Statistical tests indicated that ratings for the four highest-rated items were significantly different $(P<0.05)$ from the ratings of the five lowest-rated items. The wide differences between ratings for "a technical description" and "a nontechnical-description" were very interesting, as were the differences between "system design handbooks" and "system diagrams." 
Question \#8. I will read a list of potential information or information products on solar systems. For each, please tell me how useful that information would be to you. Would the following be: essential, very useful, somewhat useful, or not at all useful?

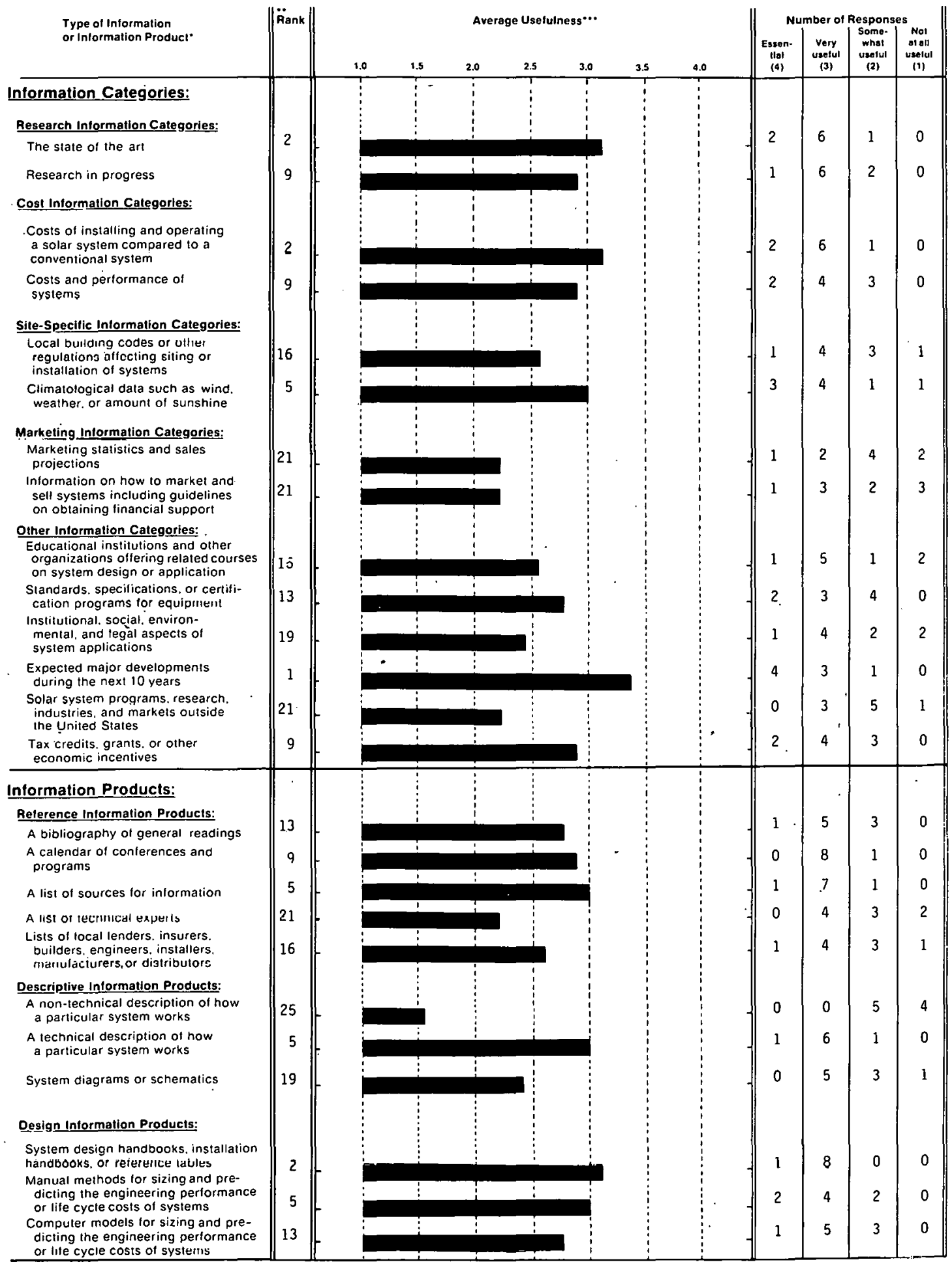
or lite cycle costs of systems

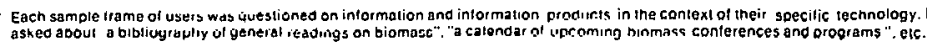

Rank - Eachintormation producl was assigned a rank based on average usefulness. Thus, the producl with the highest average usefutness was assigned the rank of " 1 ". the product with the lowest average usefulness would be ranked "25" where all tlems were asked. II iwo or more intormation products were lied lor 2 no, they were both assigneo a " 2 " The ne ul nighoct rankino was then assignest a " 4 ?

.. Average usefurness was calculated by assignining llie iescunses on a 14 geale lrom a "A" tor "occontial" to a "1" Inr "nol very useful"

Figure 13-1. Usefulness of Selected Information Items: Active Solar Heating and cooling Educators 
Question \#8. I will read a list of potential information or information products on solar systems. For each, please tell me how useful that information would be to you. Would the following be: essential, very useful, somewhat useful, or not at all useful?

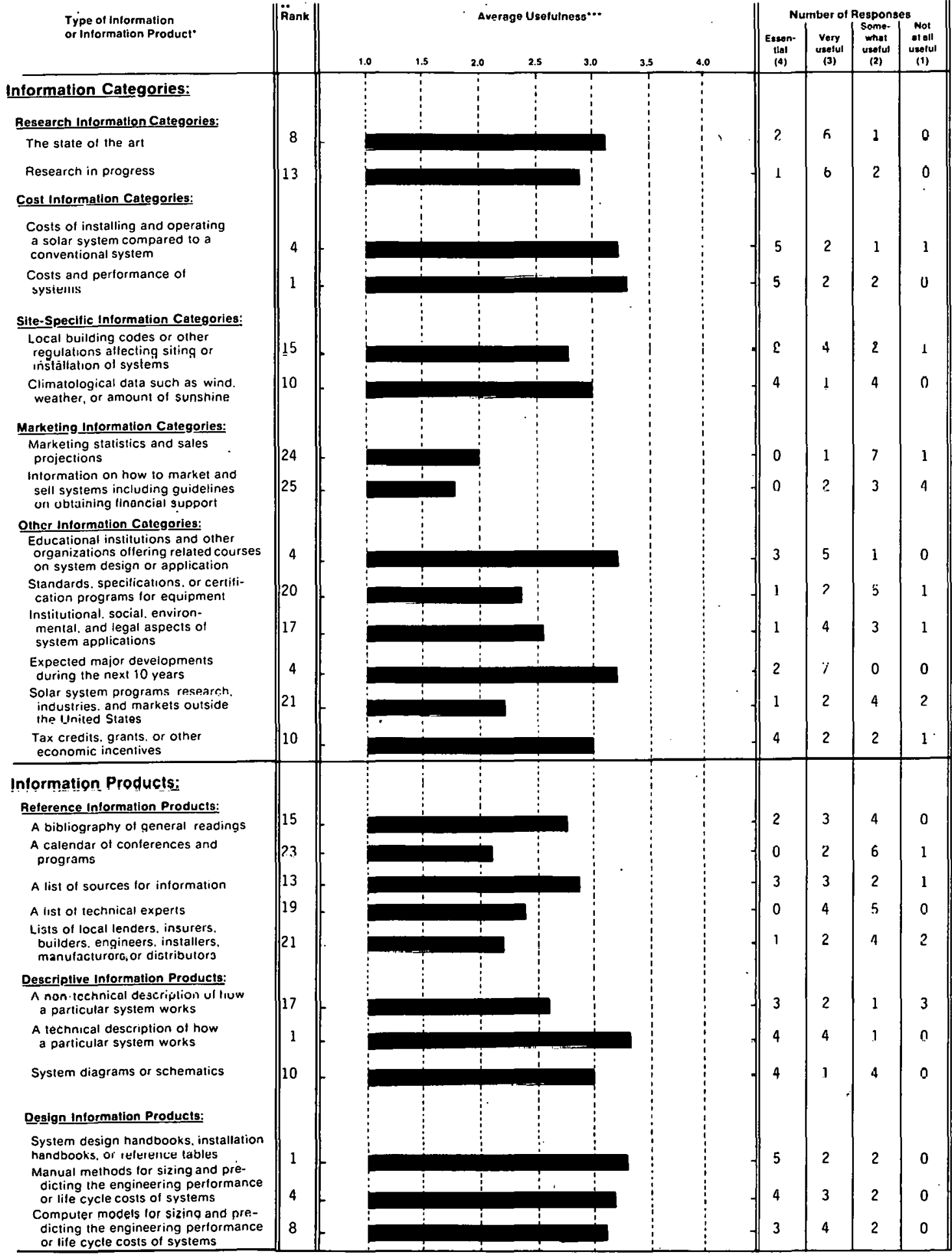

Each sample trame of users was questioned on inlormation and information products in the context of their specific technology. For example, biomass sample trames were

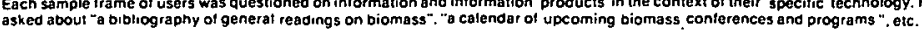

"Rank-Each intormation producl was assigned a rank based on average usefulness. Thus. the product with the hignesl average usefulness was assigned the rank of "1": Ine product with the lowest average uselulness would be ranked "25" where all items were asked, It two or more intormation products were tied tor 2 nd, they were both assigned a "2". The nex

... Average usetulness was calculated by assigning the responses on e 14 scate trom " "4" tor "essential" to a "1" tor "not very usetul". 
Question \#8. I will read a list of potential information or information products on solar systems. For each, please tell me how useful that information would be to you. Would the following be: essential, very useful, somewhat useful, or not at all useful?

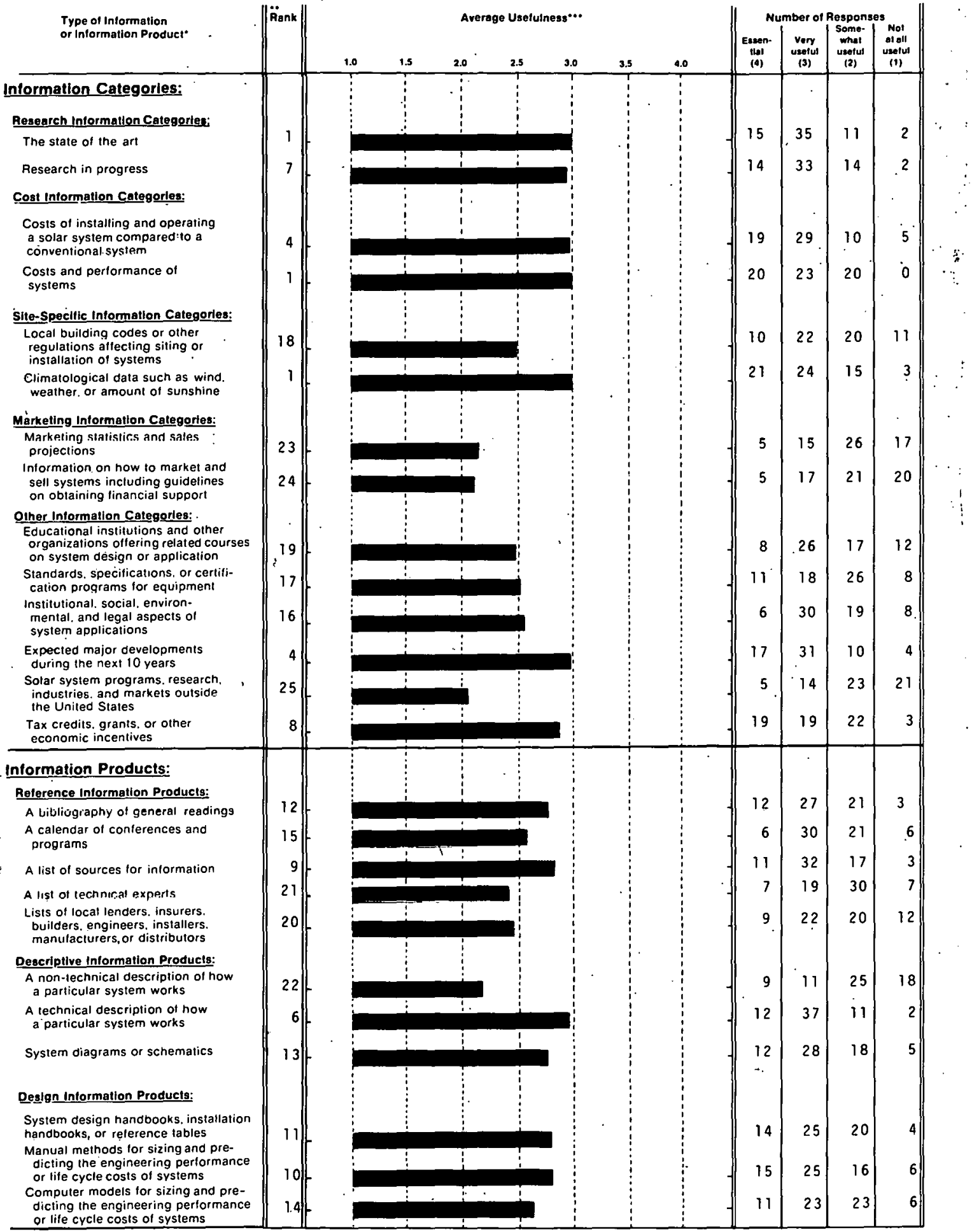

Each sample frame of users was questioned on intormation and informalion products in the context of their specific lechnology. For example. biomass sample frames were asked about "a bibliography of general rezdings on biomass"." "a calendar ol upeoming biomess conterences and programs ". etc.

Pank-Eachintormation product was assigned a rank besed on average usefulness. Thus, the product with ine highest average usgefulness was assigned the rank of "I": Ine product (tied tor 2 nd, they were both assigned a "2". The nex

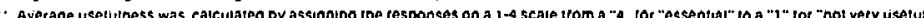


These results picture the SHAC Educator as wanting information primarily on the future. of SHAC in the United States (expected developments, state of the art, costs), and on design considerations (costs, handbooks, technical, and weather descriptive data). Typically for Educators, they also gave "lists of sources for information" high ratings.

It should be noted that these lower-rated items were not necessarily of no worth to the SHAC Educators. For example, 4 of the 9 (44\%) thought information on "how to market" was either "essential" or "very useful." Thus, these information categories/products could be useful to some of the SHAC Educators but were of a lower relative priority to the entire group.

Statistical tests were also used to determine whether the SHAC Educators rated any of these information items significantly higher (or lower) than they were rated by the Passive Educators or by All Educators. Some groups, however, tended to give higher scores in general than did other groups. To compensate for this effect, these statistical tests compared the "relative rating" given by one group to the "relative rating" given by the other groups. The procedure for calculatng the relative rating is described in Appendix E. The average overall rating SHAC Educators gave to all items was 2.70; for Passive Educators it was 2.79. The result for All Educators was lower than either at 2.64.

In comparing the results for SHAC Educators to the results for Passive Educators, both rated "costs of installing," "expected major developments," and "design handbooks" relatively high. Statistical tests indicated that the SHAC Educators rated "calendars" significantly $(P<0.05)$ higher and "a nontechnical description" significantly $(P<0.05)$. lower than did Passive Educators. Other items that SHAC Educators found less useful than the Passive Researchers were "costs and performance," "educational institutions," "a technical description," and "manual methods."

In comparing the results for SHAC Educators to the results for All Educators, similarities were found in high ratings for "costs of installing" and "expected major developments," coupled with low ratings for marketing information and "solar energy programs ... outside the United States." SHAC Educators rated "a nontechnical description" significantly $(P<0.05)$ lower than did All Educators, but All Educators seemed more interested in "costs and performance of systems."

\subsection{ACQUISTION OF INFORMATION BY RESPONDENTS}

\subsubsection{Use of Selected Information Sources}

SHAC Educators were asked which of 20 different potential sources of solar information they had used in the past few years. For this question the respondents were not asked if they had obtained information about SHAC technologies, but instead were asked if they had obtained any solar information from each specific source. Thus, the question sought to determine which information sources were the most familiar to the respondents. The results for SHAC Educators are shown in Fig. 13-4. For comparison, those for Passive Educators are provided in Fig. 13-5 and those for All Educators in Fig. 13-6.

The information sources mentioned most of ten by SHAC Educators were:

- Workshops, conferences, or training sessions;

- Periodicals, newspapers, or magazines; 
Question \#11. In the past few years, have you obtained any type of solar information from any of the following sources?

Information Sources

Percentage Responding Yes “

Public Media:
Radio or TV
Periodicals, newspapers or magazınes

Private Solar-Involved Organizations:

Private solar energy or environmental organizations

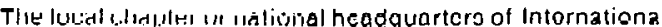

Solar Energy Society (ISES). including their publications

The local chapter or national headquarters of Solar Energy

Industrics Association (SEIA). including their publications

Contacts with Professionals:

An installer. builder, designer or manufacturer of solar systems

Workshops, conferences or training sessions

Information Services":

Your organizational library or a local library

A commercial data base: for example. Lockheed. SDC. BRS

Smithsonian Science Information Exchange (SSIE)

A Federal library or information center: for example. the National Agricultural Library or the Environmental Data System

The Government Printing Office (GPO)

National Technical Information Service (NTIS)

Technical Information Center at Oak Ridge (TIC)

Government Solar-Involved Organizations

Directly from the U.S. Department of Energy.

National Solar Heating \& Cooling Information Center

Regional Solar Energy Centers

State Energy or Solar Oflices

\section{Other:}

Some other state or local government office or publication

A public utility company

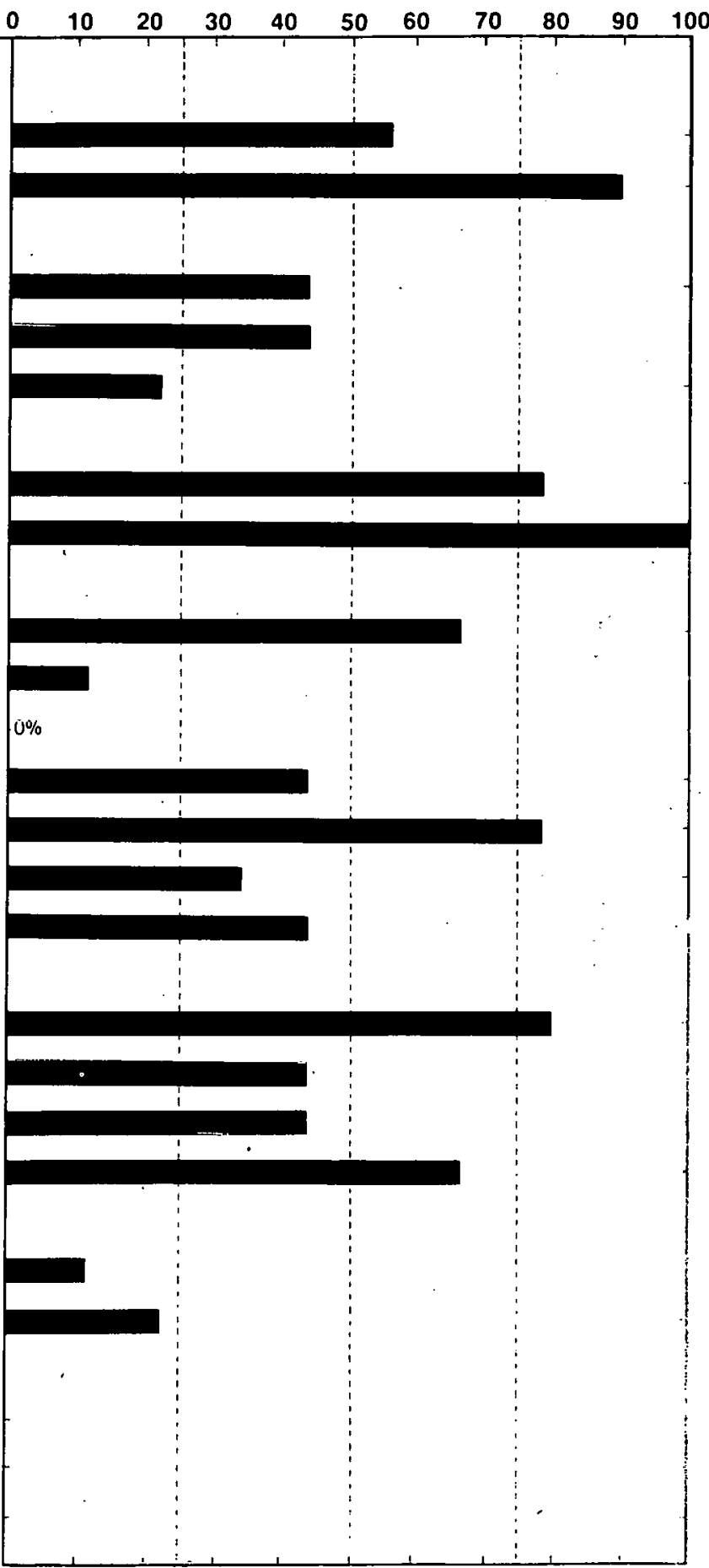

- Services and centers whose primary purpose is to disseminate information.

Thece data are based upon a total of 9 respondents.

Figure 13-4. Use of Selected Information Sources: Active Solar Heating and Cooling Educators 
Question \#11. In the past few years, have you obtained any type of solar information from any of the following sources?

\section{Information Sources}

Public Media:
nadio or TV
Periodicals. newspapers or magazines

Private Solar-Involved Organizations:

Private solar energy or environmental organizations

The local chapter or national headquarters of International Solar Energy Society (ISES). including their publications

The Iocal chapter or national headquarters of Solar Energy Industries Association (SE|A). including their publications

\section{Contacts with Professionals:}

An installer, builder, designer or manufacturer of solar systems

Workshops. conferences or training sessions

\section{Information Services*}

Your organizational library or a local library

A commercial data base: for example, Lockheed, SDC, BRS

Siritlisurian Science Information Exchange (SSIE)

A.Federal library or information center; for example. the National Agricultural Library or the Environmental Data System

The Government Printing Office (GPO)

National Technical Information Service (NTIS)

Technical Information Center at Oak Ridge (TIC)

\section{Government Solap-Involved Organizations}

Directly from the U.S. Department of Energy

National Solar Heating \& Cooling Information Center

Regional Solar Energy Centers

State Energy or Solar Offices

\section{Other:}

Some other state or local government office or publication

A public utility company

\section{Percentage Responding Yes “}

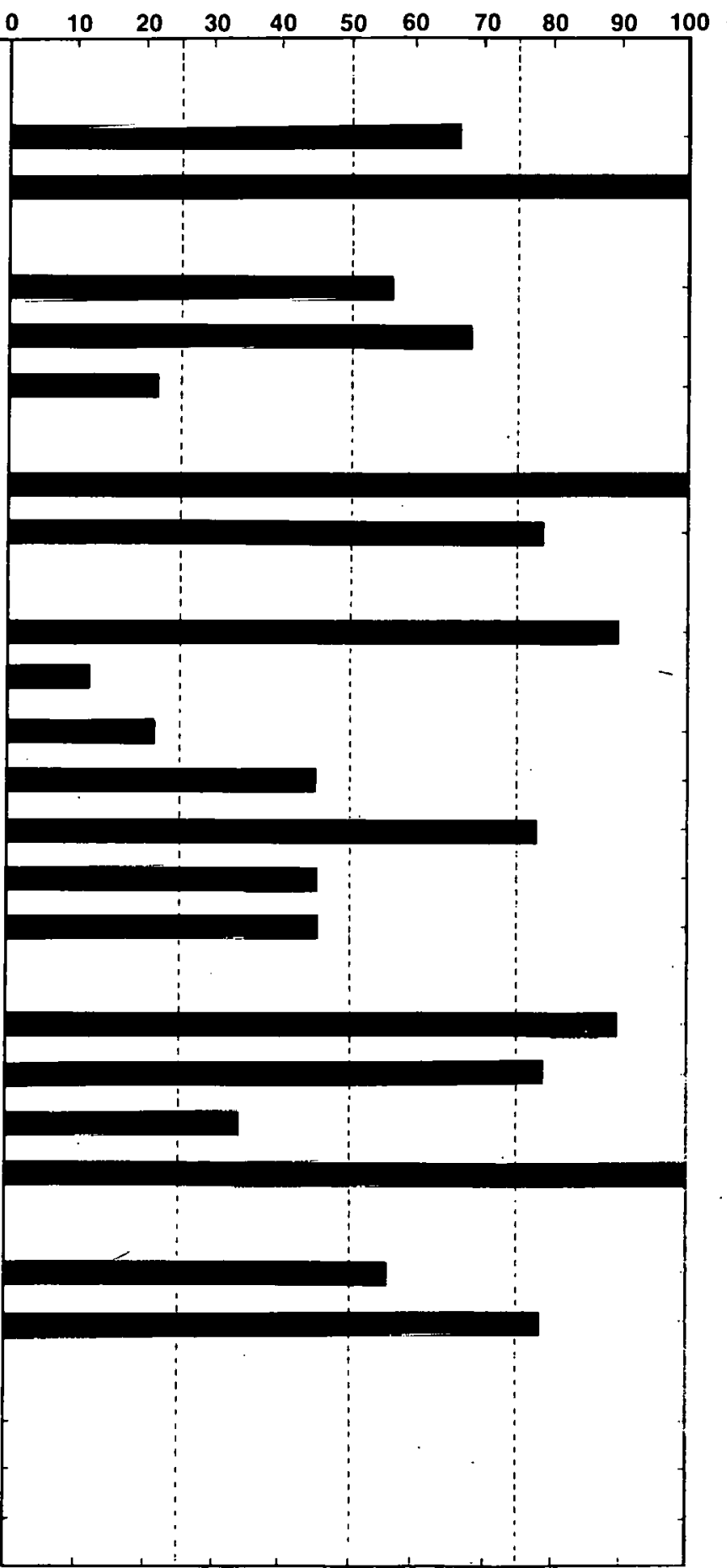

- Services and centers whose primary purpose is to disseminate information.

- These data are based upon a total of 9 respondents. 
Question \#11. In the past few years, have you obtained any type of solar information from any of the following sources?

\section{Information Sources}

Percentage Responding Yes "

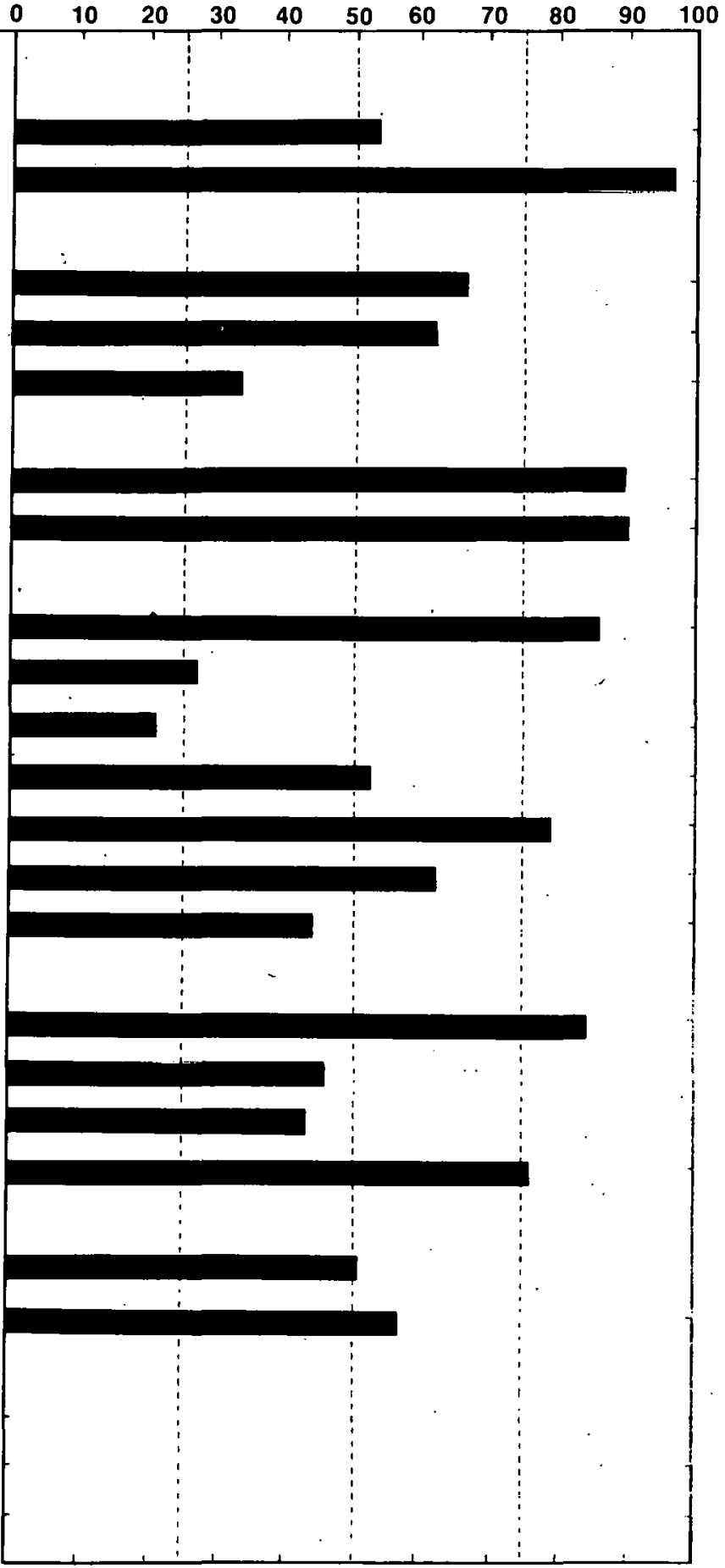

Private solar energy or environmental organizations

Tho local chapter or nationa! headịilarters of International

Solar Energy Society (ISES). including their publications

The Incal chapter or national headquarters of Solar Energy

Industries Association (SE|A). including their publications

Contacts with Protessionals:

An installer, bullder. designer or manufacturer of solar systems

Workshops. conferences or training sessions

Information Services*:

Your organizational library or a local library

A commercial data base: for example. Lockheed. SDC. BRS

Smithsonian Science Information Exchange (SSIE)

A Federal library or information center: for example. the National

Agricultural Library or the Environmental Data System

The Government Printing Office (GPO)

National Technical Information Service (NTIS)

Technical Information Center at Oak Ridge (TIC)

Government Solar-Involved Organizations

Directly from the U.S. Department of Energy

National Solar Heating \& Cooling Information Center

Regional Solar Energy Centers

State Energy or Solar Otfices

Other:

Some other state or local government office or publication

A public utitity company

- Services and centers whose primary purpose is to disseminate information.

-. These data are based upon a total of 63 respondents.

Figure 13-6. Use of Selected Information Sources: All Educators 
- An installer, builder, designer, or manufacturer;

- The Government Printing Office (GPO); and

- Directly from the U.S. Department of Energy (DOE).

The first source listed above was the only one receiving unanimous positive responses from SHAC Educators. Similarly, unanimous response from Passive Educators was found for "periodicals" and "an installer, builder, designer, or manufacturer." All Educators concurred with SHAC Educators in giving high ratings to all five of the sources listed above.

The information sources mentioned least often ( 2 or fewer of the 9 had used them) by SH AC, Fincators were:

- Smithsonian Science Information Exchange (SSIE),

- A commercial data base,

- Some other state or local government office or publication,

- Solar Energy Industries Association (SEIA), and

- A public utility company.

Both Passive Educators and All Educators were more likely to have used "some other state or local government office or publications" and "a public utility company" than were SHAC Educators. However, use of the Regional Solar Energy Centers (RSECs) was more often mentioned by SHAC Educators than by Educators in any other technology except wind energy. While there were no significant differences in the sources used by SHAC and Passive Educators, the SHAC Educators were significantly $(P<0.05)$ less likely than were All Educators to have used: "a public utility company," National Technical Information Service (NTIS), and "some other state or local government office or publicativiis."

\subsubsection{Membership in Solar-Interested Organizations}

Seven of the 9 SHAC Educators interviewed were members of a professional, technical, or other organization with an interest in solar energy. These organizations (and the number of times mentioned) included:

- American Institute of Aeronautics and Astronautics,

- American Society for Engineering Education,

- American Society of Mechanical Engineers (ASME) (2),

- American Society for Testing and Materials,

- Illinois Solar Energy Industries Association,

- International Association for Hydrogen Energy,

- International Solar Energy Society (ISES) (2),

- International Sunshine Society - American Section,

- New England Solar Energy Association, 
- Refrigeration Service Engineers Society,

- Society for Encouragement of Research and Invention, and

- SEIA.

Also mentioned by 1 respondent was an organization that could not be verified by the authors. This was the "American Institute of (Society for ?) Engineering Education." Only two organizations (ASME and ISES) were mentioned by more than 1 respondent. At least 4 were members of a solar energy association.

\subsubsection{Exposure to Publications on Solar Energy}

During the past 6 months, all 9 SHAC Educators had read publications which included information on SHAC. The publications they could specify (and the number of times mentioned) included:

- Conference proceedings at Worchester Polytechnical Institute,

- DOE reports on solar collectors,

- Energy Conservation in Homes (DOE publication),

- U.S. Department of Housing and Urban Development (HUD) publications,

- ISES newsletters,

- Mechanix Illustrated,

- New England Solar Energy Association newsletters,

- Popular Mechanics,

- Solar Age (5),

- Solar Energy (2),

- Solar Energy Digcst,

- Solar energy journals,

- Solar Engineering,

- SEM '79 Solar Engineering Master Catalog of Solar Industry Index, (SEIA book),

- Solar Heating and Cooling of Residential Buildings (book, Colorado State University),

- Sunworld, and

- The Solar Home Book (by Anderson) (2).

Alsn mentioned by one respondent was "alternate energy sources," sources that could not be further specified by the authors. Newsletters, conference procedures, periudicals, and books were all named. Both solar journals and popular magazines were among the periodicals identified. Surprisingly, virtually missing from the list were the professional journals from the organizations respondents had listed above. 


\subsubsection{Use of Special Acquisition Methods}

The respondents were asked whether they had obtained any information (not just SHAC or solar energy) in the past year by computer terminal, by Computer Output Microform (COM), or by other microform (e.g., microfiche, microfilm sheets or rolls). None of the SHAC Educators appeared accustomed to using these special aquisition methods. In the past year, none of the 9 SHAC Educators had used computer terminals, COM, nor other microforms to obtain information. Passive Educators were only slightly more likely to have used each of the three methods. Both SHAC Educators and Passive Educators made less use of microforms (other than COM) than did any other group of Educators.

\subsection{SUMMARY AND COMMENTS}

Nine postsecondary educators teaching courses in SHAC were interviewed. While onc of these was teaching at a technical institute, eight taught at a college or university (generally in the mechanical engineering or mechanical technology department). Three of the nine were doing SHAC-related research as well as teaching. Three were doing some consulting, and three were doing testing, design, and/or construction. Their level of involvement and degree of informedness were somewhat higher than those of other Educators interviewed in this study.

SHAC Educators attached the most usefulness to information on:

- The state of the art in SHAC technology;

- Expected major developments in SHAC technology during the next 10 years;

- Costs of installing and operating a SHAC system compared to a conventional system; and

- SHAC system design handbooks, installation handbooks, or reference tables.

They attached relatively less utility to marketing information, nontechnical descriptions of SHAC systems, solar programs overseas, and lists of technical experts.

The resulting picture of the SHAC Educator was as one who needs to keep abreast with the major happenings in SHAC ("state of the art," "expected major developments") but at the same time needs the nuts and bolts systems design information.

SHAC Educators were likely to be members of solar organizations and to read solar periodicals. They also were frequent users of workshops and conferences, and obtained information from local installers, builders, etc., as well as from government sources such as DOE and GPO. 
SECTION 14.0

COUNTY AGENTS, COOPERATTVE RXTENSION SERVICE

\subsection{DESCRIPTION OF RESPONDENTS}

\subsubsection{Description of Sample}

This section describes the results of a telephone study to determine the needs of county agricultural agents in the Cooperative Extension Service (CES) for information on active solar heating and cooling (SHAC) . Nine SHAC County Agents were interviewed.

The sample frame for SHAC County Agents was selected from the County Agents Directory [28], which lists CES staff members by state and county. In order to eliminate urban counties, the County and City Data Book [29] was consulted. From this source, any counties which had $35 \%$ or less of total land area in farms were eliminated from consideration. The 2,160 remaining rural counties were reduced to 300 by selecting every seventh county. (Counties were listed in alphabetical order within states, which were also in alphabetical order.) Every fifth county was then selected as a candidate for the SHAC information study.* Senior Agricultural Agents (rather than Home Economics, 4-H, or Youth Agents) were identified for each county. The 9 interview candidates were randomly selected from a sample frame of 60 names.

Respondents. In making the telephone calls to contact the randomly selected interview candidates, it sometimes occurred that the person could not be reached. In this event another randomly selected name was substituted for the original name. When individuals were contacted, it was verified that they really had some experience with SHAC and that they would be needing information on SHAC within the next year. If they were not both involved and needing information, they were asked if they could refer the interviewer to someone else in their organization who would be an appropriate respondent. If such a referral was made, a call was then made to this new candidate; if no intraorganizational referral was made, a new candidate was randomly selected from the sample frame. The results of this process may be seen in Tulble 14-1.

Comparisons. For additional insight into the information needs and the information habits of these SHAC County Agents, results from this group are compared to the results from Passive County Agents, from all of the CES county agricultural agents interviewed in this study (All County Agents), and from state level CES specialists in agriculture and information (All State Specialists). Other technologies represented by All County Agents included passive solar heating and cooling, wind, biomass, and agricultural process heat. In performing any statistical comparisons, the totals for SHAC County Agents have been subtracted from the totals for All County Agents. The data for SHAC County Agents, Passive County Agents, All County Agents, and All State Specialists can be found in Appendix F.

*The remaining counties were divided into similar groups for the studies on wind energy, passive solar heating and cooling, biomass energy, and agricultural process heat. The results of these studies are reported in other volumes. 


\section{Table 14-1. COMPLETION OF INTERVIEWS: ACTTVE SOLAR HEATING AND COOLING COUNTY AGENTS}

Event

Number of Candidates

Interview completed with initial candidate

Interview completed with referral candidate

Refusal or candidate termination

Contact attempted: could not reach candidate within three

attempts or before interviews were completed 3

Subtotal

Contact attempted: invalid candidate (e.g., inappropriate field of interest, no telephone)

TOTAL

Sample frame error rate ${ }^{a}$ (Percent)

Completion rate ${ }^{b}$ (Percent)

Invalid candidates divided by TOTAL

${ }^{b}$ Completed interviews divided by Subtotal

\subsubsection{Current Status of Respondents}

Respondents represented counties in the following nine states:

- Colorado,

- Indiana,

- Kansas,

- Minnesota,

- Montana,

- Nebraska,

- Ohio,

- South Dakota, and

- Texas.

Thus the Central United States is heavily represented. Unfortunately, no far-Western nor Eastern states appear in the list. All County Agents accounted for 24 states, picking up somewhat more representation of the West and East. Similarly, State Specialists were not interviewed in. New England nor the far West. (Geographic distribution by state of respondents in each of the County Agents' and State Specialists' groups is shown in Table B-1, Appendix B.)

Role. Five of the 9 SHAC County Agents were involved with dissemination of information on SHAC. Topies covered in these activities included: home and barn heating, grain drying, architectural structures, design, and insulation. Information audiences included 
solar home owners and prospective solar home owners, farmers, teachers, and the construction industry. Three of the SHAC County Agents had solar installations in their own homes: domestic hot water, roof and window heating units, and a "solar floor." Two agents were involved with solar $R \& D$. One of these stated he would be handling energy programs for the state in the near future. Another respondent described current involvement in active solar as "learning." In general this group gives the impression of being fairly actively involved with solar energy, more so than the Passive County Agents. Thus, those who were not involved with disseminating SHAC information were involved in collecting SHAC infomation either for current activities or for future use.

Involvement. Five of the 9 (56\%) SHAC County Agents said that they were either "very involved" or "moderately involved" in SHAC. This was the highest level of involvement of any of the County Agents' groups, and compares to 13 of the 45 (29\%) All County Agents who were at least "moderately involved." SHAC County Agents were less involved in SHAC than All State Specialists (13 of the 18 or 72\%) were in solar technologies in general.

Informedness. Five of the 9 (56\%) SHAC County Agents said that they were at least "moderately informed" about SHAC. The informedness level of County Agents in other technologies was lower than that of SHAC County Agents. While 56\% of SHAC County Agents were at least "moderately informed," only 22\% of All County Agents were as informed. State Specialists, however, considered themselves considerably more informed about solar technologies in general than the County Agents considered themselves informed about specific solar technologies. Eighty-three percent (15 of the 18) of All State Specialists were said they were at least "moderately informed" about solar energy.

Need for Information. All respondents indicated they would need information on SHAC on the job during the next year. Six of the 9 (67\%) SHAC County Agents also expected to need information on SHAC outside the job. This was a higher level of off-the-job information need than was found for All County Agents, where 21 of the 45 (47\%) responded similarly. All State Specialists (7 of the 18 or $39 \%$ ) were even less likely to need solar information outside of their jobs than were SHAC County Agents. The higher levels of need of SHAC County Agents for off-the-job information may have been related to SHAC being a commercially available solar technology, compared to the other solar technologies.

\subsubsection{Background of Respondents}

Five of the SHAC County Agents held master's degrees; the remainder held bachelor's degrees. Six had received their most recent degree in agriculture (including agricultural education) or in related fields of plant or animal science and agronomy. One held a degree in community development and two in home economics (both of these were referrals, for County Extension Offices where the "solar expert" was the Home Economics Agent rather than the Agricultural Agent). Three of the 9 had received their most recent degrees within the past 10 years, $310-20$ years ago, and 3 over 20 years ago. This was fairly typical for County Agents, as 31 of the 45 (69\%) All County Agents received degrees within the past 20 years.

Four SHAC County Agents had been in their current profession for over 10 years, 1 for less than 2 years. In addition to references to their current professions, which included "county agent" or "Extension Agent," other descriptions included educator, agricultural educator, and "distributor of practical information." 


\subsection{INFORMATION NEEDS OF RESPONDENTS}

\subsubsection{Technical Areas}

SHAC County Agents were asked to choose those areas in which they were "particularly interested in obtaining information" from a list of selected technical areas of SHAC technologies. Seven or more expressed interest in four of the five areas about which they were asked. Interest levels were highest (all 9 respondents were interested) for "water heating."

Eight of the 9 were interested in "hybrid systems" and 7 in "space cooling." No one showed an interest in "swimming pool heating."

Three SHAC County. Agents volunteered that they were also interested in agricultural applications.

\subsubsection{Types of Information}

SHAC County Agents were asked to name the information about SHAC technologies that was important for them to obtain. All 9 respondents volunteered one or more items of information which they considered important. Three felt that information on cost, return on investment, and initial cost was important. Other topies included: different methods or types of solar heating, test data on houses in their area, efficiency ratings for specific geographic areas, blueprints of existing solar homes, inexpensive installations, installation methods, supplemental solar units, problems, building instructions, currently available models, consumer information, location of demonstrations, grain and crop drying, heat pumps in conjunction with water, water exchange systems, and lists of materials and suppliers.

Five SHAC County Agents volunteered that there was information they needed but were unable to get. This information included: "everything," installation and installation costs, different types of systems, efficiency ratings, economical home heating units, heat pumps, water exchange systems, test data from local housing, and return on investment compared to conventional systems. In effect, this list included almost all of the items they mentioned as important.

Choice Between Specific Needs. A list of 11 types of SHAC information products and 11 types of SHAC information categories was read to each respondent. Each respondent described the usefulness of each particular item by assigning it a value of "essential," "very useful," "somewhat useful," or "not at all useful." The results are given in Flg. 14-1. For comparison, results for Passive County Agents are in Fig. 14-2, All County Agents are in Fig. 14-3, and those for All State Specialists in Fig. 14-4.

SHAC County Agents selected the two items in the cost class as the most important. The six top-rated information categories/products were:

- Costs of installing and operating a SHAC system compared to a conventional system;

- Costs and performance of systems;

- Climatological data; 
Question \#8. I will read a list of potential information or information products on solar systems. For each, please tell me how useful that information would be to you. Would the following be: essential, very useful, somewhat useful, or not at all useful?

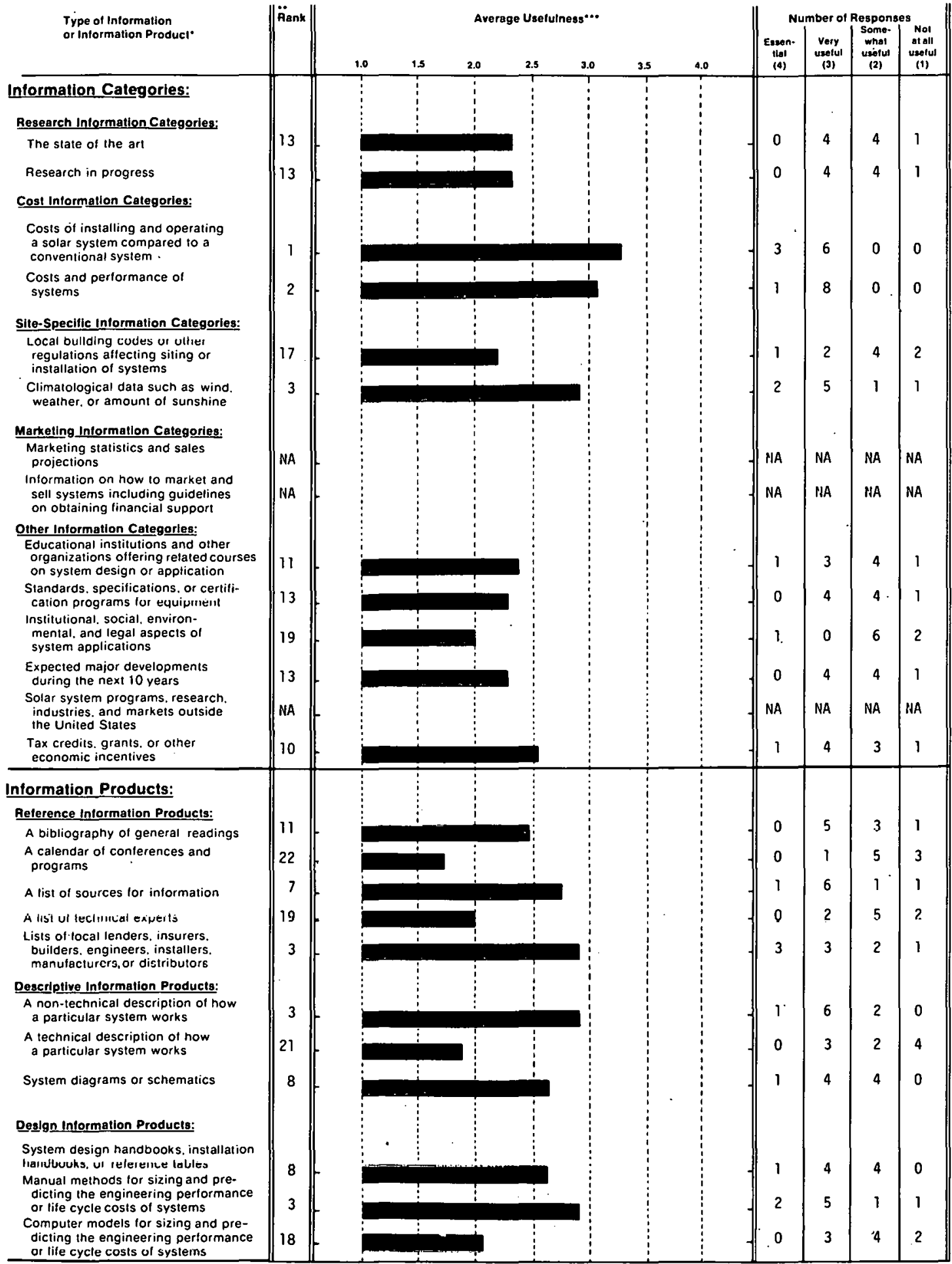

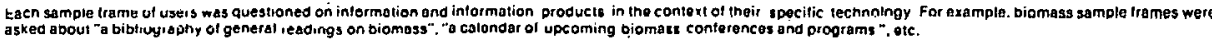

Fank - Each information product was assigned a rank based on average usefulness. Thus. the product with the highest average usefulness was assigned the rank of " 1 - : the product with the lowest average usefulness would be ranked "25" where all items were asked, 14 two or more intormation products were tied for 2 no. they were both assigned a "2"; The next

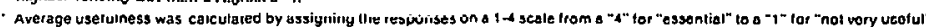

Figure 14-1. Usefulness of Selected Information Items: Active Solar Heating and Cooling Cooperative Extension Service County Agents 
Question \#8. I will read a list of potential information or information products on solar systems. For each, please tell me how.useful that information would be to you. Would the following be: essential, very useful, somewhat useful, or not at all usefui?

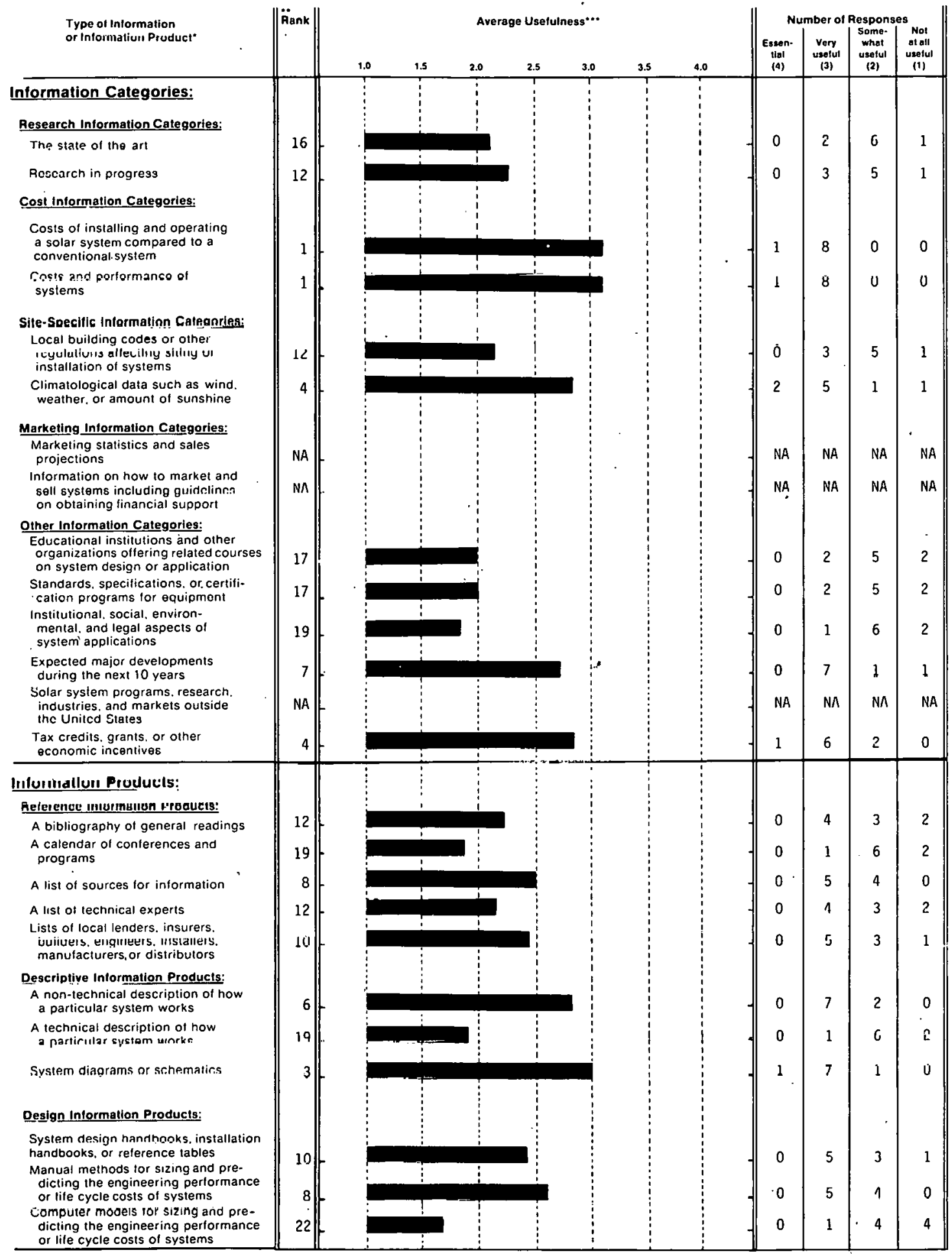

Each sample frame of users was questioned on information and intormation products in the context of their specific technology. For example, biomass sample trames were "

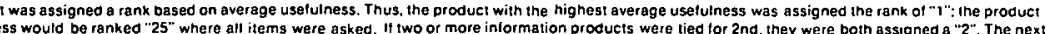
hignest ranking was inen assigned a "4:"

Average usetulness was calculated by assigning the responses on a $1-4$ scale from a "4" tor "essentiat" to a "1" for "not very useful".

Figure 14-2. Usefulness of Selected Information Items: Passive Cooperative Extension Service County Agents 
Question \#8. I will read a list of potential information or information products on solar systems. For each, please tell me how useful that information would be to you. Would the following be: essential, very useful, somewhat useful, or not at all useful?

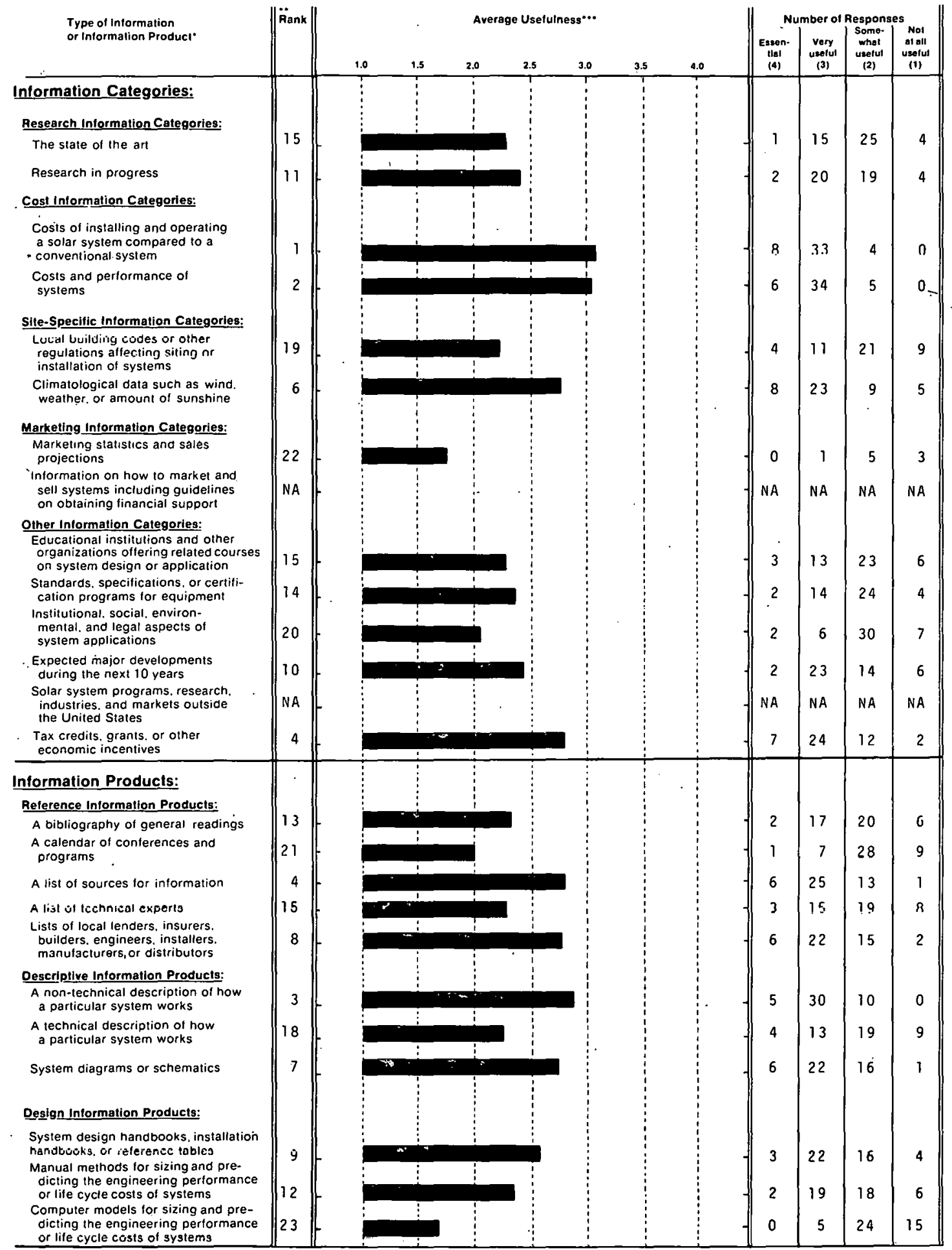

Eacn sample trame of users was questioned on intormation and intormation products in the context of their specific technology. For example, biomass sample trames were

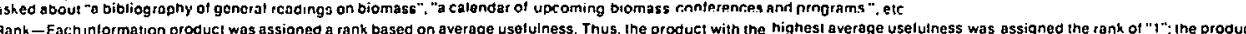

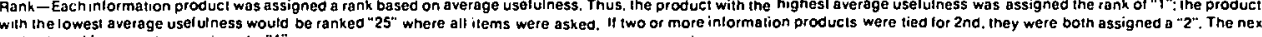
mianest ranking was then assioned a " "d "

Averaye usetulitess was calculated by assigning the respongeg

Figure 14-3. Usefulness of Selected Information Items: All Cooperative Extension Service County Agenis 
Question \#8. I will read a list of potential information or information products on solar systems. For each, please tell me how useful that information would be to you. Would the following be: essential, very useful, somewhat useful, or not at all useful?

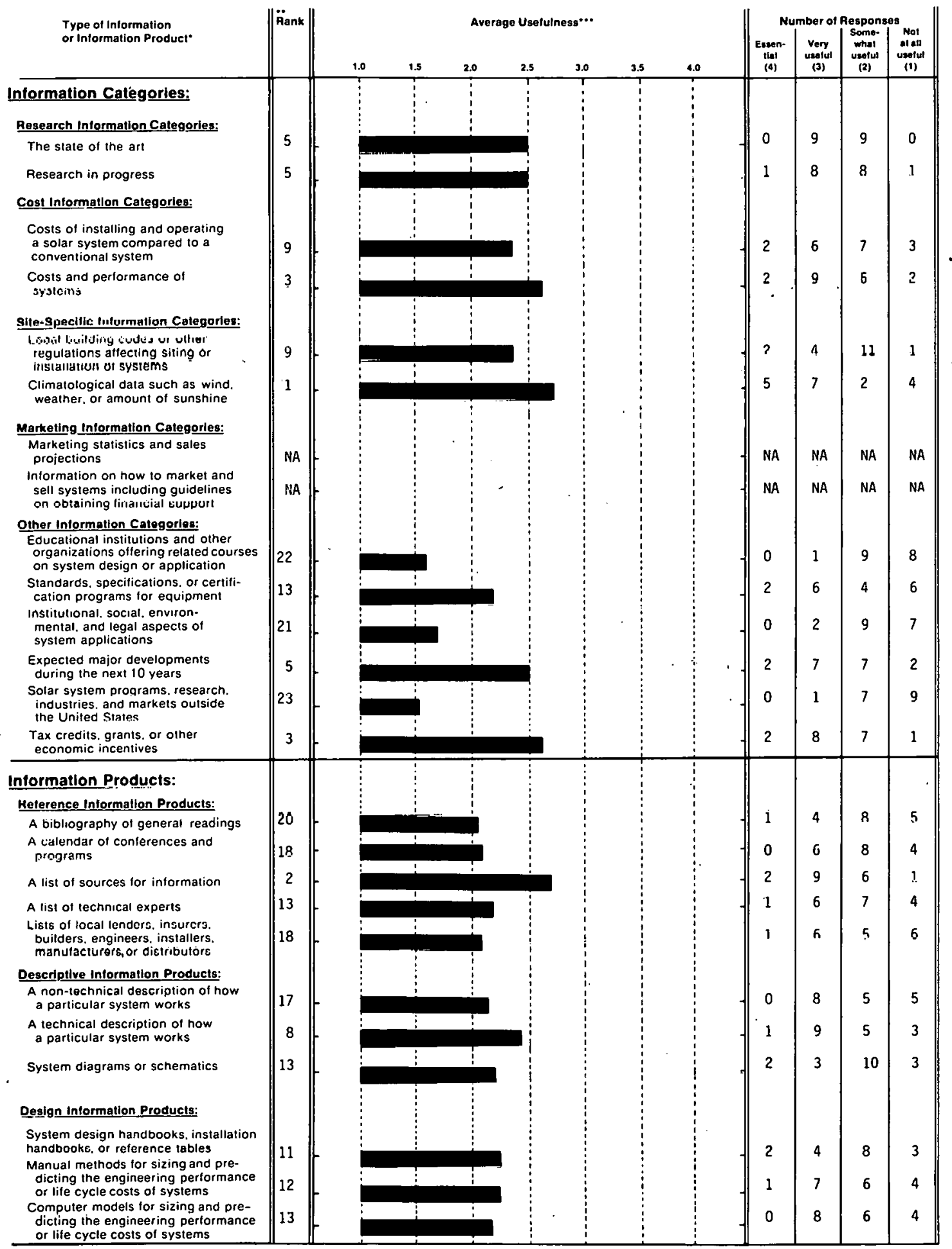

- Each sample trame of users was questioned on intormation and information products in the context of their specilic technotogy. For example. Diomass sample frames were asked about "a bibliography of general readings on biomass"." "a catendar of upcoming biomass conterences and programs". etc.

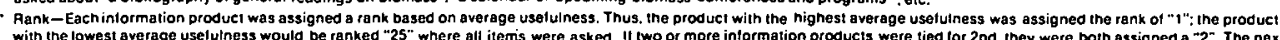
Wighest ranking was then assigneo a " $4:$ ".

... Average usefulness was calculated by assigning the responses on a 1.4 scate from a "4" tor "essential" 10 a "1" tor "not very useful".

Figure 14-4. Usefulness of Selected Information Items: All Cooperative Extension Service State Specialists 
- Lists of local lenders, insurers, builders, engineers, installers, manufacturers, or distributors;

- A nontechnical description of how a particular system works; and

- Manual methods for sizing and predicting performance and costs.

SHAC Coun'ty Agents assigned the lowest relative ratings to:

- Calendars of conferences and programs;

- A technical description of how a particular system works;

- Institutional, social, environmental, and legal aspects; and

- List of technical experts.

Statistical tests indicated all six of the top-rated categories/products were rated significantly $(P<0.05)$ higher than were the four lowest-rated items.

It should be noted that these lower-rated items were not necessarily of no worth to the SHAC County Agents. For example, 3 of the 9 (33\%) thought "a technical description" was "very useful." Thus, these information categories/products could be useful to some SHAC County Agents but were of a lower relative priority to the entire group.

Statistical tests were also used to determine whether the SHAC County Agents rated any of these information items significantly higher (or lower) than they were rated by the Passive County Agents, All County Agents, or All State Specialists. Some groups, however, tended to give higher scores in general than did other groups. To compensate for this effect, these statistical tests compared the "relative rating" given by one group to the "relative rating" given by the other groups. The procedure for calculating the relative rating is described in Appendix E. The average overall rating SHAC County Agents gave to all items was 2.49; for Passive County Agents it was 2.40; for All County Agents, 2.47; and for All State Specialists, 2.27.

In comparing the results for SHAC County Agents to the results for Passive County Agents, no statistically significant differences were found. Passive County Agents did seem more interested in "tax credits," however, and less interested in "lists of local lenders, (etc.)" and "manual methods."

In comparing the results for SHAC County Agents to the results for All County Agents, ratings were also very similar. Statistical tests indicated SHAC County Agents rated "manual methods" and "computer models" significantly $(P<0.05)$ higher than did All County Agents.

SHAC County Agents also rated "educational institutions" and "costs of installing" significantly $(P<0.05)$ higher than did All State Specialists, while rating "calendars" and "a technical description". significantly $(P<0.05)$ lower. In general, the needs of SHAC County Agents seemed very different from those of All State Specialists. 


\subsection{ACQUISITION OF INPORMATION BY RESPONDENTS}

\subsubsection{Use of Selected Information Sources}

SHAC County Agents were asked which of 21 different potential sources of solar information they had used in the past few years. For this question the respondents were not asked if they had obtained information on SHAC, but instead were asker if they had obtained any solar information from each specific source. Thus, the question sought to determine which information sources were the most familiar to the respondents. The results for SHAC County Agents are shown in Fig. 14-5. For comparison, results for Passive County Agents are shown in Fig. 14-6, All County Agents in Fig. 14-7, and All State Specialists in Fig. 14-8.

The information sources mentioned most often by SHAC County Agents were:

- Periodicals, newspapers, or magazines;

- U.S. Department of Agriculture (USDA);

- An installer, builder, designer, or manufacturer; and

- The Government Printing Office (GPO).

The first two sources had been used by all 9 of the SHAC County Agents.

The information sources mentioned least often by SHAC County Agents ( 2 or fewer of the 9 had used them) were:

- Solar Energy Industries Association (SEIA),

- International Solar Energy Society (ISES),

- National Technical Information Service (NTIS),

- Technical Information Center (TIC),

- A commercial data base, and

- A federal library or information center.

In reviewing Figs. 14-5 through 14-8, all four groups made high use of USDA and "periodicals." All County Agents made significantly $(P<0.05)$ less use of "private solar and environmental organizations" than did SHAC County Agents. In general, however, the County Agent groups were less familiar with all of the listed information sources than were All State Specialists.

\subsubsection{Membership in Solar-Interested Organizations}

Six of the 9 SHAC County Agents interviewed were members of a professional, technical, or other organization with an interest in solar energy. These organizations (and the number of times mentioned) included:

- American Farm Bureau Federation,

- Chamber of Commerce, 
Question \#11. In the past few years, have you obtained any type of solar information from any of the following sources?

. Information Sources

Public Media:
Radio or TV
Periodicals, newspapers or magazines
Private Solar-Involved Organizations:
Private solar energy or environmental organizations
The local chapter or national headquarters of International
Solar Energy Society (ISES). including theır publications
The local chapter or national headquarters of Solar Energy
liidustries Association (SEIA). including their publications
Contacts with Professionals:

An installer, builder. designer or manufacturer of solar systems Workshops, conterences or training sessions

Information Services*:

Your organizational library or a local library

A commercial data base: for example. Lockheed, SDC. BRS

Smithsonian Science Intormatıon Exchange (SSIE)

A Federal library or information center; for example, the National Agricultural Library or the Environmental Data System

The Government Printing Office (GPO)

National Technical Information Service (NTIS)

Technical Information Center at Oak Ridge (TIC)

Government Solar-Involved Organizations

Directly from the U.S. Department of Energy

National Solar Heating \& Cooling Informatıon Cente

Regional Solar Energy Centers

State Energy or Solar Offices

Other:

Some other state or local government office or publication

A public utility company

Sources for this specific sample frame**:

USDA, including the Cooperative Extension Service
Percentage Responding Yes $\cdots$

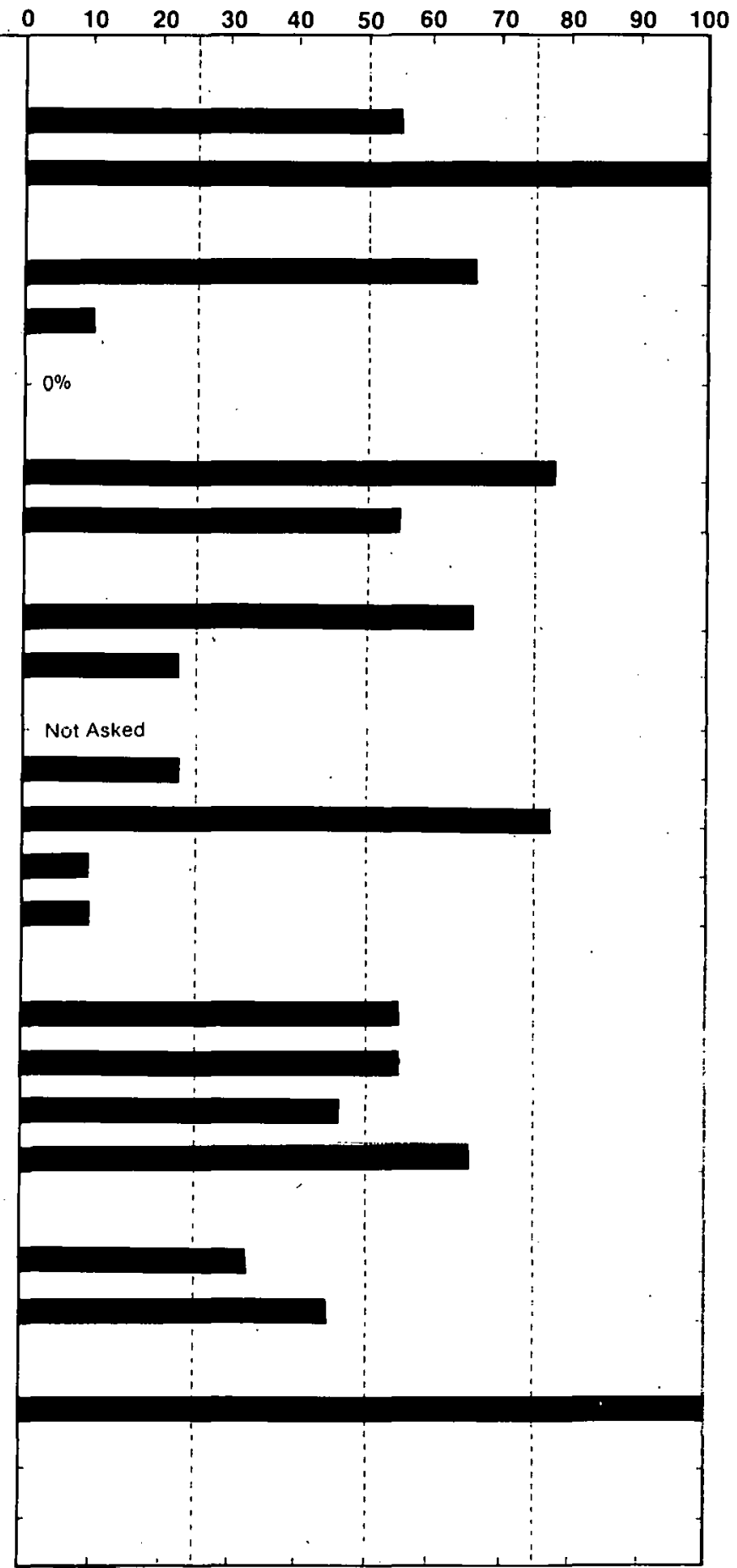

- Services and centers whose primary purpose is to disseminate informitiuri.

- Some sample frames were questioned about additional information sources which are applicable to their technology. For example the manufacturcrs of biomass conversion enuinment were also asked it they have obtained any type of solar intormation from: "the local or national office of the U.S. Uepartment of Agriculture, including Extension and Forcstry."

... These data are based upon a total of 9 respmondents.

Figure 14-5.Use of Selected Information Sources: Active Solar Heating and Cooling Cooperative Extenslon Servlce Cuunly Ayerils 
Question \#11. In the past few years, have you oblained any type of solar information from any of the following sources?

Information Sources
Percentage Responding Yes $\cdots$

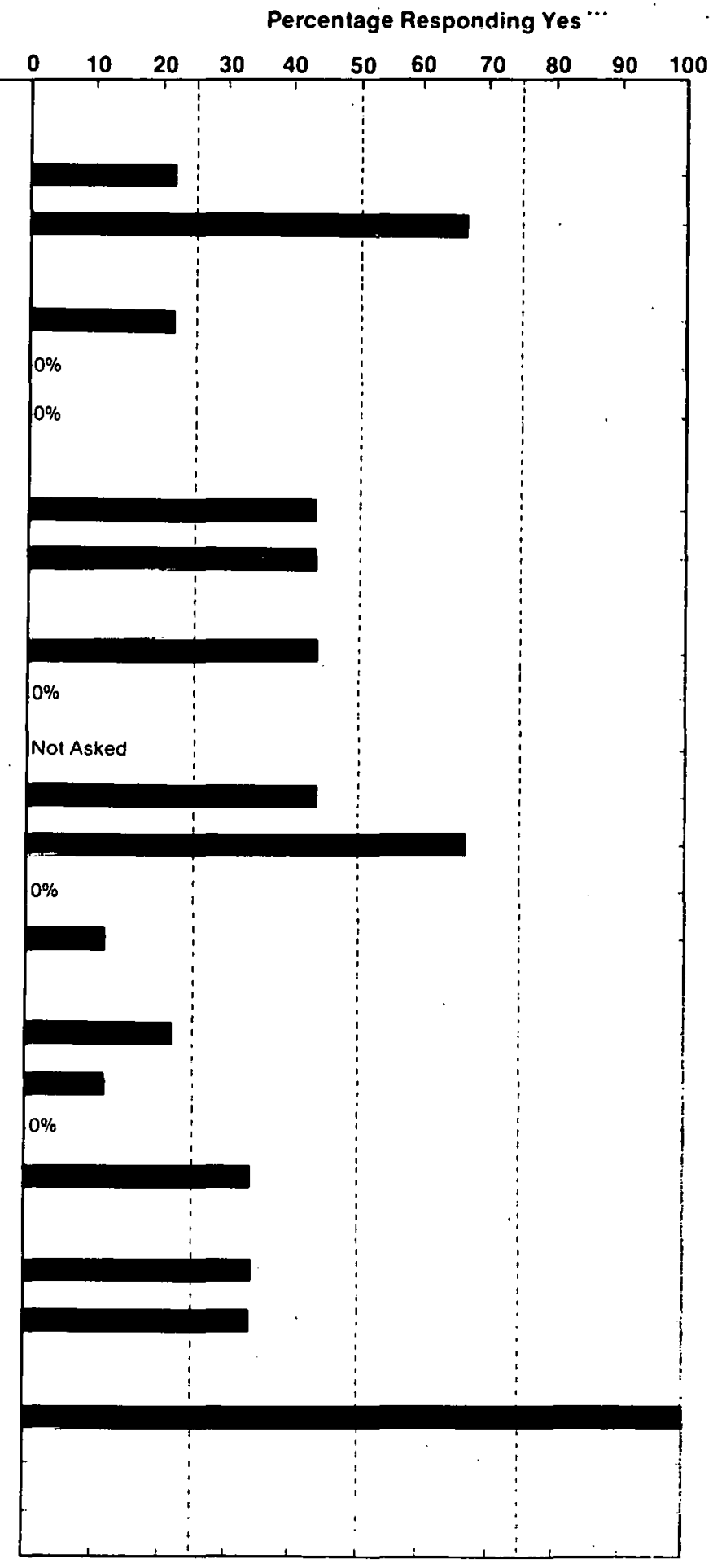

The local chajlè ur ritional heaoquarters of International Solar Energy Society (ISES), including their publications

The local chapter or national headquarters of Solar Energy Industries Association (SEIA), including their publications

Contacts with Professionals:

An installer. builder, designer or manufacturer of solar systems

Workshops. conferences or training sessions

Information Services*:

Your organizational library or a local library

A commercial data base: for example. Lockheed. SDC. BRS

Smithsonian Science Information Exchange (SSIE)

A Federal library or information center: for example. the National Agricultural Library or the Environmental Data System

The Government Printing Office (GPO)

National Technical Information Service (NTIS)

Technical Information Centęr at Oak Ridge (TIC)

Government Solar-Involved Organizations

Directly from the U.S. Department of Energy

Natıonal Solar Heating \& Cooling Information Centeı

Regional Solar Energy Centers

State Energy or Solar Offices

Other:

Some other state or local government office or publication

A publle utility company

bourccs for this specific sample trame" *:

USDA, including the Cooperative Extension Service

(2)

- Services and centers whose primary purpose is to disseminate intormation.

Some sample frames were questioned about additional information sources which are applicable to their technology. For example. the manufacturers of biomass conversion equipment were also asked if they have obtained any type of solar intormation from: "the local or national office of the U.S. Department of Agriculture. including Extension and Forestry."

... These data are based upon a total of 9 respondents.

Figure 14-6. Use of Selected Information Sources: Passive Cooperative Extension Service County Agents 
Question \#11. In the past few years, have you obtained any type of solar information from any of the following sources?

Information Sources

Percentage Responding Yes $\cdots$

Public Media:
Radio or TV
Periudicals. newspapers or magazincs

Private Solar-Involved Organizations:

Private solar energy or environmental organizations

The local chapter or national headquarters of International Solar Energy Society (ISES). including their publications

The local chapter or national headquarters of Solar Energy Industries Association (SE|A), including their publications

\section{Contacts with Professionals}

An installer. builder. desıgner or manufacturer of solar systems

Workshops. conterences or training sessions

Information Services*:

Your organizational library or a local library

A commercial data base: for example. Lockheed. SDC. BRS

Smithsonian Science Intormatıon Exchange (SSIE)

A Federal library or information center: for example. the National Agricultural Library or the Environmental Data System

The Government Printing Office (GPO)

National Technical Införmation Service (NTIS)

Technical Information Center at Oak Ridge (TIC)

Government Solar-Involved Organizations

Directly from the U.S. Department of Energy

National Solar Heating \& Cooling Information Center

Regional Solar Energy Centers

State Energy or Solar Orfices

Other:

Some other state or local government office or publication

A public utility company

Sources for this specilic sample frame*t:

USDA; including the Cooperative Extension Service

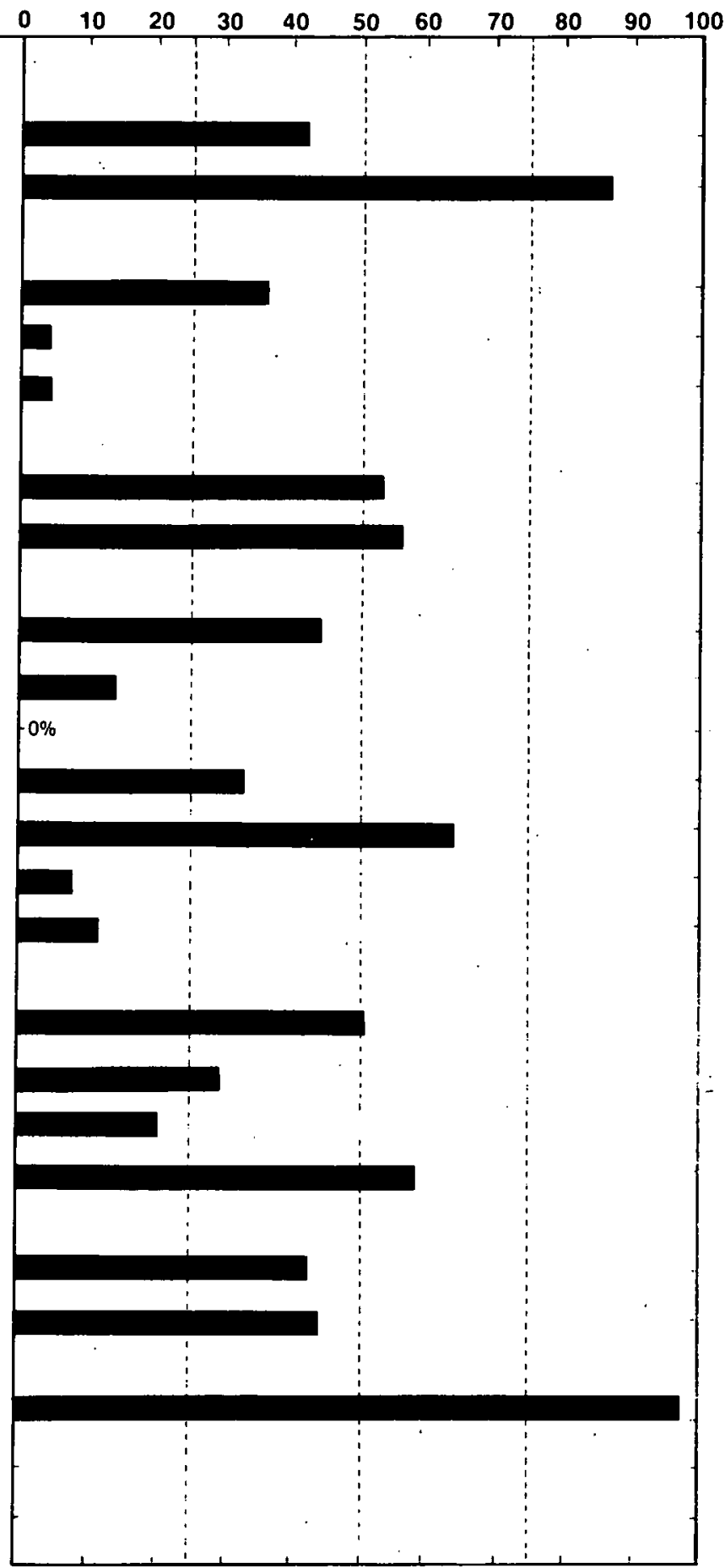

- Services and centers whose primary purpose is to disseminate information

- Some sample frames were questioned about additional information sources which are applicable to their technology. For example. the manufacturcrs of biomace conversion equipment were alsn asked if they have obtained any type of solar intormation from: "the local or national office of the U.S. Department of Agriculture. Including Exlension and Forestry"

*.* These data arc based upon a total of 45 respondents.

Figure 14-7., Use of Selected Information Sources: All Cooperative Extension Service County Agents 
Question \#11. In the past lew years, have you obtained any type of solar information from any of the following sources?

\section{Information Sources}

Public Media:

Radio or TV

Pcriodicals, newspapers or mag̃alilles

\section{Private Solar-Involved Organizations:}

Private solar energy or environmental organizations

The local chapter or national headquarters of Internatinnal

Solar Energy Society (ISES). including their publications

I he local chapter or national headquarters of Solar Energy Industries Association (SE|A), including their publications

Contacts with Professionals:

An installer, builder, designer or manufacturer of solar systems

Workshops. conferences or training sessions

\section{Intormation Services*:}

Your organizational library or a local library

A commercial data base: for example, Lockheed, SDC. BRS

Smithsonian Science Information Exchange (SSIE)

A Federal library or information center; for example. the National Agricultural Library or the Environmental Data System

The Government Printing Office (GPO)

National Technical Information Service (NTIS)

Technical Information Center at Oak Ridge (TIC)

\section{Govęrnment Solar-Involved Organizations}

Directly from the U.S. Department of Energy

National Solar Heating \& Cooling Information Centel

Regional Solar Energy Centers

State Energy or Solar Offices

Other:

Some other state or local government office or publication

A putic utility company

Sources for inl6 gpecifio sample tramen"

USDA, including the Cooperative Extension Service
Percentage Responding Yes ${ }^{\cdots}$

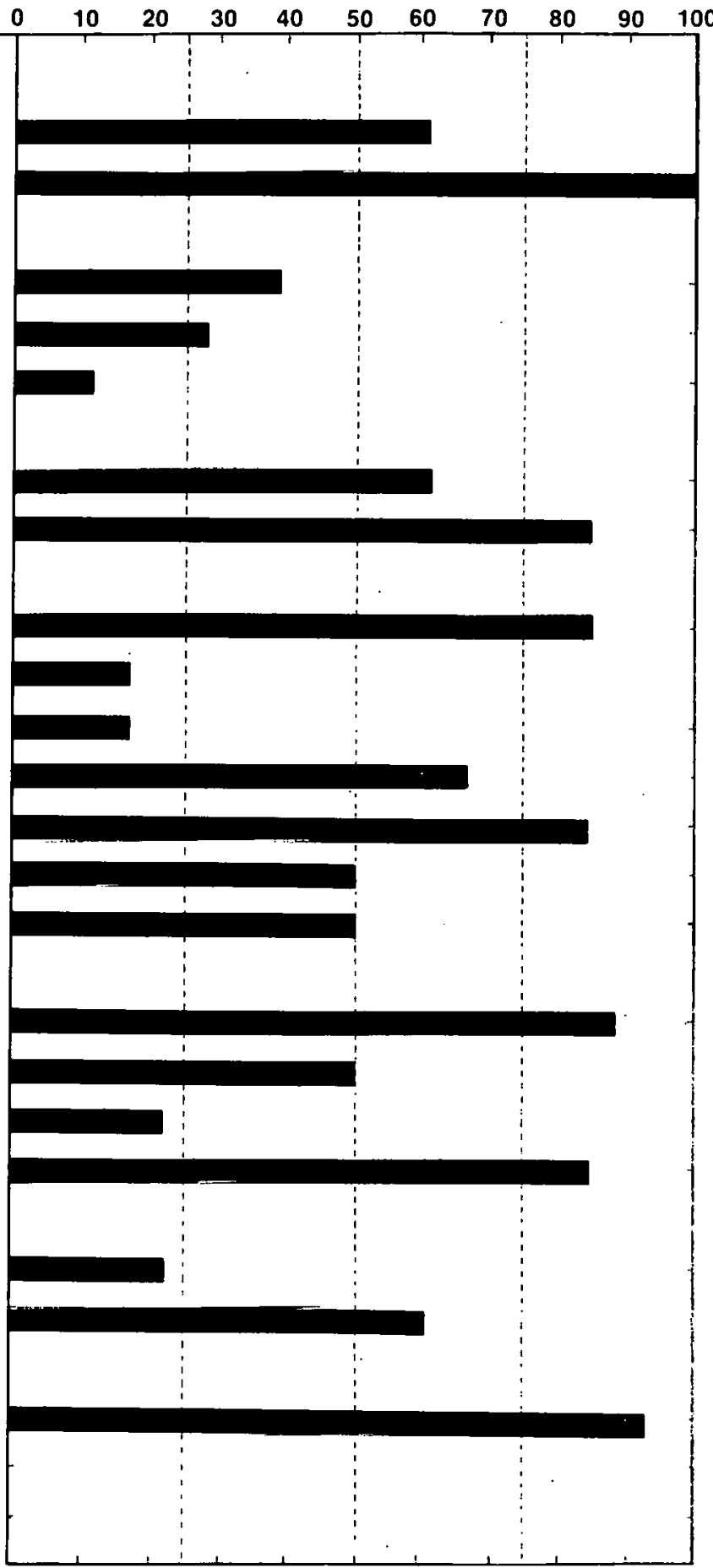

- Services and centers whose primary purpose is to disseminate information

Some sample frames were questioned about additional information sources which are applicable to their technology. For example. the manufacturers of biomass conversion equipment were also asked if they have obtained any type of solar intormation from: "the local or national office of the U.S. Department of Agriculture. including Extension and Forestry."

... These data are based upon a total of 18 respondents.

Figure 14-8.Use of Selected Information Sources: All Cooperative Extension Service State Specialists 
- National Association of County Agricultural Agents (3),

- National Association of Extension Home Economists, and

- Solar Energy Association of Northeastern Colorado.

Also mentioned were "ASCS" and "Solar Conservation Service." These organizations could not be verified by the authors. The initials "ASCS" may refer to the Agricultural Stabilization and Conservation Service, which is a USDA office, rather than a membership organization.

\subsubsection{Exposure to Publications on Solar Energy}

During the past 6 months, all 9 SHAC County Agents had read publications which included information on. SHAC technologies. The publications they could specify (each mentioned by only 1 respondent) included:

- Commercial information,

- Extension Service brochures,

- (Dir. Bruce) McKenzie's paper,

- Popular Machines Magazine,

- Promotional materials from distributors,

- Rural Electrification Magazine,

- Sunset, and

- University publications.

No publications dealing specifically with solar energy were mentioned.

\subsubsection{Use of Special Acquisition Methods}

The respondents were asked whether they had obtained any information (not just SHAC or solar energy) in the past year by computer terminal, by Computer Output Microform (COM), or by other microform (e.g., microfiche, microfilm sheets or rolls). Few of the SHAC County Agents appeared accustomed to using these special acquisitions methods, a trait common to All County Agents. In the past year, 3 of the 9 had used computer terminals, and only 1 had used COM or other microforms. Somewhat larger proportions of All State Specialists had used each of the three forms, but differences were not significant.

\subsection{SUMMARY AND COMMENTS}

Nine CES County Agents were interviewed. Seven were Agricultural Agents and two were Home Economists. All were involved with collecting and/or disseminating SHAC information. 
SHAC County Agents attached the most usefulness to:

- Costs of installing and operating a SHAC system compared to a conventional system;

- Costs and performance of SHAC systems;

- Climatological data;

- Lists of local lenders, insurers, builders, engineers, installers, manufacturers, or distributors for SHAC systems; and

- Manual methods for sizing and predicting performance and costs of SHAC systems.

Conversely, they attached little importance to "calendars of SHAC conferences and programs," "a technical description of how a particular SHAC system works," "institutional, social, environmental, and legal aspects affecting SHAC installations," and "lists of technical experts on SHAC technology."

This group gave the impression of being actively involved in SHAC both on and off the job. Their primary concerns were with practical considerations such as performance, costs, local suppliers, and how to determine when it was practical to use solar energy.

Their usual channels for receiving solar information included "periodicals, newspapers, or magazines," USDA, "an installer, builder, designer, or manufacturer," and GPO. They were more likely to belong to extension professional organizations than to solar organizations, and generally were not readers of solar periodicals. They were not used to using many of the available.information sources.

The USDA was clearly their most important information source. Thus, expanding the solar knowledge of SHAC County Agents (and other County Agents as well) can be done very effectively through the USDA-its publications, announcements, and memoranda. Attempts should be made to increase cooperation between the II.S. Department of Energy (DOE) and USDA to that end. Since CES State Specialists (responsible for both state level publications and for technical assistance to county agents and their constituents) used a wider variety of sources (including DOE and solar-specific publications), there are more opportunities for direct dissemination of solar information to that group. 
SECTION 15.0

\section{ACTIVE SOLAR HEATING AND COOLING OWNERS/MANAGERS}

\subsection{DESCRIPTION OF RESPONDENTS}

\subsubsection{Description of Sample}

This section describes the results of three telephone studies of homeowners or owners/ managers of solar buildings with active solar heating and cooling (SHAC) systems. In one study 9 homeowners with solar hot water heating systems were interviewed; in the second 9. homeowners with active solar space heating (and/or cooling) systems were interviewed; and in the third 9 owners or managers of buildings with solar energy systems were interviewed. The purpose of studying these groups was to determine the sources each respondent used to obtain information for acquiring a SHAC system and to determine, in retrospect, what type of information would have been the most useful. By learning the, information needs and the sources used, one can estimate the information needs and information habits of potential users of SHAC systems.

The sample frame for active solar Water Heating Homeowners was constructed from homeowner lists provided by the National Solar Heating and Cooling Information Center (NSHCIC) in "Selected Solar Buildings (in various states); Private Residences" [30] and from various state and regional directories. All names used were those where the contact person was the homeowner, and the home had an active solar hot water heating system but no active solar space heating system. Sources other than NSHCIC which were used included: Summaries of the Responses of the Participating Jurisdictions to the Southern Solar Energy Center Planning Project Information Request [12], the MASEC Solar Yellow Pages [9], Solar Dwellings in Kansas [31], Idaho Solar Planning Study [32], and the Catalog of Solar Energy Demonstrations and Applications in the State of Alabama [33]. Although other directories were examined, none listed homeowners names, addresses, and telephone numbers. Finally, where there were four or more names per state, this number was reduced to three by a process of random selection. After all adjustments were made, the 9 interview candidates were randomly selected from the sample frame of 33 names.

The sample frame for active solar Space Heating Homeowners was constructed from the NSHCIC "Selected Solar Buildings (in various states); Private Residences" [30] lists. Contact names were used only if that person was the homeowner and the home had an active solar space heating and/or cooling system. (It may also have had solar water heating.) No more than one name per state was used (others were eliminated through random selection). After all adjustments were made, the 9 interview candidates were randomly selected from a sample frame of 35 names.

The sample frame for SHAC Building Owners/Managers was constructed from the National Solar Heating and Cooling Commercial Demonstration Program-Key Personnel Directory (KPD) [20] and various lists from NSHCIC. The KPD listed building owners or managers associated with DOE-CS SHAC demonstration projects. Buildings owned by the Federal Government were eliminated from consideration. Other names were selected from the following NSHCIC lists: (1) "Selected Solar Buildings (in various states); Nonresidential Projects," (2) "Selected Buildings with Active Solar Cooling Systems," (3) "Schools in the U.S. with Solar Systems," (4) "Hotels and Motels with Solar Systems," 
(5) "Haspitals and Nursing Homes with Solar Systems," (6) "Housing Developments Offering Solar Systems," (7) "Solar Community/Recreation Centers in the United States," and (8) "Apartment Buildings with Solar Systems." [34] Entries which included owner or manager names were extracted, and these were combined with the qualifying entries from the KPD. The 9 interview candidates were randomly selected from the resulting sample frame of about 220 names.

Respondents. In making the telephone calls to contact the randomly selected interview candidates, it sometimes occurred that the person could not be reached. In this event, another randomly selected name was substituted for the original name. When individuals were contacted, it was verified that they really were owners or managers of homes or buildings with SHAC systems. If they were not an active solar system homeowner or building owner/manager (as appropriate), they were asked if they could refer the interviewer to someone else owning/managing an active solar home or huilding who would be an appropriate respondent. If such a referral was made, a call was then made to this new candidate; if no referral was made, a new candidate was randomly selected from the sample frame. The results of this process may be seen in Table 15-1.

Table 15-1. COMPLETION OF INTERVIEWS: ACTTVE SOLAR SPACE HEATING HOMEOWNERS, ACTIVE SOLAR WATER HEATING HOMEOWNERS, AND ACTIVE SOLAR HEATING AND COOLING BUILDING OWNERS/ MANAGERS

\begin{tabular}{|c|c|c|c|}
\hline \multirow[b]{2}{*}{ Event } & \multicolumn{3}{|c|}{ Number of Candidates } \\
\hline & $\begin{array}{c}\text { Space } \\
\text { Heating } \\
\text { Homeowners }\end{array}$ & $\begin{array}{l}\text { Water } \\
\text { Heating } \\
\text { Homeowners }\end{array}$ & $\begin{array}{l}\text { Building } \\
\text { Owners/ } \\
\text { Managers }\end{array}$ \\
\hline $\begin{array}{l}\text { Interview completed with sample } \\
\text { frame candidate }\end{array}$ & 9 & 9 & 7 \\
\hline $\begin{array}{l}\text { Interview completed with referral } \\
\text { candidate }\end{array}$ & 0 & 0 & 2 \\
\hline $\begin{array}{l}\text { Refusal or candidate termination } \\
\text { Contact attempted: could not reach } \\
\text { candidate within three attempts or } \\
\text { before interviews were completed }\end{array}$ & 4 & .4 & 3 \\
\hline Subtotal & 13 & 14 & 12 \\
\hline $\begin{array}{l}\text { Contact attempted: invalid candidate } \\
\text { (e.g., inappropriate field of interest, } \\
\text { no telephone). }\end{array}$ & $\mathbf{0}$ & 4 & 3 \\
\hline TOTAL & 13 & 18 & 15 \\
\hline $\begin{array}{l}\text { Sample frame error rate }{ }^{a} \text { (Percent) } \\
\text { Completion rate }^{b} \text { (Percent) }\end{array}$ & $\begin{array}{r}0 \\
69\end{array}$ & $\begin{array}{l}22 \\
64\end{array}$ & $\begin{array}{l}20 \\
75\end{array}$ \\
\hline
\end{tabular}

${ }^{a_{I}}$ Invalid candidates divided by TOTAL

${ }^{\mathrm{b}}$ Completed interviews divided by Subtotal 
Comparisons. For additional insight into the information needs and the information habits of the SHAC Homeowners and Building Owners/Managers, results from the two Homeowners groups are compared to the results from Passive Homeowners interviewed in this study, as well as to results for SHAC Building Owners/Managers. The data for all of these groups can be found in Appendix F.

\subsubsection{Current Status of Respondents}

In each of the Homeowners groups 3 of the 9 stated that their house, as originally built, included a solar system. Six in each group stated that the changes were made later to add the solar system. This result is in contrast to that found for Passive Homeowners, where 7 of the 9 had homes in which at least some passive designs were incorporated during construction.

Six of the 9 Space Heating Homeowners had owned their solar-heated homes 1-3 years, 3 of the 9 for over 3 years. The Water Heating Homeowners had lived with their systems for somewhat shorter lengths of time: one of the 9 had owned the system for less than a year, 7 for 1-3 years, and 3 for over 3 years.

Four of the 9 SHAC Building Owners/Managers were the manager when a solar system (not necessarily the current one) was installed; 5 of the 9 were original owners. Five of the 9 Building Owners/Managers stated that the solar system for which they were responsible was included at the time of construction of the building, and 4 stated that the system was added at a later time. One of the 9 Building Owners/Managers had been responsible for the building's solar system for less than 1 year (but more than 3 months), 4 for 1-3 years, and 4 for more than 3 years.

\subsubsection{Background of Respondents}

Four of 9 Space Heating Homeowners had master's degrees, 1 held a bachelor's degree, and 1 had an associate degree. One had received a degree 5-10 years ago, 2 10-15 years ago, and 2 more than 20 years ago (year of degree and field were not asked for associate degree holders). Three of these Homeowners had degrees in architecture, the other two degrees were in Greek and theology.

Two of the 9 Water Heating Homeowners held doctorates, 1 held a master's degree, and 2 had bachelor's degrees. Two had received their most recent degree in mechanical engineering. Other degrees were in law, business management, zoology, and oceanography. One of these degrees was granted within the past 5 years, 1 from 5-10 years ago, and the other 3 more than 15 years ago.

Current professions represented by the Space Heating Homeowner's group included architect (3), farmer, carpenter, design craf tsman, gas system manager, journalist/editor, and "solar energy advocate." Those represented by the Water Heating Homeowners were: homemaker (2), consulting engineer, heating and cooling installer and contractor, health technician, builder, entrepeneur, and retired insurance company owner.

Three of the 9 Building Owners/Managers held bachelor's degrees, and 1 held a master's degree. Their total number of college degrees was thus somewhat less than that of any of the three (SHAC and Passive) Homeowners groups. Two, however, had had some college education, and 2 had vocational/technical school training. Three had received 
their college degrees 5-15 years ago; the other more than 25 years ago. Two of the college degrees were in engineering, the others in biology and education. Present professions of the Building Owners/Managers were: construction manager (2), solar department project manager, restaurant manager, motel owner, owner of a heating and air conditioning company, utility representative, assistant director of a construction school, and a director of a private school.

\subsection{INPORMATION NEEDS OF RESPONDENTS}

Despite the fact that all respondents already had a SHAC system, most of the respondents indicated they would need information on SHAC either on the job or off the job during the next year (see Table 15-2). Five of the 9 Space Heating Homeowners expected to need information on SHAC both on their jobs and outside of their jobs compared to only 1 of the Water Heating Homeowners, 1 Building Owners/Managers, and 4 Passive Homeowners (who needed passive information). Space Heating Homeowners were only slightly more likely than any of the other groups to need SHAC information at their jobs, but were significantly $(P<0.05)$ more likely to need off-the-job SHAC information than were Water Heating Homeowners. One explanation for this difference might be that Space Heating Homeowners were more concerned with upgrading or improving the efficiency of their systems, whereas hot water systems, once in place, were relatively selfcontained. Nevertheless, the high rate of on-the-job SHAC information need (more than half needing SHAC information) was unexpected for Homeowners.

Building Owners/Managers were more similar to Water Heating Homeowners than to Space Heating Homeowners in terms of need for on-the-job versus off-the-job SHAC information need.

Table 15-2. CURRENT NEED FOR ACTIVE SOLAR HEATING AND COOLING INPORMATION BY ACTIVE SOLAR SPACE HEATING IIOMEOWNERS, ACTIVR SOLAR WATER HBATING HOMEOWNERS, ACTIVE SOLAR IIEATINO AND COOLNG BUILDING OWNERS/MANAGERS, AND PASSIVE HOMEOWNERS (Number needing information)

\begin{tabular}{lcccc}
\hline & \multicolumn{4}{c}{ Group } \\
\cline { 2 - 5 } \begin{tabular}{l} 
For Infort Need \\
\cline { 2 - 5 }
\end{tabular} & $\begin{array}{c}\text { Space Heating } \\
\text { Homeowners }\end{array}$ & $\begin{array}{c}\text { Water Heating } \\
\text { Hom }\end{array}$ & $\begin{array}{c}\text { Building Owners/ } \\
\text { Managers }\end{array}$ & $\begin{array}{c}\text { Passive } \\
\text { Homeowners }\end{array}$ \\
\hline Off the job & 7 & 1 & 2 & 4 \\
On the job & 7 & 4 & 6 & 5 \\
Both & 5 & 1 & 1 & 4 \\
None Needed & 0 & 5 & 2 & 4 \\
\hline
\end{tabular}

\subsubsection{Technical Areas}

The types of systems used by the group of active solar Space Heating Homeowners included, in addition to solar space heating, three water heating systems, and two each swimming pool heating, space cooling, and hybrid systems (see Table 15-3). Not many solar Water Heating Homeowners had solar systems other than hot water systems: 3 also 
had space heating, 2 had hybrid systems, and 1 had swimming pool heating. Building Owners/Managers were responsible for somewhat more space heating systems (8 of the 9 ), but most (6 of the 9) also had water heating systems. They were more likely than either group of Homeowners to have space cooling ( 4 of the 9).

Table 15-3. TYPES OF SYSTEMS USED BY ACTIVE SOLAR SPACE HEATING HOMEOWNERS, ACTVE SOLAR WATER HEATING HOMEOWNERS, AND ACTIVE SOLAR HEATING AND COOLING BUILDNG OWNERS/ MANAGERS (Number responding)

\begin{tabular}{lccc}
\hline & Group & \\
\cline { 2 - 4 } \multicolumn{1}{c}{ Type of System } & $\begin{array}{c}\text { Space } \\
\text { Heating } \\
\text { Homeowners }\end{array}$ & $\begin{array}{c}\text { Water } \\
\text { Heating } \\
\text { Homeowners }\end{array}$ & $\begin{array}{c}\text { Building } \\
\text { Owners/ } \\
\text { Managers }\end{array}$ \\
\hline Space heating & 9 & 3 & 8 \\
Water heating & 3 & 9 & 6 \\
Space cooling & 2 & 1 & 4 \\
Hybrid systems & 2 & 2 & 3 \\
Swimming pool heating & 2 & 2 & 2 \\
\hline
\end{tabular}

One Space Heating Homeowner volunteered also using a "water and wood combination system." One Water 'Heating Homeowner volunteered also having a heat pump and a solar air collector. Although Building Owners/Managers did not add any additional types of systems to those listed, one volunteered that the heating system was air-flow and another that the system was hydronic.

\subsubsection{Types of Information}

SHAC Homeowners and Building Owners/Managers were asked to name the information about SHAC. systems that, in retrospect, they would want to have if they were first considering the installation of a SHAC system. Seven of the 9 Space Heating Homeowners volunteered one or more items of information which they considered important. Two felt information on cost was important. However, technical information of some type was mentioned by 5 respondents: past performance data on a specific system, component specifications, useable Btu's, life span, pros and cons of various types of systems, importance of building mass and insulation, and the relative efficiency of air heating versus water heating. One respondent simply said that information from good consultants and experts was the most important information to have.

All of the 9 Water Heating Homeowners volunteered one or more important items of information that, in retrospect, they would want to have if they were first considering installation of a solar domestic water heating system. Three felt economy or cost of operation and payback was important. Other topics included: appearance, efficiency/ effectiveness, reliability, equipment and designs, proper installation of storage tank, different types of heating and cooling fluids, collectors, public information on simple passive systems, and data on amount of direct and diffuse surlight available. 
All of the 9 Building Owners/Managers also volunteered one or more important items of information they would want if starting over. Similarly to Water Heating Homeowners, 3 felt cost was important. They differed from Homeowners in that 3 specified that information on controls was important. One wanted to know how-to's of controls, 1 wanted information on different types of thermostats, and a third wanted information on passive regulation of the system. Other topies mentioned included: comparative evaluations of solar panels, equipment, technical information, expert installers, performance, efficiency, maintenance, reliability, installation instruction, and "what type to put in."

SHAC Homeowners and Building Owners/Managers were asked if there was SHAC information that they needed, but couldn't get, when they were considering solar system purchase. This question elicited responses from only 2 Space Heating Homeowners. One had received only incomplete data on component parts. The other respondent, whose solar home was designed in the late 50's, stated that solar hooks were not available then and he did not know where to look for information at that time. Water Heating Homeowncrs were somewhat more specific: 5 of the 9 stated that there was SHAC information that they could not get; 3 were able to describe the information in some detail. Two mentioned local insolation data. Two respondents lacked cost data: operating costs and installation costs. One mentioned that average temperatures for rural areas were needed. (Most temperature data is recorded in urban areas and wider daily fluctuations may be experienced in rural areas. Urban data are therefore not particularly appropriate for rural dwelling calculations.) One respondent needed sun angles in addition to insolation values; lack of this data and of performance data had made estimates of costs and payback period difficult.

The 3 Building Owners/Managers who described information they needed but had not been able to get, all stressed technical data on the systems they were considering. All 3 felt comparative performance data had not been available.

Choice Between Specific Needs. A list of 11 types of SHAC information products and 12 (11 for Building Owners/Managers) types of SHAC information categories was read to each respondent. Each respondent described the retrospective usefulness of each particular item by assigning it a value of "essential," "very useful," "somewhat useful," or "not at all useful." The values assigned to each information product/category can be used to estimate the values that would be assigned by the general public interested in SHAC. The results for the two groups of SHAC Homeowners are displayed in Figs. 15-1 and 15-2. Those for Building Owners/Managers are in Fig. 15-3.

The nine top-rated information categories/products for Space Heating Homcowners were:

- Climatological data;

- Losal huilding endes or other regulationn

- Cost and performance of systems;

- System design handbooks, installation handbooks, or reference tables;

- Costs of installing and operating a SHAC system compared to a conventional system;

- The state of the art;

- Lists of local lenders, insurers, builders, engineers, installers, manufacturers, or distributors; 
Question \#8. I will read a list of potential information or information products on solar systems. For each, please tell me how useful that information would be to you. Would the following be: essential, very useful, somewhat useful, or not at all useful?

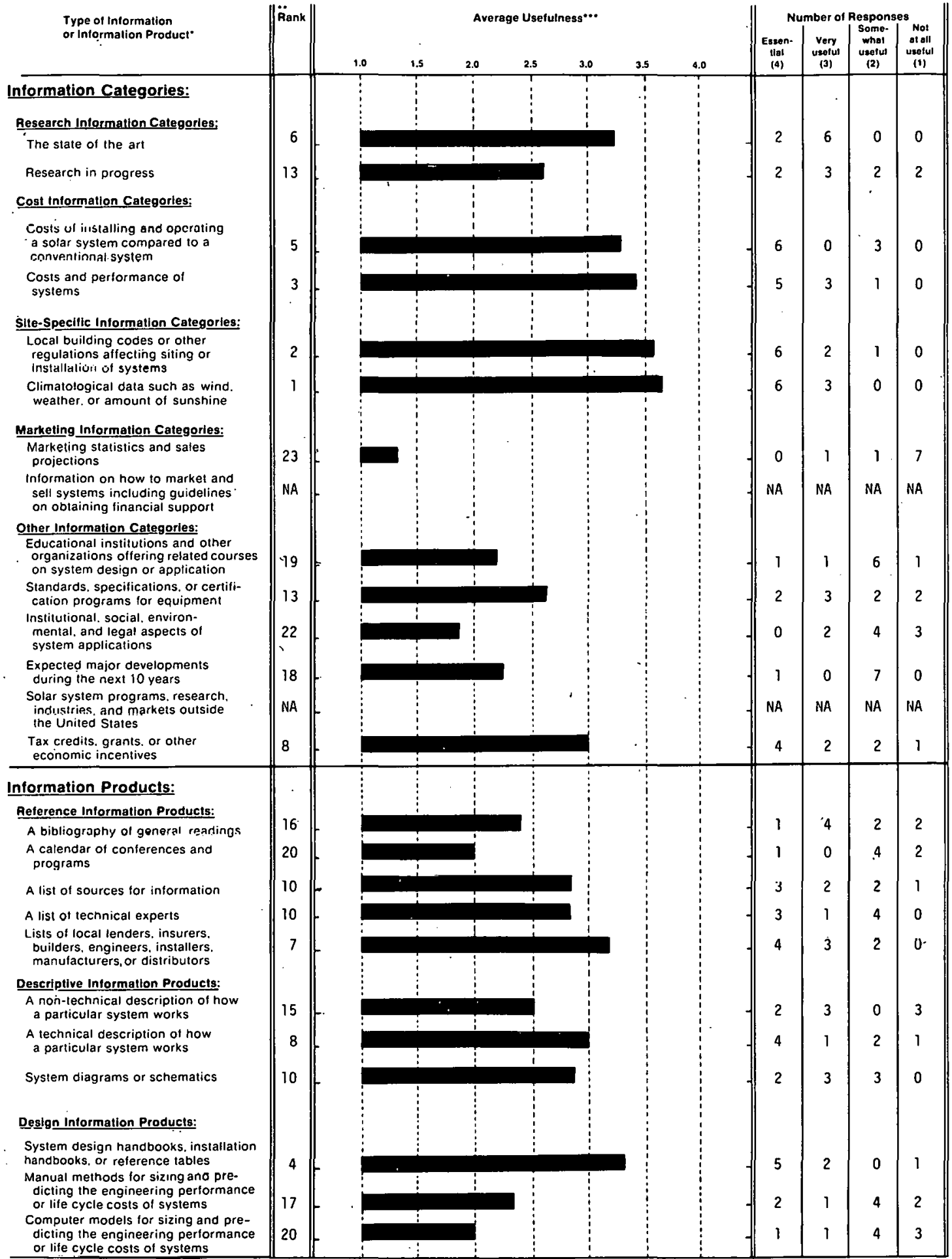

- Lach sample trame of users was nupstinned on information and intormation products in the context of their specific technology. For example, biomass sample frames were

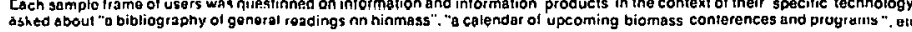

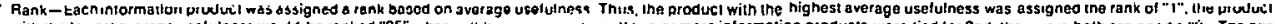

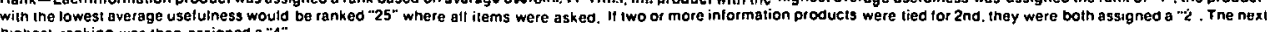

列

Figure 15-1. Usefulness of Selected Information Items: Active Space Heating Homcownore 
Question \#8. I will read a list of potential information or information products on solar systems. For each, please tell me how useful that information would be to you. Would the following be: essential, very useful, somewhat useful, or not at all useful?

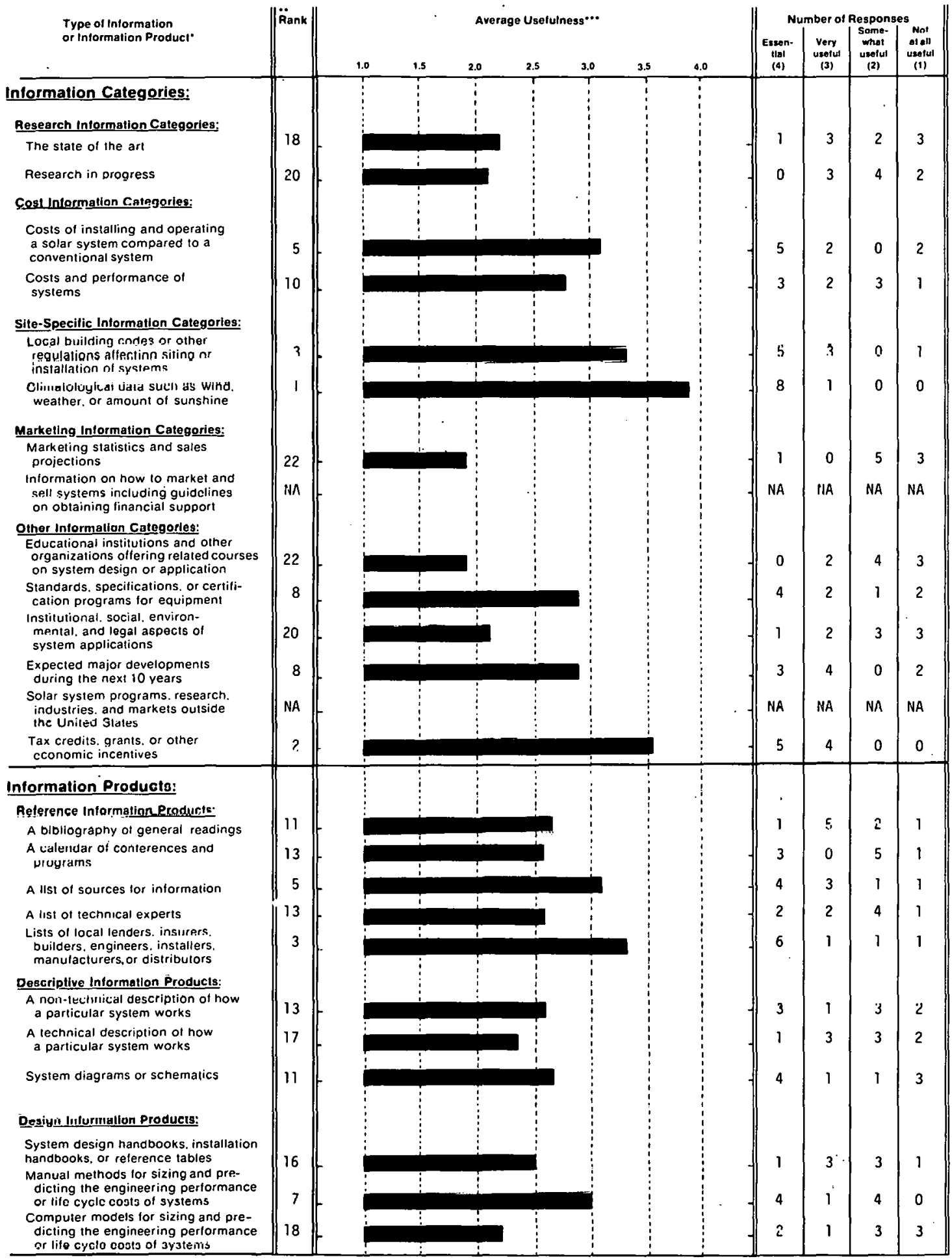

Each sample trame of users was questioned on information and intormation products in the contexi of their specilic technology. For example. oromass sample trames were (a)

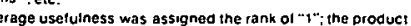
nighest ranking was then assigned a $: 4$

.. Average usefulness was calculated by assigning the responses on a 1 -4 scale from a " 4 " for "essential" to a " 1 " for "nol very useful".

Figure 15-2. Usefulness of Selected Information Items: Active Water Heating Homeowners 
Question \#8. I will read a list of potential information or information products on solar systems. For each, please tell me how useful that information would be to you. Would the following be: essential, very useful, somewhat useful, or rot at all useful?

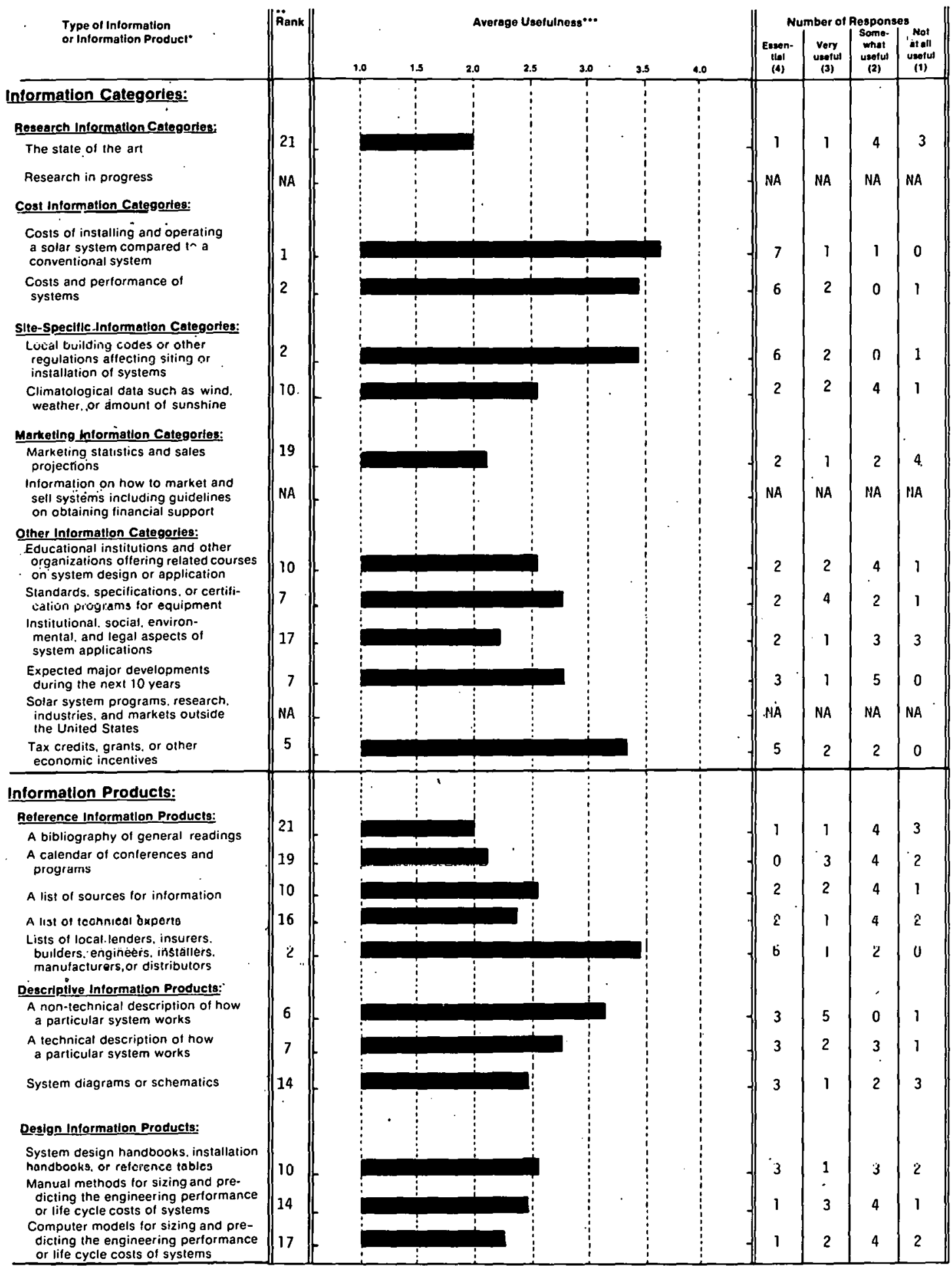

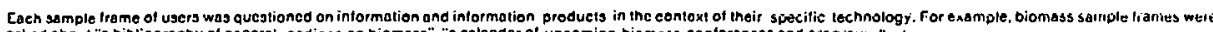

- Aank - Each information product was assigned a rank based on everage usefulness. Thus, the product with the highest average usefuthess was assigned the rank of " 1 ": the producl with the lowest average usetutness would be ranked $-25^{-}$where all tlems were asked. II two or more intormation products were tied for 2 nd. they were boin assigned a " $2 "$ "7he noxt hochesl ranking was then assigned a "4"

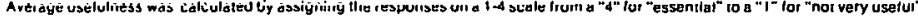

Figure 15-3. Usefulness of Selected Information Items: Active Solar Heating and Coollng Bullding Owners/Managers 
- Tax credits, grants, or other economic incentives; and

- A technical description of how a particular system works.

For Water Heating Homeowners the seven top-rated information categories/products were:

- Climatological data;

- Tax credits, grants, or other economic incentives;

- Local building codes or other regulations;

- Lists of local lenders, insurers, builders, engineers, installers, manufacturers, or distributors;

- Costs of installing and operating a SHAC system compared to a conventional system;

- Lists of sources for information; and

- Manual methods for sizing and predicting performance or costs.

SHAC Building Owners/Managers selected both items in the cost category among their highest-rated information items. Their six top-rated information items were:

- Costs of installing and operating a SHAC system compared to a conventional system;

- Costs and performance of systems;

- Local building codes or other regulations;

- Lists of local lenders, insurers, builders, engineers, installers, manufacturers, or distributors;

- Tax credits, grants, or other economic incentives; and

- A nontechnical description of how a particular system works.

Thus all three SHAC user groups agreed on relatively high utility for four of their toprated information items: "local building codes," "tax credits," "costs of installing and operating," and "lists of local lenders, insurers, builders, (etc.)."

Space Heating Homeowners assigned the lowest ratings to:

- Marketing statistics and sales projections;

- Institutional, social, environmental, and legal aspcctej

- Calendars of conferences and programs;

- Computer models for sizing and predicting performance or costs;

- Educational institutions and other organizations offering courses;

- Expected major developments during the next 10 years; and

- Manual methods for sizing and predicting performance or costs. 
Water Heating Homeowners assigned the lowest ratings to four of the same items, but also included both items in the research category:

- Marketing statistics and sales projections;

- Educational institutions and other organizations offering courses;

- Research in progress;

- Institutional, social, environmental, and legal aspects;

- The state of the art;

- Computer models for sizing and predicting performance or costs; and

- A technical discription of how a particular system works.

SHAC Building Owners/Managers gave their lowest ratings to:

- The state of the art;

- A bibliography of general readings;

- Marketing statistics and sales projections;

- Calendars of conferences and programs;

- Institutional, social, environmental, and legal aspects;

- Computer models for sizing and predicting performance or costs; and

- Lists of technical experts.

For each of the three groups, statistical tests indicated that the top-rated information items listed above were rated significantly $(P<0.05)$ higher than were the lowest-rated items listed.

Interesting differences were that SHAC Building Owners/Managers did not rate "climatological data" highly, whereas the two SHAC Homeowners groups rated it first. SHAC Building Owners/Managers rated both "a nontechnical description" and "a technical description" highly, but SHAC Space Heating Homeowners only rated "a technical descriptinn" highly. SHAC Space Heating Homeowners rated "systems design handbooks" and "state of the art" highly, while SHAC Water Heating.Homeowners found "lists of sources" and "manual methods" more useful. These data lead to the speculation that the Space Heating Homeowners required a more technical level of information than did the Water Heating Homeowners.

It should be noted that these lower-rated items were not necessarily of no worth to the SHAC Homeowners or Building Owners/Managers. For example, 2 of the 9 (22\%) Space Heating Homeowners, 3 of the 9 (33\%) Water Heating Homeowners, and 3 of the 9 (33\%) SHAC Building Owners/Managers thought that "computer models" were either "essential" or "very useful." Thus, these information categories/products could be useful to some SHAC Homeowners and Building Owners/Managers but were of a lower relative priority for each group as a whole.

Statistical tests were also used to determine whether either of these three groups of SHAC users rated any of these information items significantly higher (or lower) than they were rated by the other two groups or by Passive Homeowners. Some groups, however, tended to give higher scores in general than did other groups. The procedure for calculating the relative ratings is described in Appendix E. Among the SHAC users, the over- 
all average was highest for Space Heating Homeowners at 2.72. Water Heating Homeowners had an overall average of 2.70 and SHAC Building Owners/Managers, 2.68. Passive Homeowners, however, had a higher average (2.85) than any of the SHAC users.

Both SHAC Homeowners' groups rated "climatological data" significantly $(\mathrm{P}<0.05)$ higher than did the Building Owners/Managers. Space Heating Homeowners rated "the state of the art" significantly $(P<0.05)$ higher than did the Water Heating Homeowners.

A comparison of SHAC Homeowners (both groups combined, see Fig. 15-4) to Passive Homeowners (see Fig. 15-5) identified the passive group as significantly $(\mathrm{P}<0.05)$ more interested in "research in progress," "educational institutions," and "institutional, social, environmental, and legal aspects" than were the SHAC Homeowners. As with Space Heating Homeowners, Passive Homeowners rated "a technical description" much higher than "a nontechnical description."

\subsection{ACQUISTION OF INFORMATION BY RESPONDENTS}

\subsubsection{Initial Information Sources}

Although the SHAC Homeowners and Building Owners/Managers had already gone through the data-gathering process, they were asked in retrospect what would be the first thing they would do to obtain information about SHAC if they were starting over. Some Space Heating Homeowners seemed willing to rely on themselves, with 2 of the 9 volunteering that source. Others from this group also stated they would go to manufacturers (2), courses (2), or books (2),* architects, engineers, and others in the field. One of these Homeowners was apparently convinced of the advantages of a particular system, had obtained information from a specific contact person for that system, and would do so again.

The Water Heating Homeowners appeared to be more inclined to contact local suppliers; 4 mentioned local stores or dealers. Other mentions included: libraries, other owners, periodicals, books, installers, builders, energy associations, manufacturers, research organizations, and the contact person for a specific type of system.

SHAC Building Owners/Managers volunteered similar sources but emphasized people while eschewing books. They listed as prime information sources: U.S. Department of Energy (DOE), the local Solar Energy Information Association (SEIA), a utility company (2), an engineering firm, a plate glass company, a dealer, magazines and periodicals, a local university (2), living systems consultants, and previous users of the system under consideration. One respondent volunteered two sources he had tried unsuccessfully (the yellow pages and "Washington").

\subsubsection{Use of Selected Information Sources}

SHAC users were asked which of 20 different potential sources of solar information they had used in the past few years (for Building Owners/Managers, 21). For this question, the

*Specific books mentioned by these two respondents were: The Solar Homes Book, Bruce Anderson; The Complete Solar House, Bruce Cassiday; The Practical Guide to Solar Homes, Hudson Home Guides; Sunspots, Steve Baer; The Solar Greenhouse Book, Rodale Press; Solar Greenhouse and Swimming Pool; Harry Thomason. 
Question \#8. I will read a list of potential information or information products on solar systems. For each, please tell me how useful that information would be to you. Would the following be: essential, very useful, somewhat useful, or not at all uselul?

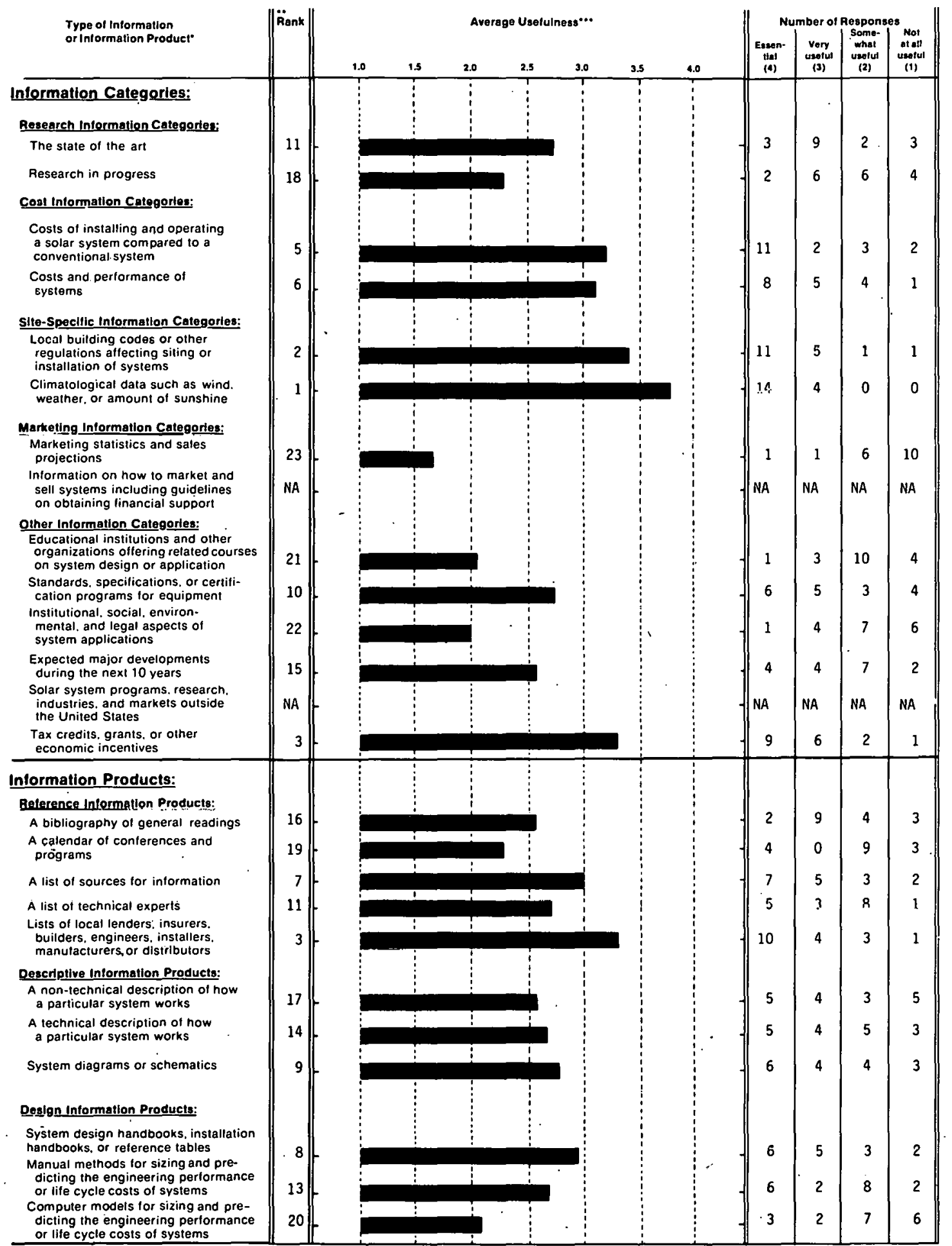

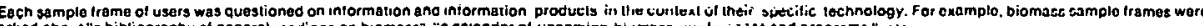

asked about "a bibliography of general readings on biomass"," "a calendar of upcoming biomass curilereinies ond programs ". otic.

Rank-Each intormetion procuct was assigned a rank basod on average usefulness. Thus. the product with the highest average usef utness was assigned ine rank of " 1 ": the procuct with the towesl average usetulness woutd be ranked "25" where all items were asked. "ll two or more intormation products were tied for 2 nd, they were both assigned a " 2 ". The next

... Average usefutness was catculated by assigning . esponses on a 1 -4 scale trom a " 4 " tor "essentral" 10 a " " " for "not very usefur".

Figure 15-4. Usefulness of Selected Information Items: Total Active Solar Heating and Cooling Homeowners 
Question \#8. I will read a list of potential information or information products on solar systems. For each, please tell me how useful that information would be to you. Would the following be: essential, very useful, somewhat useful, or not at all useful?

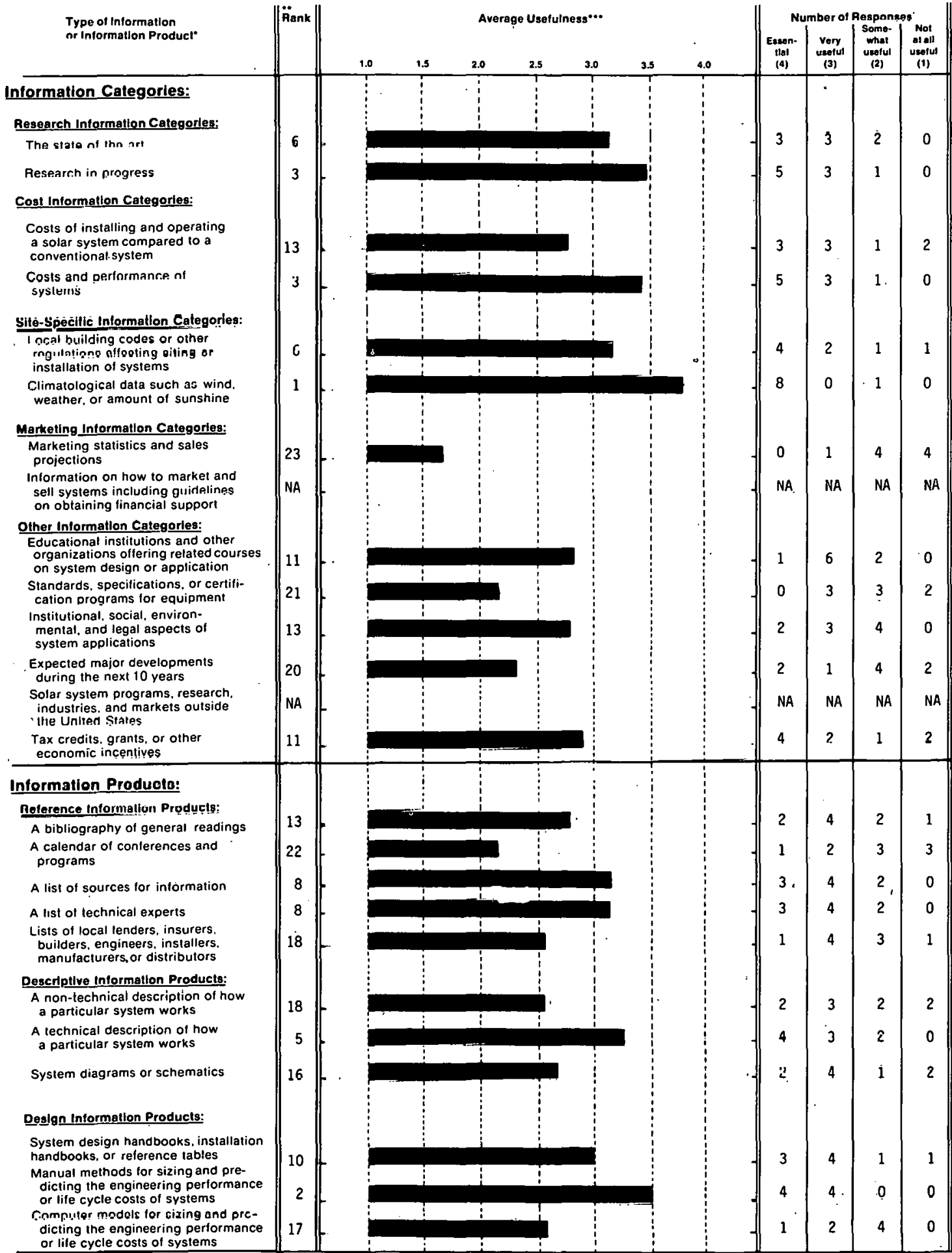

Each sample frame of users wes questioned on intormation and intormation products in the context of their specific technofogy. For example, biomass sample frames were asked aboul "a bibliography of generat readings on biomass"." "a calendar of upcoming biomass conterences end programs" "etc.

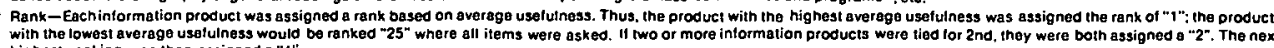

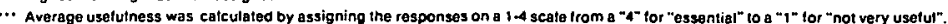

.FIgure 15-5. Usefulness of Selected Information Items: Passive Homeowners 
respondents were not asked if they had obtained information on SHAC, but instead were asked if they had obtained any solar information from each specific source. Thus, the question sought to determine which information sources were the most familiar to the respondents. The results are shown in Figs. 15-6 through 15-8. For comparison, the results for Passive Homeowners are in Fig. 15-9.

The information sources mentioned most of ten by Space Heating Homeowners were:

- Periodicals, newspapers, or magazines;

- Workshops, conferences, or 'training sessions;

- An organizational library or a local library;

- International Solar Energy Society (ISES);

- An installer, builder, designer, or manufacturer; and

- The Government Printing Office (GPO).

The information sources mentioned least often by Space Heating Homeowners were:

- Smithsonian Science Information Exchange (SSIE),

- SEIA,

- A commercial data base,

- Directly from DOE,

- Some other state or local government office or publications,

- A public utility company, and

- A state solar society or association.

Water Heating Homeowners appeared to have much less diversity in their use of information sources; only three sources had been used by more than 5 of the 9. These information sources mentioned most of ten by Water Heating Homeowners were:

- Periodicals, newspapers, or magazines;

- An installer, builder, designer, or manufacturer; and

- Private solar energy or environmental organizations.

The information sources mentioned least of ten by Water Heating Homeowners (no one of the 9 had used them) were:

- ISES,

- SFIA,

- SSIE,

- Regional Solar Energy Centers (RSECs), and

- A state solar society or association.

In addition, only 1 of the 9 Water Heating Homeowners had used: "radio or TV," "a commercial data base," or the National Technical Information Service (NTIS). Seventeen of the sources had been used by 4 or fewer respondents in this group. 
Question \#11. In the past few years, have you obtained any type of solar information from any of the following sources?

Information Sources

Public Media:
Ruviuur iv
Periodicals. newspapers or magazines

Private Solar-Involved Organizations:

Private solar energy or environmental organizations

- The local chapter or national headquarters of International Solar Energy Society (ISES). including their publications I ne local chápter or natıonal headquarters of Solar Energy Industries Association (SEIA). including thelr publications

\section{Contacts with Professionals:}

An installer, builder. designer or manufacturer of solar systems

Workshops. conterences or training sessions

\section{Information Services*:}

Your organizational library or a local library

A commercial data bảse: for example. Lockheed. SDC. BRS

Smithsonian Science Information Exchange (SSIE)

A Federal library or information center; for example, the National Agricultural Library or the Environmental Data System

The Government Printing Office (GPO)

National Technical Information Service (NTIS)

Technical Information Center at Oak Ridge (TIC)

Government Solar-Involved Organizations

Directly from the U.S. Department of Energy

National Solar Heating \& Cooling Information Center

Regional Solar Energy Centers

State Energy or Solar Offices

Other:

Some other state or local government office or publication

A public utility company

Sources for this specific sample frame**:

Your State Solar Society or Association
Percentage Responding Yes ${ }^{\cdots}$

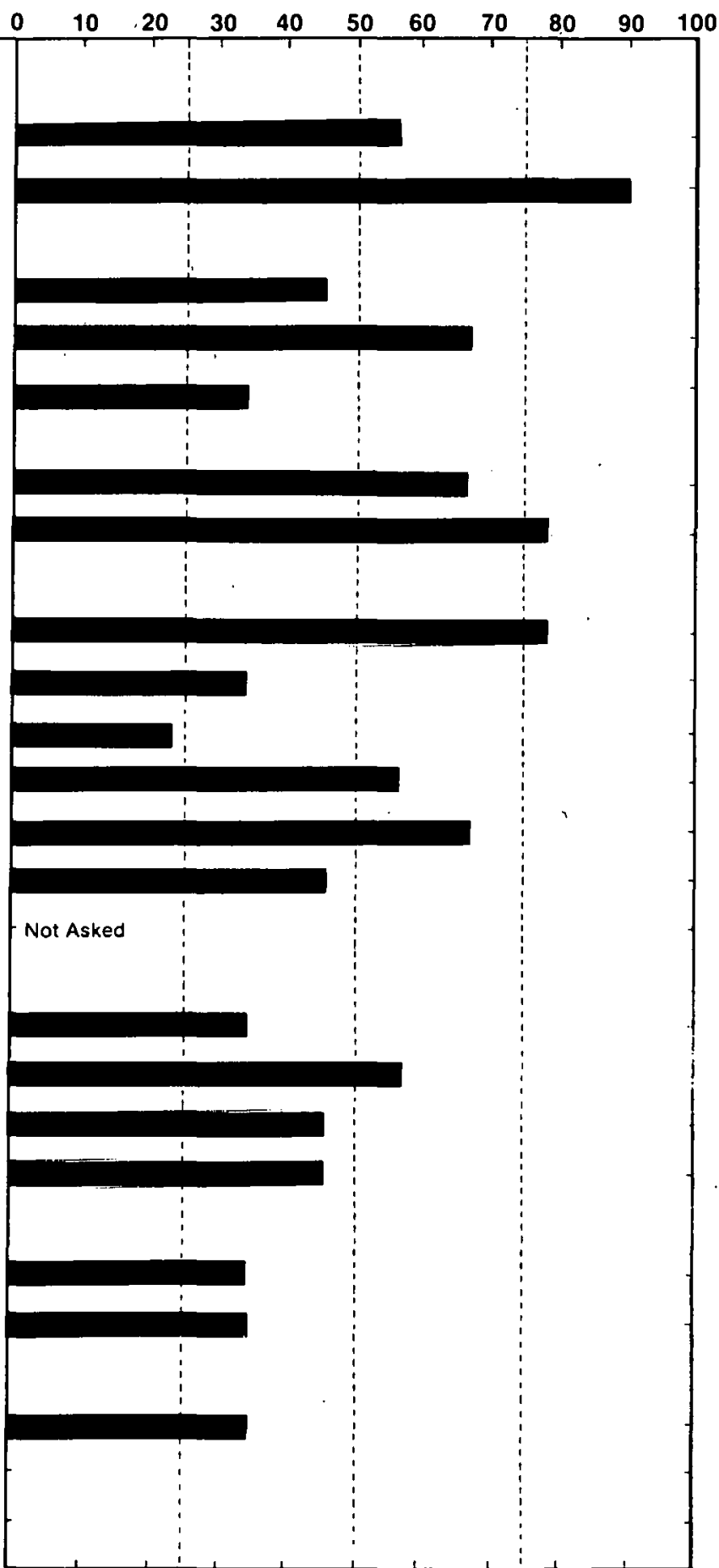

- Services and centers whose primary purpose is to disseminate information.

- Some sample frames were questioned about additional information sources which are applicable to their technology. For example. the manufacturers of biomass conversion equipment were also asked it they have obtained any type of solar information from: "the local or national office of the U.S. Department of Agriculture. including Extension and Forestry:"

$*$ These data are based upon a total of 9 respondents. 
Question \#11. In the past few years, have you obtained any type of solar information. from any of the following sources?

Information Sources

Public Media:
Periodicals. newspapers or magazines
Private Solar-Involved Organizations:
Private solar energy or environmental organizations
The local chapter or natlonal headuuarlers of International
Solar Energy Society (ISES). including their publications
The local chapter or national headquarters of Solar Energy
. Industries Association (SEIA), including their publications
Contacts with Professionals:

An installer, builder, designer or manufacturer of solar systems

Workshops, conferences or training sessions

Information Services*:

Your organizational library or a local library

A commercial data base; for example, Lockheed, SDC. BRS

Smithsonian Science Information Exchange (SSIE)

A Federal library or information center; for example, the National Agricultural Library or the Environmental Data System

The Government Printing Office (GPO)

National Technical Information Service (NTIS)

Technical Information Center at Oak Ridge (TIC)

Government Solar-Involved Organizations

Directly from the U.S. Department of Energy

National Solar Heating \& Cooling Information Cente

Regional Solar Énergy Centers

State Energy or Solar Offices

Other:

Some other state or local government office or publication

A public utility company

Sources for this specific sample frame**:

Your State Solar Society or Association
Percentage Responding Yes $\cdots$

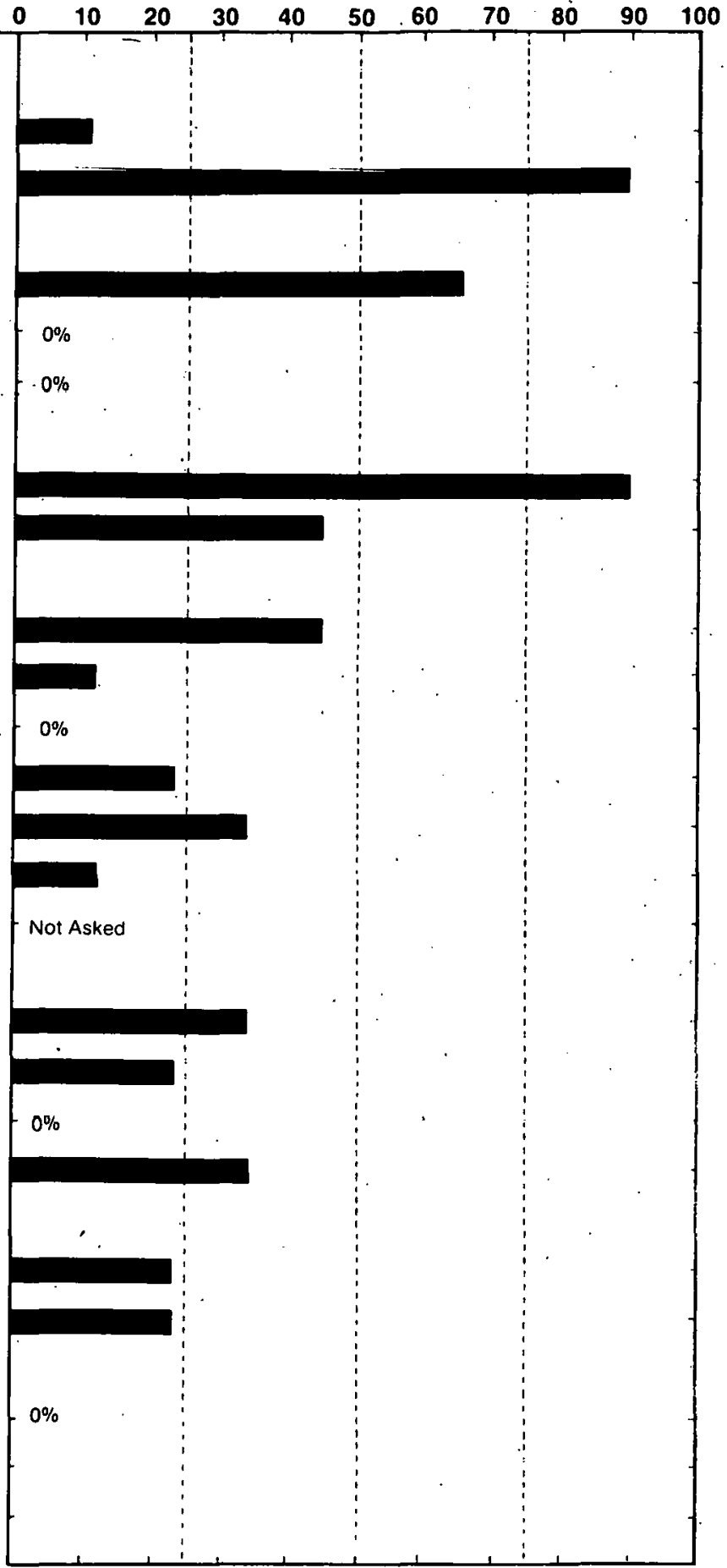

- Services and centers whose primary purpose is to disseminate information.

- Some sample framcs wore questioned about additinnal infnrmation sources which are applicable to their technology. For example. the manufacturers of biomass conversion equipment were also asked it they have obtained any type of solar intormatıon irom: "ine local or national office of the U.S. Department of Agriculture. including Extension and Forestry."

... These data are based upon a total of 9 respondents.

Figure 15-7. Use of Selected Information Sources: Active Water Heating Homeowners 
Question \#11. In the past few years, have you obtained any type of solar information from any of the following sources?

Intormation Sources

Percentage Responding Yes ***

Public Media:

Radio or TV

Periodicals, newspapers or magazines

Private Solar-Involved Organizations:

Private solar energy or environmental organizations

The local chapter or national headquarters of International Solar Energy Society (ISES), including their publications

The local chapter or national headquarters of Solar Energy IndIIstrips Assnriatinn (SFIO), insluding thoir publioationo

\section{Contacts with Prolessionals}

An installer, builder, designer or manufacturer of solar systems

Workshops, conferences or training sessions

Information Services":

Your organizational library or a local library

A commercial data base; for example, Lockheed, SDC, BRS

Smithsoniari Science inrormation Exchange (SSIE)

A Federal library or information center: for example, the National Agricultural Library or the Environmental Data System

The Government Printịng Office (GPO)

Ivationai lecnnicâl Information Service (NTIS)

Technical Information Center at Oak Ridge (TIC)

Guvernment Solar-Involved Organizations

Directly from the U.S. Department of Energy

National Solar Heating \& Cooling Information Cente

Regional Solar Energy Conters

Stato Enorgy ur Solar Offices

Other:

Some other state or local government office or publication

A public utility company

Sources for this specific sample frame**:

Your State Solar Society or Association

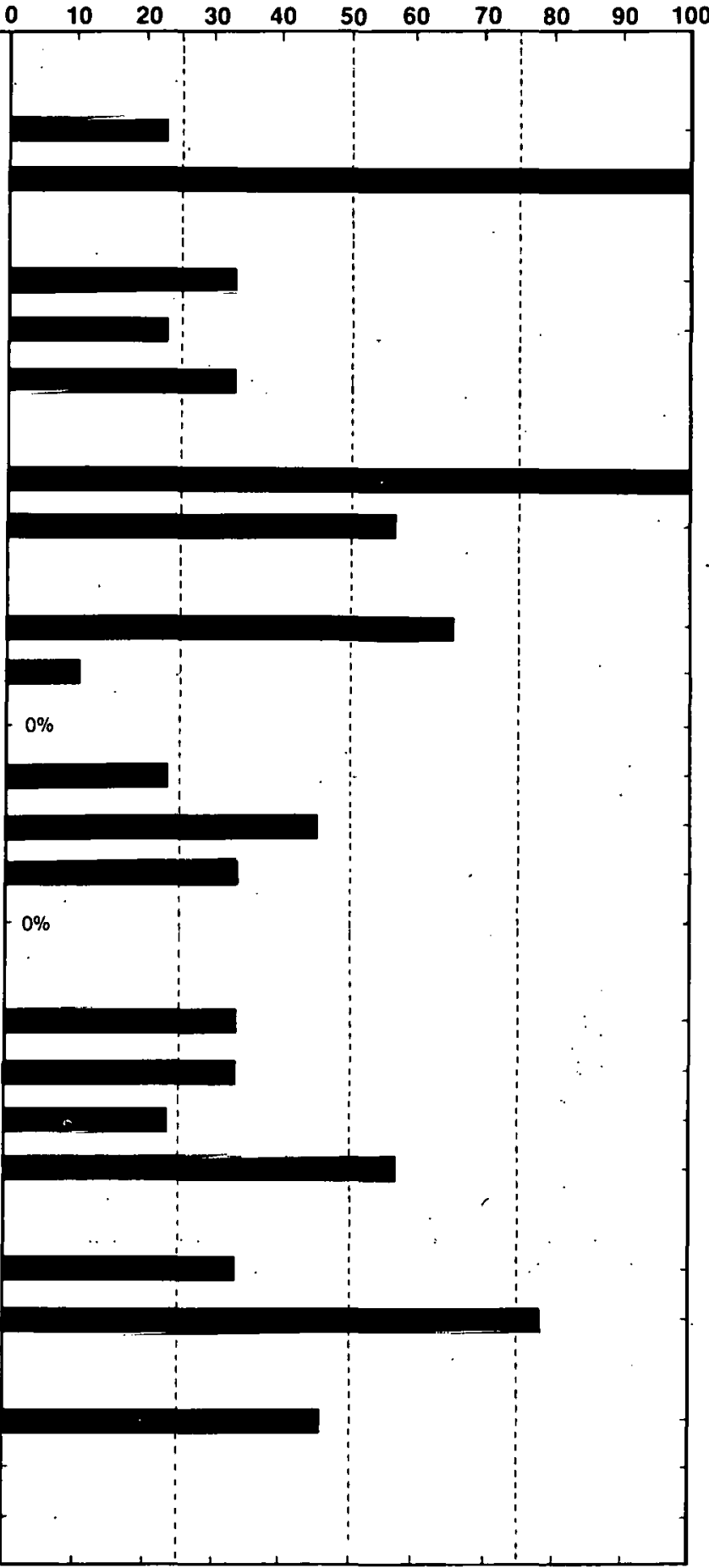

- Services and centers whose primary purpose is to disseminate information:

- Some sample frames were questioned about additional information sources which are applicable to their technology. For example. the manufacturers of biomass conversion equipment were also asked if they have obtained any type of solar information from: "the tocal or national office of the U.S. Department of Agriculture, including Extension and Forestry."

*** iThese data are based upon a total of 9 respondents.

\section{Figure 15-8. Use of Selected Information Sources: Active Solar Heating and} Cooling Building Owners/Managers 
Question \#11. In the past few years, have you obtained any type of solar information from any of the following sources?

Information Sources

\begin{tabular}{l} 
Public Media: \\
\hline Radio or TV \\
Periodicals, newspapers or magazines
\end{tabular}

Private Solar-Involved Organizations:

Private solar energy or environmental organizations

The lucal chapter or national headquarters of International

Solar Energy Society (ISES), including their publications

The local chapter or national headquarters ol Sular Energy Industries Association (SEIA), Including their publications

\section{Contacts with Professionals:}

An installer, builder, designer or manufacturer of solar systems

Workshops, conferences or training sessions

\section{Information Services*:}

Your organizational library or a local library

A commercial data base; for example, Lockheed, SDC, BRS

Smithsonian Science Information Exchange (SSIE)

A Federal library or information center; for example, the National Agricultural Library or the Environmental Data System

The Government Printing Office (GPO)

National Technical Information Service (NTIS)

Technical Information Center at Oak Ridge (TIC)

Government Solar-Involved Organizations

Directly from the U.S. Department of Energy

National Solar Heating \& Cooling Information Center

Hegional Solar Energy Centers

State Energy or Sọlar Offices

Other:

Some other state or local government office or publication

A public utility company

Sources for this specific sample frame ${ }^{n+*}$ :

Your State Solar Soçiẹty or Association
Percentage Responding Yes "**
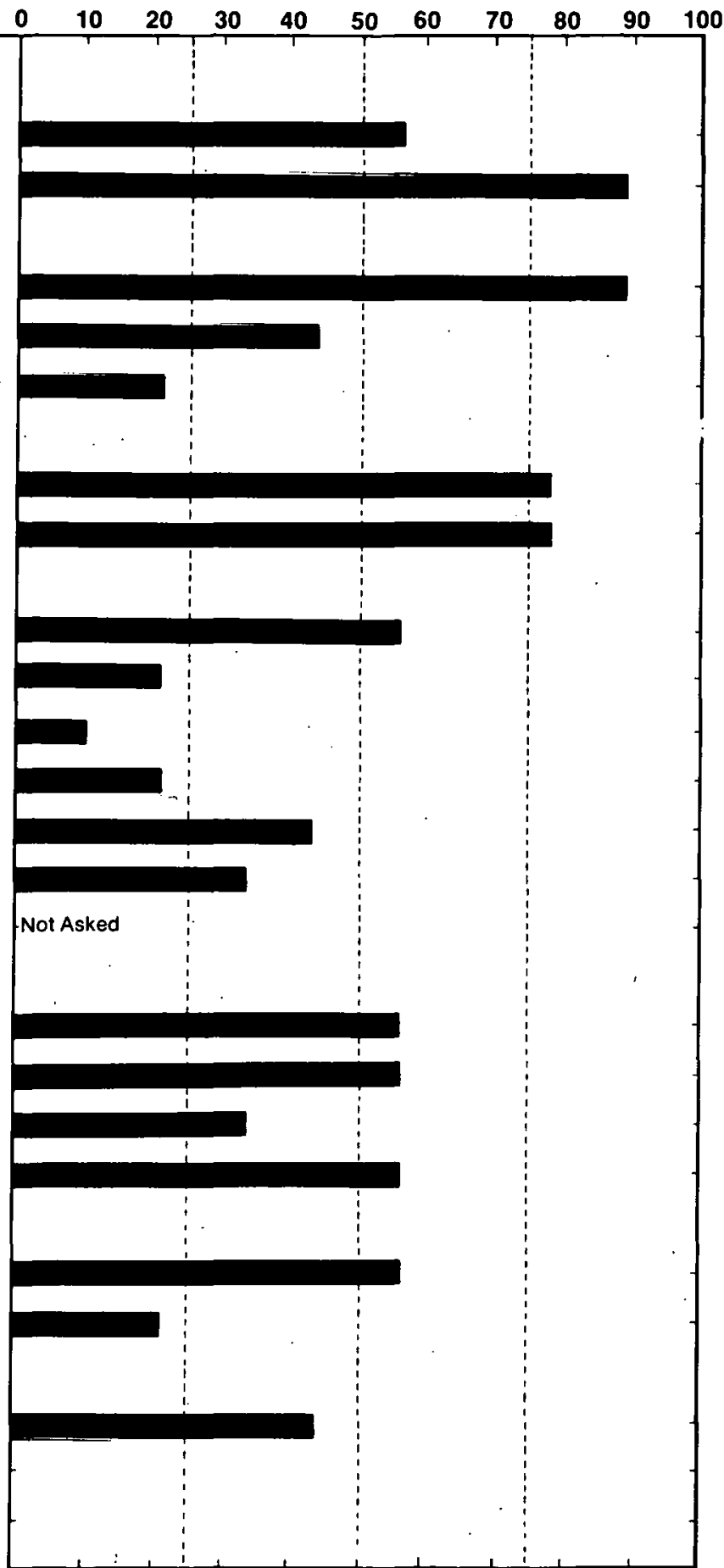

- Services and centers whose primary purpose is to disseminate information

- Some sample frames were questioned about additional information sources which are applicable to their technology. For example, the manufacturers of biomass conversion equipment were also asked it they have obtained any type of solar information from: "lite local oi natinnal office of the U.S. Department of Agriculture, including Extension and Forestry."

*.* These data are based upon a total of 9 respondents. 
The Water Heating Homeowners obviously had radically different information acquisition patterns from Space Heating Homeowners and from Passive Homeowners (both of which were relatively similar).

The information sources used most often by SHAC Building Owners/Managers were:

- Periodicals, newspapers, or magazines;

- An Instailèr, builder, designer, or manufacturer;

- A public utility company; and

- An organizational library or a local library.

SHAC Building Owners/Managers were the only one of the three groups to have a high proportion which had used "a public utility company" while. "perindireals" and "an instellor, builder, designer, or manufacturer" were among the most of ten used for all three groups.

The information sources mentioned least often by SHAC Building Owners/Managers were:

- SSIE,

- Technical Information Center (TIC),

- A commercial data base,

- Radio or TV,

- ISES,

- A federal library or information center, and

- RSECS.

The typical Space Heating Homeowner (like the Passive Homeowner) seemed to have used more sources than the typical Water Heating Homeowner, while the SHAC Building Owner/Manager was about midway between the two groups.

\subsubsection{Membership in Solar-Interested Organizations}

Less than half of the respondents in each of the three SHAC user groups reported on in this section were members of a professional, technical, or other organization with an interest in solar energy. However, only 2 of the 9 Passive Homeowners were members of such organizations, so the SHAC users showed somewhat more organizational involvement.

Four of the 9 Space Heating Homeowners, 3 of the 9 Water Heating Homeowners, and 3 of the 9 Building Owners/Managers mentioned being members of one or more such organizations. The organizations named (and the number of times mentioned) are shown in Table 15-4.

Also mentioned by a Space Heating Homeowner was an organization that the authors could not verify; i.e., "SCSA" (in Idaho?). The only organizations mentioned by more than 1 respondent in the three groups were American Society of Heating, Refrigerating and Air Conditioning Engineers (ASHRAE) and ISES, with the latter the more popular organization. 
Table 15-4. MEMBERSHIP IN SOLAR-INTERESTED ORGANIZATIONS: ACTIVE SOLAR SPACE HEATING HOMEOWNERS, ACTTVE SOLAR WATER HEATTNG HOMEOWNERS, AND ACTIVE SOLAR HEATING AND COOLING OWNERS/ MANAGERS

\begin{tabular}{cccc} 
& \multicolumn{3}{c}{ Group $^{8}$} \\
\cline { 2 - 4 } Organization & $\begin{array}{c}\text { Space } \\
\text { Heating } \\
\text { Homeowners }\end{array}$ & $\begin{array}{c}\text { Weater } \\
\text { Homeowners }\end{array}$ & $\begin{array}{c}\text { Building } \\
\text { Owners/ } \\
\text { Managers }\end{array}$ \\
& & &
\end{tabular}

\begin{tabular}{|c|c|c|c|c|}
\hline American Gas Association & - & - & 1 & 1 \\
\hline American Institute of Architects (AIA) & 1 & - & - & l \\
\hline American Institute of Aeronautics & & & & \\
\hline $\begin{array}{l}\text { and Astronautics } \\
\text { American Society of Heating, Re- }\end{array}$ & - & 1 & - & 1 \\
\hline frigerating and Air Conditioning & & & & \\
\hline Engineers (ASHRAE) & - & 1 & 1 & 2 \\
\hline $\begin{array}{l}\text { American Society of Mechanical } \\
\text { Engineers }\end{array}$ & & & & \\
\hline $\begin{array}{l}\text { Engineers } \\
\text { Association of Enerov Engineers }\end{array}$ & - & 1 & - & 1 \\
\hline Association of Energy Engineers & - & 1 & - & 1 \\
\hline Building Industry Association & - & 1 & - & 1 \\
\hline Concerned Citizens Action Associa- & & & & \\
\hline tion (Tennessee) & - & 1 & - & 1 \\
\hline Connecticut Solar Energy Society & 1 & - . & - & 1 \\
\hline Fuel Merchants Association of New & & & & \\
\hline Jersey & - & - & 1 & 1 \\
\hline Hiwassee Nature Center (Tennessee) & - & 1 & - & 1 \\
\hline Illinois Energy Society & - & 1 & - & 1 \\
\hline International Solar Energy Society & 3 & - & - & 3 \\
\hline Labor International Local 89 & - & - & 1 & 1 \\
\hline National Association of Home Builders & - & - & - & - \\
\hline New England Solar Energy Association & - & - & - & - \\
\hline New England Solar Energy Society & 2 & - & - & - \\
\hline New Jersey Solar Energy & - & - & 1 & 1 \\
\hline PC Gas Association (California) & - & $=$ & 1 & 1 \\
\hline Solar Coalition & 1 & - & - & 1 \\
\hline Solar Energy Industries Association & - & - & 1 & 1 \\
\hline Urban Land Institute & - & 1 & - & 1 \\
\hline None & 5 & 6 & 6 & 17 \\
\hline
\end{tabular}

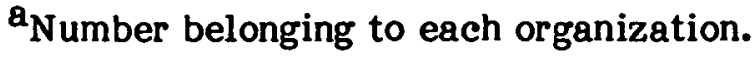

\subsubsection{Exposire to Publications on Solar Energy}

During the past 6 months, at least 7 of the 9 in each of the three groups had read publications which included information on SHAC.

The publications each group could specify (and the number of times mentioned) are shown in Table 15-5. 
Table 15-5. PUBLCATIONS READ WHICH INCLUDED INFORMATION ON SOLAR ENERGY: ACTIVE SOLAR SPACE HEATING HOMEOWNERS, ACTIVE SOLAR WATER HEATING HOMEOWNERS, AND ACTIVE SOLAR HEATTNG AND COOLING OWNERS/MANAGERS

\begin{tabular}{|c|c|c|c|c|}
\hline \multirow[b]{2}{*}{ Publication } & \multicolumn{4}{|c|}{ Group $^{\mathbf{a}}$} \\
\hline & $\begin{array}{c}\text { Space } \\
\text { Heating } \\
\text { Homeowners }\end{array}$ & $\begin{array}{c}\text { Water } \\
\text { Heating } \\
\text { Homeowners }\end{array}$ & $\begin{array}{l}\text { Building } \\
\text { Owners/ } \\
\text { Managers }\end{array}$ & Total \\
\hline Alternative News & 1 & - & - & 1 \\
\hline AIA Journal & 1 & - & - & 1 \\
\hline Architectural Record & 1 & + & - & 1 \\
\hline$\overline{\text { ASHRAE Journal }}$ & - & 1 & - & 1 \\
\hline Building Construction & 1 & - & - & 1 \\
\hline $\begin{array}{l}\text { California Energy Commission pub- } \\
\text { lications (including Solar for }\end{array}$ & & & & \\
\hline Present Homes) & - & - & 1 & 1 \\
\hline Construction & - & - & 1 & 1 \\
\hline Copper News & 1 & $-\infty$ & - & 1 \\
\hline Engineering News Record & 1 & - & - & 1 \\
\hline Illinois Institute of Natural & & & & \\
\hline Resources publications & - & 1 & - & 1 \\
\hline International Solar Energy Society & & & & \\
\hline publications & 1 & - & 2 & 3 \\
\hline Journal of Energy & - & 1 & 一 & 1 \\
\hline Mother Earth News & 1 & 一 & - & 1 \\
\hline$\overline{\text { Newsweek }}$ & - & 1 & - & 1 \\
\hline New England Solar Association & & & & \\
\hline ncwglctter & 1 & 一 & - & 1 \\
\hline $\begin{array}{l}\text { Passive Solar Energy Book (by Mazria) } \\
\text { Philadelphia Bulletin (on ceramic }\end{array}$ & 一 & 1 & - & 1 \\
\hline & & & & \\
\hline insulation) & 1 & - & - & 1 \\
\hline Pittsburgh Plate Glass publications & - & - & 1 & 1 \\
\hline Popular Mechanies & 1 & - & - & 1 \\
\hline Popular Boiencé & - & 1 & - & 1 \\
\hline $\begin{array}{l}\text { Rodell Press, (including passive } \\
\text { publications) }\end{array}$ & - & 1 & - & 1 \\
\hline Solar Age & 3 & - & 1 & 4 \\
\hline Solar Energy Digest & 1 & - & 1 & 2 \\
\hline Solar Energy Intelligence Report & - & - & 1 & 1 \\
\hline Solar Energy Thermal Processes & & & & \\
\hline (by Duffie) & 一 & 一 & 1 & 1 \\
\hline Solar Engineering & 1 & 3 & 2 & 6 \\
\hline The Solar Greenhouse Book (by & & & & \\
\hline Jaines McCullagh) & 一 & 1 & 一 & 1 \\
\hline Solar Utilization News & 1 & - & - & 1 \\
\hline Sunspots (book by Steve Baer) & - & 1 & - & 1 \\
\hline U.S. News and World Report & $\dot{-}$ & 1 & - & 1 \\
\hline Wall Street Journal & 一 & - & 1 & 1 \\
\hline
\end{tabular}

${ }^{\mathbf{a}}$ Number mentioning each publication. 
Also mentioned by one Space Heating Homeowner was the "American Architectural Journal," a publication that could not be verified by the authors. Only three publications were mentioned more than once. Solar Engineering and Solar Age were clearly the most popular.

\subsection{SUMMARY AND COMMENTS}

Twenty-seven users of SHAC systems were interviewed. Eighteen of them were homeowners with either active solar space heating, active solar domestic hot water, or both. The other nine were owners or managers of buildings which had active solar systems. Numerous professions were represented by these groups: architects, homemakers, business managers, construction contractors, engineers, builder technicians, carpenters, solar advocates, journalists, educators, farmers, and others.

As a group, these SHAC users assigned the greatest utility to information on:

- Local building codes or other regulations affecting SHAC systems;

- Costs of installing and operating a SHAC system compared to a conventional system;

- Tax credits, grants, or other economic incentives for SHAC systems; and

- Lists of local lenders, insurers, builders, engineers, installers, manufacturers, or distributors of SHAC systems.

The Homeowners also found "climatalogical data" very useful." Space Heating Homeowners also felt "state of the art" and "a technical description" were highly useful.

Relatively low utility was attributed by all three groups to "computer models," "marketing statistics," and "institutional, social, legal ... aspects."

For all three SHAC user groups, cost (including financial incentives) and site-specific information (including local contacts) were more generally important than were design information products. Space Heating Homeowners needed more technically oriented information than did the other two groups.

All of these SHAC users most of ten received solar information from "periodicals ..." and "an installer, builder, designer, or manufacturer." In all three groups, the majority of respondents were not likely to belong to organizations which provided solar information. They did, however, access a wide variety of periodicals and other publications containing solar information. Space Heating Homeowners used a wide range of information sources, SHAC Building Owners/Managers used a more restricted range of sources, and Water Heating Homeowners used very few information sources. Homeowners were inclined to receive information either from books or from people, but Building Owners/Managers seemed to prefer people strongly.

Because many of these respondents must be considered "early innovators" [3], and because respondents were asked to answer questions retrospectively, care must be taken in extrapolating these results to all potential purchasers of SHAC systems. 


\section{SEPI}




\section{SECTION 16.0}

\section{REFERENCES}

1. Belew, William W.; Wood, Barabara L. Solar Information User Priority Study. SERI/ TR-751-472. Golden, CO: Solar Energy Research Institute. May 1980.

2. Belew, William W.; Wood, Barbara L.; Marle, Terry L.; Reinhardt, Carol L. General Solar Information User Study. SERI/TR-751-753. Golden, CO: Solar Energy Research Institute; November, 1980.

3. Rogers, Everett M. Diffusion of Innovations. New York, NY: The Free Press. 1962

4. Solar Heating and Cooling_Research and Development Project Summaries. DOE/CS0010. Washington, DC: Department of Energy. May, 1978.

5. RIP (Energy Research in Progress). DOE/RECON: File 15. Washington, DC: Department of Energy. Spring/Summer, 1979.

6. SSIE (Smithsonian Science Information Exchange). Lockheed: File 65. Washington, DC: The Smithsonian Institution. 75-79/MAR.

7. Belew, William W.; et al. Photovoltaics Information User Study. SERI/TR-751652. Golden, CO: Solar Energy Research Institute. May, 1980."

8. Manufacturers Data Base. Solar Energy Information Data Bank (SEIDB). Golden, CO: Solar Energy Research Institute. Spring/Summer, 1979.

9. MASEC Solar Yellow Pages. Minneapolis, MN: Mid-American Solar Energy Complex (MASEC). July, 1978.

10. Northeast Yellow Pages of Solar Energy Resources. Second Edition. Brattleboro, VT: Northeast Solar Energy Association.' February, 1978.

11. "Preliminary List of Solar Equipment Manufacturers, Dealer/Distributors, Contractors/Installers and Consultants in New Jersey." Newark, NJ: New Jersey Department of Energy.

12. Summaries of the Responses of the Participating Jurisdictions to the Southern Solar Energy Center Planning Project Informatioin Request. Atlanta, GA: Southern Solar Energy Center-DOE. December, 1978.

13. Nevada Solar Energy Handbook. Carson, City, NV: Nevada Department of Energy; Boulder City, NV: Desert Research Institute. January, 1979.

14. Washington State Solar Networking Project. Seattle, WA: Western Washington Solar. Energy Association. March, 1979.

15. Solar Energy Directory for Utah. Salt Lake City, UT: Utah Energy Office. November, 1978. 
16. Arizona Solar Industries Guide. Phoenix, AZ: Arizona Solar Energy Research Commission. Spring, 1979.

17. Oregon Solar Energy Directory. Eugene, OR: University of Oregon. 1978.

18. A New Mexico Solar Business Directory. Las Cruces, NM: New Mexico Solar Energy Institute. July, 1978.

19. Western Regional Solar Energy Directory. California Edition. San Diego, CA: Southern California Solar Energy Association. 1978-1979.

20. National Solar Heating and Cooling Commercial Demonstration Program - Key Personnel Directory. DOE-CS,0038. Washington, DC: Department of Encrgy. June, 1978.

21. Solar Heating and Cooling Demonstration Project Summaries. DOE-CS, 0038-2. Washington, DC: Department of Energy. January, 1977.

22. "Master List of the Energy Planners Network." Chicago, IL: American Planning Association. Received from Schiffman, Yale. McLean, VA: MITRE Corporation.

23. Architectural Planners Data Base. Philadelphia, PA: National Solar Heating and Cooling Information Center.

24. The AEE Directory of Energy Professionals, 1979-1980. Atlanta, GA: Association of Energy Engineers. Fairmont Press. 1979.

25. Electric Utility Solar Energy Activities 1978 Survey. ER-966-SR. Palo Alto, CA: Electric Power Research Institute (EPRI). May, 1979.

26. Solar Energy Utilization: Natural Resource Conservation by the Gas Utility Industry. Arlington, VA: American Gas Association, Solar Energy Committee. January, 1978.

27. Education Data Base. Solar Energy Information Data Bank (SEIDB). Golden, CO: Solar Energy Research Institute (SERI). Spring/Summer, 1979. Also available in hard copy as the National Solar Energy Education Directory. SERI/SP-42-141. Golden, CO: Solar Energy Research Institute. January, 1979.

28. County Agents Directory. 63rd Edition. Flossmor, IL: C. L. Mast, Jr. 1978.

29. County and City Data Book, 1977 (A Statistical Abstract Supplement). Washington, DC: U.S. Department of Commerce, Bureau of the Census. U.S. Government Printing Office.

30. "Selected Solar Buildings (in Various States); Private Residences." Philadelphia, PA: National Solar Heating and Cooling Information Center (NSHCIC).

31. Solar Dwellings in Kansas. Manhattan, KS: George J. Pytlinski, Center for Energy Studies, Kansas State University. November 15, 1977.

32. Idaho Solar Planning Study. Pocatello, Idaho: Idaho State University. 1978. 
33. Catalog of Solar Energy Demonstrations and Applications in the State of Alabama. Huntsville, AL: Alabama Solar Energy Center. Kenneth E. Johnson Environmental and Energy Center, University of Alabama. January, 1979.

34. "Selected Solar Buildings (in Various States); Nonresidential Projects." "Selected Buildings with Active Solar Cooling Systems." "Schools in U.S. with Solar Systems." "Hotels and Motels with Solar Systems." "Solar Community/Recreation Centers in U.S." "Apartment Buildings with Solar Systems." "Hospitals and Nursing Homes with Solar Systems." "Housing Developments Offering Solar Systems." Philadelphia, PA: National Solar Heating and Cooling Information Center. 


\section{S=강}

1 
APPENDIX A

\section{GROUPS NCLUDED}

IN STUDY 


\section{SER|}


The following table (Table A-1) lists the 86 groups included in this study of solar information users. Major headings are the same as those of individual reports. Ten separate reports will be issued which will analyze the study results by technology.

In general, results for each group are reported in only one volume, although comparisons to similar groups in other technologies are often part of the analysis. There are two exceptions: the results for Concentrating Collector Manufacturers are discussed in both the Solar Thermal Electric Power and the Industrial and Agricultural Process Heat reports; the results for Nonconcentrating Collector Manufacturers are discussed in both the Active Solar Heating and Cooling and the Industrial and Agricultural Process Heat reports. 
Table A-1. GROUPS STUDIED

\section{A. PHOTOVOLTAICS}

1. DOE-Funded Researchers

2. Non-DOE-Funded Researchers

3. Researcher Manufacturers

4. Manufacturers

5. Utility Engineers

6. Utillities

7. Educators

B. PASSIVE SOLAR HEATING AND COOLING

1. Federally Funded Researchers

2. Manufacturers

3. Architects

1. Buildere

5. Educators

6. Cooperative Extension Service (CES) County Agents

7. Homeowners with Passive Systems

\section{ACTIVE SOLAR HEATING AND COOLING}

1. DOE-Funded Researcher3

2. Non-DOE-Funded Researchers

3. Heating and Cooling System Manufacturers

4. Water Heating System Manufacturers

5. Nonconcentrating Collector Manufacturers (see also Industrial and Agricultural Process Heat)

6. Other Component Manufacturers

7. Distributors 
Table A-1. GR̉OUPS STUDIED (Continued)

C. ACTIVE SOLAR HEATING AND COOLNNG (Cont'd.)

8. Installers

9. Architects

10. Builders

11. Planners

12. Heating, Ventilating, and Air Conditioning Engineers

13. Industrial Engineers

14. Utilities

15. Educators

16. CES County Agents

17. Homeowners with Space Heating Systems

18. Homeowners with Water Heating Systems

19. Owners/Managers of Buildings with SHAC Systems

D. BIOMASS ENERGY

1. Federally Funded Researchers in Production and Collection

2. Federally Funded Researchers in Conversion

3. Nonfederally Funded Researchers in Production and Collection

4. Nonfederally Funded Researchers in Conversion

5. Production and Collection Equipment Manufacturers

6. Conversion Equipment Manufacturers

7. State Forestry Offices

8. Private Foresters

9. Forest Products Engineers and Consultants

10. Educators

11. CES County Agents

12. Owners/Managers of Biomass Systems 
Table A-1. GROUPS STUDIED (Continued)

E. SOLAR THERMAL ELECTRIC POWER

1. DOE-Funded Researchers

2. Non-DOE-Funded Researchers

3. Concentrating Collector Manufacturers (see also Industrial and Agricultural Process Heat)

4. Engineers

5. Utilities

6. Educators

F. INDUSTRIAL (IPH) AND AGRICULTURAL (APH) PROCESS HEAT

1. IPH Researchers

2. APH Researchers

3. Concentrating Collector Manufacturers (see ulso Solar Thermal Electric Power)

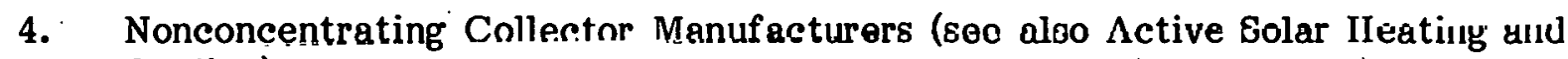
Cooling)

5. Plant Engineers (IPH)

6. Industrial Lingineers (IPH)

7. Private Agricultural Engineers (IPH)

8. Educators (IPH)

9. State Agricultural Offices (APH)

10. CES County Agents (APH)

\section{G. WIND ENERGY}

1. DOE-Funded Researchers

2. Non-DOE-Funded Researchers

3. Manufacturers

4. Distributors 
Table A-1. GROUPS STUDIRD (Continued)

G. WIND ENERGY (Cont'd.)

5. Wind Engineers

6. Utility Engineers

7. Utilities

8. Educators

9. CES County Agents

10. Small Wind Energy System Owners

H. OCEAN ENERGY SYSTEMS

1. DOE-Funded Researchers

2. Non-DOE-Funded Researchers

I. SOLAR ENERGY STORAGE

1. DOE-Funded Researchers

2. Non-DOE-Funded Researchers

J. GENERAL SOLAR

1. Loan Officers

2. Real Estate Appraisers

3. Tax Assessors

4. Insurers

5. Lawyers

6. Nonsolar Utilities

7. Public Interest Groups

8. CES State Agricultural Specialists

9. CES State Information Specialists

10. State Energy/Solar Offices (Western SUN states) 
Table A-1. GROUPS STUDIED (Concluded)

J. GENERAL SOLAR (Cont'd).

11. State Energy/Solar Offices (MASEC states)

12. State Energy/Solar Offices (NESEC states)

13. State Energy/Solar Offices (SSEC states) 
APPENDIX B

STUDY DEVELOPMENT

AND PROCEDURE 


\section{SEPI}


This Appendix describes several aspects of the way in which the studies were developed and conducted.

\section{FACTORS IN STUDY DESIGN}

Studies of 86 groups, each interested either in one of nine different solar technologies or in solar energy in general, provided an extremely broad view of the information needs of the solar community. Although the sample size of nine respondents per group was small, the data still proved to be quite adequate for planning purposes. It was possible to determine which information was the most important to the respondents and what was the best channel for disseminating that information. There were a number of valid statistical tests that could be made, both to compare the priorities a group gave to different information items and to compare the priorities different groups gave to the same item.

Several major factors resulted in the decision to conduct a study with these characteristics. First, there were very few data available on the information needs and information-acquiring activities of the various segments of the solar community, and those data that did exist were related almost exclusively to the area of active solar heating and cooling. Many people had strong opinions as to which information products should be developed first, but data obtained directly from the information users was virtually nonexistent. Due to this general lack of information, most of the potential users of the findings of these studies could not define highly-specific questions that they needed to have answered by these studies. Instead, baseline data was needed. It did not make sense to ask a researcher detailed questions on whether he needed a calendar of solar events to be updated monthly or updated quarterly, when no one knew whether he even needed calendars at all. Thus, the lack of baseline data dictated that most of the potential users of study findings framed their questions at the level of "What information do you need the most?" For such a level of questions there was obviously no great need to use large sample sizes to obtain extremely precise, quantitative answers. Since qualitative data would be quite adequate, there was no need for a large sample size.

Further, there was a need to obtain this baseline data as rapidly as possible so that realtime programmatic decisions about development of information products and data bases could be based upon data rather than conjecture. As a result, the decision was made to conduct the studics by telephone in an attempt to speed up the data collection process. Interviewing by telephone also had the result of improving the response rates (over those using a mail questionnaire).

Thus, these factors dictated the final study design: a broad-based study (the final number of groups included, 86 , was determined primarily by the number of meaningful sample frames that could be constructed) to collect qualitative data by obtaining completed telephone interviews, with approximately 9 randomly selected respondents from each of the 86 groups being interviewed.

\section{Impact on Questionnaires}

As a result of using telephone interviews to conduct the studies, it was necessary to limit the number of questions to be asked. Telephone interviews had to be kept relatively short (preferably under twenty minutes) to keep the respondents from prematurely terminating the interview. Even if a respondent did not hang up in mid-questionnaire, his attention span could be tried severely by lengthy interviews; respondents would then 
answer questions without much thought in order to terminate the interview as rapidly as possible. In the final study the interviews took an average of about 18 minutes to complete (with a range from 10 minutes to 50 minutes) and incorporated very simple question formats, sometimes open-ended questions. For each of the 8.6 studies a separate and distinct sample frame, letter of introduction, and questionnaire were developed and separate computer runs and analyses were performed.

Perhaps a more important effect of deciding to do a telephone study was the necessity of using interviewers without solar backgrounds to conduct the study. With almost 800 interviews to be conducted, each requiring an average of 35 to 40 minutes to complete an 18 minute interview (due to callbacks, referrals, busy signals, wrong numbers, etc.), there was too much effort required to conduct the interviews using internal staff. Thus, the effort had to be contracted. The choice was whether to conduct the interviews by contracting solar experts (who would not know anything about interviewing techniques) or by contracting a professional telephone interview firm (whose interviewers would not know anything about solar energy). Due to the significantly lower cost and to the significantly reduced chance of biasing the responses, it was decided to use a professional telephone interview firm.

As a consequence of this decision, there were some problems caused by using nonsolar interviewers to pose questions of solar experts. If a respondent asked for a question to be clarified, the interviewer could not assist. Instead, the interviewer could only repeat the question. The biggest problem involved the open-ended questions. Sometimes the interviewer simply did not understand what the respondents were talking about. Interviewers were briefed in solar terminology and instructed to ask respondents to spell out words the interviewers did not understand. Nevertheless, some of the verbatims (i.e., quotes from the respondents that were copied down verbatim by the interviewers) were not intelligible. For example, one interviewer recorded "small square train feeders" when the respondent really said "small-scale terrain features," another recorded "nel lenses" instead of "Fresnel lenses." To minimize errors in translation, all of the questionable verbatim items listed in this report were reviewed and verified by SERI terchnical experts. However, based upon listening to live interviews and comparing the results to the verbatims, usually the interviewers were able to transcribe the salient points of the responses.

\section{Impact on Statistical Characteristics}

The sample size of nine respondents per group was limiting for the analyst. To illustrate the lack of precision in the results, if five of the nine respondents answered "yes" to a particular question, there was a 95\% chance that the true proportion saying "yes" was between 0.212 and 0.862 . Obviously this was an extremely wide confidence interval. For such a small sample size, it was not feasible to make national estimates (e.g., the number of DOE-funded active solar heating and cooling (SHAC) researchers in the country who need bibliographies), and it was not meaningful to construct cross-classification tables (e.g., "type of information needed" versus "degree of informedness"). Because of these small sample sizes, the authors were sometimes forced to propose hypotheses rather than draw conclusions.

Nonetheless, the results were extremely useful when taken as qualitative, baseline results. Certain statistical tests could still be performed (see Appendix E). One could test whether SHAC Researchers wanted "state-of-the-art" information significantly more than they wanted "marketing statistics." Several tests could be made comparing 
one group with another. Thus, one could test whether Passive Architects wanted cost data significantly more than did SHAC Architects. This type of comparison usually highlighted basic differences between technologies. One could also test whether SHAC Researchers responded differently from All Researchers.

Comparisons of this type were valuable for several reasons. First, they allowed the comparison of the information needs of a relatively unknown group against those of a more familiar group. For example, the information needs of Wind Manufacturers were easier to understand when compared to the more familiar information needs of Solar Heating and Cooling Manufacturers.

Second, if one can establish basic similarities in information habits and the types of information needed, it will eventually become possible to use the results of other information science studies. For example, many studies have detailed the types of information researchers need and the ways of getting information to them. Thus, if SHAC Researchers were quite similar in needs to All Researchers, it was an indication that many of the well-known findings for researchers in general may also apply for SHAC Researchers.

\section{STUDY DEVELOPMENT}

There were several tasks which had to be completed before the studies could be conducted. These tasks are described in the following subsection.

\section{Development of Sample Frames}

Sample frame development was the single most difficult, time-consuming task in the entire study. As discussed in Section 2.2, the initial attempt was to obtain lists of the names, addresses, and phone numbers of members of as many meaningful groups as possible. A total of about 86 such sample frames was the maximum that could be developed adequately within a reasonable amount of time.

The services of reference and research librarians were used in this process, much of it on a subcontractor hasis. Over 200 documentary sources (printed, published, and unpublished sources, and data bases) were consulted. Staff searched the Solar Energy Information Center and Denver-area public and academic libraries to examine directories, catalogs, periodicals, and data bases. Directories of professionals, organizations and associations, and solar-related individuals and groups were examined, both to obtain sample frames and to obtain individual names. Periodicals were searched both to identify associations whose members might be eligible for sample frames and to identify authors who could be contacted because they represented certain target groups. Various data bases were identified which contained names of individuals categorized by sample frame categories (e.g.; educators, researchers, manufacturers). Lists of conference attendees were accumulated. Sample frames were also constructed by establishing numerous personal contacts with professional, technical, and special interest organizations, with authors of solar articles, technical staff at SERI, federal offices, publishers, solar groups, at least 30 state solar and state energy offices, etc.

Both the Mid-American Solar Energy Complex and the Northeast Solar Energy Center were subcontracted to provide additional names and addresses. Western SUN also provided many names on a voluntary basis. The Southern Solar Energy Center was asked 
to participate on either a contractual or a voluntary basis, but declined. Additionally, the Technical Information Dissemination (TID) program subcontracted a consulting firm to develop lists of members of the solar community. Although the resulting lists were significantly smaller than had been anticipated, they provided valuable backup information for some sample frames. The National Solar Heating and Cooling Information Center provided several of the data bases and other lists used.

It sometimes occurred that the person contacted was not in the presumed field; for example, an installer was no longer involved with solar energy. The proportion of the time that this or a similar sample-frame error occurred has been calculated for each group and is included in the section documenting the results for the group. Sample frame error included such factors as no known telephone number, individual not in the specific field or employment sector, etc. Averaging over all groups, 20\%-25\% of the candidates in the sample frames were no longer valid.

\section{Pilot Testing}

In August 1979 Market Opinion Research (MOR) conducted a pilot test by doing telephone studies of 10 groups ( 9 respondents for each). The groups were:

- Wind: Engineers,

- Wind: County Extension Agents,

- Active Solar Heating and Cooling: DOE-Funded Researchers,

- Active Solar Heating and Cooling: Installers,

- Active Solar Heating and Cooling: Utilities,

- Active Solar Heating and Cooling: Educators,

- Active Solar Heating and Cooling: Commercial Building Owners,

- Passive Solar Heating and Cooling: Equipment Manufacturers,

- Solar Industrial Process Heat: Industrial Engineers, and

- General Solar Energy: Lawyers.

These groups were selected specifically to test a range of questionnaires, the peculiarities of selected sample frames, and the receptiveness of certain target groups to telephone interviews on solar energy. The persons contacted in the pilot were not contacted in the full study.

The pilot test proved very useful. There were no major revisions resulting, but several refinements improved the interview procedure and the questionnaire content and format. The interviews were completed within a reasonable time, an average of about 18 minutes per interview. The most important finding of the pilot test was the enthusiasm of the respondents for solar energy. Most respondents were very cooperative and were excited about receiving solar information. Because of this attitude, interviewers had no difficulty in getting respondents through long lists of information products and sources or in keeping respondents on the telephone to finish the interview.

SERI personnel visited MOR while the pilot test was being conducted, personally participating in monitoring interviews, reviewing tape recordings of previously conducted interviews, and debriefing interviewers. Based upon these inputs, several changes were made 
in the basic questionnaire concept, resulting in changes for each of the 86 distinct questionnaires. Among these changes were: the addition of a question designed to defuse the respondent by allowing expression of the respondents individual concerns; deleting two questions which were not working; changing the sequence of a few questions; making a few small wording changes to sharpen questions, and changing MOR's suggested questionnaire format in order to minimize interviewer errors.

Upon realizing that there was more sample frame error than had been anticipated, the screening procedure was revised to a double screening procedure. Only people who said they needed solar information within the next year, and who were truly in the proper group (e.g., "an architect doing work in passive solar heating and cooling") were to be interviewed. The rules for handling referrals were revised to allow interviews with intraorganizational referrals only.

Perhaps the most important change was in the interviewer training procedure. More specific instructions were developed for each question so that the interviewers would know the real point of the question, would ask the question properly, and would know what to emphasize. Lists of words being mispronounced by the interviewers were developed. Specific interviewers with pronunciation problems were singled out for additional coaching. Because of the interviewers' lack of familiarity with solar energy terminology, glossaries and other background information on solar energy were provided for interviewers.

\section{Interviewer Training and Monitoring}

The MOR interviewers used for these studies were all experienced interviewers. They went through three separate training sessions: a pilot test briefing, a pilot test debriefing (with question and reaction session), and a full study briefing. The full study briefing was held in four separate sessions so that the interviewers could be trained in small groups. SERI representatives were present for and assisted with the second two sessions.

These training sessions covered the purpose of the study, question wording, recording procedures, the screening procedure, and pronunciation of unfamiliar words. The training was built around the use of an annotated briefing questionnaire. Notes concerning each question were written on a questionnaire which the interviewer studied during the briefing. Additional written materials covered included a list of solar energy terms, a list of common solar acronyms, and a list of words for pronunciation reminders.

\section{Randomized Selection of Respondents}

Once the sample frames were developed for each group, a random sample of 30 to 40 potential respondents was drawn by systematic sampling. (If the sample frame for a group only had 30 to 40 names in the beginning, this step was omitted.) These reduced sample frames were then forwarded to MOR. At MOR, these randomly selected names were put through a second randomization process which assigned the order in which these names were to be called. The MOR process used systematic sampling to identify the first nine candidates for interviewing; the total number of potential candidates was divided by nine to obtain " $i$," the "skip interval." Starting from a random point (R), every $i^{\text {th }}$ name then became one of the first nine candidates.

An initial call and up to two callbacks (at different times of day on different days of the week) were made, attempting to reach each designated respondent. If an interview was 
not completed after three attempts, the interviewer took the questionnaire to the interviewing supervisor. The supervisor then designated the next person in the sequence as the substitute candidate: if the $(R+i)^{\text {th }}$ person could not be reached, the $(R+i+1)^{\text {th }}$ became the replacement candidate. If after three attempts to reach the substitute, no interview was completed, this process was repeated. (This time the $(R+i+2)$ th person would become the candidate, etc.) For the entire study, 54\% of the completed interviews were with the originally designated respondent and $26 \%$ were with the first substitute. The remainder were completed with a second or higher substitute.

There is evidence that for some sample frames MOR did not use a random starting point to commence the skip interval, but instead used the sequence of $1^{s t},(1+i)^{\text {th }},(1+2 i)^{\text {th }}$, etc. names for initial candidates. Such a practice clearly does not conform to professional standards. This practice was not critical in those of the sample frames with a large initial size or no particular order, since SERI did a valid random subsampling to reduce the sample size to 30 or 40 . In small sample frames or in frames with a definite pattern, however, this procedure could have caused biases. All seven of the Cooperative Extension Service sample frames were arranged in a state-by-state order. As a result of not randomly changing the starting point, there was a strong tendency towards sampling from the same states for these sample frames. The final distribution of CES respondents by state is shown in Table B-1. Some clustering did occur for some states. Thus, for these groups results were geographically biased.

\section{STUDY PROCEDURE}

The procedure was the same for each study. Each of the potential respondents was sent a letter of introduction one to three weeks before they were telephoned (see Appendix C). This letter explained that the person was selected as 'a candidate and may be called by MOR, that MOR was calling for SERI, the purpose of the call, the type of information being sought, and that the respondent's identity would be kept confidential.

'The telephone interviews were conducted in one of MOR's two telephnne ronms, with each individual interviewer in an acoustically insulated booth. Throughout the study, interviews were monitored by MOR's phone room supervisors. They were responsible for randomly listening to interviews to determine whether the operators were conducting the interviews correctly. If mistakes were being made, the supervisor explained the proper procedure to the interviewer. The supervisors were able to monitor calls without the interviewers knowing they were being monitored.

Candidates were telephoned during business hours (except for homeowners who were called during the early evening and weekends). If the interview candidate could not be contacted in the initial call, as many as two additional callbacks were made. These callbacks were made at different times of the day and on different days of the week. If no interview was completed after three attempts, a substitute candidate replaced the initial candidate and the process started over. If a secretary indicated the candidate would be in later at a specified time and day, the callback was scheduled accordingly. If a candidate was too busy to talk when initially contacted, an appointment was made to call back at a specified time. Only $3 \%$ of the candidates contacted refused to be interviewed or terminated the interview before it was completed. Once a candidate was contacted, a screening procedure.was used to verify that the respondents being interviewed actually represented the group to which they ostensibly belonged. For example, a respondent who was presumably an educator teaching courses in SHAC was read the following statement at the beginning of the interview: 
Table B-1. COOPERATIVE EXTENSION SERVICE (CES): STATES REPRESENTED IN SAMPLES ${ }^{\mathrm{B}}$ (Number of respondents)

\begin{tabular}{|c|c|c|c|c|c|c|c|c|c|c|}
\hline \multirow[b]{2}{*}{ State } & \multicolumn{6}{|c|}{ County Agents } & \multicolumn{3}{|c|}{ State Specialists } & \multirow{2}{*}{$\begin{array}{c}\text { All } \\
\text { CES }\end{array}$} \\
\hline & $\begin{array}{l}\text { Bio- } \\
\text { mass }\end{array}$ & Wind & APH & $\begin{array}{l}\text { Pas- } \\
\text { sive }\end{array}$ & $\begin{array}{l}\text { Ac- } \\
\text { tive }\end{array}$ & Total & Info. & Agri. & Total & \\
\hline Alabama & - & 1 & - & 1 & - & 2 & - & - & - & 2 \\
\hline California & - & 1 & - & - & - & 1 & - & - & - & 1 \\
\hline Colorado & - & 1 & - & - & 1 & 2 & - & - & - & 2 \\
\hline Connecticut & - & - & - & - & - & - & 1 & - & 1 & 1 \\
\hline Delaware & - & - & - & - & - & - & - & 1 & 1 & 1 \\
\hline Georgia & - & - & - & 1 & - & 1 & - & - & - & 1 \\
\hline Idaho & - & - & 1 & - & - & 1 & 1 & 1 & 2 & 3 \\
\hline Illinois & - & 1 & - & - & - & 1 & - & - & - & 1 \\
\hline Indiana & 2 & 1 & - & 1 & 1 & 5 & - & - & - & 5 \\
\hline Iowa & - & 1 & - & - & - & 1 & - & - & - & 1 \\
\hline Kansas & - & - & 2 & - & 1 & 3 & - & - & - & 3 \\
\hline Kentucky & - & 1 & - & 1 & - & 2 & 1 & 1 & 2 & 4 \\
\hline Louisiana & - & - & - & - & - & - & 1 & - & 1 & 1 \\
\hline Maryland & $1:$ & - & - & - & - & 1 . & $i$ & - & - & 1 \\
\hline Michigan & - & 1 & - & - & - & 1 & 1 & 1 & 2 & 3 \\
\hline Minnesota & - & - & - & 1 & 1 & 2 & - & - & - & 2 \\
\hline Missouri & - & 1 & - & - & - & 1 & - & - & - & 1 \\
\hline Montana & 1 & - & - & - & 1 & 2 & - & - & - & 2 \\
\hline Nebraska & - & - & 1 & 1 & 1 & 3 & 1 & 1 & 2 & 5 \\
\hline New Mexico & 1 & - & - & - & - & 1 & - & - & $\dot{-}$ & 1 \\
\hline New York & - & - & - & - & - & - & 1 & 1 & 2 & 2 \\
\hline N. Carolina & - & - & 1 & 1 & - & 2 & - & - & - & 2 \\
\hline Ohio & 1 & - & - & - & 1 & 2 & - & - & - & -2 \\
\hline Oklahoma & - & - & 1 & - & - & 1 & 1 & - & 1 & 2 \\
\hline Oregon & 1 & - & - & - & - & 1 & - & - & - & 1 \\
\hline S. Carolina & - & - & - & - & - & - & - & 1 & $\cdot 1$ & 1 \\
\hline S. Dakota & - & - & 1 & 1 & 1 & 3 & 1 & - & 1 & 4 \\
\hline Tenllessee & 1 & - & 1 & 1 & - & 3 & - & - & - & 3 \\
\hline Texas & 1 & - & 1 & - & 1 & 3 & - & 1 & 1 & 4 \\
\hline W. Virginia & - & - & - & - & - & - & - & 1 & $\overline{1}$ & 1 \\
\hline $\begin{array}{l}\text { Sample Size } \\
\text { by Technology }\end{array}$ & 9 & 9 & 9 & 9 & 9 & 45 & 9 & 9 & 18 & 63 \\
\hline Total States & & & & & & & & & & \\
\hline Represented & 8 & 9 & 8 & 9 & 9 & 24 & 9 & 9 & 13 & $30^{\mathrm{a}}$ \\
\hline
\end{tabular}


Hello (respondent's name). This is (interviewer's name) of Market Opinion Research. A week or so ago you were sent a letter from the Solar Energy Research Institute describing a survey of solar energy information needs and requesting your participation.

Your name has been provided to us as someone who has been teaching courses related to active solar heating and cooling. Is that correct?

If the respondent answered "yes," the interview continued. If the respondent answered "no," then the respondent was not interviewed but instead was asked if there was another person within the same university who was teaching courses related to SHAC. If the initial candidate could give the name of another person, the referral person (or "referral") was called as a substitute for the initial candidate. If no intraorganizational referral was given, another candidate was telephoned.

A second screen was used to eliminate those people who did not feel they would be needing information in the near future. For example, SHAC respondents were asked the following two questions:

- In the next year do you expect to need information on active solar heating and cooling systems for your job?

- In the next year do you expect to need information on active solar heating and cooling systems outside your job?

For all respondents other than SHAC users, these questions were asked at the beginning of the interview and if the answer to both questions was "no," the interview was terminated and a substitute candidate telephoned. No request for a referral was made.

Once an interview was completed, the questionnaire was reviewed for completeness by the phone room supervisor. Incomplete questionnaires were returned to interviewers to recall the respondents.

Completed questionnaires were forwarded from the phone rooms to the Coding Department where they were checked in and assigned a unique identification number. They were subsequently sent to the Data Entry Department where they were keyed directly into computer data files. Since no computerized editing system could prevent the incorrect entry of a data value that was within the proper range (e.g., entering a " 3 " when the correct number was a "2," but where the numbers " 1, " "2," " 3, " and "4" are all valid numbers), SERI did a random sample of supposedly correct values to verify that they were correct. Out of 225 allowable values reviewed, only 1 had been incorrectly entered. Once the data were entered on the computer file, data tables were printed and analyzed.

Nonuniform Group Sample Size. The study was originally designed to sample nine respondents from each group. For most groups this was done correctly. Upon analysis of the completed questionnaires, however, it was sometimes apparent that a respondent obviously belonged in a group other than the one in which originally sampled. This was generally due to two simultaneous errors: a sample frame error and a screening error.

First, the person was included on the wrong sample frame. For example, a person listed as doing non-DOE-funded research could have received DOE funding after the sample frames were completed. Second, the screening process did not successfully remove this 
person from the non-DOE-Funded Researchers: instead the interview was completed. During the interview the respondent mentioned that he was receiving DOE funds for his research. As a result the analyst received eight interviews completed with Non-DOEFunded Researchers and one completed with a DOE-Funded Researcher.

For such cases, the dissimilar interview was removed from the original group (in the example above, the Non-DOE-Funded Researchers). If there was another group into which that interview naturally fit (above, the DOE-Funded Researchers); the interview was included with the interviews for the second group. Although the added interview did not have exactly the same probability of selection as did the original interviews, the resulting inaccuracy was minimal given the qualitative nature of the data. 


\section{S=괗ㅎ}




\section{APPENDIX C}

\section{LETTER OF INTRODUCTION}




\section{SE尺ㅋ.*}


All potential respondents from the initial sample frames were sent the following letter (see. Fig. C-1) from one to three weeks prior to being contacted by telephone. There are three phrases (underlined in this example) which were changed to describe the group and the solar technology. For example, "a researcher" was changed to read "a manuf acturer" or "an educator," etc., as appropriate for the specific sample frame. Similarly, "passive solar heating and cooling" read "photovoltaics" or "wind energy systems," etc., according to the technology about which this potential respondent was to be interviewed. About 3,500 such letters were mailed over a period of several weeks. Less than 100 were returned as undeliverable.

It should be noted that in cases where the actual respondent was a referral, the respondent had not necessarily received this letter.

There were numerous telephone calls to SERI from people who had received this letter. Most volunteered they were eager to participate (and concerned that they had not yet been called) or that they wanted study results. A few volunteered referrals or gave the best times for them to be called. 
September, 1979

\section{Dear Colleague:}

The Solar Energy Research Institute (SERI) is currently developing a Solar Energy Information Data Bank (SEIDB). The SEIDB is designed to include many categories of solar information and will serve the needs of a variety of groups: among them, researchers, manuf acturers, architects, builders, lawyers, and homeowners. Services provided to you by the SEIDB may include an inquiry response service, computer access to models or large sets of data and free brochures, handbooks, etc.

The U.S. Department of Energy has defined solar energy as encompassing techmolngies which involve both direct and indirect uses of sunlight; information for all of the following technologies will be included in the SEIDB:

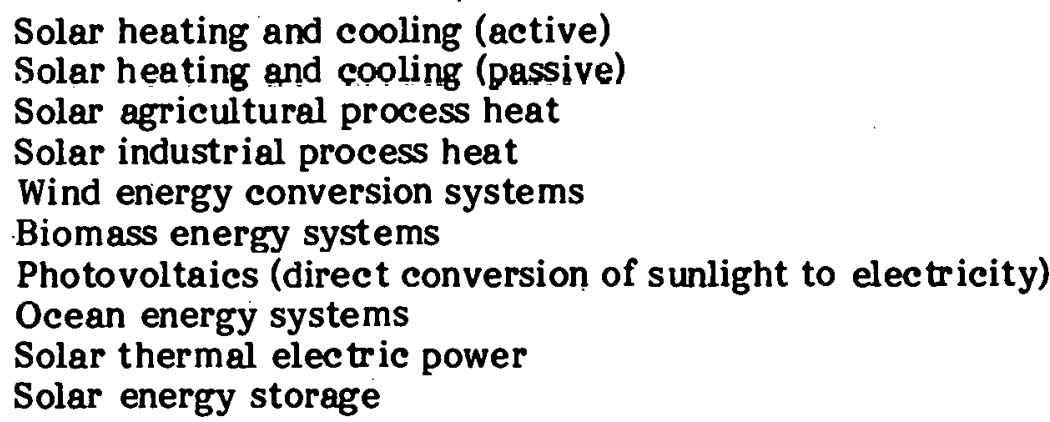

So that this data bank can be developed to meet your present or future solar infor mation needs, SERI is surveying information users like yourself. You have been selected as a candidate for this interview because you are a researcher with an active or potential interest in passive solar heating and cooling.

We believe your participation in this survey will be beneficial to you and to the country. If called, you will have an opportunity to express your opinions and to define your solar information needs. This will help us ensure that the data bank will be responsive to the needs of researchers as well as those of other groups.

Market Opinion Research of Detroit, Michigan, has been chosen to conduct this survey for SEKI. A trained interviewer may contact you within two weeks to interview you. The telephone interview will last no more than 20 minutes. You can be assured that your responses to this survey are strictly confidential. No names will be used in reporting the results.

If you have questions about this survey, its purpose, or the interview methods to be used, please feel free to contact me at (303) 231-1155. Thank you for your assistance.

Sincerely,

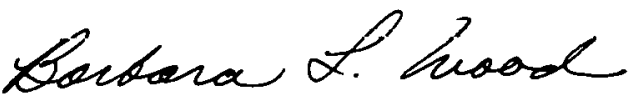

Barbara L. Wood,

Staff Market Research Information Specialist,

Inf ormation Disse mination Branch,

Information Systems Division

Figure C-1. Letter of Introduction 
APPENDIX D

STUDY QUESTIONNAIRE 


\section{SEPI站}


A different questionnaire was developed for each distinct group in this study. These questionnaires were very similar, however, in that the same type of information was being sought from each of the groups. The individual questionnaires were developed by constructing a core questionnaire, then making appropriate revisions, additions, and deletions to produce a distinctly tailored questionnaire for each group.

Two sample questionnaires are provided in this appendix. A version of the first (Fig. D-1) was used for all samples except for users of solar systems (homeowners, building and plant owners/managers.) The second (Fig. D-2) was used only for users. The basic difference is that phraseology was changed for users so that their queries were related to information about the period of time their system was being considered for purchase or was under construction. The question numbering system for the user questionnaires follows that of the standard core questionnaire, although the sequence does not. For example, question $\mathrm{Bl}-6 \mathrm{a}$ of the user questionnaire is similiar to question $6 a$ of the standard core questionnaire.

The questionnaires used in the active solar heating and cooling (SHAC) technology study were very similar to those used for the other studies. The two instruments which follow (see Figs. D-1 and D-2) contain references to SHAC technologies in Questions 1 through 9. Questionnaires that were used for respondents from other technologies substituted references to their appropriate technologies instead of to SHAC technologies.

Certain variations were made in the SHAC technology questionnaires for different SHAC technology groups in Questions $8 \mathrm{a}, 8 \mathrm{~b}$, and 11 , in that certain items were not asked of groups if the item seemed inappropriate. For example, SHAC Researchers were not asked Question 8b (11) about "how to market," and SHAC Distributors were not asked Question 11 (7) about SSIE. While it would have been less complicated to have all questions asked of all respondents, concern over questionnaire length and the desire to avoid asking questions that were not relevant to the group led to deleting questions wherever possible. Questions that were not asked of each group may be noted in the data tables (Appendix F) whenever an individual group shows no entries for that item.

Slight variations in wording were made on the questionnaire of each individual group. For example, in Question 11 (18), which asked if information had been obtained from "a public utility company," the phrase "other than your employer" was inserted for SHAC Utility Representatives.

\section{Standard Core Questionnaire}

Question 5. This question asked, "What is the most important information that could be provided to you about active solar heating and cooling?" This question allowed respondents to volunteer the information need that came to mind spontaneously, without reflecting any of the biases of the questionnaire designers as to what was the most important. Most of the time, however, it did not result in an answer which could be compared to another respondent's answer; for nine respondents, there were typically seven or eight distinct answers given. Since each respondent did not rate these items, it was impossible to determine which of these information needs was the most important. Afforded a second thought, respondents of ten gave items they had mentioned as "most important" in Question 5 a lower rating in Question 8 than they gave to items that they had not even mentioned in Question 5. As a result, the data from Question 5 could not provide a valid measurement of the most important information items which could be 
1. In the next year, do you expect to need information on active solar heating and cooling ... (a) For your job? Yes. .... I I

No ..... 2

Don't know.. 8

NA...... 9

(b) Outside of your job?
Yes.....TI

No $\cdot \cdot \cdot \cdot \frac{1}{2}$

Don't know.. 8
(IF "YES"

TO EITHER, CONTINUE. OTHERWISE TERMINATE

31 32

\section{. NA..... 9}

2. To what extent are you currently involved with active solar heating Very involved. ........ 4 ano cobling? Would you say you are:

Moderately involved, or. . . . . 3

Slightly involved. • • . . . 2 Not at all involved (VOLUNTEERED). I

Don't know........... 8

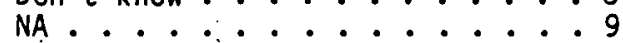

3. What are you doing in the field of active solar heating and cooling? (ASK AS OPEN END)

4. How well informed would you say you are about active solar heating and cooling? Would you say you are:
Very informed. ........... 4

Mnderately informed, or........ 3

Slightly informed ........, 2

Not at all informed (VOLUNTEERED). . 1

Don't know. .......... . 8

NA. . . . . . . . . . . . 9
34

$35 \mathrm{C}+\mathrm{V}$

lst Mention

$36-42$ B1k

Figure D-1. Questionnaire 
Cd 2

$1-10$ as 1

$11-58$ B1k

6. For which of the following areas of active solar heating and cooling are you particularly interested in obtaining information? [READ LIST. CIRCLE ONE RESPONSE PER ITEM.]

Don't

Yes No Know NA

(1) Water heating

(2) Swimming pool heating

(3) Space heating

(4) Space cooling

(5) Hybrid systems (combining active and passive)

\begin{tabular}{|c|c|c|}
\hline 1 & $\begin{array}{l}2 \\
2 \\
2 \\
2\end{array}$ & $\begin{array}{l}8 \\
8 \\
8 \\
8\end{array}$ \\
\hline & 2 & 8 \\
\hline
\end{tabular}

Are there any other areas of active solar heating and cooling for which you are especially interested in obtaining information? (SPECIFY)

(Ist Mention)

(2nd Mention)

7. What publications have you read in the past six months that include information on active solar heating and cooling?

None. ........... 001

Read, but can't remember titles. 002 (VOLUNTEERED)

(VOLUNTEERED)....... . . 003

(ASK) Which are most important?

(RECORD TITLES)

-Names publications. . . . . 004

1st Mention

(RECORD TITLFS)

2nd' Mention

3rd Mention 
Cd 1

8a. I will read a list of potential information products on active solar heating and cooling. For each; please tell me how useful that information would be to you. Would the following be: essential, very useful, somewhat useful, or, not at all useful? [READ LIST. ROTATE. CIRCLE ONE RESPONSE PER ITEM].

$\begin{array}{cccc}\text { Very } & \begin{array}{c}\text { Somewhat } \\ \text { At All }\end{array} & \begin{array}{c}\text { Don't } \\ \text { Essential Useful }\end{array} \text { Useful } \\ \text { Useful Know }\end{array}$

(1) A bibliography of general readings on active solar heating and cooling 4

$$
3
$$

(2) A list of sources for information on active solar heating and cooling. . 4

(3) A caléndar of upcoming solar heating and cooling conferences and programs. ....

(4) Diagrams or schematics of an active solar heating and cooling system. . 4

(5) A non-technical description of how a particular active solar heating and cooling system works.....4

(6) A technical description of how a particular active solar heating and cooling system works. . . . .

(7) Lists of local lenders, insurers, builders, engineers, installers or distributors for active solar heating and cooling....

(8) Solar heating and cooling design handbóoks, installation handbooks or reference tables.

(9) A list of technical experts in active solar heating and cooling. . 4

2

.2

1

8943

$?$

1

8.944

4

3

3

2

1

8946

(10) Manual methods for sizing and predicting the engineering performance or life cycle costs of active solar heating and cooling systems....

(11) Computer models for sizing and predicting the engineering nerformance or life cycle costs. ..... 
8b. I will next read a list of types of information on active solar heating and cooling. For each, please tell me how useful inforination of that type would be to you. Would the following be: essential, very useful, somewhat useful or not at all useful? (READ LIST. ROTATE. CIRCLE ONE RESPONSE PER ITEM).

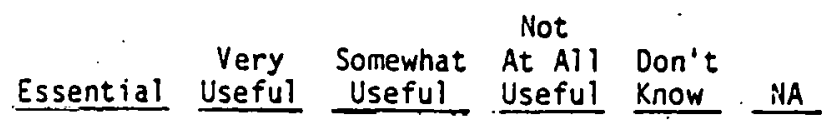

(1) Educational institutions and other organizations offering courses on active solar heating. and cooling. . .4

(2) Solar heating and cooling research currently in progress. : . 4 3$$
2
$$$$
1
$$$$
8
$$$$
955
$$

(3) The state-of-the-art in active
solar heating and cooling...

$$
4
$$

$$
2
$$$$
1
$$$$
8 \quad 9 \quad 56
$$

(4) Costs and performance of solar heating and cooling installations. . 4

3

(5) Costs of installing and operating a solar heating and cooling system compared to a conventional system. . 4

$$
3
$$

(6) Local building codes or other regulations affecting siting or installation of solar heating and cooling systems. 4

(7) Tax credits, grants, or other economic incentives for active solar installations...

4

(8) Standards, specifications, or certi-fication programs for active solar equipment and installations. . . 4

(9) Marketing statistics and sales projections for solar equipment. . .

(10) Solar heating and cooling programs, research, industries and markets outside the United States: : . 4

(11) Information on how to market and sell solar heating and cooling systems, including guidelines on obtaining financial support. . .

$\begin{array}{lllll}2 & 1 & 8 & 9 & 65\end{array}$

(12) Institutional, social, environmental, and legal aspects of solar applications...

(13) Expected major developments in active solar heating and cooling during the next ten years. ... 4

(14) Climatological data such as wind. weather, or ainount of sunshine. . 4

$\begin{array}{cccccc}3 & 2 & 1 & 3 & 9 & 67 \\ 3 & 2 & 1 & 8 & 9 & 58\end{array}$

\section{Figure D-1. Questionnaire (continued)}


9. Is there active solar heating and cooling information which you need but are not able to get?

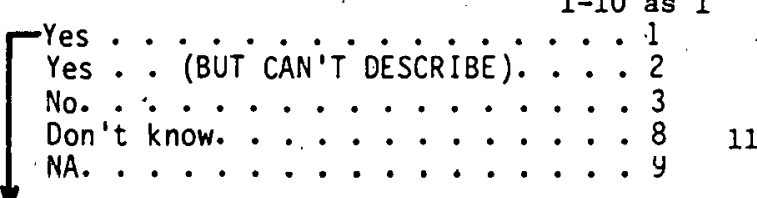

(IF YES) What information do you need?

1st Mention

Verb.

2nd Mention

10. In the past year have you obtained any information, not just solar, in the following forms? [READ LIST. CIRCLE ONE RESPONSE PER TTEM.
1 Yes $\frac{\text { No }}{2} \frac{\begin{array}{l}\text { Don't } \\ \text { know }\end{array}}{8}$ NA
(a) On-line access to a central data $1 \quad 2 \quad 309$ bank via computer terminal
(b) Microform from a computer, somet imes referred to as $C-0-M$
(c) Other microforms, for example, microfiche, microfilm sheets or rolls


11. Solar information refers to information about any solar technology, and

factors which may relate to its use such as weather, economics, legislation, architecture, environment, etc. In the past few years, have you obtained any type of solar information from any of the following sources? [READ LIST. CIRCLE ONE RESPONSE PER ITEM.]

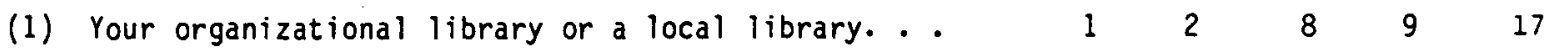

(2) A public utility company. - * $\quad-\quad \begin{array}{lllll}2 & 2 & 8 & 9 & 18\end{array}$

(3) An installer, builder, designer or manufacturer of solar systems. :

(4) Workshops, conferences or training sessions. .

(5) A commercial data base, for example, Lockheed, SOC, BRS. - I $2 \begin{array}{lllll}8 & 8 & 9 & 21\end{array}$

(6) A Federal library or information center, for example, the National Agricultural Library or the Environmental Data System. .

(7). Smithsonian Science Information Exchange (SSIE) * * * $\quad 1 \quad 2 \quad 2 \quad 8 \quad 9$

(8) The Government Printing Office (GPO) . . .

How would you evaluate the service you received from GPO?

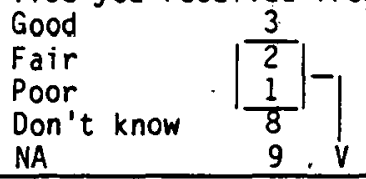

What are some of the reasons you do not consider their service "good"?

lst Mention

Verb.

2nd Mention

(9) National Technical Information Service (NTIS). ...

\begin{tabular}{|l|}
\hline How would you evaluate the service you received from NIIS? \\
Good. \\
Fair \\
Poor \\
Don't know \\
NA
\end{tabular}


(10) Technical Information Center at 0ak Ridge (TIC)... How would you evaluate the service you received from.TIC?

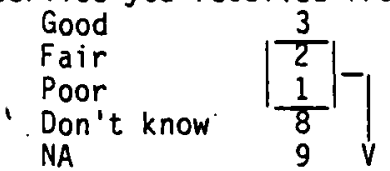

What are some of the reasons you do not consider their service "good"? 1st Mention 2nd Mention

(11) National Solar Heating and Cooling Information Center. $\mid T_{V} 2 \quad 8 \cdot 90$

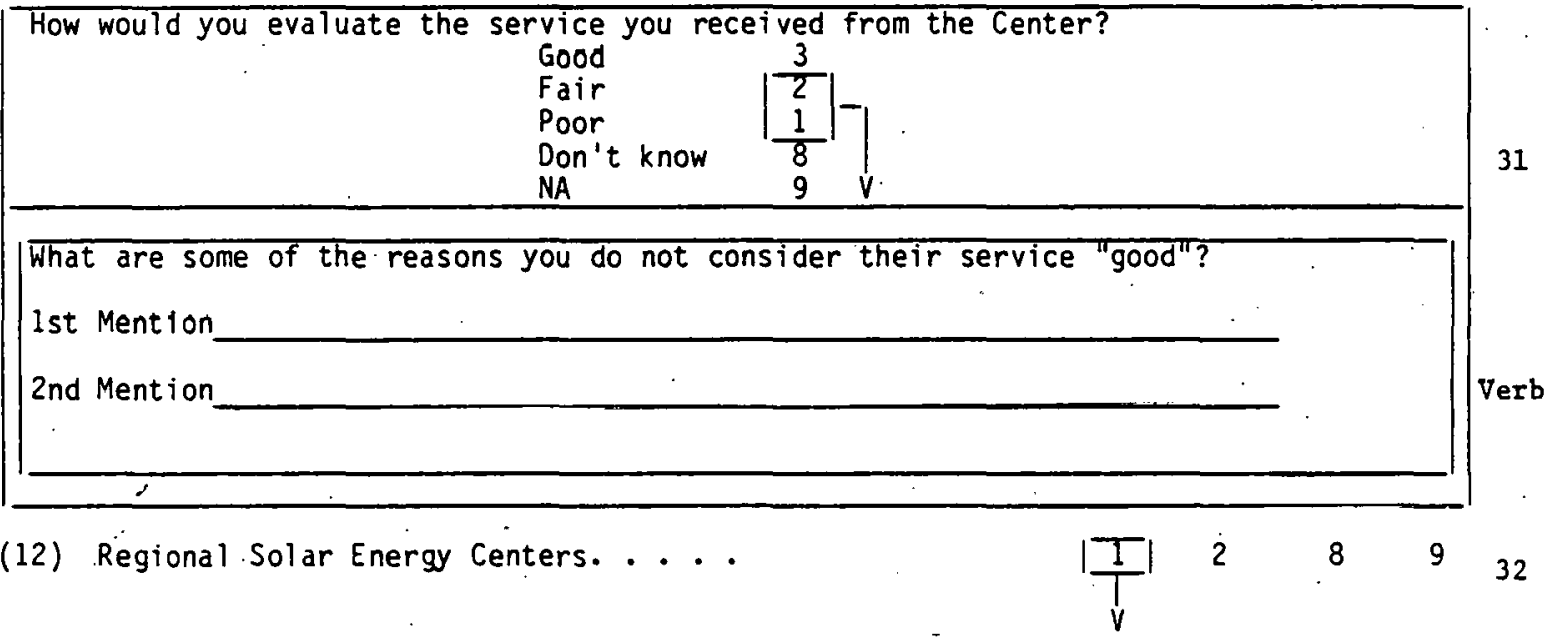

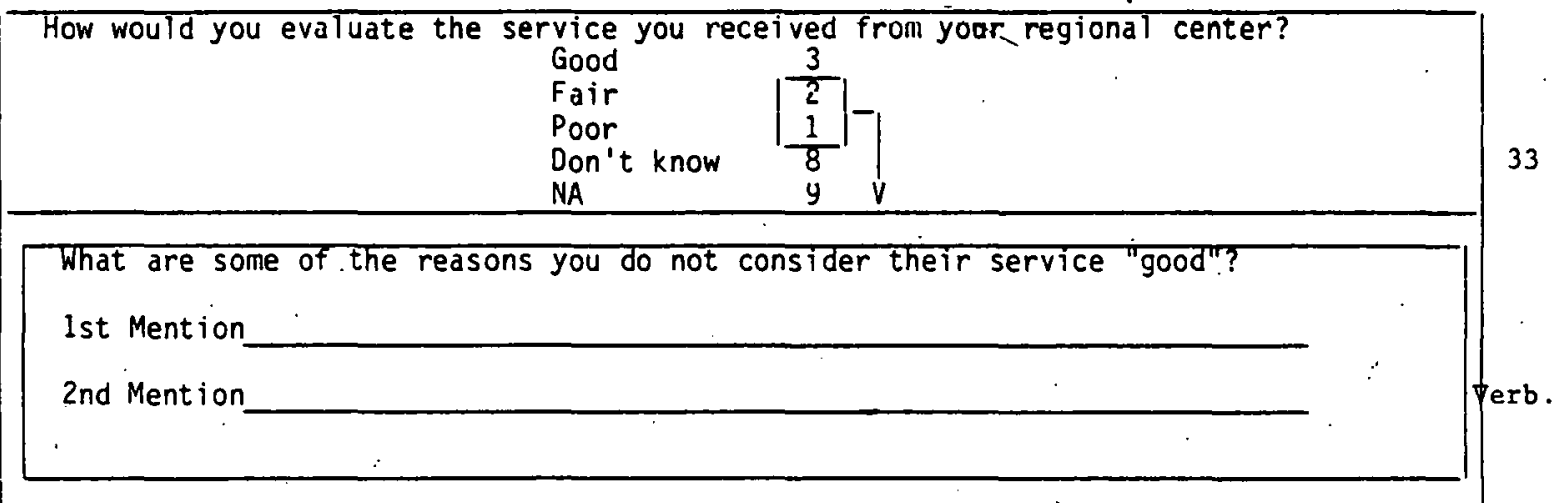


(13) Directly from the U. S. Department of Energy. . .

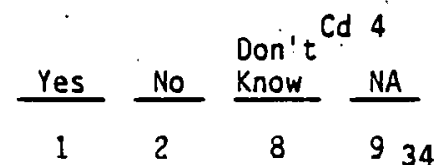

(14) Radio or TV .......

$12 \quad 2 \quad 8 \quad 935$

(15) Periodicals, newspapers or magazines. . . .

1. $2 \quad 8 \quad 936$

(16) Private solar energy or environmental örgantzations . . $1 \quad 2 \quad 8 \cdot 937$

(17). State Energy or Solar Offices * . . $\quad \cdots \quad 1 \quad 2 \quad 8 \quad 8 \quad 938$

(18) Some other state or local government office or publication 1 $22 \quad .8 \quad 939$

(19) The local chapter or national headquarters of the International Solar Energy Society (ISES), including their publications.......

(20) The local chapter or national headquarters of the Solar Energy Industries Association (SEIA), including their

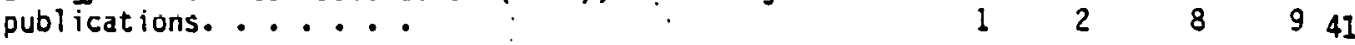

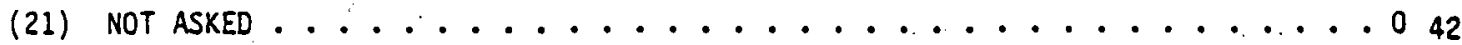

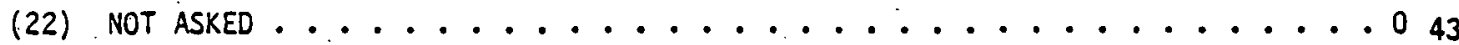

(23 NOT. ASKED . . . . . . . . . . . . . . . . . . . . . . 044

(24) NOT ASKED ................................. . . . . 45 
Cd 4

In conclusion, I would like to ask you some questions about yourself. Your anstiers will be kept coinjletely confidential.

Dla. What is the higinest level of education you have completed? (DO NOT REAO) 8th grade or less........ 01

Soine high school ...... 02

High school graduate....... 03

Post high school vocational/

Technical...........04

$48-49$

Attended col lege/IIniversity:

ivo dégrèe. .......... 05

Assuciale (2 year juntor)

Community college) ..... OG

Bachelors. ....... 07

Hasters.......... 08

Ph.D/Doctorate ....... 09

JO/LLD................ 10

other

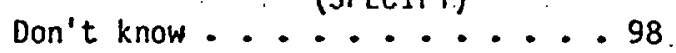

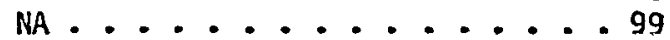

D1b. In what field is your most recent degree?

DIC. In what year did you get that degree?

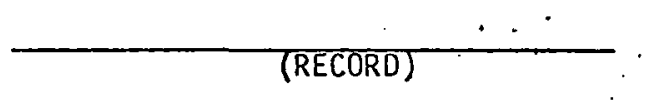

D2a. Please describe your present profession by completing the following statenent: "Based on my total education and experience, I now regard inyself professionally as a (an) - (NVOID USING JOB TITLE IF POSSIBLE).

D2b. How many years have you been in this profession? (CIRCLE CODE)
0-2................ 1

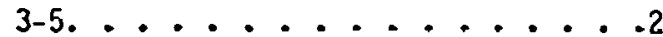

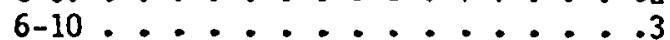

Over 10............. . . . 4

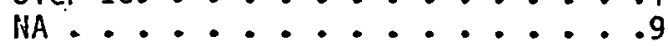


Cd \&

D3. Do you belony to any professional, technical, or other organizations which have an interest in solar?

Yes. ................ 1

YES (BUT CAH'T N'AHE).... .2

Ho . . . . . . . . . . . 3

Jon't know ................. 53

NA.............. 9

a. Hhat organizations?

1st Mention

2nd Mention

3rd Mention

4th Mention

Thank you very much for your time.

Figure D-1.. Questionnaire (concluded) 
cd 2

$1-10$ as 1

$11-58$ Blk

B1-6a. What type of solar system do you currently have? Do you have. . [READ

LIST. CIRCLE ONE RESPONSE PER ITEM.] [IF RESPONDENT OWNS OR MANAGES MORE

THAN ONE BUILDING WITH SOLAR, THIS QUESTION APPLIES TO ALL BUILDINGS FOR WHICH RESPONDENT IS CURRENTLY RESPONSIBLE'.]

(1) Water hoating

(2) Swimming pool heating

(3) Space heating

(4) Space cooling

5) Hybrid system, combining active and passive

Yes No $\begin{aligned} & \text { Don't } \\ & \text { Know }\end{aligned}$ NA

Do you have any other type? (SPECIFY)

$\begin{array}{rrrrr}1 & 2 & 8 & 9 \\ 1 & 2 & 8 & 9 \\ 1 & 2 & 8 & 9 \\ 1 & 2 & 8 & 9 \\ 1 & 2 & 8 & 9\end{array}$

64-75 Blk

$76 \mathrm{Cd} \#$

77-80 Job \#

(1st Mention)

(2nd Mention)

$1-10$ as 1

B1-6b. Was the solar system included when the

Included at construction .... 1

building was first constructed or

Added later . . . . . . . 2

added later?

Some of both (VOLUNTEERED).... 3

Dun't know. ....... 8 
$\mathrm{Cd} 2$

$1-10$ as 1

$11-58$ Blk

B1-6a. What type of solar system do you have? Do you have. . . . . . [READ

LIST. CIRCLE ONE RESPONSE PER ITEM.]

(1) Water heating

(2) Swimming pool heating

(3) Space heating

(4) Space cooling

(5) Hybrid systems, combining active and passive

\begin{tabular}{|c|c|c|c|}
\hline Yes & No & $\begin{array}{l}\text { Don't } \\
\text { Know } \\
\end{array}$ & NA \\
\hline $\begin{array}{l}1 \\
1 \\
1 \\
1\end{array}$ & $\begin{array}{l}2 \\
2 \\
2 \\
2\end{array}$ & $\begin{array}{l}8 \\
8 \\
8 \\
8\end{array}$ & $\begin{array}{l}9 \\
9 \\
9 \\
9\end{array}$ \\
\hline 1 & 2 & 8 & 9 \\
\hline
\end{tabular}

Do you have any other type? (SPECIFY)

(1st Mention)

$64-75 \mathrm{~B}] \mathrm{k}$

(2nd Mention)

B1-6b. Was the solar system included when the

Included when built . . . . . 1

house was first built, or added later?

Added later . . . . . . . . 2

Some of both (VOLUNTEERED). . . 3

Don't know. . . . . . . . 8

NA. . . . . . . . . . . 9

Figure D-2. Questionnaire (continued) 


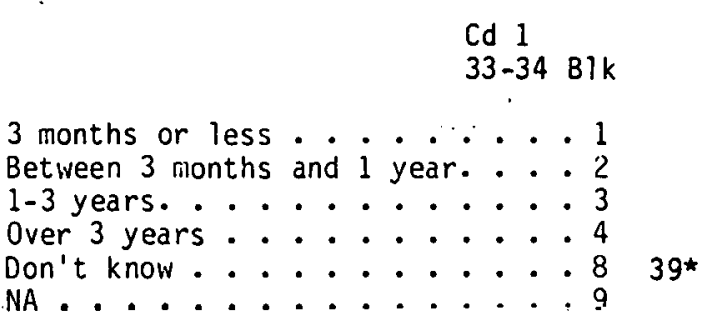

b3-5. Knowing what you now know in terms of obtaining information about active solar heating and cooling systefils, please answer the following questions as if you were starting over again and first considering the installation of an active solar heating and cooling system.

What would be the most important information product or service about active solar heating and cooling that you would want to have? (PROBE FOR. TWO MENTIONS)

Ist ilention

2nd Mention

B4-14. What is the first thing you would do to obtain information about active solar heating and cooling? That is, where would you go or who would you contact to get the information you needed? (PROBE FOR TWO MFNTIONS)

- Ist Mention

2nd Mention 
Cd 1

33-34 Blk

B2-12. Are you the original owner or manager of this or any other solar system?

Yes, original owner. . . . . . 1

Yes, original manager. . . . . . 2

No (TERMINATE) .......

Don't know (TERMINATE) . . . . . 8

NA (TERMINATE) ......

B3-13. How many years have you been an owner/a manager (REFER TO Q.B2) of a solar system? (INCLUDE YEARS WHEN SYSTEM WAS UNDER CONSTRUCTION.)

3 months or less . . . 40-42 B! . $_{1}$

Between 3 months and 1 year. .... 2

$1-3$ years. . . . . . . . . 3

Over 3 years .........4

Don't know ............... 8

NA . ............... . . .

B4-5. Knowing what you now know in terms of obtaining information about active solar heating and cooling systems, please answer the following questions as if you were starting over again and first considering the installation of an active solar heating and cooling system.

What would be the most important information product or service about active solar heating and cooling that you would want to have?' (PROBE FOR TWO.MENTIONS)

1st Mention

$35 \mathrm{C}+\mathrm{V}$

2nd Mention

35-14. What is the first thing you would do to obtain information about active solar heating and cooling? That is, where would you go, or who would you contact to get the information you needed?. (PROBE FOR TWO MENTIONS)

lst Mention

$36 \mathrm{C}+\mathrm{V}$ *

2nd Mention

Figure D-2. Questionnaire (continued) 
Cd 1

B5-8a. I will read a list of potential information products on active solar heating and cooling. For each, please tell me how useful that information would be to you if you were obtaining a new system. Would the following be: essential, very useful, somewhat useful, or not at all useful? [READ LIST. ROTATE. CIRCLE ONE RESPONSE PER ITEM.] Not

Eery Somewhat At All Don't
Essential Useful Useful Useful Know

(1) A bibliography of general readings on active solar heating and conling 4

(2) A list of sources for information on active solar heating and cooling. 4

(3) A calendar of upcoming active solar heating and cooling conferences and programs. . . . .

(4) Diagrams or schematics of an active solar heating and cooling system. . 4

(5) A non-technical description of how a particular active solar heating and cooling system works .....4 4

$$
3
$$

3

8

343

A technical description of how a particular active solar heating and couling sysiem works. . ....

(7) Liszs of local lenders, insurers, builders, engineer's, illsbdllers or distributors for active solar heating and cooling ....

(8) Solar heating and cooling design handbooks, installation handbooks, or reference tables.......

(y) A list of technical experts in active solar heating and cooling. . 4

Manual methods for sizing and predicting the engineering performance or life cycle costs of active solar heating and cooling systems....

3

2

1

$8 \quad 952$

(11) Computer models for sizing and predicting the engineering performance or life cycle costs...... 
1.

$\operatorname{cd} 1$

B6-8b. I will next read a list of types of information on active solar heating and cooling. For each, please tell me how useful information of that type would be to you if you were obtaining a new system. Would the following be: essential, very useful, somewhat useful or not at all useful? [REAO LIST. ROTATE. CIRCLE ONE RESPONSE PER ITEM.

$54 \mathrm{~B} 7 \mathrm{k}$

\begin{tabular}{ccc} 
Very & $\begin{array}{c}\text { Somewhat At All } \\
\text { Essential Don't }\end{array}$ \\
Useful Useful Useful & Know \\
\hline
\end{tabular}

(1) Educational institutions and other organizations offering courses on active solar heating and cooling. . .4

3

2

$\cdot 1$

$8 \quad 955$

(2) Solar heating and cooling research currently in progress. .

(3) The state-of-the-art in active solar heating and cooling...

$\begin{array}{llllll}4 & 3 & 2 & 1 & 8 & 9^{57}\end{array}$

(4) Costs and performance of solar heating and cooling installations. . 4

(5) Costs of installing and operating a solar heating and cooling system comparad to a conventional system. . 4

(6) Local building codes or other regulations affecting siting or installation of solar heating and cooling systems. 4

(7) Tax credits, grants, or other economic incentives for active solar installations. .

(8) Standards, specifications, or certification programs for active solar equipment and installations. ... 4

(9) Marketing statistics and sales pro-

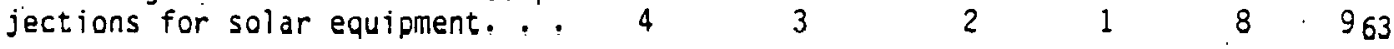

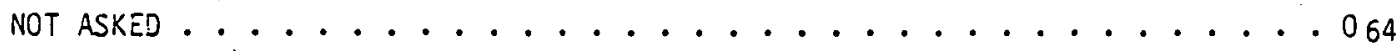

(12) Institutional, social, environmental, and legal aspects of solar applications. .

(13) Expected major developments in active solar heating and cooling during the next ten years.....

(14) Climatological data such as wind, weather, or amount of sunshine. . .

$\begin{array}{llllll}4 & 3 & 2 & 1 & 8 & 967 \\ 4 & 3 & 2 & 1 & 8 & 968\end{array}$




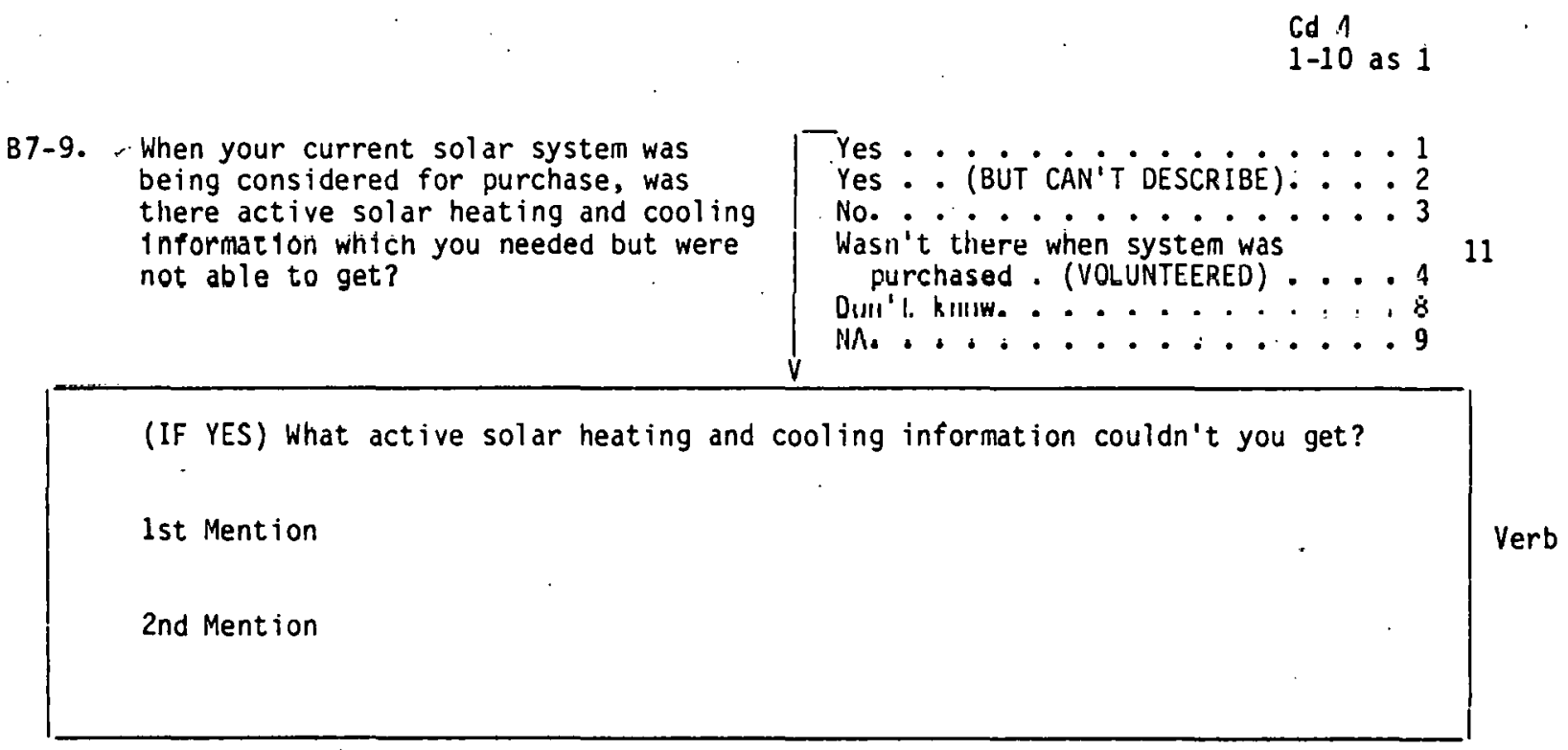

Figure D-2. Questionnaire (continued) 
38-11. Solar information refers to information about any solar technology, and factors which may relate to its use such as weather, economics, legislation, architecture, environment, etc. In the past few years, have you obtained any type of solar information from any of the following sources? [READ LIST. CIRCLE ONE RESPONSE PER ITEM.]

(1) Your organizational library or a local library. .

$$
\text { Yes No }
$$
$\begin{array}{lllll}1 & 2 & 8 & 9 & 17\end{array}$

(2) A public utility company. . . $\begin{array}{lllll}1 & 2 & 8 & 9 & 18\end{array}$

(3) An installer, builder, designer or manufacturer of solar systems. .

(4) Workshops, conferences or training sessions...

(5) A commercial data base, for example, Lockheed, SDC, BRS. . $1 \quad 2 \quad 2 \quad 8 \quad 921$

(6) A Federal library or information center, for example, the National Agricultural Library or the Environmental Data System. . .

(7) Smithsonian Science Information Exchange (SSIE) . . . $\quad 1 \quad 1 \quad 2 \quad 4 \quad 8 \quad 923$

(8) The Government Printing Office (GPO) ...

How would you evaluate the service you received from GPO?

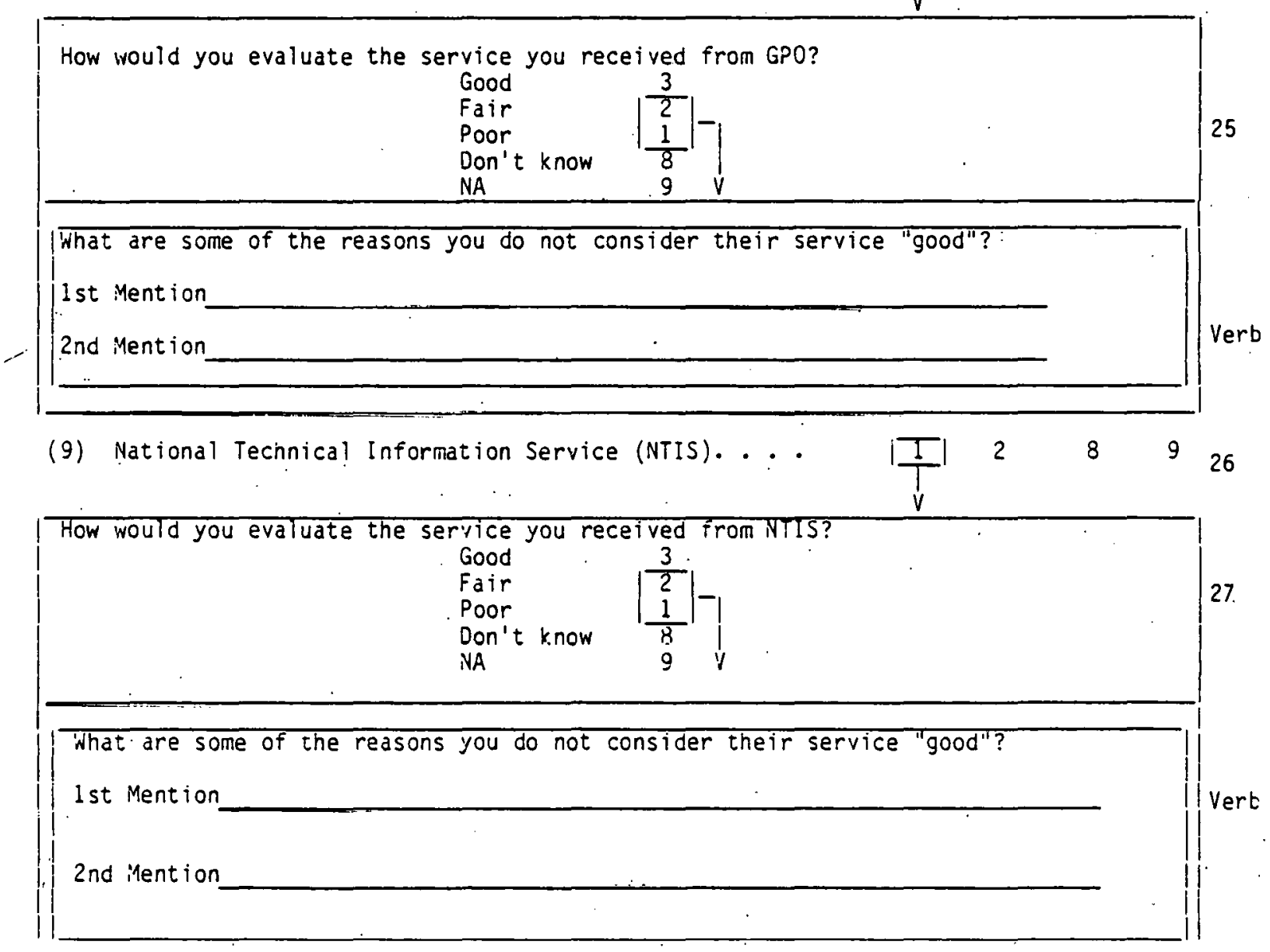

Figure D-2. Questionnaire (continued) 
Cd 4

Don't

Yes No know NA

(10)

(11) National Solar Heating and Cooling Information Center. $\cdot \mid \begin{array}{llllll}\mid T & 2 & 8 & 9 & 30\end{array}$

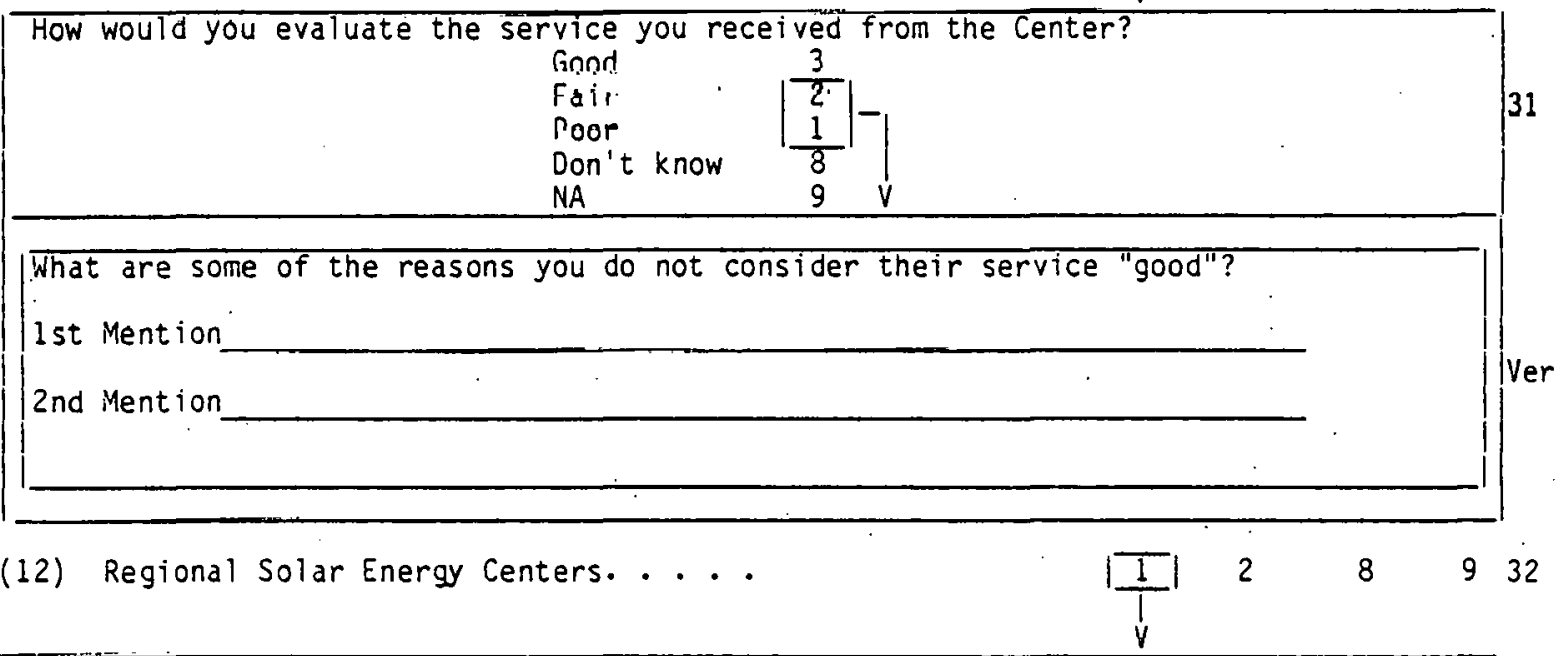

How would you evaluate the service you received from your regional center?

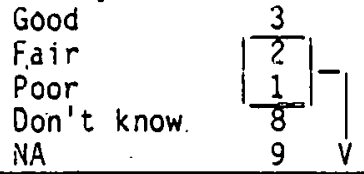

NA

What are some of the reasons you do not consider their service "good"?

lst Mention

?nd Mention

Figure D-2. Questionnaire (continued) 
Cd 4

B8-11. (Cont'd)

(13) Directly from the U. S. Department of Energy. . . $\quad 1 \quad 2 \quad 8 \quad 8 \quad 934$

(14) Radio or TV ........ $\quad 1202835$

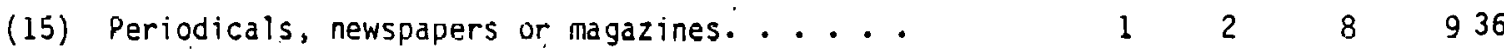

(16) Private solar energy or environmental organizations . . . $1 \quad 2 \quad 8 \quad 8 \quad 937$

(17) State Energy or Solar Offices... $\quad 1 \quad 2.28938$

(18) Some other state or local government office or publication $1 \quad 2 \quad \begin{array}{llll}2 & 8 & 9\end{array}$

(19) The local chapter or national headquarters of the International Solar Energy Society (ISES), including their publications.......

(20) The local chapter or national headquarters of the Solar

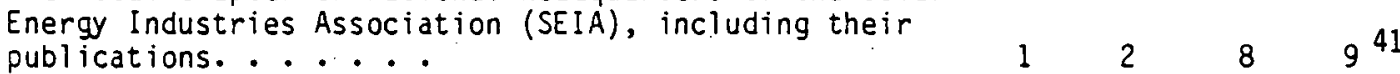

(21) Your State Solar Society or Association ..... $1122 \quad 8 \quad 9^{42}$

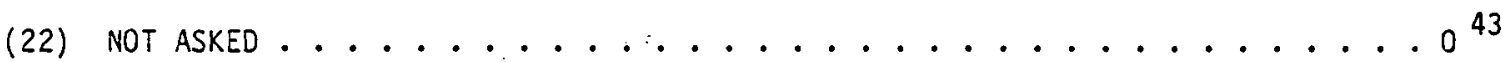

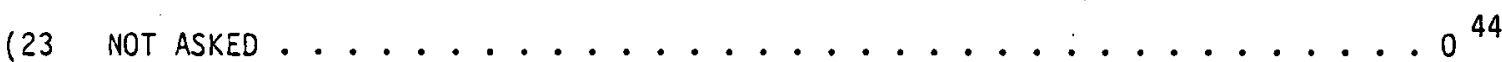

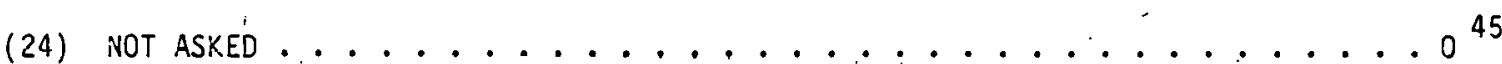
$46-\bar{a} 7$ BIk

89-7. What publications have you read in the past six months that include inforination on active solar heating and cooling?
None. . . . . . . . . . 001 Cd 3

Read, but can't remember titles. 002 (VOLUNTEERED)

- Read too many to name

(VOLUNTEERED) ........ 003

(A.JK) Which are most important?

(RECORD TITLES)

$52-54$

- Names publications. . . . . 004 (RECORD TITLES)

-1st Mention

2nd Mention

3rd Mention 
Cd 4

In conclusion, I would like to ask you some questions about yourself. Your answers will be kept completely confidential.

Dla. What is the highest level of education you have completed? (DO NOT READ) 8th grade or less....... 01

Some high school . . . . . . 02

High school graduate....... 03

Post high school vocational/

Technical......... . 04

Attended college/University:

No degree. . . . . . . . . 05

Assucidle (2 year funtor)

Community college) . . . . 06

Bashclons. . , . . : : 07

Mastars: . . . ....,. 08

Ph.D/Doctorate........09

JD/LLD............. 10

Other ___ 11

Don't know.......... 98

NA................ 99

01b. In what field is your most recent degree?

D1C. In what year didlyou get that degree?

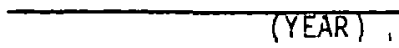

B10-1. In the next year do you expect to need additional active solar heating and cool-

ing information.....
(a) On your job? Yes....... I
No.:..... 2
Don't know. - 831
NA. . . . . 9

(b) Qutside of your job?

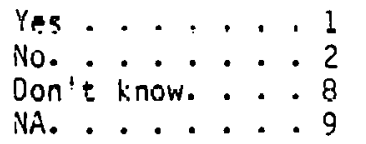

02a. Please describe your present professinn by cnmpleting tho following statcment: "Based on my total education and experience, I now regard myself professionally as a (an) ." (AVOID USING jOB TITLE IF POSSIBLE). 


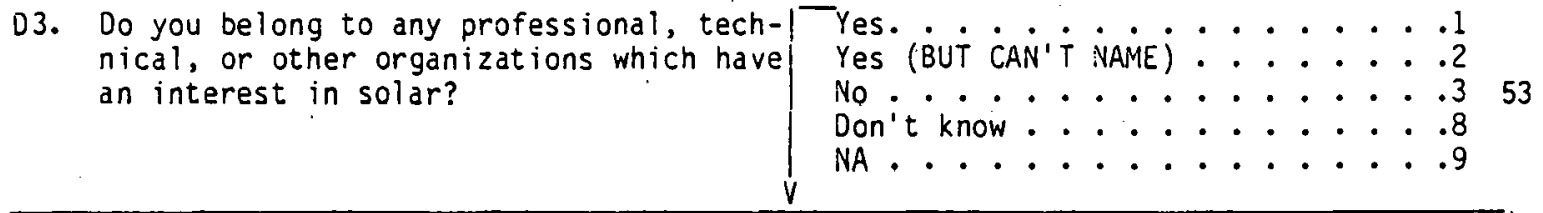

a. What organizations?

1st Mention

2nd Mention

CL

3rd Mention

4th Mention

$54-69$ B1k

Thank you very much for your time.

Figure D-2. Questionnaire (concluded) 
provided to the respondent. Therefore, this report refers to the responses to Question 5 as "information which was important for the respondents to obtain."

Question 6. In this question, a list of different active solar heating and cooling applications was read to the respondent, and the respondent was asked'which application he was particularly interested in obtaining information for. After this was completed, respondents were asked "Are there any other areas of active solar heating and cooling for which you are particularly interested in obtaining information?" Responses to this question fell into one of two areas: additional SHAC applications of interest or specific types of information wanted. The former were discussed with other results from Question 6; the latter were included with the responses from Question 5.

Question 8. In this question a list of up to 25 specific information products or types of information was read to the respondent. The respondent rated each item as "essential," "very useful," "somewhat useful," or "not at all useful" as it applied to himself. In contrast to Question 5, this question assessed each respondent's ratings for each of a set of items that the study designers thought might be important to the respondents. Question 8 did not allow respondents to add and rate items not already on the list. To reduce the possibility of introducing bias due to item order within Question 8, the interviewers rotated their starting point by randomly selecting which item would be read to the respondent first. Items in Question $8 \mathrm{a}$ were rotated separately from those in Question 8b.

Question 9. This question asked, "Is there any active solar heating and cooling information which you need but are not able to get?" Unfortunately, this question just did not work. Answering Questions $8 \mathrm{a}$ and $8 \mathrm{~b}$ required the respondent to assign a rating to each of 22-25 information items. By the time the respondents had completed Question 8 they were usually starting to get fatigued with the interview. As a result many did not answer Question 9 at all.

Question 11. In this question respondents were not asked if they had obtained solar Information from SÉkI. 'l'he principal reason was the probability of obtaining biased responses. All respondents had received a letter describing the SEIDB and introducing SERI. It was felt that many respondents would attempt to encourage information flows from SERI by responding positively when asked whether they had used SERI as an information source-whether or not they actually received information directly from SERI. Since explaining the nature of SERI and the SEIDB was necessary to promote a good response rate, no questions about SERI were included.

In Question 11, items 21-23 require some explanation: they are shown as "NOT ASKED" on the sample questionnaire (readers may note that data for items 2.1-2.3 dnes oceur on the tables in Appendix $F$ for some groups). These items were left open for the inclusion of specific organizations which seemed most appropriate for each group. Table D-1 lists the organizations, the respondent groups, and the question numbers for each item used for the groups covered in this report. 


\section{User Questionnaire}

B1-6a. Users were asked about their present system, rather than areas of interest; the list differs somewhat from Question 6 of the standard questionnaire.

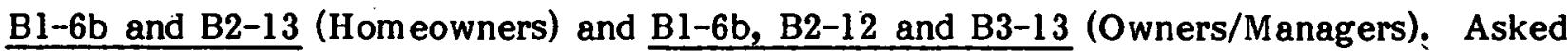
only of users.

B3-5 and B4-14 (Homeowners) and B4-5 and B5-14 (Owners/Managers). These questions differ from the standard Question 5 in that the user respondent is asked about information and information sources that would be sought out if the system were currently being considered for purchase or construction

B5-8a and B6-8b. These items listed are the same as those on Questions $8 a$ and $8 b$ in the standard questionnaire, except that users are asked the qualifying "if you were obtaining a new system."

B7-9. The standard Question 9 is altered by referring to "when your current system was being considered."

B10-1. The standard Question 1 is altered by asking about "additional" active solar heating and cooling information. 
Table D-1. SELECTED ORGANIZATIONS ABOUT WHICH ACTIVE SOLAR HEATING AND COOLING (SHAC) RESPONDENTS WERE ASKED

\begin{tabular}{|c|c|c|}
\hline Group & Item $^{\mathbf{a}}$ & Organization \\
\hline \multicolumn{3}{|l|}{$\begin{array}{l}\text { Passive Manufacturer Represen- } \\
\text { tatives }\end{array}$} \\
\hline Wind vistributors & 21 & American Wind Energy Association (AWEA) \\
\hline SHAC Installers & 21 & $\begin{array}{l}\text { Sheet Metal and Air Conditioning } \\
\text { Contractors National Association } \\
\text { (SMACNA) }\end{array}$ \\
\hline SHAC Architects & 21 & $\begin{array}{l}\text { American Institute of Architects (AIA) or } \\
\text { AIA Research Corporation }\end{array}$ \\
\hline $\begin{array}{l}\text { Passive Arclitẹts } \\
\text { SHAC Builders }\end{array}$ & $\begin{array}{l}21 \\
21\end{array}$ & $\begin{array}{l}\text { AIA nr AIA Kesearch Corporation } \\
\text { National Assooiation of Home Buildcrs } \\
\text { (NAHB) }\end{array}$ \\
\hline Passive Builders & 21 & NAHB \\
\hline SHAC Planners & 21 & American Planning Association (APA) \\
\hline $\begin{array}{l}\text { SHAC Heating, Ventilating, and } \\
\text { Air Conditioning (HVAC) Engineers }\end{array}$ & 21 & $\begin{array}{l}\text { American Society of Heating, Refrigerating } \\
\text { and Air Conditioning Engineers (ASHRAE) }\end{array}$ \\
\hline SHAC HVAC Engineers & 22 & SMACNA \\
\hline SHAC HVAC Engineers & 23 & $\begin{array}{l}\text { American Society of Mechanical Engineers } \\
\text { (ASME) }\end{array}$ \\
\hline SHAC Industrial Engineers & 21 & Association of Energy Engineers (AEE) \\
\hline \multicolumn{3}{|l|}{ Industrial Process Heat } \\
\hline Industrial Engineers & 21 & AEE \\
\hline \multicolumn{3}{|l|}{ Industrial Process Heat } \\
\hline Industrial Engineers & 22 & $\begin{array}{l}\text { Institute of Electrical and Elertronirs } \\
\text { Engineers (IEEE) }\end{array}$ \\
\hline \multicolumn{3}{|l|}{ Industrial Process Heat Plant } \\
\hline \multicolumn{3}{|l|}{ Industrial Process Ileat Plaint } \\
\hline Engineers & 22 & IEEE \\
\hline SHAC Utility Representatives & 21 & Electric Power Research Institute (EPRI) \\
\hline All Solar Utility & & 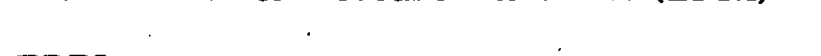 \\
\hline Kepresentatives & 21 & EPRI \\
\hline Nonsolar Utility Representatives & 21 & EPRI \\
\hline SHAC CES County Agents & 21 & $\begin{array}{l}\text { U.S. Department of Agriculture (USDA) } \\
\text { including the Cooperative Extension } \\
\text { Service (CES) }\end{array}$ \\
\hline Passive CES County Agents & 21 & USDA including CES \\
\hline All CES County $\Lambda$ gents & 21 & USDA including CES \\
\hline $\begin{array}{l}\text { All CES State Specialists } \\
\text { SHAC Heating and Cooling }\end{array}$ & 21 & USDA including CES \\
\hline $\begin{array}{l}\text { Systems Homeowners } \\
\text { SHAC Hot Water Systems }\end{array}$ & 21 & Your state solar society or association \\
\hline Homeowners & 21 & Your state solar society or association \\
\hline Total SHAC Homeowners & 21 & Your state solar society or association \\
\hline SHAC Building Owners/Managers & 21 & Your state solar society or association \\
\hline Passive Homeowners & 21 & Your state solar society or association \\
\hline Total SHAC Owners/Managers & 21 & Your state solar society or association \\
\hline
\end{tabular}

athe number of the item in which the group was asked about the particular organization. For example, 21 is Item 21 of Question 11 . 
APPENDIX $\mathrm{E}$

STATISTICAL TESTING 


\section{SERP整}


Despite the small sample sizes, selected statistical tests could be used. All of these tests used a $5 \%$ rejection region unless otherwise noted. Thus, if a test result indicated that a difference between two means was statistically significant $(P<0.05)$, it meant that there was only a one-out-of-twenty chance that the two means were not different. Actual calculations were made with the Statistical Package for the Social Sciences (SPSS) sof tware and other computer packages.

The tests conducted fell into three main types: tests of proportions between two groups, $\mathrm{t}$-Tests between two groups, and Paired $\mathrm{t}$-Tests within a group. Each of these are discussed below.

For all except Question 8, tests of proportions were used. For example, the proportion of SHAC Architects using computer terminals was compared to the proportion of SHAC Builders using computer terminals. If the sample sizes were small, Exact Binomial Tests were used. When the sample sizes were larger (e.g., a comparison of SHAC DOE-Funded Researchers to All Researchers), Chi-Square Tests were used.

For analysis of the results from Question 8, t-Tests were used. In Question 8 each respondent was asked to describe the usefulness of up to 25 information products/ categories as either "essential," "very useful," "somewhat useful," or "not at all useful." The "average usefulness" rating that the group assigned an item was then calculated by assigning the responses a "4" for "essential," a "3" for "very useful," a "2" for "somewhat useful," and a "l" for "not very useful," then calculating the average for the entire group. A t-Test was used to determine whether group A rated a specific information. item significantly higher (or lower) than it was rated by group B. Some groups, however, tended to give higher scores in general than did other groups. To compensate for this effect, these statistical tests compared the "relative rating" given by one group to the "relative rating" given by the other groups. The relative rating given by a group to a particular item was calculated as follows: take the average usefulness rating the group gave that item (for example, suppose "a bibliography" received a 3.15 rating), then subtract the average overall rating this group gave to all items (suppose the average rating the group gave all items was 2.75); the difference was the relative rating (for this example $3.15-2.75=+.40$ ). The $t$-Test then was used for the comparison of the relative rating group A gave to the item to the relative rating group B gave the item.

For the tests of proportions (or the t-Tests involving Question 8), if group A was being. compared to group B and group A was a subset of group B (e.g., a comparison of DUEFunded SHAC Researchers to All Researchers), the totals for group A were subtracted from the totals for group $B$ and the proportions (or the relative ratings) for group B were recalculated from the adjusted totals.

For Question 8 it sometimes occurred that the researcher wanted to compare the rating a group gave one item to the rating they gave another item. For example, did SHAC Manufacturer Representatives rate "lists of sources for information" significantly higher (or lower) than they rated "lists of technical experts?" This test was conducted using a Paired t-Test. 


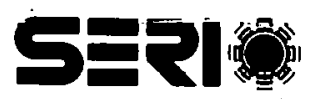




\section{APPENDIX $\mathbf{F}$}

ACTIVE SOLAR HEATING

AND COOLNG DATA TABLES 


\section{SEPI得:}


In the following SHAC data tables, each table entry shows counts and percentages displayed in the format $\left(\%^{\#}\right)$, where $\%$ is the column percentage for each group, and \# is the number of respondents in each group who gave the response shown in the row title. Each column shows the results for an individual group or for a combination of groups.

Table F-1 lists the groups and combinations for which data are shown in the data tables. Table F-2 shows which groups are included in each of the combination groups listed in Table F-1. Table F-3 lists the data tables and Fig. F-1 contains the data tables themselves. 


\section{Table F-1. GROUPS AND COMBINATION GROUPS WTTH DATA INCLUDED IN APPENDIX $\mathbf{F}$}

\begin{tabular}{|c|c|c|}
\hline Group & Report & Section \\
\hline DOE-F unded SHAC Researchers (SHAC DOE-FUND RES) & SHAC & 3.0 \\
\hline $\begin{array}{l}\text { Non-DOE-Funded SHAC Researchers } \\
\text { (SHAC N DOE-FUND RES) }\end{array}$ & SHAC & 3.0 \\
\hline Total SHAC Resarchers (TOTAL SHAC RES) & SHAC & 3.0 \\
\hline Federally Funded Passive Researchers (PASS RES) & Passive & 3.0 \\
\hline All Researchers (ALL RES) & SHAC, Passive & $3.0,3.0$ \\
\hline $\begin{array}{l}\text { SHAC Heating/Cooling Systems Manufactuer Representatives } \\
\text { (SHAC SPACE HEAT MANUF) }\end{array}$ & SHAC & 4.0 \\
\hline $\begin{array}{l}\text { SHAC Water Heating Systems Manufacturer Representatives } \\
\text { (SHAC WATER HEAT MANUF) }\end{array}$ & SHAC & 4.0 \\
\hline $\begin{array}{l}\text { SHAC Non Concentrating Collector Manufacturer Representatives } \\
\text { (SHAC NCONC COLL MANUT) }\end{array}$ & SHAC & 4.0 \\
\hline $\begin{array}{l}\text { Total SHAC Collector Manufactuer Representatives ' } \\
\text { (TOTAL SHAC COLL MANUF) }\end{array}$ & SHAC & \\
\hline $\begin{array}{l}\text { SHAC Other Component Manufacturer Representatives } \\
\text { (SHAC OTHER COMP MANUF) }\end{array}$ & SHAC & 4.0 \\
\hline $\begin{array}{l}\text { Total SHAC Manufacturer Representatives } \\
\text { (TOTAL SHAC MANUF) }\end{array}$ & SHAC & 4.0 \\
\hline $\begin{array}{l}\text { Passive Equipment Manufacturer Representatives } \\
\text { (PASS EQUIP MANUF) }\end{array}$ & Passive & 4.0 \\
\hline All Manufacturer Representatives (ALL MANUF) & SHAC, Passive & $4.0,4.0$ \\
\hline SHAC Architects (SHAC ARCH) & SHAC & 7.0 \\
\hline Passive Architects (PASS ARCH) & Passive & 5.0 \\
\hline SHAC Builders (SHAC BUILD) & SHAC & 8.0 \\
\hline Passive Builders (PASS BUILD) & Passive. & 6.0 \\
\hline SHAC Educators (SHAC EDUC) & SHAC & 13.0 \\
\hline Passive Educators (PASS EDUC) & Passive & 7.0 \\
\hline All Educators (ALL EDUC) & SHAC, Passive & $13.0,7.0$ \\
\hline SHAC CES County Agents (SHAC CES CO AGENT) & SHAC & 14.0 \\
\hline Passive CES County Agents (PASS CES CO AGENT) & Passive & 8.0 \\
\hline All CES County Agents (ALL CES CO AGENT) & SHAC, Passive & $14.0,8.0$ \\
\hline All CES State Specialists (ALL CES STATE SPEC) & SHAC, Passive & $14.0,8.0$ \\
\hline SHAC Distributors (SHAC DISTR) & SHAC & 5.0 \\
\hline Wind Distributors (WIND DISTR) & SHAC & 5.0 \\
\hline SHAC Installers (SHAC INST) & SHAC & 6.0 \\
\hline SHAC Planners (SHAC PLAN) & SHAC & 9.0 \\
\hline SHAC Heating, Ventilating and Air Conditioning & & \\
\hline (HVAC) Engineers (SHAC HVAC ENG) & SHAC & $10.0,11.0$ \\
\hline SHAC Industrial Engineers (SHAC INDUS ENG) & SHAC & $10.0,11.0$ \\
\hline Industrial Process heat Industrial Engineers & & \\
\hline (IPH INDUS ENG) & SHAC & 11.0 \\
\hline Industrial Process Heat Plant Engineers & & \\
\hline (IPH PLANT ENG) & SHAC & 11.0 \\
\hline All Engineers (ALL ENG) & SHAC & $10.0,11.0$ \\
\hline SHAC Utility Representatives (SHAC UTIL REPS) & SHAC & 12.0 \\
\hline All Solar Utility Representatives (ALL SOLAR UTU REPS) & SHAC & 12.0 \\
\hline Nonsolar Utility Representatives (NONSOLAR UTIL REPS) & SHAC & 12.0 \\
\hline
\end{tabular}


Table F-1. GROUPS AND COMBINATION GROUPS WITH DATA INCLUDED IN APPENDIX F (Concluded)

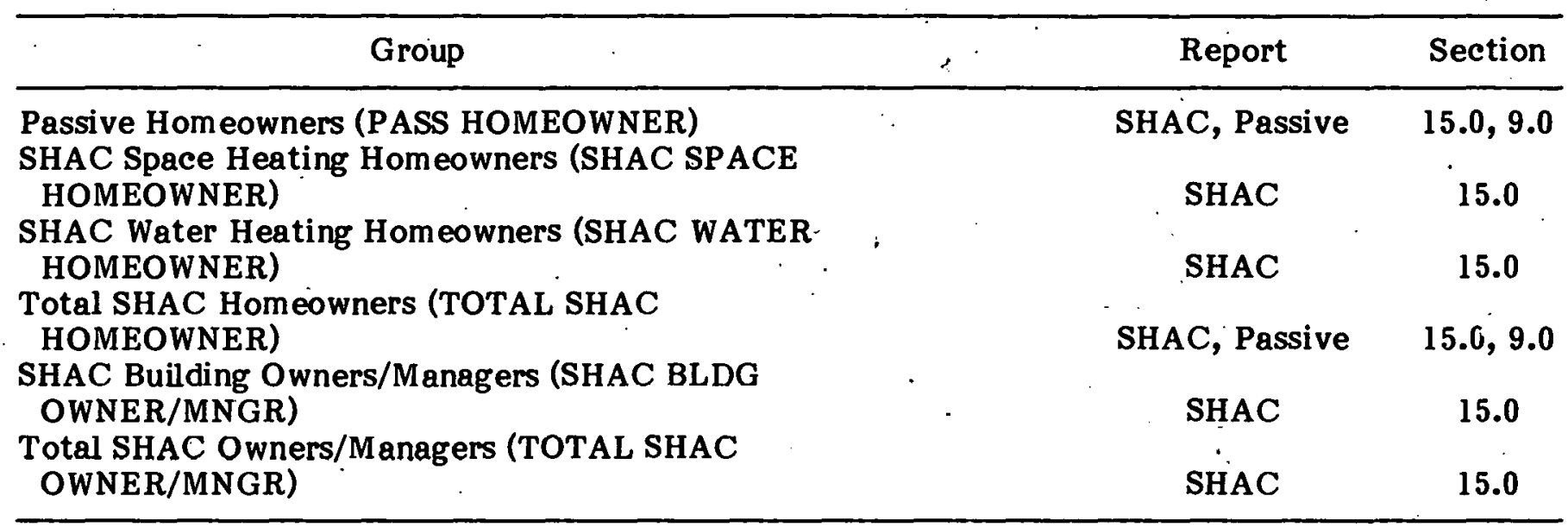


Table F-2. COMBINATION GROUPS

Total SHAC Researchers (TOTAL SHAC RES)

DOE-Funded SHAC Researchers

Non-DOE-Funded SHAC Researchers

All Researchers (ALL RES)

Photovoltaics DOE-Funded Researchers

Photovol taics Non-DOE-F unded Researchers

Photovoltaics Researcher Manufacturer Representatives

Biomass Federally Funded Researchers in Production and Collection

Biomass Federally Funded Researchers in Conversion

Biomass Nonfederally Funded Researchers in Production and Collection

Biomass Nonfederally Funded Researchers in Conversion

Wind DOE-Funded Researchers

Wind Non-DOE-Funded Researchers

Solar Thermal Electric Power DOE-Funded Researchers

STEP Non-DOE-Funded Researchers

Ocean Energy DOE-Funded Researchers

Ocean Energy Non-DOE-Funded Researchers

Solar Energy Storage DOE-Funded Researchers

Solar Energy Storage Non-DOE-Funded Researchers

SHAC DOE-Funded Researchers

SHAC Non-DOE-Funded Researchers

Passive Federally Funded Researchers

Industrial Process Heat (IPH) Researchers

Agricultural Process Heat (APH) Researchers

Total SHAC Collector Manufacturer Representatives (TOTAL SHAC COLL MANUF)

SHAC Heating and Cooling System Manufacturer Representatives

SHAC Water Heating System Manufacturer Representatives

SHAC Nonconcentrating Collector Manufacturer Represèntatives

Total SHAC Manufacturer Representatives (TOTAL SHAC MANUF)

SHAC Heating and Cooling System Manufacturer Representatives

SHAC Water Heating System Manufacturer Representatives

SHAC Nonconcentrating Collector Manufacturer Representatives

SHAC Other Component Manufacturer Representatives

All Manufacturer Representatives (ALL MAN.UF)

Photovoltaics Manufacturer Representatives

Biomass Production and Collection Equipment Murlufacturer Representatives

Biomass Conversion Equipment Manufacturer Representatives

Wind Manuf acturer Representatives

STEP and IPH Concentrating Collector Manufacturer Representatives

SHAC Heating and Cooling System Manufacturer Representatives

SHAC Water Heating System Manufacturer Representatives

SHAC Nonconcentrating Collector Manufacturer Representatives

SHAC Other Component Manufacturer Representatives

Passive Manufacturer Representatives 
Table F-2. COMBINATION GROUPS (Concluded)

All Educators (ALL EDUC)

Photovoltaics Educators

Biomass Educators

Wind Educators

STEP Educators

SHAC Educators

Passive Educators

IPH Educators

All Cooperative Extension Service (CES) County Agents (ALL CES CO AGENT)

Passive County Agents

SHAC County Agents

Biomass Energy County Agents

APH County Agents

Wind County Agents

All CES State Specialists (ALL CES STATE SPEC)

State CES Agricultural Specialists

State CES Information Specialists

All Engineers (ALL ENG)

Photovoltaics Electric Power Engineers

Biomass Forest Products Engineers and Consultants

Wind Engineers

Wind Electric Power Engineers

STEP Engineers

SHAC Heating, Ventilating, and Air Conditioning (HVAC) Engineers

SHAC Industrial Engineers

IPH Plant Engineers

IPH Industrial Engineers

IPH Private Agricultural Engineers

State Level CES Agricultural Specialists

(Agricultural Engineers)

All Solar Utility Representatives (ALL SOLR UTIL REPS)

Photovoltaics Utility Representatives

SHAC Utility Representatives

Wind Utility Representatives

STEP Utility Representatives

'l'otal SHAC Hom eowners (TOTAL SHAC HOMEOWNER)

SHAC Space Heating Homeowners

SHAC Water Heating Homeowners

Total SHAC Owners/Managers (TOTAL SHAC OWNER/MNGR)

SHAC Space Heating Homeowners

SHAC Water Heating Homeowners

SHAC Building Owners/Managers 
Table F-3. LIST OF ACTIVE SOLAR HEATING AND COOLNGG DATA TABLES

Question

Number ${ }^{\mathrm{a}}$

Table Title

Page

Nonuser Questionnaire

Question 1

Question 2

Question 3

Question 6

Question 8A

Question 8B

Question 10

Question 11

Question D2

Question D3

Need for Information On the Job and Outside the Job ........ 279

Involvement ................................ 282

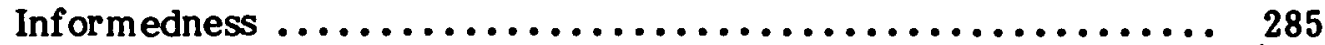

Interest in Specified SHAC Areas.................... 288

Usefulness of Specified Information Items ............... 291

Usefulness of Specified Information Items ............... 309

Use of Epceial $\Lambda$ cquisition Methods ................... 330

Use of Selected Solar Information Sources . . . . . . . . . . . 333

Years in Current Profession ......................... 354

Membership in Solar-Interested Organizations ........... 357

\section{User Questionnaire}

Question 1

Question 6

Question 8A

Question 8B

Question 11

Question D3

Question B1-6B

Question B2-13

Question B2-12
Specified Types of Wind Energy System Used............. 360

Interest in Specified SHAC Areas.................... 361

Usefulness of Specified Information Items .............. 362

Usefulness of Specified Information Items $\ldots \ldots \ldots \ldots \ldots \ldots \ldots \ldots$

Use of Selected Solar Information Sources ............... 375

Membership in Solar-Interested Organizations ............. 382

Inclusion of Solar............................... 383

Number of Years ............................... 384

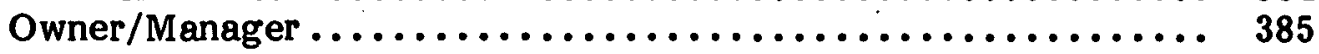

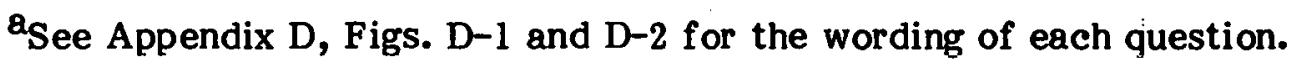




\section{IOCTOBER, 19791}

NEED FOR INFOHMATICN ON THE JOB ANO OUTSIDE. THE JOH $\left(0 U_{E} S T I O M\right.$ II
ACTIVE SHAC + PASSIVE

YES FOR JDB

NO FOR JOB

DON T KNOH/NA

a18 TOTAL

YES OUTSIDE JOB

NO OUTSIDE JOB

$\underset{10}{3}$
YES, JOB + OUTSIOE
SHAC SHLC TOTAL PASS ALL FUND FUNID RE

100 ? 100 ? $106^{8}$. 100 ? $168 \%$

19. $100^{\circ}$. $94^{7} \cdot 100^{\circ}$. $98^{\circ}$.

11. $1^{1}$. 1?

1.

100 . 100. $100^{8} .1009 .117$

$33^{3} \cdot 67^{6}, 50^{9} \cdot 33^{3} \cdot 41^{48}$

$67^{6} .33^{3} \quad 50^{9} .44^{4} .61$.

$22^{2} \cdot 8^{9}$

22. $67^{6} \cdot 44^{\circ} \cdot 33^{3} \cdot 39$.
SPHAC WHAC WHAC TOTAL SHAC TOTAL PAOSS ALL MENT HEOT COLL COLL CUMP MANOF MANUF

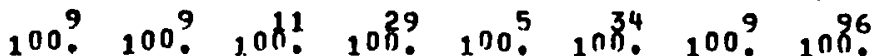

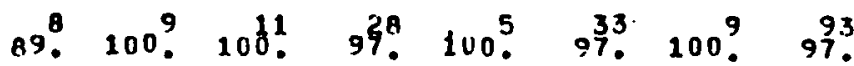

$11^{1}$ 3. $3^{1}$. $2^{2}$ 1.

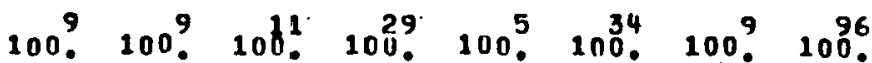

$44^{4} \quad 56^{5} \cdot 64^{7} \cdot 55^{16} \cdot 40^{2} \cdot 53^{18} \cdot 56^{5} \cdot 49^{4}$.

$22^{2} \quad 22^{2} \quad 36^{4} \quad 28^{\circ} \quad 60^{3}, \quad 32^{12} \quad 44^{4} \cdot 34^{3}$.

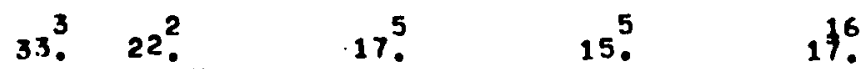

44. $56^{5} \cdot 64^{7} \quad 55^{16} \quad 40^{2} \cdot 53^{18} \quad 56^{5} 4^{46}$

Figure F-1. Active Solar Heating and Cooling Data Tables 
IOCTOBER, 19791

NEED FCR INFORMATION ON THE JOB AND OUTSIDE THE JOB IOLESTION 11

ACTIVE SHAC + PASSIVE ICONTODI

SHAC PQSE SHAC PAAS

1009.100 ? 1009.100 ?

YES FOR JOB

NO FOR JOB

DON'T KNOW/NA

Q1B TOTAL

YES OUTSIDE JOB

NO OUTSIDE JOB

DON'T KNOW/NA

YES, JOB + OUTSINE

100. 1000? 100? 100 ? i00. $1009.100^{63}$

100 . $100^{9}$. $100^{63}$

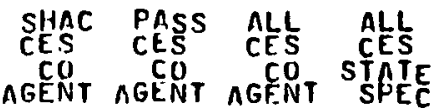

100 . 100 ? $100^{45} \quad 100^{18}$.

100. $99^{8} .99^{4} .4100^{8}$.

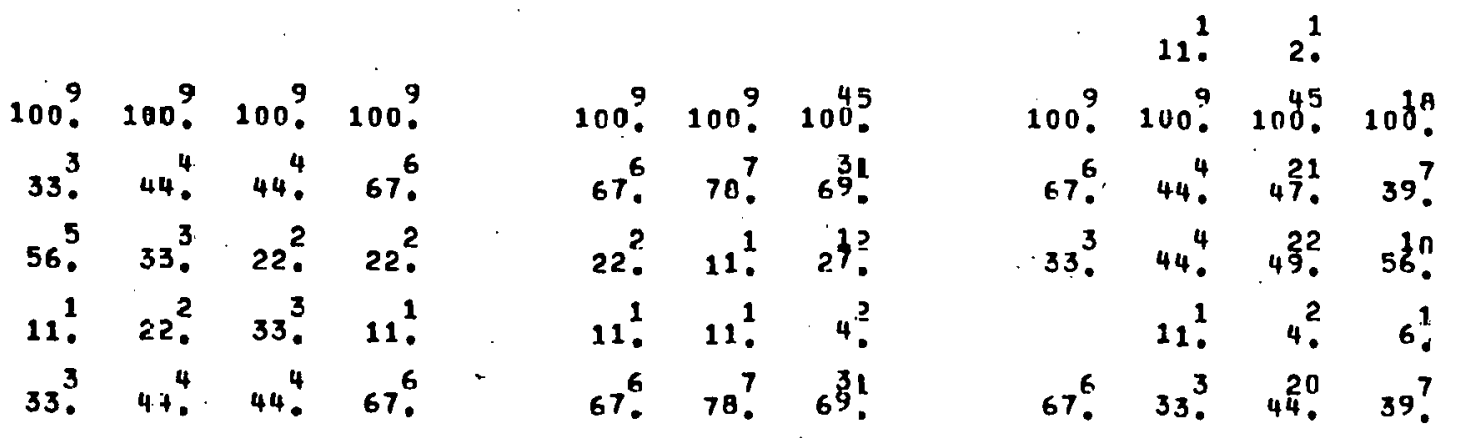

SHAC PASS ALL EOUC

Figure F-1. Aclive Solar Heating and Cooling Data Tables (continued) 
(OCTOBER, 1979)

NEED FOR. INFORMATION ON THE JOB ANO OUTSIDE THE JOB IOUESTION 11

ACTIVE SHAC

YES FOR JOB

NO FOR JOB

DON'T KNOW/NA

Q1B TOTAL

YES OUTSIOE J03

NO OUTSIDE JOB

DON'T KNOW/NA

$\stackrel{\cong}{\infty}$
OHAC HINC SHAC SHAC

SHAC
HWAC INDOS INDUS PLANT
ENG ENG

100 . 100 ? 100 ? 100 ?

100 ? $100 ? 100$ ? 100 ?

$1009.100 \% 1009.100 \% 1096$

$100 \% 100 \% 100 \% 100 \% 93$

3.

100. 100. 100\% 100 .

$233^{3} \cdot 22^{2} .56^{5} .233^{3}$.

$23.37^{6} .22^{2} .56^{5}$.

$333^{3} \quad 11 \cdot \frac{1}{1} \cdot 22^{2} \cdot 11$.

$33^{3} . \quad 22^{2} . \quad 56^{5}, \quad 33^{3}$.
1009.1009.

67. $44^{4}$.

$33^{3} . \quad 56$.

67. $44^{4}$.
SHAC SOLLL NON-

REPS UTIAR SOLAR

100 . $100^{35}, 100$ ?

100 . $93^{3} .100$.

3.

$100^{9} .100^{27} \cdot 100^{8}$.

$67^{6} . \quad 48^{3} . \quad 63^{5}$.

$33^{3} . \quad 52^{14} \cdot \quad 38^{3}$.

67. $\quad 44^{12} \cdot \quad 63^{5}$.

Figure F-1. Active Solar Heating and Cooling Data Tables (continued) 


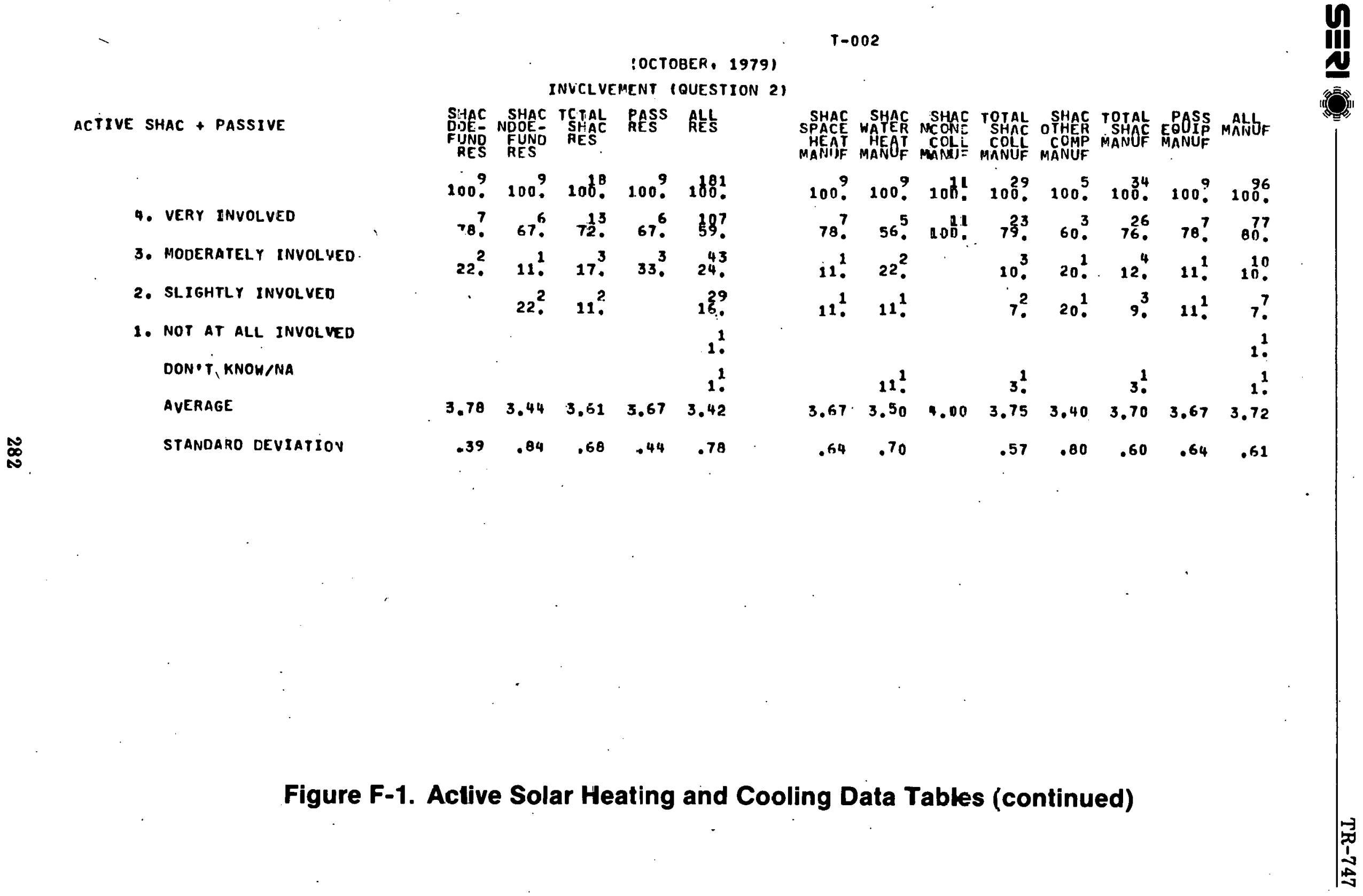


IOCTOBER, 1979.)

INVOLVEMENT (OUESTION 2 )

ACTIVE SHAC + PASSIVE (CONTIO)

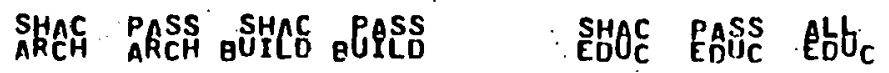

4. VERY INVOLVED

$$
\begin{array}{rrrr}
1009 & 100^{9} & 100^{9} & 100^{9} \\
44^{4} & 44^{4} \cdot & 33^{3} & 56 ! \\
56^{5} & 33^{3} & 22^{2} & 11 ! \\
& 22^{2} & 33^{3} & 33^{3} \\
& & 11 ! &
\end{array}
$$

$1009.1009 .100^{63}$

56. $22^{2} \quad 43^{27}$

3. MODERATELY INVOLVED

1. NOT AT ALL INVOLVED

DON T KNOW/NA

AVERAGE

STANDAFD DEVIATION

\begin{abstract}
$\begin{array}{llll}3.44 & 3.22 & 2.78 & 3.22\end{array}$
\end{abstract}
$3.56 \quad 3.00 \quad 3.21$

$.52 \quad .79 \quad 1.02 \quad .92$

$.46 \quad .66 \quad .76$

$2.67 \cdot 2.112 .31 \cdot 3.06$

$.65 \quad .32 \quad .51 \quad .76$

Figure F-1. Active Solar Heating and Cooling Data Tables (continued) 

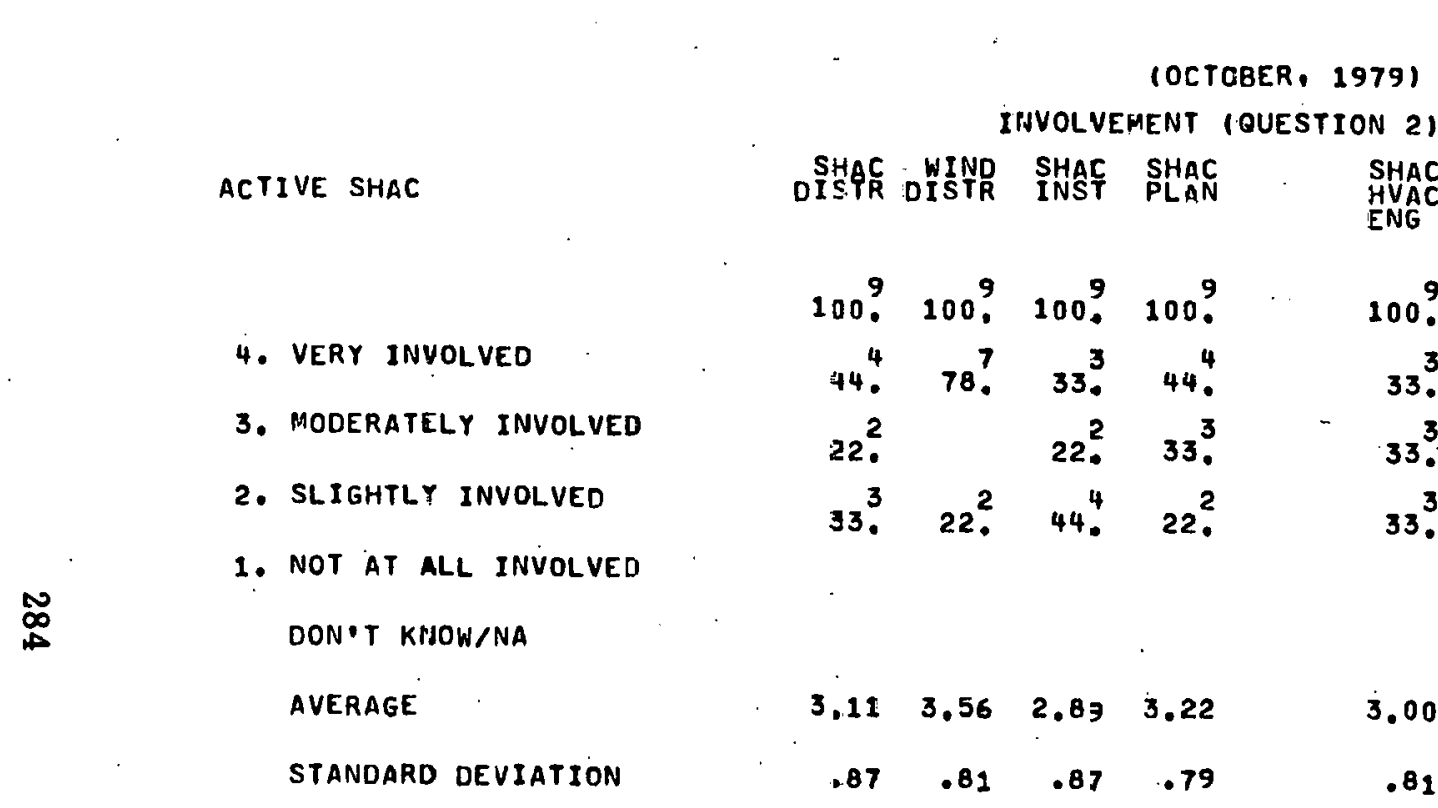

Figure F-1. Active Solar Heating and Cooling Data Tables (continued) 
nCTIVE SHAC + PASSIJE

4. VERY INFORHED

3. MODERATELY INFORMED

2. SLIGHTLY IHFORMEO

1. NOT AT ALL INFORMED
(OCTOBER, 1979)

INFORMEDNESS (OUESTION 3)

SHAC SHAC TOTAL RASS RLE - SPAC SHAC SHAC TOTAL SHAC TOTAL PASS ALL RES RES RES

100 . 100 ? $100^{8}: 100$ ? 1081.

$63^{8} \quad 78^{7} \cdot 83^{15} \cdot 89^{8} \cdot 65^{7}$.

$11^{1} \quad 22^{2} \cdot 17^{3} \cdot 11^{1} \cdot 33^{5}$

3.

DON'T KNOHINA

AVERAGE

$\begin{array}{lllll}3.89 & 3.78 & 3.83 & 3.69 & 3.62\end{array}$

$.30 .39 \quad .40 \quad .30 \quad . .53$ $\begin{array}{llllllll}3.78 & 3.78 & 4.00 & 3.86 & 3.40 & 3.79 & 3.56 & 3.72\end{array}$

$T-003$ MANOF MANOF MANUF MANUF MANUF $100^{9}$. 100? $100^{1}$. $100^{29}$. 100 . $100^{34} 100$. 1096 89. $78^{7} \cdot 100^{11} \quad 90^{26} \cdot 40^{2} \cdot 82^{28} \cdot 56^{5} \cdot 75 \%$ $22^{2} \quad 7^{2} \cdot 60^{3} \cdot 15^{5} \cdot 44^{4} \cdot 22^{21}$ 11. $3^{1}, 3^{1}, 3^{3}$

$\begin{array}{lllllll}.61 & .39 & .45 & .49 & .50 & .46 & .50\end{array}$

Figure F-1. Active Solar Heating and Cooling Data Tables (continued) 


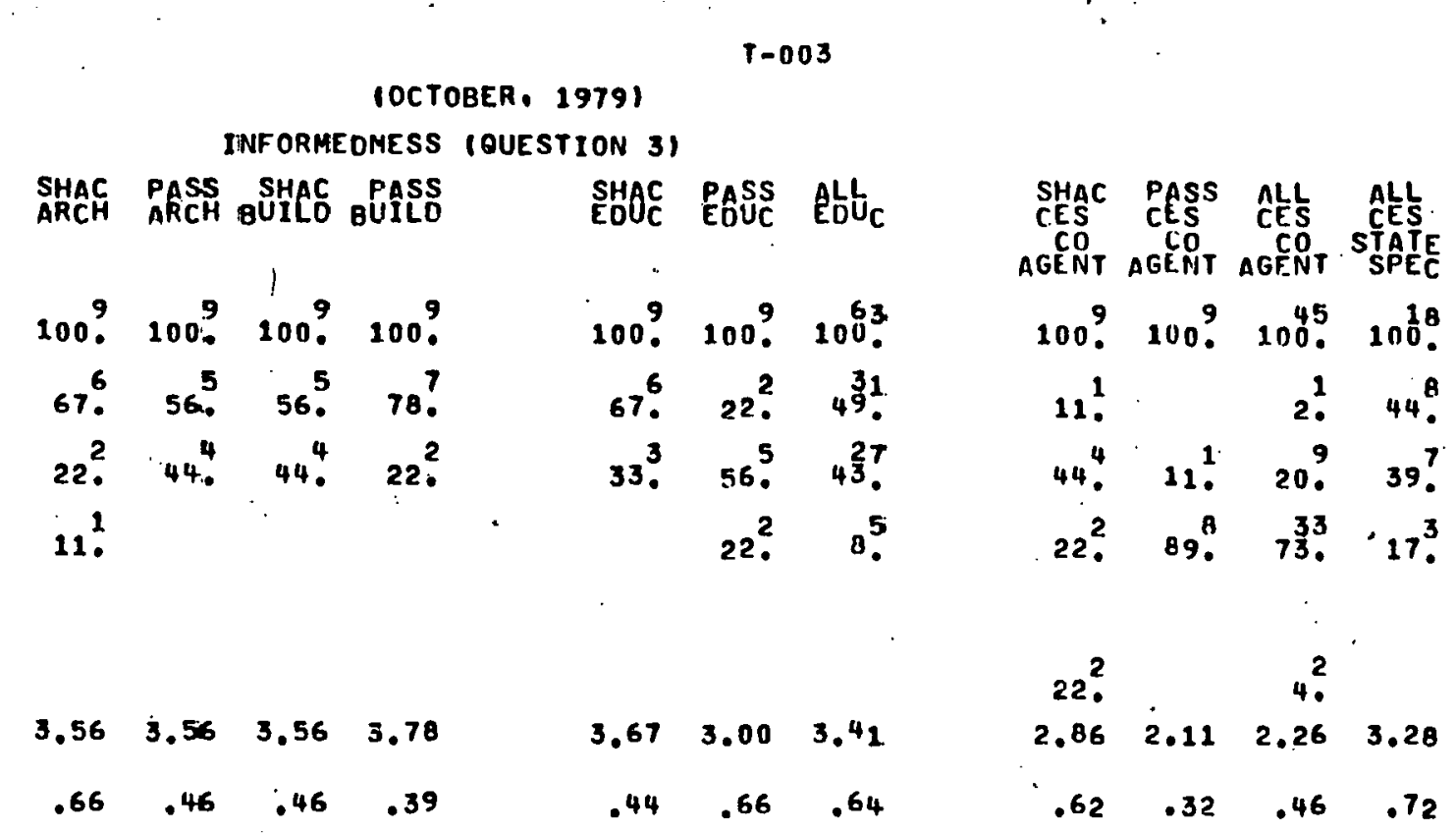

4. VERY INFORMED

3. MODERATELYY INFCRMED

2. SLIGHTLY INFORMEC

1. NOT AT ALL INFCRMED

DON'T KNOW/NA

AVERAGE

STANOARO DEVIATION

Figure F-1. Active Solar Heating and Cooling Data Tables (continued) 


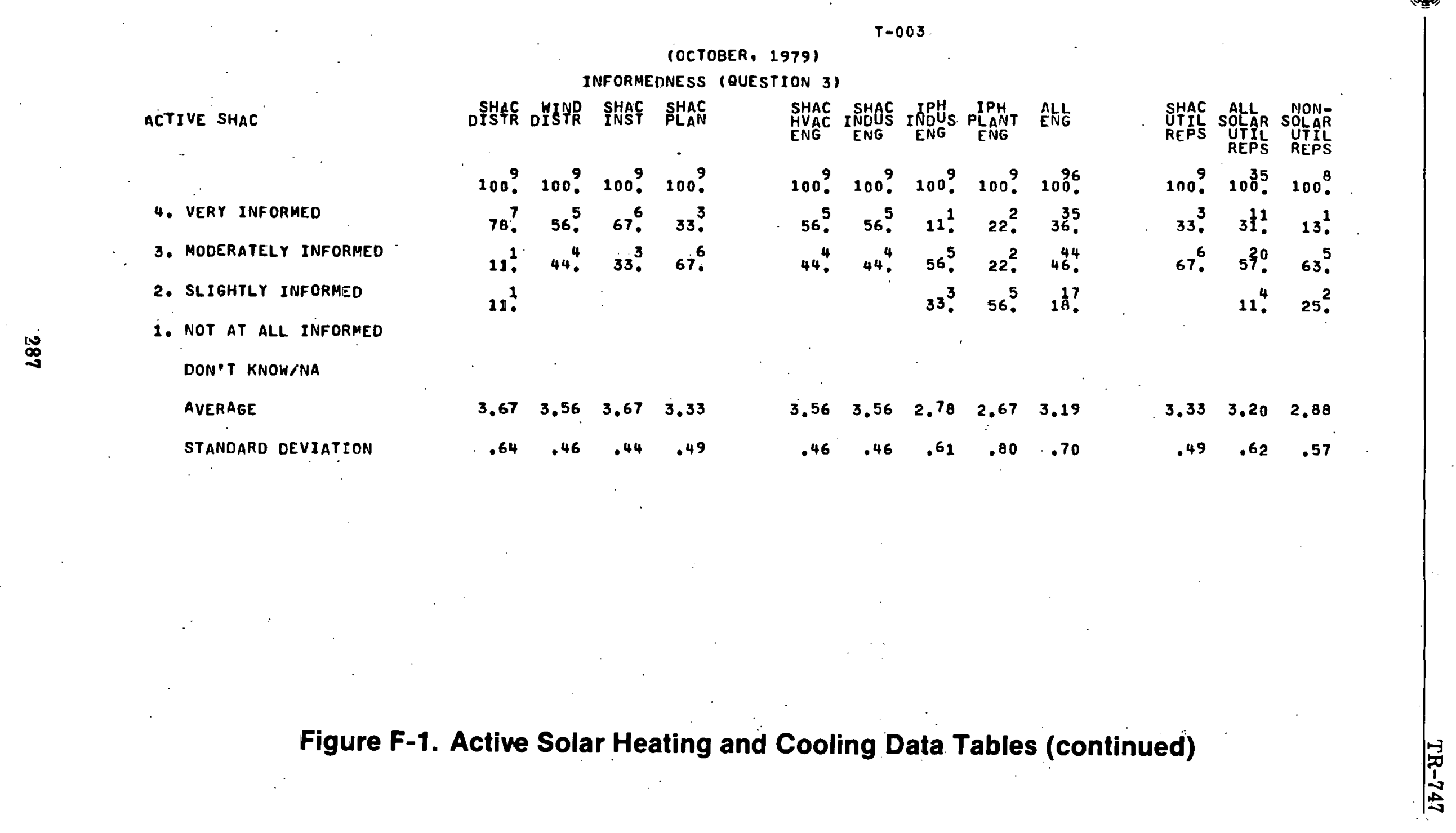


(OCTOBER, 1979$)$

INTEREST IN SPECIFIED SHAC AREAS (OUESTION 6):

ACTIVE SHAC + PASSIVE (CONTDO) SHAC PASS SHAC PASS
ARCH ARCH BUILD BUILD
EDUC EASS ALL

WATER HEATING
1. YES

2. ND

DON T KNOW/NA

SWIMMING POOL HEATING

$$
\begin{aligned}
& \text { 1. VES } \\
& \text { 2. NO }
\end{aligned}
$$

DON T KNOW/RA

SPACE HEATING
1. YES
2. $\mathrm{no}$

CON'T KNOW/NA

SPACE COOLING
1. YES
2. NO

DON'T KNOW/MA

$\begin{array}{rr}100^{9} & 78^{7} \\ & 22^{2}\end{array}$

$78 ?$
$22 ?$

$$
\begin{aligned}
& 78 ! \\
& 22^{2}
\end{aligned}
$$

78 ?

78 ?

$22^{2} .22^{2}$

HYBRID SYSTEMS
1. TES
2. NO

100

$$
\text { 11: }
$$

$100^{9}$.

$100^{5}$

DON'T KNOW/NA

Figure F-1. Active Solar Heating and Cooling Data Tables (continued) 
(OCTOBER, 19791

INTEREST IN SPECIFIED SHAC AREAS (QUESTION 6)

ACTIVE SHAC

WATER HEATING

i. YES

2. NO

DON'T KNOW/NA

SWIMNING POOL HEATING
1. YES
2. NO

DON'T KNOH/NA

SPACE. HEATING
1. YES
2. NO

DON'T KNOH/NA

SPACE COOLING
1. YES
2. NO

DON?T KNOH/NA

HYBRIO SYSTEMS
i. YES
2. NO

DON'T KNOW/NA
DHSAC OHIND SHAC SHAC

SHAC SHAC IPH IPH
HVAC INDUS INDUS PLANT EHL
ENG

100. 1009100 ? 100 ? 100 ?

SHAC SALL NONREPS UTIL SUT STL

$100^{9} 100$ ?

89. $100^{9} 1000^{\circ} \quad 1000^{\circ} 100$ ?

$100^{18}$

$78^{7}, 78 ?$

11 .

11. 11 .

11 . 11 .

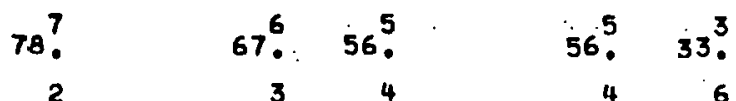

$44^{\circ}$.

$33^{3} \cdot 33^{3}$.

$22^{2} . \quad 33^{3} .44^{4}$.

$44^{4} .67^{6}$.

56.

$67^{6} .67^{6}$.

100 ?

$788^{7} \quad 67^{6}$

$100 ?$ i8?

${ }_{89}^{16} . \quad 100^{9}, 100$ ?

$22^{2} .33^{3}$.

$22^{2}$

$11^{2}$

$67^{6} .-89^{8} .89^{8}$.

$89^{8} .189^{8}$.

89.

$67^{6} .67^{6}$.

$33^{3}$ 11! $11^{1}$

11. 11 .

$11^{2}$

33. $33^{3}$.

$89^{\circ} \quad 78^{7} \quad 89^{8}$

$11^{1} \quad 22^{2} \quad 11^{1}$

$1000^{9} \quad 70^{7}$
$2 ?^{2}$

$89 . \quad 67^{6} .67^{6}$.

$11^{2}$ 22. $22^{2}$.

11.11 . 
(OCTOBER, 1979)

ACTIVE SHAC + PASSIVE

WATER HEATING
1. YES
2. NO

DON T KNOW/NA

SWIMMING POOL HEATING
1. YES
2. NO

DON T KNOW/NA

๕

SPACE HEATING
1. YES
2. NO

DON T KNOW/NA

SPACE COOLING
1. YES
2. NO

DON T KNOW/NA

HYBRID SYSTEMS
1. YES
2. NO

DON T KNOW/NA

INTEREST IN SPECIFIED SHAC AREAS (QUESTION 6)

SHAC SHAC TRTAL 'RASS ALE FUND. FUND RES

SHAC SHAC SHAC TOTAL SHAC TQTAL EPASS MAHbF HENOF MANOF MANUF MANUF MANUF MANUF MANUF

100 . $100^{9}$. $10 f^{8}$.

100 ? 100 ? $100^{8}$ ?

$\ln 0^{8}$

$100^{8}$

$56.78, \quad 57^{2}$

33. $22^{2} \cdot 28^{5}$.

11. 6.

$\begin{array}{rrr}44^{4} & 44^{4} & 4 .^{8} \\ 44^{4} & 56.5 & 50 \\ 11 . & 0 \\ 11 . & 6 .\end{array}$

78. 78 ? $78^{4}$

$111^{1}=22^{2}, \quad 17^{3}$

$11{ }^{2}$.

56. $\quad 78 . \quad 63^{2}$.

$333^{3} \quad 222^{2} \quad 288^{5}$

11 .

6.

56. $50^{5} \quad 89^{8} \quad \frac{13}{20}$

33. 11.2 .22$.

11 .

$\begin{array}{ll}63^{2} & 78^{7} \cdot 100^{9} \\ 28 . & 22^{2}\end{array}$

6.

$\begin{array}{rrr}44^{8} & 566^{5} & 56^{5} \\ 50 ? & 44^{4} & 44^{4}\end{array}$

6.

$78^{4}$

$17^{3}$

6.

$67^{2}$.

28.

6.

$\begin{array}{lll}723 & 44^{4} . & 676 \\ 22 . & 44^{4} . & 33^{3} . \\ 6 . & 11 . & \end{array}$

$1000^{9} \quad 78^{7}$.
$22^{2}$

67. $22^{2} \cdot$

$222^{2} \quad 78$ ?

11.

B9.

$11^{2}$.

ค9.

$11^{2}$.

89.

$11^{2}$

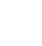


IOCTOBER, 19791

USEFULNESS OF SPECIFIED INFORMATION ITEMS (OUESTION B)

aCtive SHAC + PASSIHE

OBA(1) BIBLIOGRAPHY

ESSENTIAL

VERY USEFUL

SOMEWHAT USEFUL

NOT AT ALL USEFUL

ESSEFTILAL + VERY

DON'T KNOW

STANDARD DEVIATION

OAA (2) LIST OF SOUACES

\section{ESSENTIAL}

VERY USEFUL

SOMEWHAT USEFUL

NOT AT ALL USEFUL

GSSENTIAL + VERY

DON'T KNOW

AVERAGE

STANOARD DEVIATION

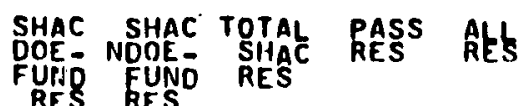

100 . 100 . $107^{8}, 100$. 180.

100. 100. $106^{8}$. 100. 1801

11. $\quad 60^{1} .22 .215$.

$13^{1} \quad 33^{3}$. $22.411^{1}$. 30 .

67. 67. 67? $44^{6}$. 49 .

11. $\quad 6122^{2}$. 12 .

$22^{2} . \quad 33^{3} .288^{5} \quad 33^{3}, \quad 39^{30}$.

1

$\begin{array}{lllll}2.22 & 2.33 & 2.28 & 2.33 & 2.35\end{array}$

$\begin{array}{lllll}.79 & .48 & .64 & 1.06 & .79\end{array}$

$100^{9}, 1009.100^{18}, 100^{\circ} 10^{180}$

$22^{2} \quad 11^{1} \quad 17^{3}, 22^{2} \cdot 13^{3}$.

33. $56^{5} \cdot 44^{\circ} .41^{1} \quad 44^{9}$.

$22^{2} \quad 33^{3} \cdot 28^{5} \cdot 56^{5} \quad 37^{67}$

$22^{2}$ 11. $11^{2}$.

56. $67^{6} . \quad 61 . \quad 333^{3} . \quad 57$ ?

$\begin{array}{lllll}2.56 & 2.78 & 2.67 & 2.44 & 2.63\end{array}$

$\begin{array}{lllll}1.05 & .61 & .87 & .96 & .79\end{array}$
SHAC SHAC SHAC TUTAL SHAC TOYAL PASS AAHEF HEAI HEAT COLL COLL COMP MANOF MANÜ

$10 n^{9} 100^{9} 106^{1} 10 \mathrm{n}^{2} \quad 100^{5} 1034100^{9} 100^{9}$ 100 ? 100 ? $100^{1}, 100^{29} 1005.34,100.100$ ? 100 ? 9. $3 ! \quad 3^{1} \quad 11^{1} \quad 5^{5}$ 11! 11!. $\quad 7^{2} \quad 6^{2} \quad 22^{2} \quad 15^{4}$

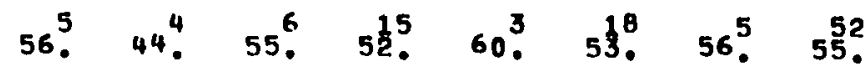

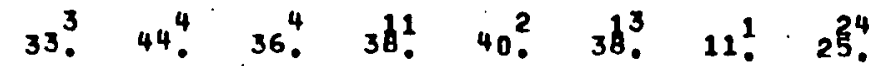

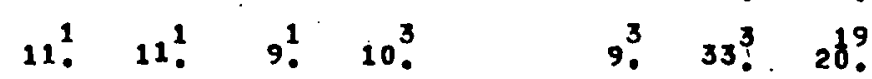

$\begin{array}{llllllll}1.78 & 1.67 & 1.82 & 1.76 & 1.60 & 1.74 & 2.33 & 2.00\end{array}$ $\begin{array}{llllllll}.52 & .65 & .82 & .72 & .49 & .68 & .82 & .78\end{array}$

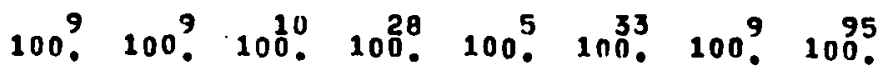

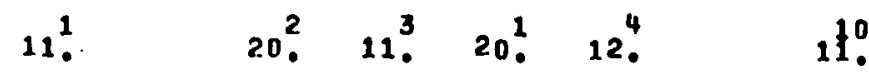
33. $22^{2} .10^{1} \cdot 21^{6} \cdot 20^{2} \cdot 21 ?^{?} \quad 56^{5} \quad 3 ?^{3}$ ?

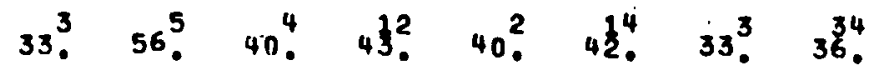

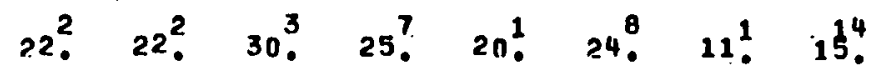

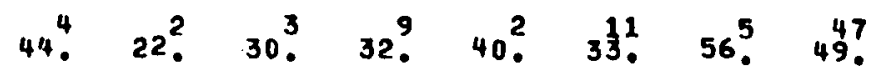

$2.33 \quad 2.00 \quad 2.20 \quad 2.18 \quad 2.40 \quad 2.21 \quad 2.44 \quad 2.45$ $\begin{array}{lllllllll}.95 & .66 & 1.07 & .92 & 1.01 & .95 & .70 & .07\end{array}$

SCALE: ESSENTIAL $=4$, VERY USEFUL $=3$, SOMEWHAT USEFUL $=2$, NOT NT ALL USEFUL $=1$

Figure F-1. Active Solar Heating and Cooling Data Tables (continued) 
IOCTOBER, 19791

USEFULNESS OF SPECIFIED INFORMATION ITEMS (QUESTION B)

ACTIVE SHAC +PASSIVE (CONTID) SHAC PASS SHAC BPSS ARCH ARCH BUILU BULD PASS ALfC

DBAI1) BIBLIOGRAPHY

ESSENTIAL

VERY USEFUL

SOMEWHAT USEFUL

NOT AT ALL USEF $J$

ESSEEULIAL + VERT

DCN T KNOW

AUERAGE

N

AVERAGE
STANDARD DEVIATION
OAA(2) LIST OF SOURCES
ESSENTIAL
VERY USEFUL
SOMEWHAT USEFUL
NOT AT ALL USEFUL
ESSENTIIAL + VER
DON'T KNOW
AVERAGE
STANDARO DEVIATION

\begin{tabular}{|c|c|c|c|c|c|c|}
\hline $100^{9}$ & $100^{9}$ & $100^{9}$ & $100^{9}$ & 1009 & $100^{9}$ & $100^{63}$ \\
\hline $1000^{9}$ & $10 c^{9}$ & 1009 & 100 . & 1009 & $100 ?$ & $100^{62}$ \\
\hline & $11 !$ & & $11^{1}$ & 11 . & $22^{2}$. & 192 \\
\hline $33^{3}$ & $2 \varepsilon^{2}$ & $56^{5}$ & $44^{4}$. & $36^{5}$ & $33^{3}$ & $43 ?$ \\
\hline $44^{4}$ & $32^{3}$. & $33^{3}$ & $33^{3}$. & $33^{3}$ & $44^{4}$. & $33^{21}$ \\
\hline $22^{2}$ & $32^{3}$. & $11^{1}$ & $11^{i}$ & & & 3 \\
\hline $33^{3}$ & $33^{3}$. & 56. & $56^{5}$ & $67^{6}$. & $56^{5}$ & 629 \\
\hline 2.11 & 2.11 & 2.44 & 2.56 & 2.78 & 2.78 & 2.76 \\
\hline .74 & 99 & .70 & .81 & .61 & .77 & $\theta_{1}$ \\
\hline $100^{9}$. & $100^{9}$ & 1009 & $100^{9}$ & 1009 & 1009 & $10^{53}$ \\
\hline & $33^{3}$ & 11 & $22^{2}$ & 11 & $33^{3}$ & 131 \\
\hline $67^{6}$ & $22^{2}$ & $67^{6}$ & 56 ? & $78^{7}$ & $33^{3}$ & $5 \mathfrak{l}^{3}$ \\
\hline $33^{3}$ & $44^{4}$ & $11 ?$ & $22^{2}$ & $11^{1}$ & $22^{2}$ & $23^{7}$ \\
\hline & & 11 & & & $11 !$ & $5^{3}$. \\
\hline $67^{6}$. & $56^{5}$ & 78 ? & $78 ?^{7}$ & $89^{8}$ & $67^{6}$ & $6 t^{3}$ \\
\hline 2.67 & 2.89 & 2.78 & 3.00 & 3.00 & 2.89 & 2.31 \\
\hline • & .87 & .77 & .66 & 47 & 99 & 7 \\
\hline
\end{tabular}

SHAC FASS Afts A cEs AGENT NEENT AGENT STPEC 100 . 100 . $1045.100^{8}$. 100 ? 100? $100^{45} 100^{8}$. 4.26 . $566^{5} \quad 44^{4}, \quad 38^{7} \cdot 22^{4}$. 33. $33^{3}$. $44^{20} 44^{8}$. 11. $22^{2} \cdot 13^{6} \quad 28^{5}$ $56.44^{4}, \quad 42^{19} \cdot 28^{5}$.

$2.44 \quad 2.22 \quad 2.33 \quad 2.06$ $\begin{array}{llll}.70 & .79 & .77 \quad .83\end{array}$ $100^{9}$. 100 ? $100^{45} .100^{10}$. 11 . $13^{6} .11^{2}$. 67. $56^{5} .56^{2} .509$ 11. $44^{4} .29^{3} .33^{6}$. 11 . $\quad 2126$. $73^{7} 56^{5}$. 69 ! 61 !

$2.78 \quad 2.56 \quad 2.80 \quad 2.67$

$\begin{array}{llll}.77 & .47 & .68 & .73\end{array}$ 
(OCTOBER, 1979)

USEFULAESS OF SPECIFIED INFORMATION ITEMS (QUESTION 8)

ACTIVE SHAC

QBA(1) BIBLIOGRAPHY

ESSENTIAL

VERY USEFUL

SOMEWHAT USEFUL

NOT AT ALL USEFUL

ESSEEVTIAL + VERY

DON'T KNOW

AyERAGE

$\mathfrak{W}$

STANDARD DEVIATION

QBAI2I LIST OF SOURCES

ESSENTIAL

VERY USEFUL

SOMEWHAT USEFUL

NOT AT ALL USEFUL

ESSEENTIAL + VERY

DON'T KNOW

AVERAGE

STANDARO OEVIATION

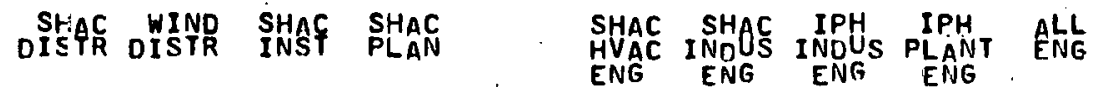

$$
\begin{aligned}
& 100^{9}, 1009.1009 .100 \text { ? } \\
& 100^{9} \text {. } 100 \text { ? } 100 \text { ? } 100 \text { ? } \\
& 22 \% \\
& \text { 33. } 33^{3} .233^{3} .222^{2} \\
& 56^{5} .33^{3} .56^{5} .566^{5} \\
& 11^{1} 22^{2} .11^{1} \text {. } \\
& \text { 33. } 33^{3} .43^{3} \text {. } 44^{4} \text {. } \\
& 11 \text {. } \\
& \begin{array}{llll}
2.22 & 2.13 & 2.22 & 2.67
\end{array} \\
& \begin{array}{llll}
.63 & .76 & .63 & .80
\end{array} \\
& 100 \text {. 100. 100. } 100 \text { \% } \\
& 11 \text {. } 11^{1} \text {. } 33^{3} \\
& 44^{4} \text {. 44. } 44^{4} .33^{3} . \\
& 44^{4} .22^{2}, 56^{5}, \quad 33^{3} \text {. } \\
& 222^{2} \\
& 56^{5} . \quad 56.544^{4} \cdot 67^{6} \text {. } \\
& 2.67 \quad 2.44 \quad 2.44 \quad 3.00 \\
& \begin{array}{llll}
.65 & .96 & .51 & .81
\end{array}
\end{aligned}
$$

SHAC ALL NONRE:PS UTIL UTIL 100 . $100^{35}$. 100 . $1009.100^{35} 100^{8}$. 11.3 . 17. $38^{3}$. $67.699^{6} .50$. $22^{2} .11^{4} .13^{1}$. 11. $20^{7} \quad 38^{3}$.

$2.00 \quad 2.11 \quad 2.25$

$.81 \quad .63 \quad .66$

$\begin{array}{lllll}.82 & .30 & .82 & .81 & .77\end{array}$

100 . 1009. 1009. 100 \% 1006 .

$100^{9} .100^{35} .100^{8}$.

22. $\quad 33^{3} \cdot 11^{1} \cdot 15^{14}$.

44. $22^{2} . \quad 33^{3} . \quad 33^{3} .43^{4}$.

$33^{3} . \quad 67^{6} .11^{1} \quad 22^{2} \cdot 33^{3}$.

$33^{3} .14^{5}$.

$22.48^{2} .48$ ?

44. $33^{4}$.

$11.222^{2} \quad 33^{3}$. 9 .

$67^{6} . \quad 22^{2} \cdot \quad 67^{6} \cdot \quad 44^{4} \cdot \quad 57^{5}$.

9. 13 .

$56^{5} \quad 54^{19} \cdot 88^{7}$.

$\begin{array}{lllll}2.89 & 2.11 & 2.78 & 2.22 & 2.63\end{array}$

$2.89 \quad 2.60 \quad 2.75$

$\begin{array}{lllll}.73 & .57 & 2.12 & 1.03 & .82\end{array}$

$.87 \quad .83 \quad .66$

SCALE: ESSENTIAL $=4$, VERY USEFUL $=3$, SOMEWHAT USEFUL $=2$, NOT AT ALL USEFUL $=1$

Figure F-1. Active Solar Heating and Cooling Data Tables (continued) 
(OCTOBER, 19791

USEFULNESS OF SPECIFIED INFORMATION ITEMS - CONTINUED (QUESTINN AI

ACTIVE SHAC + PASSIVE

OBAS3! CCALENDAR-CONFERENCES,

ESSENTIAL

VERY USEFUL

SOMEWHAT USEFUL

NOT AT ALL USEFUL

ESSENTIAL + VERY

DON'T KNOW

AVERAGE

幽 SHAC SHAC TOTAL PASS ALL
DOE- NOOE SHAC RES RES
FUND OUND RES FUND FUND

100 . 100 ? 10 10. $^{8}$. 100 ? 1601.

100 . 100 . 1000.100 . 1001

$33^{3} .22^{2} \cdot 28^{5} \cdot 11^{1} 10^{19}$.

11. $44^{4} \quad 28.533^{3}-38^{69}$.

$44^{4} \cdot 33^{3} \cdot 39^{7} \cdot 33^{3} \cdot 39^{1}$.

11. $\quad 6^{1} \quad 22^{2} \cdot 1^{22}$.

$44^{4} . \quad 67^{6} . \quad 56 . \quad 44.49^{80}$.

$\begin{array}{lllll}2.67 & 2.89 & 2.78 & 2.33 & 2.47\end{array}$

$\begin{array}{lllll}9.04 & .73 & .90 & .95 & .03\end{array}$

$1009.1009,100^{8}, 100,100 \%$

22. 11 . $17^{3} .11 !$ है.

22. $\quad 67^{6}, 44^{8}, 44^{4}, 35^{62}$.

$22^{2} \quad 11^{1} \quad 17^{3} \quad 22^{2} \cdot \quad 44^{7} \cdot$

33. $11^{1} \cdot 22^{4}, 22^{2}, 14^{25}$.

$44^{4}, \quad 78^{7}, E 1^{11} \quad 56^{5}, 42$.

$2 . .33 \quad 2.78 \quad 2.56 \quad 2.44 \quad 2.36$

$\begin{array}{lllll}1.16 & .77 & 1.00 & .96 & .02\end{array}$ SHAC SHAC SIIC TOTAL SHAC TOTAL PASS ALLT MAF̂F MANGF MANUF MANUF MANUF

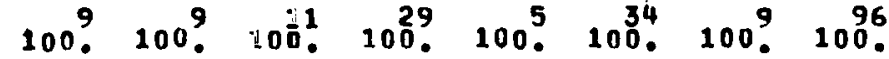

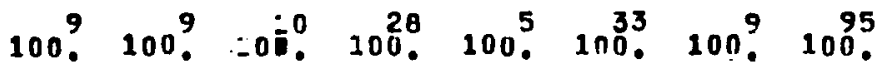
. 11 ! 4 ! $\quad 3 . \quad 11^{10}$. $33^{3} \cdot 33^{3} \cdot \quad 61^{6} \cdot 43^{2} \cdot 40^{2} \cdot 42^{\frac{1}{4}} \quad 22^{2} \cdot 35^{3} \cdot$ $67^{6} \cdot 33^{3} \cdot 30^{3} \cdot 43^{2} \cdot 40^{2} \cdot 42^{14} \quad 33^{3} \cdot 38$. $33^{3} .21^{3} \quad 20^{1} \cdot 12^{4} .44^{4}, 13^{6}$. 33. $33^{3} \cdot 70^{7} \cdot 46^{3} \cdot 40^{2} \cdot 45^{5} \quad 22^{2} \cdot 45^{3}$

$\begin{array}{llllllll}2.33 & 2.00 & 2.60 & 2.39 & 2.20 & 2.36 & 1.78 & 2.39\end{array}$

$\begin{array}{llllllll}.48 & .81 & .60 & .73 & .74 & .74 & .78 & .88\end{array}$

$100^{9} 100$. $10 \mathrm{C}^{10}, 100^{28}, 1000^{5}, 100^{33} 100 \% 100^{9}$.

11 . $\quad 4.11$ 3. $11^{1}$ 5.

$44^{4}, \quad 56^{5}, \quad 30^{3}, \quad 43^{2}, \quad 60^{3}, 45^{5}, 67^{6}, 46^{44}$

$44^{4} \quad 33^{3} \quad 50^{5} \quad 43^{2} \cdot 40^{2} \quad 42^{\frac{14}{4}} \quad 22^{2} \cdot 41^{39}$

11. $20^{2} \quad 11^{3}$. 9.

$56^{5} .56^{5}, \quad 30^{3} \cdot \quad 46^{3}, \quad 60^{3} \cdot 48^{6}, \quad 7 \theta^{7} \cdot 52^{49}$.

$\begin{array}{llllllll}2.67 & 2.44 & 2.10 & 2.39 & 2.60 & 2.42 & 2.89 & 2.49\end{array}$

$\begin{array}{llllllll}.65 & .70 & .70 & .73 & .49 & .71 & .56 & .72\end{array}$

SCALE: ESSENTIAL $=4$, VERY USEFUL $=3$, SOMEWHAT USEFUL $=2$, NOT 11 ALL USFFUL $=1$

Figure F-1. Active Solar Heating and Cooling Data Tables (continued) 
(OCTOBER: 1979$)$

USEFULNESS OF SPECIFIED INFORMATION ITEMS - CONTINUED (QUESTION B)

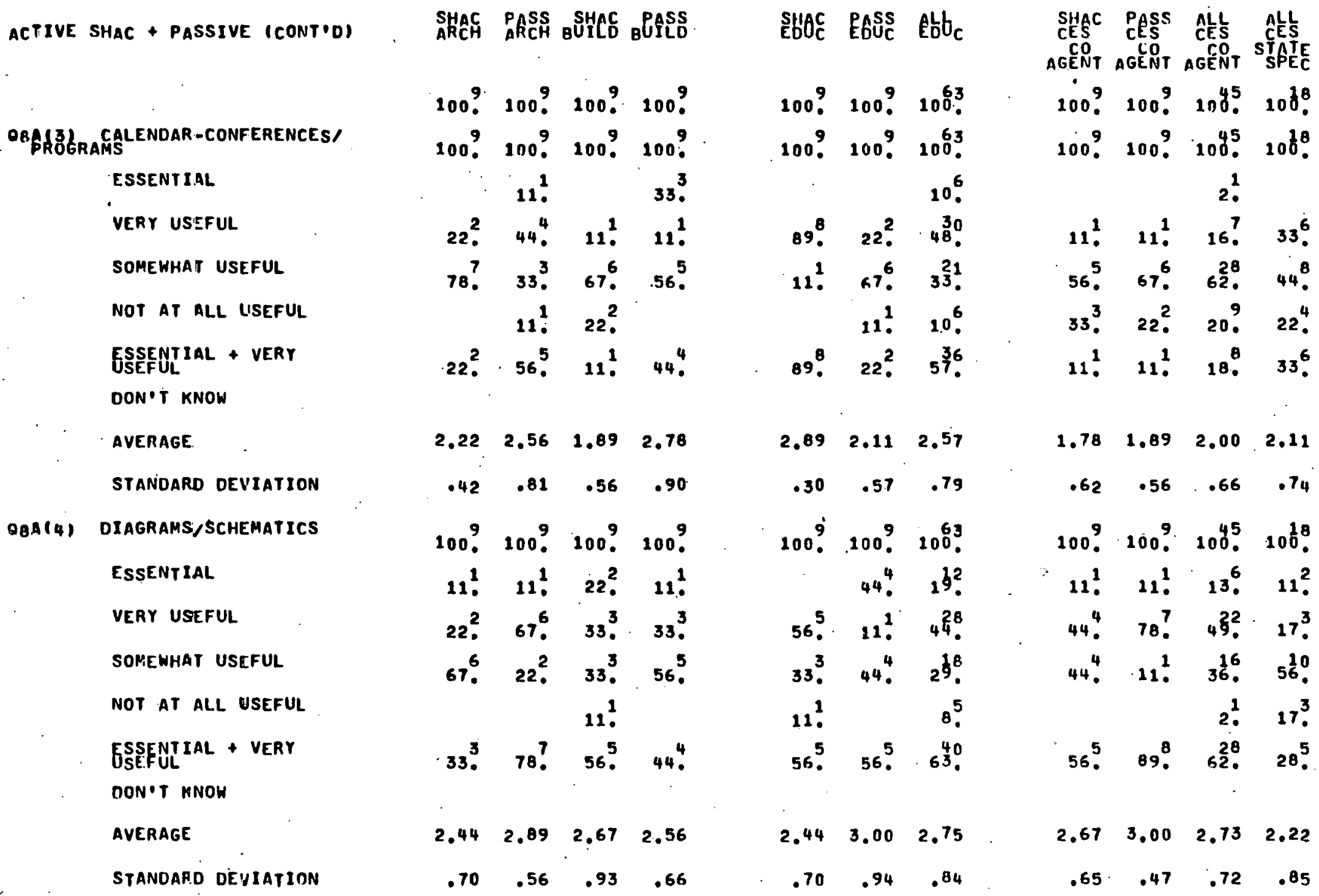


(OCTOBER, 1979$)$

USEFULNESE OF SPECIFIEO INFORMATION ITEMS:- CONTINUED (OUESTION B)

ACTIVE SHAC

QBA ${ }_{\text {PRÓGRAMS }}$ CALENDAR-CONFERENCES/ ESSEMTIAL

VERY USEFUL

SOMEWHAT USEFUL

NOT A.T ALL USEFUL

ESSEETIIAL + VERY

DON'T KNOW
SHAC WIND SHAC SHAC
DISTR DISTR INST PLAN

1009.1009 .1009 .100 .

100 . 100 ? 100 . 100.

11.111.

33. $3^{3} \quad 22^{2}, \quad 566^{5} \quad 222^{2}$

56. $33^{5}, \quad 333^{3} \quad 73^{7}$ ?

$33^{3} .2: 1$.

$44^{4} . \quad 33^{3}, \quad 56^{5} \quad 22^{2}$.

$2.56 \quad 2.11^{\circ} 2.44 \quad 2.22$

$\begin{array}{llll}.66 & .99 \quad .70 \quad .42\end{array}$

$1000^{9} 100 \%, 100 \% 100 \%$

$22^{2} .111^{1} \quad 111^{1} \quad 111^{1}$

$222^{2}, \quad 33^{3}, 44^{4} .33^{3}$.

$44.433^{3} . \quad 33 . \quad 56$.

$11.222^{2} \quad 11$.

44. $44^{4} . \quad 56.544^{5}$.

$2.56 \quad 2.33 \quad 2.56 \quad 2.56$

$.94 . .95 \quad .81 \quad .66$

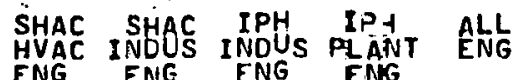

1009 ? 100 ? 100 ? 100? $100^{9}$ ?

$1009.1009 .100^{9}$. $100 \% 100^{9}$.

i1. 11 . 5 .

33. $3^{3} \quad 11^{1} \quad 22^{2}, \quad 22^{2}, \quad 24^{3}$.

$44^{4} .44^{4} .56 .544^{4} . \quad 44^{5}$.

11. $\quad 33^{3} .22^{2} . \quad 33^{3} . \quad 2^{23}$.

44. $\quad 22^{2} \cdot \quad 22^{2} \cdot \quad 22^{2} \cdot \quad 29^{2}$.

$2.44 \quad 2.00 \quad 2.00 \quad i .39 \quad 2.10$

$\begin{array}{lllll}.84 & .94 & .66 & .73 & .83\end{array}$

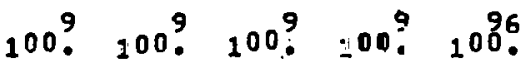

22. 33 . 11 .

$33^{3} . \quad 56^{5} . \quad 44^{4} .44^{4} . \quad 31^{30}$.

$33^{3} .22^{2} \quad 56 \% 3^{3}$.

$111^{1}{ }_{11}^{1}$. $11^{1}$. $1^{13}$.

$56^{5} \quad 89^{8} .56^{5} .44^{4} .520$

i11. 1 .

$\begin{array}{lllll}2.67 & 3.11 & 2.63 & \approx .44 & 2.60\end{array}$

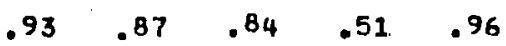

SHAC SALL NON: UTIL SOLAR SOLAR 100 . $100^{35} .100$. $100^{9} .100^{35} .100^{8}$. 9. $22^{2} .20^{7} .25^{2}$. $44^{4} .51^{8} .38^{3}$. $33^{3} .20$ ? $38^{3}$. $22^{2} .29^{\frac{1}{0}} .25^{2}$

$\begin{array}{lll}1.89 & 2.17 \quad 1.88\end{array}$

$.73 \quad .84 \quad .76$

100 ?. $100^{35} \cdot 100^{8}$.

11.93

$44^{4} .43^{5}, \quad 38^{3}$.

33. $33^{33} .50^{4}$.

11.11 .413 .

$56.51^{18} \cdot 38^{3}$.

$2.56 \quad 2.49 \quad 2.25$

$.81 \quad .79 \quad .66$

SCALE: ESSENTIAL $=4$, VERT USEFUL $=2$, SOMEWHAT USEFUL $=2$, NOT AT ALL USEFUL $=1$

Figure F-1. Active Solar Heating and Cooling Data Tables (continued) 
(OCTOBER, 1979$)$

USEFULNESS OF SPECIFIED INFORMATION ITEMS - CONTINUED (QUESTION A)

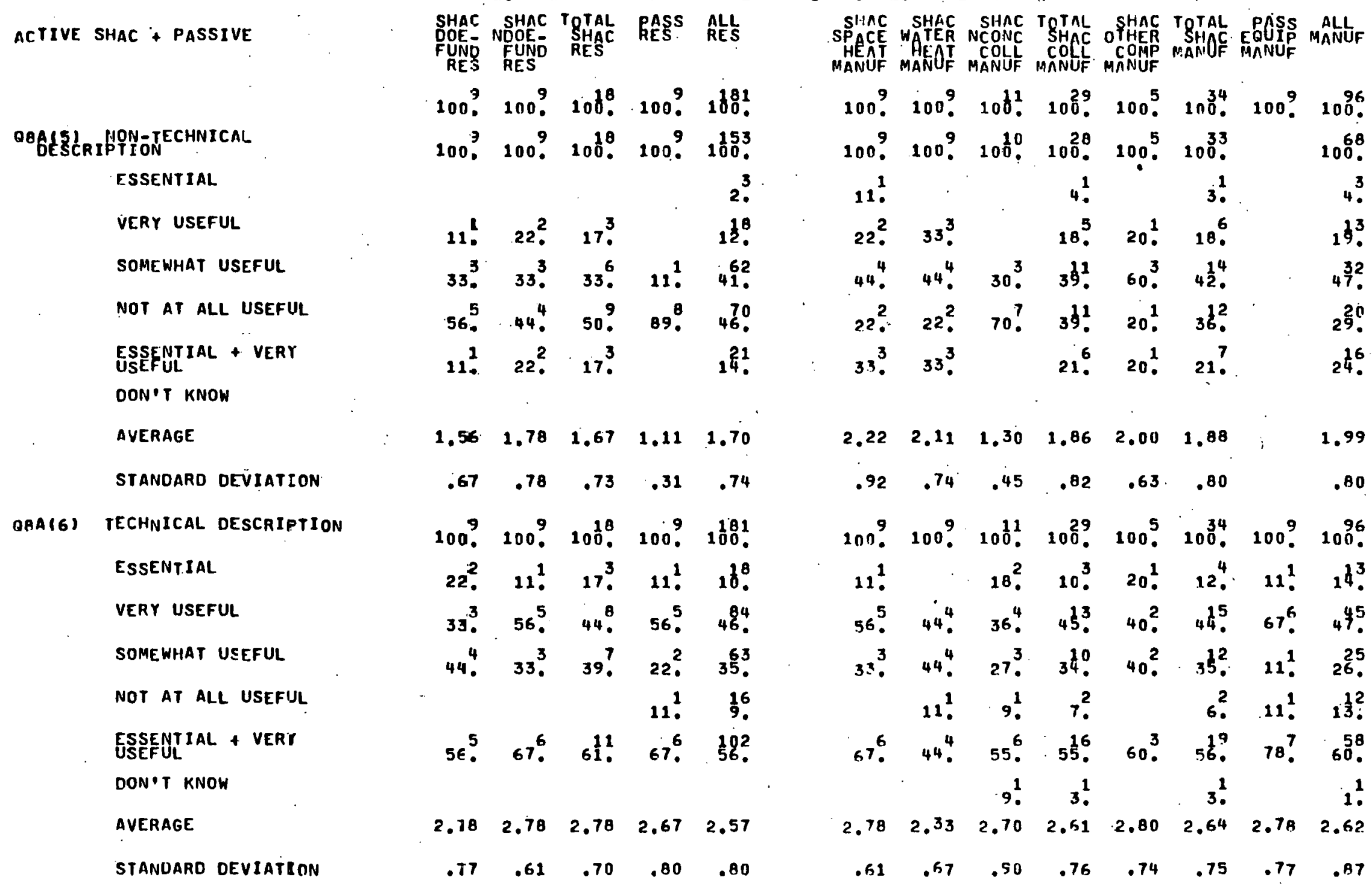

SCALE: ESSENTIAL $=4$, VERY USEFUL $=3$, SOMEWHAT USEFUL $=2$, NOT AT ALL USEFUL $=1$

Figure F-1. Active Solar Heating and Cooling Data Tables (continued) 
(OC TOBEA, 1979)

USEFULNESS OF SPECIFIED INFOPMATION ITEMS - CONTINUED (OUESTION B)

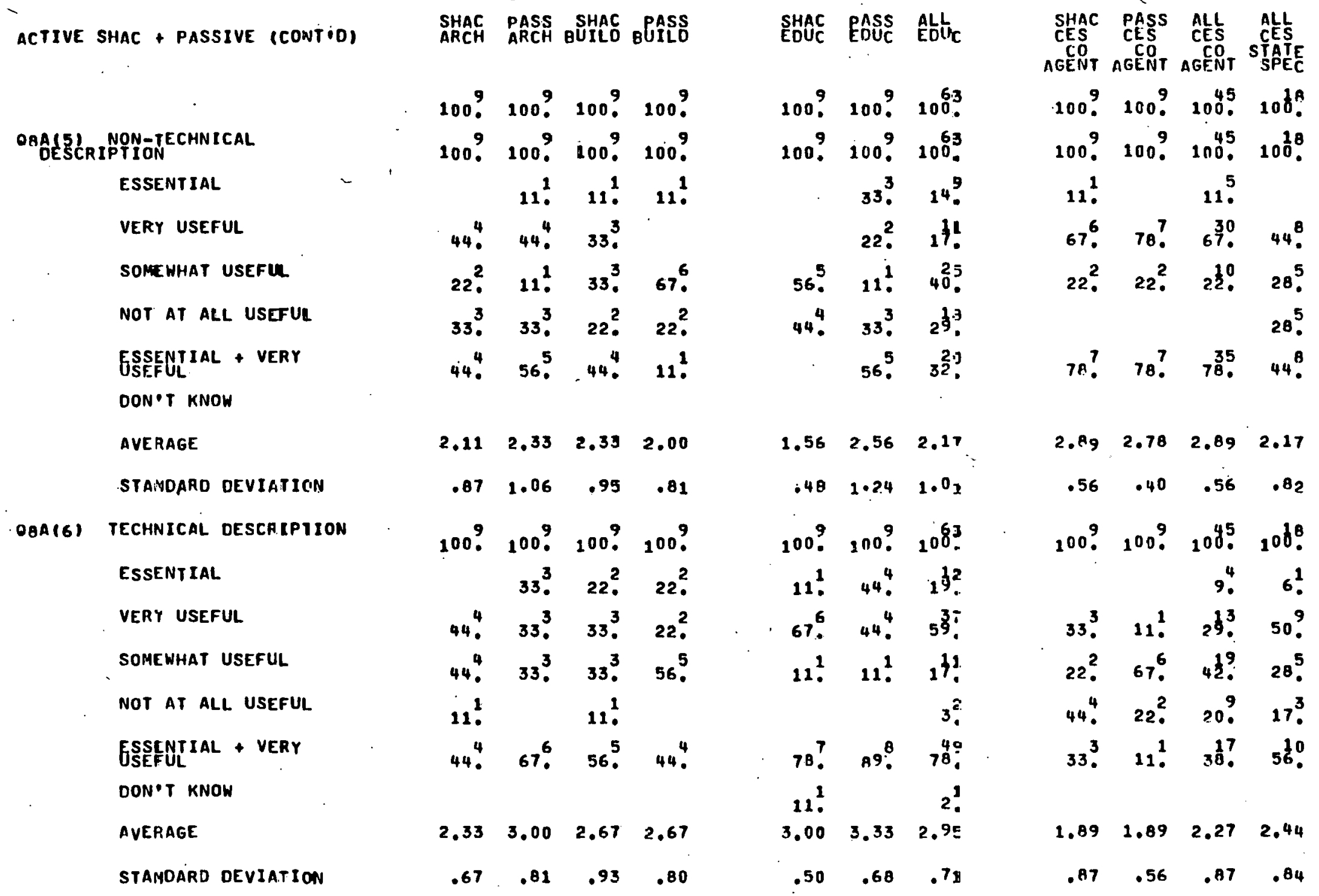


(OCTOBER, 1979)

USEFULNESS OF SPECIFIED INFORMATION ITEMS - CONTINUED (RUESTION B)

ACTIVE SHAC

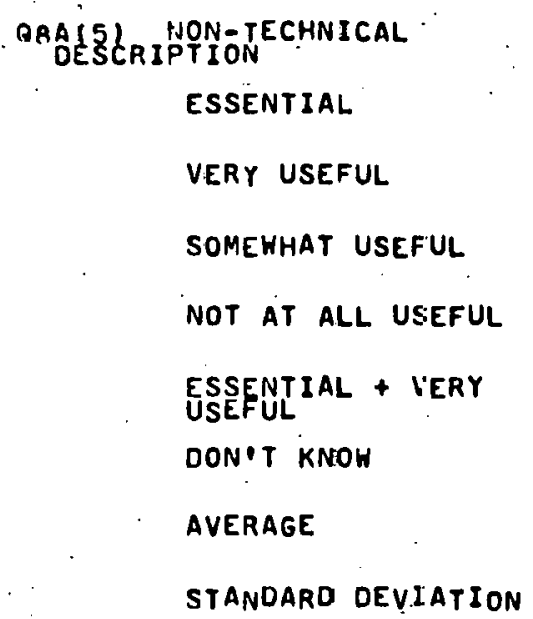

OIHAC WIND SHAC SHAC SHAC SHHAC IFUU PIPH ANG ALL
HVAC INUUS INOUS PLANT ENG
ENG ENG ENG ENG

4009 . 1009 . 100? 100 ? $100 \% 100 \% \cdot 100$ \% 100 ?

$11^{1}$ 22.

$11^{1} \quad 33^{3} \cdot 22^{2}$

44. $22^{2} . \quad 44^{4} .677^{6}$.

33. $44^{3} .433^{3} \cdot 11$ ?

$22^{2} .33^{3}, 22^{2} .22^{2}$.

$2.00 \quad 1.89 \quad 2.11 \quad 2.11$

$\begin{array}{llll}.94 & .87 & 1.10 & .57\end{array}$

$100^{9}$. $100^{9}$. $100^{9}, 100^{9}$.

33. $11^{1} \cdot 11^{1}$. $22^{2}$.

22. $33^{3} .44^{4}, 33^{3}$.

33. $22^{2} .433^{3} .44^{4}$

11. $33^{3}$. 11 .

56. $54^{4} .56^{5} . \quad 56^{5}$

$\begin{array}{llll}2.78 & 2.22 & 2.56 & 2.78\end{array}$

$1.02 .1 .03 \quad .01 \quad .77$
1009.1009 .1009 .1009 .1096$. 100 . $100^{9}$. $100^{9}$. 100 . $100^{52}$. 11 . 11 . 5 . 22. $22^{2} \cdot 44^{4} \cdot 33^{3} \cdot 26^{16}$. 22. $44^{4} \cdot \quad 22^{2} \cdot \quad 22^{2} \cdot 35^{2}$. $44^{4}, 33^{3}, 33^{3}, 33^{3} \cdot 34^{21}$ 33. $22^{2} .44^{4}$. $44^{4}$. 31?

$2.00 \quad 1.89 \quad 2.11 \quad 2.22 \quad 2.02$ $\begin{array}{lllll}1.05 & .73 & .87 & 1.03 & .08\end{array}$ 100 . 100, 100? 1009. $100^{96}$. 33. $\quad 11^{1} \cdot 22^{2} \cdot \quad 33^{3} \cdot 21^{20}$. 22. $67^{6} .44^{4} \cdot 44^{4}, 46^{44}$ $22^{2} \quad 11^{1} \quad 33^{3} \cdot 11^{1} \quad 22^{21}$ 22. $11^{1}$. $11^{1}$. $1^{11}$. 56. $78.767^{6} \cdot \quad 78.76 ?^{64}$.

$\begin{array}{llllll}2.67 & 2.78 & 2.89 & 3.00 & 2.76\end{array}$

$\begin{array}{lllll}1.14 & .77 & .73 & .94 & .91\end{array}$
SHAC SOLL NONREPS UTIL UTIL $100^{9} .100^{3} .100$. 100 . $200^{35} 100^{\circ}$. $22^{2} .11^{4}$ 44. $37^{3} .63^{5}$ $22^{2} .344^{2} \cdot 38^{3}$ 11 . $17^{6}$. $67^{6} \cdot 49^{7} \cdot 63^{5}$

$2.78 \quad 2.43 \quad 2.63$

$.90 \quad .89 \quad .45$

$100^{9} .100^{35} 1000^{\circ}$ $22^{2} .11^{4}$.

$22^{2} \cdot 46^{16} .50^{4}$

$33^{3} .34^{2} .50^{4}$.

$22^{2} .93$

$44^{4} .5 \%$. $50^{4}$.

$2.44 \quad 2.60 \quad 2.50$

$1.07 \quad .00 \quad .50$

Figure F-1. Active Solar Heating and Cooling Data Tables (continued) 
(OCTOBER, 1979)

USEFULHESS OF SPECIFIED INFORMATION ITEMS - CONTINUED (QUESTION B)

ACTIVE SHAC + PASSIVE

QBAIT) LISTS OF SUPPLIERS ESSENTIAL

VERY JSEFUL

SOMEWHAT USEFUL

NOT AT ALL USEFU:

ESSENTIAL + VERY

DON'T KNOW

AVERAGE

.

STANDARD DEVIATION

GBA(B) HANUBOOKS/TABLES

ESSENTIAL

VERY USEFUL

SOMEWHAT USEFUL

NOT AT ALL USEFUL

ESSENTIAL + VERY

DON+T KNOW

AVERAGE

STANOARD DEVIATION
SHAC SHAC TSTAL RASS ALL
DOE. NOOE SHAC RES RES
FUND FUND TAES RES RES RES

$100^{9} 100^{9} 100^{8} \quad 100^{9} 10^{81}$

$100 \% 100^{9}, 100^{18}, 100^{9}, 10^{146}$

11. $60^{1} \quad 11$. ${ }^{1}$ ?

56.56 .556 .259

$222^{2} . \quad 11^{1} \cdot \quad 17^{3} . \quad 56^{5} \quad 38^{56}$.

$22^{2} . \quad 22^{2}, \quad 22^{4} . \quad 33^{3} . \quad 27^{39}$.

$56.57^{6} .611 .011 . \quad 351$.

$2.33 \quad 2.56 \quad 2.44 .1 .89 \quad 2.16$

$\begin{array}{lllll}.82 & .94 & .90 & .97 & .92\end{array}$

1009.1009 .100 .1009 .181

33. $11^{1} \cdot 22^{4} \cdot 22^{2}$. ${ }^{3}$ ?

$44^{4} .56^{5} \quad 50^{9} \quad 22^{2} \quad 37^{67}$

11. $33^{3} .222^{4} \quad 44^{4} .365$

$11^{1} \quad 61 \cdot 11^{1} \quad 171$

$78^{7} \quad 67^{6} \cdot 72^{13} \cdot 44^{4} \cdot 46^{84}$

1 1.

$\begin{array}{lllll}3.00 & 2.78 \quad 2.89 & 2.56 \quad 2.39\end{array}$

$\begin{array}{lllll}.94 & .61 \quad .80 & .94 & .87\end{array}$
SHAC SHAC SHAC TQTAL SHAC TRTAL EPASS MALL HEAT HEAT COLL COLL COMP MANUF MANUF

100 ? 100 ? $10 \hbar^{1} \cdot 100^{29} 10051034.1009 .1006$

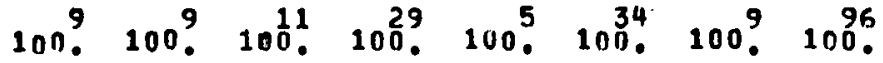

$22^{2} \quad 11^{1} \quad 2 \pi^{3} \cdot 21^{6} \quad 40^{2}$ 24. $22^{2} \cdot 20^{19}$

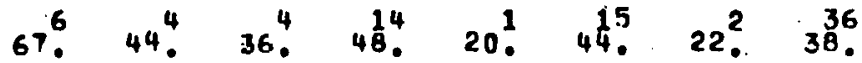

$33^{3} \cdot 9^{1} \quad 14^{4} \cdot 40^{2} \quad 18^{6} \cdot 33^{3} \cdot 28^{27}$

11. 11. 27. $17^{1} \cdot \quad 15^{5}, 22^{2} \cdot 14^{3}$.

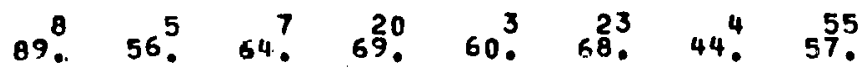

1.

$\begin{array}{llllllll}3.00 & 2.56 & 2, E 4 & 2.72 & 3.00 & 2.76 & 2.44 & 2.64\end{array}$

$\begin{array}{llllllll}.81 & .81 & 1.144 & .99 & .89 & .98 & 1.07 & .95\end{array}$

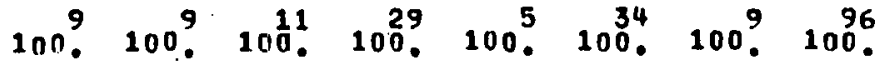

11! $\quad 3 ! 40^{2}$. 9. $22^{2} .99$

56. $33^{5} \cdot 45^{5} \quad 45^{13} \cdot 20^{1} \quad 41^{4} \cdot 33^{3} \quad 42^{40}$

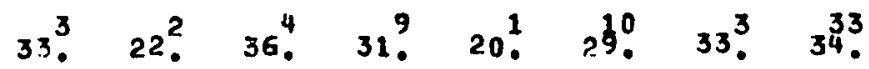

11. $33^{3}, \quad 18^{2}, 21^{6}, 20^{1} \quad 21^{7} \quad 11^{1} \quad 15^{14}$

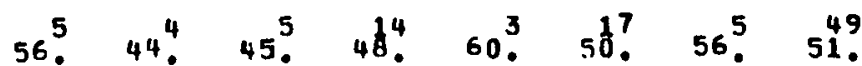

$\begin{array}{llllllll}2.44 & 2.22 & 2.27 & 2.31 & 2.80 & 2.38 & 2.67 & 2.46\end{array}$

$\begin{array}{llllllll}.70 & 1.03 & .75 & .03 & 1.16 & .91 & .93 & .84\end{array}$

SCALE: ESSENTIAL $=4$, VERY USEFUL $=3$, SOMEWHAT USEFUL $=2$, NOT AT ALL USEFUL $=1$ 
(OCTOBER, 1979)

USEFULNESS OF SPECIFIEO INFORMATION ITEMS - CONTINUED (QUESTION B)

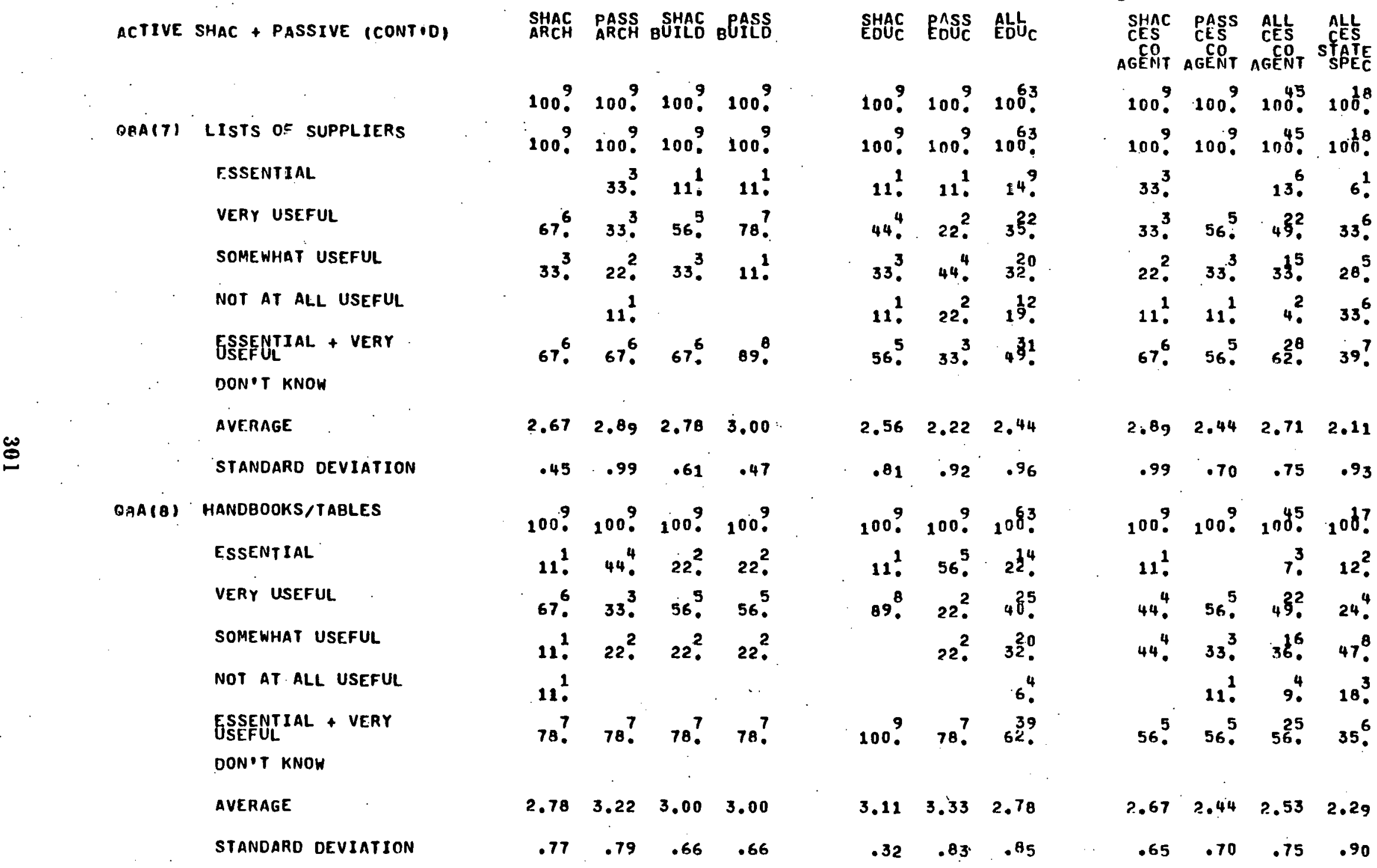

SCALE: ESSENTIAL $=4$, VERY USEFUL $=3 i$ SOMEWHAT USEFUL $=2$, NOT AT ALL USEFUL $=1$

Figure F-1. Active Solar Heating and Cooling Data Tables (continued) 


\begin{tabular}{|c|c|c|c|c|c|c|c|c|c|c|c|c|c|}
\hline \multicolumn{2}{|c|}{ ACTIVE SHAC } & \multicolumn{2}{|c|}{$\begin{array}{l}\text { SHAC WIND } \\
\text { OISTR DISTTR }\end{array}$} & \multirow{2}{*}{$\begin{array}{l}\text { SHAf } \\
\text { INS } \\
100 \%\end{array}$} & \multirow{2}{*}{$\begin{array}{l}\text { SHAF } \\
\text { PLAN } \\
1009\end{array}$} & \multicolumn{2}{|c|}{$\begin{array}{l}\text { SHAE SHAC } \\
\text { HNAE INOUS } \\
\text { ENG ENG }\end{array}$} & $\begin{array}{l}\text { IPH } \\
\text { IND } \\
\text { ENG }\end{array}$ & $\begin{array}{l}\text { PPA- } \\
\text { PLANT } \\
\text { ENG }\end{array}$ & ENL & \multirow{2}{*}{$\begin{array}{l}\text { SHAC } \\
\text { SWTP } \\
\text { REPS } \\
100 .\end{array}$} & \multirow{2}{*}{ 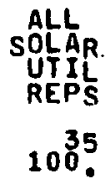 } & \multirow{2}{*}{$\begin{array}{l}\text { NON- } \\
\text { SOLAR } \\
\text { UTII } \\
\text { REPS } \\
100^{8} \\
100 .\end{array}$} \\
\hline & & 100 . & 100 . & & & ioo? & $100 \%$ & 100 . & $100^{9}$ & $100^{96}$ & & & \\
\hline QBA(7) & LISTS OF SUPPLIEPS & 100 . & $100{ }^{\circ}$ & $1000^{9}$ & $1000^{9}$ & $100^{\circ}$. & $1000^{9}$ & $1000^{\circ}$ & $1000^{9}$ & 1006 & 100. & 100. & $100^{8}$. \\
\hline & ESSENTIAL & $44^{4}$. & i1! & $33^{3}$ & $33^{3}$. & $11^{1}$ & & $11^{1}$ & & ${ }_{11}^{11}$ & $33^{3}$. & $17^{6}$. & $13^{1}$ \\
\hline & VERY USEFUL & $22^{2}$ & $67^{6}$. & $67^{6}$ & $22^{2}$. & $22^{2}$. & 56. & $22^{2}$ & & 236. & $22^{2}$ & 290 & $63^{5}$. \\
\hline & SOMEWHAT USEFUL & 33. & 11. & & $44^{4}$. & $56^{5}$. & 11. & $22^{2}$ & $56^{5}$. & 34. & $22^{2}$ & $34^{3}$. & $25^{2}$. \\
\hline & NOT AT ALL USEFUL & & $11^{1}$ & & & 112 & $33^{3}$. & $44^{4}$. & $44^{4}$. & 276. & $22^{2}$. & $17^{6}$. & \\
\hline & $\begin{array}{l}\text { ESSEFTIAL + VERY } \\
\text { USEUL } \\
\text { OON'T KNOW }\end{array}$ & $67^{6}$. & $78 ?$ & 100. & 56. & 33. & 56. & $33^{3}$ & & 397 & 56. & $4 \frac{16}{6}$ & $75^{6}$ \\
\hline & AVERAGE & 3.11 & 2.78 & 3,33 & 2.89 & 2.33 & 2.22 & 2.00 & 1.56 & 2.23 & 2.67 & 2.46 & 2.88 \\
\hline & STANDARD DEVIATION & .87 & $.77^{\circ}$ & .49 & .87 & .82 & .92 & 1.05 & .48 & .97 & 1.14 & .95 & .57 \\
\hline$Q A A(B)$ & HANDBOOKS/TABLES & 100 . & 100 . & 100 ? & $100 \%$ & 100 . & 1009 & 100 . & 100 ? & 1005 & 100 ? & 1085 & $100^{8}$ \\
\hline & ESSEMTIAL & $33^{3}$. & $22^{2}$ & $22^{2}$ & $33^{3}$ & $11 \%$ & $22^{2}$ & $33^{3}$ & & $18 ?$ & $33^{3}$ & $17^{6}$ & \\
\hline & VERY USEFUL & $33^{3}$ & $44^{4}$. & $44^{4}$. & $22^{2}$. & $78 ?$ & 67. & $33^{3}$ & 78 ? & $47^{45}$. & $44^{4}$. & $33^{3}$. & $63^{5}$. \\
\hline & SOMEWHAT USEFUL & $22^{2}$ & $11{ }^{1}$ & $33^{3}$. & $44^{4}$. & $11^{1}$ & & $22^{2}$. & $22^{2}$ & 298. & & 290. & $38^{3}$. \\
\hline & NOT AT ALL USEFLLL & $11{ }^{1}$ & $22^{2}$. & & & & i1. & $11^{1}$. & & $5^{5}$ & $22^{2}$ & $17^{6}$ & \\
\hline & $\begin{array}{l}\text { ESSENTIAL + VERY } \\
\text { USEFUL } \\
\text { DON.T KNOW }\end{array}$ & $67^{6}$. & $67^{6}$ & $67^{6}$. & 56. & 89. & 89. & $67^{6}$ & $78 ?$ & $65^{62}$ & $78 ?$ & 54. & $63^{5}$ \\
\hline & AVERAGE & 2.89 & 2.67 & 2.89 & 2.89 & 3.00 & 3.00 & 2.89 & 2.78 & 2.78 & 2.89 & 2.54 & 2.63 \\
\hline & STANDARD DEVIATIION & .99 & 2.04 & .73 & .87 & .47 & .81 & .99 & .40 & .79 & 1.09 & .97 & .45 \\
\hline
\end{tabular}


(OCTOBER, 19791

USEFULNESS OF SPECIFIED INFORMATION ITEMS - CONTINUED (QUESTION B)

aCTIVE SHAC + PASSIVE

QBA(9) TECHNICAL EXPERTS LIST

ESSENT I AL

VERY USEFU

SOMEWHAT USEFUL

NOT AT ALL USEFUL

ESSEENTIAL + VERY

DON'T KNOW

AVERAGE

$\stackrel{\omega}{\omega}$
SHAC SHAC 'RHAL RASS ALL FUND FUND RES

100 ? 100 ? $108^{8}$. 100, 1881. $1000^{9} 100$. $108^{\circ}, 100$. 168 ?

$$
11^{2} \quad 16
$$

$44^{4} \cdot 33^{3} \cdot 39^{7}, \quad 22^{2} . \quad 36$.

$44^{4}, 56^{5}, 50^{9}$. $44^{4}, 40^{2}$.

11. $11^{2}$ 11. $22^{2}$. $15^{2}$.

44. $33^{3} .39$. $33^{3} .45^{2}$.

$\begin{array}{lllll}2.33 & 2.22 & 2.28 & 2.22 & 2.39\end{array}$

$\begin{array}{lllll}.67 & .63 & .64 & .92 & .85\end{array}$

$1000^{9} 1009.100^{18}, 100 \% 1001$.

$22^{2} .11^{1} .17^{3}, 22^{2} .130$

$56^{5} .44^{4}, \quad 50^{9} . \quad 33^{3} .36^{65}$.

11. $22^{2} \cdot 17^{3} \cdot 33^{3} \cdot 2.9^{3}$.

11. $22^{2} \cdot 17^{3} \cdot 11.218$.

78 . $56.53^{3}, \quad 56.525$

$\begin{array}{lllll}2.89 & 2.44 & 2.67 & 2.67 & 2.51\end{array}$

$.07 \quad .96 \quad .93 \quad .93 . \quad .96$
SPAC SHAC SHAC 'RTAL SHAC TRTAL EASS MALL HEOT HEOT COLL COLL CUMP MANUF MANUF

100 ? 100 ? $100^{1}$. 1029 . 100 . $100^{34} 100$. $100^{6}$.

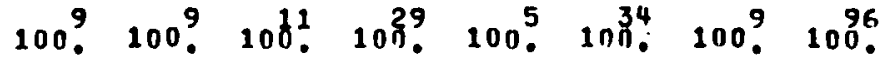
$40^{2} \quad 6_{0}^{2} \quad 22^{2}, \quad 11 \frac{11}{3}$ 33. $\quad 36^{4} .244^{?}$ 21. $33^{3} .31^{30}$ 56. $\quad 67^{6} \cdot 27^{3} \cdot 48^{4} \cdot \quad 20^{1} \cdot \quad 44^{5} \cdot 44^{4} \cdot 38^{36}$ 11. $33^{3} .36^{4} \quad 28^{8} .40^{2}$ 29. 33. $\quad 36^{4} . \quad 24^{7} .40^{2} .266^{9} .566^{5} \quad 43^{41}$.

$\begin{array}{llllllll}2.22 & 1.67 & 2.00 & 1.97 & 2.40 & 2.03 & 2.78 & 2.34\end{array}$ $\begin{array}{llllllll}.63 & .45 & .85 & .70 & 1.35 & .85 & .77 & .93\end{array}$ $1100^{9} .100^{9}: 100^{10} \cdot 100^{28}, 100^{5} \cdot 100^{33}, 1009.100$.

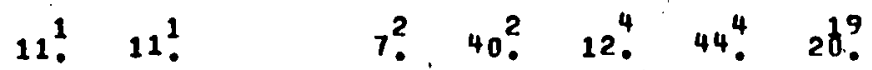
$22^{2} \cdot 44^{4} \cdot 50^{5} \cdot 39^{1} \cdot \quad 33^{1} \cdot 22^{2} \cdot 36^{4}$.

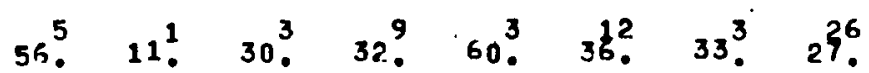
$11^{1} \quad 33^{3} .20^{2} .21^{6} . \quad 10^{6}$. $17^{16}$.

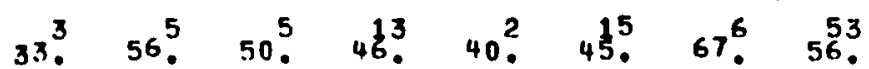

$\begin{array}{lllllllll}2.33 & 2.33 & 2.30 & 2.32 & 2.80 & 2.39 & 3.11 & 2.59\end{array}$

$\begin{array}{llllllll}.82 & 1.06 & .78 & .89 & .97^{\prime} & .92 & .87 & .98\end{array}$ 
(OCTOBER, 1979$)$

USEFULNESS OF SPECIFIEO INFORMATION ITEMS - CONTINUED (GUESTICN B)

ACTIVE SHAC + PASSIVE (CONT'D) SHAC PESS SHAC PASS ARC AFCH BUILD BUILD SHAC PASS ALL

QBAIg) TECHNICAL EXPERTS LIST

ESSENTIAL

VERY USEFUL

SOMEWHAT USEFUL

NOT AT ALL USEFU

ESSENTIAL + VERY

DOM'T KNOH

AVERAGE

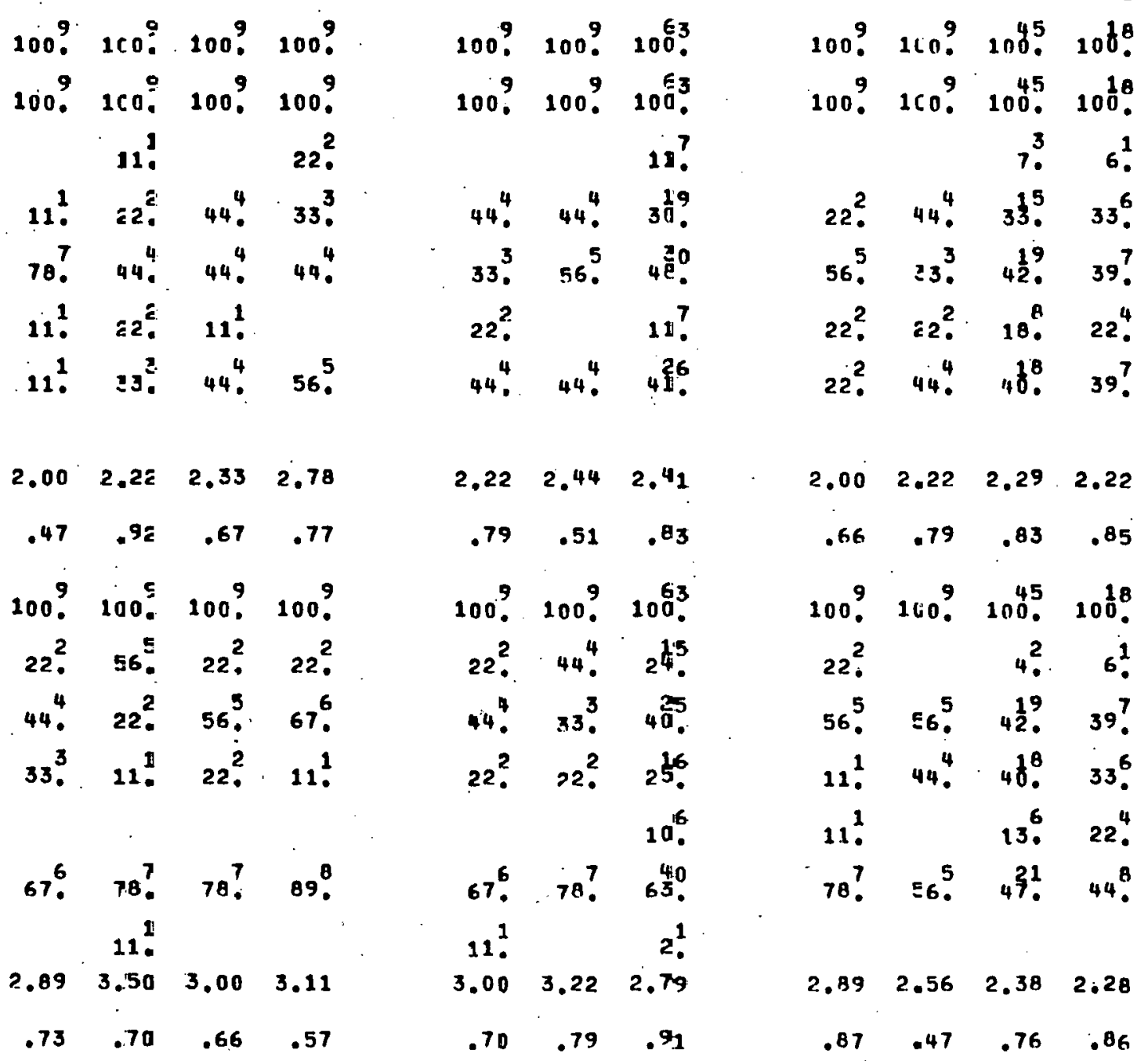

SCALE: ESSENTIAL $=4$, VERY USEFUL $=3$, SOMENHAT USEFUL $=2$, NOT $A T$ ALL USEFUL $=1$

Figure F-1. Active Solar Heating and Cooling Data Tables (continued) 
(OCTOBER, 1979 )

USEFULNESS OF SPECIFIED INFORMATION ITEMS - CONTINUED (QUESTION B)

ACTIVE SHAC

QAA(9) TECHNICAL EXPERTS LIST

ESSENTIAL

VERY USEFUL

SOMEWHAT USEFUL

NOT AT ALL USEFUL.

ESSENTIAL + VERY

DON'T KNOW

STANDARD DEVIATION

QBA(10) MANUAL METHODS

ESSENTIAL

VERY USEFUL

SOMEWHAT USEFUL

NOT AT ALL USEFUL

ESSENTIAL + VERY

DON'T KNOW

AVERAGE

STANDARD DEVIATION

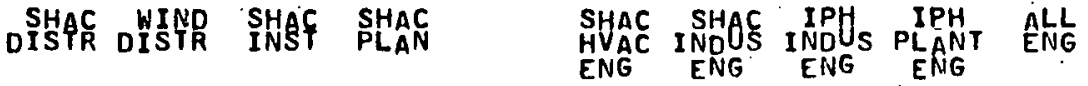

\begin{tabular}{|c|c|c|c|}
\hline $100 ?$ & $100 ?$ & 1009 & 100 ? \\
\hline 1009 & 1009 & $100^{9}$. & $100^{9}$ \\
\hline $44^{4}$. & $33^{3}$ & $33^{3}$ & $56^{5}$. \\
\hline $33^{3}$ & $44^{4}$. & $56^{5}$ & $22^{2}$ \\
\hline $2 \dot{2}^{2}$ & $22^{2}$ & 11 ! & $11^{1}$ \\
\hline $44^{4}$. & $33^{3}$. & $33^{3}$ & $67^{6}$. \\
\hline 22 & 2.11 & 2.22 & 2.67 \\
\hline 79 & 74 & 63 & .80 \\
\hline 00 ? & 1009 & 1009 & $1000^{9}$ \\
\hline $44^{\circ}$ & 11 . & $22^{2}$. & $33^{3}$ \\
\hline $22^{2}$ & $22^{2}$ & $33^{3}$. & $56^{5}$. \\
\hline $33^{3}$ & $44^{4}$. & $33^{3}$. & \\
\hline & 11. & $11^{1}$ & $12^{1}$ \\
\hline $67^{6}$. & $33^{3}$. & 56. & $89^{8}$. \\
\hline & $11^{1}$ & & \\
\hline 1. & 2.38 & 2.67 & 3.11 \\
\hline & 84 & 93 & 87 \\
\hline
\end{tabular}

$1009.1009 .100^{9} \cdot 1009.100^{\circ}$.

100 . 1009 . 1009 . 1009 . $100^{96}$.

$11^{1} \quad 11^{1}$ ?.

22. 22. 11: $11^{2} \cdot 22^{2}$.

$56^{5} \cdot 56^{5} \cdot \quad 67^{6} \cdot \quad 56^{5} \cdot \quad 46^{4}$.

11. $22^{2} \cdot 11^{1} \quad 33^{3}, 11^{16}$.

33. 22. $22^{2}$. 11. 336.

$\begin{array}{lllll}2.33 & 2.00 & 2.22 & 1.78 & 2.30\end{array}$

$\begin{array}{lllll}.82 & .66 & .79 & .62 & .86\end{array}$

100 ? 100 ? 100 ? 100 ? 1086

$22^{2} .33^{3} \quad 11^{1}$. $20^{19}$.

$44^{4} .44^{4} \cdot 67^{6} .44^{4} .47^{45}$.

$33^{3} 22^{2} .56^{5} 2^{27}$.

22. 5

67. $78^{7} \cdot \quad 78^{7} \cdot \quad 44^{4} \cdot \quad 67^{64}$.

$\begin{array}{llllll}2.89 & 3.11 & 2.67 & 2.44 & 2.81\end{array}$

$\begin{array}{lllll}.73 & .74 & .93 & .51 & .81\end{array}$
SHAC SALL NONREPS UTIL UTIL $100^{9} \cdot 108^{35} 100^{8}$. 100 . $100^{35} \cdot 100^{8}$. $11^{4}$. $33^{3} .26^{9} \cdot 38^{3}$. 56 . $49^{7}$. $63^{5}$. $11^{1} 14^{5}$. $33^{3}-37^{3} \quad 38^{3}$.

$2.22 \quad 2.34 \quad 2.38$ $.63 \quad .86 \quad .45$

$100^{9} 10^{35} \cdot 100$. 22. 20 ?

$33^{3}$. 29. $25^{2}$.

11. $33^{3}$. $50^{4}$.

33. $14^{5} .25{ }^{2}$

56 . $49^{17} \cdot 25$.

$2.44 \quad 2.54 \quad 2.00$

$1.17 \quad .97 \quad .70$ 


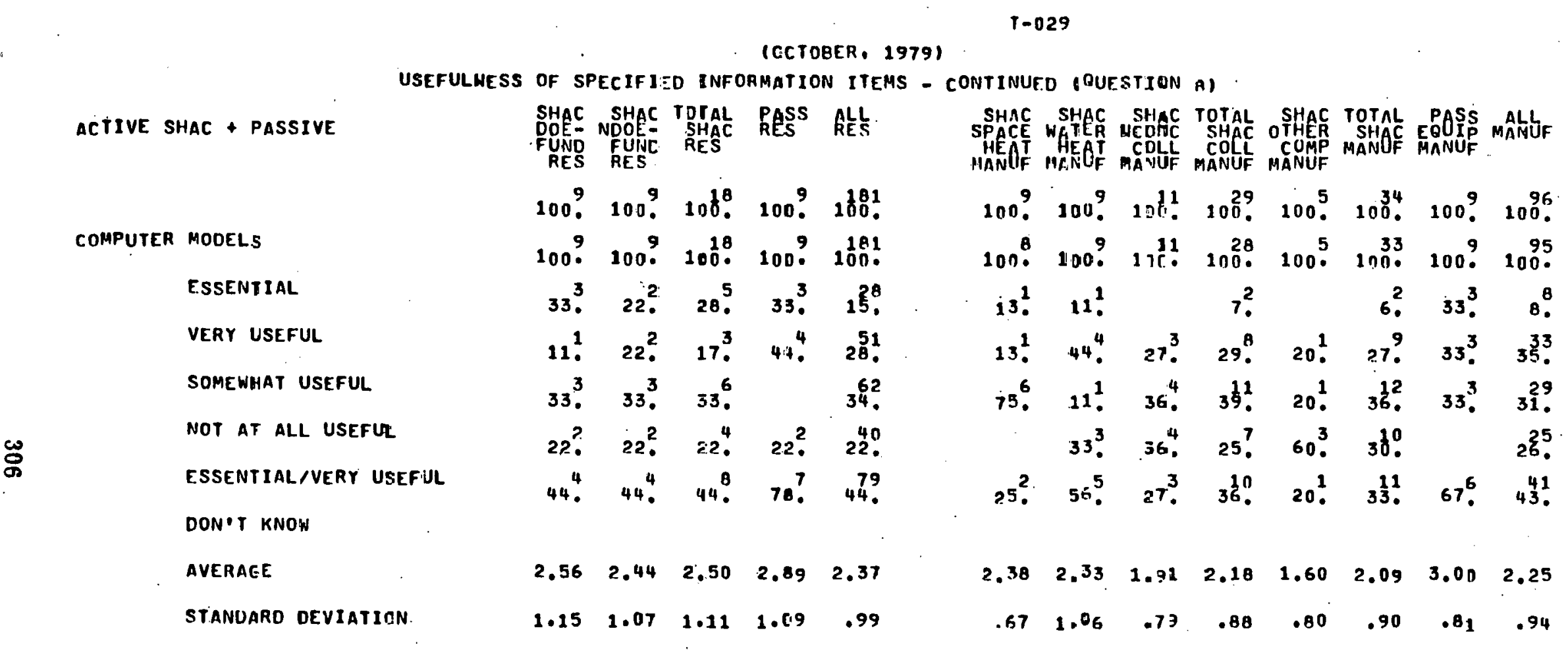

SCALE: ESSENT.IAL $=4$, VERY USEFUL $=3$, SOMEWHAT JSEFUL $=2$, NOT AT ALL USEFUL $=:$

Figure F-1. Active Solar Heating and Cooling Data Tables (continued) 


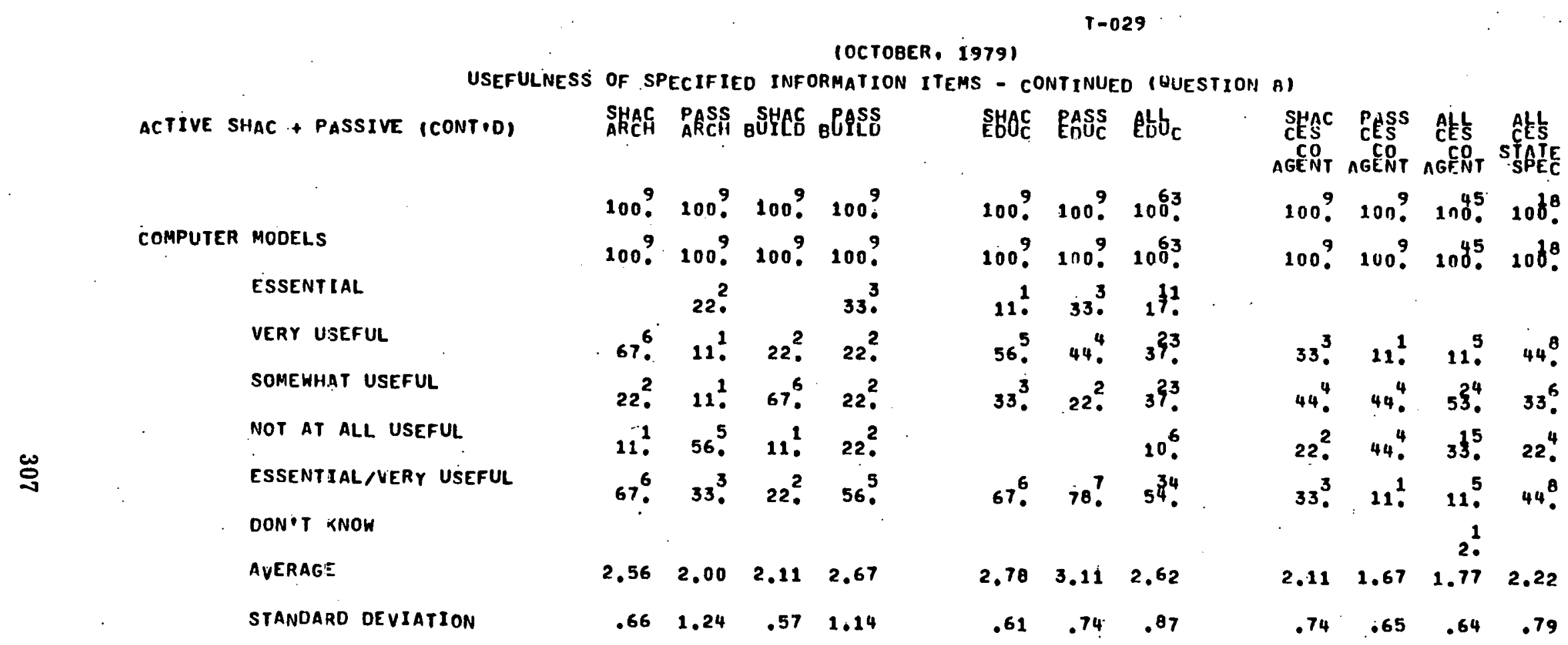

SCALE: ESSENTIAL $=40$ VEAY USEFUL $=30$ SOMEWHAT USEFUL $=20$ NOT AT ALL USEFUL $=1$

Figure F-1. Active Solar Heating and Cooling Data Tables (continued) 


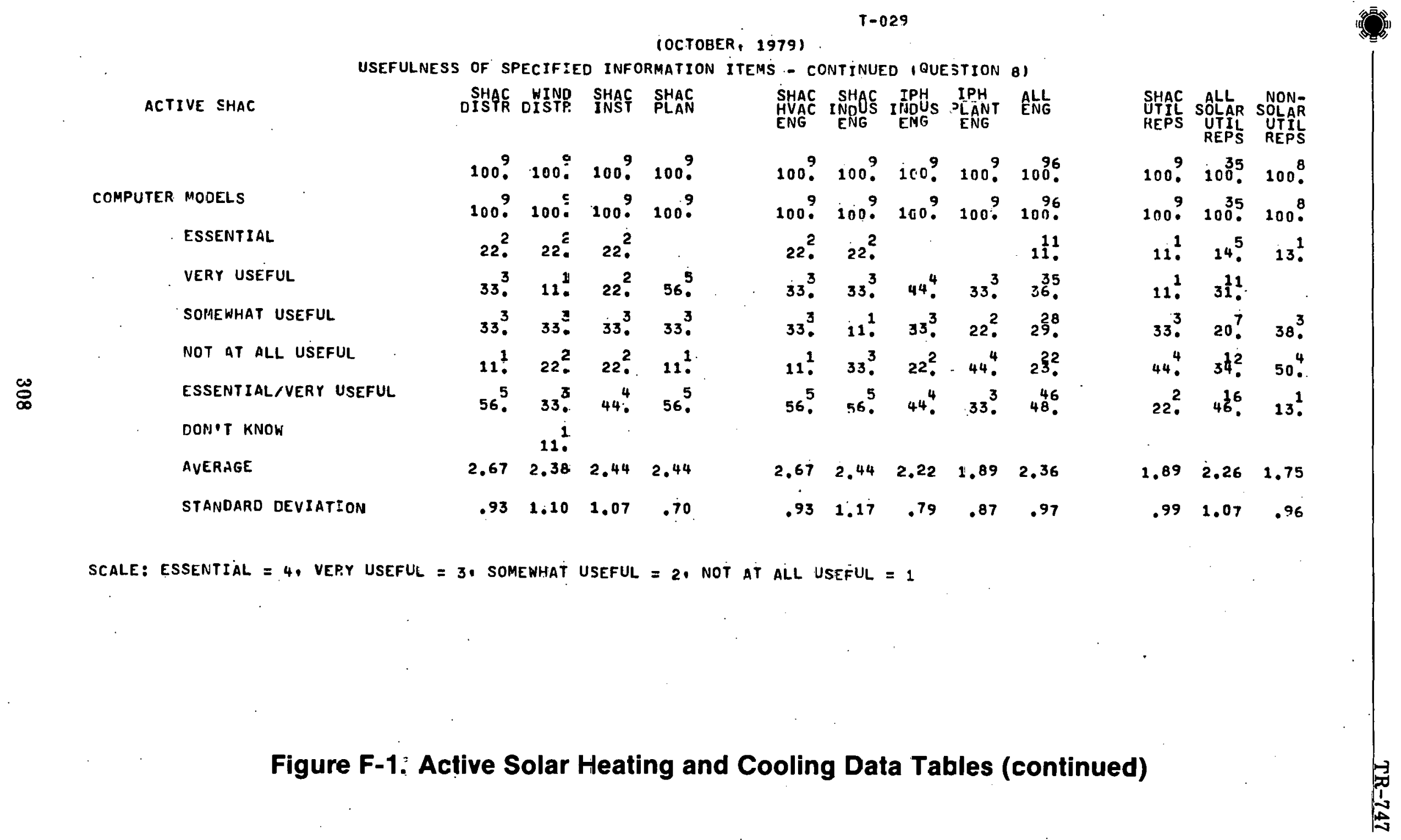


IOCTOBER, 1979)

USEFULNESS OF SPECIFIEO INFORMATION ITEMS - CONTINUED (QUESTION B)

ACTIVE SHAC + PASSIVE

DABNS ITEPYCAIIONAL

ESSENTIAL

VERY USEFUL

SOMEWHAT USEFUL

NOT AT ALL USEFUL

ESSENYTIAL + VERY

DON'T KNOH

AVERAGE
SHAC SHAC 'GTAL RASS RLL

100 ? 100 ? 108. 100 ? 1681.

$100^{9}$. 100. $100^{8} .100$ ? 1001.

- 1 ?

$22^{2} \cdot 22^{2} \cdot 22^{4} \cdot 11^{1} \cdot 1^{26}$.

56. $44^{4}$. $50^{9} \cdot 44^{4}$. 55.

$22^{2} .33^{3}, 28^{5} \quad 44^{4}, 30^{54}$.

$22^{2}$. 22. $22^{4} \cdot 11^{1}$. 15?

1.

$2.00 .1 .89 \quad 1.94 \quad 1.67 \quad 1.86$

$\begin{array}{lllll}.66 & .73 & .71 & .65 & .65\end{array}$

$1009.100^{9} .100^{18} .100^{9}, 100$.

11. $22^{2}$. $17^{3}$. $11^{1} 1^{33}$

67. $56^{5} . \quad 61^{1} . \quad 67^{6} . \quad 56^{2}$.

$22^{2}$ 22. $22^{4} .11^{1}$ 2.?

NOT AT ALL USEFUL

ESSEENLIAL + VERY

DON'T. KNOW

AVERAGE

STANOARO DEVIATION

78. $78^{7}, 78^{4}, \quad 78^{7}$. 755 .

$2.89 \quad 3.00 \quad 2.94 \quad 2.78 \quad 2.89$ FUND FUND RES

SHAC SHAC SHAC 'RTAL SHAC TSTAL PPOSS MALT HE T HEAT COHC CORC COMP MANOF MANUF MANOF MANOF MANUF MANUF MANUF

100 . 1009 . $100^{1}$. $100^{29}$. 100 . $100^{34} 100$ ? $100^{6}$. $100^{9} .100^{9} .100^{11} 100^{29} .1000^{5} 100^{34}, 1009.1006$

$40^{2} \quad 6^{2} \quad 11^{1}$. $0^{\mathrm{B}}$

11. 11. $10^{2} \cdot 14^{4} . \quad 12^{4}, 22^{2} \cdot 16^{5}$.

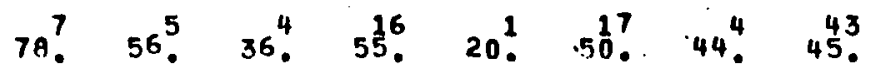

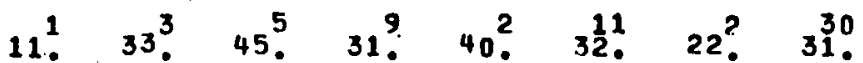

11. 11! $10^{2} \cdot 14^{4} \cdot 40^{2}, 18^{6}, 33^{3} \cdot 24^{3} \cdot$

$\begin{array}{llllllll}2.00 & 1.78 & 1.73 & 1.83 & 2.40 & 1.91 & 2.22 & 2.01\end{array}$

$\begin{array}{llllllll}.47 & .62 & .74 & .64 & 1.35 & .82 & .92 & .89\end{array}$

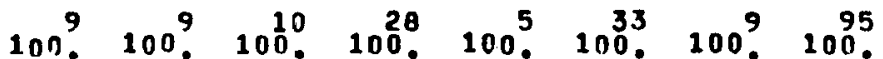

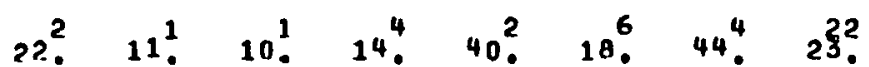

56. $44^{4}, \quad 30^{3}, 43^{2} . \quad 36^{2} . \quad 40^{3}$.

$22^{2} \cdot 22^{2} \cdot 40^{4} \cdot 29^{8} \cdot 20^{1} \cdot 27^{9} \cdot 44^{4} \cdot 27^{6}$.

$22^{2} .20^{2} \cdot 14^{4} \cdot 40^{2} \cdot 18^{6} \cdot 11^{1} \cdot 9$ ?.

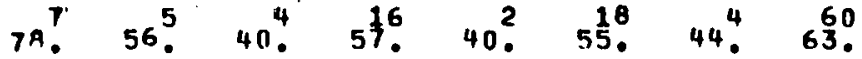

$\begin{array}{llllllll}3.00 & 2.44 & 2.30 & 2.57 & 2.40 & 2.55 & 2.78 & 2.77\end{array}$

$\begin{array}{llllllll}.66 & .96 & .90 & .90 & 1.35 & .97 & 1.12 & .90\end{array}$

SCALE: ESSENTIAL $=4$, VERY USEFUL $=3$, SOMEWHAT USEFUL $=2$, NOT AT ALL USEFUL $=1$

Figure F-1. Active Solar Heating and Cooling Data Tables (continued) 
(OCTOBER, 1979 )

USEFULNESS OF SPECIFIED INFORMATION. ITEMS - CONTINUED (OUESTION B)

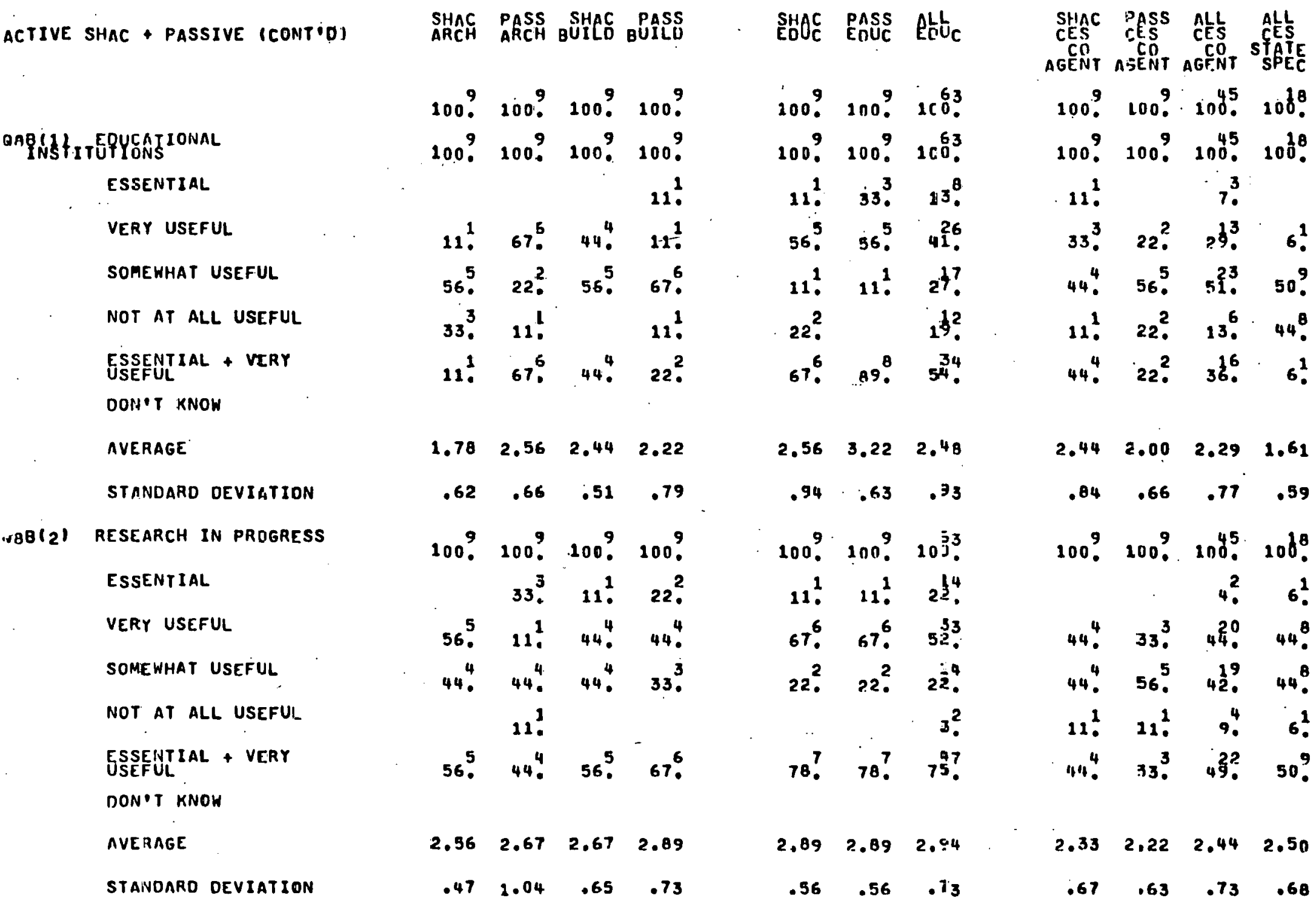

Figure F-1. Active Solar Heating and Cooling Data Tables (continued) 
(OCTOBER, 1979$)$

USEFULNESS OF SPECIFIED INFORMATION ITEMS - CONTINUED (QUESTION $\theta$ )

ACTIVE SHAC

QOBNSt ITUPYCATIONAL

ESSENT IAL

VERY USEFUL

SOMEWHAT USEFUL

NOT AT ALL USEFUL

ESSEFOLIAL + VERY

DON'T KNOW

\section{AVERAGE}

STANDARD DEVIATION

QBB(2) RESEARCH IIJ PROGRESS

ESSENTIAL

VERY USEFUL

SOMEWHAT USEFUL

NOT AT ALL USEFUL

ESSEENTIAL + VERY DON'T KNOW

AVERAGE

STANOARO DEVIATION

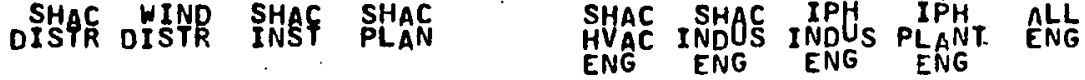

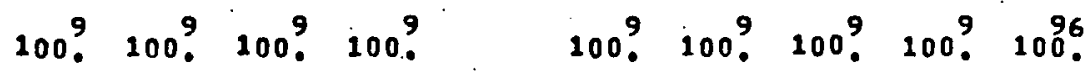

100 ? 100 ? 100 ? 100 ?

100 ? 100 ? 100 ? 100 ? 1009

$11^{1}$

33. 11 . 11 ? $33^{3}$.

$56^{5} . \quad 67^{6}, \quad 56.54^{4}$.

22. $33^{3} \cdot 22^{2}$.

$44^{4} \cdot 11^{1} \cdot 11^{1} \cdot 33^{3}$.

$22^{2}$.

4.

$22^{2} \quad 11^{1} \cdot 11^{2} \cdot 33^{3} \cdot 26^{1}$.

44. $\quad 67^{6} . \quad 67^{6}, \quad 33^{3} . \quad 51^{49}$

11. $22^{2}, 22^{2}, \quad 33^{3} \cdot 25^{4}$.

44. $4^{4} 1^{1}$ 11. $33^{3} \cdot 24^{23}$.

$\begin{array}{llll}2.56 & 1.89 & 1.78 & 2.11\end{array}$

$\begin{array}{llll}.66 & .56 & .62 & .74\end{array}$

$\begin{array}{lllll}2.56 & 1.89 & 1.89 & 2.00 & 2.03\end{array}$

$\begin{array}{lllll}.94 & .56 & .56 & .81 & .78\end{array}$

$100^{9}, 1009.1009$ ? 100 ?

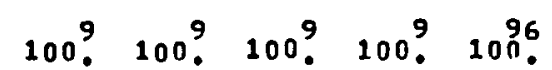

$22^{2} .11^{1}$ 11.

$56^{5} \quad 44^{4} \cdot 22^{2} \cdot 22^{2} \cdot \quad 36^{3}$.

56. $33^{3} . \quad 89.78$.

33. $22^{2}$.

11. 11 ! 11 .

$56^{5} .67^{6} .99^{8} .100$.

$22^{2} . \quad 33^{3} \cdot 56^{5} \cdot 67^{6}, \quad 44^{42}$

11. $22^{2} \quad 11^{1}$ a.

$78^{7} \quad 56^{5} \cdot 22^{2} \cdot 22^{2} \cdot \quad 48^{46}$.

$\begin{array}{llllll}3.00 & 2.56 & 2.00 & 2.11 & 2.51\end{array}$

$\begin{array}{lllll}.66 & .81 & .66 & .57 & .80\end{array}$
SHAC SOLLAR SOLNR

REPS UTIT UTIL

$100 \% 100^{3} .100^{\circ}$.

$100^{9} 100^{35} 100^{\circ}$

$3^{1}$

$22^{2} .14^{5} .13^{1}$.

$44^{4}$. 51. $50^{4}$.

33. $33^{\frac{1}{1}} \quad 38^{3}$.

$22^{2}$. $17^{6} .13^{1}$

$1.89 \quad 1.89 \quad 1.75$

$\begin{array}{lll}.73 & .73 & .66\end{array}$

$100^{9} 100^{35} 1000^{8}$

$22^{2} .14^{5}$.

$11^{1} 26^{9} \quad 38^{3}$.

56. $55^{2} .63^{5}$.

11. 3?

33. $40^{14} .38^{3}$

$2.44 \quad 2.51 \quad 2.38$

$.96 \quad .78 \quad .45$

\begin{tabular}{|c|c|c|c|c|c|c|c|c|c|c|}
\hline .44 & 2.89 & 2.78 & 3.22 & 3.00 & 2.56 & 2.00 & 2.11 & 2.51 & 2.44 & $2.51 \quad 2.38$ \\
\hline .70 & .99 & .61 & .43 & .66 & .81 & .66 & .57 & .80 & .96 & .78 \\
\hline
\end{tabular}

Figure F-1. Active Solar Heating and Cooling Data Tables (continued) 
:OCTOBER, 19791

USEFULNESS OF SPECIFIED INFORMATION ITEMS - CONTINUED (QUESTION BI

ACTIVE SHAC + PASSIVE

OAB (3) STATE OF. ART

ESSENTIAL

VERY USEFUL

SOMEWHAT USEFUL

NOT AT ALL USEFUL

ESSENTIAL + VERY

DON'T KNOW

AVERAGE

$\sum_{\text {is }}^{30}$

STANDARO DEVIATION

QAB (4) COSTS/PERFORMANCE

ESSENTIAL

VERY USEFUL

SOMEWHAT USEFUL

NOT AT ALL USEFUL

GSSENTIAL + VERY

DON'T KNOK

AVERAGE

STANDARD DEVIATION
SHAC SHAC TCTAL PASS ALL
DOE- NDOEE SIAC RES RES
FUND FUND FES
RES RES

100? 100 ? $100^{8}$. -00 ? 1001

100 , 100 , $1000^{18}, 100$, 1001

$=11^{1} \quad 11^{1} \quad 11^{2} \quad 22^{2} \quad 19^{34}$

67. $67^{6} . \quad 67^{2} \quad 22^{2} \cdot \quad 51^{93}$

$22^{2} \cdot 22^{2} \quad 22^{4} \quad 33^{3}, 24^{44}$.

$22^{2} \cdot 5$ ?

i8:. 78 ? $\quad 78^{4}, \quad 44^{4}, \quad 727$.

1.

$\begin{array}{lllll}2.89 & 2.89 & 2.89 & 2.44 & 2.84\end{array}$

$\begin{array}{lllll}.55 & .56 & .56 & 1.07 & .79\end{array}$

$100.100^{\circ} .100^{17} 100^{9} 10^{180}$

$22^{2} \cdot 13^{1}, 13^{3}, 22^{2} \cdot 22^{39}$.

$44^{4} .75^{6}, \quad 59^{0} .56^{5} . \quad 43^{8}$.

$22^{2} . \quad 12^{2} \cdot 11.027$.

11. $13^{1}$. $12^{2}$ 11. 14.

67. $68^{7} \cdot 76^{13}, 78^{7} \cdot 6^{117}$.

$\begin{array}{lllll}2.78 & 2.88 & 2.02 & 2.89 & 2.79\end{array}$

$\begin{array}{lllll}.90 \quad .76 & .86 & .87 & .86\end{array}$
SHAC SHAC SHAC TOTAL SHAC TOTAL PASS MALL
SPACE WATER NCONC SHAC OTHER SIIOC EOUIP MANUF STE WET MANUF MANOF MANUT MANUF MANUF

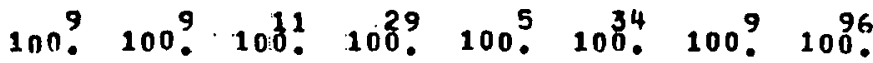
$100^{9} 1009.1010 .100^{28}, 100.100 .100$. $100^{95}$

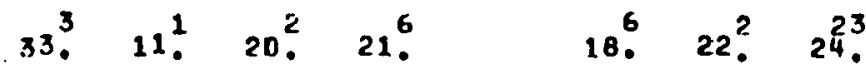

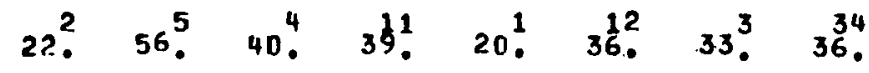
33. $11^{3} \cdot 20^{2} \cdot 21^{6} \quad 60^{3} \quad 27^{9} \quad 33^{3} \quad 27^{6}$. $11^{1} \quad 11^{1}$ 20. $14^{4} \cdot 20^{1}$ 15. $11^{1}$. $11^{0}$.

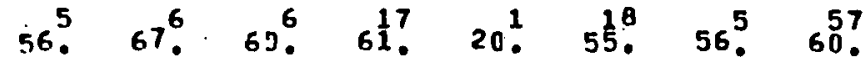

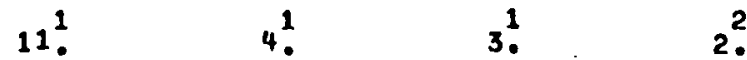
$\begin{array}{lllllllll}2.78 & 2.75 & 2.50 & 2.70 & 2.00 & 2.59 & 2.67 & 2.75\end{array}$

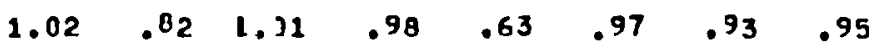

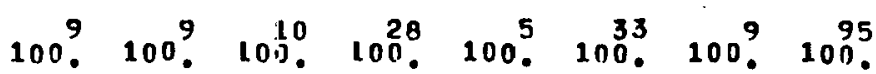
$11^{1} \quad 22^{2} \cdot 20^{2} \cdot 10^{5} \quad 20^{1} \quad 18^{6} \quad 33^{3} \quad 26^{9}$.

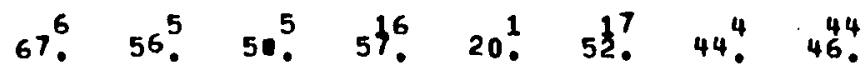
$22^{2} . \quad 30^{3} \cdot 10^{5} \cdot 40^{2} \cdot 21^{7} \cdot 11^{1} \cdot 2 ?^{6}$. $22^{2} \quad 7^{2} \quad 20^{2} \quad 9^{3} \quad 11^{2} \quad 6^{6}$ $70^{7} \quad 78^{7} \cdot 70^{7}, 75^{21}, 40^{2} \cdot 70^{23} \cdot 78^{7} \cdot 66^{63}$.

$\begin{array}{llllllll}2.89 & 2.78 & 2.90 & 2.86 & 2.40 & 2.79 & 3.00 & 2.80\end{array}$ $\begin{array}{llllllll}.56 & 1.02 & .70 & .77 & 1.01 & .83 & .94 & .82\end{array}$

SCALE: ESSENTIAL $=4$, VERY USEFUL $=3$, SOMEWHAT USEFUL $=2$, NOT AT ALL USEFUL $=1$

Figure F-1. Active Solar Heating and Cooling Data Tables (continued) 
(OCTOBER, 1979)

USEFULNESS OF SPECIFIED INFORMATION ITEMS - CONTINUED (QUESTION B)

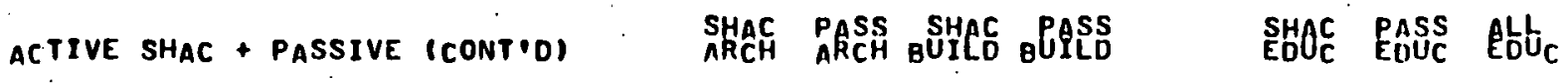

AEB(3) STATE OF ART

ESSENTIAL

VERY USEFUL

SOMEWHAT USEFUL

NOT AT ALL USEFUL

ESSEENTIAL + VERY

DON?T KNOW

$\stackrel{\omega}{\omega}$

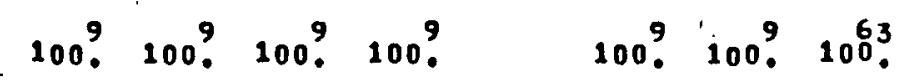

100 \% $100 \% 100$ \% 100 \% 100 \% 100 \% $100^{6}$.

$11^{1} 22^{2} \quad 11^{1} \quad 33^{3} . \quad 22^{2} \quad 52^{2} \cdot 2^{\frac{15}{4}}$.

56. $33^{3} \cdot 33^{3} \cdot 22^{2} \quad 67^{6} \quad 67^{6} \quad 56^{3}$.

$22^{2} \quad 33^{3} \cdot 44^{4} \cdot 44^{4} . \quad 11^{1} \quad 11^{1} 1^{1}$ !

$11^{1} 11^{1}$ 11: $1^{1}$.

$67^{6} .56^{5} \cdot 44^{4} \cdot 56^{5} . \quad 89^{8} \quad 89^{8} \cdot 7^{50}$.

$\begin{array}{lllllll}2.67 & 2.67 & 2.44 & 2.69 & 3.11 & 3.11 & 3.00\end{array}$
$.80 \quad .93 \quad .84 \quad .87$

100 ? 100 ? 100 ? 100 ?

$22^{2} \quad 33^{3} \cdot 22^{2} \cdot 22^{2}$.

$56.54 .56^{5}, 67^{6}$.

$22^{2} 22^{2} \cdot 22^{2} \cdot 11^{1}$

$78^{7} \quad 78^{7} \cdot 78^{7} \cdot 89^{\circ}$

$3.00 \quad 3.11 \quad 3.00 \quad 3.11$

$\begin{array}{llll}.66 & .74 & .66 & .57\end{array}$

$\begin{array}{lll}.57 & .57 & .73\end{array}$

100 . 100 . $100^{63}$.

$22^{2} .56^{5} .320$

44. $22.23^{23}$.

$33^{3}, \quad 22^{2}, \quad 32^{20}$.

NOT AT ALL USEFUL

ESSENTIAL + VERY

DON'T KNOW

AVEAAGE

STANDARO DEVIATION

$67^{6} \quad 78^{7} \cdot 68^{43}$

$2.893 .33 \quad 3.00$
SHANC PASS ALL ALL$$
100 \text { ? } 100^{9} \text {. } 1005 \text {. } 100^{18} \text {. }
$$$$
\text { 100. } 100 \text {. } 100^{45} \text {. } 108^{8} \text {. }
$$$$
2^{2}
$$$$
44^{4} .222^{2} \quad 33^{5}, 50^{9} \text {. }
$$$$
\text { 44. } 67^{6} \text {. } 56^{25} \text {. } 50^{9} \text {. }
$$$$
\text { 11. } 11.29
$$$$
\text { 44. } 22^{2} \cdot 36^{16} \cdot 50^{9} \text {. }
$$

$$
\begin{array}{llll}
2.33 & 2.11 & 2.29 & 2.50
\end{array}
$$$$
\begin{array}{llll}
.67 & .57 \quad .65 \quad .50
\end{array}
$$$$
100 \% 100 \text {. } 100^{45} 100^{2} \text {. }
$$$$
11^{1} 11^{1} \cdot 13^{6}, 11^{2}
$$$$
\text { 89. } 89^{\circ} .76^{\circ} .50^{\circ} \text {. }
$$$$
\text { 11. } 28^{5} \text {. }
$$

$11^{2}$

1009.1009 . 49.611

$3.11 \quad 3.11 \quad 3.02 \quad 2.61$

$.32 \quad .32 \quad .50 \quad .82$

Figure F-1. Active Solar Heating and Cooling Data Tables (continued) 
(OETOBER, 1979)

USEFULNESS OF SPECIFIED INFORMATION ITEMS - CONTINUED (QUESTIJN 8 )

ACTIVE SHAC

QAB (3) STATE OF ART

ESSENTIAL

VERY USEFUL

SOMER'HAT USEFUL

NOT AT ALL USEFUL

ESSENTIAL + VERY

DON'T KNOW

$\underset{\infty}{\infty}$

AVERAGE

STANDARO DEVIATION

QBB (4) COSTS/PEAFORMANCE

ESSENTIAL

VERY USEFUL

SOMEWHAT USEFUL

NOT AT ALL USEFLL

ESSEMTIAL + VERY

DON'T KNOW

AVERAGE

STANDARO DEVIATION

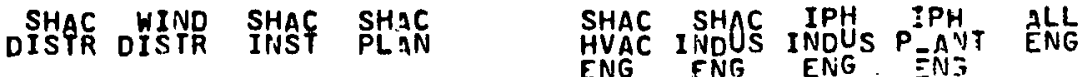

$$
\begin{aligned}
& 1009^{9} 100 \text {. } 100 \text {. } 103^{9} \text {. } \\
& 100 \text {. 100. } 100 \text {. } 103^{9} \text {. } \\
& 11^{1} . \quad 33^{3} .22^{2} .222^{2} \text {. } \\
& 22^{2} . \quad 33^{3} .56^{5} .73^{7} \text { ? } \\
& \text { 56. 11. } 11 \text {. } \\
& \text { 11. } 22^{2} .111^{1} \\
& 33^{3} .67^{6} . \quad 78 \text {. } 100 \text {. }
\end{aligned}
$$$$
100 \text {. } 100 \text { ?. } 100 \text {. } 100 \% \text {. } 100^{96}
$$$$
2.33 \quad 2.78 \quad 2.89,3.22
$$$$
.82 \quad 1.12 \quad .87 \quad .+3
$$

100. 100. 100. 100 ?

$22^{2} .22^{2} .33^{3} \cdot 53^{5}$

$56.56 .566^{5} . \quad 33^{3}$.

$22^{2}$. $111^{1}$. 11 . $11^{1}$.

11 .

$78^{7} \quad 78^{7} .89^{8} .89^{8}$.

$3.00 \quad 2.89 \quad 3.22 \quad 3.44$

$\begin{array}{llll}.66 & .87 & .63 & .70\end{array}$
100 . 100. 100.1100 ? 100 .

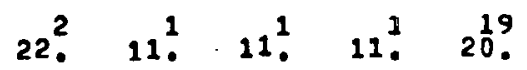

44. $\quad 33^{3} . \quad 33^{3}, \quad 33^{3} \cdot 40^{38}$.

33. $44^{4} \cdot 44^{4}, \quad 56^{5}, \quad 36^{34}$.

$111^{1} 111$.

67. $44^{4} . \quad 44^{4} \cdot \quad 44^{4}, \quad 60$ ?

$\begin{array}{llllll}2.89 & 2.44 & 2.44 & 2.56 & 2.76\end{array}$

$\begin{array}{lllll}.73 & .84 & .84 & .56 & .81\end{array}$

100 . $100^{9} \cdot 100$. 100 ? $100^{96}$.

$22^{2} \quad 11^{1} \quad 33^{3} \cdot 22^{2}, \quad 25^{4}$.

78. $\quad 56^{5} . \quad 56^{5} . \quad 22^{2} . \quad 49^{4}$.

$33^{3}$.

56.221.

11.

$100^{9} . \quad 67^{6} .89^{8} . \quad 44^{4} . \quad 74$.

$\begin{array}{llllll}3.22 & 2.78 & 3.11 & 2.67 & 2.95\end{array}$

$\begin{array}{lllll}.43 & .61 & .07 & .80 & . .78\end{array}$
SHAC SALL NON-

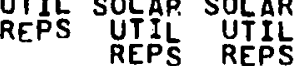

$100^{9} .100^{35} .100^{8}$.

100.100 .1008 .

22.20 ?

33. $3^{3} \quad 4 \frac{15}{3} .43$.

11. $23^{8} .63^{5}$.

$33^{3} .14^{5}$.

$56^{5} . \quad 6^{2} 3^{2}, \quad 38^{3}$.

$2.44 \quad 2.69 \quad 2.38$

$1.17 \quad .93 \quad .45$

100. $100^{35} .100^{8}$.

$56.546^{5} .255^{2}$

$22.034^{2} .50$.

$11.214^{5} .25$.

$111^{1} \quad 6^{2}$.

$78.70^{28} .75^{6}$

$3.22 \quad 3.20 \quad 3.00$

$1.03 \quad .88 \quad .70$

Figure F-1. Active Solar Heating and Cooling Data Tables (continued) 
(OCTOBER, 19791

USEFULNESS OF SPECIFIED INFORMATION ITEMS - CONTINUED (GUESTION 8 )

ACTIVE SHAC + PASSTVE SHAC SHAC TOTAL RASS ALL FUND FUNO RES

100 ? 100 ? $100^{8}$. $100 \%$ ? 1801

QBB(5) COȘTS INSTALL/OPERATE

ESSENTIAL

VERY USEFUL

SOMEWHAT USEFUL

NOT AT ALL USEFUL

ESSEFULIAL + VERY

DON T KNOW

AVERAGE

en 100 ? 100 ? $100^{10} .100 \% 1003$

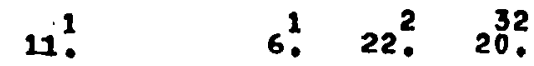
67. 78 . $72^{3} . \quad 22^{2} . \quad 43^{\circ}$. 11. $\quad 6^{1} .44^{4}$. $28^{45}$. 11 . $22.217 .211 .216^{6}$. 78 . 78 . $78^{4}, \quad 44^{4}, \quad 632$

$\begin{array}{lllll}2.78 & 2.56 & 2.67 & 2.56 & 2.72\end{array}$ $\begin{array}{lllll}.77 & .81 & .00 & .94 & .90\end{array}$ ESSENTIAL + VEAY DON T KNOH

AVERAGE

STANDARD DEVIATION $100 \% 100 \% 100^{8} \cdot 1009.160^{3}$. $33^{3} . \quad 17_{0}^{3} \quad 222^{2} \quad 12^{19}$.

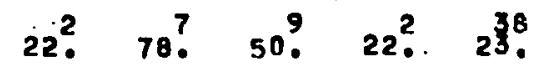
$33^{3} .22^{2} .288^{5} \quad 44^{4}, \quad 36^{56}$

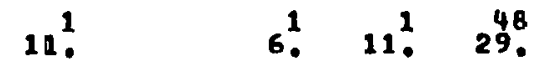
55. $788^{7} \quad 67^{2}$ ? $44^{4}$. 35 ?

SPBAC WHAC SHAC TOTNL SHAC TOTAL EBOSS MALL HFOT HEAT COLL COLL COMP MANOF MANUF

$100^{9} 100^{9} 100^{1} 100^{29} 100^{5} 103^{4}, 100^{9} 100^{9}$

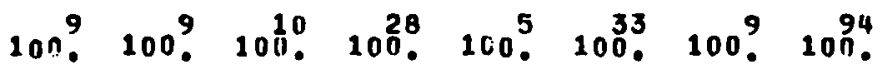
11. $33^{3} \cdot 10^{1} \cdot 18^{5}, 20^{1}, 18^{6}, 44^{4}, 20^{9}$. $67^{6} \quad 44^{4} \cdot 50^{5} \cdot 54^{15} \quad 20 ! 48^{1} \cdot 33^{3} \cdot 46^{3}$. 11. $40^{4}$ 10. $40^{\circ}: 21^{7} \quad 11^{1} \cdot 24^{23}$ 11. $22^{2} \cdot \quad 11^{3}, 20^{1}, 12^{4}, 11^{1}, 9^{8}$. $78^{7} \cdot 70^{7} \cdot 60^{6} \cdot 71^{20} \cdot \quad 40^{2} \cdot 67^{22} \cdot 70^{7} \cdot 66^{\circ}$.

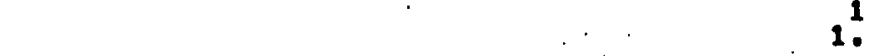
$\begin{array}{llllllll}2.78 & 2.89 & 2.70 & 2.79 & 2.40 & 2.73 & 3.11 & 2.78\end{array}$ $\begin{array}{lllllllll}.77 & 1.09 & .64 & .84 & 1.01 & .88 & .99 & .88\end{array}$

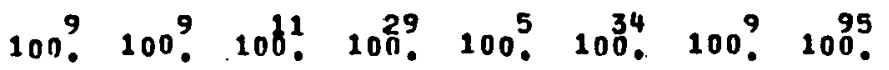
$11^{1} \quad 33^{3} \cdot 27^{3} \cdot 24^{7} \quad 40^{2} \quad 26^{9}, 11^{1} \quad 22^{2}$ 44. $22^{2} \cdot \quad 45^{5} \quad 36^{1} \cdot 20^{1} \quad 3 \frac{12}{5} \quad 56^{5} \cdot 34^{5}$. 44. 11. $9^{1}$. 21. $10^{6} .33^{3} .24^{3}$. $33^{3} \cdot 18^{2}, 17^{5}, 40^{2} \cdot 21^{7}, 20^{9}$ $56^{5} \quad 56^{5} \quad 73^{8}, 62^{18} 60^{3} \quad 62^{21} \quad 67^{6} \cdot 56^{53}$

$2.78 \quad 2.78 \quad 2.78 \quad 2.56 \quad 2.17$

$\begin{array}{lllll}1.32 & .40 & .77 & .94 & .98\end{array}$

Figure F-1. Active Solar Heating and Cooling Data Tables (continued) 
(OCTOBER, 1979$)$

USEFULNESS OF SPECIFIED INFORMATION ITEMS - CONTINUED (QUESTION B)

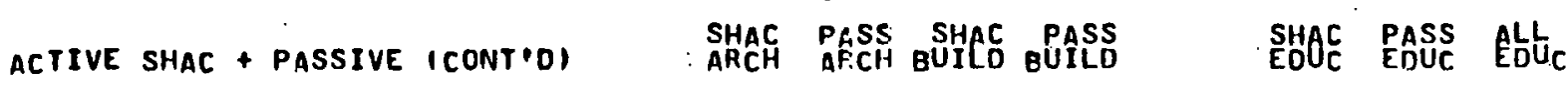

QAB(5) COSTS INSTALL/OPERATE

ESSENTIAL

VERY USEFUL

SOMEWHAT USEFUL

NOT AT ALL USEFUL

ESSENTIAL + VERY

क.

$$
\begin{array}{rrrr}
1009 & 100^{5} & 100 \% & 1009 \\
1009 & 100^{9} & 100^{9} & 100^{9} \\
33^{3} & 56^{5} & & 33^{3} \\
56^{5} & 22^{2} & 67^{6} & 22^{2} \\
11^{1} & 22^{2} & 22^{2} & 44^{4}
\end{array}
$$

AVERAGE

STANDARD DEVIATION
DOM'T KNOW

QBB(6) BUILDING CODES,REGS

$$
\text { ESSENTIAL }
$$

VERYY USEFUL

SOMEWHAT USEFUL

NOT AT ALL USEFU

ESSEENTIAL + VERY

DON'T KNOW

AVERAGE

STANDARO OEVIGTION

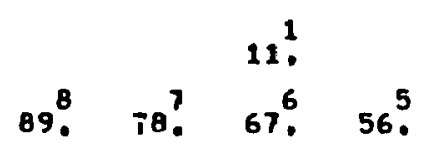

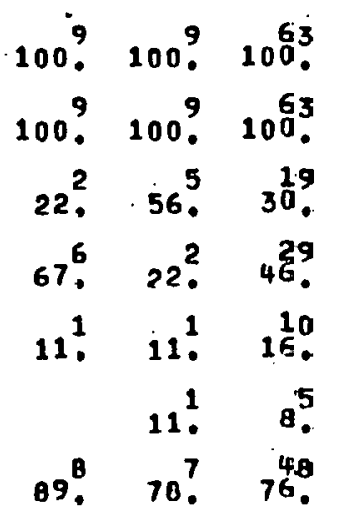

$\begin{array}{llll}3.22 & 3.33 & 2.56 & 2.89\end{array}$

$.63 \quad 03 \quad .66 \quad .87$

$100^{9}$. $100^{5}$. $100^{9}$. $100^{9}$.

44. 4.4. $22^{2} .33^{3}$

$33^{3}, 22^{2} \quad 44^{4}, 56^{5}$.

$22^{2} .11^{1}, 33^{3}, 11^{1}$.

22

$78^{7} \quad 67^{\epsilon} .67^{6}, \quad 89^{8}$.

$\begin{array}{llll}3.22 & 2.89 & 2.89 & 3.22\end{array}$

$\begin{array}{llll}.79 & 1.19 & .73 \quad .63\end{array}$

$3.11 \quad 3.22 \quad 2.90$

$.57 \quad 1.03 \quad .09$

$100^{9} .1009$. $100^{63}$.

11. $22^{2}$. $16^{10}$

44. 44.352

$33^{3} .22^{2} .22^{20}$

11. 11 . 11!

$56^{5}, 67^{6}, 51^{32}$.

$2.56 \quad 2.78 \quad 2.49$

$.81 \quad .90 \quad .96$

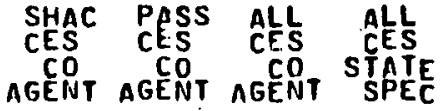
100. 100 . $100^{45} .106^{8}$. $100.2100^{9} .100^{4.5} 100^{18}$. 33. 11. $18.211^{2}$. 67. $\quad 29.8 . \quad 73^{3} . \quad 33^{6}$

9. 39 ?

$177^{3}$

$1000^{\circ} 100^{9}$. $91^{4} .44^{8}$.

$\begin{array}{llll}3.33 & 3.11 & 3.09 & 2.39\end{array}$

$.49 \quad .32 \quad .50 \quad .88$

100 ? $1009.100^{45} 100^{\circ}$.

11 . $\quad 9^{4} 11^{2}$

$22^{2} \quad 33^{3} \quad 24^{1} \cdot 22^{4}$

44. $56.547 .6 \frac{11}{21}$

22. $11^{1}$. 20 ? 6 ?

$33^{3} .23^{3} .3^{\frac{15}{3}} .33^{6}$.

$2.22 \quad 2.22 \quad 2.22 \quad 0.39$

Figure F-1. Active Solar Heating and Cooling Data Tables (continued) 
(OCTOBER, 1979)

USEFULNESS OF SPECIFIED INFORMATION ITEMS - CONTINUED (QUESTION B)

ACTIVE SHAC

AQB(5) COSTS INSTALL/OPERATE

ESSENTIAL

VERY USEFUL

SOMEWHAT USEFUL

NOT AT ALL USEFUL

ESSENTIAL + VERY DON'T KNOW

\section{AVERAGE}

STANDARO DEVIATION

QBB(6) BUILOING CCIDES/REGS

ESSENTIAL

VERY USEFULL

SOMEWHAT USEFUL

NOT AT ALL USEFUi

ESSEENTIAL + VERY

DON'T KNOW'

AVERAGE

STANDARD LEVIATION
DISTC DISTR SHAC SHAC

SHAC SHHC IPH IPH. ALL

$$
\begin{array}{rrrr}
100^{9} & 100^{9} & 1000^{9} & 100^{9} \\
100^{9} & 100^{9} & 100^{9} & 100^{9} \\
22^{2} & 22^{2} & 33^{3} & 67^{6} \\
55^{5} & 44^{4} & 56^{5} & 22^{2} \\
22^{2} & 11^{1} & 11^{1} & 11^{1} \\
& 22^{2} & & \\
78^{7} & 67^{6} & 89^{8} & 89^{8}
\end{array}
$$

$$
1009 \text {. 100? } 1009 \text {. 100? } 100^{96}
$$$$
100 \text { \% } 1009 \text { : } 1009 \text {. 1009. } 100^{96} \text {. }
$$$$
22^{2} \quad 33^{3} \cdot 11^{1} \quad 232 .
$$$$
56.58^{7}, \quad 56.533^{3} .49^{4} \text {. }
$$$$
22^{2} .22^{2} .56^{5} \quad 22^{21}
$$

$11^{1} .66^{6}$

$78^{7} \quad 78^{7} \quad 89^{8} . \quad 44^{4} .72^{69}$.

$3.00 \quad 2.67 \quad 3.22 \cdot 3.56$

$\begin{array}{lllll}.66 & 1.04 & .63 & .66\end{array}$

$\begin{array}{lllll}3.00 & 2.78 & 3.11 & 2.56 & 2.89\end{array}$

$\begin{array}{lllll}.66 & .40 & .87 & .66 & .81\end{array}$

100 . 100\% 100? 100 .

22. $44^{2} .433^{3} 44^{4}$.

44. $22^{2} .56^{5} .44^{4}$.

11. 22. 11! $11^{1}$.

22. 11 ?

67. $67^{6} . \quad 89.899^{8}$.

$\begin{array}{llll}2.67 & 3.00 & 3.22 & 3.33\end{array}$

$\begin{array}{llll}1.04 & 1.05 & .63 & .68\end{array}$

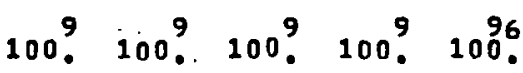

$44^{4} \quad 44^{4}$ 11? $19^{8}$.

$22^{2} \quad 11^{1} \quad 33^{3} \quad 11^{1} \quad 25^{4}$

$33^{3}$. $22^{2} \cdot 33^{3} \quad 44^{4}, 40^{38}$.

$22^{2} \quad 33^{3} \cdot 33^{3} \quad 17^{6}$.

$67^{6} \quad 56^{5} \quad 33^{3} .22^{2} 4^{42}$.

$\begin{array}{lllll}3.11 & 2.78 & 2.00 & 2.00 & 2.46\end{array}$

$\begin{array}{lllll}.87 & 1.22 & .81 & .94 & .97\end{array}$
SHAC SALL NON-

REPS. UTIR UTIL

100 ? 10035 . 100 .

$100^{9}$. $100^{35} 100^{8}$.

$44^{4} \cdot 43^{\frac{1}{5}} \cdot 13^{1}$.

11. 31. 75 .

$44^{4}$ 23. $13^{1}$.

3 .

56. 74.68 .

$3.00 \quad 3.14 \quad 3.00$

$\begin{array}{lll}.94 & .07 \quad .50\end{array}$

$100^{9} \cdot 100^{35} \cdot 100^{8}$

$33^{3} .26^{9} \cdot 38^{3}$.

$22^{2} \quad 23^{8} \cdot 25^{2}$

11. $40^{14} \quad 38^{3}$.

$33^{3} .11^{4}$

$56.59^{5}$. $63^{5}$.

$2.56 \quad 2.63 \quad 3.00$

$1.24 \cdot .98 \quad .86$

SCALE: ESSENTIAL $=4$, VERY USEFUL $=3$, SOMEWHAT USEFUL $=2$, NOT AT ALL USEFUL $=1$

Figure F-1. Active Solar Heating and Cooling Data Tables (continued) 
IOCTOBER, 1979)

USEFULNESS OF SPECIFIEO INFORMATION ITEMS - CONTINUED (QUESTION 8.)

ACTIVE SHAC + PASSIVE

DQB (7) TAX/ECONOMIC INCENTIVE ESSENTIAL

VERY USEFUL

SOMEWHAT USEFUL

NOT AT ALL USEFUL ESSENITAL + VEAY

DON.T KNOW

$\underset{\infty}{\infty}$

STANDARD DEVIATION

QRB(B) STANDARDS/SPECS

F.SSENIIAL

VERY USEFUL

SOMEWHAT USEFUL

NOT AT ALL USEFUL

ESSEEULIAL + VERY

DON'T KNOH

AVERAGE

STANOARO DEVIATION

SHPC SHAC TEYTAL RASS ALL
DOE NOEE THAC RES RES
FUND FUND HES RES RES

SHAC SHAC SHAC TOTAL SHAC TOTAL PASS ALL HFAT HEVI CCLLL COLL COMP MANOF MANUF MANOF MANUF MANUEF MANUF MANUF

$1000^{\circ} 100$. $108^{8} .100$. 1001

100 . 100 . $100^{18}, 100$ \% 1003

11 11. $11^{2} .22 \%$ 17?

$5 E^{5} \quad 67^{6}, \quad 61^{11} \quad 56.527^{5}$.

$22^{2} \quad 11^{1} \quad 17^{3} \cdot \quad 22^{2} \cdot 32^{52}$

11. 11. 11. 25 .

67. $78^{7} \cdot 72^{13} \cdot 78^{7} \cdot 44^{71}$.

$\begin{array}{lllll}2.67 & 2.78 & 2.72: & 3.00 & 2.36\end{array}$

$\begin{array}{lllll}.80 & .77 & .81 & .66 & 1.01\end{array}$

$1009.1009 .100^{18}, 1009.1603$

$33^{3} \quad 17^{3} \cdot 33^{3} \quad 11^{8}$

44. $78.71^{1} \cdot 34$.

11. $22^{2} \cdot 17^{3} .33^{3} \cdot 33^{53}$.

11. $\quad 6^{1} \cdot 33^{3} \cdot 23^{37}$.

$78^{7} \quad 78^{7}, 78^{14}, \quad 33^{3}, \quad 45$.

$\begin{array}{lllll}3.00 & 2.78 & 2.89 & 2.33 & 2.33\end{array}$

$\begin{array}{lllll}.94 & .40 & .73 & 1.25 & .95\end{array}$
100 . $100^{9} 1011.1029 .1005100 .100$ ? 1006 .

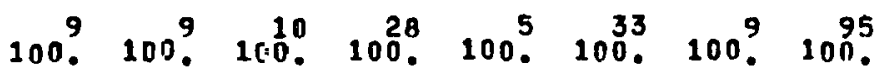
$22^{2} \quad 33^{3} .50 .536 .030^{10} \quad 44^{4} .320$ $70^{7} \quad 56^{5} . \quad 40^{4} \quad 53^{6} .200^{1} \quad 52^{17} \quad 33^{3} .43^{41}$. 10. $40^{1} \quad 40^{2}$ 9. $\quad 11$. $16^{15}$.

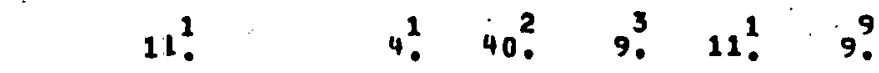
$100^{9} \quad 89^{8} .90^{9} \quad 93^{26} \quad 20^{1} \quad 82^{27} \quad 70^{7} \quad 75^{1}$. $\begin{array}{llllllll}3.22 & 3.11 & 3.40 & 3.25 & 1.80 & 3.03 & 3.11 & 2.97\end{array}$ $\begin{array}{llllllll}.43 & .87 & .66 & .68 & .74 & .87 & .99 & .91\end{array}$

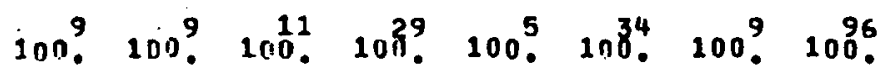
$22^{2} \quad 33^{3} .36^{4} \quad 31^{9}$. 2.6. $33^{3} .30^{29}$.

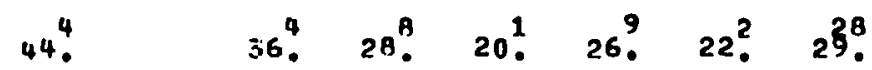

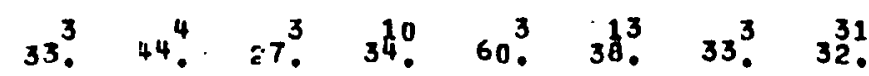
$22^{2} .0 \quad 7^{2} \quad 20$. $9_{0}^{3} 11^{1} \cdot 0^{A}$

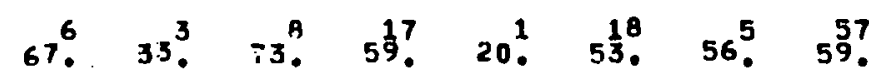

$\begin{array}{llllllll}2.89 & 2.44 & 3.03 & 2.83 & 2.00 & 2.71 & 2.78 & 2.81\end{array}$

$\begin{array}{llllllll}.73 & 1.17 & .79 & .94 & .63 & .94 & 1.02 & .96\end{array}$ 
(OCTOBEA, 1979 )

USEFULNESS OF SPECIFIED INFORMATION ITEMS - CONTINUED (OUESTION A)

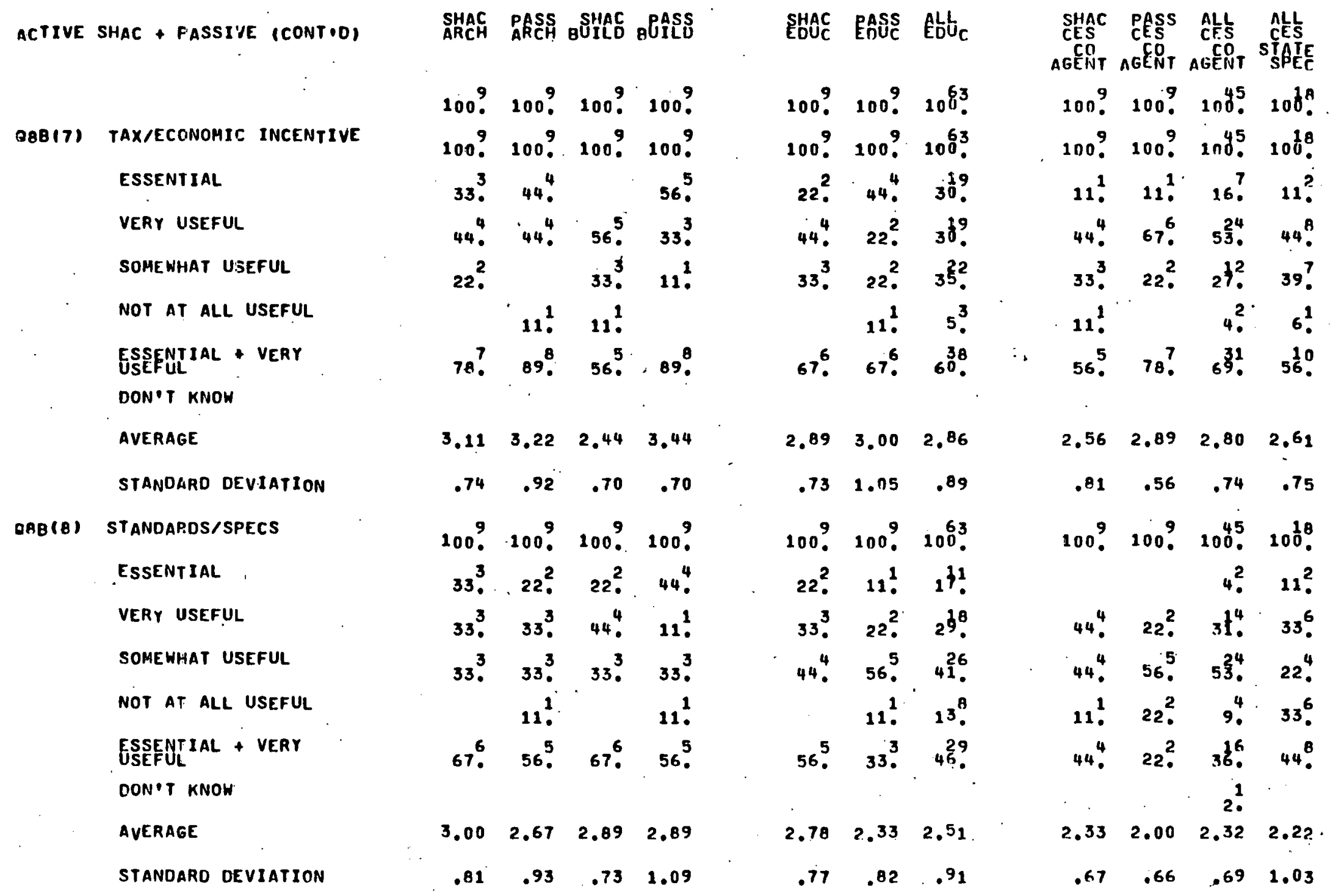




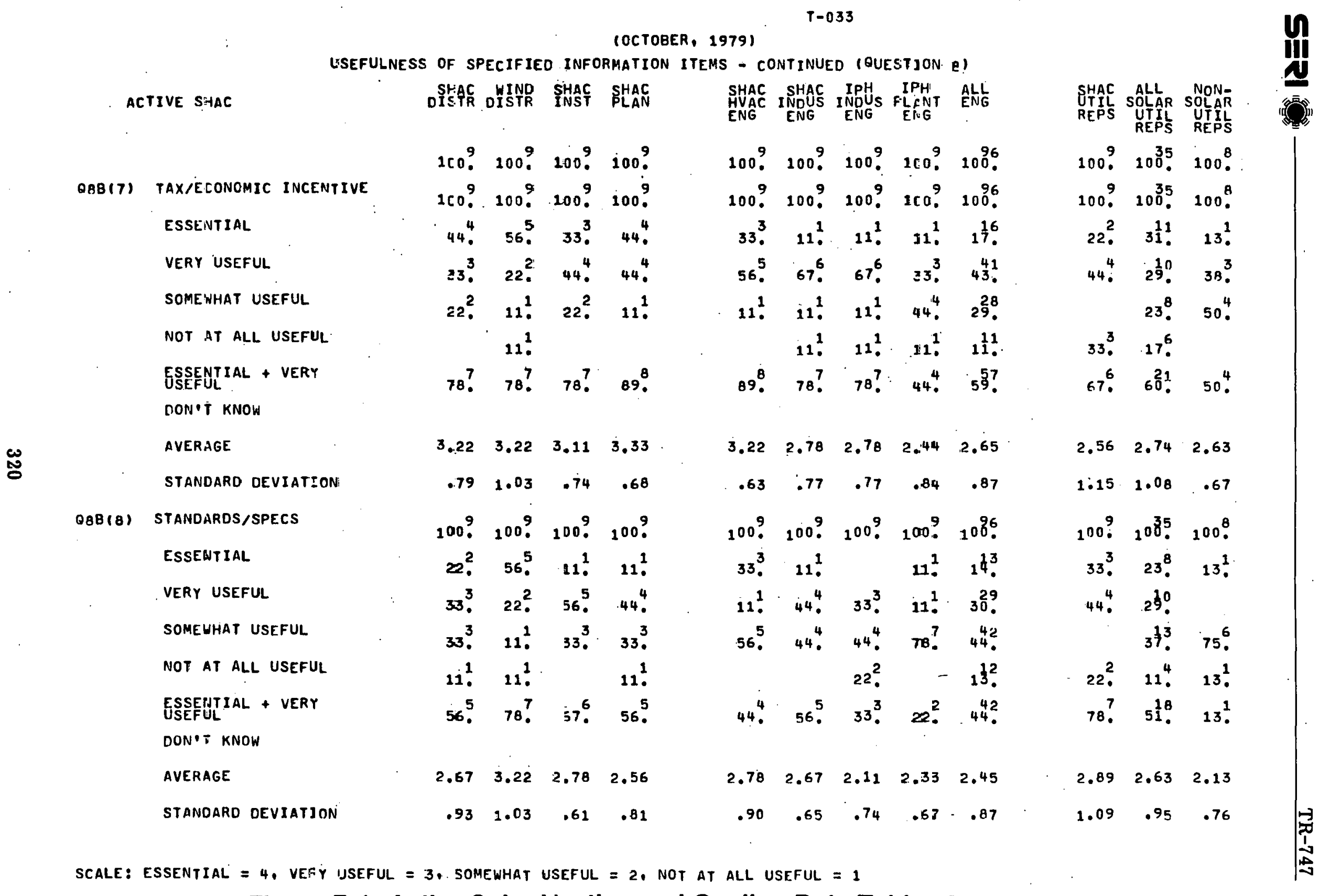

Figure F-1. Active Solar Heating and Cooling Data Tables (continued) 
(OCTOBER, 1979)

USEFULNESS OF SPECIFIED INFORMATION ITEMS - CONTINUEO (QUESTION B)

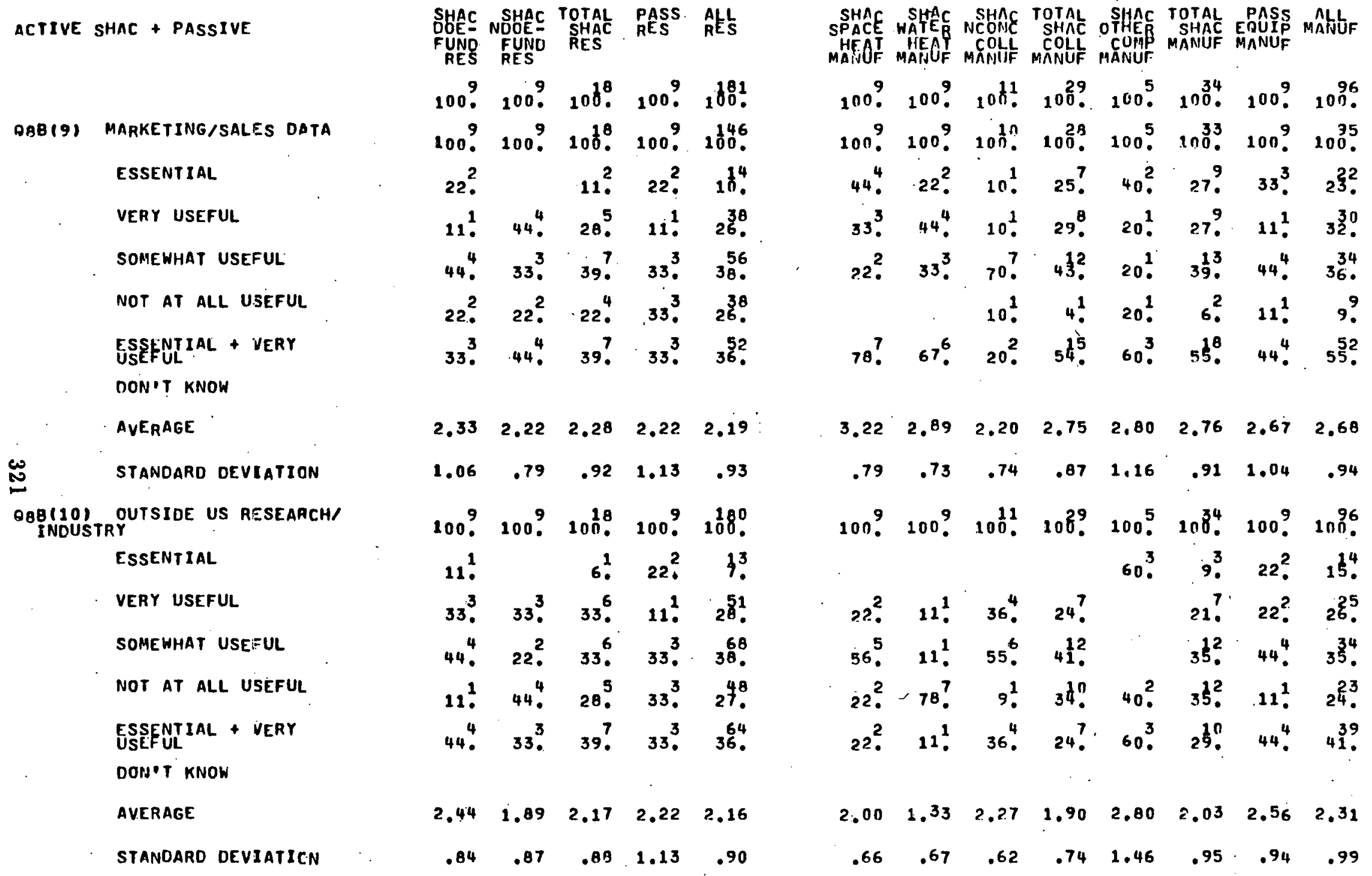


(OCTOBER, 19791

USEFULAESS OF SPECIFIED INFORMATION ITEMS - CONTINUED (DUESTION 8 )

ACTIVE SHAC + PASSIVE (CONTOO) SHAC PASS SHAC PPASS ARCH ARCH BUILO BUILU SHOC PASS ELLO

GaB(g) MARKETING/SALES DATA

ESSENTIAL

VERY USEFUL

SOMEWHAT USEFUL

Nat AT ALL USEFUL.

ESSEFULIAL + VERY

DON'T KNOW.

:

$$
\begin{aligned}
& \text { 100? } 100 \text { ? } 100 \text { ? } 100 \text { ? } 100 \text {. } 1009.1003 \\
& 100 \text { ? 100? } 100 \text { \% } 100 \text { \% } 100^{63} \text {. } \\
& 44^{4} \text {. } 44^{4} \cdot \quad 22^{2} \cdot 11 \text { ! } 2^{\frac{12}{4}} \text {. }
\end{aligned}
$$

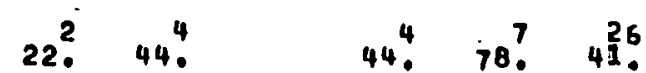

$$
\begin{aligned}
& \text { 33. } 11^{1} \text { 22. } 11^{1} \text { 2!? } \\
& 44^{4} .44^{4} \text {. } 33^{3} .11^{1}, \quad 32^{20} \\
& 2.112 .33 \\
& .87 \quad .67 \\
& 2.22 \quad 2.00 \quad 2.13 \\
& .92 \quad .47 \quad .39 \\
& 1009.1009 .1009 .1009 \text {. } \\
& 11 \text {. } 11 \text {. } \\
& \text { 11: 11: } 22^{2} \text {. } 22^{2} \\
& 22^{2} \text { 44. } 33^{3} . \quad 56 . \\
& \text { 56. } 54.44 .411 \\
& 22^{2} \quad 11^{1} \quad 22^{2} \quad 33^{3} \text {. } \\
& 1009.1009 .105^{5} \text {. } \\
& 11.35 \\
& \text { 33: } 22^{2} \cdot 22^{14}, \\
& \text { 56. } 44^{4} \cdot 3^{23} \cdot \\
& \text { 11. 22. } 35 \text { ! } \\
& 33^{3}-33^{3} \cdot 3^{19} \text {. } \\
& \begin{array}{lll}
2.22 & 2.22 \quad 2.05
\end{array}
\end{aligned}
$$$$
\text { ESSEETTIAL + VERY }
$$$$
\text { DON'T KNOW }
$$$$
\text { AVERAGE }
$$

STANOARU DEVIATION

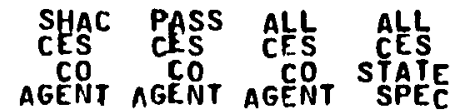
100 ? 100 ? $100^{45} 106^{8}$. 100 ?

$$
11 \text {. }
$$$$
56 \text {. }
$$$$
33 \text {. }
$$$$
11^{1}
$$$$
1.78
$$$$
.62
$$

QRBILOSTRQUTSIDE US RESEARCH

VERY USEFUL

SOMEWHAT USEFUL

NOT AT ALL USEFUL

Figure F-1. Active Solar Heating and Cooling Data Tables (continued) 


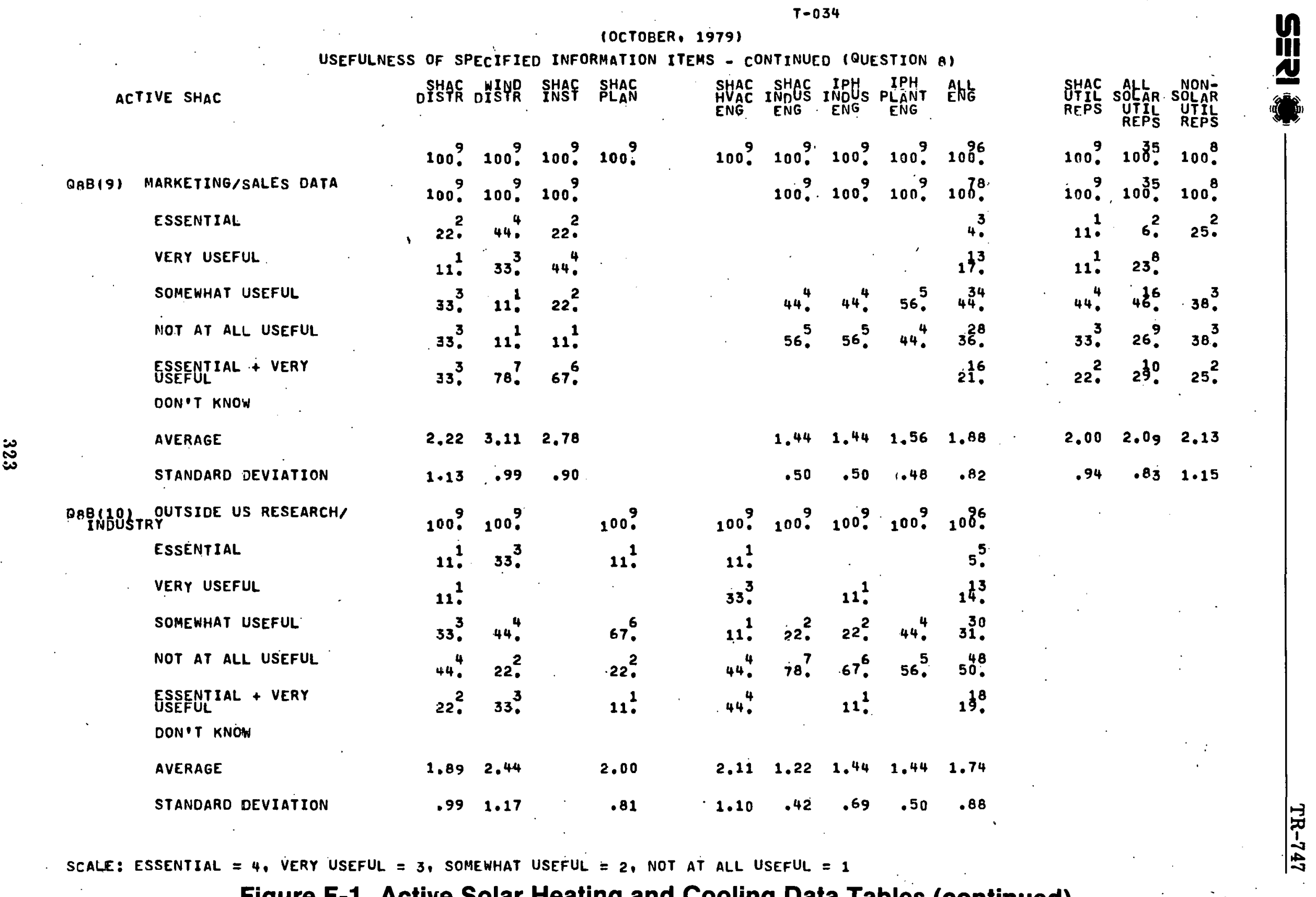

Figure F-1. Active Solar Heating and Cooling Data Tables (continued) 
(OETOEER, 1979$)$

USEFULNESS OF SPECIFIEO INFORMATION ITEMS - CONTINUED (RUESTION 6 )

ACTIVE SHAC + PASSIVE

QBB (21) INFO ON MARKETING

ESSENT I AL

VERY USEFUL

SOMEWHAT USEFUL

NOT AT ALL USEFUL

ESSENTIAL + VERY

DON'T KNOW

AVERAGE

STANDARU DEVIATION SHAC SHAC TOTEL PASS ALL
DOOE NDOEE SHEC RES RES
FUND FUND RES

100 ? 100 ? $10 \mathrm{~K}^{8}, 100$ ? $10^{801}$

$100^{18}$.

17 .

$39 ?$

44 .

$17^{3}$

QBBIIZ) INST/SOCIAL/ENVIRON/

ESSENTIAL

VERY USEFUL

SOMEWHAT USEFUL

NOT AT ALL USEFUL

ESSENTIAL +'VERY

DON'T KNOW

AVERAGE

STANUARD DEVIATION

1.04

1009.1009 .100 .1009 .1003

$111^{1} \quad \epsilon_{0}^{1} \quad 8^{3}$

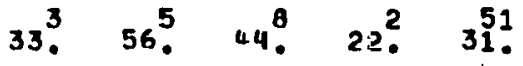

22. $33^{2}, \quad 28^{5} .67^{6} \cdot 45^{3}$.

33. $11^{1}$. 22. $11^{1} \cdot 16^{26}$

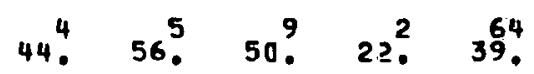

$\begin{array}{lllll}2.22 & 2.44 & 2.33 & 2.11 & 2.31\end{array}$

$\begin{array}{lllll}1.03 & .70 & .89 & .57 & .84\end{array}$
SHAC SHAC SHAC TOTAL SHAC TOTAL PASS ALL SPACE WATEA MCCNC SHAC OTHER SHAC EQNUF MAEOF MANOF MANUF MNNUF MANUF

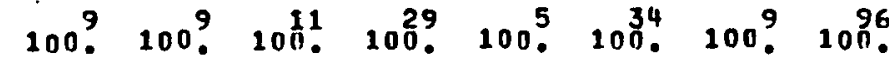

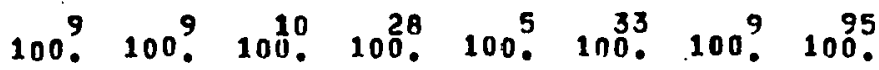
$222^{2} \quad 44^{4} \cdot \quad 211^{6} \quad 20.221$.

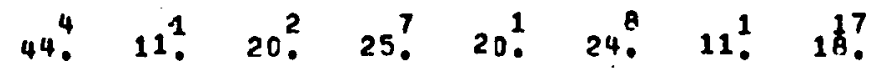

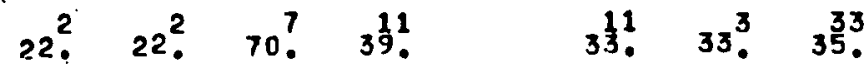

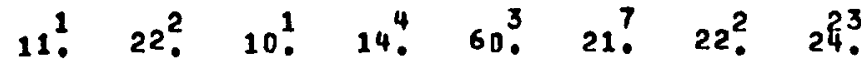
67. . $56^{5} \quad 20^{2} \quad 46_{0}^{3} \quad 40_{0}^{2} .45_{0}^{5} \quad 44^{4} \quad 41^{39}$.

$\begin{array}{lllllllll}1.89 & 2.78 & 2.78 & 2.10 & 2.54 & 2.00 & 2.45 & 2.56 & 2.40\end{array}$ 
(OCTOBER, 19791

USEFULNESS GF SPECIFIED INFORMATION ITEMS - CONTINUED (NUESTION A)

ACTIVE SHAC + PASSIVE (CONT'D)

QBB(11) INFO ON MARKETING

ESSENTIAL

VERY USEFUL

SOMEHHAT USEFUL.

NOT AT GLL USEFUL

ESSENTIAL + VERY

DON'T KHOW

心్

AVERAGE
STANDARD DEVIATION
OABLI2)
INST/SOCIAL/ENVIRON
ESSENTIAL
VERY USEFUL
SOMEWHAT USEFUL
NOT AT ALL USEFUL
ESSENTIAL + VERY
DON P T KNOH
AVERAGE
STANOARD DEVIATION

SHAF PASS SSHAG BPASS

1009.1009 .100 ? 100 ?$$
56^{5} \quad 33^{3} .22^{2} \quad 56^{5} \text {. }
$$$$
\begin{array}{llll}
2.56 & 2.11 & 2.00 & 2.78
\end{array}
$$$$
\begin{array}{llll}
.47 & .74 & .94 & .77
\end{array}
$$

shac eAsS Abto

$$
\begin{aligned}
& 100 \text {. } 1009.100^{63} \\
& 100^{9} .1000^{9} 100^{6.3} \\
& 11 \text {. } \quad 5 \text {. } \\
& 33^{3} \cdot 22^{2} \quad 2^{7^{7}} \text {. } \\
& \text { 22. } 33^{2}, \quad 33^{2} \text {. } \\
& 33^{3} \cdot 44^{4} \quad 320 \\
& 44^{4} .22^{2}, \quad 35^{2} \text {. } \\
& 2.22 \quad 1.78 \quad 2.11 \\
& 1.03 \quad .78 \quad .94 \\
& 1009.1009 .1083 \\
& 11^{1} 11^{1} \quad 10^{6} \text {. } \\
& 44^{4} .44^{4}, 48^{30} \text {. } \\
& 22^{2} .33^{3} \text { 30. } \\
& 22^{2} \text {. } 11^{1} \text {. } 13^{8} \text {. } \\
& 56.56 .537^{5} \text {. }
\end{aligned}
$$

SYAC CASS ALL CLL AGENT AGENT AGENT STATEC 100 ? 100 . 1n0. $100^{\circ}$.

$1009.1009 .1045 .100^{\circ}$.

11 ! 4 ?

11. 13. 11?

67. $67^{6} .67 .50$.

$22^{2} .22^{2} . \quad 16 ? .39$ ?

11 . 11. $10^{8} .11^{2}$.

Figure F-1. Active Solar Heating and Cooling Data Tables (continued) 
(OCTOBER, 1979)

USEFU:NESS OF SPECIFIED INFORMATION ITEMS - CONTINUED (QUESTION B)

ACTIVE SHAC

QBB(11) INFO ON MARKETIVE

ESSENTIAL

VERY USEFUL

SOMEHHAT USEFUL

NOT AT ALLL USEFLL

ESSEATIAL + VERT

DON'T KNOW

\begin{tabular}{|c|c|c|c|c|c|}
\hline & AVERAGE & 2.56 & 3.00 & 2.89 & \\
\hline & STANDARD OEVIATION & 1.05 & .94 & .87 & \\
\hline OBB(12) & INST/SOCIAL/ENVIP.ON/ & $100^{9}$ & $100^{9}$ & $100^{9}$ & $100^{9}$ \\
\hline & ESSENTIAL & & $11^{2}$ & & $36^{5}$ \\
\hline & VERY L'SEFUL & $44^{4}$ & $11^{1}$ & $33^{2}$ & $12 !$ \\
\hline & SOMEWHAT USEFUL & $44^{4}$ & $67^{6}$ & 56 & $33^{3}$. \\
\hline & NOT AT ALL USEFUL & $11^{1}$ & $11^{1}$ & $11^{1}$ & - \\
\hline & ESSEFNTIAL + VERY & $44^{4}$ & $22^{2}$ & $33^{3}$ & $\epsilon 7^{\epsilon}$ \\
\hline & DON T KNOW & & & & \\
\hline & AVERAGE & 2.33 & 2.22 & 2.22 & 3.22 \\
\hline & STANDAF:D DEVIATION & .67 & .79 & .63 & .32 \\
\hline
\end{tabular}

$100 \% 100 \% 100$ ?

$22^{2} 33^{3} \cdot 22^{2}$

33. $44^{4} .56^{5}$.

22. 11. 11:

22. 11. $11^{1}$.

56. 78 ? $78^{5}$ ?

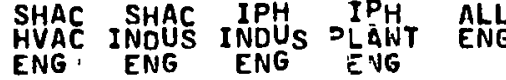

$1009100 \% 10091009.100$.

100 .

$6^{2}$

20 ?

31 .

$43^{5}$.

26 .

1.89

.90

1009.1009 .1009 .1009 . $100^{9}$

22. $11^{2}$

$33^{3} 22$

22. $44^{4}, 44^{4} \cdot 78_{-}^{\circ} 35$

$22^{2} \quad 44^{4} \cdot 33^{3} \cdot 11.265$

56. $6^{5} 1^{1} \quad 22^{2} \cdot 11^{3} \quad 39^{37}$.

$\begin{array}{lllll}2.56 & 1.78 & 1.89 & 2.000 & 2.24\end{array}$

$\begin{array}{lllll}1.05 & .91 & .73 & .47 & .97\end{array}$

$.79 \quad .83 \quad .82$
$2.22 \quad 2.37 \quad 2.25$

SHAC ALL NONUTIL SOLAR SOLAR REPS REPS $100^{9} .100^{35} .100^{8}$. 100 . $100^{27}, 100^{8}$. $7^{2}$, $22^{2} .22^{6} . \quad 13^{1}$. $33^{3} .30 .238^{3}$. $44^{4} .411 .504$ 22. $30^{8} . \quad 13^{1}$.

$1.78 \quad 1.96 \quad 1.63$ $.78 \quad .96 \quad .68$ 100 . $100^{35}, 100$. 93 44. $34^{4} .504$ 33. $43^{3} \cdot 25^{2}$. $22^{2}, 14^{5}, 25^{2}$ $44^{4}, 43^{15}, 50^{4}$.

Figure F-1. Active Solar Heating and Cooling Data Tables (continued) 
(OCTOBER, 1979$)$

USEFULNESS OF SPECIFIED INFORMATION ITEMS - CONTINUED (QUESTION B)

ACTIVE SHAC' + PASSIVE

ESSENTIAL

VERY USEFUL

SOMEHHAT USEFUL

NOT AT ALL IJSEFUL

ESSEFULIAL + VERY

OON'T KNOH

STANDARO DEVIATION

OBB1141. Climatological oata

ESSENTIAL

VERY USEFUL

SOMEWHAT USEFUL

NOT AT ALL USEFUL

ESSENTIAL + VERY

DON'T KNOW

AVERAGE

STANDARO DEVIATION

SHAC SHAC TOTAL PASS ALL
DOE- NDOE- SHAC RES RES
FUND FUND RES

RUNS RUN

$100^{3}$. 100 ? $10 f^{6}$. 100 ? 1601

$100^{3} 100$. $108^{\circ}$. 100\%. 1881 .

11. 11. $11^{2}$. $22^{2}$ 134.

56. $67^{6} .61^{1} \cdot 22^{2} .49^{88}$.

33. $22^{2} \cdot \quad 28^{5} \cdot 22^{2}, 28^{51}$

33. 9 ?

$67^{6} \cdot 78^{7} \cdot 72^{3} \cdot \quad 44^{4} \cdot \quad \frac{112}{2}$

1.

$2.78 \quad 2.89 \quad 2.83 \quad 2.33 \quad 2.66$

$\begin{array}{lllll}.61 & .56 & .61 & 1.16 \quad .82\end{array}$

100. 100 \% $100^{18}, 100$ \% 1003

11! $11^{1} \cdot 11^{2} \cdot 67^{6} \cdot 21^{34}$

44. $\quad 67^{6} .56^{\circ} .22 .2 \quad 34$.

$44^{4} .22 .28$.

22. $11^{2} .11^{1} \quad 17^{8}$.

$56^{5} . \quad 70^{7}, \quad 67^{2}, \quad 89 . \quad 55^{89}$

$\begin{array}{lllll}2.67 & 2.67 & 2.67 & 3.44 & 2.58\end{array}$

$\begin{array}{lllll}.65 & .93 & .80 & .97 & 1.00\end{array}$
SHAC SHAC SHAC TOTAL SHAC TOTAL PASS ALL HFAT AEOT COLL COLL COMP MANOF MANUF

MANOF MANOF MANUF MANUF MANUF

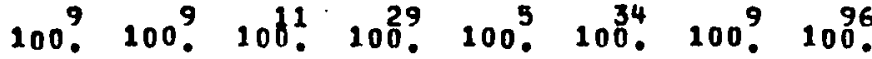

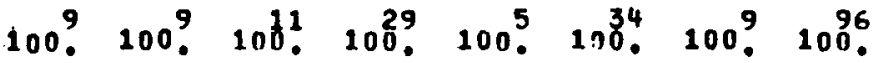
$22^{2} .11^{1} . \quad 10^{3}, 20^{1} \cdot 12^{4} \cdot 22^{2} \cdot 20^{19}$. 56. $22^{2} . \quad 36^{4} \quad 3 t_{0}^{1} \quad 20^{1} \quad 35_{0}^{2} \quad 22^{2} \quad 38_{0}^{36}$

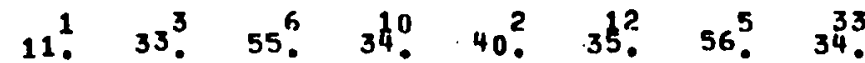
11 . $33^{3}$ 9. $17^{5} \quad 20$. $10^{6}$. 78. $33^{3}, \quad 36^{4} \cdot 4 t^{4}, 40^{2} \quad 47^{6}, 44^{4}, 57$.

$\begin{array}{llllllll}2.89 & 2.11 & 2.27 & 2.41 & 2.40 & 2.41 & 2.67 & 2.69\end{array}$ $\begin{array}{llllllll}.87 & .99 & .62 & .90 & 1.01 & .91 & .80 & .87\end{array}$ $100^{9} .100^{9}, 100^{10}, 100^{28}, 100^{5}, 100^{3}, 100 \% 100^{9}$. $22^{2} \cdot 11^{1} \cdot 10^{1} \cdot 14^{4} \cdot 40^{2} \cdot 10^{6} \quad 56^{5} \cdot 29^{8}$.

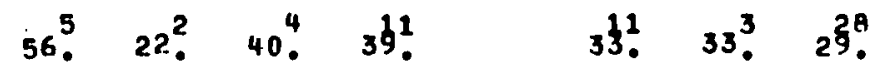
$22^{2} .44^{4}, 300^{3} \quad 32^{9}$. $27^{9} \cdot 11$. $21^{20}$. $22^{2} \cdot 20^{2} \quad 14^{4} \cdot 60^{3} \quad 21$ ? $20^{3}$ ?

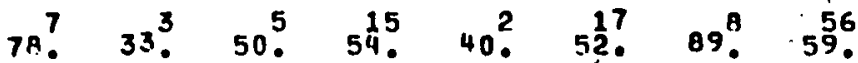

$\begin{array}{llllllll}3.00 & 2.22 & 2.40 & 2.54 & 2.20 & 2.48 & 3.44 & 2.68\end{array}$

$\begin{array}{llllllll}.66 & .92 & .91 & .89 & 1.46 & 1.03 & .70 & 1.10\end{array}$

SCALE: ESSENTIAL $=4$, VERY USEFUL $=3$, SOMEWIAT USEFUL $=2$, NOT AT ALL USEFUL $=1$

Figure F-1. Active Solar Heating and Cooling Data Tables (continued) 
(OCTOBER, 1979$)$

USEFULHESS OF SPECIFIED INFORMATION ITEMS - CONTINUED (QUESTION B)

\begin{tabular}{|c|c|c|c|c|c|c|c|c|c|c|c|c|}
\hline \multirow[t]{2}{*}{ ACtive $s$} & \multirow[t]{2}{*}{ SHAC + PASSIVE ICONTDOI } & \multirow{2}{*}{$\begin{array}{l}\text { SHAC } \\
\text { ARCH } \\
100 \text { ? }\end{array}$} & \multicolumn{3}{|c|}{$\begin{array}{l}\text { PASS SHAC PPSS } \\
\text { ARC } \text { BUILD BUILD }\end{array}$} & \multirow{2}{*}{$\begin{array}{l}\text { SHAC } \\
\text { EDUC } \\
1009\end{array}$} & \multirow{2}{*}{$\begin{array}{l}\text { PAsS } \\
\text { EuUC } \\
100 ?\end{array}$} & \multirow{2}{*}{$\begin{array}{l}\text { ALDU } \\
10 \% 3 \\
60\end{array}$} & \multirow{2}{*}{$\begin{array}{r}\text { SHAC } \\
\text { CES } \\
\text { CO } \\
\text { AGENT } \\
1009 \\
109\end{array}$} & \multirow{2}{*}{$\begin{array}{c}\text { PASS } \\
\text { CES } \\
\text { CO } \\
\text { AGENT } \\
1009 \\
100\end{array}$} & \multirow{2}{*}{$\begin{array}{r}\text { ALL } \\
\text { CES } \\
C D \\
A G E N T \\
1045 \\
100\end{array}$} & \multirow{2}{*}{$\begin{array}{c}\text { ALL. } \\
\text { CES } \\
\text { STATE } \\
\text { SPEC } \\
100^{8} .\end{array}$} \\
\hline & & & $100 ?$ & $100 ?$ & $100 ?$ & & & & & & & \\
\hline \multirow[t]{9}{*}{ OAB (13) } & EXPECTED OEVELOPMENTS & $100 ?$ & $100 ?$ & 1009 & $100^{9}$ & $100 ?$ & 1009 & $100^{63}$ & 1009 & $100 ?$ & $100^{45}$ & $100^{8}$. \\
\hline & ESSENTIAL & 11 & $22^{2}$ & $33^{3}$ & $33^{3}$ & $44^{4}$. & $22^{2}$ & 27 & & & $4^{2}$ & $11^{2}$ \\
\hline & VERY USEFUL & $78^{7}$ & $22^{2}$ & & $44^{4}$ & $33^{3}$. & $i^{7}$. & 49 & $44^{4}$ & $78^{7}$ & 51. & \\
\hline & SOMEWHAT USEFIJL & 11 & 44. & 56. & $22^{2}$ & $11^{1}$ & & 160 & $44^{4}$. & 11 & $31^{4}$. & \\
\hline & NOT AT ALL USEFLL & & $11 \div$ & $12 !$ & & & & $6^{4}$ & 11 & 11 & $13^{6}$ & 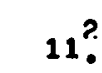 \\
\hline & $\begin{array}{l}\text { ESSENTIAL + VERY } \\
\text { USEFUL }\end{array}$ & 89. & 44 . & $33^{3}$ & 78. & $78 ?$ & $100^{9}$ & $7 E^{L}$ & $44^{4}$. & 787 & 525 & \\
\hline & DOH'T KNOW & & & & & 11 & & $\varepsilon^{1}$ & & & & \\
\hline & AVERAGE & 3.00 & 2.56 & 2.56 & 3.11 & 3.38 & 3.22 & $2.5=8$ & 2.33 & 2.67 & 2.47 & 2.50 \\
\hline & STANDARD DEVIATION & .47 & .94 & 1.05 & .74 & .67 & .43 &.$e_{4}$ & .67 & .65 & .76 & 83 \\
\hline \multirow[t]{8}{*}{$\theta 8 B(14)$} & CLIMATOLOGICAL OATA & $100^{9}$ & 100 & $100 ?$ & 1009 & 1009 & $100 ?$ & $10 a^{63}$ & 1009 & 1009 & $\begin{array}{r}45 \\
100\end{array}$ & 10.0. \\
\hline & ESSENTIAL & $33^{3}$ & $67 !$ & 44. & $44^{4}$ & 33 & $44^{4}$ & $33^{2 !}$ & $22^{2}$ & $22^{2}$ & $18^{8}$ & 28 . \\
\hline & VEAYY USEFUL & $44^{4}$ & $222^{2}$ & $22^{2}$ & $33^{3}$ & $44^{4}$ & $11^{1}$ & j触. & $56^{5}$ & 56. & 513. & \\
\hline & SOMEHHAT USEFUL & $22^{2}$ & $11^{1}$ & $33^{3}$ & $22^{2}$. & $11 !$ & $44^{4}$ & 24 & 11 & 11 & 209 & \\
\hline & NOT AT ALL USEFUL & & & & & $11 !$ & & 53 & 11 & 11 & 115 & \\
\hline & $\begin{array}{l}\text { ESSENTIAL + VERY } \\
\text { USEFUL } \\
\text { DON'T KNOW }\end{array}$ & $78 ?$ & 89. & $67^{6}$ & $78 ?$ & $78 ?$ & 56. & 715 & 79 . & $78 ?$ & 531 & $67 ?$ \\
\hline & AVERAGE & 3.11 & 3.56 & 3.11 & 3.22 & 3.00 & 3.00 & $3.0 \mathrm{D}$ & 2.89 & 2.89 & 2.76 & 2.72 \\
\hline & STANDARD DEVIATION & .74 & .66 & .87 & .79 & .94 & .94 & .87 & .87 & .87 & 85 & 1. \\
\hline
\end{tabular}




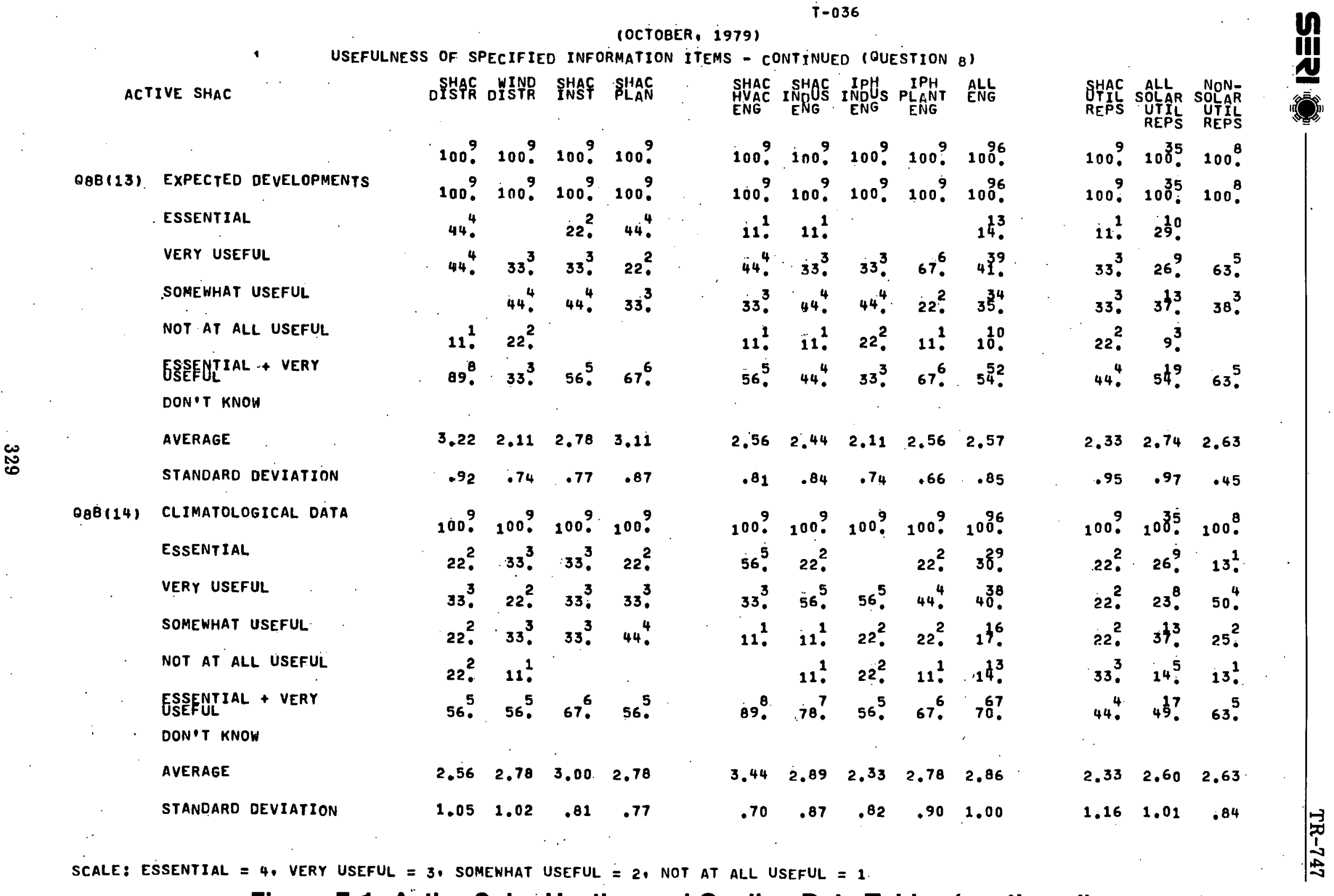

Figure F-1. Active Solar Heating and Cooling Data Tables (continued) 
(OCTOBER, 1979$)$

USE OF SPECIAL ACOLISITION METHOOS IQUESTION 101

ACTIVE SHAC + PASSIVE

OIOA COMPUTER TERMINAL
1. YES
2. NO
B. DON T KNOW/NA

Q10B MICROFORM - COMPUTER
1. YES
2. NO
B. DON T KNOW/NA

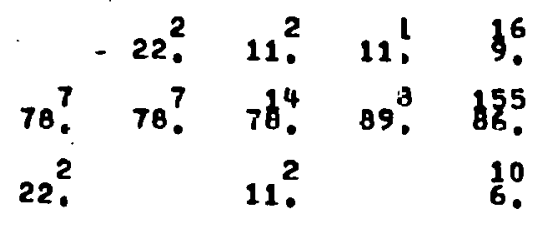

SHAC SHAC SHEC TEIAL SHAC TOTAL PASS ALLL

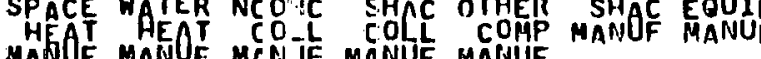

SHAC SHAC TOTAL PASS ALL RES RES

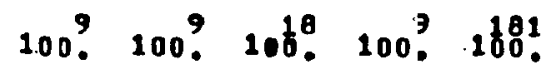

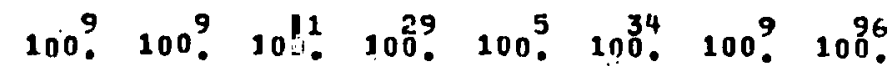
$22^{2} \quad 33^{3} \cdot \quad 13^{2} \quad 24^{7}, \quad 20^{1} \cdot 24^{8}, \quad 33^{3} \cdot 23^{2}$.

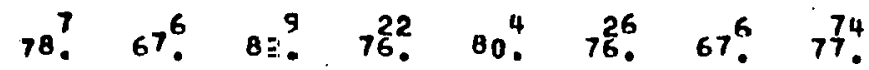

2.

Figure F-1. Active Solar Heating and Cooling Data Tables (continued) 
(OCTOBER, 19791

USE OF SPECIAL ACOUISITION METHODS IOUESTION 101. ACTIVE SHAC + PASSIVE (CONTIO) SHAC PASS SHAC BPASS ARCH SHAC RESS ALL EUTC

Q1DA COMPUTER TERMIMAL

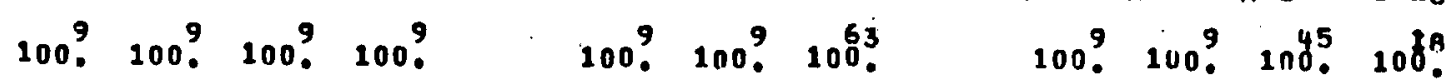

1. YES

2. NO

8. DON'T KNOW/MA

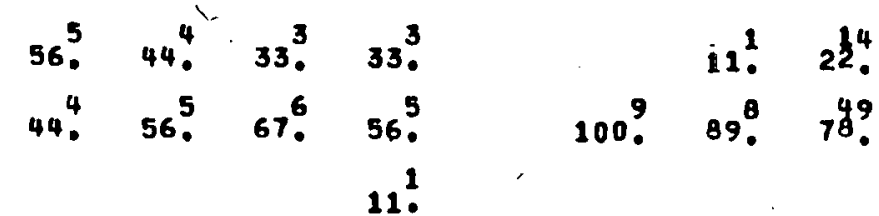

33. $11^{1} \cdot 16^{7} \cdot 44^{8}$.

$67^{6} \quad 49^{8} .84^{38} .56$.

O1DB MICROFORM - COMPUTER
1. YES
2. NO
8. DONIT KNOW/MA

$$
\text { 78? } 100^{\circ} .09^{\circ} \cdot 100^{\circ}
$$$$
\text { 100. } \quad 0^{2} .6^{4}
$$$$
\text { 11. } 11^{1} \text { 7. } 28 \text {. }
$$$$
89^{8} \text { 89. } 91.61 \text {. }
$$$$
\text { 2. } 11^{2} \text {. }
$$

QIDC OTHER MICROFORM
1. YES
2. No.
8. DON!T KNOW/HA

$$
\begin{aligned}
& 22^{2} \text {. } 33^{3} \\
& \text { 78. } 100 \text { ? } 67^{6} .100 \text {. }
\end{aligned}
$$

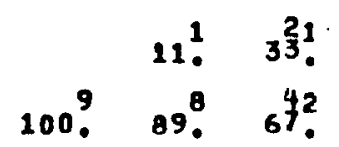

11. $11^{1}$ 9. $33^{6}$$$
\left.89.89^{8} . \quad 91^{42} \quad 6\right\}^{2} \text {. }
$$

Figure F-1. Active Solar Heating and Cooling Data Tables (continued) 


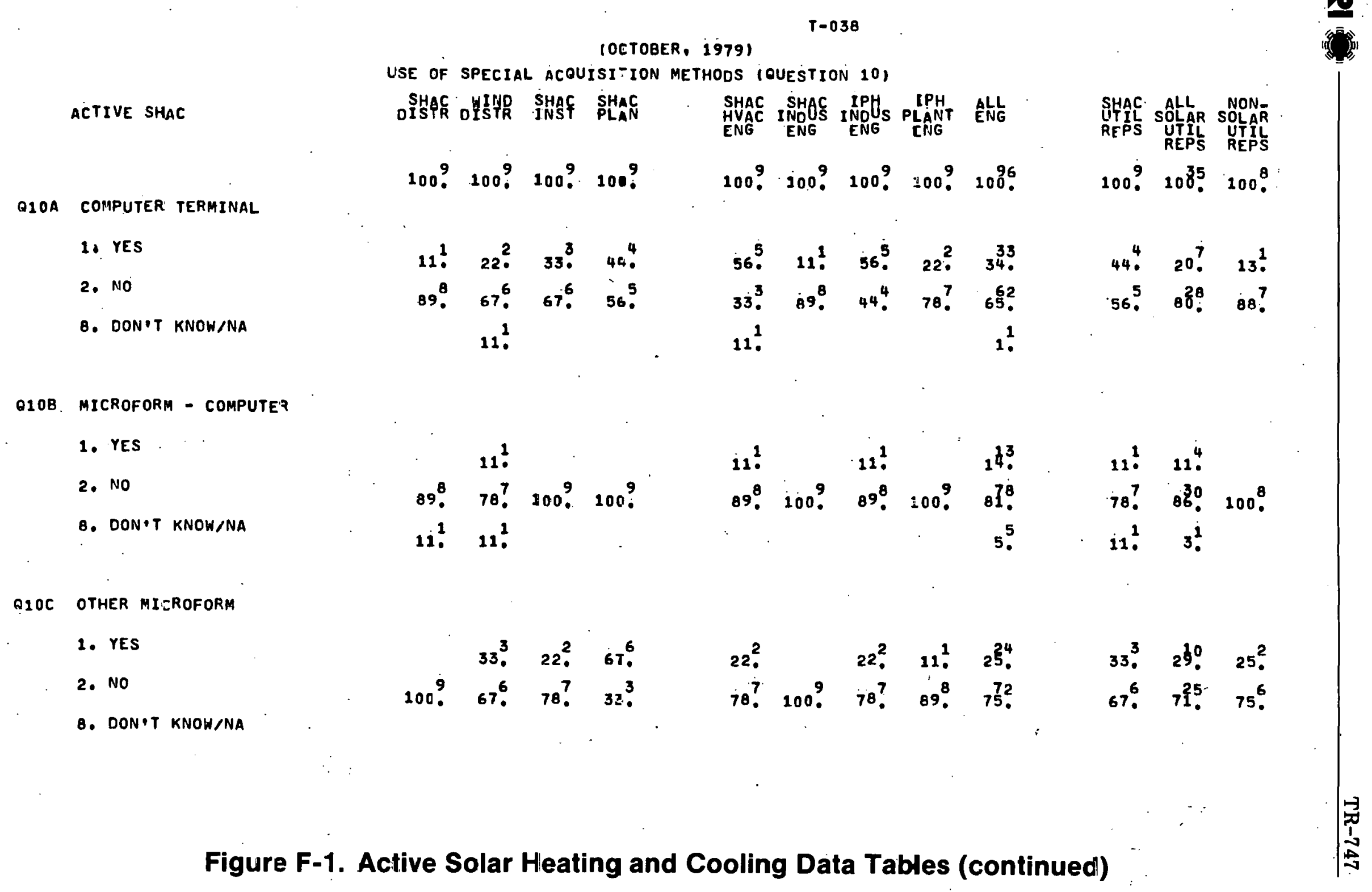


(OCTOBER, 1979 )

USE OF SELECTED SOLAR INFORMATION SOURCES IOUESTION 111

ACTIVE SHAC + PASSIVE

DIIII) LIBRARY (ORG/LOCALI

1. YES

2. No

8. DON'T KNOW

Q11(2) PUBLIC UTILITY

$$
\text { 1. YES }
$$

$\stackrel{\omega}{\omega}$

2. NO

a. DON T KNOW

O1
1. YES
2. No
8. DONPT KNOW

O11(4) WORKSHOPS/CONFERENCES
1. YES
2. NO
B. DON.T KNOW

SHAC SHAC TOTAL. PASS ALL
DOOE- NDOE- SHAC RES RES
FUND FUND RES

FUND FUND

100. 100 \% $108^{8} .100$. 1881

100 , 100. 106. 100, 1009.

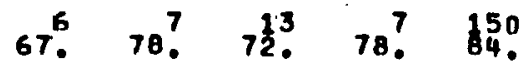

$33^{3} \cdot 22^{2} \cdot 28^{5} \cdot 22^{2} \cdot 16^{28}$

i.

100. 100 , $10 t^{8}, 100$. 1600.

44. $78^{7} .61 . \quad 44.591$.

56. $52^{2} \quad 39^{7} \quad 56 . \quad 49^{\circ}$

1.

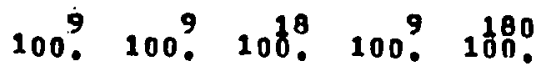

78. 100. 89. 89. 65?

22? $\quad 11^{2} \quad 11^{1} \quad 3^{63}$.

100. 100. $100^{8} .1009 .1000$

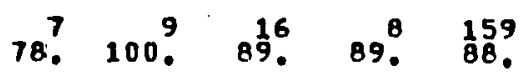

22. $\quad 11^{2} \cdot 11^{1} 1^{21}$

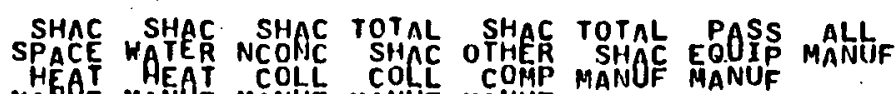
MAEOF MANOT MANUF MANUF MANUF

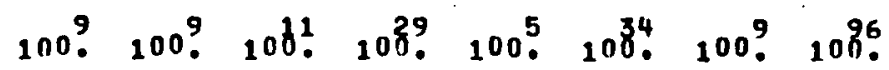

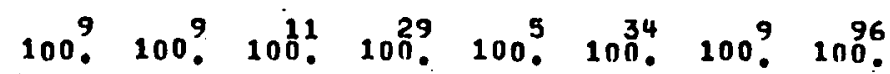

89. $56^{5} \cdot 73^{8} \quad 72^{21} \quad 60^{3} \cdot 71^{24} \quad 56.566^{5}$.

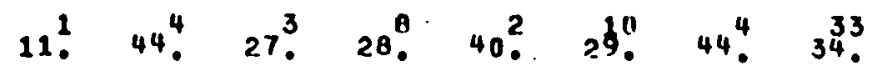

$100^{9} \cdot 100$. $100^{1} \cdot 100^{29} \cdot 100$. $100^{34} 100$. 100 .

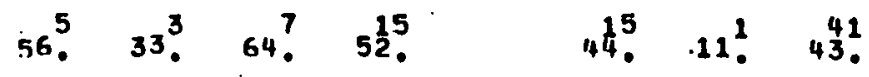

$44^{4} \quad 67^{6} \cdot 36^{4} \cdot 48^{4} \cdot 100^{5} \cdot 56^{\frac{9}{9}} \quad 89^{8} .57^{\circ}$

$1009.1009,100.1029,1005,100^{34}, 1009.1006$ 89. $78^{7}$. $82^{9} . \quad 83^{24} .60^{3} .69^{27} \quad 67^{6} .696$. $11^{1} \quad 22^{2}, 18^{2}, \quad 17^{5} \cdot 40^{2} \cdot 21^{7} \quad 33^{3}, \quad 31^{30}$.

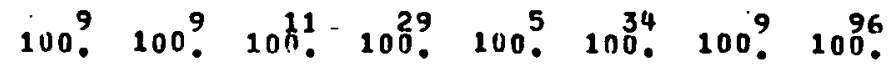
100. $67^{6} .73^{8} \quad 79^{23} \quad 80^{4} .79^{27} \quad 67^{6} .75 \%$

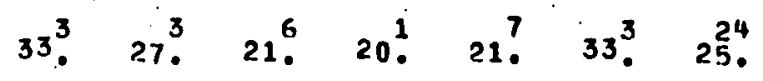

Figure F-1. Active Solar Heating and Cooling Data Tables (continued) 
USE OF SELECTED SOLAR IMFORMATION SOURCES IOUESTIION 111

ACTIVE SHAC + PASSIVE (CONTID)

QI1(1) LIBRARY IORG/LOCAL)

1. YES

2. No

8. DON'T KNOW

Q11(2) PUBLIC UTILITY

$\underset{\substack{\infty \\ \mathbb{N}}}{\infty}$

2. No

8. DON T KNOH

\section{OIES I ${ }^{3}$ GER INSTALLER/BUILOER/}

1. YES

2. No

8. DON.T KNOW

D11(4) WORKSHOPS/CONFERENCES

2. YES

2. NO

8. DON'T KNOW

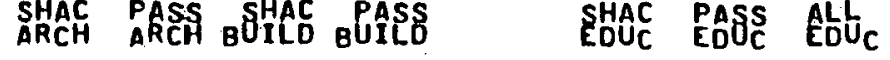

$$
\begin{array}{rrrr}
1009 & 100^{9} & 1000^{9} & 1009 \\
1009 & 1009 & 1009 & 1009 \\
67^{6} & 33^{3} & 56 . & 56 . \\
33^{3} & 67^{6} & 44^{4} & 44^{4}
\end{array}
$$$$
1009.1009 \text {. } 100^{63}
$$$$
100 \text { ? } 100 \text { ? } 100 \text {. }
$$$$
67.89^{\circ} .86^{5} \text {. }
$$$$
\text { 33. 11. } 14^{9} \text {. }
$$

SHAC PASS ALL ALL AGENT AGENT AGENT SPAEC 100 . 100 . $100.100^{4}$. 1009 . 100 ? 1045.100 . 67. $44^{4} .44^{20}: 8 \frac{15}{3}$ 33. $56^{5}, 56^{5}, \quad 17^{3}$

$$
\begin{aligned}
& 1009 \text {. 100. 100? } 100 \text { ? } \\
& 1009.1009 .1003 \\
& 78^{7} \quad 44^{4} \quad 33^{3} .56 \text {. } \\
& \text { 22. } 78^{7} \cdot 5^{336} \text {. } \\
& 22^{2} .56^{5} \quad 57^{6} .44^{4} \text {. } \\
& \text { 78. } 22^{2} \cdot 43 \text { ? }
\end{aligned}
$$$$
\text { 1009. 100, } 100^{45} 100^{28}
$$

44. 33.320 .611

56 . $56.52 ?^{3} . \quad 39$ ? 11. 4 ?

$$
\begin{array}{rrrr}
1009 & 100 \% & 1009 & 1009 \\
89 & 899^{9} & 09 . & 89 . \\
11 ! & 11 ! & 11^{\circ} & 11 !
\end{array}
$$$$
100^{9} \cdot 1009 \cdot 100^{63}
$$$$
78 \text {. } 1100^{9} .8^{56} \text {. }
$$$$
22^{2}
$$

11 ?

100\% $1009.100^{45} 100^{18}$.

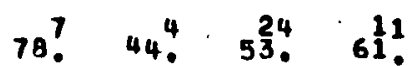

22. $56^{5}, 47^{2}$. 39?
1009. 1009. $100^{63}$
100. $70^{7}$. 90?
$22^{2} .10^{6}$.

$1009.1009 .100^{45} 106^{8}$

$56.54 .456 . \quad 8 \frac{15}{25}$

$44^{4}$. $56^{5}$. $44^{20} \cdot 17^{3}$.

Figure F-1. Active Solar Heating and Cooling Data Tables (continued) 
(OCTOBER, 1979)

USE OF SELECTED SOLAR INFORMATION SOURCES (QUESTION 11)

ACTIVE SHAC

Q11(1) LIBRARY (ORG/LOCAL)

1. YES

2. NO

8: DON T KNOW

Q11(2) PUBLIC UTILITY

i. YES

$\stackrel{\mathscr{w}}{\sim}$

2. NO

8. DONIT KNOW

OIISISHER INSTALLER/BUILDER/

1. YES

2. No

6. DON.T KNON

Q11(4) WORKSHOPS/CONFERENCES
1. YES

2. NO

8. DON T KNON

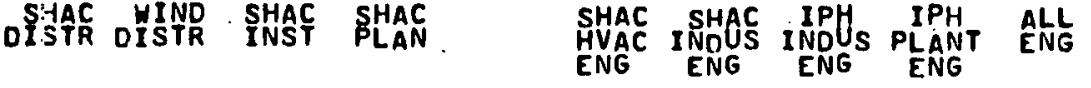

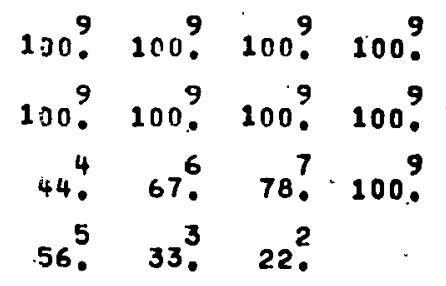

$100^{9} 100$ ? 1009 ? 100 ? $100^{96}$ $100 ? 10091009.1009 .1096$ $78^{7} \cdot 44^{4} \cdot 22^{2} \cdot 22^{2} \cdot 64^{6} \cdot$ $22^{2} \cdot 56^{5}: 78^{7} \cdot 78^{7} \cdot 36^{3}$.

$1009.1009 \cdot 1009.100 \%$

1009.1009 .1009 ? 100 ? 100 ? $67^{6} .56^{5} \cdot 11^{1} \cdot 22^{2} .50^{4}$. $67^{6} \quad 56^{5}, 44^{4}, 89^{8}$.

33. $33^{3}, 56^{5}, 11^{1}$ $33^{3} \quad 44^{4} \quad 89^{8} \cdot 78^{7} \cdot 50^{48}$ 11.

$$
\begin{aligned}
& 100 \% \text {. 100? } 100 \text { \% } 100^{9} \text {. } \\
& 100^{9}, 100^{\circ} \text {. } 78^{7}, 89^{8} \\
& \text { 22. } 11^{2}
\end{aligned}
$$

$100 \% 100 \% 100 \% 100 \% 100^{9}$.

$100.98^{7}, \quad 78^{7}, \quad 89^{8} . \quad 86$. $22.222^{2}, 11^{2} \cdot 14^{3}$.

1009.1005 .1008 89. $77^{2}$ ? 75 . 11. $23^{8} .25^{2}$

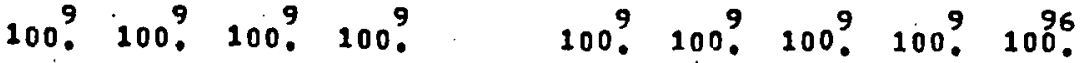

$$
\begin{aligned}
& 56.100^{9} \cdot 67^{6} \cdot 44^{4} \cdot 72^{69} \\
& 69^{8} \cdot 78^{7}, 100 \text { ? } 100 \text { ? } \\
& \text { 11. } 22^{2}
\end{aligned}
$$
SHAC SOLL NOR SOLAR $100^{9} 100^{35} \cdot 100^{8}$ $100.900^{3}: 100^{8}$. $70^{7} .71^{25} 63^{5}$. $22^{2} 29^{\circ} 38^{3}$.

$100 \%$ : $100^{35} \cdot 100^{8}$ $78^{7} .71^{25} 50^{4}$. $22^{2}$ 29! $50^{4}$. REPS REPS

Figure F-1. Active Solar Heating and Cooling Data Tables (continued) 
(OCTOBER, 1979$)$

USE OF SELECTED SOLAR INFORMATION SOURCES - CONTINUED (NUESTION 1.1)

ACTIVE SHAC + FASSIVE

Q12(5) COMMEACIAL DATA BASE

1. YES

2. NO

8. DON'T KNOW

Q11 1 CENTER FEOERAL LIBRARY/INFO

$\stackrel{\omega}{\omega}$
1. YES
2. No
Q. DON?T KNOH

Q1117) SSIE - SMITHSONIAN
1. YES
2. NO
B, DON?T KNOH SHAC SHAC TOTAL PASS ALL
DOE NOOE TSAC RES RES
FUND EUNO RES

100? 100 ? $106^{8}$. 100? $180^{81}$ 1009 . $100,100^{8}, 100$. 100 . 67. $67^{6} .67^{2} \cdot 78 \%$ 38. 33. $33^{3}, 33^{6}, 22^{2}$. 610 $2^{3}$ SHAC SHAC SHAC TOTAL SHAC TOTAL PASS MLLL HEOT MEAT COLL COLL COMP MANOF MANUF

\begin{tabular}{|c|c|c|c|c|c|c|c|}
\hline $10 ?$ & $100^{9}$ & 1011 & 100. & 5 & 34 & 9 & 9 \\
\hline 8 & $100^{9}$ & 1071 & $100^{29}$ & 00 & 4 & 100 ? & $100^{\circ}$ \\
\hline & $22^{2}$ & & 21 & & 8. & 11 & 2 \\
\hline & 7 & s10. & $79^{33}$ & 10 & ${ }^{2} 2^{8}$. & 39 & \\
\hline
\end{tabular}

$$
\begin{aligned}
& 1000^{9} 1009.1011 .1009 .1004 .1033,100,1005
\end{aligned}
$$

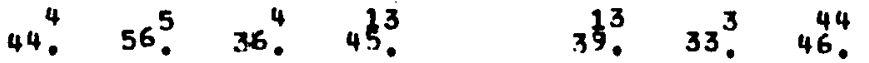

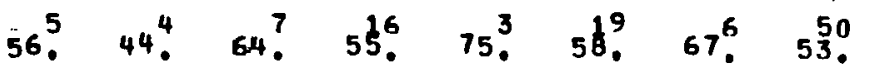

$$
\begin{aligned}
& \text { 25. 3. 1? }
\end{aligned}
$$

1009 . $1009,100^{8} \cdot 1009$. $16^{81}$.

22 . $33^{3}, 28.211^{1}, 17^{30}$.

78 . $\quad 67^{6}, \quad 72^{3} \cdot 78^{7}, \quad 81^{46}$.

11.3 .

Figure F-1. Aclive Solar Heating and Cooling Data Tables (continued) 
IOCTOBER, 19791

USE OF SELECTED SOLAR INFORMATION SOURCES - CONTINUED (QUESTION 11)

ACTIVE SHAC + PASSIVE (CONTPD)

Q11(5) COMMERCIAL DATA BASE

1. YES

2. No

6. OON?T KNOW

Q11 16 CE) FEDERTAL LIBRARY/IMIFO

$\stackrel{\omega}{\omega}$
Q11(7) SSIE - SMITHSONIAN
1. YES
2. No
8. DONIT KNOW

SHAC PASS SHAC BPASS
ARCH ARCH BUILO BUILD

100 . 100 . 100 ? 100 \%

100? 100'. 100? 100?

11 . $22^{2} .22^{2}$.

67. 1009 . $78^{7}, 67^{6}$.

$22^{2}$.

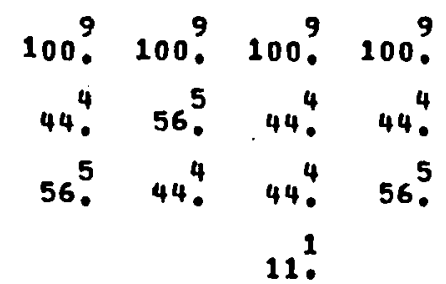

11 .

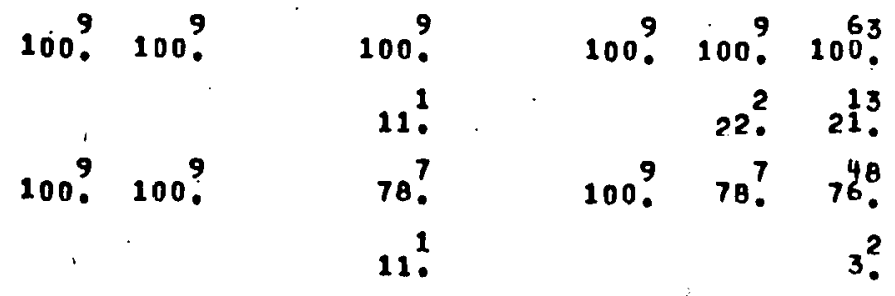

SHAC PASS ALL

100. 1009 , $100^{63}$

1009.1009 .1003

11 . 11 . 27.

$89^{6}$. $89^{\circ}$. $73^{46}$.

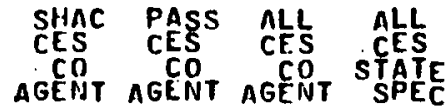
100 . 10n' $10^{45}$. $100^{8}$. $100^{9} 1009.100^{45} 100^{18}$. $22^{2} .13^{6} 17^{3}$. 78. 100 . $83^{9}$. 83 .

$1009.100^{9} .1003$

$44^{4} .44^{4} .52$.

56 . $56^{5} .48$.

$100^{9} 100^{9} \cdot 100^{45} 100^{18}$

22. $44^{4} \cdot 3 \frac{15}{3} \cdot 67^{2}$.

$78^{7} .56^{5}, \quad 6 ?^{30} \quad 33^{6}$.

$100 \% 100^{\frac{10}{8}}$

$17^{3}$.

100. $78^{4}$.

6 .

Figure F-1. Active Solar Heating and Cooling Data Tables (continued) 
(JCTOBER, 1979 )

USE OF SELECTED SOLAR INFORMATION SOURCES - CONTSNUEO IOUESTION 111

ACTIVE SHAC

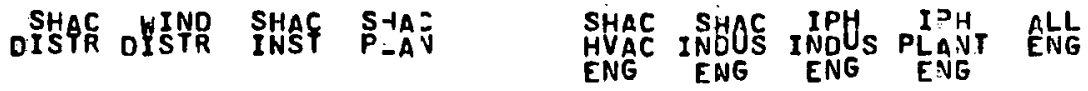

Q11(5) COMHERCIAL DATA BASE

1. YES

2. NO

B. DON?T KNOW

Q11 16 CENTER FEDERAL LIBRARY/ITJFO

1. YES

2. NO

8. DON?T KNOW

Q11(7) SSIE - SMITHSONIAN
1. YES
2. NO
8. DON'T KNOW

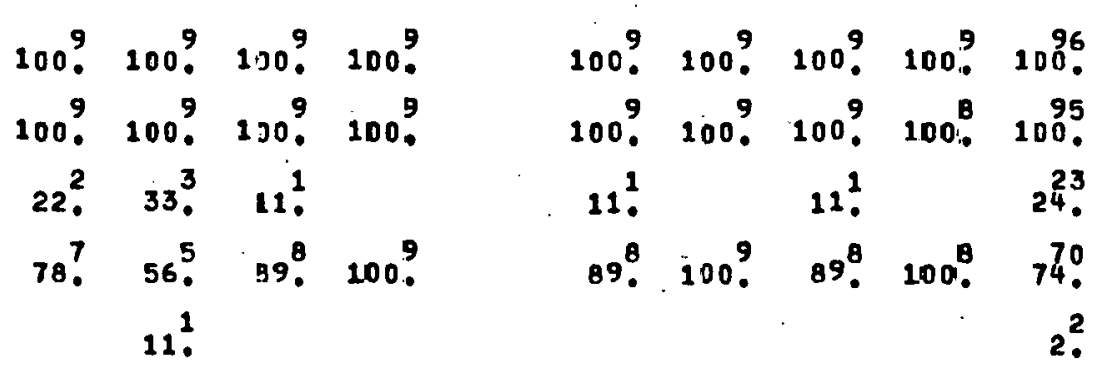

1009.1009 .1009 .1009

1009.1009 .1009 .1009 . 1006

$78.744^{4}, 33,44^{4}$.

$22^{2} .44^{4}, \quad 67^{6}, 56$.

11 .

$22^{2} \quad 33^{3} . \quad 56^{5} \cdot 11^{1} \quad 46^{44}$.

$78^{7} \quad 67^{6} .44^{4}$ eะ. $55^{\circ}$.

$2^{2}$

100. $10 c^{9} .100^{70}$.

$11^{8}$

1009 . 1009 . 891

1.
SHAC ALL NON-
UTIL SOLAR SOLAR
REPS UTIL UTIL

$100^{9} .108^{3}$. 100 ?

100 ? $100^{35}$. 100 .

11 . $17^{6} .13^{1}$

99. $80^{8} .88^{?}$ ?

3!

$1009.100^{35} 100$.

56. 54 .

$44^{4} 46^{6}, 100$.

$100^{9} .100^{35} .1000^{\circ}$.

$22^{2}$. 17. 13 .

78 . 83 ? 88 ?

Figure F-1. Active Solar Heating and Cooling Data Tables (continued) 
(OCTOBER, 1979)

USE OF SELECTEO SOLAR INFORMATION SOURCES - CONTINUED (OUESTION 11)

ACTIVE SHAC + PASSIVE

O11

1. YES

2. NO

B. DONTT KNON

$\underset{\mathscr{\omega}}{\omega}$

O1 INFGRMATIONAL SERVICHNICALS
1. YES
2. NO
B. DON'T KNOW

Q11 CIFETE TECHNICAL INFORMATION
1. YES
2. NO
8. DONT KNOH

SHAC SHAC TOTAL PASS ALL

FUND KUES

100 ?. 100 ? 1078 . 100 ? 1801

1019 . 100 . $100^{8}, 100$ ? 100 .

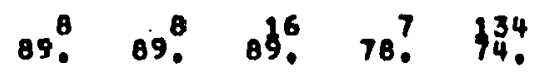

11. $11^{1}$. $11^{2}$. 22, $24^{44}$.

$2^{3}$

100. 100? 108. 100 ? 1681

100 . 100 \% $100^{\circ}$. 100 \% 1801 .

67. $78^{7} \cdot 72^{13} \cdot 89^{8} \quad 14^{5}$.

33. $22^{2} .28 .211^{1}$. 33.

4.

100 . 100 . $100^{\circ}, 100$. 1001

100 . 100 . $100^{17} 100$. 100 .

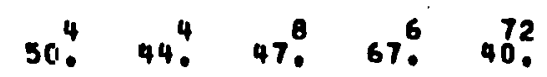

$50^{4} .56^{5} .53^{9}, \quad 33^{3} .56$.

4.
SHAC SHAC SHAC TOTAL SHAC TOTAL PASS MALL MANOF MANOF MANUF MANUF MANUF MANOF MANUF

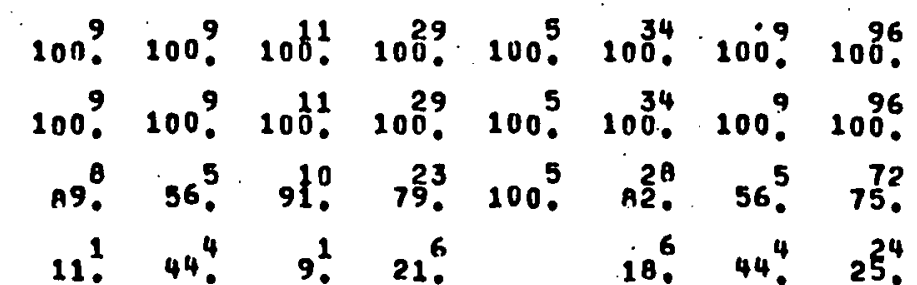

100 ? $1009.100^{1}, 100^{29} 1005.100^{34} 100$ ? $100^{6}$. 100 . 100 . $100^{1}$. $100^{29} \cdot 100^{5}$. $100^{34}$. 100 ? $100^{96}$ 56. $33^{3}, \quad 55^{6}, 48^{4}, \quad 40^{2}, 47^{6}, \quad 33^{3} \cdot 44^{4}$. $44^{4} \cdot \quad 67^{6} \cdot \quad 45^{5} \cdot 52^{\frac{15}{2}} \quad 40^{2} \cdot 5 f^{7}: \quad 67^{6} \cdot 54^{52}$. $20^{1} \quad 3^{1}$ 2.

100 . 100 ? $100^{11}$. $100^{29}$. 100 . $100^{3}$. 100 ? $100^{96}$ 100 . 100 . $100^{11}, 100^{29} 1005.100^{34} 100$. 1006 $36.5 \quad 9.211^{6} .210^{6} \quad 11^{1} .21^{20}$

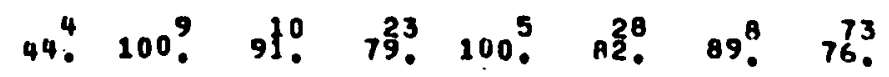
3.

Figure F-1. Active Solar Heating and Cooling Data Tables (continued) 
(OCTOBER, 1979 )

USE CF SELECTEO SOLAR IMFORMATION SOURCES - CONTINUED (OJESTION 111

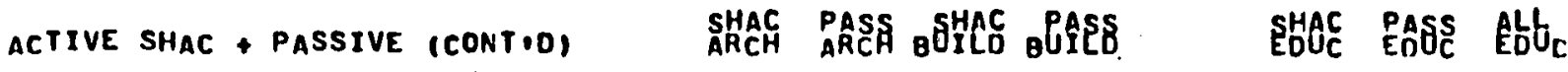

DI GROP GOVיT PRINTING OFFICE-

1. YES

2. NO

B. OON'T KNOW

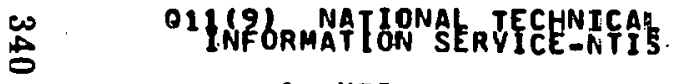

1. YES

2. NO

8. DONIT KNOW

Q11 CEAPER IECHNICAL INFORMATION

1. YES

2. NO

8. DON"T KNON
$100^{9} 100^{9} \cdot 100^{9} \cdot 100^{9} \quad 100^{9} \cdot 100^{9} \cdot 100^{63}$

100. 100 ? 100 \% 100 . 100 , 100 ? $100^{63}$.

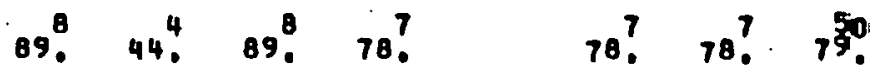

$11^{1} .56 .511^{2}$. $22^{2}$.

100 ? $100 \% 100$ ? 100 ?

100 ? $1000^{\circ} 100^{\circ}$. 100?

44. 33. 44. 44.

$56.57^{5}, \quad 56.566^{5}$

100 ?. 100 ? 100 ? 100 ?

100. 100 \% 100 . 100 .

$22^{2}, 33^{3}, 44^{4}, 11$ ?

78. 67. $36^{5}$. 78?

11 ?
$22^{2}$. $22^{2} .29^{2}$.

2.

100 . 100 . $100^{63}$.

100 . 100 , $100^{63}$.

$33^{3} .44 .630$.

67. $44^{4} .35^{2}$.

i1. 2 ?

$100 ? .100 ? \cdot 100^{63}$

100. 100 ? $100^{63}$.

44. 44. 44.

44." 44 . 4 ?

11. 11. $\epsilon^{4}$.
SHAC PASS ALL ALL AGENT AGENT AGENT STATEC 100 . 100 ? $100^{45}$. $100^{80}$. 100. 100 . $100^{45}$. $100^{8}$. 78 . $67.64 .63^{5}$. $22^{2}$. $23^{3} .33^{5}, \quad 17^{3}$. 2

100? 130 ? $100^{45}, 100$. 100 . 130 ? $100^{45}, 100^{8}$. $11.270^{3} \quad 50$. 78?. 100 . 83 ?. 50 . 11. $\quad 7^{3}$

$1009.100 \% 100^{45} \cdot 100$. 100 . 1009 . $100^{45}, 108^{8}$. 11 . $111^{2}$. 11 . 50 . 89 . $89^{8}$. 839 . 50 . $2^{1}$

Figure F-1. Aclive Solar Heating and Cooling Data Tables (continued) 


\section{IOCTOBER, 19791}

USE OF SELECTED SOLAR INFORMATION SOURCES - CONTINUED (QUESTION 11)

ACTIVE SHAC

D11 GPO GOV'T PRINTING OFFICE-
1. YES
2. No
8. DON'T KNOH

O1 ING ORMATIONNAL TEEHNICAL

2. YES

2. No

B. DON T KNOW

Q11110) TECHNICAL INFORMATION
1. YES
2. NO
B. DON'T KNOW

DSHAC OWINO SHAC SHAC

$$
100^{9} \text { : 100? } 100 \text { ? } 100 \text { ? }
$$
$100^{9} \cdot 100$ \% 100 ? 100 ?

48. 89.78 . 89.

55. $11^{2} \cdot 22^{2} .11^{1}$

$$
\begin{array}{rrrr}
100^{9} & 100^{9} & 100 \% & 1009 \\
100^{9} & 100^{9} & 100^{9} & 1009 \\
56 . & 56^{5} & 33^{3} & 89^{8} \\
44^{4} & 33^{3} & 44^{4} & 11^{1} \\
\vdots & 11^{1} & 22^{2} &
\end{array}
$$

\begin{tabular}{|c|c|c|}
\hline a? & 1009 & $100^{9}$ \\
\hline 1009 & $100 ?$ & $100^{9}$ \\
\hline $22^{2}$ & 112 & $44^{4}$. \\
\hline $67^{6}$. & 56 & 56 ? \\
\hline $1: 1$ & 33 & \\
\hline
\end{tabular}

SHAC SHAC IPH IPH
HVAC INDUS INDUS PLANT ELTG
ENG ENG
ENG ENG

100\% 100 ? 100 ? 100 \% $100^{96}$ 100 ? 100 ? 100 ? 100 ? 100 .

44. 78. $89^{\circ} .44^{4} 7^{7} \quad 76^{3}$.

56. $22^{2} \cdot 11^{1} \quad 56^{5} .24^{3}$.

1009.1009 .1009 . 1009.1006 100 . 1009. 1009. 100\% $100^{9}$. 44. $56.533^{3} .11^{2} .47^{4}$. 36. $44^{4} .36^{5} . \quad 89^{8} .51^{49}$ 11 .

$2^{2}$.

SHAC ALL NONUTIL SOLAR SOLAR
REPS UTIL UTIL
REPS REPS 100 ? $100^{35} 100$. 100 . $100^{35} 100$. 89. $7 ?^{7} \cdot 75^{6}$ $11^{1} \cdot 23^{8} 25^{2}$

$1009.100^{35} 100$. 100 . $100^{3}$. 100 . 56: $60^{2}: \quad 13$ ? 44. 48. 88 ?

100 ? 100 \% 1009.100 ? $100^{96}$ 100. 100. 100. 100\% 1006 .

$33^{3} .33^{3} .56^{5} \quad 22^{2} \quad 33^{32}$

$67^{6} .67^{6} .44^{4} .67^{6} .63^{6}$.

$11^{1} 4^{4}$.
100 . $108^{3} \cdot 100$. 100 . $100^{35} .100^{\circ}$. 67. $4 \frac{19}{9} .231$ 22. $49^{2}$. 88 ? 11 . 3 ?

Figure F-1. Active Solar Heating and Cooling Data Tables (continued) 


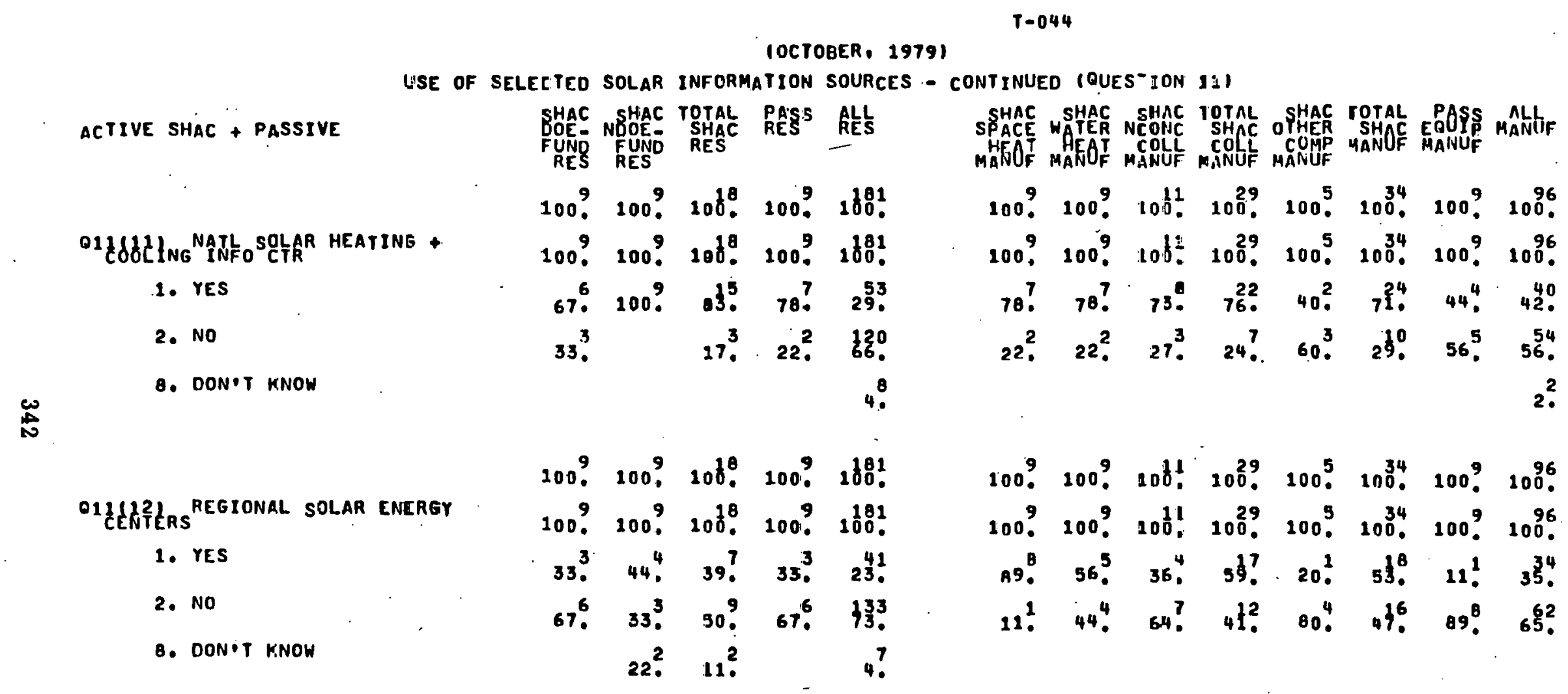

Figure F-1. Active Solar Heating and Cooling Data Tables (continued) 
IOCTOBER, 19791

USE OF SELECTEO SOLAR INFORMATION SOURCES - CONTINUED IOUESTION 111

ACTIVE SHAC + PASSIVE (CONTOO) SHAC PASS SHAC BPSS ARCH ARH SHAC PASS ALL

$\underset{\omega}{\omega}$
O11'112 NOOL NATL SOLAR HEATING +

1. YES

2. NO

8. DONIT KNOH

O11112) REGIONAL SOLAR ENERGY

1. YES

2. NO

8. DON T KNOW

$$
\begin{aligned}
& 100 \text { ? } 100 \text { ? 100? 100? } \\
& \text { 100? 100? 100? 100? } \\
& \text { 44. } 78^{7} \text {. } 56^{5} \text {. } 69^{\circ} \\
& \text { 44. } 22^{2} \text { 44. } 11^{1} \\
& 11 \text { ? }
\end{aligned}
$$

$$
\begin{aligned}
& 100 \text { ? } 1009.100^{63} \\
& 100 \text { ? } 100 \text { ? } 100^{63} \text {. } \\
& \text { 44. 78? 46? } \\
& 56^{3} \quad 22^{2} .54^{34} \text {. }
\end{aligned}
$$

1009. 100? 100? 100?

100 . 100 . 100 \% 100 ?

11. $67^{6} .44^{4} .67^{6}$.

69. $33^{3} .56^{5} .33^{3}$.

100. 1009.1003

1009.1009 . 100 .

44. $333^{3} 43$ ?

$56.566^{5} 54^{34}$

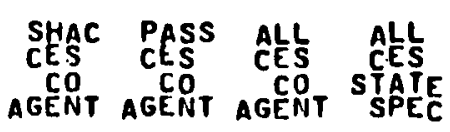

$1009.1009100^{45}$. $108^{\circ}$. 100 ? 100 ? $100.100^{4}$.

56. $21^{1} \cdot 29^{3}, 50$ ?

44. 69. $63^{\circ}$. 44.

4. 6 .

11. $3^{2}$. 
(OCTOBEA, 2979$)$

USE OF SELECTEO SOLAR INFORMATION SOURCES - CONTINUED (OUESTIOV 11 )

ACTIVE SHAC

${ }^{011}$ COLIING NATL SOLAR HEATING *

1. YES

2. NO

B. DON T KNOW

$\underset{\Delta}{\mathbb{A}}$

Q11 CEATERTS REGIONAL SOLAR EMEREY

1. YES

2. No

8. DON T KNOW

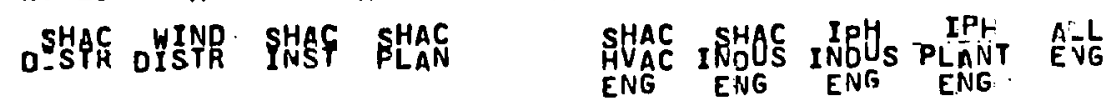

\begin{tabular}{|c|c|c|c|}
\hline 9 & 9 & 9 & 9 \\
\hline $100^{9}$ & $100^{9}$ & $100^{\circ}$ & $100^{\circ}$ \\
\hline $69^{8}$ & $44^{4}$. & $67^{6}$. & $44^{4}$. \\
\hline 11 . & & $33^{3}$ & $44^{4}$. \\
\hline
\end{tabular}

100. 100 ? 1009 . 100. 1096 .

100 \% 100 \% $100^{9}$. 100. $100^{8}$.

$33^{3} .56^{5} \cdot 22^{2} \cdot 11^{1} \quad 36$.

$67^{6} \cdot 44^{4} .67^{6}$. $69.60^{8}$ ?

$11^{1} .3$

$\begin{array}{rrrr}100^{9} & 1009 & 100 \% & 1009 \\ 100^{9} & 100^{9} & 100^{9} & 100^{9} \\ 33^{3} & 33^{3} & 10 ! & 11^{1} \\ 44^{4} & 36^{5} & 22^{8} & 09^{8} \\ 22^{2} & 11^{1} & & \end{array}$

100 . $100^{9} \cdot 100^{9} \cdot 1009$. $100^{96}$.

100 \% 100 ? 100 ?. 100. 100 .

22. $11^{2}$. 27.

100. $78^{7}$. $89^{8} .100^{9} .69^{6}$.

4.
SHAC SALL NON-

REPS UTIL UTIL

100 , $100^{35}, 100^{8}$.

$100^{\circ} .100^{3} .100^{\circ}$.

44. $33^{3} .13$.

22. $51^{\circ} .88^{7}$.

$33^{3} .11^{4}$.

$100^{9} \cdot 100^{35} .100^{8}$.

$100 \%$. $100^{35} .100$.

$44^{4} .34^{12}$.

33. $60^{2}: 100$.

$22^{2} 6^{2}$.

Figure F-1. Active Solar Heating and Cooling Data Tables (continued) 
(OCTOBER, 1979$)$

USE OF SELECTEO SOLAR INFORMATION SOURCES - CONTINUED (QUESTION 11)

ACTIVE SHAC + PASSIVE

Q11(13) US DEPT. OF ENERGY

1. YES

2. NO

8. DON T KNOW

D11 (14) RADIO/TV

1. YES

兽

2. No

3. DONET KNOW

DIKERESAPEERIODICALS,

1. YES

2. NO

B. DON'T KNOW

-1ENOGKONPEIYATE OROLAR/

1. YES

2. NO

B. DON'T KNOW
SHHAC SHAC TOTAL PASS ALL
DOEE NODE- SHAC RES RES
FUND FUND RES.

$100 ? 100 \% 100^{8} \cdot 100 \% 1881$

$100^{9}, 100^{9}, 100^{8}, 100^{9} \cdot 1001$

$\begin{array}{ccccc}78^{7} & 78^{7} . & 78^{14} & 78^{7} & 140^{4}\end{array}$

$22^{2} \cdot 22^{2} \cdot 22^{4} \cdot 22^{2} \cdot 20^{36}$

1.

SHAC SHAC SHAC TOTAL SHAC TOTAL PPASS NALL HEAI HEOT COL COLL COMP MANOF MANU MANOF MANOF MANIJ MANIJF MANUF

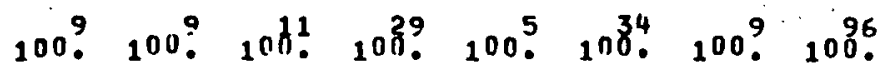

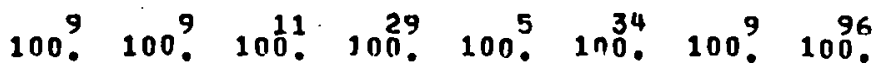
$78^{7} \quad 67^{6} \cdot 73^{8} \cdot 72^{21} \cdot 100^{5} \cdot 76^{26} \cdot 67^{6} \cdot 74^{71}$ $22^{2} \quad 33^{3} \cdot 27^{3} \cdot 28^{\circ} \quad 24^{8} \quad 33^{3} \cdot 25^{4}$.

$$
\begin{array}{rr}
100 . & 100 \% \\
220^{2} & 282 \\
70^{7} & 71 ? \\
& 1 ! \\
& 1 !
\end{array}
$$$$
100^{11} 100^{11} 1005100.251
$$$$
\text { 36. } 36^{4}, 40^{2}, 38^{6} \text {. } 41^{21} \text {. }
$$$$
64^{7} \cdot 64^{7} \cdot 60^{3} \cdot 63^{\frac{10}{0}} \text {. } 59^{30}
$$

100\% 1889

$1009100^{9} \cdot 100^{1} \cdot 100^{29} \cdot 1005100^{34}, 1006$

$100^{9} \cdot 98^{3}$.

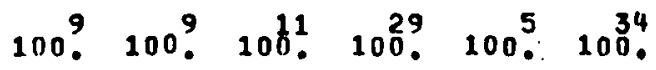

983

$6^{6}$

100. $1009.100^{8} .100$. 1801.

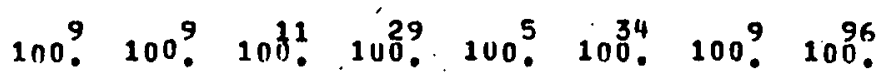

78.78 . $78^{4}, \quad 78^{7} \cdot 53$.

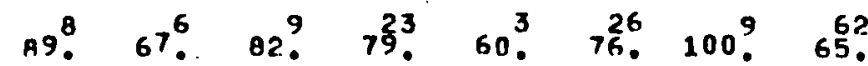

$22^{2} \cdot 22^{2} \cdot 22^{4}, \quad 22^{2} \cdot \quad 45^{82}$

11. $33^{3} \cdot 10^{2}, 211^{6} 40^{2} 24^{n}$ 32.

$2^{3}$

Figure F-1. Active Solar Heating and Cooling Data Tables (continued) 
ACTIVE SHAC + PASSIVE IEONTODI SHAC PASS SHAC BASS PUCH BUAC PASS' ALt

Q11113) US DEPT. OF ENERGY
1. YES
2. NO
B. DON?T KNOH

Q11(14) RADIO/IV

1. YES

$\stackrel{\omega}{*}$

2. NO

B. DON?T KNOW

\section{OHELESBAPERS TOOICALS, \\ 1. YES \\ 2. NO \\ B. DON'T KNOW}

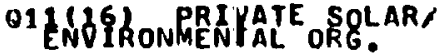

1. YES

2. NO

B. DON?T KNOW
(OCTOBER, 1979)

USE OF SELECTED SOLAR INFORMATION SOURCES - CONTINUEO IQUESTIOH 111

$$
\begin{aligned}
& \text { 100? 100? 100? 100? } 100 \text { ? } 100 \text { \% } 100^{63} \\
& 100^{9}, 100^{9}, 100^{9} 100^{9} \text {. } 1000^{9} 100^{9}, 100^{63} \text {. }
\end{aligned}
$$

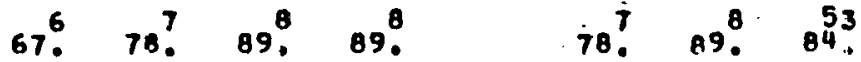

$$
\begin{aligned}
& 22^{2}, 22^{2} .11^{1} 11^{1} \\
& 11^{2} \\
& 22^{2} .11^{1} \cdot 16 .
\end{aligned}
$$

$$
\begin{array}{rrr}
100^{9} & 100 \text { ? } & 100 \text { ? } \\
22^{2} & 22^{2} & 560^{5} \\
73^{7} & 78^{7} & 44^{4}
\end{array}
$$

$1009.1009 .100^{62}$.

$56.57^{6} \cdot 53$.

$44^{4}$. $33^{3}, 45^{3}$.

2.

$$
\begin{array}{rrrr}
1009 & 1009 & 1009 & 1009 \\
09^{\circ} & 09^{\circ}, 1009 & 1009 \\
11 ! & 11^{2} & &
\end{array}
$$$$
1009.1000^{9} \cdot 100^{6} .
$$$$
\text { 89. } 1009 \text {. } 99^{6}:
$$$$
11 \text {. }
$$$$
3^{2}
$$

100. 100 . $100.100^{8}$. 56. $22^{2} \cdot \quad 4 \frac{19}{2} \cdot \quad 6 \frac{11}{2}$ 44. $78^{7}$. 56. 39 ? 2 .

SHAC PASS ALL ALL AGENT AGENT AGENT SPEC 100. 100? $100^{45} 100^{8}$. $100^{9} 1009.100 .100^{19}$ 56. $22^{2} .51^{23} . \quad 896$. 44. 78. 44. 11 ? 4.

Figure F-1. Active Solar Heating and Cooling Data Tables (continued)

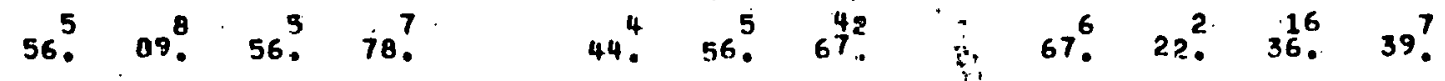

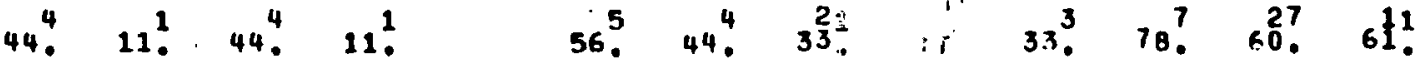

11 .

$4^{2}$ 
(OCTOBER, 1979$)$

USE OF SELECTED SOLAR INFORMATION SOURCES :- CONTINUED (QUESTION 11)

ACTIVE SHAC

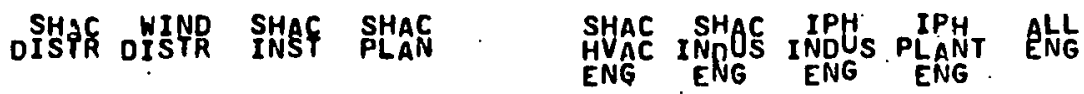

Q11(13) US DEPT. OF ENERGY

$$
\begin{array}{rrrr}
1009 & 1009 & 1009 & 1009 \\
1009 & 1009 & 1009 & 1009 \\
67^{6} & 78^{9} & 67^{6} & 100 \text { ? } \\
22^{2} & 22^{2} & 33^{3} & \\
11^{1} & & &
\end{array}
$$

1009.100 ? 1009 ? 1009 ? 1006 ?

1. YES

2. NO

8. DON'T KNOH

100 ? 100 ? 100 ? 1009 . 100 .

$44^{4} \quad 67^{6} \cdot 67^{6} \cdot 22^{2} .630$.

$44^{4} \quad 33^{3} \cdot 33^{3} \cdot 78$. $35^{34}$.

11 .

SHAC ALL NON-

UTIL SOLAR SOLAR

$100^{9} 100^{35} 100^{\circ}$

100 ? $100^{35} \cdot 100$ ?

67. $77^{27} .25$.

33. $23^{3}$. 6

$2^{2}$

Q11(14) RADIO/TV

1. YES

2. NO

100 ? 100 ?

56.56.

44. $44^{4}$.

100 .

590

41 ?

B. DON'T KNOW

Q11115 PAPERI ODICALSI.

1. YES

2. NO

8. DON'T KNOW

Q11 ENWTKONMENYAL OROLART

1. YES

2. No

8. DON'T KNOW

$\begin{array}{rrrr}1009 & 1009 & 1009 & 1009^{9} \\ 789^{7} & 78^{7} & 78^{7} & 899^{8} \\ 22^{2} & 22^{2} & 22^{2} & 11^{1}\end{array}$

$100^{9} .100$.

100 ? 100 ?

$100 \%$
$100 ?$

100 ? 100 ?

89. $100^{\circ}$.

11 .

$1009.1009 \cdot 1009.1009$. 1005

$100^{51}$

980

$2^{1}$

$100^{8} \cdot 100^{34} \cdot 100^{8}$

$100^{\circ} .94^{3} .100^{8}$.

$6^{2}$

33. $33^{3} . \quad 56.516^{2} . \quad 41^{39}$.

$56.57^{6} \cdot 44^{4}, \quad 89^{8} .586$.

Figure F-1. Active Solar Heating and Cooling Data Tables (continued)

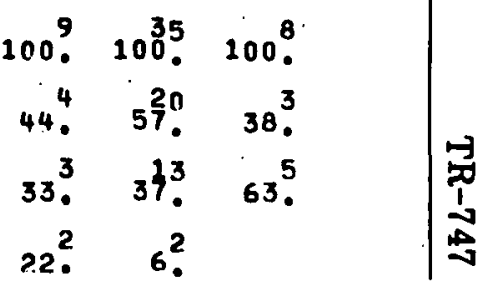


IOCTOBER, 1979$)$

USE OF SELECTED SOLAR IN=ORMATION SOURCES - CONTINUED (OUESTION 11 )

ACTIVE SHAC + PASSIVE

Q11117tES STATE ENERGY OF: SOLAR

1. YES

2. NO

8. DON T KNOW

OIIDERL GOVHEF STATEL SOORCE

1. YES

$\underset{\infty}{\infty}$

$$
\text { 2. NO }
$$

8. DON?T KNOW

O1ISOCIETY-ISES SOLAR ENEREY

1. YES

2. NO

B. DON?T KNOW
SHAC SHAC TOTAL FASS RLL

FUND FUND

100 ? 100 ? $100^{8} .1009$. 1801 $100 \% 100 \% 100.100 \% 1001$

$33^{3}, \quad 677^{6} \quad 500^{3} \quad 78 \%, \quad 486$

67. $33^{3} . \quad 500^{9} \quad 22^{2} \quad 52^{94}$

1.

$1009.100 \%$. $1070.1009 .160^{8}$.

$33^{3} \quad 56^{5} \quad 44^{\circ} \cdot 22^{2} \quad 28^{4}$.

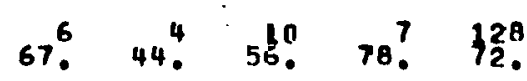

1.

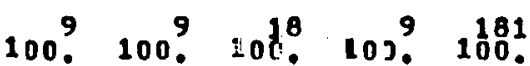

67. $78^{7}$. $77^{3} . \quad 89.987$.

33. $22^{2} .28 .211^{1} .51^{92}$

$1^{2}$

-100 . 100 . $100^{8} .10 c^{9}$. $100^{181}$

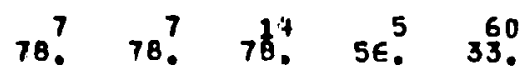

$22^{2} .222^{2}, \quad 32^{4}, \quad 44^{4}, \quad 65^{8}$.

SHAC SHAC SHAC TOTNL SHAZ TOTAL PPOSS AALLF HFA HEAT COL COL CUM: MANOF MANUF

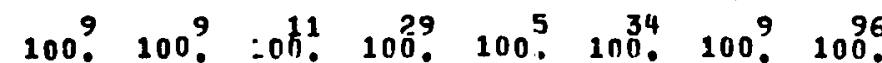
100 . 100, $100^{11}, 100,100,100^{29}, 100 \% 1006$

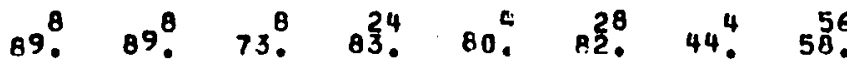

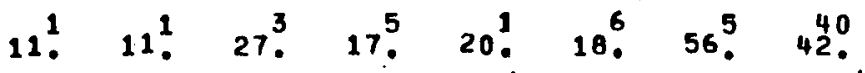
$100^{9} \cdot 100^{9}$. iof $100^{29} \cdot 100^{5} \cdot 100^{34}, 100^{9} \cdot 100^{9}$ $67^{6} \quad 44^{4} \cdot 55^{6} \cdot 55^{16} \quad 20^{1} \quad 50^{17} \quad 33^{3} \cdot 42^{40}$. $22^{2} \quad 56^{5} \quad 45^{5} \quad 41^{12} \quad 60^{4} \cdot 47^{6} \quad 67^{6} \quad 56^{4}$. $11^{1}$ 3. $\quad 3_{0}^{1}$ 2.

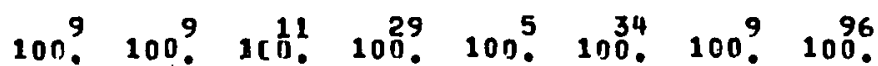

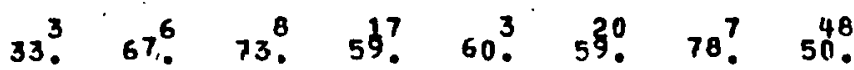

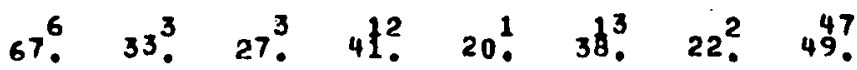
20.13 . 1 .

01 HNOOSTR SOLAR ENEERGY 1. YES

2. NO

B. DON T KNOW

Figure F-1. Active Solar Heating and Cooling Data Tables (continued)

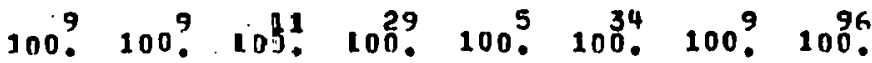

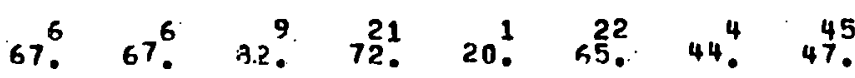

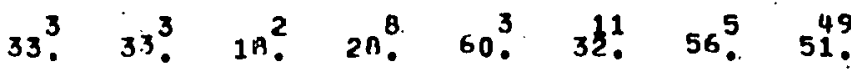
$20.13 .2 \quad 2^{2}$. 
IOCTOBER, 19791

USE OF SELECTED SOLAR INFORMATION SOURCES - CONTINUED (OUESTION 11 )

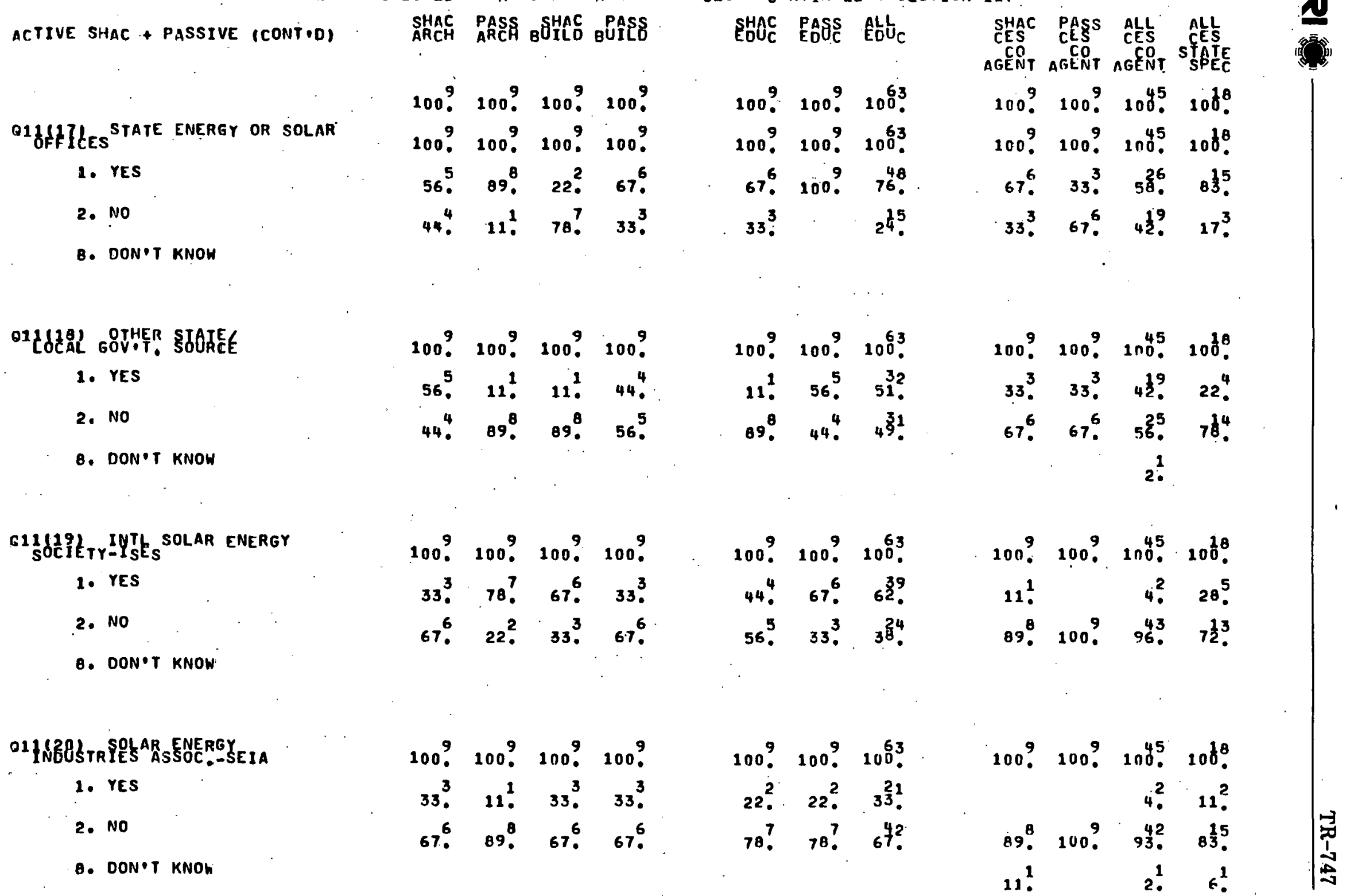

Figure F-1. Active Solar Heating and Cooling Data Tables (continued) 
(OCTOBER, 1979)

USE OF SELECTED SOLAR INFORMATION SOURCES - CONTINUED (QUESTION 11 )

ACTIVE SHAC

OIIIIZCES STATE ENERGY OR SOLAR

1. YES

2. No

8. DONיT KNOW

Q11(18) OTHER STATEE
LOCAL GOV'T. SOURCE

$$
\text { 1. YES }
$$

寓
2. No

8. DONIT KNOW

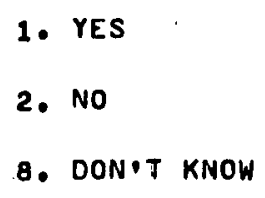

2. No

8. DON?T KNOW

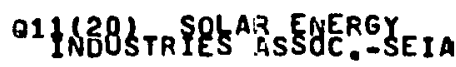
1. YES
2. NO
Q. DONDT KNOW

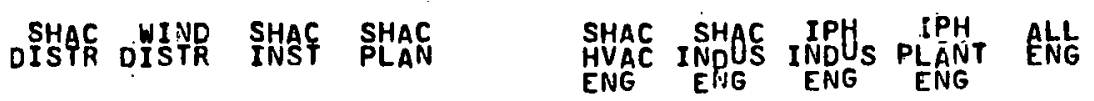

$$
\begin{aligned}
& 1009.103^{9} 100 \text {. } 1000^{9} \\
& 100 \text {. 1010. 100. 100? } \\
& \text { 67. } 56^{5} .100^{9} \text {. } 89^{8} \\
& \text { 33. } 33^{3} \text {. } \\
& 11^{1} \\
& 11 \text {. }
\end{aligned}
$$

100 . $100^{9}$. $1000^{9} 1009$. $100^{96}$

100 . 100 . 1009 . 1009 . $100^{96}$.

$22^{2} .89 .44^{4} \cdot 56.56^{5}$.

$78^{7}$

56.44 .440

$11^{1}$

$$
\begin{array}{rrrr}
100^{9} & 100^{9} & 1009 & 100{ }^{9} \\
44^{4} & 56^{5} & 33^{3} & 33^{3} \\
56^{5} & 33^{3} & 44^{4} & 67^{6} \\
& 11^{1} & 22^{2} &
\end{array}
$$

100 \%. 100, 100? 100 ?

67. $67^{5} .44^{4} \cdot 44^{4}$.

$22^{2}$. 11 ! $44^{4} .56$. $^{5}$

$11 ! 22^{2} \quad 11$.

100 . 1009. 1009. $1009.100^{9}$.

$22^{2}, \quad 33^{3}, 22^{2}, 11^{1} \quad 30^{29}$

$78^{?} \quad 67^{6} . \quad 78^{7} . \quad 39^{8} \quad 696$.

1 .

$100^{9} 1009$. $100^{9}, 1009.100^{96}$

$33^{3} .33^{3}$.

67. $67^{6} .100^{9}$. $09^{8} .63^{60}$.

100 . 100? 100 ? 100 ?

$56^{5} .22^{2} .55^{5} .56$.

44. 67. $33^{3} .44^{4}$.

11. 11 ?
SHAC ALL. NONUTII SOLAR SOLAR REPS REPS 100 . $100^{35} 100$. 100 . $100^{35} 100^{8}$. $78^{7} 71^{25} 63^{5}$ $22^{2} .2 \frac{10}{9} 3^{3}$. $2^{2}$.

Figure F-1. Active Solar Heating and Cooling Data Tables (continued) 
(OCTOBER, 19791

USE OF SELECTED SOLAR INFORMATION SOURCES - CONTINUEO (QUESTION 11 )

ACTIVE SHAC + PASSIVE

Q11 121 ) QUESTIONNAIRE SOURCE (AIA)

1009

1. VES

100 ?

2. No

8. DON?T KNOH

$22^{2}$

78 .

ध̈

Figuire F-1. Active Solar Heating and Cooling Data Tables (continued) 
USE OF SELECTED SOLAR INFORMATION SOURCES - CONTINUED IQUESTION 11 I

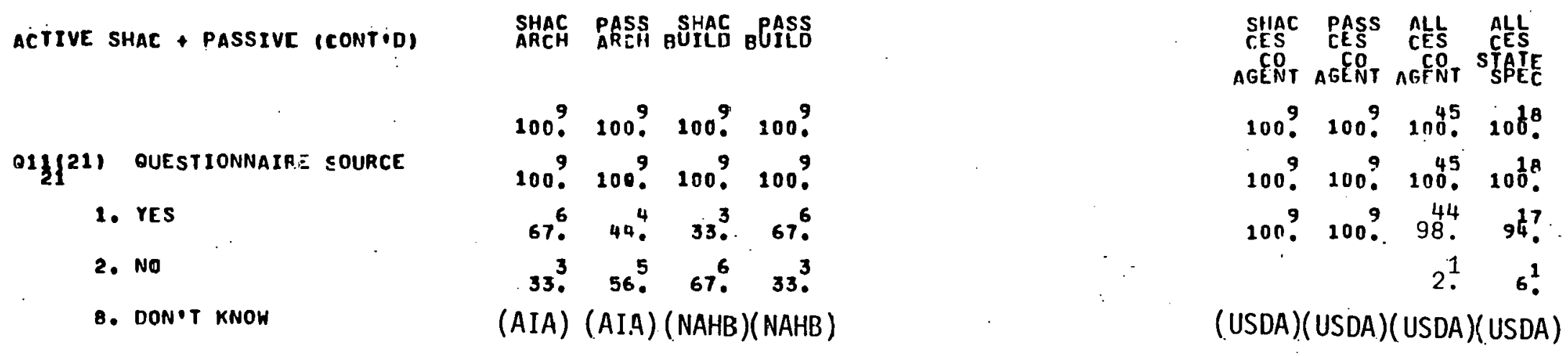

Figure F-1. Aclive Solar Heating and Cooling Data Tables (continued) 
(OCTOBER, 1979)

USE. OF SELECTED SOLAR INFORMATION SOURCES - CONTINUED (QUESTION 11)

ACTIVE SHAC

Q11 $\frac{1}{21}$ (21) QUESTIONNAIRE SOURCE

1. YES

2. NO

B. DON'T KNOW

O1 $\frac{1}{22}(22)$ OUESTIONNATRE SOURCE

$\mathscr{\omega}_{\omega}^{\omega}$

1. YES

2. No

B. DON'T KNOW

A $1 \frac{1}{23}(23)$ QUESTIONHAIRE SOURCE

1. YES

2. NO

8. CON T KNOW
DISTR INST PLAC

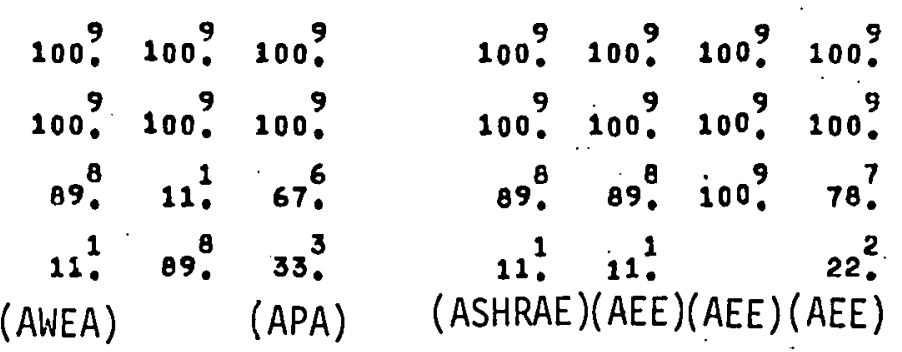

(SMACNA)

$$
\begin{aligned}
& \text { SHAC SALL NON- } \\
& \text { REPS UTIL UTIL } \\
& 100 \text { ? } 108^{35} 100 \text {. } \\
& 100^{\circ}, 100^{35} 100 \text {. } \\
& \text { 89. } 94^{33} .63^{5} \text {. } \\
& 11^{2} 6{ }^{2} \quad 38^{3} \text {. } \\
& \text { (EPRI) } \quad 3 \text { (EPRI) } \\
& \text { (EPRI) }
\end{aligned}
$$

Figure F-1. Active Solar Heating and Cooling Data Tables (continued) 
(OCTOBER, 1979$)$

$\mathbf{T}-051$

YEARS IN CURRENT PROFESSION (OUESTION D2B)

ACTIVE SHAC + FASSIVE

SHAC SHAC TOTAL PASS ALL

SHAC SHAC SHAC TOTAL SHAC TOTAL POSS MALL SPACE HATER NCONC SHAC OTHER SHOC EQUIP
MEAT REOT CDLL COUL COMP MANOF MANUF
MANOF MANOF MANJF MANUF MANUF

1. 0-2 YEARS

100 . 100. $100^{8}$. 100 ? 1801 .

11. $6^{1} .11^{2}$. 6 .

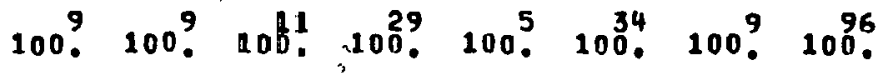

2. 3-5 YEARS

3. 6-10 VEARS

4. OVER 10

11. $11^{1} .11^{2} .222^{2} 195$.

$22^{2} .11^{2} \quad 33^{3}, 18^{33}$

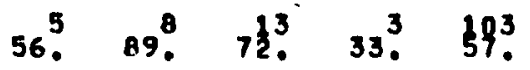

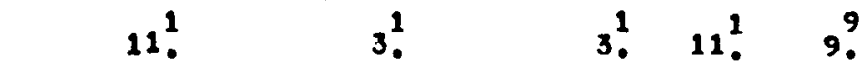

$22^{2} \quad 56^{5} .35^{4} \quad 38^{11} \quad 20 . \quad 35^{12} \quad 33^{3} \cdot 23^{22}$.

$22^{2} \quad 33^{3} \cdot 35^{9} \quad 31^{9} \cdot 20^{1} \quad 290.22^{2} \cdot 22^{21}$

$56^{5} . \quad 27^{3} \quad 28^{8} .60^{3} \quad 32^{12} \quad 33^{3} .46^{4}$.

Figure F-1. Active Solar Heating and Cooling Data Tables (continued) 
(OCTOBER, 1979)

YEARS IN CURRENT PROFESSION IQUESTION D2BI

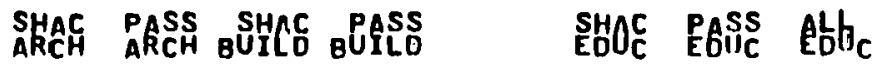

$\begin{array}{rrrrrrr}100^{9} & 100^{9} & 100^{9} & 1009 & 100^{9} & 100^{9} & 100^{63} \\ 11^{1} & 11^{1} & & 11^{1} & & & 2^{1} \\ 11^{1} & & & 33^{3} & 11^{1} & 11^{1} & 13^{8} \\ 22^{2} & 33^{3} & 67^{6} & 22^{2} & 33^{3} & 22^{2} & 21^{3} \\ 56^{5} & 56^{5} & 33^{3} & 33^{3} & 56^{5} & 67^{6} & 65^{4}\end{array}$

1. $0-2$ YEARS

2. 3-5 YEARS

3. 6-10 YEARS

4. OVER 10
DON'T KNOW/NA

ACTIVE SHAC + PASSIVE (CONTPD)

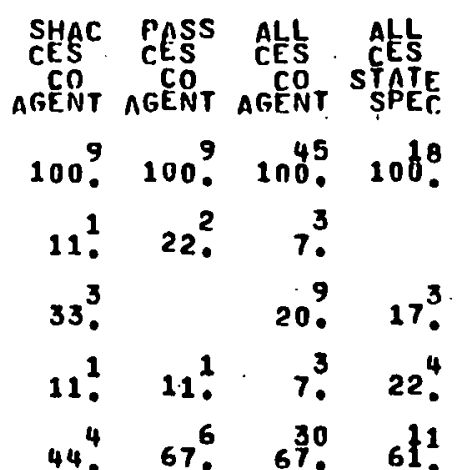

Figure F-1. Active Solar Heating and Cooling Data Tables (continued) 
COC-OBER, 19791

YEARS IN CLIRPENT PROFESSION IOUESTION D2BI DIISAC DISTTR IMAC SHAC PAT

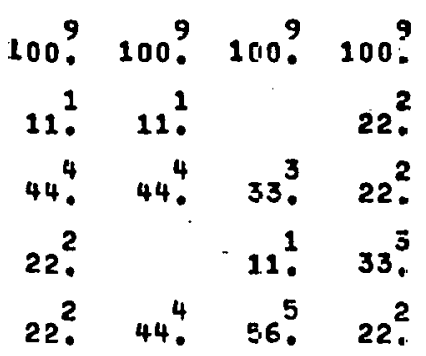

$1009.1009 .1009 .100 \% 100^{9}$

UHAC SOLL NONA SOLAR F.EPS UTIL UTIL

1. 0-2 YEARS

2. 3-5 YEARS

3. 6-10 VEARS

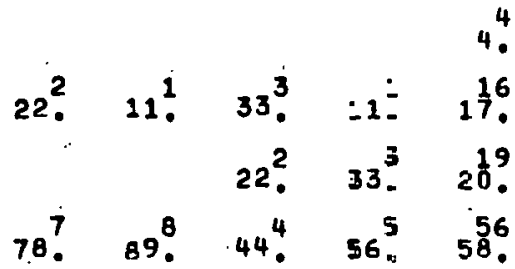
$100^{9} \cdot 108^{3} \cdot 100^{8}$ 33

1 .

Figure F-1. Active Solar Heating and Cooling Data Tables (continued) 


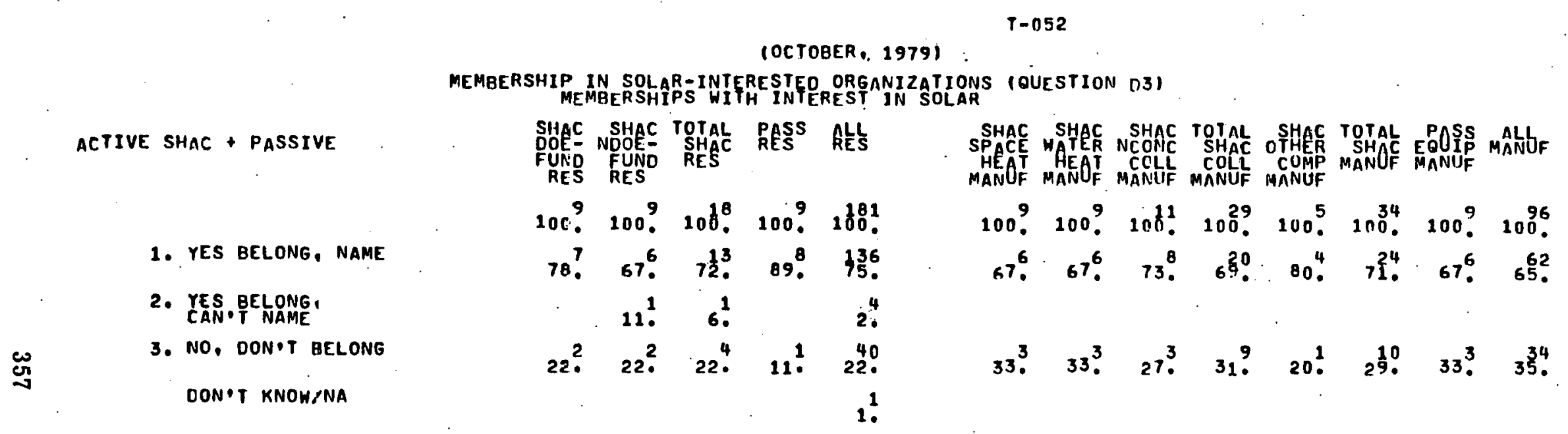

Figure F-1. Active Solar Heating and Cooling Data Tables (continued) 
Figure F-1. Active Solar Heating and Cooling Data Tables (continued) 


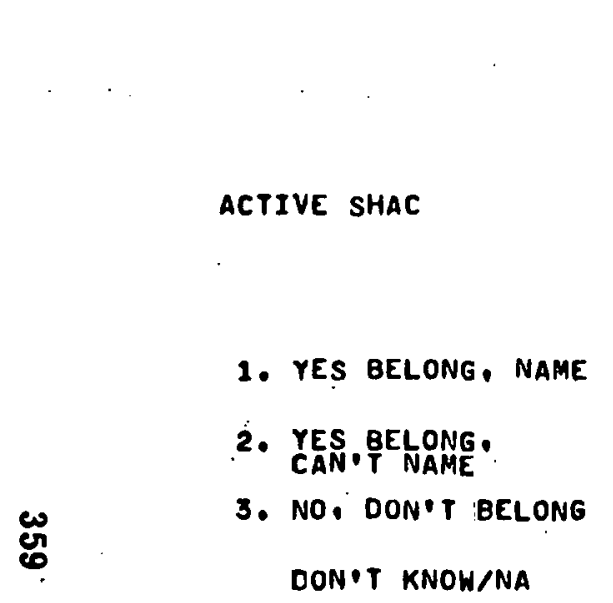

$$
\begin{gathered}
\text { (OCTOBER, } 19791 \\
\text { MEMBERSHIP IN SOLAR-INTERESTEO ORGAWIZATIONS (QUESTION D3) }
\end{gathered}
$$

\begin{tabular}{|c|c|c|c|c|c|c|c|c|c|c|c|}
\hline $\begin{array}{l}\text { SHAC } \\
\text { OISTR }\end{array}$ & $\begin{array}{l}\text { HIND } \\
\text { OISTR }\end{array}$ & $\begin{array}{l}\text { SHAC } \\
\text { INS }\end{array}$ & SHAAF & $\begin{array}{l}\text { SHAC } \\
\text { HVAE } \\
\text { ENG }\end{array}$ & $\begin{array}{c}\text { INHACC } \\
\text { ENG }\end{array}$ & $\underset{\text { ENG }}{\text { IPOH }}$ & $\begin{array}{c}\text { IPH } \\
\text { PLANT } \\
\text { ENG }\end{array}$ & ALL & $\begin{array}{l}\text { SHAE } \\
\text { UTII } \\
\text { REPS }\end{array}$ & $\begin{array}{l}\text { ALL } \\
\text { SOLAR } \\
\text { UTI } \\
\text { REPS }\end{array}$ & $\begin{array}{l}\text { NON- } \\
\text { SOLAAR } \\
\text { WTII } \\
\text { REPS }\end{array}$ \\
\hline 1009 & $1000^{\circ}$ & $100^{\circ}$ & $1000^{9}$ & 100 ? & 1009 & $1000^{\circ}$ & $100^{\circ}$ & 1096 & $100^{\circ}$ & 1085 & $100^{8}$ \\
\hline $67^{6}$ & $67^{6}$. & 78 ? $^{7}$ & $67^{6}$ & 1009 & $100{ }^{9}$ & $780^{7}$ & $78{ }^{7}$ & 841 & $78^{7}$ & 69. & $63^{5}$ \\
\hline $33^{3}$ & $33^{3}$ & $22^{2}$ & $33^{3}$ & & & $22^{2}$ & $22^{2}$ & $15^{4}$ & $11^{1}$ & $23^{8}$ & $38^{3}$. \\
\hline
\end{tabular}

\section{MEMBERSHIP IN SOLAR-INTERESTED ORGANIZATIONS (QUESTION D3)}

Figure F-1. Active Solar Heating and Cooling Data Tables (continued) 


\begin{tabular}{|c|c|c|c|c|c|c|c|}
\hline \multirow[b]{2}{*}{ USERS } & \multicolumn{7}{|c|}{ (OCTOBER, 1979) } \\
\hline & & $\begin{array}{l}\text { PASS } \\
\text { HOME- } \\
\text { OWNER }\end{array}$ & $\begin{array}{l}\text { SHAC } \\
\text { SPACE } \\
\text { HOAEE } \\
\text { OWNER }\end{array}$ & $\begin{array}{l}\text { SHAC TOTAL } \\
\text { WATER SHAC } \\
\text { HOMAE HOME } \\
\text { OWNER OWNER R }\end{array}$ & 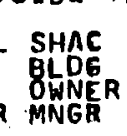 & $\begin{array}{l}\text { TOTAL } \\
\text { SHAC } \\
\text { OWNER } \\
\text { MNGR }\end{array}$ & \\
\hline & & $=009$. & 1009 & $1009.100^{10}$ & 100? & $100 ?$ & \\
\hline YES FOR JOB & & 56. & 78. & $67 . \quad 72^{3}$ & $67^{6}$. & 70 & \\
\hline NO FOR JOB & & $33^{3}$. & $22^{2}$. & $33^{3} .280^{5}$ & $22^{2}$. & $26 ?$ & \\
\hline DONיT KNOW/NA & & 11. & & & 11. & 4. & \\
\hline 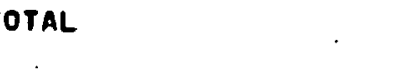 & & $100 \%$ & 100. & $1000^{9} 108^{8}$ & $100^{\circ}$ & $10 \%$ & \\
\hline YES CUTSIOE JDB & & 44. & $789^{7}$ & $11^{1} .44^{8}$ & $22^{2}$ & 37. & \\
\hline NO OUTSIDE JOB & & 44. & $22^{2}$. & 78 . 50 . & $67^{6}$. & $\begin{array}{l}15 \\
56 .\end{array}$ & \\
\hline DOV'1 KNOW/NA & & $11{ }^{2}$ & & 11. & 11 & $7^{2}$ & \\
\hline YES, JOB + OUTSIDE & & $44{ }^{4}$ & 56.5 & $11^{1} .33^{6}$ & $111^{\prime}$ & $26 ?^{\top}$ & \\
\hline
\end{tabular}

Figure F-1. Aclive Solar Heating and Cooling Data Tables (continued) 


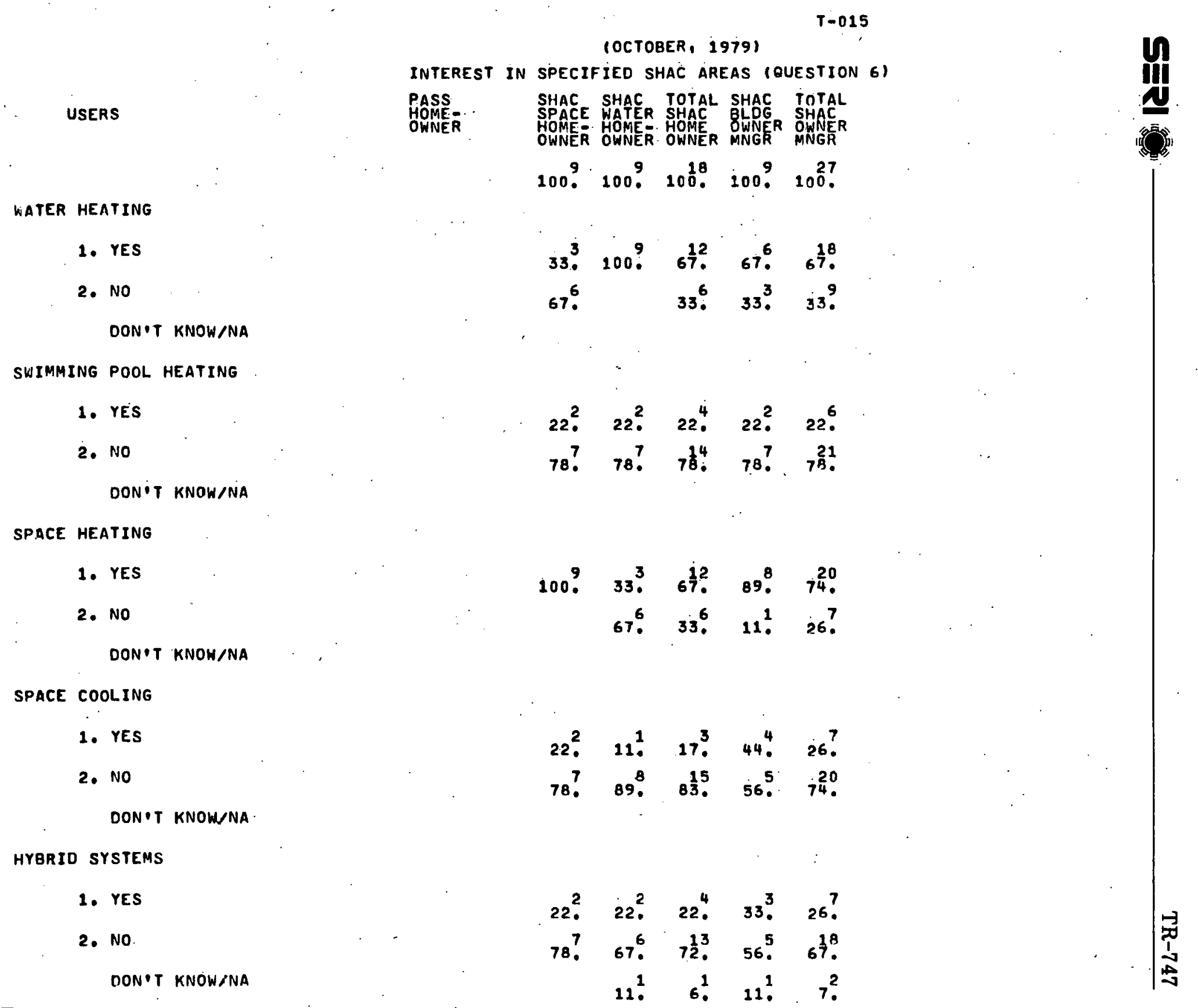

Figure F-1. Active Solar Heating and Cooling Data Tables (continued) 
COCTOBER, 19791

LISEFULNESS OF SPECIFIED INFORMATION ITEMS (NUESTION B.)

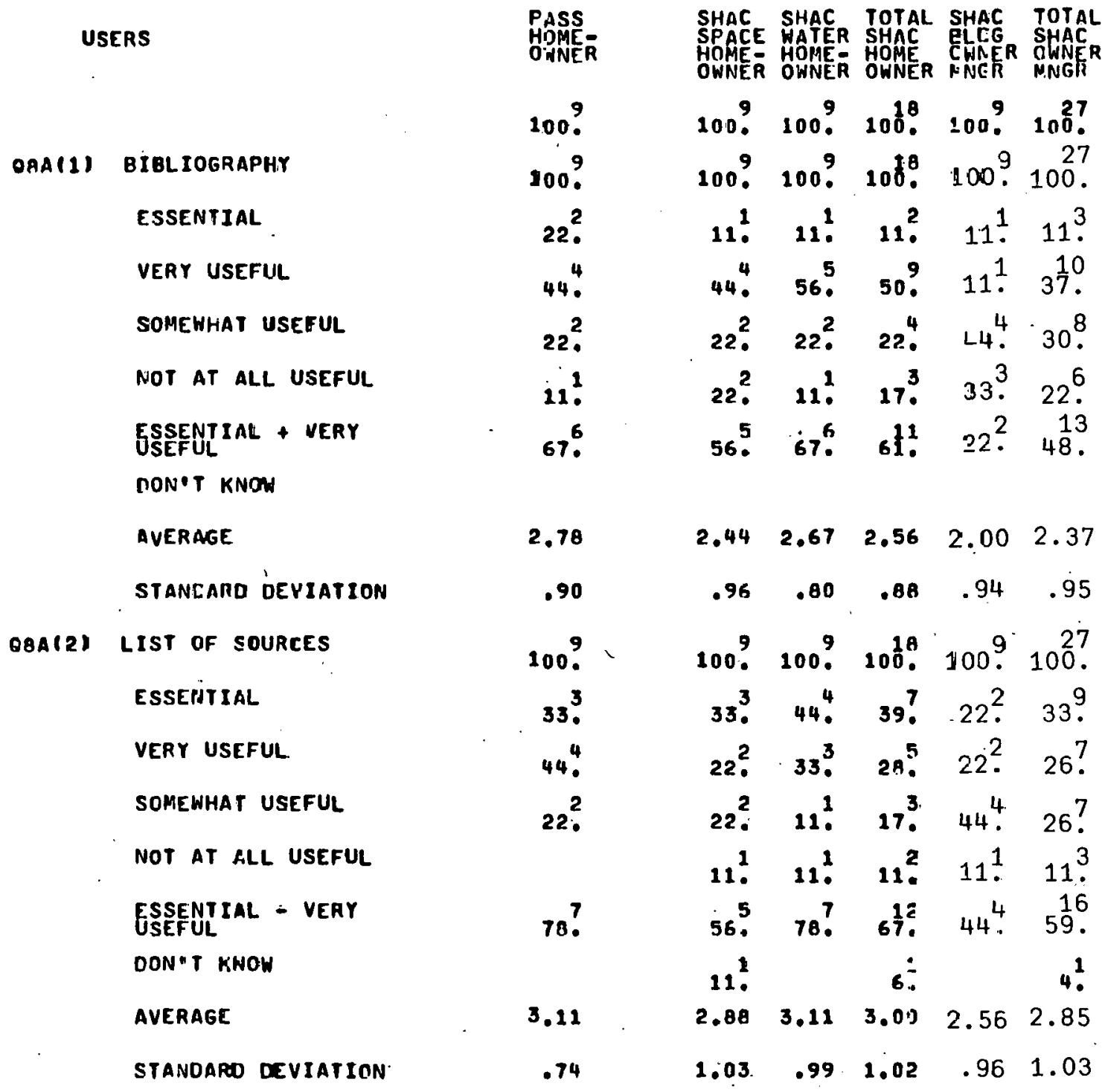


(OCTOBER; 1979$)$

USEFULNESS OF SPECIFIED INFORMATION ITEMS - CONTINUED (QUESTION $\theta$ )

USERS

OBÁPB́ ĆRALENDAR-CONFERENCES/

ESSENTIAL

VEAY USEFUL

SOMEWHAT USEFUL

NOT AT ALL USEFUL

ESSENTIAL + VEMY

DON T KNOH

AVERAGE

STANDARD DEVIATION

OAAI4) DIAGRAMS/SCHEMATICS

ESSENTIAL

VERY USEFUL

SOMEHHAT USEFUL

NOT AT ALL USEFUL

ESSENTIAL + VERY

DON'T KNOW

AVERAGE

STANDARU OEVIATION
PASS.

HOME:

$100^{\circ}$

100 ?

11 .

$22^{2}$

$33^{3}$

33 .

33 .

2.11

.99

100 ?

$22^{2}$.

44.

11.

$22^{2}$

$67^{6}$.

2.67

1.04
SHAC SHAC TOTAL SHAC TRTAL

HOME HOME HOME OWNER OWNER

100 . 100 . $108^{8} .100$. 100 ?

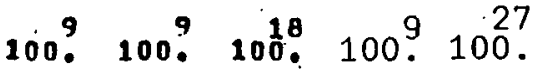

$11 . \quad 333^{3} .222^{4}, \quad 15$.

$33^{3} \cdot 111^{3}$

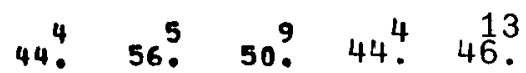

$22.2 \quad 11.217^{3} \cdot 22.218$.

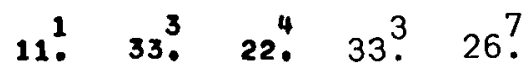

$22^{2} . \quad 110^{2} \quad-8.2$

$\begin{array}{lllll}2.00 & 2.56 & 2.31 & 2.11 & 2.24\end{array}$

$\begin{array}{llllll}.92 & 1.05 & 1.04 & .74 & .95\end{array}$

100. 100 . $100^{8} .100 .927$.

$22^{2} .44^{4}, \quad 33^{6} \cdot 33^{3} .33^{9}$.

33. $\quad 11.222^{4} . \quad 11 ! \quad 18$.

33. $\quad \mathbf{1 1}^{1}, \quad 22^{4} .22$. $222^{6}$

33. $\quad 213^{3} \quad 33^{3} \quad 222^{6}$.

$56^{5} \cdot \quad 56^{5} . \quad 6^{10} \cdot \quad 44^{4} \quad 52$.

$11^{2} \quad 6_{0}^{1} \quad 4^{2}$.

$\begin{array}{llllll}2.88 & 2.67 & 2.76 & 2.44 & 2.65\end{array}$

$\begin{array}{lllll}.76 & 1.32 & 1.12 & 1.26 & 1.17\end{array}$

SCALE: ESSENTIAL $=4$, VERY USEFUL $=3$, SOMEWHAT USEFUL $=2$, NOT AT ALL USEFLL $=1$

Figure F-1. Active Solar Heating and Cooling Data Tables (continued) 
(OCTOBER, 1979)

USEFULNESS OF SPECIFIED INFORMATION ITEMS - CONTINUED (OUESTION 8 )

USERS

QRACSI MONETECHNICAL

ESSENTIAL

VERY USEFUL

SOREWHAT USEFUL

NOT AT ALL USEFUL

ESSENTIAL + VERY

DON'T KMOW

AVERAGE

STANDARL DEVIATION

PAS.S

SHAC SHAC TOTAL SHAC TOTAL

OWNER

HOMAE HOHE HOME CLWG SWAC

$100 \%$ 100? 100 \% $100^{13}, 100$ \% $100 \%$

$100^{9} \quad 100^{9} .100^{9} \cdot 100^{8}, 100^{9} \cdot 10^{27}$.

$22^{2} \quad 22^{2} \cdot 33^{3} \cdot 28^{5} \cdot 33^{3} \cdot 30^{8}$

33. $33^{3}$ 11. 22. $56^{5} .33^{9}$

22. $33^{3}+17^{3}=1^{3}$

$22^{2} \quad 33^{3} \cdot 22^{2} \quad 28^{\circ} \quad 11^{1} \cdot 22^{6}$

56. $56^{5} \cdot 44^{4} \quad 50^{9} \cdot \varepsilon 9^{8} \cdot 6{ }^{\frac{1}{3}}$.

$11^{1}$. 6 ? 4 ?

$2.50 \quad 2.56 \quad 2.53 \quad 3.11 \quad 2.73$

2.56

1.05

$\begin{array}{lllll}1.22 & 1.15 & 1.19 & .87 & 1.13\end{array}$

QBA(G) TECHAICAL DESCRIPTION

ESSENTIAL

NEAT USEFUL

SOMEWHAT USEFUL

MOT AT ALL USEFUL.

ESSENTLAL + VERY

CHON T KNOW

$100 \%$ 100? $100^{9} \cdot 10^{18} \cdot 100^{9} \cdot 10^{2}$.

44. $44^{4} \cdot 11^{1} \cdot 28^{5} \cdot 3.3^{3} \cdot 30^{8}$.

33. $\quad 11^{1} \cdot 33^{3} \cdot 22^{4} \cdot 22^{2} \cdot 22^{6}$

$22^{2} \cdot \quad 22^{2} \cdot 33^{3} \cdot 28^{5} \cdot 33^{3} \cdot 30^{8}$.

11. $22^{2}$. $17.31 \div \quad 15^{4}$

$78^{7} \quad 56^{5} \quad 44^{4} \quad 50^{9} .56^{5} 52^{-4}$.

AYERAGE

3.22

11.261

STIANDARD DEVIATION

.79

$\begin{array}{llllll}3.00 & 2.33 & 2.65 & 2.78 & 2.59\end{array}$

$\begin{array}{lllll}1.11 & .95 & 1.07 & 1.03 & 1.07\end{array}$

SCALE: ESSENTIAL $=4$, VEAY USEFUL $=3$, SOMEWHAT USEFUL $=2$, NOT AT ALL USEFUL $=1$

Figure F-1. Active Solar Heating and Cooling Data Tables (continued) 
COCTOBER, 19791

USEFULNESS OF SPECIFIED INFORMATION ITEMS - CONTINUED (QUESTION O)

USERS

PASS SHAC SHAC TOTAL SHAC TOTAL

HOME- SPACE WATER SHAC OLDG SHAC

HOME- HOME- HOME OWNER OWNER

OAAITI LISTS OF SUPPLIERS

ESSENTIAL

VERY USEFUL

SOMEWHAT USEFUL.

NOT AT MLL USEFUL

ESSENTIAL + VERY

DON'T KNOW

AVERAGE

STANOARD DEVIATION

QRA(B) HANOBOOKS/TABLCS

ESSENTIAL

VERY USEFUL

SOMEWHAT USEFUL

NOT AT ALL USEFUL

ESSENTINL + VERY

DON'T KNOW

AVERAGE

STANOARD DEVIATION
100?. 100 ? 100 ? $100^{\circ}$. 100 ? $100^{2}$ ?

1009. 100? 100 ? $100^{18}, 100$ ? 100 .

$11^{1} \quad 44^{4} \cdot 67^{6} \cdot 56^{10}, 67 \% 59$.

44. $\quad 33^{3} .11^{2} \cdot 22^{4} .11^{1} \quad 18^{5}$.

33. $\quad 22^{2} \cdot 11^{2} \cdot 17^{3} \cdot 22^{2} \cdot 18^{5}$.

11. 111 6. $6^{1}$.

56. $\quad 70^{7} \cdot 78^{7} \quad 78^{\frac{1}{4}} \quad 78^{7} \cdot 78^{2}$ !

$\begin{array}{llllll}2.56 & 3.22 & 3.33 & 3.28 & 3.44 & 3.33\end{array}$

.81

$\begin{array}{lllll}.79 & 1.06 & .92 & .83 & .90\end{array}$

$100^{9}$

$100^{9}, 100 \% 100^{17} 100^{9} \cdot 100^{26}$.

$33^{3}$

44.

$11^{2}$

11 .

78 .

56. $13^{1} .35^{6} .33^{3} .35^{9}$.

$22^{2} .38^{3} .29^{5} .11^{1} .23$.

$38^{3} \cdot 183^{3} \cdot 33^{3} \cdot 23^{6}$.

11. 13. 12. $22^{2} .15^{4}$.

$78^{7} 50^{4} .65^{11}, 44^{4} .56$.

11 1. 6 ! 4 !

$\begin{array}{lllll}3.38 & 2.50 & 2.94 & 2.56 \cdot 2.80\end{array}$

$\begin{array}{lllll}.97 & .86 & 1.02 & 1.17 & 1.10\end{array}$

SCALE: ESSENTIAL $=4$, VERY USEFUL $=3$, SOMEHHAT USEFUL $=2$, NOT AT ALL USEFUL $=1$

Figure F-1. Active Solar Heating and Cooling Data Tables (continued) 
IOCTOBER, 19791

USEFULNESS OF SPECIFIED INFORMATION ITEMS - COVTINUED (OUESTION AI

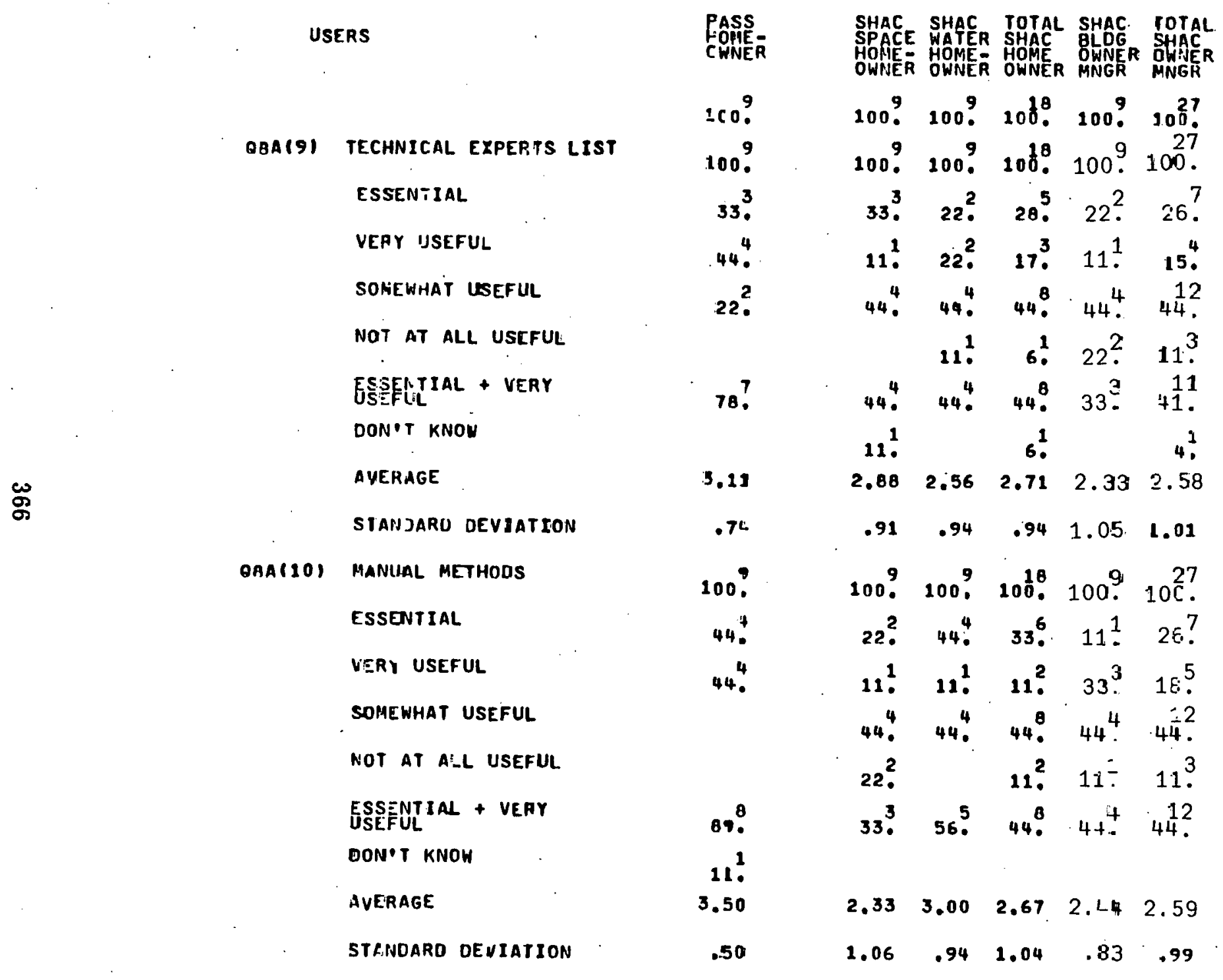

SCALE: ESSEWTIAL $=4$, VERY USEFUL $=3$, SOMEWHAT USEFUL $=2$, NOT AT ALL, USEFUL $=1$

Figure F-1. Active Solar Heating and Cooling Data Tables (continued) 


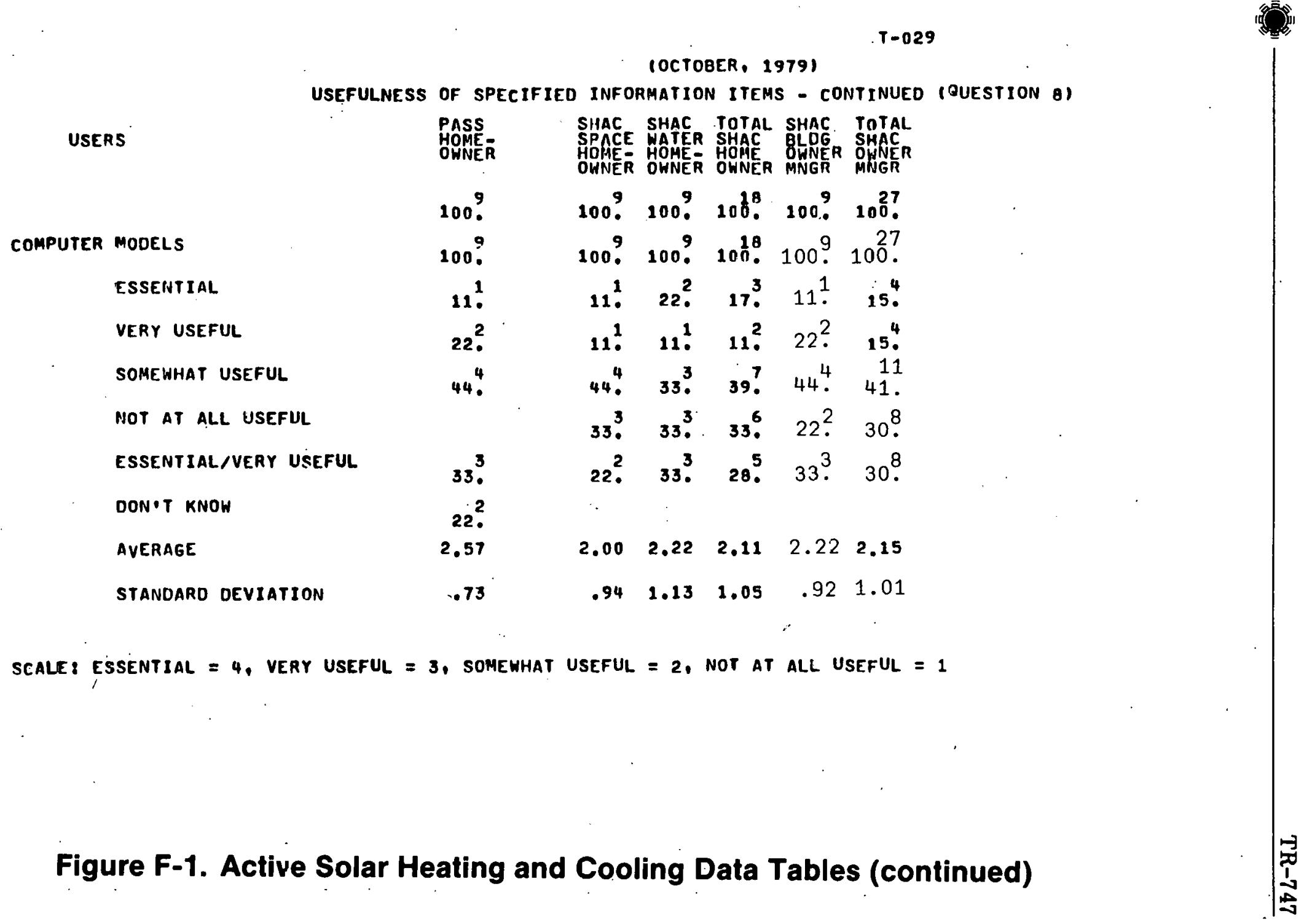


IOCTOBER, 19791

USEFULNESS OF SPECIFIED INFORMATION ITEMS - CONTINUED (QUESTIJN B)

USERS

PASS SHAC SHAC TOTAL SHAC TOTAL

HOME- SPACE WATER SHAC BLpG SHAC

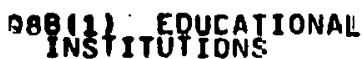

100 ? $1000^{9} 100^{9} \cdot 100^{8} .100 \% 100^{2}$.

$100^{\circ} \quad 100 \% 100^{\circ} .100^{\circ} .100 \% 100$.

ESSEMTIAL

VEPY USEFUL

SGMEHHAT USEFUL

NOT MT ALL USEFUL

11. $11 . .622^{1}$. $11^{3}$.

67. $\quad 11^{1} \cdot 22^{2} \cdot 17^{3} \cdot 22^{2} \quad 18^{5}$.

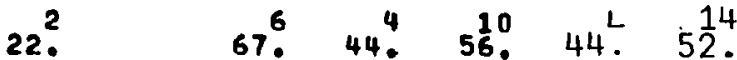

ESSEETIAL + VERT

DOW'T KNOW

11. $33^{3} .222^{4} .11 \div 18^{5}$

78. $\quad 22^{2} . \quad 22^{2} . \quad 22^{4} . \quad 44^{2} . \quad 30^{8}$.

AVERAGE

STANDARD DEVIATION

2.89

$\begin{array}{llllll}2.22 & 1.89 & 2.06 & 2.56 & 2.22\end{array}$

.56

$\begin{array}{lllll}.79 & .73 & .76 & .96 & .87\end{array}$

Q8B(2) RESEARCH IN PROGAESS

ESSENTIAL

VEFYY JSEFUL

SO:UEW TAT USEFUL

NOI AT ALL USEFUL

ESEERTIIAL + VERT

DON'T KNOW

$100^{9} \cdot 100^{9} 100^{9} \cdot 10^{18} . \quad 10^{18}$.

56. $22^{2} .11^{2}$ 11.

33. $33^{3} \cdot 33^{3} \quad 33^{6} \cdot 33^{6}$

11. $22^{2}, 44^{4} \cdot 33^{6} . \quad 33^{6}$.

$22^{2} 22^{2} 222^{4}$. $22^{4}$.

89. $\quad 56^{\circ} \cdot 33^{3} \quad 44^{\circ}$.

AVERAGE

3.44

$2.56 \quad 2.11 \quad 2.33$

2.33

STANDARO OEVIATION

.70

$1.05 .74 \quad .95$

.94

SCALE: ESSERTIAL $=4$, VEFY USEFUL $=3$, SOMERHAT USEFUL $=2$, NOT AT ALL JSEFUL $=1$

Figure F-1. Active Solar Heating and Cooling Data Tables (continued) 
(OCTOBER, 1979 )

USEFULNESS OF SPECIFIED INFORMATION ITEMS - CONTINUEO (OUESTION \&)

USERS

\begin{tabular}{|c|c|c|c|c|c|c|c|}
\hline \multirow[t]{9}{*}{$A B B(3)$} & STATE OF ART & 100 ? & 100 ? & 100 ? & $100^{18}$ & $100 ?$ & 100 . \\
\hline & ESSENTIAL & $33^{3}$. & $22^{2}$ & $11{ }^{2}$ & $17^{3}$ & $11^{1}$ & $15^{4}$ \\
\hline & VERY USEFUL & $33^{3}$ & $67^{6}$ & $33^{3}$ & 50 ? & $11^{1}$ & $\begin{array}{l}10 \\
37\end{array}$ \\
\hline & SOMEWHAT USEFUL & $22^{2}$ & & $22^{2}$. & $11^{2}$ & $44^{4}$ & $22^{6}$ \\
\hline & NOT AT ALL USEFUL & & & $33^{3}$ & $17{ }^{3}$ & $33^{3}$. & $22^{6}$ \\
\hline & $\begin{array}{l}\text { ESSENTILL + VERY } \\
\text { USEFUL }\end{array}$ & $67^{6}$. & $899^{8}$ & $44^{4}$ & $67^{2}$ & $22^{2}$ & $5 \frac{14}{2}$ \\
\hline & DON'T KNOW & $11 !$ & $11 !$ & & $6 !$ & & $4 !$ \\
\hline & AVERAGE & 3.13 & 3.25 & 2.22 & 2.71 & 2.00 & 2.46 \\
\hline & STANUARD DEVIATION & .76 & .43 & 1.03 & .94 & .94 & 1.01 \\
\hline \multirow[t]{9}{*}{ QAB (4) } & COSTS/PERFORMANCE & $\therefore 1009$ & 1009 & $100{ }^{9}$ & $100^{18}$ & $100^{9}$ & $\begin{array}{l}27 \\
100\end{array}$ \\
\hline & ESSENTIAL & 56. & 56. & $33^{3}$ & $44^{8}$. & $67^{6}$ & 52 \\
\hline & VERY USEFUL & $33^{3}$ & $33^{3}$ & $22^{2}$ & $28^{5}$ & $22^{2}$ & $26^{7}$ \\
\hline & SOMEWHAT USEFUL & $11^{1}$ & $11^{1}$ & $33^{3}$ & $22^{4}$. & & $15^{4}$ \\
\hline & NOT AT ALL USEFUL & & & 11 & $6 !$ & $11^{1}$ & $7^{2}$ \\
\hline & $\begin{array}{l}\text { ESSENTIAL + VERY } \\
\text { USEFUL }\end{array}$ & 89. & 89. & 56.5 & 72 & $89^{8}$ & $\begin{array}{r}21 \\
78\end{array}$ \\
\hline & DON'T KNOW & & & & & & \\
\hline & AVERAGE & 3.44 & 3.44 & 2.78 & 3.11 & 3.44 & 3.22 \\
\hline & STANOARD DEVIATION & .70 & .70 & 1.02 & .94 & .96 & .96 \\
\hline
\end{tabular}

SCALE: ESSENTIIAL $=4$, VERY USEFUL $=3$, SOMEHHAT USEFUL $=2$, NOT AT ALL USEFUL $=1$

$\begin{array}{ll}\text { PASS } & \text { SHAC SHAC TOTAL SHAC INTAL } \\ \text { HOME- } & \text { SPACE WATER SHAC OQDG SHAC } \\ \text { OWNER } & \text { HOMEE HOME HOME OWNER OHNER } \\ \text { OWNER OWNER OWNER MNGR MNGR }\end{array}$

$\begin{array}{ll}\text { PASS } & \text { SHAC SHAC TOTAL SHAC TRTAL } \\ \text { HOME- } & \text { SPACE WATER SHAC OLLG SHAC } \\ \text { OWNER } & \text { HOME HOME HOME OWNER OWNER } \\ \text { OWNE OWNER OWNER MNGR MNGR }\end{array}$

100? 100 ? 100 ? $100^{18}, 100$ ? 1002 ?

$100^{9} \cdot 100^{9} \cdot 10^{18} \cdot 1009.100^{27}$.

$22.11^{2} \cdot 17^{3} \cdot 11^{1} \cdot 15^{4}$

$67^{6} \quad 33^{3} \cdot 50^{9} \cdot 11^{1} .37$.

ESSENTIAL + VERY

1

AVERAGE 
(OCTOBER, 1979$)$

USEFULNESS OF SPECIFIED INFORPATION ITEMS - GONTINUED (DUESTION $n$ )

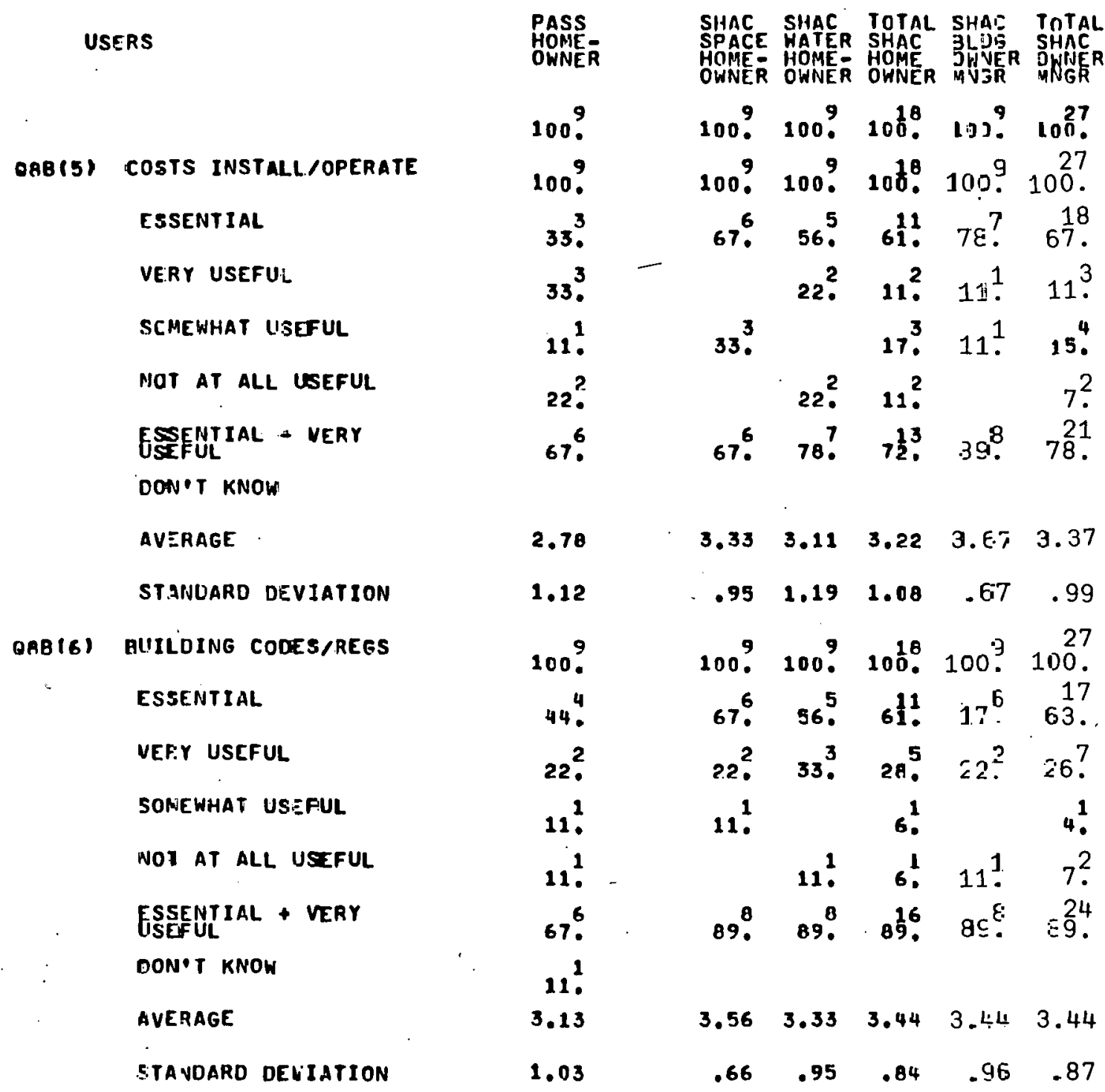


(OCTOBER, 19791

USEFULNESS OF SPECIFIED INFORMATION ITEMS - CONTINUED (QUESTION B)

\begin{tabular}{|c|c|c|c|c|c|c|c|}
\hline \multicolumn{2}{|c|}{ USERS } & \multirow{2}{*}{$\begin{array}{c}\text { PASS } \\
\text { HOME- } \\
\text { OWNER } \\
1009\end{array}$} & \multirow{2}{*}{$\begin{array}{c}\text { SHAC } \\
\text { SPACE } \\
\text { HOME } \\
\text { OWNEA } \\
100^{9} \\
1\end{array}$} & \multirow{2}{*}{$\begin{array}{c}\text { SHAC } \\
\text { HAIVR } \\
\text { HOMEE } \\
\text { OWNER } \\
100^{9} .\end{array}$} & \multirow{2}{*}{$\begin{array}{c}\text { TOTAL } \\
\text { SHAC } \\
\text { HOOME } \\
\text { OWNER } \\
1018 \\
100 .\end{array}$} & \multirow{2}{*}{ 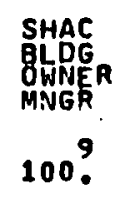 } & \multirow{2}{*}{$\begin{array}{c}\text { TOTAL } \\
\text { SHAC } \\
\text { ONAER } \\
\text { MNGR } \\
\text { 20? } \\
100 .\end{array}$} \\
\hline & & & & & & & \\
\hline QAB $(7)$ & TAX/ECONOMIC INCENTIVE & 1009 & $100{ }^{9}$ & $100 \%$ & 100 & $100^{9}$ & 100. \\
\hline & ESSENTIIAL & $44^{4}$. & $44^{4}$ & 56. & 50 ? & $56^{5}$ & 52 \\
\hline & VERY USEFUL & $22^{2}$ & $22^{2}$ & $44^{4}$. & $33^{6}$ & $22^{2}$ & $30^{8}$ \\
\hline & SOMEWHAT USEFUL & 11 . & $22^{2}$ & & $11^{2}$ & $22^{2}$ & $15^{4}$ \\
\hline & NOT AT ALL USEFUL & $22^{2}$ & $11 !$ & & $6 !$ & & 4. \\
\hline & $\begin{array}{l}\text { ESSENTIAL * VEAY } \\
\text { USEEFL }\end{array}$ & $67^{6}$. & $67^{6}$. & 1009 & $83^{15}$ & $78 ?$ & 822 \\
\hline & DON'T KNOW & & & & & & \\
\hline & AVERAGE & 2.89 & 3.0 .0 & 3.56 & 3.28 & 3.33 & .3 .30 \\
\hline ' & STANDARD DEVIATION & 1.19 & 1.05 & .46 & .86 & .82 & .85 \\
\hline $08 B(8)$ & STANDARDS/SPECS & 100 ? & 1009 & 1009 & $100^{18}$ & 1009 & 100. \\
\hline & ESSENTIAL & & $22^{2}$ & $44^{4}$. & $33^{6}$ & $22^{2}$ & $30^{8}$ \\
\hline & VERY USEFUL & $33^{3}$ & $33^{3}$ & $22^{2}$ & $28^{5}$ & $44^{4}$. & $33^{9}$ \\
\hline & SOMEWHAT USEFUL & $33^{3}$ & $22^{2}$ & $11^{1}$ & $17^{3}$ & $22^{2}$ & $18^{5}$ \\
\hline & NOT AT ALL USEFUL & $22^{2}$ & $22^{2}$ & $22^{2}$ & $22^{4}$ & $11^{1}$ & $18^{5}$ \\
\hline & $\begin{array}{l}\text { ESSENTIAL + VERY } \\
\text { USEEUL }\end{array}$ & 33 & 56. & 67.6 & 611. & $67^{6}$ & $6 \stackrel{17}{3}$ \\
\hline & DON•T KNOW & $11^{1}$ & & & & & \\
\hline & AVERAGE & 2.13 & 2.56 & 2.89 & 2.72 & 2.78 & 2.74 \\
\hline & STANDARD DEVIATION & .76 & 1.05 & 1.19 & 1.15 & .92 & 1.07 \\
\hline
\end{tabular}

SCALE: ESSENTIAL $=4$, VERY USEFUL $=3$, SDMEWHAT USEFUL $=2$, NOT AT ALL USEFUL $=1$

Figure F-1. Active Solar Heating and Cooling Data Tables (continued) 
IOCTOBER, 19791

USEFULNESS OF SPECIFIED INFORMATION ITEMS - CONTINUED (OUESTION AI

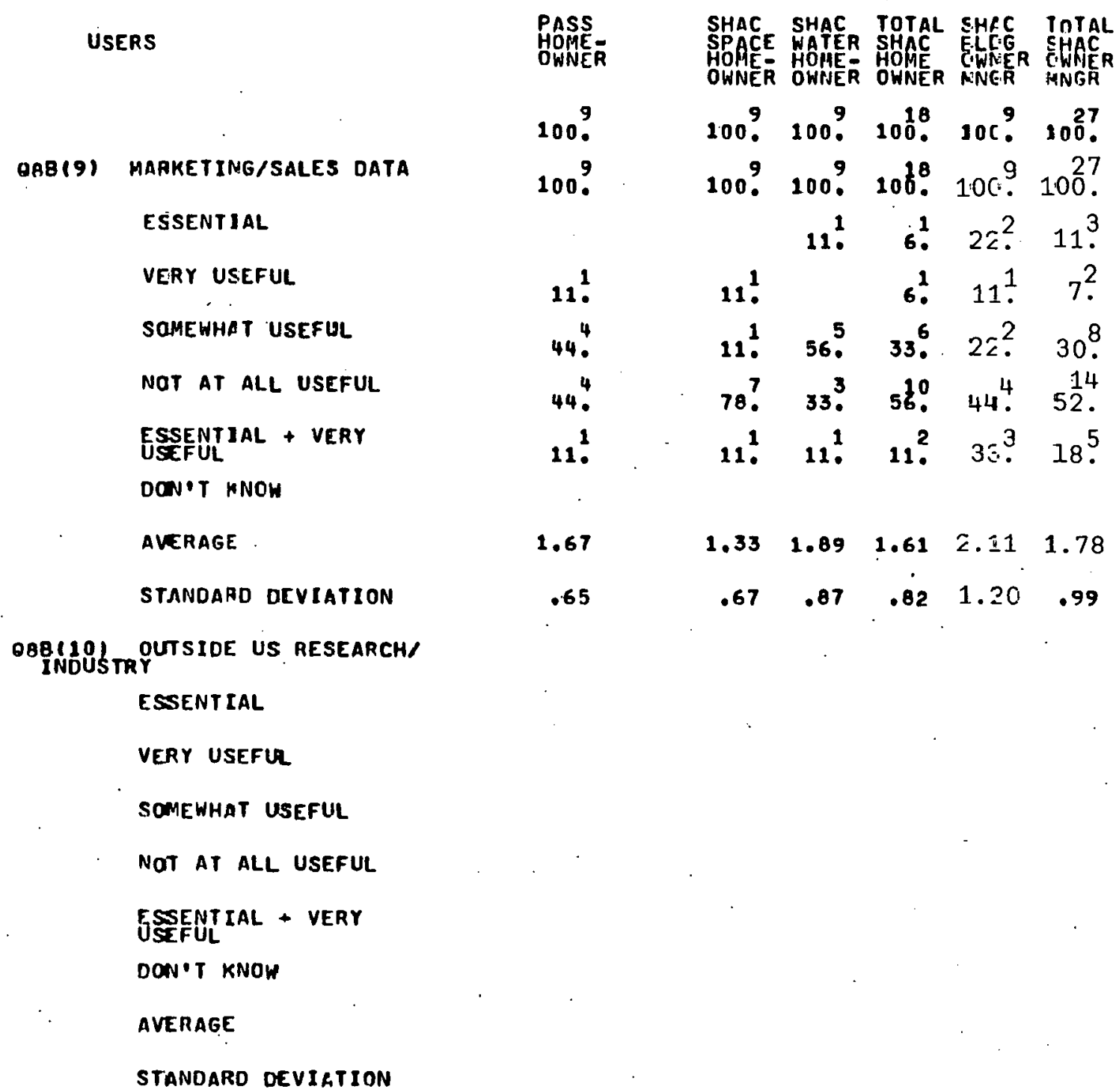

USERS

Figure F-1. Active Solar Heating and Cooling Data Tables (continued) 
(OCTOBER, 1979)

USEFULNESS OF SPÉCIFIEO INFORMATION ITEMS - CONTINUED (QUESTION B)

USERS

PASS SHAC SHAC TOTAL SHAC TOTAL

SPACE WATER SHAC OLOG SHAC
HOME HOME HOMME OWNER OHNER
OWNER OWNE OWNER MNGR MNGR

100 . 100 ? 100 ? $108^{8}$. 100 . 108 ?

QQB(11) INFO ON MARKETING

ESSENTIAL

VERY USEFUL

SOMEWHAT USEFUL

NOT AT ALL USEFUL

ESSENTIAL + VERY

DON'T KNOW

AVERAGE

STANDARO DEVIATION

OAB(12) INST/SOCIAL/ENVIRON/

ESSENTIAL

VERY USEFUL

SOMEWHAT USEFUL

NOT AT ALL USEFUL

ESSENTIAL + VEAY

DON'T KNOW

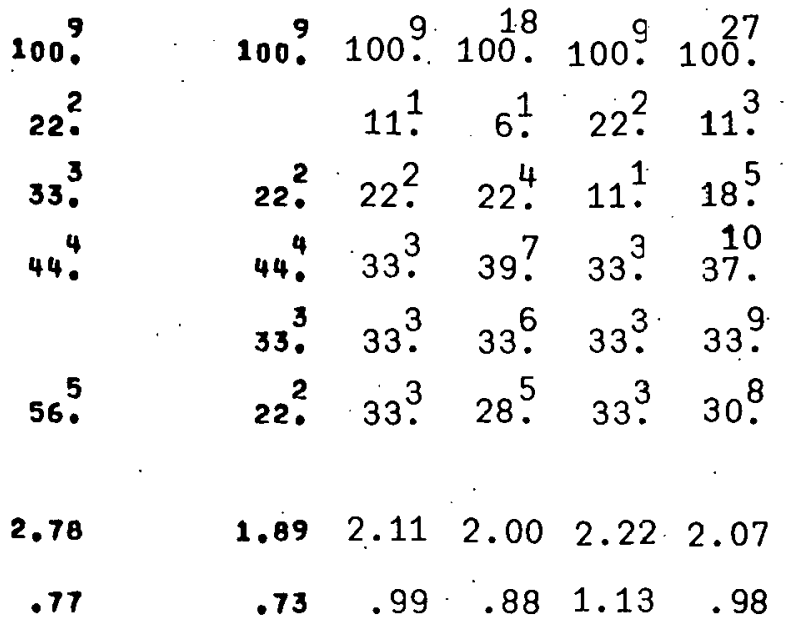

AVERAGE

STANOARD DEVIATION

Figure F-1. Active Solar Heating and Cooling Data Tables (continued) 
(OCTOBER, 1979)

USEFULNESS OF SPECIFIEO INFORMATION ITEMS - CONTINUED (QUESTION B)

USERS

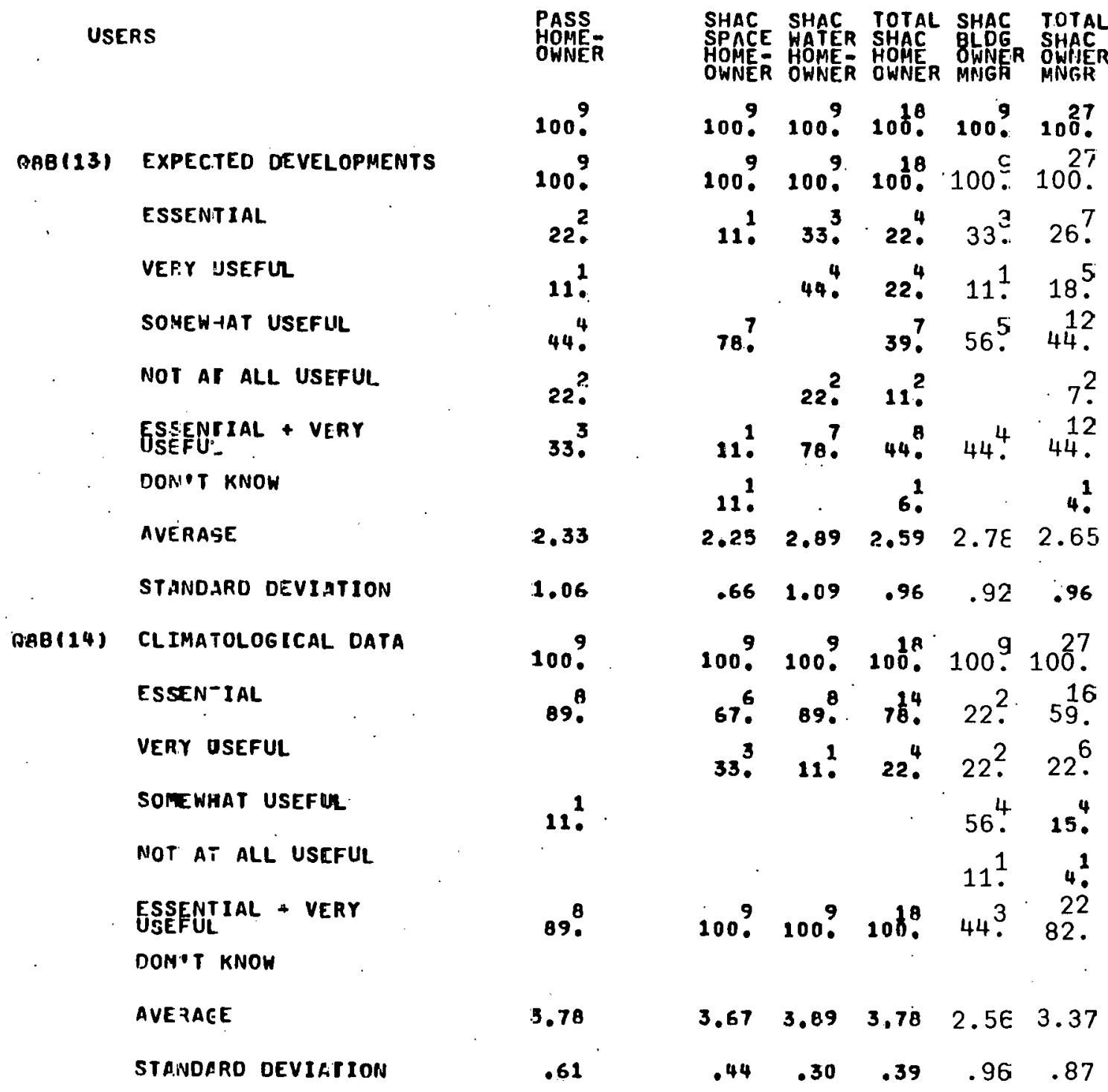

SCALE: ESSENTIAL $=4$, VERY USEFUL $=3$, SOMEWHAT USEFUL $=2$, NOT AT ALL USEFUL $=1$

Figure F-1. Active Solar Heating and Cooling Data Tables (continued) 


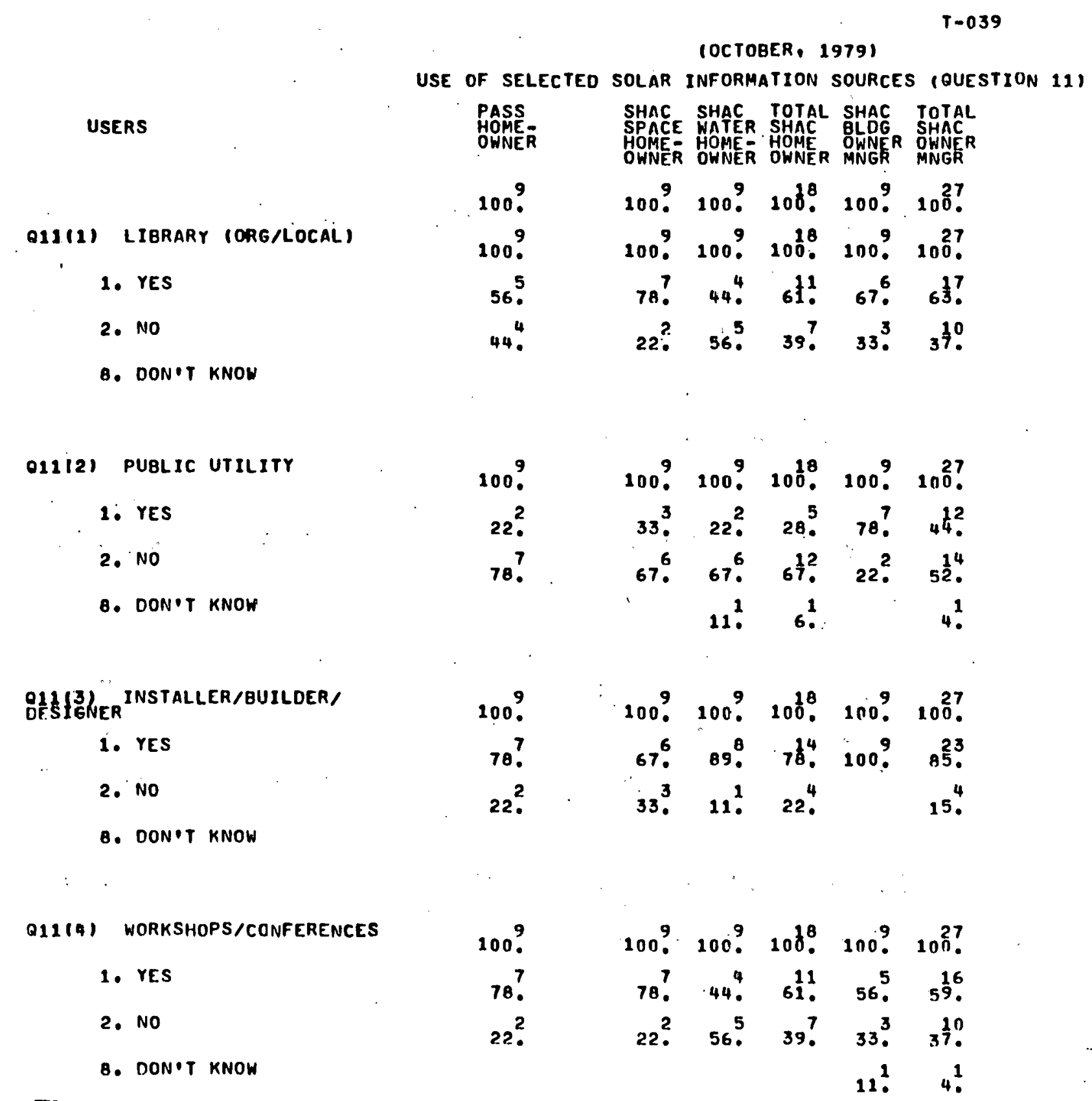

Figure F-1. Active Solar Heating and Cooling Data Tables (continued) 


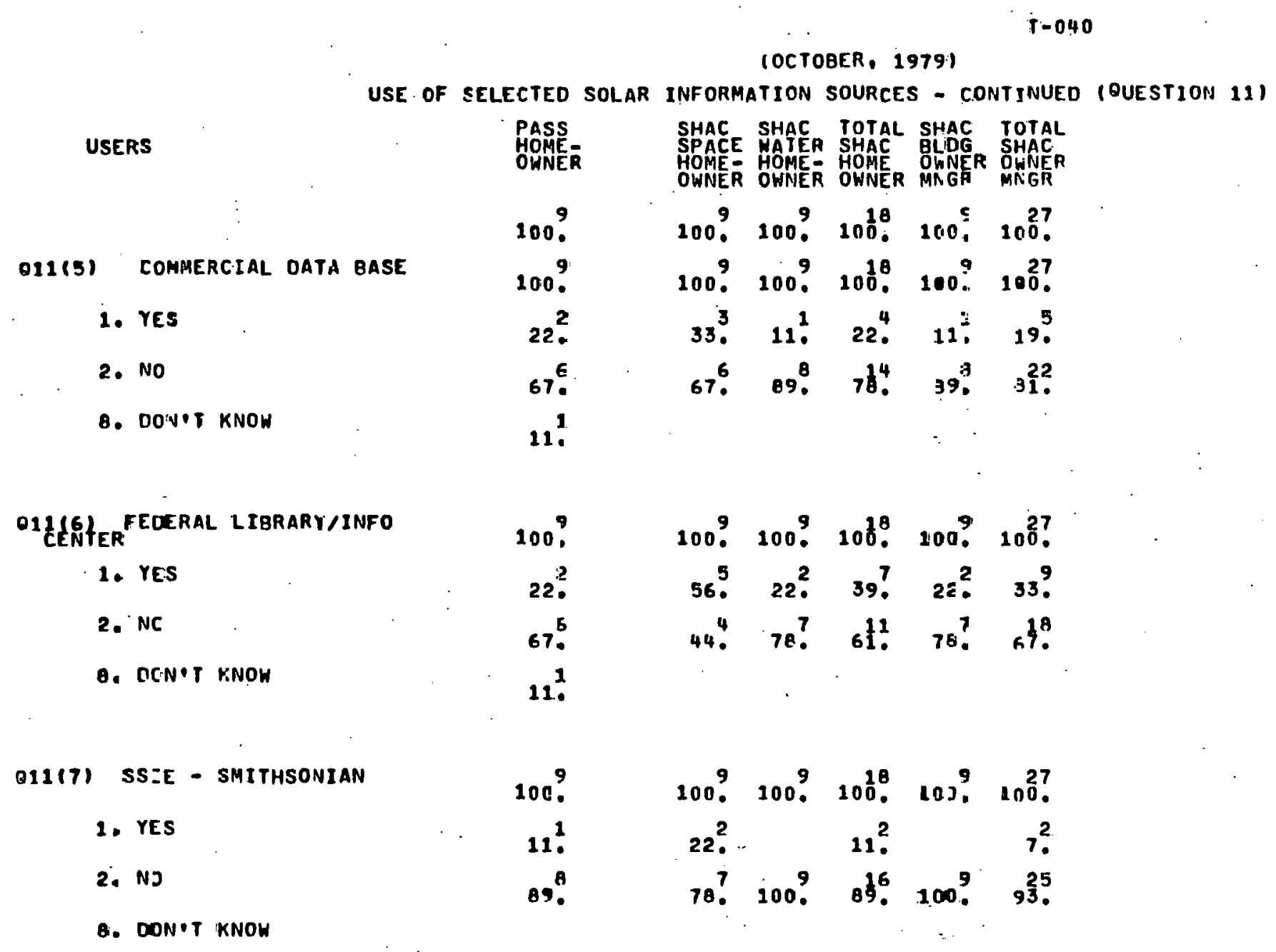

Figure F-1. Active Solar Heating and Cooling Data Tabłes (continued) 


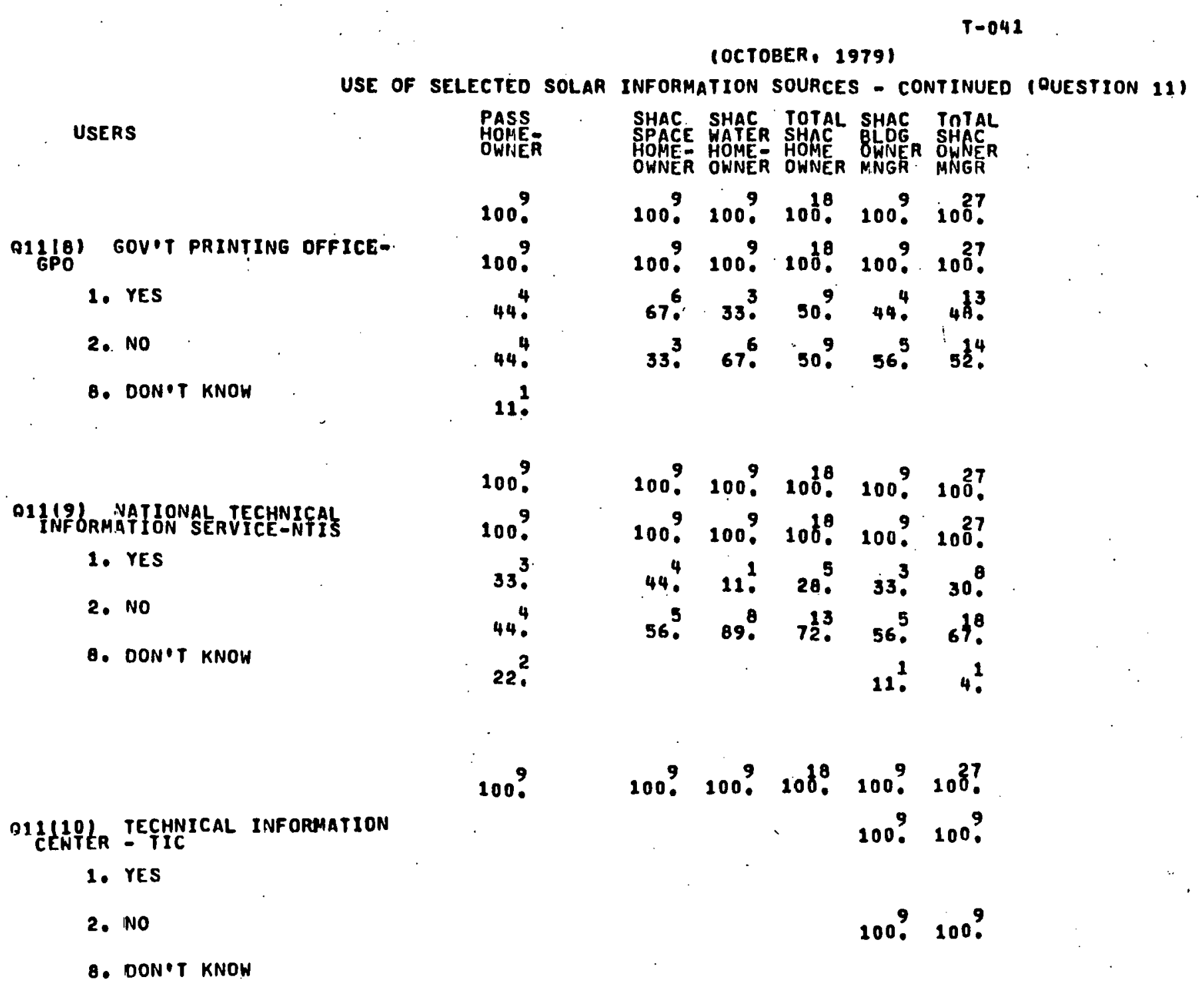

Figure F-1. Active Solar Heating and Cooling Data Tables (continued) 


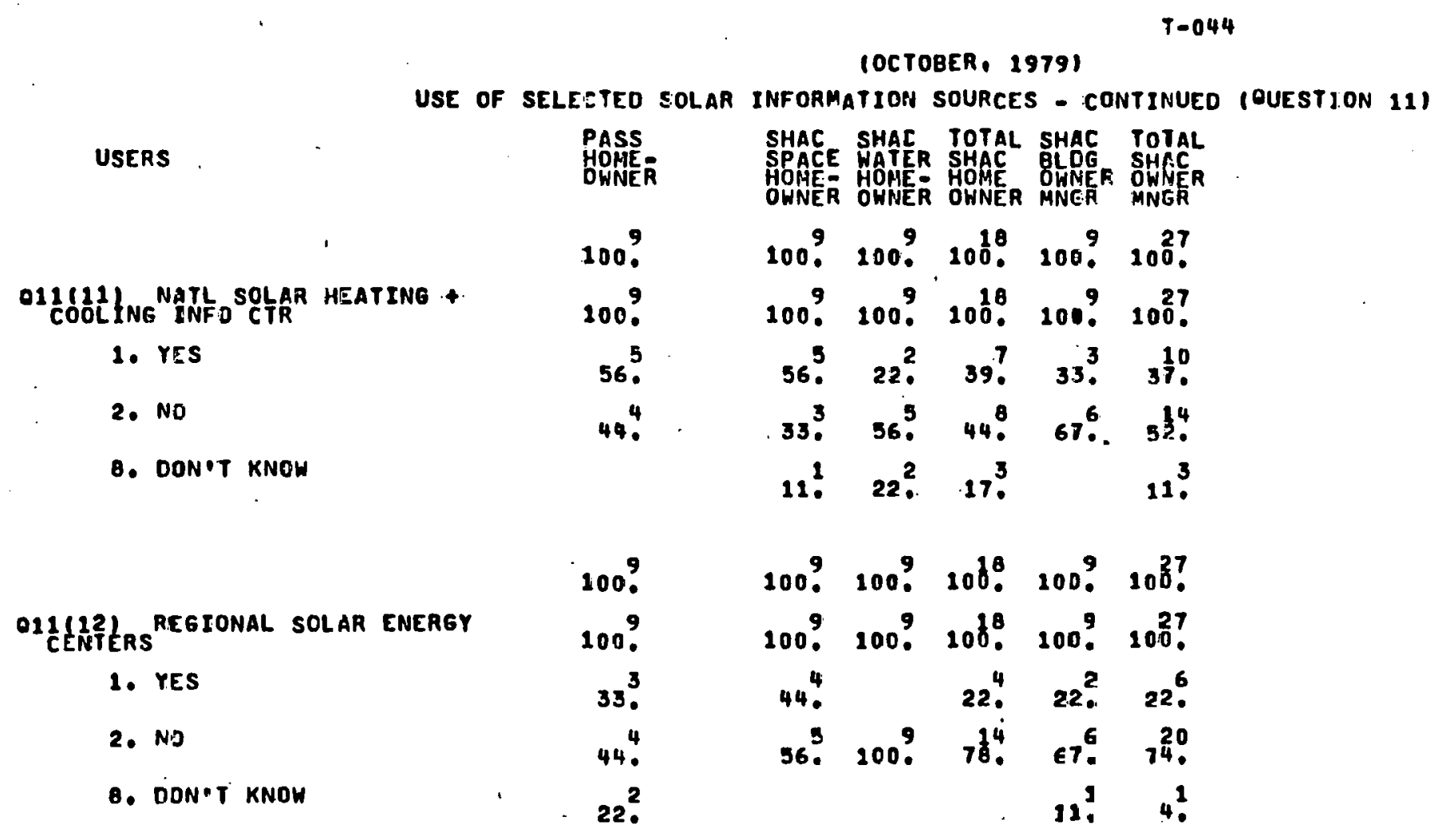

Figure F-1. Active Solar Heating and Cooling Data Tables (continued) 
(OCTOBER, 1979$)$

USE OF SELECTEO SOLAR INFORMATION SOURCES - CONTINUED (OUFSTION 11 )

USERS

PASS SHAC SHAC TOTAL SHAC TOTAL

OWNER S HOAEE HAMER SHAC OLOG SHAC

Q12(13) US DEPT. OF EHERGY

100 . 100 ? 100 ?. 100 . 100 ? 100 ?

1. YES

2. NO

8. DONIT KNOH

$100^{9} \quad 100$ ? 100 ? $100^{8}, 100^{9}$. $100^{2}$ ?

56. $\quad 33^{3}, 33^{3} \cdot 33^{6}, 33^{3}, 33^{9}$

44. $\quad 56^{5}, 56^{5} .52^{10} \cdot 67^{6} \cdot 59^{16}$.

i1. 11. 11. $1^{2}$... $7^{2}$

0111241 RADIO/TV

1. YES

2. No

B. DON'T KNOW

\begin{tabular}{|c|c|c|c|c|c|}
\hline $100 ?$ & $100 ?$ & $100 ?$ & $100^{8}$. & 100 ? & 1007 \\
\hline 56. & 56. & 11 ! & $33^{6}$. & $22^{2}$ & 30. \\
\hline & $44^{4}$ & $89^{8}$ & $67^{2}$ & $78^{7}$ & $70^{9}$. \\
\hline
\end{tabular}

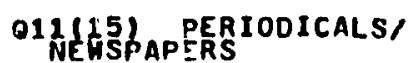

1. YES

$1009 . \quad 100^{9}, 1009.100^{18}, 1009.100^{27}$

89. $\quad 89.89 .8099^{8} .2100$. $99^{25}$.

2. No

0. DON T KNOW

$11^{1} \quad 111^{1} 11^{2}$.

Q11126GOPRIVATE SOLAR/
ENVIRONENTAL OPG.

1. YES

1009. $1009.1009 .100^{8}, 1009.100 \%$

2. No

B. DCN'T KNOW

$89^{8} \quad 44^{4} .67^{6} . \quad 56.233^{3} . \quad 4$ H. $^{13}$

$11^{1} \quad 56^{5}, \quad 33^{3}, \quad 44^{8}, \quad 67^{6} . \quad 52^{14}$.

Figure F-1. Active Solar Heating and Cooling Data Tables (continued) 
(OCTOBER, 1979$)$

USE OF SELECTED SOLAR INFORMATION SOURCES - CORTIMUED IOUESTION 111

\begin{tabular}{|c|c|c|c|c|c|c|}
\hline USERS & $\begin{array}{l}\text { PASS } \\
\text { Hopk } \\
\text { OWEA }\end{array}$ & $\begin{array}{l}\text { SHAC } \\
\text { SPACE } \\
\text { HOMNE } \\
\text { OWNER }\end{array}$ & $\begin{array}{l}\text { SHAC } \\
\text { MAAER } \\
\text { HOME } \\
\text { OWHE }\end{array}$ & $\begin{array}{l}\text { TOTAL } \\
\text { SHAC } \\
\text { HOME } \\
\text { OHNER }\end{array}$ & 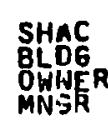 & $\begin{array}{l}107 \\
\text { So } \\
\text { Oh } \\
\text { MNh }\end{array}$ \\
\hline$\cdots$ & 1009 & $100 ?$ & 1009 & $108^{8}$ & 1009. & 1007 \\
\hline $\begin{array}{l}\text { O11117? STATE ENERGY OP SOLAR } \\
\text { DFFICES }\end{array}$ & $100^{9}$ & 100 ? & 100. & 100. & 100 ? & 10. \\
\hline 1. YES & $55^{5}$ & 44. & $33^{3}$ & $39 ?$ & 96. & \\
\hline 2. vo & $44^{4}$. & 56. & 67.6 & 61. & 4. & \\
\hline B. DOMIT KMOH & & & & & & \\
\hline 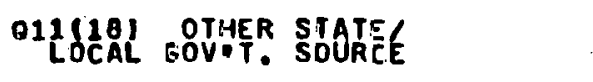 & 100. & $100^{9}$. & $100 \%$ & $.200^{8}$ & $100^{9}$ & 100 \\
\hline 1. YES & $566^{5}$ & $33^{3}$. & $22^{2}$ & $28^{5}$ & $32^{3}$ & \\
\hline 2. NO & 74 . & $67^{6}$. & $78 ?^{7}$ & $72^{3}$ & $6 i^{6}$ & \\
\hline 8. OCN'T HENOW & & & & & & \\
\hline 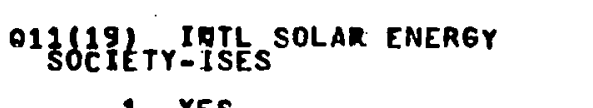 & 100.? & 100 ? & 100. & $100^{18}$ & $100 ?$ & 10 \\
\hline 1. YES & $44^{4}$. & 67.6 & & $33^{6}$. & 22. & \\
\hline 2. ND & 33. & $333^{3}$ & 78 . & 56. & $18 ?$ & \\
\hline A. חON. TNMOH & $22^{2}$ & & $22^{2}$ & $11^{2}$ & & \\
\hline 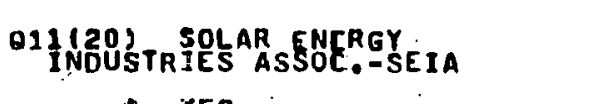 & 100 . & 1009 & 1009 & $100^{18}$ & 1 30.9. & 10 \\
\hline D. res & $22^{2}$ & 33 & & $17^{3}$. & $33^{3}$ & \\
\hline 2. vo & 67. & 67. & 89. & $78^{4}$ & $6.7^{6}$ & \\
\hline B. DON.T KNOW & 11 & & $11 !$ & $6:$ & & \\
\hline
\end{tabular}

Figure F-1. Active Solar Heating and Cooling Data Tables (continued) 


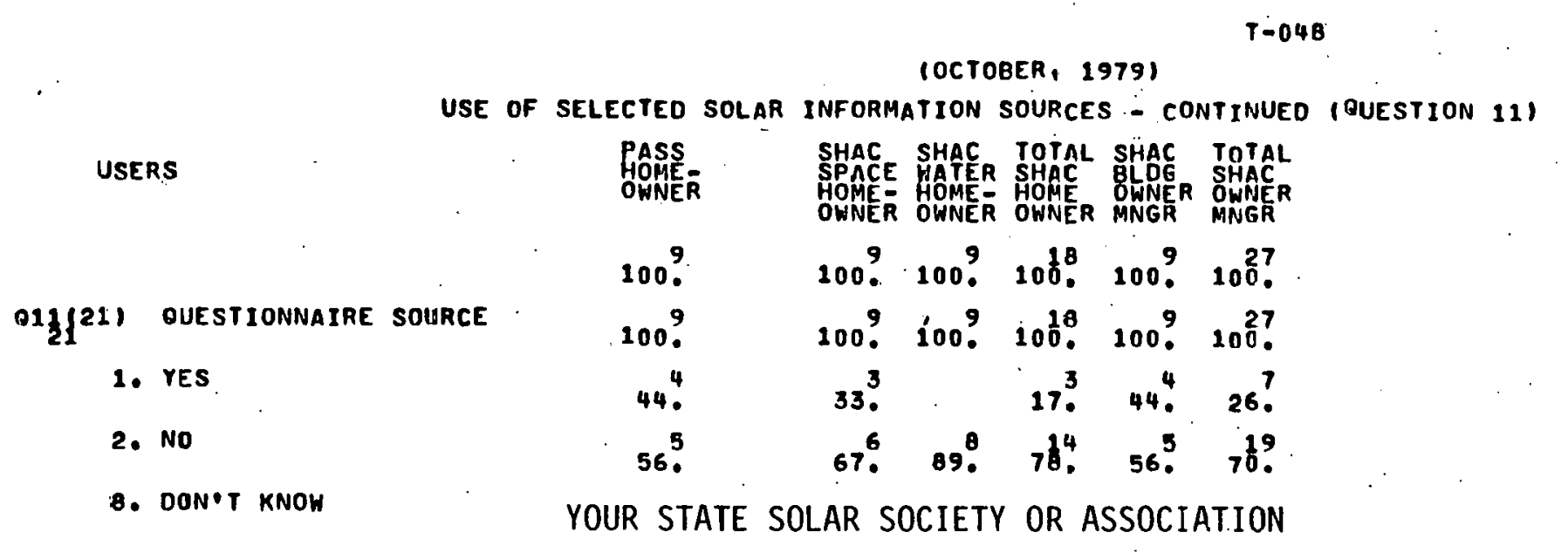

Figure F-1. Active Solar Heating and Cooling Data Tables (continued) 
Figure F-1. Active Solar Heating and Cooling Data Tables (continued) 


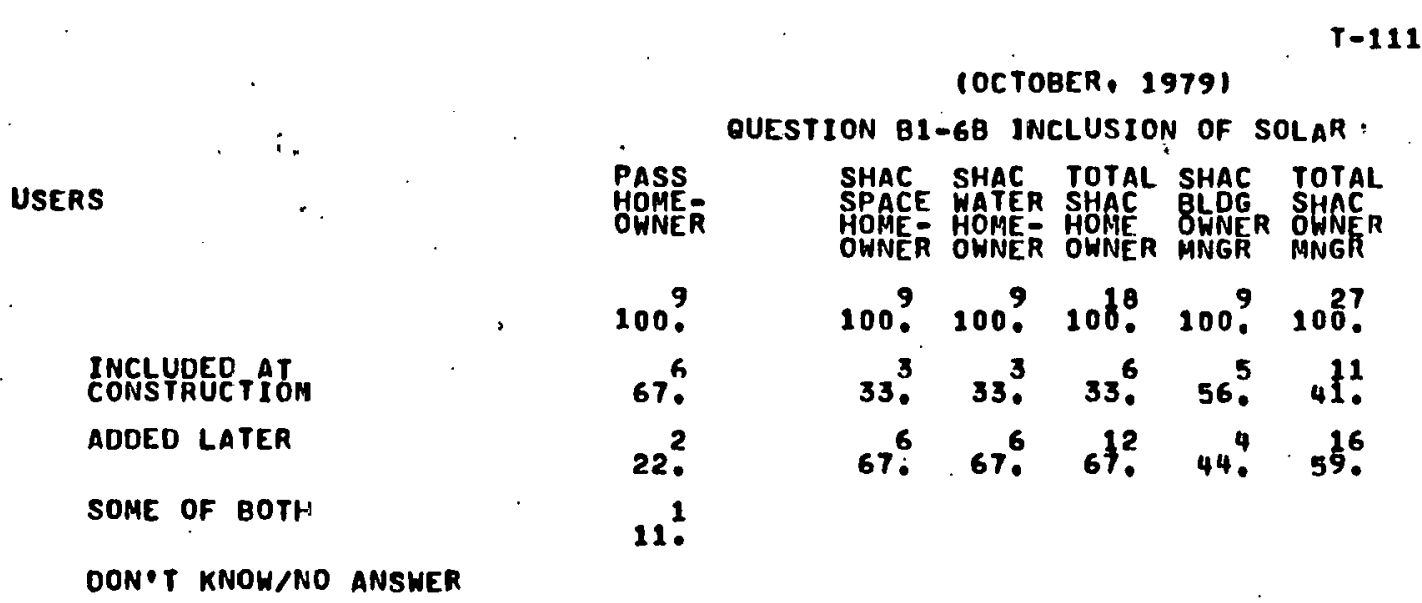

Figure F-1. Active Solar Heating and Cooling Data Tables (continued) 


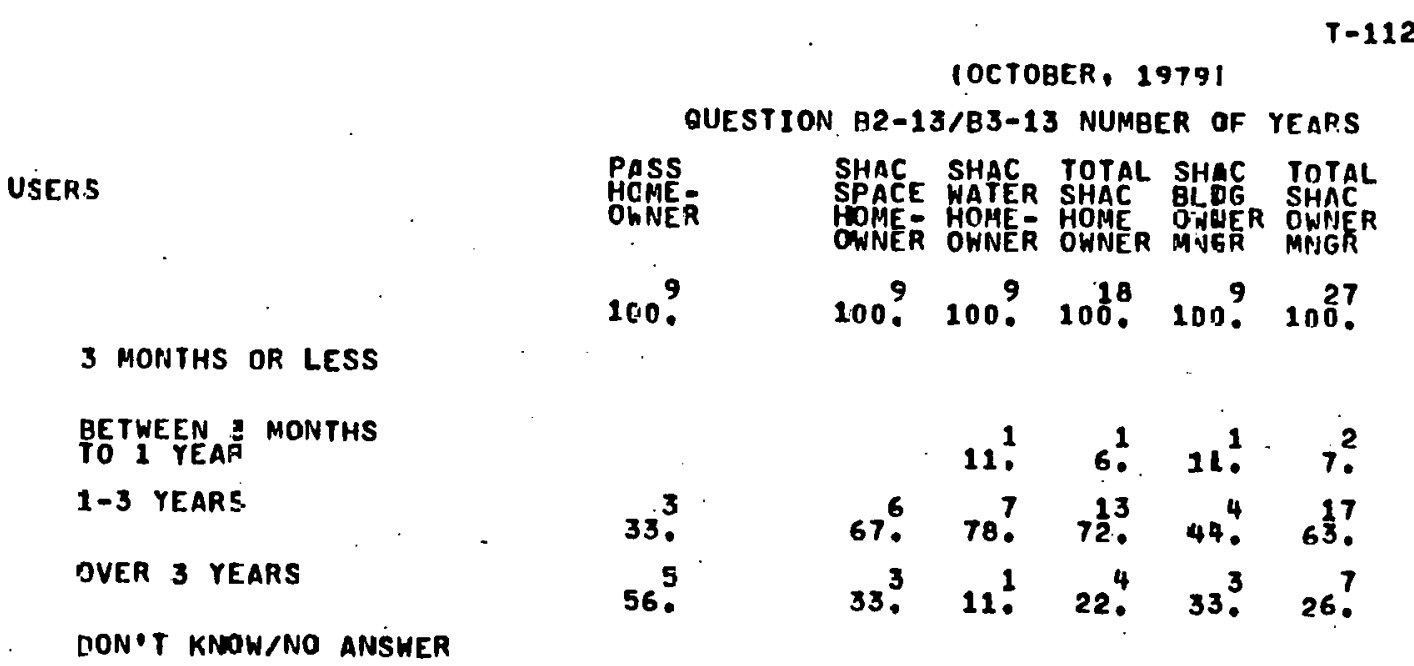

Figure F-1. Active Solar Heating and Cooling Data Tables (continued) 
COCTOBER, 19791

$T-115$

OUESTION B2-12/B2-12A OWNER/MANAGER

USERS

SHAC SHAC TOTAL SHAC TOTAL

PASS

SPACE WATER SHAC BLDG SHAC

OWNER

$$
\begin{array}{rr}
1009 & 100 \text { ? } \\
44^{4} & 44^{4} \\
56 . & 56 .
\end{array}
$$

PREVIOUS MANAGER

NO/DOND' KNOW/

ORIGINAL OWNER

ORIGINAL MANAGER

Figure F-1. Active Solar Heating and Cooling Data Tables (concluded) 


\begin{tabular}{|c|c|c|}
\hline $\begin{array}{c}\text { Document Control } \\
\text { Page }\end{array}$ & $\begin{array}{l}\text { 1. SERI Report No. } \\
\text { TR }-751-747\end{array}$ & 3. Recipient's Accession No. \\
\hline \multirow{2}{*}{\multicolumn{2}{|c|}{$\begin{array}{l}\text { 4. Title and Subtitle } \\
\text { Active Solar Heating and Cooling Information User } \\
\text { Study }\end{array}$}} & \multirow{2}{*}{$\begin{array}{l}\text { 5. Publication Date } \\
\text { January } 1981 \\
6 .\end{array}$} \\
\hline & & \\
\hline \multicolumn{2}{|c|}{$\begin{array}{l}\text { 7. Author(s) } \\
\text { W. W. Belew, B. L. Wood, T. L. Marle, C. L. Reinhardt }\end{array}$} & 8. Performing Organization Rept. No. \\
\hline \multirow{2}{*}{\multicolumn{2}{|c|}{$\begin{array}{l}\text { 9. Performing Organization Name and Address } \\
\text { Solar Energy Research. Institute } \\
1617 \text { Cole Boulevard } \\
\text { Golden, Colorado } 80401\end{array}$}} & \multirow{2}{*}{$\begin{array}{l}\text { 10. Project/Task/Work Unit No. } \\
8420.11 \\
\text { 11. Contract (C) or Grant (G) No. } \\
\text { (C) } \\
\text { (G) }\end{array}$} \\
\hline & & \\
\hline \multirow{2}{*}{\multicolumn{2}{|c|}{ 12. Sponsoring Urganization Name and Address }} & $\begin{array}{l}\text { 13. Type of Report \& Perlod Covered } \\
\text { Iechnical Repurt }\end{array}$ \\
\hline & & 14. \\
\hline
\end{tabular}

15. Supplemenentary Notes

16. Abstract (Limit: 200 words) This report describes the results of a series of telephone interviews with groups of users of information on active solar heating and cooling (SHAC). These results, part of a larger study on many different solar technologies, identify types of information each group needed and the best ways to get information to each group. The report is 1 of 10 discussing study results. The overall study provides baseline data about information needs in the solar community. It covers these technological areas: photovoltaics, passive solar heating and cooling, SHAC, biomass energy, solar thermal electric power, solar industrial and agricultural process heat, wind energy, ocean energy, and advanced energy storage. An earlier study identified the information user groups in the solar community and the priority (to accelerate solar energy commercialization) of getting information to each group. In the current study only high-priority groups were examined. Results from 19 SHAC groups respondents are analyzed in this report: DOE-Funded Researchers, Non-DOE-Funded Researchers, Representatives of Manufacturers ( 4 groups), Distributors, Installers, Architects, Builders, Planners, Engineers (2 groups), Representatives of Utilities, Educators, Cooperative Extension Service County Agents, Building Owners/Managers, and Homeowners ( 2 groups). The data will be used as input to the determination of information products and services the Solar Energy Research Institute, the Solar Energy Information Data Bank Network, and the entire information outreach community should be preparing 17. Document Analysis and diseminating.

a. Descriptors Cost ; Data Acquisition; Data Analysis ; Data Base Management ; Data Compilation; Evaluated Data ; Information Needs:Q1Q2;Marketing Research ; Sampling ; Site Selection ; Solar Cooling Systems:T1 ; Solar Heating:T2 ; Solar Industry ; b. Identifiers/Open-Ended Terms Telephones ; Communications ; Data ; Industry ; Information ; Management ; Heating Systems ; Numerical Data

c. UC Categories

$$
58 \mathrm{c}, 59
$$

18. Availability Statement

National Technical Information Service

U.S. Department of Commerce

5285 Port Royal Road

Springfield, Virginia 22161 